$5-1996$

\title{
Confederate Veterans At Rest: Archeological and Bioacheological Investigations at the Texas State Cemetery, Travis County, Texas
}

Helen Danzeiser Dockall

Prewitt and Associates, Inc.

Douglas K. Boyd

Prewitt and Associates, Inc.

Martha Doty Freeman

Prewitt and Associates, Inc.

Rolando L. Garza

Prewitt and Associates, Inc.

Kevin E. Stork

Prewitt and Associates, Inc.

See next page for additional authors

Follow this and additional works at: https://scholarworks.sfasu.edu/ita

Part of the American Material Culture Commons, Archaeological Anthropology Commons, Environmental Studies Commons, Other American Studies Commons, Other Arts and Humanities Commons, Other History of Art, Architecture, and Archaeology Commons, and the United States History Commons

Tell us how this article helped you.

This Article is brought to you for free and open access by the Center for Regional Heritage Research at SFA ScholarWorks. It has been accepted for inclusion in Index of Texas Archaeology: Open Access Gray Literature from the Lone Star State by an authorized editor of SFA ScholarWorks. For more information, please contact cdsscholarworks@sfasu.edu. 
Confederate Veterans At Rest: Archeological and Bioacheological Investigations at the Texas State Cemetery, Travis County, Texas

\section{Authors}

Helen Danzeiser Dockall, Douglas K. Boyd, Martha Doty Freeman, Rolando L. Garza, Kevin E. Stork, Karl W. Kibler, and Joan E. Baker

\section{Creative Commons License}

\section{(c) (1) $(9)$}

This work is licensed under a Creative Commons Attribution-NonCommercial-No Derivative Works 4.0 International License. 


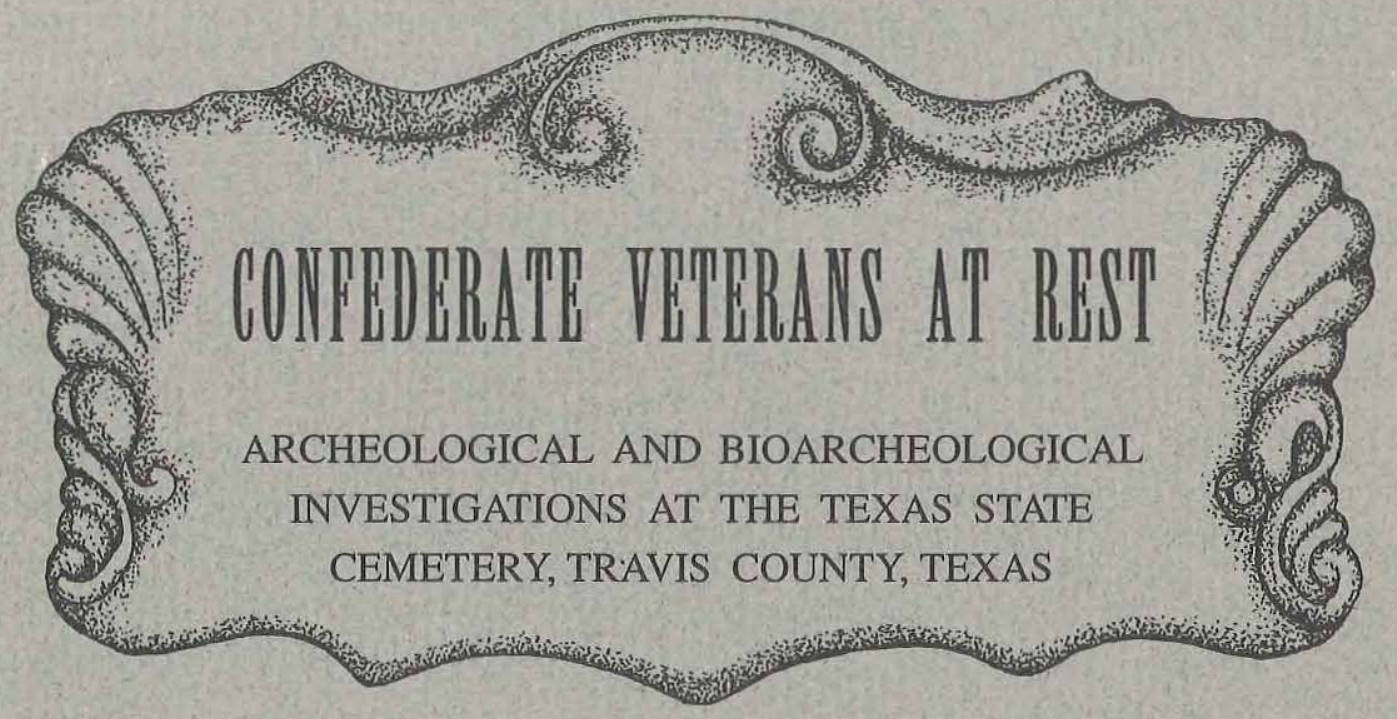

REPORTS OF INVESTIGATIONS, NUMBER 107

by

Helen Danzeiser Dockall

Douglas K. Boyd

Martha Doty Freeman

Rolando L. Garza

Kevin E. Stork

Karl W. Kibler

and

Joan E. Baker

Principal Investigator: Douglas K. Boyd
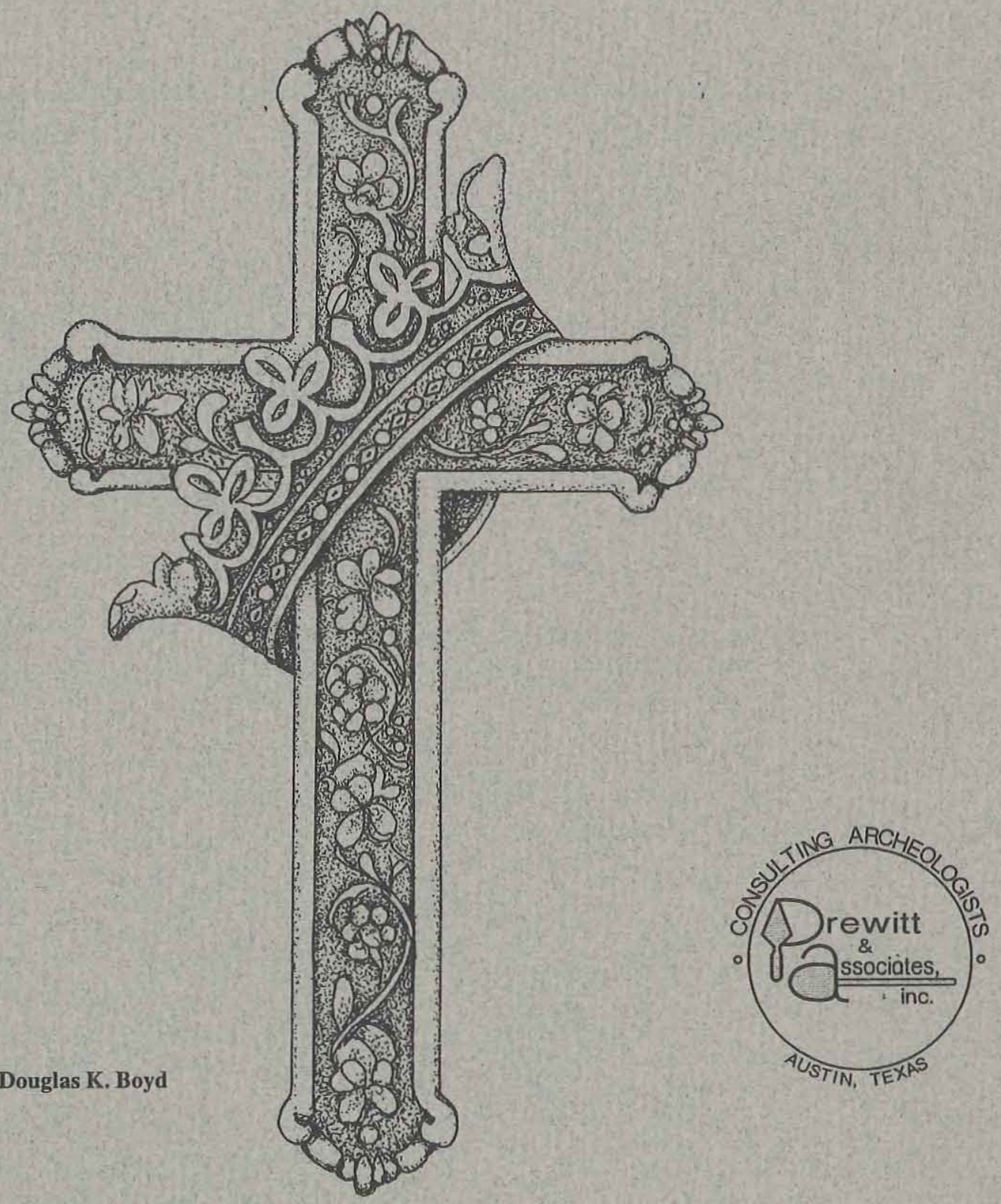


\title{
CONFEDERATE VETERANS AT REST: ARCHEOLOGICAL AND BIOARCHEOLOGICAL INVESTIGATIONS AT THE TEXAS STATE CEMETERY, TRAVIS COUNTY, TEXAS
}

by

\author{
Helen Danzeiser Dockall \\ Douglas K. Boyd \\ Martha Doty Freeman \\ Rolando L. Garza \\ Kevin E. Stork \\ Karl W. Kibler \\ and \\ Joan E. Baker
}

Principal Investigator: Douglas K. Boyd

REPORTS OF INVESTIGATIONS, NUMBER 107

Submitted to

Texas Parks and Wildlife Department

by

Prewitt and Associates, Inc.

Consulting Archeologists

Austin, Texas

May 1996 


\section{DEDICATION}

This report is respectfully dedicated to the families of the Confederate veterans and their wives whose remains were moved; the Albert Sidney Johnston Chapter 105 of the United Daughters of the Confederacy; and the Texas Division of the Sons of Confederate Veterans.

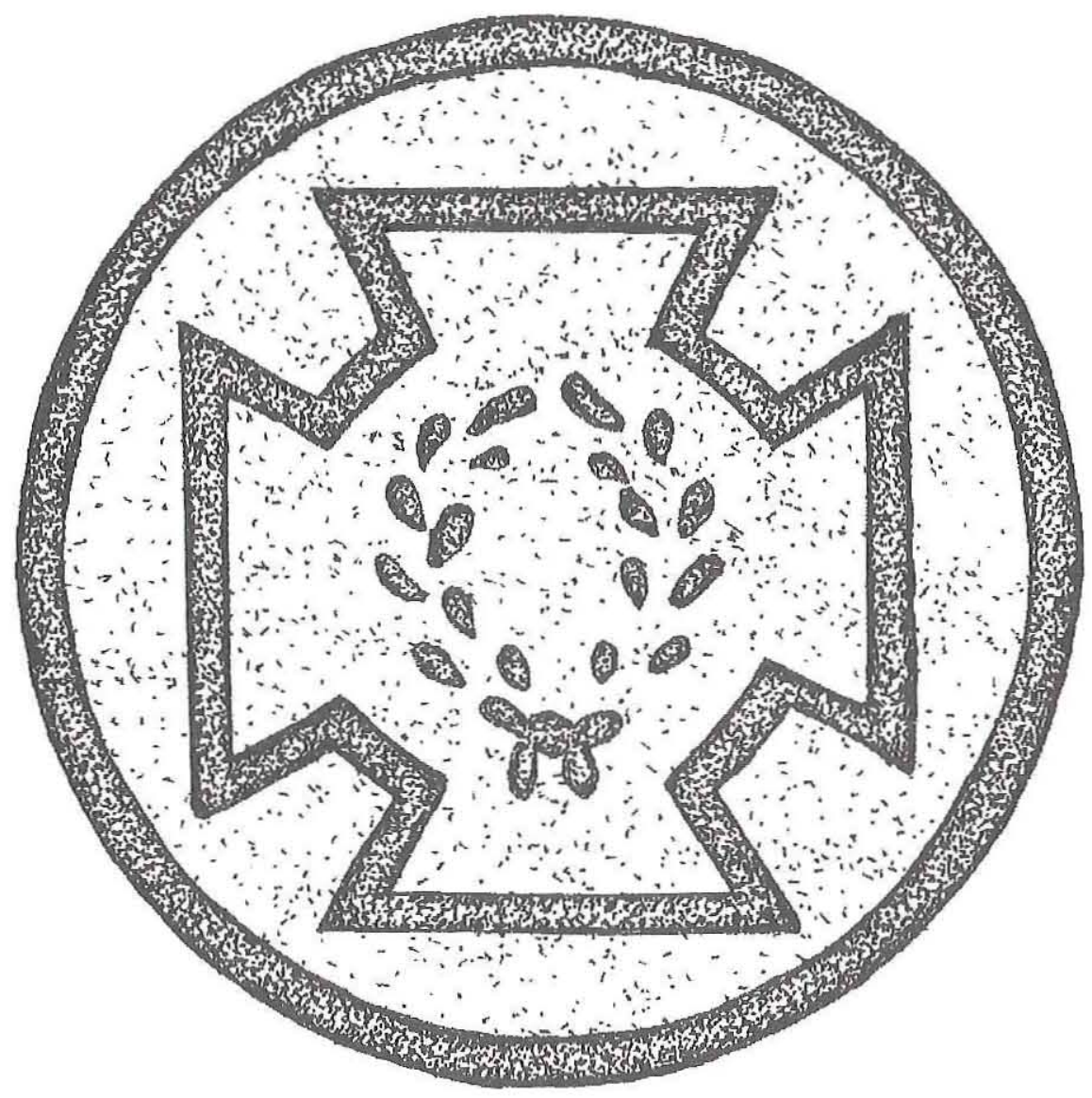

SOUTHERN CROSS OF HONOR 


\section{TABLE OF CONTENTS}

ABSTRACT $\ldots \ldots \ldots \ldots \ldots \ldots \ldots \ldots \ldots \ldots \ldots \ldots \ldots \ldots \ldots \ldots \ldots \ldots \ldots \ldots \ldots$

ACKNOWLEDGMENTS $\ldots \ldots \ldots \ldots \ldots \ldots \ldots \ldots \ldots \ldots \ldots \ldots \ldots \ldots \ldots \ldots \ldots$

CHAPTER 1: INTRODUCTION

Douglas K. Boyd . . . . . . . . . . . . . . . . 1

CHAPTER 2: METHODS

Helen Danzeiser Dockall, Douglas K. Boyd, and Martha Doty Freeman . . . . . . . 11

Archival Research . . . . . . . . . . . . . . . . . . . . . . . . 11

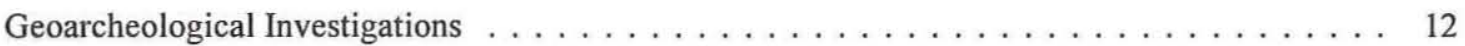

Confederate Burial Relocation . . . . . . . . . . . . . . . . . . . . 13

Burial Excavations and Analysis . . . . . . . . . . . . . . . . . 13

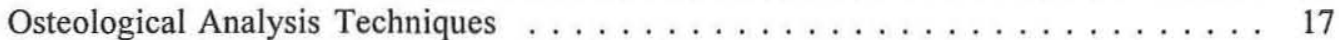

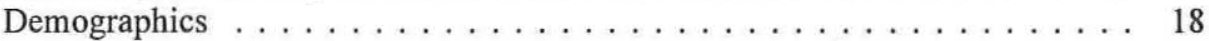

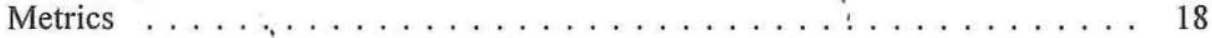

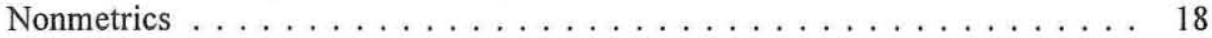

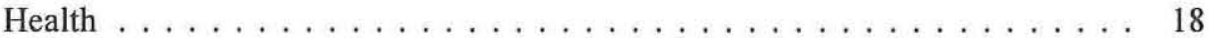

Research Orientation for Burial Relocation . . . . . . . . . . . . . . . . . . . . . . 19

Demography and Health Status . . . . . . . . . . . . . . . . . . . . . . . 19

Social and Socioeconomic Characteristics . . . . . . . . . . . . . . . . 20

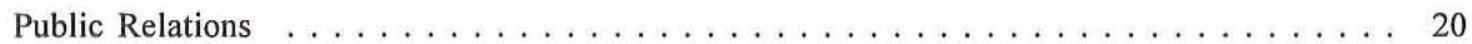

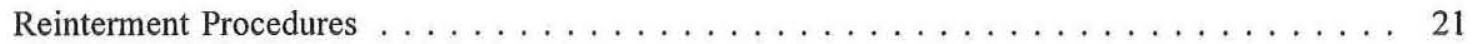

CHAPTER 3: HISTORY OF THE TEXAS STATE CEMETERY

Martha Doty Freeman . . . . . . . . . . . . . . . . . . . . . 23

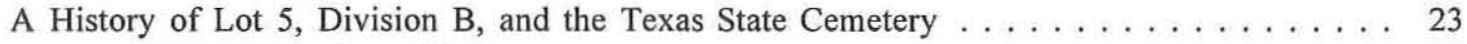

1839-1851: Preamble ......................... 23

1851-1865: Death of Burleson and Early History of the Cemetery . . . . . . . . 24

1866-1900: "The Condition of the State Cemetery Is Not Good" . . . . . . . . . 26

1901-1919: A Resurgence of Interest . . . . . . . . . . . . . . . . . . 28

1919-1940: The Cemetery Flourishes . . . . . . . . . . . . . . . . . . . . 29

1941-Present . . . . . . . . . . . . . . . . . . . . . . . . 30

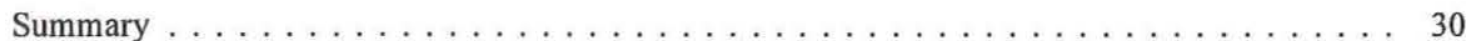

CHAPTER 4: RESULTS OF ARCHEOLOGICAL SURVEY AND SUBSURFACE GEOARCHEOLOGICAL INVESTIGATIONS

Douglas K. Boyd and Karl W. Kibler . . . . . . . . . . . . . . . . . 33

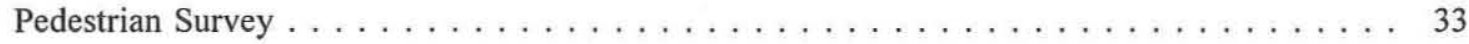

Mechanical Testing and Geomorphic Assessment $\ldots \ldots \ldots \ldots \ldots \ldots \ldots \ldots \ldots$

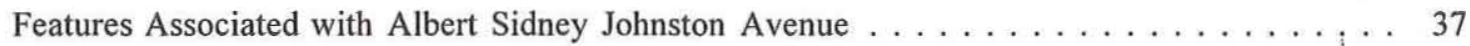

Archeological and Archival Investigations . . . . . . . . . . . . . 37

Summary and Recommendations . . . . . . . . . . . . . . . . . . . 40

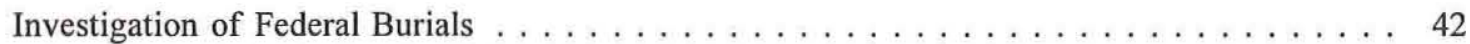

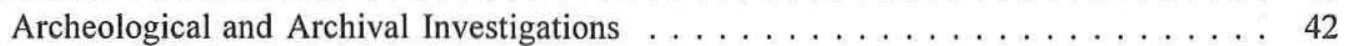

Summary and Recommendations . . . . . . . . . . . . . . . . 46 
CHAPTER 5: BURIAL DESCRIPTIONS

Helen Danzeiser Dockall, Rolando L. Garza, and Kevin E. Stork . . . . . . . . . . . 49

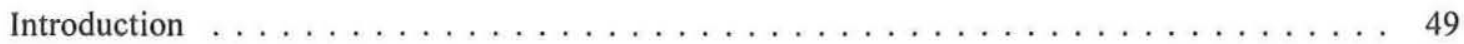

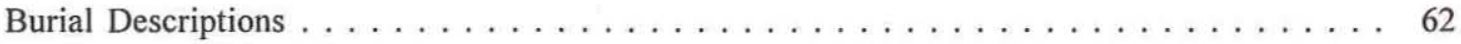

CHAPTER 6: ANALYSIS OF MATERIAL CULTURE

Helen Danzeiser Dockall . . . . . . . . . . . . . . . . . . . . . . . . . . 123

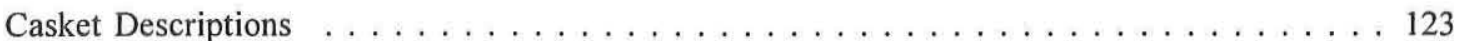

Outer Boxes . . . . . . . . . . . . . . . . . . . . . . . . . . . . . . . . . . . . 129

Decorative Paint and Grooving . . . . . . . . . . . . . . . . . . . . . . . . . . 129

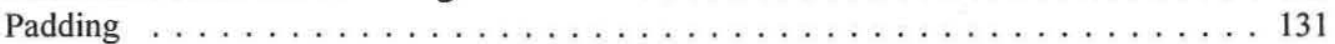

Casket Hardware . . . . . . . . . . . . . . . . . . . . . . . . 131

Viewing Windows ........................ 131

Casket Handles . . . . . . . . . . . . . . . . . . . . . . . . 135

Escutcheons and Thumbscrews . . . . . . . . . . . . . . . . . 140

Latches . . . . . . . . . . . . . . . . . . . . . . . . . . . . . . . . . . . 143

Caplifters . . . . . . . . . . . . . . . . . . . . . . 144

Plaques . . . . . . . . . . . . . . . . . . . . . . . . . . 144

Decorative Ornaments/Tacks . . . . . . . . . . . . . . . . . . . . . . 146

Nails/Screws/Corrugated Fasteners . . . . . . . . . . . . . . . . . 148

Personal Items . . . . . . . . . . . . . . . . . . . . . . . . . . . . . 148

Personal Casket Hardware . . . . . . . . . . . . . . . . . . . . . . . . . . . . . 149

Clothing . . . . . . . . . . . . . . . . . . . . . . . . . . . . . . . . 149

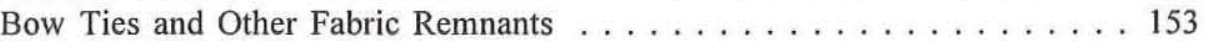

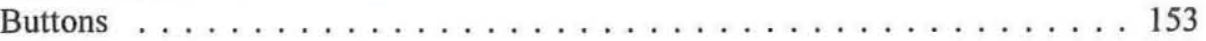

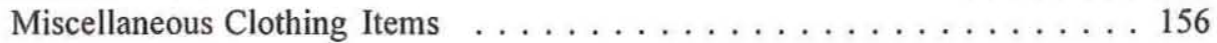

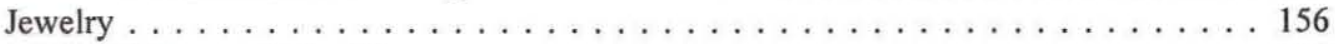

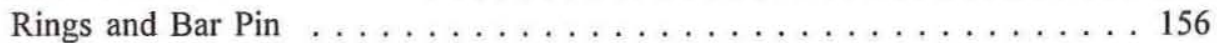

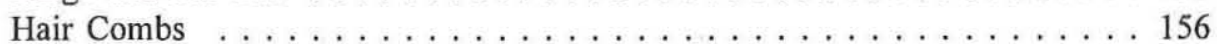

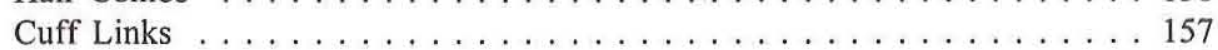

Collar Studs . . . . . . . . . . . . . . . . . . . . . . . . 158

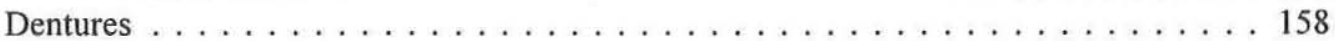

Miscellaneous Personal Items . . . . . . . . . . . . . . . . . . . . . 159

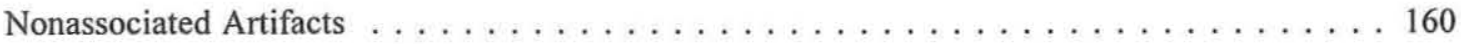

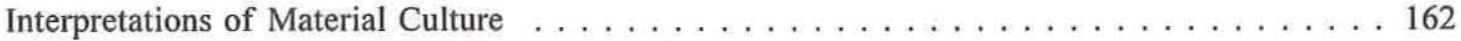

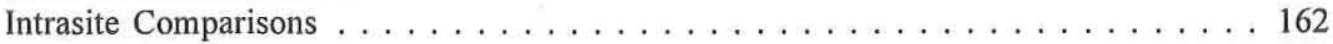

Socioeconomic Analysis . . . . . . . . . . . . . . . . . 162

Chronological Analysis . . . . . . . . . . . . . . . . 166

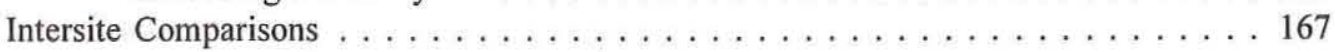

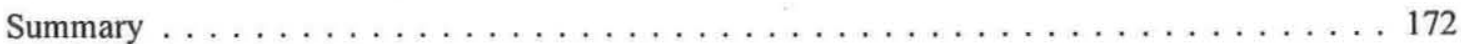

CHAPTER 7: ANALYSIS OF OSTEOLOGICAL REMAINS

Helen Danzeiser Dockall and Joan E. Baker . . . . . . . . . . . . . . . . . 173

Demographic Data . . . . . . . . . . . . . . . . . . . . . . . . 175

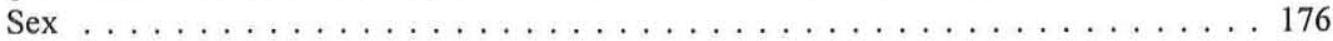

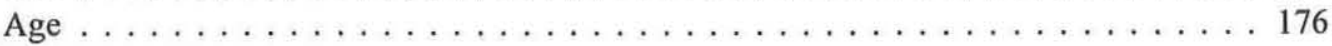




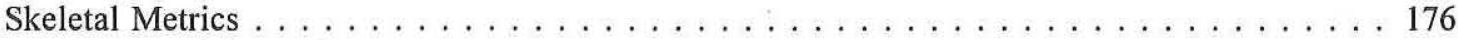

Cranial Metrics . . . . . . . . . . . . . . . . . . . . . . 176

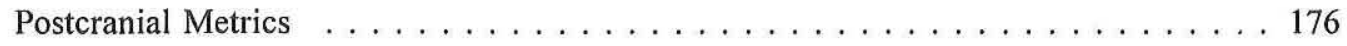

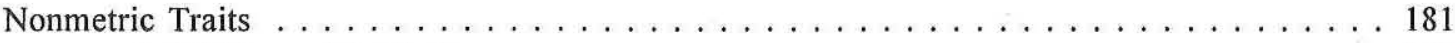

Axial Nonmetric Traits . . . . . . . . . . . . . . . . . . . . . . . 183

Bilateral Nonmetric Traits . . . . . . . . . . . . . . . . . . . . . . . . 183

Nonmetric Traits of Variable Expression . . . . . . . . . . . . . . . . 185

Other Nonmetric Variation . . . . . . . . . . . . . . . . . . . . . . 186

Cranial Nonmetric Traits . . . . . . . . . . . . . . . . . 186

Nonmetric Traits of the Hand and Foot . . . . . . . . . . . . . . . 187

Vertebral Column Nonmetric Variations . . . . . . . . . . . . . . . 188

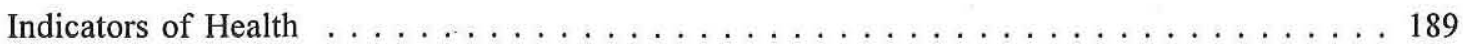

Dental Disorders . . . . . . . . . . . . . . . . . . . . . . . . . . . . . 189

Antemortem Tooth Loss . . . . . . . . . . . . . . . . . . . . . . . . 189

Wear . . . . . . . . . . . . . . . . . . . . . 192

Alveolar Resorption . . . . . . . . . . . . . . . . . . . 192

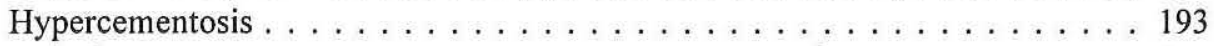

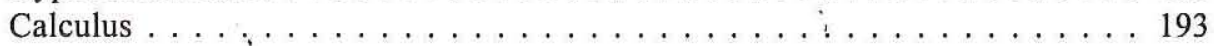

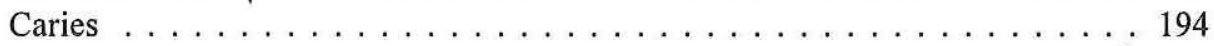

Abscesses . . . . . . . . . . . . . . . . . . . . 196

Interproximal Grooves . . . . . . . . . . . . . . . . . 197

Linear Enamel Hypoplasia . . . . . . . . . . . . . . . . . . . . 197

Congenitally Missing Teeth . . . . . . . . . . . . . . . . . . . 198

Tooth Fractures . . . . . . . . . . . . . . . . . . . . . . . . . 199

Skeletal Disorders . . . . . . . . . . . . . . . . . . . . . . . . . . . . . 199

Degenerative Joint Disease . . . . . . . . . . . . . . . . . . . 199

Periostitis/Osteitis . . . . . . . . . . . . . . . . . 203

Trauma . . . . . . . . . . . . . . . . . . . 205

Metabolic/Hematological Disorders . . . . . . . . . . . . 207

Neoplasms . . . . . . . . . . . . . . . . . . . . . . . 208

Enthesophytes and Improper Ossification _ . . . . . . . . . . 209

Other . . . . . . . . . . . . . . . . . . . . . 209

Comparison of Written Records with Skeletal Evidence . . . . . . . . . . . 210

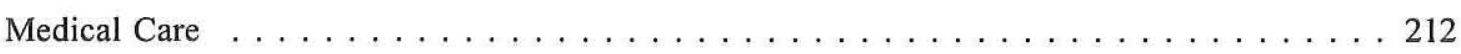

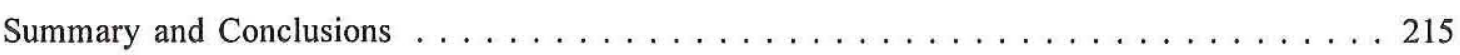

CHAPTER 8: SUMMARY AND CONCLUSIONS

Helen Danzeiser Dockall . . . . . . . . . . . . . . . . . . . . . . . . . 217

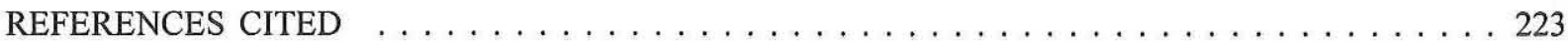

APPENDIX A: Federal Interments in the Texas State Cemetery

APPENDIX B: Backhoe Trench Profile Descriptions

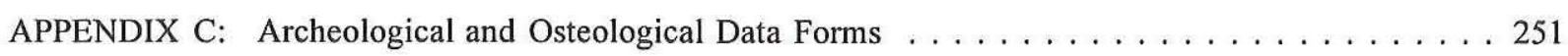

APPENDIX D: Skeletal Inventory for Analyzed Individuals at the Texas State Cemetery

Compiled by Helen Danzeiser Dockall . . . . . . . . . . . . . . . 275 
APPENDIX E: Skeletal Cranial and Postcranial Metric Data from Analyzed Individuals at the Texas State Cemetery

Compiled by Helen Danzeiser Dockall . . . . . . . . . . . . . . . . . . . . 285

APPENDIX F: Skeletal Cranial and Postcranial Nonmetric Traits for Analyzed Individuals from the Texas State Cemetery

Compiled by Helen Danzeiser Dockall . . . . . . . . . . . . . . . . . 297

APPENDIX G: Dental and Skeletal Pathology Data for Analyzed

Individuals from the Texas State Cemetery

Compiled by Helen Danzeiser Dockall . . . . . . . . . . . . . . . . 307

APPENDIX H: Notification of Next of Kin of Excavated Individuals

at the Texas State Cemetery

Douglas K. Boyd . . . . . . . . . . . . . . . . . . . . . . . . 329

APPENDIX I: Memorial Service for Confederate Reinterment, Texas State Cemetery, 7 August 1995

Douglas K. Boyd . . . . . . . . . . . . . . . . . . . . . 337 


\section{LIST OF FIGURES}

1. General map of the Texas State Cemetery project area $\ldots \ldots \ldots \ldots \ldots \ldots$

2. Project area map showing locations of proposed construction zones discussed in the text $\ldots .5$

3. Project area map showing locations of subsurface testing $\ldots \ldots \ldots \ldots \ldots \ldots \ldots \ldots \ldots$

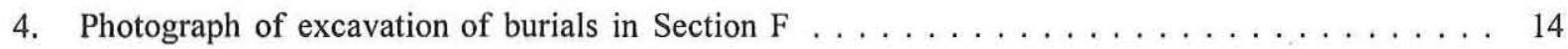

5. Composite sketch of typical burial divided into excavation zones $\ldots \ldots \ldots \ldots \ldots$

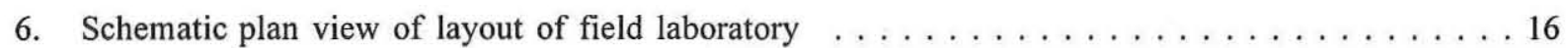

7. Pre-1928 hand-drawn map entitled "The State of Texas Cemetery at Austin" . . . . . . . . 38

8. Photographs of Gradall testing and concrete roadway features in the proposed Plaza de Recuerdos construction area . . . . . . . . . . . . . . . . . . . . 39

9. Photographs of concrete curb feature in Gradall Trench $30 \ldots \ldots \ldots \ldots \ldots \ldots \ldots$

10. Plan and profile views of the proposed Plaza de los Recuerdos area showing the location of Gradall trenches and concrete curbing of Albert Sidney Johnston Avenue . . . . . . . . 41

11. Hypothetical reconstruction of the concrete curb layout of

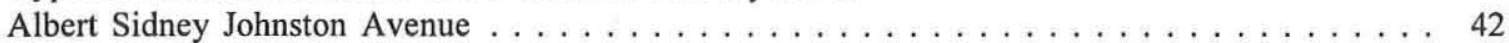

12. Photograph and plan view of the grave pits exposed in the northeast corner

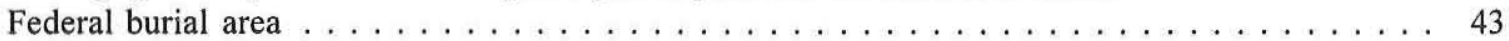

13. Photograph of wooden coffin remnants in Federal Grave $1 \ldots \ldots \ldots \ldots \ldots \ldots \ldots$

14. Map of original grave and headstone locations for the 57 excavated burials $\ldots \ldots \ldots \ldots$

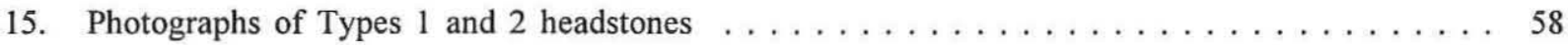

16. Photographs of Types 3 , 4, and 7 headstones $\ldots \ldots \ldots \ldots \ldots \ldots \ldots \ldots \ldots \ldots$

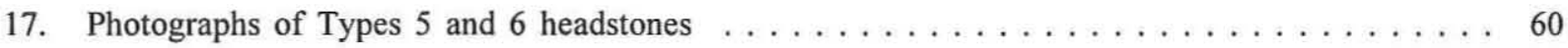

18. Drawings of metal casket associated with Burials 51 and $52 \ldots \ldots \ldots \ldots \ldots \ldots \ldots$

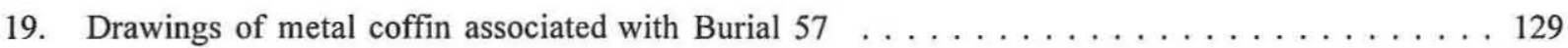

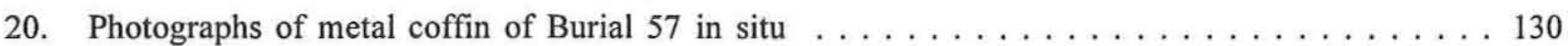

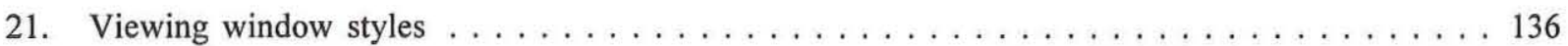

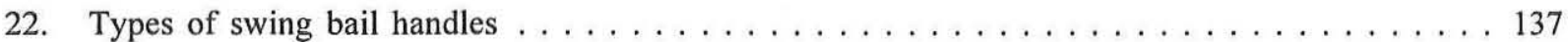

23. Single lugs from double lug short bar handles $\ldots \ldots \ldots \ldots \ldots \ldots \ldots \ldots \ldots \ldots$

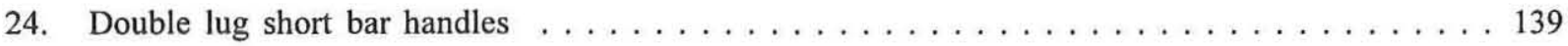

25. Type 9 and Type 14 single lug extension bar handles $\ldots \ldots \ldots \ldots \ldots \ldots \ldots \ldots \ldots \ldots \ldots$

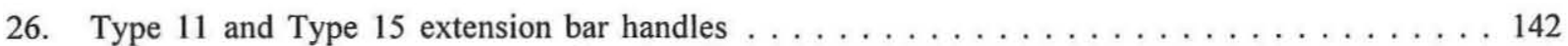

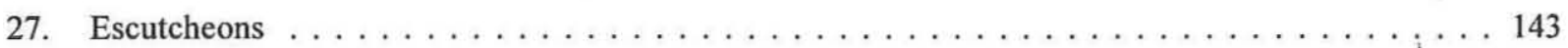

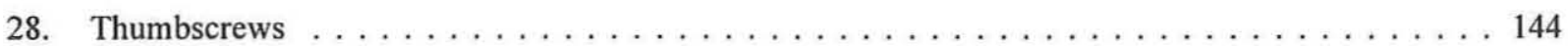

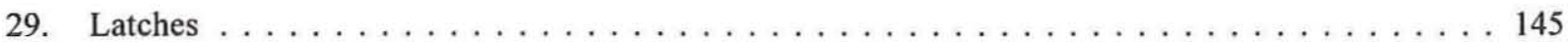

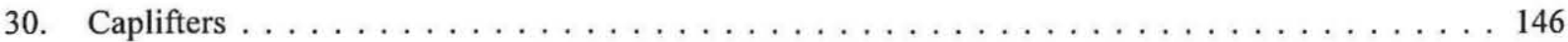




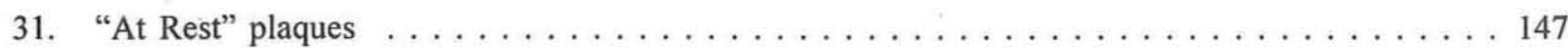

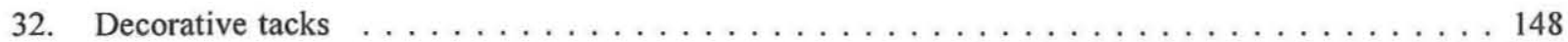

33. Decorative ornament recovered from Burial $25 \ldots \ldots \ldots \ldots \ldots \ldots \ldots$

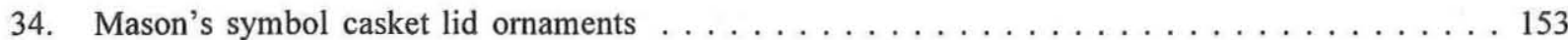

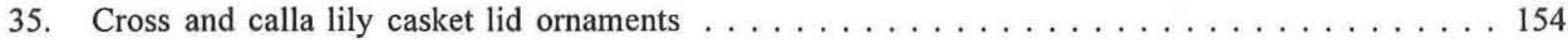

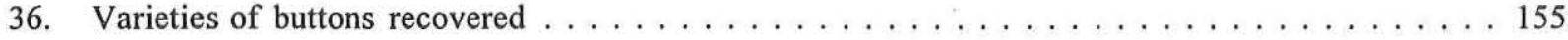

37. United Confederate Veterans buttons from Burial $47 \ldots \ldots \ldots \ldots \ldots \ldots \ldots \ldots \ldots$

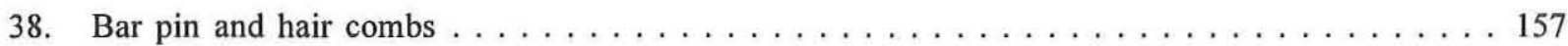

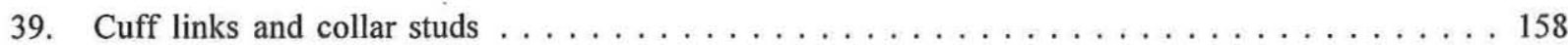

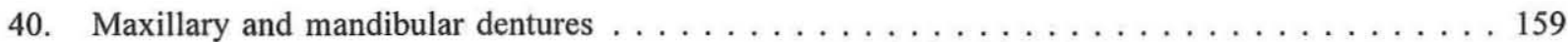

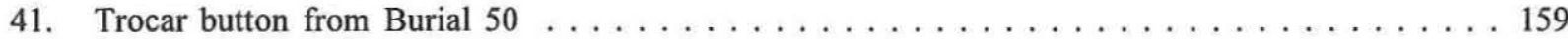

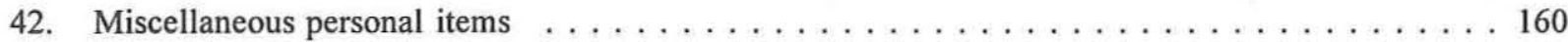

43. Relative frequency of occurrence of swing bail, short bar, and extension bar
handles in the excavated burials $\ldots \ldots \ldots \ldots \ldots \ldots \ldots \ldots \ldots \ldots \ldots \ldots \ldots \ldots$

44. Demographic composition of the burial population $\ldots \ldots \ldots \ldots \ldots \ldots \ldots \ldots \ldots$

45. Photograph of fused thoracic vertebrae, Burial $47 \ldots \ldots \ldots \ldots \ldots \ldots$

46. Photograph of lesions perforating the temporal bone of Burial $35 \ldots \ldots \ldots \ldots \ldots \ldots$

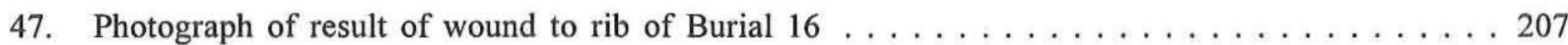

48. Photograph of pubii from Burial 46 showing neoplastic growths $\ldots \ldots \ldots \ldots \ldots$

49. Photograph showing improper ossification of a toe phalanx from Burial $10 \ldots \ldots \ldots \ldots$

50. Page from Record Book of Interments, National Cemetery, at San Antonio, Texas . . . . . . 240

51. Plat of U.S. National Cemetery, San Antonio, Texas (Paso Hondo Street) . . . . . . . . . 243

52. Photograph of memorial service for the Confederate reinterments $\ldots \ldots \ldots \ldots \ldots \ldots$ 


\section{LISTS OF TABLES}

1. Summary of backhoe and Gradall trenching results by proposed construction zone $\ldots \ldots \ldots 35$

2. Summary of historical data for the 57 individuals whose remains were

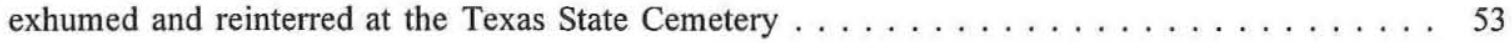

3. Occupations of men excavated from the Texas State Cemetery $\ldots \ldots \ldots \ldots \ldots \ldots$

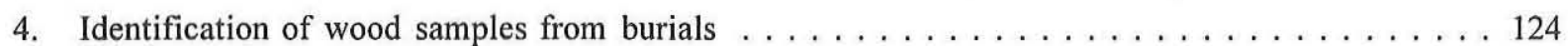

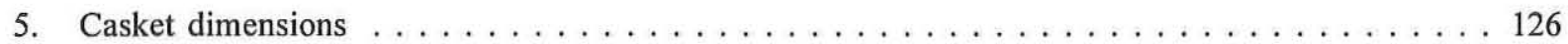

6. Comparison of casket length to estimated stature $\ldots \ldots \ldots \ldots \ldots \ldots \ldots \ldots \ldots \ldots \ldots \ldots$

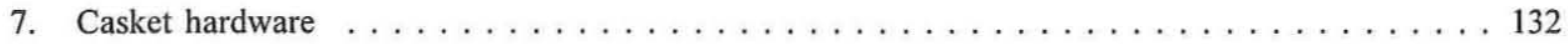

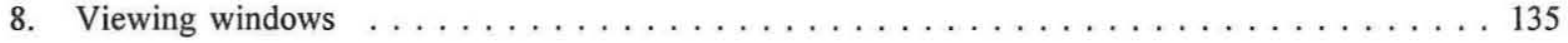

9. Personal goods associated with the excavated individuals $\ldots \ldots \ldots \ldots \ldots \ldots \ldots \ldots \ldots \ldots$

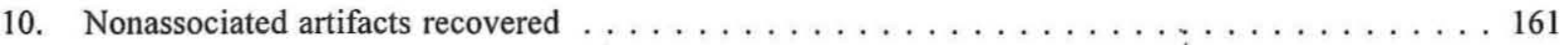

11. Comparison of types and frequencies of casket hardware from the Texas State Cemetery and other historic cemeteries . . . . . . . . . . . . . . . 170

12. Cranial metrics for the skeletal sample $\ldots \ldots \ldots \ldots \ldots \ldots \ldots \ldots \ldots \ldots \ldots$

13. Skeletal metrics for the skeletal sample $\ldots \ldots \ldots \ldots \ldots \ldots \ldots \ldots \ldots \ldots$

14. Comparison of cranial indices for the Texas State Cemetery and other skeletal samples . . . . 179

15. Postcranial metrics for the skeletal sample $\ldots \ldots \ldots \ldots \ldots \ldots \ldots \ldots \ldots \ldots \ldots$

16. Comparison of postcranial indices for males and females from the

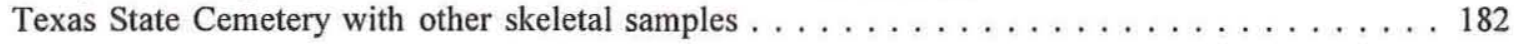

17. Comparison of stature of individuals from the Texas State Cemetery

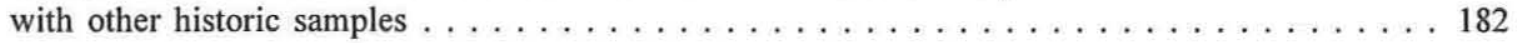

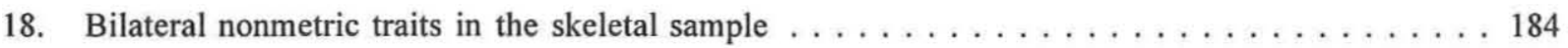

19. Nonmetric traits of variable expression (I) in the skeletal sample $\ldots \ldots \ldots \ldots \ldots \ldots \ldots$

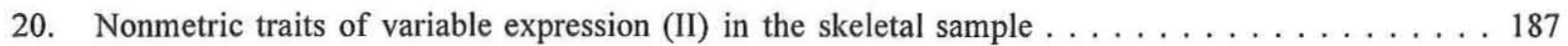

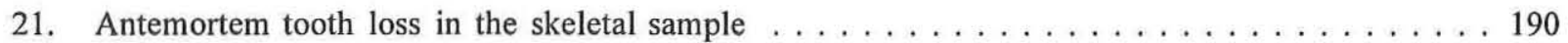

22. Antemortem tooth loss by age in the skeletal sample $\ldots \ldots \ldots \ldots \ldots \ldots \ldots \ldots \ldots$

23. Antemortem tooth loss rates per tooth type for the Texas State Cemetery

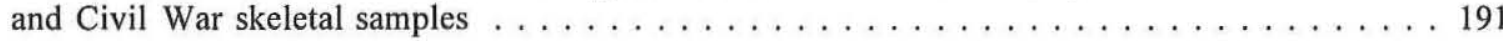

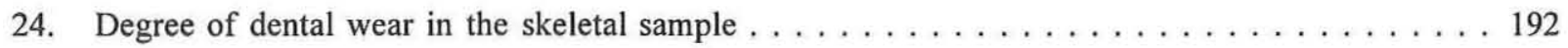

25. Degree of dental wear per tooth type in the skeletal sample $\ldots \ldots \ldots \ldots \ldots \ldots \ldots \ldots$

26. Alveolar resorption per tooth in the skeletal sample $\ldots \ldots \ldots \ldots \ldots \ldots \ldots \ldots$

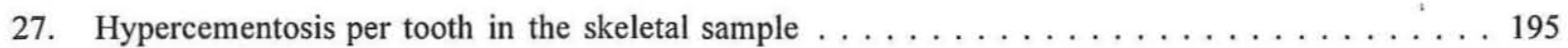

28. Percent of hypercementosis per tooth type in the skeletal sample $\ldots \ldots \ldots \ldots \ldots \ldots \ldots$

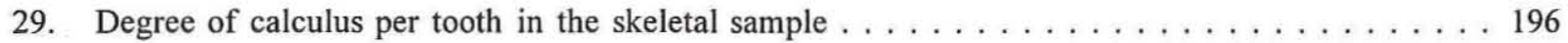

30. Percent of calculus per tooth type in the skeletal sample $\ldots \ldots \ldots \ldots \ldots \ldots \ldots \ldots$ 
31. Frequencies of caries per tooth in the skeletal sample $\ldots \ldots \ldots \ldots \ldots \ldots \ldots \ldots \ldots$

32. Comparison of percentages of caries per tooth type in the Texas State Cemetery

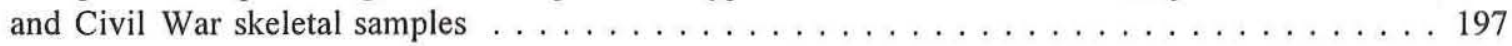

33. Frequency of caries types/locations per tooth in the skeletal sample $\ldots \ldots \ldots \ldots \ldots$

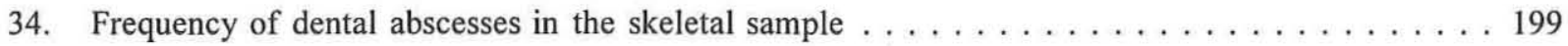

35. Percent of dental abscesses per tooth type in the skeletal sample . . . . . . . . . . . 199

36. Frequency of linear enamel hypoplasia per tooth in the skeletal sample $\ldots \ldots \ldots \ldots \ldots$

37. Percent of linear enamel hypoplasias per tooth type in the skeletal sample $\ldots \ldots \ldots \ldots$

38. Degenerative joint disorder of the appendicular skeleton in the sample . . . . . . . . . 201

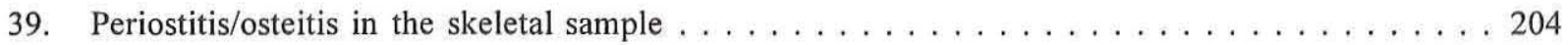

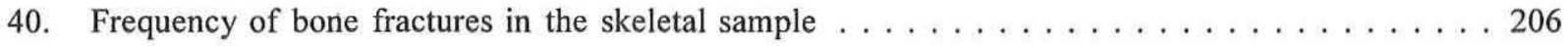

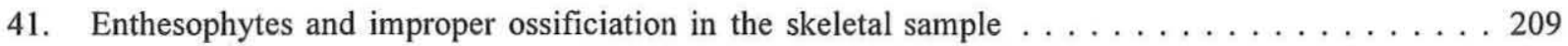

42. Primary cause of death as listed in the 1908 surgeon's report for the Confederate Home and on death certificates $\ldots \ldots \ldots \ldots \ldots \ldots \ldots \ldots \ldots$

43. Reinterments from Austin, Texas, in the United States National Cemetery

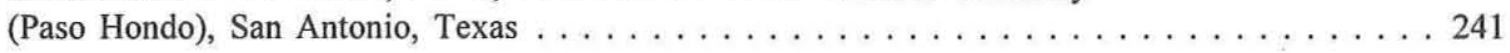


Since its inception in 1851, the Texas State Cemetery in Austin has risen in stature to become the state's premier burial place for state officials, historical figures, and prominent citizens. Extensive renovation work that began in 1995 necessitated an archeological study that included historic archival research, pedestrian survey, geomorphological assessment, mechanical testing in proposed construction zones, recording and investigation of historical features (including three unmarked graves) found in construction zones, and excavation and relocation of 57 graves of Confederate veterans and spouses. Prewitt and Associates, Inc., conducted these investigations between April and August of 1995.

Archival research provides a concise history of the development and historical significance of the 145-year-old State Cemetery. Although it was sometimes neglected and remained an obscure burial place prior to 1900 , the current project marks the third major renovation phase to be undertaken this century. The earliest extensive improvements occurred between 1910 and 1915 under the direction of Governor O. B. Colquitt. The second major overhaul, promoted by businessman and historian Louis W. Kemp, occurred during the late 1920s and early 1930s. The 1995-1996 renovations are an interagency cooperative effort, overseen by Lieutenant Governor Bob Bullock and funded in 1995 as a, Statewide Transportation Enhancement Project under the Intermodàl Surface Transportation Efficiency Act (ISTEA) of 1991. True to the visions of all its supporters, the Texas State Cemetery is destined to be more than a simple burial ground-it is becoming a cemetery-museum for the curation of Texas history.

The pedestrian survey and geomorphological investigation yielded nothing unexpected, but subsurface testing uncovered unusual features in two proposed construction zones. Three previously unknown grave pits were exposed in a Gradall trench in the northeastern corner of the cemetery where construction of a cenotaph is planned. Hand testing revealed outlines of wooden coffins that contained no human remains. Archival research uncovered two facts relating to the empty graves: (1) the northeastern 1 -acre of the cemetery was set aside between 1866 and ca. 1875 for the burial of Federal soldiers stationed in Austin during the post-Civil War Reconstruction period; and (2) the Federal burials were later exhumed and reinterred in a National Cemetery in San Antonio, Texas. Gradall trenching in the proposed Plaza de los Recuerdos construction zone uncovered extensive concrete curbing associated with a former north-south roadway that entered the cemetery from Seventh Street. Subsequent research identified these features as remnants of Albert Sidney Johnston Avenue, constructed by the short-lived Austin construction firm of Brown \& Reissig in 1912-1913 during the Colquitt renovation era. This roadwork was covered over during the 1929-1930 construction of Lou Kemp Highway.

The greatest archeological effort involved the moving of historic graves, necessitated by the master renovation plan which called for landscaping to provide a buffer between vehicular traffic along the main cemetery road and the closest graves in Sections D and F. These sections contain the graves of over 2,000 Confederate veterans, soldiers, and wives. Of these, 57 graves fronting along the central roadway were exhumed and reinterred in a safer location in Section D. Headstones associated with each grave, along with additional archival research, provided a great deal of information (minimally name and age at death) on the 1884 to 1951 burials of 51 Confederate veterans and 6 spouses whose remains were excavated. The mortuary artifacts associated with these burials, and detailed osteological analyses on skeletal remains of 56 individuals, are described. The archeological and bioarcheological data reported herein provide a rare look at the evolution of funerary traits during the early twentieth century, as well as insights into the health of an elderly group of people, many of whom fought in and survived the Civil War. Average age at death for the individuals comprising this sample is 77.3 years. An osteological examination of the remains showed that most observable skeletal disorders consisted of age-progressive changes such as arthritis, antemortem tooth loss, and caries. Signs of trauma also were common, with some skeletal conditions interpreted as evidence of war-related wounds. 


\section{ACKNOWLEDGMENTS}

The Texas State Cemetery archeological project was a successful venture - in archeological terms, because of the quantity and quality of knowledge gained, and, in human terms, because of the attendant spirit of good will and cooperation. Although the exhumation and relocation of human remains can be an emotional issue and may cause ill feelings among relatives and descendants when handled improperly, this was not the case at the State Cemetery. All aspects of the Confederate burial relocation, from prefield planning to the final memorial service for the reinterment, went smoothly and received considerable support from all parties involved. Most important in this equation was the cooperation of the families of the Confederate veterans and spouses whose remains were relocated, the local chapter of the United Daughters of the Confederacy (UDC), and the state chapter of the Sons of Confederate Veterans (SCV). Next of kin were identified for seven of the disinterred individuals. Family members who were notified of the burial relocation effort and gave their support are Mary Boyd of Manor, Texas (descendant of Jacob and Mary Ivy Burleson); Robert Bradfield of Boulder, Colorado (descendant of James O. and Louisa A. Bradfield); Jackie Fickel of Austin, Texas (descendant of George W. and Emma J. Kyser); and Jackie Tomerlin of San Antonio, Texas (descendant of Dr. John R. Ward). Ms. Fickel was especially interested in our work; she not only visited the cemetery on the day that the Kysers' burials were excavated but also provided us with important historical information pertaining to George Kyser.

For the remaining 46 persons for whom no next of kin could be found, the Albert Sidney Johnston Chapter No. 105 of the UDC and the Texas Division of the SCV acted as next of kin. This was certainly fitting since both of these organizations view the men and women of the former Confederate States of

America as family. The UDC and SCV were extremely supportive of the renovation project as a whole and of our archeological work in particular. We worked closely with these groups to insure that they knew why the burial relocations were necessary, precisely how the work would be done, and, most importantly, that the burial remains would be treated with great care and respect. We thank the following individuals for their various roles in the project: Doris Birden, Chaplain, Texas Division of UDC; Martha Hartzog, Chapter No. 105, UDC; Gregory Hector, Commander, Texas Division, SCV; Betty DuLaney Kaiser, President, Chapter No. 105, UDC; Dr. James Lewis, Texas Division, SCV; and Edith Williams, Memorial Chairman, Chapter No. 105, UDC, and Past President, Texas Division, UDC. Notably, Ms. Williams acted as liaison between Prewitt and Associates, Inc. (PAI) and the UDC and SCV organizations, and her many efforts above and beyond the call of duty are especially appreciated by the two senior authors. We are grateful for the opportunity to have worked with the family members and the many fine people of the UDC and SCV. It was their participation that truly made the Texas State Cemetery archeological project a success.

From a logistical standpoint, coordination of the archeological project was a cooperative effort primarily involving three organizations - Emily Little Architects (ELA) as Project Manager, and Texas General Services Commission (GSC) and Texas Parks and Wildlife Department (TPWD) as Project Cosponsors. Throughout the project, Emily Little did a superb job of coordinating the archeological work and keeping GSC, TPWD, and PAI informed at all times. Coordinating the cemetery work for the GSC were Carl Mullen (Deputy Executive Director), Janice Hughes (Director of the Historic State Cemetery Project Development and Public Information), and Amy Bryant (Administrative Assistant). The TPWD's involvement was coordinated by Laura David (Head of Project Management for the Construction, Design, and Maintenance Branch of TPWD). We sincerely appreciate the efforts of all of these people. The Principal Investigator extends his personal thanks to Emily, Janice, and Laura. It was a pleasure to work with these individuals because of their professional attitudes and competent supervision of the myriad details associated with this complex project. Their concern for the sensitive nature of historic grave excavations was clearly expressed in the diplomatic ways in which they dealt with public relations- 
simultaneously and skillfully attending to the needs and concerns of the relatives and descendant organizations, interested parties, the news media, and a multitude of curious visitors.

At the State Cemetery, several individuals assisted the archeologists in many ways. GSC on-site personnel Harry Bradley (Texas State Cemetery Superintendent) and John Sanchez (Texas State Cemetery Foreman) were very cooperative. Mr. Sanchez was extremely helpful on a day-to-day basis, and his extensive knowledge of the cemetery grounds, particularly with respect to locations of things under the ground (such as utility and sprinkler lines) was essential to our work. The GSC also allowed our archeological crew to set up its field laboratory in one of the on-site greenhouses, provided tables and other supplies for us to use in the lab, and let our crews use other important on-site facilities (i.e., restrooms).

While PAI's field investigations were in progress, TPWD's Force Account was on-site conducting their headstone cleaning project. Directed by David Morris, Force Account personnel (particularly John Potter, Phil McDonald, and Mike Wiggins) assisted us in many ways, providing a backhoe and an operator as needed and supplies to facilitate our excavations, as well as handling the little crises that arose from time to time. Morris also allowed us to use the TPWD photographs of the Confederate veterans' headstones and supervised the construction of the reburial containers. The TPWD also arranged for the large locking crate where the reburial boxes were stored on-site and provided assistance by mapping archeological features and integrating these data with all of the cemetery mapping data. Field mapping of archeological features was done by TPWD personnel Thomas Powell (Head of Survey and Mapping Program) and Dick Wilkinson and Harry "Corky" Kuhlmann (Survey Crew Chiefs); L. C. Williams (Head of Production Support Program) and Eric Harden (Interactive Graphic Technician) provided us with map printouts and computerized mapping data.

Official documentation of the renovation project by the state, including videotaping of various aspects of the archeological investigations, was supervised by Kevin Kennedy of GSC, Richard Galord of the Lower Colorado River Authority, and Debbie Head, House Correspondent with the Texas House of Representatives.

The Texas Department of Transportation also provided assistance to our field archeologists. Gradall operator Larry Flippin became an important part of our archeological team, for both the trenching in construction zones and the trenching to remove overburden from the burials. His skillful Gradall operation precisely exposed the top of each burial and saved us a great deal of hand digging.

Texas Historical Commission (THC) staff members provided their expertise during our field investigations. Gerron Hite (Architecture Division) participated in planning meetings and freely shared much of his historical knowledge and data on the State Cemetery with the field archeologists and Project Historian. Overseeing the Texas Antiquities Permit for the archeological work, Mark Denton (Department of Antiquities Protection) was involved in several planning and on-site progress meetings where decisions regarding historic features were made.

Jerry Henderson, Principal Investigator of the Freedman's Cemetery project in Dallas for the Texas Department of Transportation, was extremely helpful in planning the burial relocation work and provided specifications for the construction of reburial containers. James Davidson reviewed data pertaining to the mortuary artifacts from the State Cemetery and provided information about similar burial artifacts from the Freedman's Cemetery that otherwise would have been unavailable since the results are not yet published. Dr. Gentry Steele, with the Physical Anthropology Laboratory, Department of Anthropology, Texas A\&M University, loaned some of the lab's osteometric equipment for use at the State Cemetery. $\mathrm{He}$ also reviewed some photographs of skeletal anomalies and provided insights on questionable diagnoses. 
Other organizations and individuals who took an interest in our archeological work and visited the excavations, helped in the planning stages, expressed their support, or otherwise participated in the project include Bill Brinkman, Camp Commander, Sam Houston Camp of the Sons of Union Veterans of the Civil War; John Culberson, Texas State Representative, District 130; Carl Deichmann, 8th Texas Cavalry, Texas State Guard; Lee Kinard, Austin Genealogical Society board member; Carl R. McQueary, Daughters of the Republic of Texas Museum Director and Commissioner of the Texas Historical Commission; Daniel Laney, Austin Civil War Round Table; and Jerry Patterson, Texas State Senator, District 11.

Historical research was aided by numerous persons and organizations. The Project Historian was aided in her research by the competent staffs of the Austin History Center and the Texas State Archives and Library as well as the Perry-Castañeda Library and Center for American History at The University of Texas at Austin. Marcella Reissig and Janet Long Fish provided historical data in interviews, and Alvin J. Sander, Assistant Director of the Fort Sam Houston National Cemetery, assisted research relating to reinterments of Federal soldiers from Austin. Research to identify next of kin was conducted by Janice Hughes and Amy Bryant for the GSC and by TPWD Research Assistant Vicki Hagen. Peggy Fox, Associate Director of the Harold B. Simpson Confederate Research Center in Hillsboro, Texas, conducted considerable research for us, free of charge, and provided index cards to the Compiled Service Records of the Confederate veterans and regimental histories. Senator Patterson, whose grandfather is among the Confederate veterans buried at the State Cemetery, directed us to the Roster of Inmates for the Confederate Home for Men at the Texas State Archives. Kinga Perzynska, archivist at the Catholic Archives of Texas, aided in researching the religious symbolism of certain mortuary artifacts.

Key PAI project personnel were Douglas K. Boyd, Principal Investigator; Helen Danzeiser Dockall, Project Archeologist/Osteologist; Joan Baker, Assistant Osteologist; Karl W. Kibler, Project Geomorphologist; and Martha Doty Freeman, Project Historian. Field personnel for the burial relocation effort were, in addition to Dockall and Baker, excavators Rolando Garza and Kevin Stork, assistant excavator and photographer Wayne Klement, and assistant excavator Jon Geiselbrecht. These cheerful, hard-working, and dedicated crew members were responsible for the timely and efficient completion of the burial excavations. There could have been no better group of people to have had at the site on a daily basis. Artist Ellen Atha, whose superb pen and ink illustrations greatly enhance this report, was on call every day and made frequent trips to the cemetery to make field sketches of burial artifacts. Brent Scott assisted in the geomorphological investigations. Volunteers who helped excavate burials on a few occasions were Greg Baker and John Dockall.

And finally, the PAI office staff are thanked for their many contributions to the project. Elton Prewitt and Ross Fields provided thoughtful guidance in the planning and execution of the project. Jeanine Cuellar and Karen Gardner made sure that the project was well equipped with field and lab supplies. In addition, Gardner kept track of the project records and prepared them for permanent curation, while Cuellar kept the field crew happy by providing the all-important paychecks. Other PAI personnel were involved in report preparation. Helen Holum did the initial wordprocessing of some of the chapters. After initial technical editing by the Principal Investigator, Linda Nance Foster did her usual high-quality editing job. The many fine figures (other than artifact illustrations) were produced by Sandy Hannum and Brian Wootan. Foster and Wootan completed the final production of this report. 


\section{INTRODUCTION}

Douglas K. Boyd

At the time of the cemetery's inception with the burial of Edward Burleson in 1851, a handful of people saw the potential of the little plot of land on the prominent hill 1 mile southeast of the Texas State Capital. They envisioned this spot as Texas's premier burial place for prominent state citizens and heroes. Their prophesy fulfilled, the property now known as the Texas State Cemetery is indeed the prominent burial ground of which these early visionaries dreamed. Although the cemetery has suffered many years of benign neglect during its 145 -year history, it has continued to grow in importance since the turn of the century. The state's attitude toward caring for the property has shifted from one of obligation to one of respect and reverence. Unique among the 50 United States, Texas is the only state to wholly own, support, and manage its own official state cemetery.'

Located in Austin, Texas, between Comal, Navasota, Seventh, and Eleventh Streets, the Texas State Cemetery is the final resting place for over 3,000 important Texans and their spouses. Among them are many high-ranking state officials and former governors, such as "Pa" and "Ma" Ferguson; veterans and heroes of the Army of the Confederate States of America, the most notable being General Albert Sidney Johnston; Republic of Texas leaders, patriots, and signers of the Texas

'No other state cemeteries appear among the properties listed on the National Register of Historic Places.
Declaration of Independence, such as William "Bigfoot" Wallace, Jacob de Cordova, Edwin Waller, and Robert Potter; and many citizens, such as Stephen F. Austin, whose names are synonymous with important events in the history of the Lone Star State. Of the many notable persons interred or memorialized there, 18 are mentioned in a recent pamphlet produced by Austin's Historic Landmark Commission for self-guided walking tours of the cemetery. Noting "Cemeteries have lives of their own," the pamphlet proclaims, "As the state of Texas has changed, so has the character of her official cemetery" (Germany 1995:2-3).

As the steward of this honored burial ground, the State of Texas has undertaken at least two major and numerous minor renovations of the cemetery during this century. The first extensive improvements, which included landscaping and roadwork, were made between 1910 and 1915 under the direction of Governor O. B. Colquitt. Also during this time, the remains of several important Texas heroes, including Stephen F. Austin, Joanna Troutman, and General John A. Wharton, were reinterred there. The second major renovation occurred between 1926 and 1936, the decade immediately preceding the Texas Centennial celebration. Vigorously promoted by businèssman and historian Louis W. Kemp, these improvements included construction of State Road Spur 165 . Now known as the Lou Kemp Highway, this stretch of pavement constructed by the State Highway Department has the distinction of being the shortest state highway in Texas. In addition to 
the roadwork, the remains of 76 prominent Texas heroes were removed from their original burial locations and reinterred in the cemetery in the 1920 s and early 1930 s.

The cemetery continued to rise in status over the next half-century, although few improvements were made with the exception of construction of a substantial enclosing fence. By 1963 , the cemetery had become so popular that the Texas Legislature passed a bill restricting interments there to individuals who met specific criteria (see Chapter 3).

Before the close of the twentieth century, the State of Texas will have completed yet another major renovation of the cemetery. This most recent renovation project was planned in the early 1990s and began to materialize in 1995. A master plan for the renovation was developed by JVR and Associates and the Texas Parks and Wildlife Department (1995), and the project was funded in 1995 as a Statewide Transportation Enhancement Program under the Intermodal Surface Transportation Efficiency Act (ISTEA) of 1991. The project received widespread support and was promoted by many prominent Texas officials, most notably the current lieutenant governor, Bob Bullock. This work was not undertaken simply to upgrade the physical setting of an important old cemetery. Rather, and more importantly, the project sought to promote the cemetery as a historical site, to increase public access to and visitation of the cemetery, and to foster public awareness of the many important historical figures who are buried there. The Texas State Cemetery is more than a burial ground - it has become a cemetery-museum for the curation of Texas history.

One of the primary considerations during the early planning stages of construction projects on state-owned lands is the identification, evaluation, and management of cultural resources. This is particularly true for the State Cemetery, which itself is a cultural property encompassing many important features that must be carefully managed. As part of the overall planning of the renovation, Prewitt and Associates, Inc. (PAI), of Austin, Texas, was hired as an archeological consultant to conduct specific investigations within the overall program of cultural resources management. PAI became involved rather late in the planning stages and did not participate in the formulation of the renovation plan. In addition, because of the unusual nature and scope of this project, PAI did not assume the normal cultural resources management role that it usually does for most projects. While many archeological projects utilize archeological consultants to conduct all aspects of the cultural resources study, PAI was responsible only for the archeological and historic archival portion of the cultural resources study. Independent of the archeological study, the Architecture Division of the Texas Historical Commission was responsible for documenting and evaluating standing architecture, and the National Register Division of the Texas Historical Commission was responsible for reviewing issues of overall site integrity and significance since the southern half of the cemetery was listed on the National Register of Historic Places as part of the East Austin Historic District in 1985.

The overall organizational structure of the Texas State Cemetery Renovation Project is complex, but only a few state agencies and private entities were directly involved with the archeological study. The General Services Commission (GSC) is the owner/manager of the cemetery and a project co-sponsor. The other project co-sponsor, Texas Parks and Wildlife Department (TPWD), is the lead agency responsible for developing the renovation master plan, project design, and implementation. The Austin firm of Emily Little Architects (ELA) was hired by TPWD to serve as an independent Project Manager to coordinate the work of various consultants and contractors, including the archeological work. PAI contracted with TPWD to conduct the archeological investigations as required by the Texas Antiquities Code (Title 9, Chapter 191 of the Texas Natural Resources Code of 1977) - the state's primary law dealing with protection and investigation of cultural resources. The Department of Antiquities Protection (DAP) is the division of the Texas Historical Commission that reviews archeological work on state properties done under the Texas Antiquities Code.

Prior to the beginning of the fieldwork, a meeting was held on 20 April 1995 among GSC, TPWD, ELA, DAP, and PAI. Based on discussions during this meeting, PAI developed a "Plan of Work for Stage I Archeological Investigations at the Texas State Cemetery." This work plan was submitted to DAP as part of an application to receive a Texas Antiquities Permit that would allow PAI to conduct the archeological work in 
accordance with the Texas Antiquities Code. DAP subsequently approved the application and work plan and issued Texas Antiquities Permit No. 1549 to PAI.

The archeological investigations were conducted from April through July 1995. The work conducted by PAI consisted of (1) archival research, (2) on-site geoarcheological investigations, including subsequent archeological recording and testing of selected historic features that were discovered, and (3) excavation of 57 burials of Confederate veterans and spouses. All of the archival and archeological investigations described in this report were done to fulfill the requirements of the Texas Antiquities Permit and were conducted according to specifics defined in the work plan mentioned above. These activities are summarized briefly below, and the specific methods for accomplishing each of these tasks are described in Chapter 2.

PAI began its archeological investigations in April of 1995 with historic archival research conducted by Austin historian Martha Doty Freeman. This research had three primary goals: (1) to construct a chain of title for the cemetery property and determine if there were any historic improvements on the land prior to its designation and use as the State Cemetery; (2) to research records relating to the historical development of the cemetery in order to document the locations of all graves and burial areas and any other improvements (e.g., buildings, roads, and walkways) that were made over the years; and (3) to review general literature and archival documents to define the historical context of the cemetery. The result of these endeavors is a concise history of the cemetery, presented in Chapter 3.

On-site investigations began with a pedestrian survey of the 18-acre cemetery area (Figure 1) to locate surface evidence of prehistoric or historic activities and to define the areas where subsurface testing would be most productive. Other than occasional pieces of historic/modern debris and considerable evidence of disturbances (i.e., dumping of gravelly fill and land leveling) in some areas, nothing unusual was found. The surface examination took into account the areas that would be disturbed by proposed cemetery renovation construction (Figure 2).

A series of 12 backhoe trenches was excavated down to sterile, ancient sediments to define the geomorphology of the cemetery area (Figure 3). No prehistoric or historic materials were encountered, but the geomorphic evidence revealed that the cemetery area is characterized by thin soils situated on a late Pleistocene-age high lag gravel terrace of the Colorado River. Based on the investigations, the potential for encountering intact prehistoric cultural deposits was considered to be extremely low (see Chapter 4). Many of the trenches were located intentionally in or adjacent to the proposed construction zones, but no cultural features were encountered.

Backhoe trenching was followed by a series of 31 Gradall trenches excavated primarily to search for unmarked graves and other historic features in the proposed construction zones (see Figure 3). The Gradall tests resulted in relatively unimportant historical finds in several areas, but significant finds were made in only two proposed construction zones. Three unmarked graves, suspected of being burials of Federal troops from the Reconstruction period, were encountered in the Northeast Cenotaph construction zone, and old concrete curbing and roadwork features were uncovered in the Plaza de los Recuerdos construction zone. On 1 June 1995, an on-site review meeting among PAI, ELA, GSC, TPWD, DAP, and representatives of the Texas Historical Commission's National Register and Architecture Departments was held to review these archeological findings and discuss what additional work should be done. Based on these discussions, a preliminary summary report making specific recommendations for additional work was submitted to DAP and subsequently approved on 3 July 1995 .

Another archeological project planning meeting was held on 2 August 1995 among PAI, ELA, TPWD, and DAP to reach a consensus on additional archival research and archeological work needed. PAI then produced another document, called the "Plan of Work for Stage II Archeological Investigations at the Texas State Cemetery," that specified what archeological work remained to be done before clearance could be given for construction activities to proceed. After being reviewed and approved by DAP, the Stage II work plan became an attachment to Texas Antiquities Permit No. 1549. The Stage II archival and archeological work focused on identifying and investigating the unmarked graves and concrete features found in the construction zones. Archival 


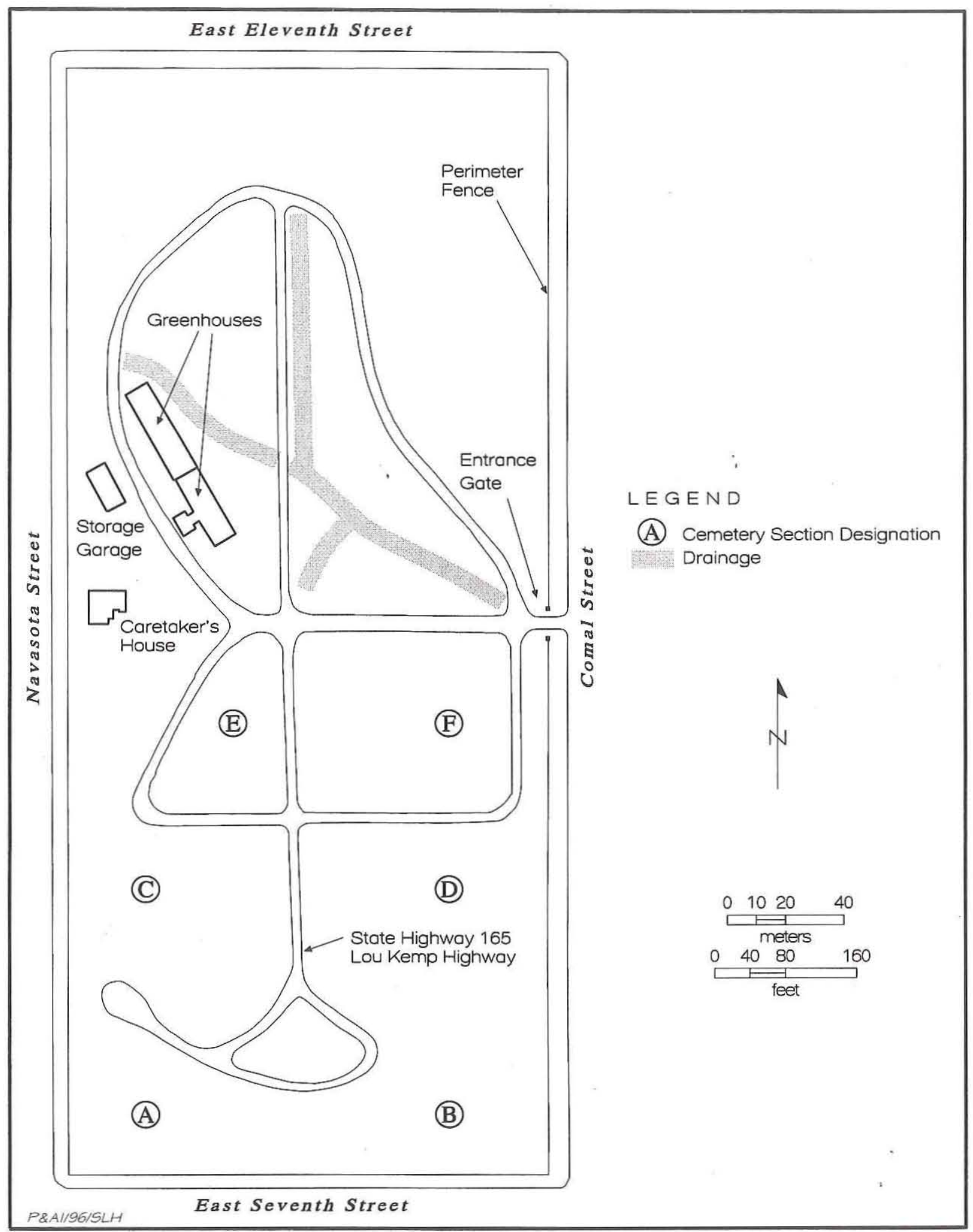

Figure 1. General map of the Texas State Cemetery project area. 


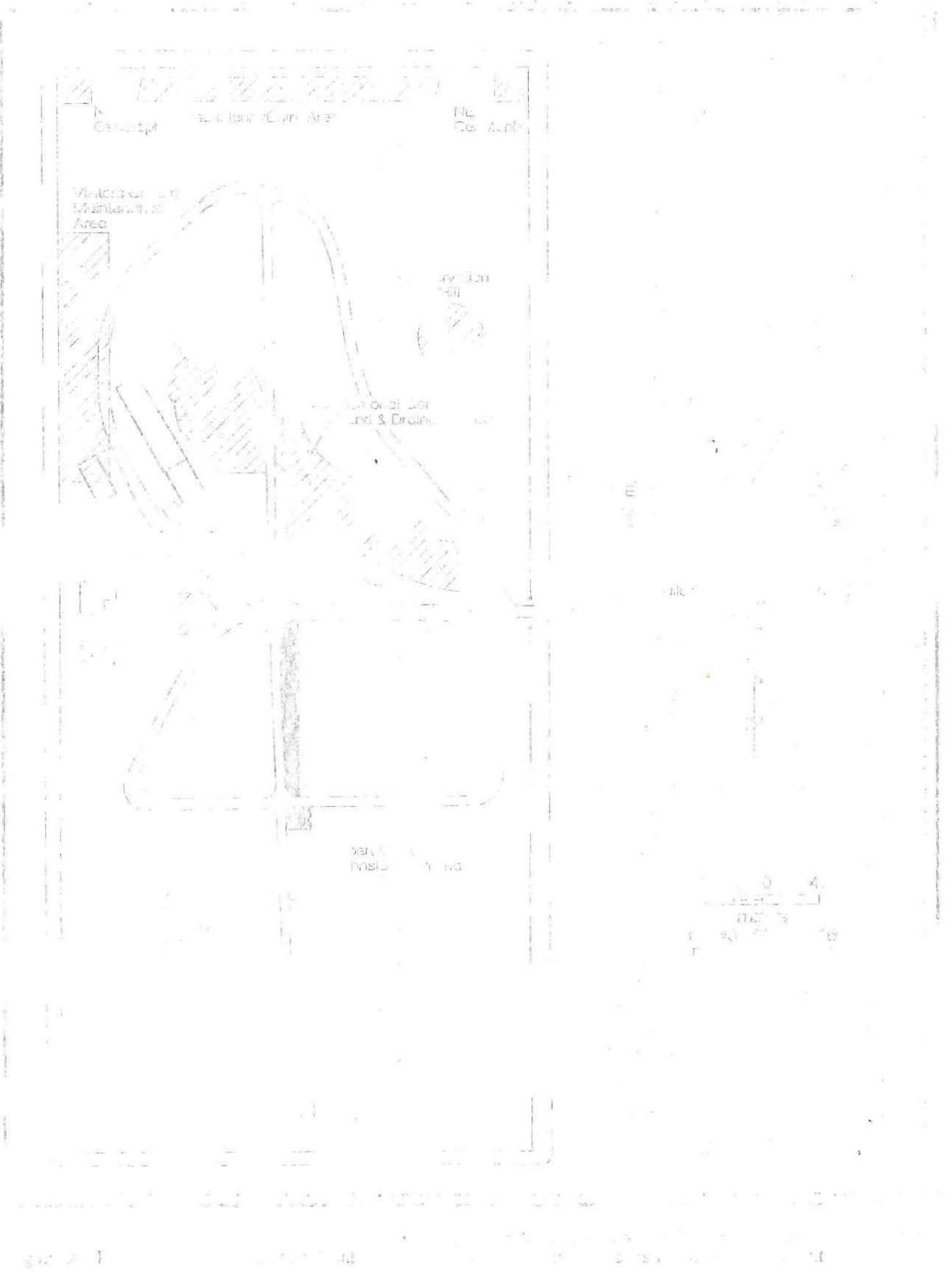




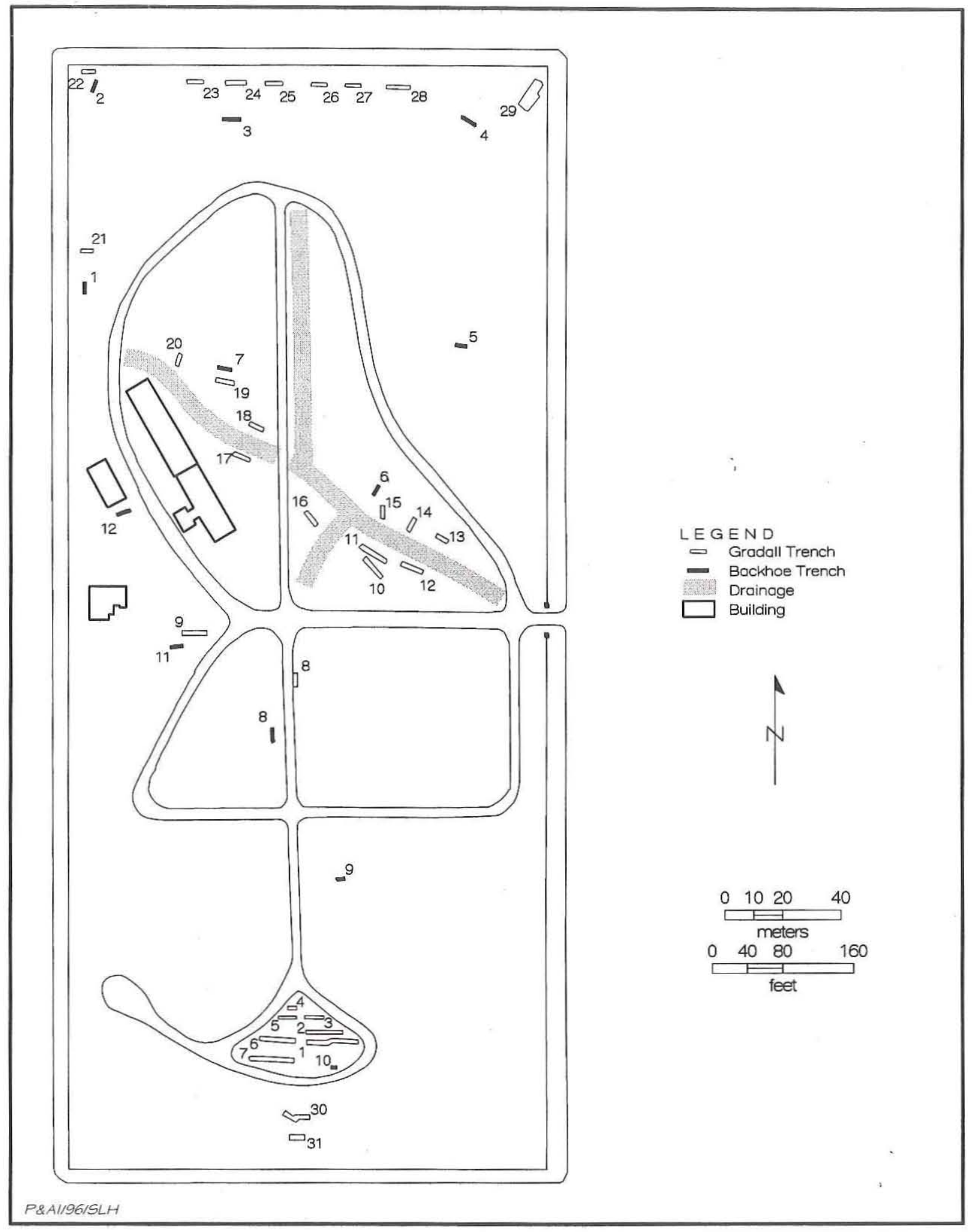

Figure 3. Project area map showing locations of subsurface testing. 
research related to the unmarked graves confirmed that Federal Reconstruction troops had been buried in the cemetery but that their remains subsequently were reinterred in a National Cemetery in San Antonio, Texas. This historical information is presented in Appendix A. Archival research also confirmed the age of the concrete roadwork found in the Plaza de los Recuerdos construction zone and identified the contractor who constructed the features (see Chapter 3). All of the geoarcheological investigations (Stages I and II), including the subsequent archeological testing and recording of historic finds in the construction zones, are described in Chapter 4. Detailed descriptions of selected geologic profiles from subsurface tests are presented in Appendix B.

The most intensive effort of the field archeological investigations was the exhumation of 57 burials of Confederate veterans and spouses located in Sections D and F. All of the exhumed burials were located immediately adjacent to the Lou Kemp Highway that runs north-south through the cemetery. These graves had to be moved to a safer location in Section D because the renovation plan called for roadway expansion and landscaping to provide a buffer zone between vehicular traffic and the burial areas (see Figures 2 and 3). Beginning on 12 June 1995, 2 graves were excavated each work day until all 57 were removed. Except for one burial containing a complete iron coffin that was moved intact, the remains from all of the other burials were replaced into speciallyconstructed reburial boxes. All burial remains were temporarily stored at the cemetery, under lock and key in a large metal storage vault, to await reburial.

A few words of explanation are warranted regarding the archeological investigations of historic burials. All of the burial excavations were done using standard archeological techniques. The caskets and skeletal remains in each area were carefully exposed by hand, sketched, photographed, and then removed from the ground. The remains were then taken to the nearby laboratory set up in a greenhouse at the cemetery, where additional studies were conducted. At the end of each day, the skeletal remains and all associated artifacts from each burial were put into reburial boxes. All of the physical remains - casket wood and hardware, personal items buried with individuals, and human skeletal remains-were examined and recorded using well-established historic archeologi$\mathrm{cal}$ and osteological techniques. The great wealth of data that was accumulated in the process and the interpretations of these data are the subject of much of this report. There are many kinds of information that may be gained from careful archeological excavation and analysis of historic burial remains (see Chapter 2).

Because of construction activities associated with modern developments such as highways and reservoirs, it sometimes becomes necessary to move historic graves and even entire cemeteries. Regardless of the reasons for moving graves, archeological investigation of historic burials has become commonplace in the United States only within the last 20 years. Prior to the use of archeological techniques, historic burials were usually hand dug by laborers who knew or cared little about the remains they were exhuming. There are numerous examples of cemetery relocations where nonprofessional excavation techniques have resulted in entire graves being missed or substantial amounts of skeletal materials being left behind in graves that were exhumed (Deming et al. 1993; Dockall 1996; Murray and Perzigian 1995; Nawrocki 1995). At the Phillips Memorial Cemetery, for example, most of the excavated individuals had been disinterred previously by the Road and Bridge Committee of Galveston County in 1927 , but the county workers frequently left behind portions of the skeletons, although usually only the smaller elements (e.g., fibulae, patellae, carpals, tarsals, and vertebrae), while the larger bones and any remains still contained within clothing generally were removed (Dockall 1996). Even worse, backhoes often were used to exhume burials quickly (Carter and Ragsdale 1976:36) in a crude and callous manner that, not surprisingly, offended descendants who witnessed such acts. In a few extreme cases, historic cemeteries simply have been bulldozed away without any attempt to protect and rebury the remains. Such atrocities are not relegated to the past, unfortunately, as evidenced by recent events at a cemetery near Los Angeles, California; in 1995, cemetery officials routinely were digging up and discarding historic burials so that the plots could be resold (Austin American-Statesman, June 24, 1995:A17).

Fortunately, however, the use of historic archeological techniques has been clearly established during the last two decades as the most 
acceptable means of excavating graves slated for relocation. This transition has occurred primarily because those involved with burial and cemetery relocations came to realize that archeological techniques are, without a doubt, the most nondestructive, respectful, and cost-effective way to exhume historic human remains. In return for the careful and reverent treatment of the remains, archeologists learn many unrecorded facts and a great deal of history. Burial excavations have become so common that entire books have been written about historic cemetery relocations. One such book, entitled Bodies of Evidence: Reconstructing History through Skeletal Analysis (Grauer 1995), contains 14 articles summarizing historic burial excavations across the United States. Among the anthropological subjects studied during these and other cemetery relocations are such topics as evolution of mortuary traits and attitudes toward death, socioeconomic patterns in burial populations, historic patterns of health and disease in urban and rural settings, and demographic patterns, mortuary traits, and health/disease patterns of specific ethnic groups. Research questions that guided the State Cemetery burial relocations and analysis are presented in Chapter 2.

In Texas, many excavations and relocations of nineteenth- and early-twentieth-century burials and cemeteries have been conducted, in both urban and rural settings. Investigations of family, community, or church cemeteries have been done in San Antonio (Schuetz 1974), Laredo (McReynolds 1981), Galveston (Dockall and Steele 1995; Dockall et al. 1996), at Choke Canyon Reservoir in south Texas (Fox 1984), at Lake O. H. Ivie in north-central Texas (Earls et al. 1991), at Cooper Lake in east Texas (Lebo 1988; Winchell et al. 1992, 1995), and at a proposed lignite mine in east-central Texas (Taylor et al. 1986). The largest cemetery excavation effort to date was the relocation of a small portion of the large AfricanAmerican Freedman's Cemetery in Dallas. Investigated in conjunction with the construction of the Central Expressway, the cemetery was originally thought to be less than 1 acre in size, but it turned out to cover about 4 acres. Only a small portion of the entire cemetery was excavated, and 1,156 intact burials were exhumed and relocated between 1990 and 1994. As many as 6,000 or more burials may remain in privately owned areas that were not excavated (Henderson 1995).
While descendants, relatives, and related ethnic group organizations occasionally are displeased when remains of their ancestors need to be moved because of proposed developments, they almost always are pleased when they learn that careful archeological techniques will be used to exhume the remains. Descendants and others involved with the process (e.g., federal and state agencies, private construction contractors and developers, and the archeological community) have been quite successful in negotiating, on a projectby-project basis, specific methods and procedures that are acceptable to all parties.

The results of the burial studies are described in Chapters 5 through 7 , and excavation and analysis methodologies are described in Chapter 2. Additional supporting data are presented in Appendixes $\mathrm{C}$ through I. The, archeological and osteological forms that were used to record field and lab data are presented in Appendix C. Much of the technical data relating to the analysis of human remains is reported in Appendixes D through G.

As part of the prefield process, the General Services Commission (GSC) attempted to identify the next of kin of some individuals whose remains were to be moved. The majority (i.e., 47 of 57 individuals) of the Confederate veterans and spouses whose remains were moved were poor people who had lived in the state-supported Confederate Home for Men in Austin. Since no records of relatives could be found in the GSC's cemetery files or in the Confederate Home roster, it became clear that there was little hope of identifying next of kin. Consequently, the local Albert Sidney Johnston Chapter 105 of the United Daughters of the Confederacy (UDC) was consulted and agreed to speak on behalf of these individuals. The UDC was notified of the proposed relocations of Confederate veteran burials as the master renovation plan was being formulated. Since the vast majority of individuals interred in the Texas State Cemetery are Confederate veterans and spouses (over 2,047 according to Germany [1995:3]), the support of this organization was considered critical to the entire renovation project. Knowing that the ultimate goal of the renovation was to promote visitation and increase historical awareness, the UDC wholeheartedly supported the renovation project.

The GSC was successful in identifying next of kin for 7 of the 11 individuals buried in Section 
D. When notified of the cemetery renovation project and the necessity of relocating the burials, relatives of all these individuals gave their approval, and many were very supportive of the project. The process of identifying and notifying these individuals and the next of kin of the individuals buried in Section $F$ is discussed in Appendix H.

As soon as the burial excavations began, PAI invited the UDC and the Texas Division of the Sons of Confederate Veterans (SCV) to visit the cemetery and witness firsthand the archeological process of excavating, removing, and studying the remains. Both organizations visited on more than one occasion and stated their approval of the archeological procedures and treatment of the remains. In addition to the UDC and SCV, representatives of several other historical groups visited the excavations (i.e., the Texas Military, Forces Museum at Camp Mabry, Austin Genealogical Society, Save Texas Cemeteries, Daughters of the Republic of Texas, and Daughters of the Republic of Texas Museum) and noted their approval of the investigative methods.

The burial excavations concluded on 31 July
1995, at which time the remains of 55 of the 57 individuals were moved to new locations in Section $\mathrm{D}$ and reinterred. The reburial boxes containing the remains of Confederate Army captain John S. Pannell and his wife, Margaret C. Pannell, were retained for a reburial ceremony the following week. On Monday, 7 August 1995, in a solemn memorial service commemorating the 57 people whose remains were moved, the Pannells were laid to rest again. The memorial service, organized by the UDC and SCV, was an appropriate tribute to the former men and women of the Confederacy and a fitting conclusion to the burial relocation effort (Austin American-Statesman, August 8, 1995:B1). More information on the Confederate memorial service is found in Appendix I.

After all of the archeological work was completed, a final letter'report summarizing the project investigations and findings was sent to DAP in late September. Based on the recommendations in that letter, the DAP gave their approval on 3 October 1995 for construction activities associated with the Texas State Cemetery Renovation Project to proceed. 



\section{METHODS}

\section{2}

Helen Danzeiser Dockall, Douglas K. Boyd, and Martha Doty Freeman

The archeological investigations conducted by Prewitt and Associates, Inc., at the Texas State Cemetery met three goals: (1) to locate historic features that would be impacted by construction work; (2) to excavate and analyze 60 burial features that would be disturbed by subsequent architectural work; and (3) to address general research questions relating to the burial population. This chapter documents the archival and archeological methods used to locate nonburial historic features, as well as techniques used to excavate and document the burials. Descriptions of crew tasks, laboratory set-up, and photographic techniques are included in the discussion of the burial exhumations. Osteological techniques applied to the skeletal analysis of excavated individuals are described. Due to the historic nature of this site, archival records played an important role in interpreting the data from both nonburial and burial contexts. Therefore, a discussion of the historic records examined also is incorporated into this section. Lastly, public relations management for the archeological project and the procedures for reinterment of the exhumed individuals are discussed.

\section{ARCHIVAL RESEARCH}

Stage I investigations called for archival research involving four subtasks: (1) compiling a chain of title for the cemetery tract; (2) documenting the locations of known graves and the development of the State Cemetery for the purpose of verifying that there were no areas where unmarked graves were located; (3) reviewing primary and secondary sources to place the cemetery in an appropriate context; and (4) completing a report on the findings. Initial work on the project involved the compilation of deeds and other legal documents at the Travis County Courthouse and the Texas State Archives for the purposes of establishing a history of the ownership and use of the cemetery property prior to 1851 and understanding the mechanisms by which the private tract became public property. This endeavor led to a general review of legislative and other public documents that contained information about nineteenth-century interments, the development of policy concerning interments, and the passage of appropriations for the development of the cemetery and its infrastructure.

Review of documents at the courthouse and cemetery was followed by a review of materials in the offices of Janice Hughes (General Services Commission), Laura David (Texas Parks and Wildlife Department), and Gerron Hite (Texas Historical Commission); and conversations with Janet Reed, former superintendent of the State Cemetery, and Jack Hightower, Chairman of the Executive Committee of the Austin Scottish Rite of Freemasonry. Supplementary material 'was collected at the Austin History Center and Center for American History at The University of Texas at Austin. Finally, a limited amount of research about American and European cemeteries was completed at the Perry-Castañeda and Architecture 
Libraries at The University of Texas at Austin. This information was supplemented by data provided by Toni Lee at the National Park Service (National Register Programs) in Washington, D.C.

Information about the Confederate veterans and their wives was also gained by examining pension records, Confederate Home reports, surgeon reports, general index cards of compiled service records, obituaries, and death certificates. Pension records and the roster for the Confederate Home for Men were examined at the Texas State Archives. The Biennial Report of the Board of Managers of the Texas Confederate Home (1908) provided data on cause of death for all individuals who died in the Confederate Home in 1907 or 1908. Cause of death for people who died in other years was attained through obituaries or death certificates. The general index cards to the compiled service records of Confederate soldiers, provided by the Harold B. Simpson Confederate Research Center, Hillsboro, Texas, listed beginning and ending ranks and regimental information for most people excavated from the cemetery.

The Stage II archival research had specific goals relating to two different sets of archeological features encountered during the Stage I investigations. Research relating to the buried concrete road curbs found in the proposed Plaza de los Recuerdos construction zone concentrated on identifying basic historic details such as who built the features and when. As mentioned in Chapter 3 , this work consisted of a review of selected Austin city telephone directories and Travis County records, along with oral history interviews with a descendant of one of the people thought to have built the features. Additional Stage II research was done to identify further the nature of the unmarked but empty (i.e., containing no human remains) graves found in the Northeast Cenotaph construction zone. This work, which consisted primarily of a review of records at Fort Sam Houston National Cemetery in San Antonio, Texas, is described in detail in Appendix A.

\section{GEOARCHEOLOGICAL INVESTIGATIONS}

Geoarcheological work was an important part of the Stages I and II investigations (see Chapter 4). The initial tasks were a reconnaissance and intensive pedestrian survey of the entire 18 -acre cemetery by the Principal Investigator and Project Geomorphologist. Finding nothing of significance, the Project Geomorphologist then directed the excavation of 12 backhoe trenches to define the site sediments and interpret the evolution of the current landforms (see Figure 3). Following this, the Principal Investigator and Project Archeologist selected locations for stripping sediments in each of the proposed construction zones. Thirty-one Gradall trenches were excavated to sterile sediments throughout the project area (see Figures 2 and 3), primarily to search for unmarked graves but secondarily to provide additional geomorphic data. Geological profiles for selected backhoe and Gradall trenches were subsequently described. Profile descriptions and the methods used to document the site sediments are described in Appendix B. Backhoe work was done by Texas Parks and Wildlife Department personnel using a machine that was kept on-site; Gradall work was done by Texas Department of Transportation personnel who brought the machine to the site on several occasions. The locations of all trenches were plotted on large-scale $(1 \mathrm{inch}=30 \mathrm{ft})$ maps by triangulating from two or more known points. Selected trench profiles also were photographed using both black-and-white print and color slide film.

Historic features found in several Gradall trenches necessitated detailed recording and/or hand excavations. The presence of historic and/or modern debris in several trenches (including a dense trash midden in one trench) was recorded, and notes and sketches of diagnostic artifacts were made. Hand excavations were required for better exposure of the buried concrete in the proposed Plaza de los Recuerdos construction zone. These features were documented thoroughly through measured sketches, written descriptions, and photographs. Since the objective was simply to define the features, it was not necessary to employ many standard archeological techniques such as uniform excavation units and levels and screening of sediments. Rather, it was more appropriate to use shovels, trowels, and brushes to quickly clean the features exposed.

Two complete rectangular grave pits were identified in the floor of Gradall Trench 29, and a third was identified in the floor and east wall profile of the trench. The fill from each of these unmarked graves was excavated entirely by hand, 
although a backhoe was used to remove the remainder of the overburden from the third grave and to dig a trench beside each grave to facilitate excavation (i.e., the excavator could stand in the trench and excavate the grave just above waist level). In general, the upper fill of all three graves was excavated by shovel skimming, while the lower fill was troweled down to the bottom of the coffin or burial pit. No human remains were found in any of these graves, thus corroborating the archival evidence indicating that these features represent burials of Federal soldiers whose remains were subsequently moved (see Chapter 3 ). Lacking human remains, no detailed recording of these features (such as that described below for the Confederate burial exhumations) was warranted. Each of the three burial pits and any coffin remnants were measured and sketched, photographs were taken, and artifacts from the lower grave shaft fill or associated with the coffins were collected. In addition, wood samples were collected from two of these graves.

The archeological investigations and interpretations of the historic features found in the construction zones are discussed in Chapter 4 . The precise locations of all excavations and features within the Plaza de los Recuerdos and Northeast Cenotaph construction zones were mapped by Texas Parks and Wildlife Department personnel.

\section{CONFEDERATE BURIAL RELOCATION}

Fifty-seven burial features were excavated in conjunction with the Confederate burial relocation effort. These graves were located in Sections D and F (see Figure 2) and contained the remains of Confederate veterans and their spouses. Grave locations were marked by headstones placed along the eastern side of Lou Kemp Highway (also called State Highway 165 or State Road Spur 165). Although most of the headstones faced west toward the road, the individuals were interred to the east of the headstones.

\section{Burial Excavations and Analysis}

Heavy machinery, either a Gradall or a backhoe, was used to remove the overburden from the 57 Confederate graves (Figure 4). A crew member monitored the machine excavations and halted overburden removal when casket wood or a soil change was noted. Shovel skimming was done until the outline of each rectangular grave pit was defined. The east and west ends of each grave were marked with stakes labeled with the cemetery plot number. This was especially important because all Confederate headstones from Sections D and $\mathrm{F}$ were removed by employees of the Texas Parks and Wildlife Department so that they could undergo an extensive cleaning process as part of the renovation work. After the overburden was removed mechanically and the graves were staked, the upper fill in each grave shaft (i.e., down to the casket top) was removed manually the day prior to removal of the burials (see following).

A crew composed of six members excavated the burial features. The process involved the excavation and analysis of two burials each day. In terms of tasks, the on-site crew was composed of a Project Archeologist/Project Osteologist (Helen Danzeiser Dockall), two excavators (Rolando Garza and Kevin Stork), a photographer (Wayne Klement), and two laborers (Joan Baker and John Geiselbrecht). Baker also served as assistant osteologist. An illustrator (Ellen Atha) was available on an "on-call" basis when artifacts requiring detailed drawings were excavated (such as casket handles, thumbscrews, escutcheons, and plaques). So that artifacts never left the cemetery grounds, pencil sketches of all illustrations were done in the field laboratory. Final inking was done in the Prewitt and Associates laboratory, and copies of the completed drawings were brought back to the field lab and placed in a notebook. The on-site sketches were used for assigning numbers to different hardware types, as well as to show visitors examples of recovered artifacts.

A team of three people worked on the excavation of each burial, and two teams worked concurrently throughout the project. Each team was responsible for the exhumation of one burial each day, including filling out excavation and artifact forms (described below).

Although not a legal requirement, standard practice among archeologists working on historic burial excavations in Texas has been to analyze all human remains and associated burial artifacts and place them into new burial containers on the same day that they were excavated. Out of respect for the relatives and descendant groups, this practice was observed at the State Cemetery. As burial 


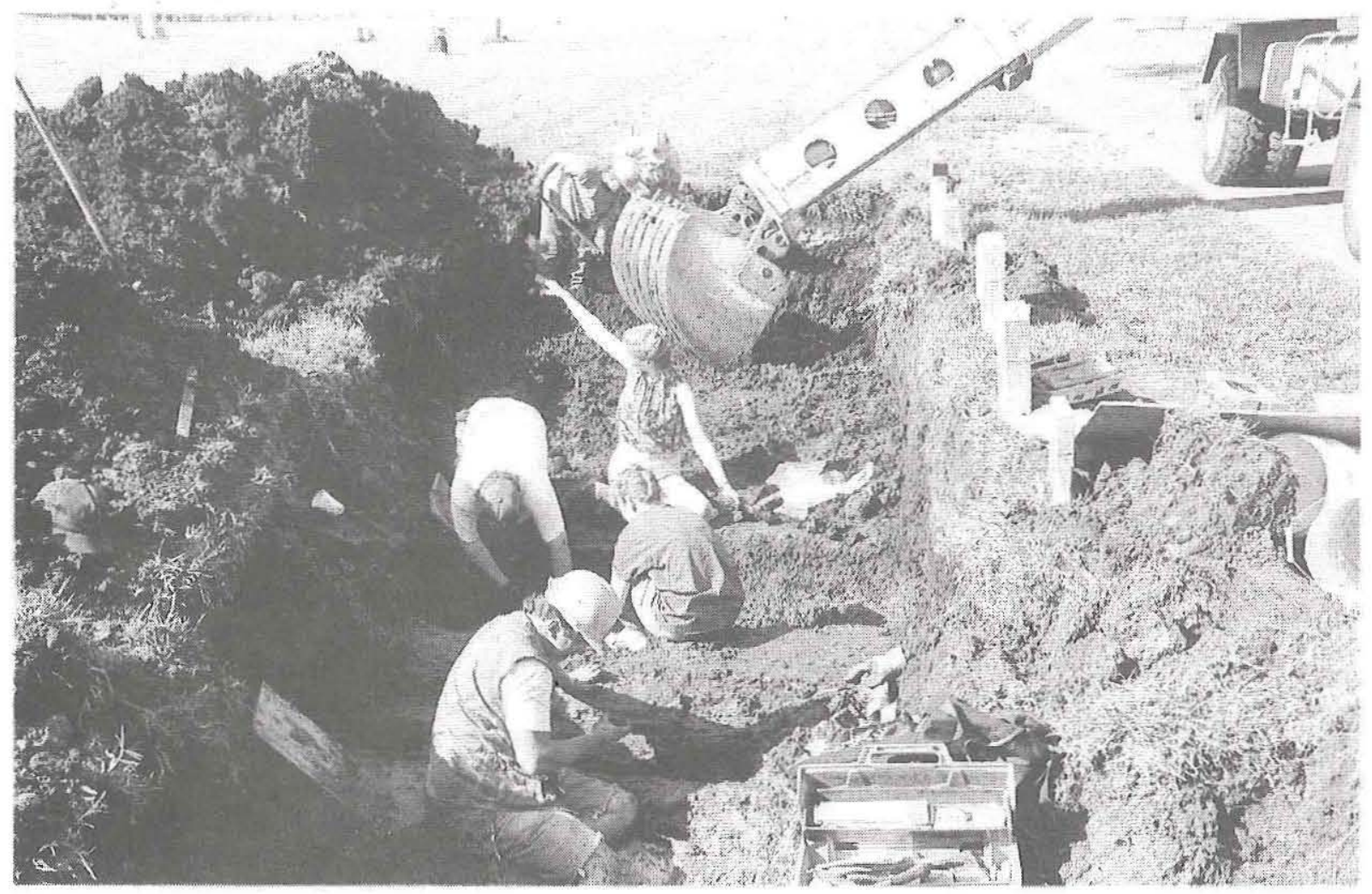

Figure 4. Archeological excavation of burials in Section F. View is to the south, with excavators exposing burials in the foreground while the Gradall and other archeologists clear overburden in the background.

items and human remains were placed into reburial containers at the end of each day, these boxes were stored on-site in a locking cabinet to insure their protection. All items associated with a burial were kept at the cemetery at all times and were eventually reinterred there, with three exceptions. First, in a few cases, fragments of wooden or metal caskets that were too large to be placed into reburial containers were left in place and reburied in their original locations once all human remains and other burial items had been removed. Second, small fragments of wood were collected from each wooden casket so that wood types could be identified. And third, selected examples of different types of casket hardware and a few clothing items such as buttons and cuff studs were collected (21 items from 17 burials) at the request of the United Daughters of the Confederacy and family members. The collected wood samples and burial items are curated at the State Cemetery, along with other project records, for future research and/or possible on-site public displays at the Visitors Interpretive Center.
When skeletal remains began to be removed, the Project Osteologist and her assistant went to the field lab to begin analysis, while the remaining four crew members completed the excavations. Once all artifacts and skeletal materials had been removed, subsequent analysis was conducted in the field lab. While the artifacts were being cleaned, processed, photographed, and described, one laborer worked on clearing the overburden from the two graves scheduled to be excavated on the following day. When possible, the laborer or a member of the Texas Parks and Wildlife Department used a backhoe to dig a trench alongside the graves to make the next day's excavations easier.

A transit datum was established near the intersection of the main drive to the cemetery and Lou Kemp Highway, across from the first burials in Section F. Transit readings were taken on the ground surface at the base of each headstone and at the east and west ends of the tops of all caskets. The only exception to this occurred with Burial 10, in which the Gradall removed the lid; in that case, the transit reading of Burial 10 represents the casket floor. 
All burials were excavated using a modified version of the zone system described in Guendling et al. (1985) for use at the Cedar Grove Cemetery and successfully applied during the excavation of the 41DT105 cemetery in east Texas (Winchell et al. 1992) and the Phillips Memorial Cemetery (41GV125) in Galveston County (Dockall et al. 1996). This system divides each burial into five zones labeled A through E (Figure 5). All skeletal remains coming from the region of the skull are classified as Zone $\mathrm{A}$, while the right upper portion of the body (shoulder, ribs, and upper arms) is designated as Zone $\mathrm{B}$, and the left upper portion is Zone C. The lower arms and hands always were classified according to their respective upper body section (i.e., right lower arm and hand in Zone B), regardless of whether arms were folded or extended. The right pelvis, leg, and foot are considered Zone D, and the left pelvis, leg, and foot fall into Zone E. All postcranial axial elements (vertebrae and sacrum) are placed in the right side zones (B and D). Artifacts recovered from the casket walls and inside the casket also were assigned to this zone system. Excavation techniques included quickly exposing each burial and photographing, mapping, and then removing the skeletal remains by zone, beginning with Zone A.

This allowed the osteologists to begin cleaning and analyzing the most time consuming portion of the skeleton (the skull) before other zones were brought to the laboratory.

Burial excavations were generally completed in a 4-hour period each morning. Artifact description and analysis were conducted each afternoon in the field laboratory. A greenhouse in the northern portion of the cemetery served as the field laboratory for osteological and artifact analyses, as well as photography of artifacts and skeletal remains. This lab was divided into four major areas: two burial analysis stations, an osteology station, and a photography station (Figure 6). The burial analysis areas were composed of two excavator's tables. Each excavator was assigned a set of tables for the purpose of insuring that remains from the burials were not unintentionally intermingled with each other. Artifacts and skeletal materials from separate zones were placed on these tables to await 


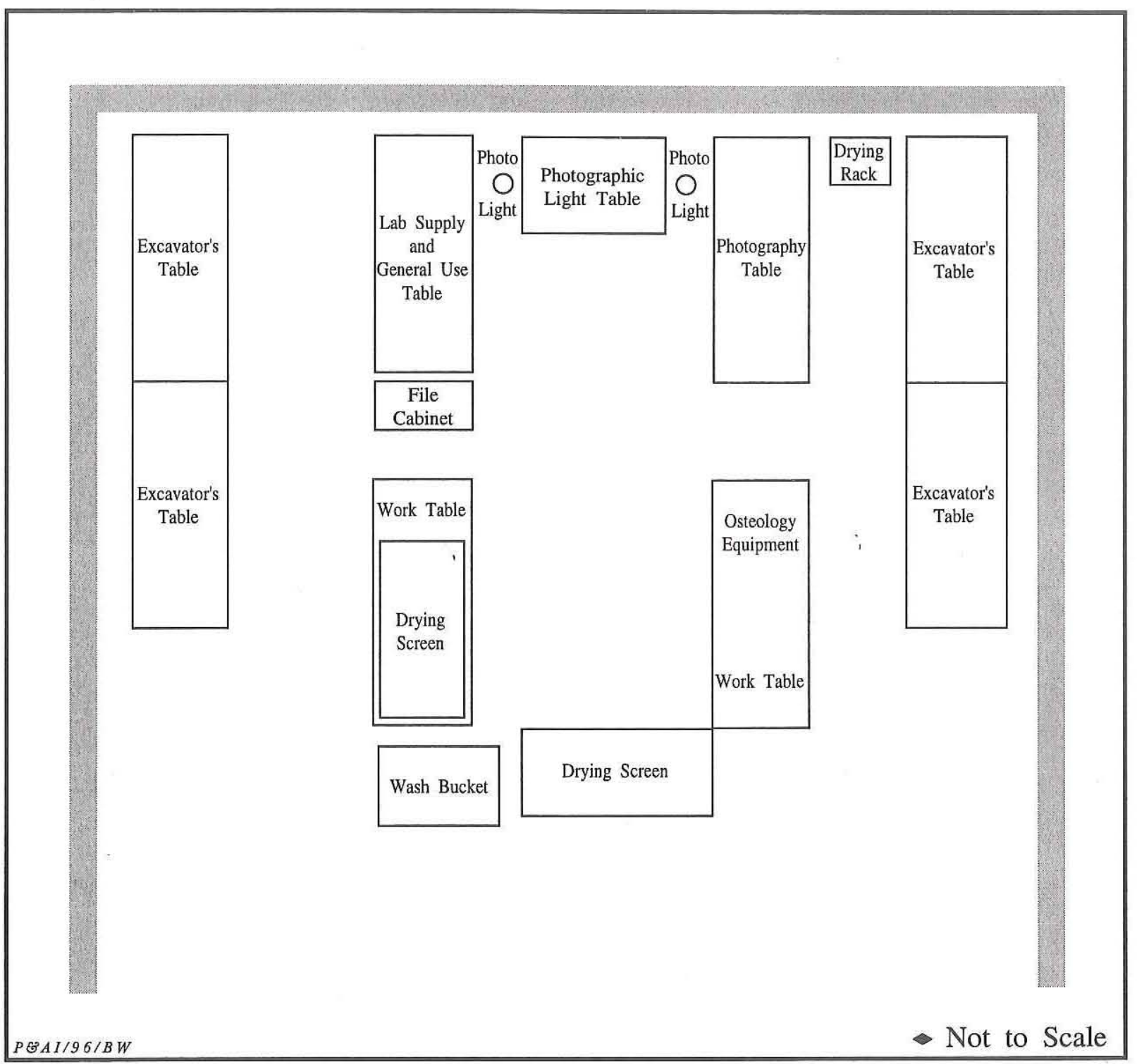

Figure 6. Schematic plan view of layout of field laboratory.

analysis. Once the analysis was completed, they were returned to the table to await placement in the reinterment box (see following). The photography and osteology stations were placed between the excavator's tables. Their central location allowed the photographer and osteologists easy access to material from either of that day's excavated burials. The photography area contained a light table, two lamps, and a work table. The osteology section of the lab was composed of a centrally placed washing bucket, two drying screens set on work tables, and a table with osteometric equipment. Each of the osteologists was responsible for the cleaning and analysis of one burial each day. The use of two screens and work tables insured that commingling of the individuals never occurred, but the close proximity of the osteologists to one another allowed easy discussion pertaining to osteological questions.

Archeological and osteological data forms were filled out for each excavated individual (see Appendix C). Excavators were responsible for completing the archeological forms and associated artifact forms. Archeological information noted with each burial included soil type and color and a description of the casket, including materials 
used in its construction, casket shape, orientation, length, and width. In addition, the position of the individual within the casket and any disturbance to the skeleton was recorded. Grave goods, such as buttons, jewelry, and clothing items, were noted as to number and recovery zone, as were mortuary items, including casket handles, thumbscrews, escutcheons, and viewing window glass. Excavators also noted the presence and location of miscellaneous objects like bottle glass, cans, and animal bones. A detailed plan drawing illustrating the casket, the position of the body within the casket, and associated grave goods and mortuary hardware was completed for each burial. Each artifact excavated from a grave was described on a form that includes information about the object's type, size, material, and location. Photographs were taken of casket hardware, and detailed drawings were made. The excavators completed field sketches of artifacts that were too poorly preserved to be illustrated clearly using a photograph or artist's rendering.

\section{Osteological Analysis Techniques}

The osteologists completed a 13-page form for each individual (see Appendix C). The first two pages consist of a generalized skeletal inventory. This is followed by a pathology form for recording observations on infectious, degenerative, metabolic/ hematological, and developmental disorders, and/or evidence of neoplasms and traumas. Detailed metric and nonmetric data and observations on cranial and postcranial elements are recorded on pages 4-11. The final two pages of the form document dental wear and pathology.

Each skeletal element was examined for any sign of disorder; when a disorder was noted, it was described and the location of the lesion was recorded. Although these individuals were of known sex, a nonmetric assessment of sex was made based on characteristics of the skull and pelvis, and metric sex assessment was made using dimensions of the talus and calcaneus. Independent confirmation of sex was necessary to insure that headstones or personal information on headstones were not reversed, particularly for husbands and wives buried together. Cranial characteristics of biological affinity were recorded, and cranial and postcranial metrics were taken. Each individual was examined for a series of 33 nonmetric traits.
Occasionally a nonmetric trait was observed that was not listed on the coding form. In these cases, the traits were noted at the bottom of the form. In addition, maxillary and mandibular dentition were inventoried and notes were made as to whether each tooth was present, lost antemortem, or lost postmortem. The degree of wear on each observable tooth was recorded, as was alveolar resorption. The presence or absence of abscesses, calculus, linear enamel hypoplasias, and hypercementosis was observed, and the size and location of any caries were recorded. The archeological and osteological data forms filled out for each of the excavated burials are curated at the Texas State Cemetery.

The photographer was responsible for documenting the progress of field excavations and for taking overall burial shot's and laboratory photographs of artifacts and human skeletal remains. Four 35-mm single-lens reflex cameras were used on-site, two in the field and two in the lab. Laboratory photographs of the human remains were limited to elements bearing evidence of health or developmental disorders as well as genetic variations. All photographs were taken using both Kodachrome 64 color-slide film and Plus X Pan 125 black-and-white print film. Photographs of artifacts and skeletal remains taken in the lab were shot on a light table using additional lighting from both sides provided by flood lamps.

The methods used in the osteological analysis are described below. Because two burials had to be excavated and analyzed each day, the amount of data that could be obtained was limited. However, an effort was made to collect those data that would best describe this sample and prove most useful to other researchers (see Appendix C). It was especially important to collect as much information as possible given that this sample was of such a unique demographic composition and because all individuals were to be reburied and therefore would not be available for other osteologists to examine. Since cleaning the material is a necessary step in analysis, all skeletal material from each burial was carefully washed with water only. A screen was placed in the bottom of the wash tub to catch any small bones or pieces of bones that fell into the tub during the cleaning process. It was not possible to retain any elements for future research or to obtain radiographs. 


\section{Demographics}

Age and sex data were recovered from historical sources such as headstones, pension records, or death certificates. Age was not assessed based on the recovered skeletal remains, but sex determinations were made using both nonmetric and metric assessments. Nonmetric evaluations were made based on cranial and pelvic indicators (see Appendix C) using the Acsadi and Nemeskeri (1970) technique of ranking each trait on a scale from -2 (hyperfeminine) to +2 (hypermasculine). Metric sex assessments were based on the measurements of the femoral head diameter (with $45 \mathrm{~mm}$ as a sectioning point for males and females) and talus and calcaneus. We originally intended to take five measurements from each talus, but time constraints limited us to maximum length and maximum width, measured according to Steele (1976). Body height and load arm width of the calcaneus were also measured following Steele (1976). From these measurements, discriminant functions 2 and 5 in Steele and Bramblett (1988:Table 11.7) were calculated.

\section{Metrics}

Cranial and postcranial measurements listed in Standards for Data Collection from Human Skeletal Remains (Buikstra and Ubelaker 1994) served as a guide when composing the osteology forms. All 34 of the cranial metrics suggested in Standards were recorded with the exception of bizygomatic diameter, mastoid length, and mandibular angle (see cranial metric sheet in Appendix C). All 44 postcranial measurements listed in Standards were measured when possible, as was transverse diameter of the humeral head (see postcranial metric sheet in Appendix C). Maximum height of the scapula was the only postcranial measurement that we originally planned on recording but were not able to take. Fragmentation of this element prevented measurement in every case.

All skeletal metrics were taken according to the descriptions provided in Standards (Buikstra and Ubelaker 1994:74-84). All diameter and breadth metrics were taken using GPM sliding or spreading calipers. A plastic-coated cloth tape was used to record circumference, and a portable infant recumbent board was used to record maximum length of long bones. Where applicable, all measurements were taken on the left side when possible. Right-side measurements were recorded in cases in which the left side was poorly preserved or a health disorder prevented an accurate reflection of the bone's growth.

Stature was estimated using Trotter and Gleser's (1952) formulae as presented in Bass (1987:Tables 4 and 5). Maximum length measurements were taken on all long bones when available, but preference for estimating stature from long bone length was given to bones of the leg. The age-correction factor of subtracting $.06 \mathrm{~cm}$ per each year of age over 30 years (Bass 1987) was considered when estimating overall stature at time of death. For the two analyzed individuals possessing an extra lumbar vertebra, this additional element was not factored into the height equation. A more-accurate stature estimation for these two individuals would have been provided by the use of an anatomical method for stature reconstruction (see Lundy 1988), but time constraints and poor preservation of the vertebral column prevented the implementation of this detailed technique.

\section{Nonmetrics}

All nonmetric traits of primary importance suggested in Standards were recorded, when observable (see nonmetric forms in Appendix C). These 33 traits (including the sutural bones) were defined following Buikstra and Ubelaker (1994: 87-92). In addition to these discrete traits, several others that were not placed on the original coding list were observed in the sample. These traits consisted primarily of extra vertebrae and sacralization of the fifth lumbar, although other discrete traits of the hands, feet, and skull were noted. All of these instances were added to the coding form and are discussed with the original nonmetric traits in Chapter 7.

\section{Health}

Indicators of skeletal health provide much information about childhood and adult stressors, from disease to trauma. In addition, skeletal changes can provide data on general age changes. All dental and skeletal elements associated with each of the excavated individuals were examined for signs of pathological disorders.

Examined dental disorders include alveolar 
resorption, abscesses, calculus, hypercementosis, linear enamel hypoplasia, and caries. In addition, occlusal dental wear was assessed using the method described in Smith (1984). All teeth observable in each individual's maxillary and mandibular dental arcades were coded as to the degree of dental wear with 1 representing no wear and 8 representing destruction of crown. Alveolar resorption was coded only when the alveolar margin was complete and uneroded. Resorption was divided into slight (1-3 $\mathrm{mm})$, moderate $(4-5 \mathrm{~mm})$, and severe $(>5 \mathrm{~mm})$ categories; 0 represented none. Dental abscesses (cervical or apical) were coded as to location (buccal/labial or lingual) and size. Abscesses measuring $3 \mathrm{~mm}$ or less were considered small, 3-5 $\mathrm{mm}$ were medium, and greater than $5 \mathrm{~mm}$ were large. Because alveolar bone is thin and thus subject to taphonomic processes resulting in erosion, care was taken to record only those defects with rounded margins. Calculus was differentiated into small areas, coalesced areas, or three-dimensional deposits. Hypercementosis was noted on teeth with observable roots and was coded strictly on a presence/absence basis. Only enamel hypoplasias of a linear nature were noted, but all available teeth were examined for their presence. The number of defects per affected tooth was noted, but measurements of the defect from the cementoenamel junction were not recorded. Dental caries were recorded on all observable teeth based on surface location and type. Size of the lesions was coded as small $(<3 \mathrm{~mm})$, medium $(3-5 \mathrm{~mm})$, and large $(>5 \mathrm{~mm})$. It was not possible to conserve any teeth for future research as recommended in Standards, which suggests retention of the central maxillary incisor, mandibular canines, a mandibular third and fourth premolar, and the mandibular second molar (Buikstra and Ubelaker 1994:58). In addition, time restrictions prevented the casting of teeth.

Skeletal disorders were divided into several major categories, including infectious/reactive, degenerative, metabolic/hematological, neoplastic, and developmental disorders. In addition, trauma in the form of fractures and wounds was observed. Each lesion was described in terms of location and bone response. Diagnoses were based primarily on Ortner and Putschar (1985) and Steinbock (1976), as well as paleopathological and medical journal articles. Plaques on the surface of bone or striations incorporated into the cortex of the bone were considered to be indicative of periostitis, while swelling of the bone with medullary involvement was considered indicative of osteitis. Small pits on the surface of the skull were coded as a general cranial infection, unless they were accompanied by expansion of the diploë, in which case the lesion was coded as porotic hyperostosis. Degenerative joint disease was coded when associated with lipping and porosity or eburnation of the articular surface. Fractures were coded as to type, location, and alignment. The majority of skeletal lesions were photographed.

\section{RESEARCH ORIENTATION FOR BURIAL RELOCATION}

Although done out of necessity to facilitate renovation plans, the exhumation and relocation of State Cemetery historic buirials provided a unique research opportunity. Unlike many cemetery relocations where little is known about the excavated individuals, the detailed information for the 57 Confederate veterans and spouses allowed for formulation of very specific research goals. These research goals were divided into two broad categories: (1) assessment of demographic characteristics and health status of the burial population as evidenced by skeletal remains; (2) sociological and socioeconomic characteristics and changes evident in mortuary traits and archival data. Because the true research potential was unknown until excavations revealed the precise nature and state of preservation of mortuary artifacts and skeletal remains, only general research questions could be formulated prior to the fieldwork. The general research questions that were initially proposed and guided the data analyses are stated below. These and many other more-specific research questions are addressed using the skeletal and material culture data in Chapters 6, 7, and 8.

\section{Demography and Health Status}

Prior to fieldwork, the State Cemetery burial population was known to be composed primarily of people over 60 years of age and include 51 men who fought in the Civil War and 6 of their wives. Consequently, the following general research questions relating to demographic and health issues were proposed:

1. What was the general health status of the elderly population? 
2. Can any age-related health problems be identified? If so, at what frequencies do they occur in the population?

3. Is there any evidence of health-related problems that might be due to unusual Civil Warera stress?

4. Can any health-related problems be attributed to post-Civil War stress?

5. Are there any significant differences between the men and women in terms of health conditions or care?

6. Is there any skeletal evidence of Civil War battle injuries? If so, what injuries are represented and how frequent are they?

7. How does the State Cemetery burial population compare with excavated burial populations from other historic cemeteries in terms of health and demography?

\section{Social and Socioeconomic Characteristics}

Before the exhumations occurred, historic records indicated two important facts about the State Cemetery burial population. First, although burials spanned the period 1884-1951, most of the individuals were interred at two different times, with the largest group dating to 1907/1908 and a smaller group dating to the $1920 \mathrm{~s} / 1930 \mathrm{~s}$. Secondly, the burial population consists of two distinct socioeconomic groups - a large group of dependent people who lived at the Confederate Home for Men vs. a smaller group of well-to-do individuals. Consequently, the following social and socioeconomic research questions were proposed:

1. What stylistic characteristics and elements are evident in the funerary equipment associated with these burials, and are any significant changes apparent between the early and late groups? If so, what are the sociological implications behind such changes, and do these stylistic trends fit the patterns observed in other historic cemeteries?

2. Is the economic differentiation apparent in the archival records also reflected in the funerary equipment associated with the burials?

3. Is the economic differentiation apparent in the archival records also reflected in the personal items buried with individuals?

4. If economic differentiation is manifest in the material culture associated with the burials, does the evidence reflect apparent or real differ- ences in the socioeconomic status of the individuals?

5. Within the burial population, were the dependents, i.e., those whose burials were paid for by State and other public funds, given pauper's burials or did they receive a more dignified burial than evident in other pauper cemeteries?

\section{PUBLIC RELATIONS}

Archeological excavations occurring in an urban area attract the public's attention. Because the excavation and relocation of human remains is almost always fraught with emotion, great care was taken to (1) locate descendants of the excavated individuals and other interested groups (in this case, the United Daughters of the Confederacy and the Sons of Confederate Veterans), and (2) inform the public of the reasons for and methods employed in the excavation and relocation. The General Services Commission assumed responsibility for the notification of kin (see Appendix H) and most public relations. Because these actions were taken, the excavations proceeded with significantly greater ease than many other similar excavations (see especially Harrington 1993 and Powell 1996). While many news stories were generated by the activities taking place at the cemetery, none resulted in overt negative responses toward the project in general or crew members in particular.

When conducting public archeology, one needs to educate visitors as to what is occurring, preferably without disrupting the work output of the crew. Although the burial excavation area was cordoned off from the public, there were probably fewer than 5 working days during the course of the field excavations (12 June to 31 July 1995) on which no visitors came to the site. These visitors ranged from individuals, to families, to large groups. Due to the support of other groups involved in the renovation, particularly the General Services Commission, Texas Parks and Wildlife Department, and Emily Little Architects, the excavations were carried out with minimal disruption. Texas Parks and Wildlife printed a laminated questionand-answer sheet that was attached in several places to a temporary fence around the burial excavation area. This sheet included a discussion of the restoration project, a list of organizations involved in the project, and the nature of the archeological work being conducted. It clearly 
stated which graves were being relocated and why, in addition to explaining briefly the archeological methodology employed by the excavators. Copies of this form were made available to site visitors.

Janice Hughes, director of the Texas State Cemetery Renovation Project for the General Services Commission, was in charge of public information. In this capacity, she led many organized tours through the field excavation and laboratory analysis areas. At least four groups composed of members of the United Daughters of the Confederacy and Sons of Confederate Veterans toured the site, as did a group of Daughters of the Republic of Texas. In addition, Ms. Hughes led smaller groups through the site, including some descendants of the excavated individuals, members of the Texas legislature and various state agencies, and news reporters. Because Ms. Hughes assumed responsibility for public relations, it allowed the Project Archeologist to spend her time working with the site excavation itself, while still ensuring that the responsibility of educating the public, a crucial aspect of urban archeology, was achieved.

Several articles pertaining to the excavations were published in the Austin-American Statesman and the West Austin News while the excavations were in progress. In addition, the Texas Parks and Wildlife Department produced a story about the cemetery renovation and burial excavations that was distributed to 17 news stations in Texas. A crew from the House of Representatives Audio/ Video Services also spent a morning at the site recording the excavations for their archives. Other videotape documentation of the archeological investigations was done periodically by the Lower Colorado River Authority for the General Services Commission. In all cases, news reporters and camera men were reminded of the importance of respecting the excavated individuals and advised not to photograph or record the skeletal remains.

In dealing with the public, Prewitt and Associates followed advice suggested by Goldstein (1995:6) when excavating historic cemeteries: "... we followed several common-sense, but critical, principles: 1) be inclusive . . ; 2) don't lie ... ; and 3) keep your promises. . .." By following this advice and having support from the Texas Parks and Wildlife Department, General Services Commission, United Daughters of the Confederacy, and Sons of Confederate Veterans, the excavations proceeded in a timely and respect- ful fashion. When informed of the cemetery renovation and burial excavations, the United Daughters of the Confederacy and Sons of Confederate Veterans lent their support and asked only that the excavations not become a public spectacle. Due to the many efforts made by all of the organizations and individuals involved, the responsibility to inform the public was fulfilled, as was deference to the buried individuals.

\section{REINTERMENT PROCEDURES}

All human remains, associated objects, and casket hardware excavated from Sections D and F were reburied in another area of Section D. Prior to their reburial, the individuals were placed into separate reinterment boxes. Each reburial container was constructed of $3 / 4$-inch fir plywood cut into six pieces and nailed together with small finishing nails to form a rectangular box 36 inches long, 17.5 inches wide, and 12 inches tall. For each box, the interior top edges of all side walls and the interior edges of the lid were notched so that the lid fit securely into the box. The lid was a separate piece that was fastened on by eight brass screws. The exterior was then stained dark brown to bring out the wood grain; although plain, the reburial boxes were aesthetic in appearance. They were constructed by the Texas Parks and Wildlife Department according to specifications drawn up by Prewitt and Associates.

Before the burial excavations began, 57 circular aluminum tags were engraved with the State Cemetery burial plot numbers for each grave to be exhumed. After all burial remains were placed into a reburial box at the end of each day, the lid was secured and the appropriate aluminum tag was screwed onto the end of the box. Because the reinterments were to take place at one time after all of the individuals were excavated, all reinterment boxes were placed into a locked, secure storage facility on the cemetery grounds. At the end of each day, it was the responsibility of each excavator to see that all skeletal material, casket hardware, casket wood, and personal goods were placed into the correct reinterment box and locked into the storage facility. Once the lids were sealed onto the boxes, they were not reopened. All items that were excavated from a grave were reburied with the individual, with the exceptions previously noted.

On the last day of excavation (July 31), the 
mortuary firm of D\&M Services, under the direction of Jimmy Owens, arrived at the site to reinter all excavated individuals into their new plots. Personnel from the General Services Commission and Texas Parks and Wildlife Department kept records correlating the original burial plot numbers and grave identifications with the new plot locations. All individuals except two were reinterred by the end of that day; these two individuals, a married couple, were not reburied at that time but were reinterred on August 7 during a formal ceremony conducted by the United Daughters of the Confederacy and the Sons of Confederate Veterans. This ceremony included a re-enactment of a burial ceremony that commonly was held at funerals of Confederate veterans around the turn of the century as well as a roll call of the individuals whose remains were reinterred. A summary of events that took place during the reinterment ceremony is presented in Appendix I. 


\section{HISTORY OF THE TEXAS STATE CEMETERY}

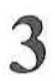

Martha Doty Freeman

The Texas State Cemetery, located on Lot 5 , Division B, of the City of Austin, is an apparently unique site that contains the remains of elected and appointed public officials, persons recognized by proclamation or resolution, individuals who served in the military, and the spouses of eligible individuals.

The cemetery, which began in 1851 with the burial of General Edward Burleson, a distinguished soldier, politician, and Mason, was designated "a State Burying Ground" from its inception (Texas. Fourth Legislature 1851:186). Within a week, a legislative proposal to move the remains of Stephen F. Austin, that "instrument in the hands of a wise Providence," from Peach Point in Brazoria County to the new "State Cemetery," placed the site within the continuum of nineteenth-century European and American cemetery-museums (Ragon 1983:89). Such places, typified by the interment of great historical figures and artistic, sometimes monumental tombs, were expressions of a nineteenth-century concern for posterity and memory (Ragon 1983:238) and a need to present, celebrate, and commemorate history (Jackson and Vergara 1989:5). In midcentury, Texas looked forward. It also looked back to a "national" as well as a "state" history. The institution of a State Cemetery thus represented one mechanism for honoring the great individuals who had helped to create the state's identity; at the same time, it was an expression of the chauvinism that celebrated Texas's unique history.

\section{A HISTORY OF LOT 5, DIVISION B, AND THE TEXAS STATE CEMETERY}

\section{9-1851: Preamble}

Settlement of a bend in the Colorado River in present-day central Travis County by the mid 1830s was followed in 1839 by designation of a tract as the new permanent capital of the Republic of Texas. In August, Edwin Waller surveyed a townsite, which included a cemetery east of Waller Creek, and the city was incorporated in December. The sale of city lots and outlots occurred simultaneously, and on February 24, 1840, an individual named Thomas G. Gorden (also apelled Gordon in some documents) purchased lot 5, Division B, for $\$ 410.00$. This future site of the Texas State Cemetery was located east of the center of town and southeast of the city cemetery. The lot embraced approximately 21 acres of rolling land downhill from what became Robertson Hill, and elevations varied from approximately $490 \mathrm{ft}$ in the southeast corner to $537 \mathrm{ft}$ in the northeast corner.

Gorden owned lot 5 for eight months and then sold it, with other acreage and a Negro slave, to James A. Coldwell (Travis County Deed Record A:145-146). After that date, legal records do not indicate that Coldwell sold the property or that it became part of his estate. What is more likely is that he was unable to pay for the land, which appears to have reverted to the state's ownership 
by June 6,1849 , when lot 5 , Division B, was sold at public auction to Austin resident Andrew Jackson Hamilton (Texas. General Land Office 1849a).

On August 10, 1849, Governor George T. Wood issued title to Hamilton (Texas. General Land Office 1849b), who was soon to begin serving as attorney general of Texas. Two years later, in 1851, he was elected to the Texas House of Representatives, by which time he owned 23 lots in Division B that were evaluated at $\$ 5,805.00$ (Texas. State Comptroller 1851).

It may have been during his years of early public service that Hamilton became acquainted with General Edward Burleson, a legendary Texas hero who was born in Tennessee on November 26, 1826, and emigrated to Bastrop County, Texas, in 1830. At the age of 19 , he organized volunteers at Gonzales and was elected Stephen F. Austin's senior colonel. He participated in the Grass Fight and, with Ben Milam, organized and carried forward the Seige and Storming of Bexar. In the spring of 1836, Burleson commanded the 1st Regiment of Texas Volunteers at San Jacinto. These activities were followed by participation in the Cherokee War and Mexican War and paralleled by service as a member of the Texas House of Representatives and of the Senate, vice-president of the Republic of Texas, and president pro tempore of the state legislature between 1846 and 1851 (Texas. House of Representatives 1852: 390-394).

\section{1-1865: Death of Burleson and Early History of the Cemetery}

On the morning of December 26, 1851, General Edward Burleson died in Austin at the home of N. C. Raymond. Referring to the deceased as "one of the links to the great and glorious past history of the Republic of Texas," the legislature immediately announced Burleson's death and began to plan for his funeral, an event that was envisioned as being elaborate, formal, and public.

An initial decision was made to appoint a committee of 10 senators that would make the arrangements for Burleson's funeral and superintend his interment at the "City burying ground" (present-day Oakwood Cemetery) at 10:00 A.M. on December 27, 1851. Senators Wilson, Grimes,
Dancy, Bigelow, Burks, Davis, Day, Scott, Bogart, and Eddy were appointed the committee of arrangements. At that point, some general discussion must have ensued concerning the place of burial, for Senator T. H. Duggan made a motion and the committee was instructed "to select a suitable place for a State Burying Ground" (Texas. Fourth Legislature 1851:186).

No records appear to exist that chronicle the deliberations of the senate committee. However, they must have included discussions about the proposed state burying ground and an offer by Representative Andrew Jackson Hamilton to provide land for that purpose. As a member of the legislature, Hamilton was familiar with Burleson's illustrious service to the Republic and the state. $\mathrm{He}$ was the chairman of the House committee charged with organizing' Burleson's funeral, and the individual who formally announced Burleson's death to the House on December 26. Noting the falling of "another pillar of the former Republic," Hamilton summarized Burleson's contributions, pointing out that "the history of Texas from the moment she became ... a separate and independent government, is emphatically the history of the man whose death it has been my solemn duty to announce." Further, Hamilton said, no separate monument would be needed to perpetuate Burleson's memory because the honor, glory, and public history were "the repositories of his name." Indeed, the Alamo and San Jacinto were his monuments (Texas. House of Representatives 1852: 381-383).

Hamilton's laudatory speech described Burleson's identity as an important historical figure whose personal and professional characteristics had helped to create a state's identity. The fact that he would become the first interment in a new State Cemetery revealed the importance that the legislature ascribed to the site and said much about the state's self awareness as a country with a "great and glorious past history" (Texas. House of Representatives 1852:390).

Burleson was removed from N. C. Raymond's home to the Capitol on December 27. Inclement weather forced a postponement of the funeral until the following day when Austin Lodge No. 12 of Freemasons took charge of the corpse and led a large procession of relatives, the legislature, governor, department heads, judges, army officers, local officials, Sons of Temperance, ex-soldiers of 
the Republic, and citizens. The entourage crossed Waller Creek and arrived at Hamilton's property where Burleson was interred on an elevation in the western portion of lot 5 , Division B.

The burial of Burleson, described by The Texas State Gazette (December 27, 1851) as an event when the "nation [Texas] stands beside his coffin with wet eyes," both defined the esteem in which Burleson was held and, by association, identified one aspect of what the legislature had envisioned for the State Cemetery. A second aspect - that the cemetery would become a site where the disinterred remains of other important historical figures were reinterred-was identified a week after Burleson's funeral. At that point, the legislature passed a joint resolution, the purpose of which was "the removal of the remains of the late Stephen F[.] Austin, for interment in the State Cemetery at the City of Austin" (Texas. Fourth Legislature 1852).

The idea represented by the legislature's resolution was not a new one in Texas. According to Muir (1950:16), the citizens of La Grange in Fayette County had aspired to be designated the capital of the Republic and the location of a cemetery where the remains of important citizens would be interred or reinterred. They buried the bodies of participants in the Mier Expedition on what became known as Monument Hill, and shortly after 1842, they added the remains of Captain Dawson's men, who had been killed by forces under General Woll on Salado Creek near San Antonio. In the late 1840s, a group of La Grange residents even traveled to San Antonio where they exhumed Ben Milam's remains and tried to move them to the new cemetery. Residents of San Antonio had formed their own attachment to Milam, however, and retrieved his remains before the visiting delegation left town.

The legislature's desire to move Stephen F. Austin's remains from Peach Point was an expression of the landmark status they envisioned for the State Cemetery and the esteem in which they held Austin. Indeed, the language of the resolution referred to "the memory of an individual who was the instrument in the hands of a wise Providence in laying the foundation of their prosperity, and but for whose enterprise and fortitude this fertile and beautiful land would now and perhaps for ages to come have been a wild waste uninhabited by civilized man" (Texas. Fourth Legislature 1852).
However, the state was unsuccessful in obtaining the permission of Austin's family, and the subject of his reinterment was dropped.

Failure to reinter Austin marked the beginning of a period during which no burials occurred and the state made no effort to secure title to the lot in which Burleson was buried. Hamilton continued to pay taxes on lot 5 during 1852 and then, perhaps as a ploy to force the legislature's hand or because the Burleson family was concerned about the disposition of the land, he sold lot 5 to Edward Burleson Jr. for $\$ 200.00$ (Travis County Deed Record G:101-102).

There does not appear to be a deed or other legal record by which Hamilton reacquired the land in either Travis County or Hays County, where Edward Burleson Jr. lived. But the sale of the property must have had the desired effect, for a year later, on February 13, 1854, the legislature passed two joint resolutions. The first resolution appropriated $\$ 1,000.00$ to build a tomb over the grave of General Edward Burleson. The second authorized the comptroller of public accounts to estimate the value of lot 5, Division B, and accept a conveyance of the lot to the state from Andrew Jackson Hamilton. The comptroller then was authorized to convey to Hamilton title for other Austin lots of equal value (Gammel 1898:III: 1555-1557). A certificate of exchange was executed on August 15, 1854, and lot 5 officially became the property of the state (Travis County Deed Record 142:436-437).

Formal acquisition of the State Cemetery property in 1854 failed to spur interest, and between 1852 and 1861 , only two burials occurred there. The first of these was the interment of Abner S. Lipscomb, associate justice of the Texas Supreme Court, who died on December 8, 1856. The second was the interment of Forbes Britton, state senator from Corpus Christi, who died in 1861 during the session of the Eighth Legislature (Muir 1950:16-17). Then, activity increased somewhat during the Civil War when a number of the state's most illustrious leaders died. John Hemphill, a Confederate senator, former United States senator, and long-time chief of the Texas Supreme Court, died in Richmond, Virginia, in January 1862 , and his remains were transported to Austin. The same year, Generals Hugh McLeod and Benjamin McCulloch were buried near Burleson. McLeod, an 1836 immigrant to Texas, 
had served as adjutant general and adjutant and inspector general of the Texas Army, participated in the 1840 Council House Fight, commanded the Texan Sante Fe Expedition, and served as a member of the House of Representatives before participating in the Mexican War. He died while directing Confederate movements against U.S. forces on the Rio Grande. McCulloch, a friend of David Crockett, fought at San Jacinto and Plum Creek and in the Mexican War; during the Civil War, he directed volunteers who forced the surrender of Union forces at San Antonio. He died in March 1862 when he was shot by Union sharpshooters at the battle of Elk Horn. These illustrious men were soon joined by General William R. Scurry, an attorney and legislator who fought in the Mexican War, the January 1, 1863, battle of Galveston, and the battles of Mansfield and Pleasant Hill in Louisiana. He was mortally wounded in the Battle of Sabine, and his remains were brought to Austin and interred in May 1864. By the end of the Civil War, there were seven graves in the southwestern portion of the State Cemetery (Muir 1950:17). ${ }^{2}$

\section{6-1900: "The Condition of the State Cemetery is Not Good"}

If events during the first decade-and-a-half of use of the State Cemetery failed to match the stature of the illustrious men who were buried there, the balance of the century was hardly more outstanding. Burials continued and, with the deaths of Confederate veterans, even increased during the last quarter of the nineteenth century. But the state seemed unwilling to appropriate more than minimal funding for the upkeep of the cemetery, and the condition of the grounds and grave markers became "deplorable." In addition, the legislature had failed to enact guidelines that specified which individuals were eligible for interment. As a result, politicians, soldiers, and other illustrious historical figures continued to be

\footnotetext{
${ }^{2}$ On November 15,1864 , the legislature passed an act to appropriate $\$ 10,000.00$ "for the enclosure of the State Cemetery" (Gammel 1898:V:821). No evidence was found that the enclosure was constructed, and the legislature made an additional, more-specific appropriation for the same purpose in 1866 (Gammel 1898: V:1081-1082).
}

buried in the State Cemetery, but, as one superintendent complained, "some strangers have been placed therein" (Superintendent of Public Buildings and Grounds 1879:6).

The legislature, despite its failure to support the cemetery monetarily, remained true to the vision of the site as a cemetery-museum. On October 3, 1866, the legislature approved a joint resolution to remove and rebury the remains of General Albert Sidney Johnston, which were then in St. Louis Cemetery No. 1 in New Orleans (Gammel 1898:V:1179-1180; Germany 1995:20; Muir 1950:17). At the same time, the legislature acknowledged the role of the cemetery as a burial site for rank-and-file military personnel and responded to a specific need that resulted from Federal occupation of the capital city after 1865 . Reconstruction brought with it U.S. cavalry and infantry troops, and volunteers who arrived under Custer's command by June 1865 were joined and/or replaced by regulars under General Wright by August 1866. Between 1865 and 1870, as few as 3 and as many as 12 cavalry troops and infantry companies were stationed in Austin (Richter 1987:14-15, 54-55, 68-69, 92-93, 134-135, 152-153, 162-163, 176-177, 184-185). As might be expected, a number of the men died. By November 1866, the number of deaths probably had become sufficiently great to require the legislature's action. On November 9, the lawmakers approved an act to set aside a plot of ground for use by the U.S. military. According to the act, 1 acre was to be "laid off in a square ... out of the north-east corner of the State Cemetery lot, by lines run at a right angle with the east and north lines of said lot, from points, and said lines equidistant from the north-east corner of said lot, and set apart to be used exclusively as a Cemetery for the United States military forces . . ." (Gammel 1898:V:1043).

During the same period, the legislature acknowledged the necessity to mark the boundaries of the cemetery and to make some attempts to protect it from "waste and depredation." An act passed in November 1866 provided a modest amount $(\$ 1,500.00)$ to enclose the part of the southern portion of the cemetery then in use with cedar pickets. The funds also were to be spent for two 8-ft-wide gates (Gammel 1898:V:1081-1082). The same month, the legislature authorized the governor to appoint a sexton and keeper of the 
State Cemetery. His duties, for which he was to be paid $\$ 400.00$ a year, included superintending burials and taking care of and protecting the grounds, timber, graves, and grave enclosures (Gammel 1898:V:1188-1189). Five years later, in 1871 , the legislature authorized the keeper to erect a permanent marker at the head of each grave not then marked (Gammel 1898:VI:937), an act that suggested that grave designation and identification were erratic at best.

Attempts to mark graves were paralleled by efforts to formalize the actual boundaries of the property by civil engineer C. D. Anderson in 1872 . However, local and nonlocal visitors continued to be appalled by conditions in this place that had been "set apart for the burial of our "distinguished dead." One visitor described the State Cemetery as "a bleak and rocky hillside in Austin" enclosed by "a rough and dilapidated picket fence, and without a solitary tree or bush to break the sod and dreary prospect." Another observer noted that, except for its "commanding position," the cemetery was "devoid of natural advantages or beauty. . . . Not a tree or shrub [was] to be seen inside the 4acre enclosure," which consisted of a whitewashed fence. Two $30-\mathrm{ft}$ avenues had been laid off from north to south and east to west, and these crossed in the center of the 4 acres. In addition, "about two hundred holes [had] been dug for the planting of cedars and shade trees." But the observer could see "no system or regularity" to the placement of graves, which had been laid off "in a zigzag manner." Graves were neglected, headstones rough and broken. One individual even proposed that a "more desirable place" be selected for the burial of the state's dead (Daily Democratic Statesman, March 31, 1874, and August 7, 1875; Superintendent of Public Buildings and Grounds 1879:6).

Criticisms of the condition of the grounds, graves, and monuments were paralleled by calls for a law that would "specifically define the class of persons entitled to burial in the grounds, and by what rule the Superintendent shall be governed in granting permits." A lack of such a guideline meant that the cemetery superintendent was subjected to strong appeals by which he was bound to be "greatly embarrassed." The absence of a law concerning eligibility may have accounted for the burial of an individual listed only as "Gwinn" in the 1879 superintendent's report, which also listed all of the luminaries interred until that date:
Edward Burleson, Albert Sidney Johnston, William R. Scurry and his wife, Benjamin McCulloch, August Buchel, Hugh McLeod, Thomas William Ward, Forbes Britton, E. J. Davis, George W. Smyth, John Hemphill, A. S. Lipscomb, William M. Varnell, Donald Campbell, Thomas Plasters, J. C. Walker, and Amos Clark (Superintendent of Public Buildings and Grounds 1879:6).

One group whose right to be buried in the State Cemetery was generally acknowledged was comprised of Confederate veterans. In 1884, the John B. Hood Camp of United Confederate Veterans had obtained a charter from the state for the purpose of establishing a home for disabled and indigent Confederate veterans. Two years later, the Camp purchased $16^{2} / 3$ acres at $1600 \mathrm{~W}$. 6th Street in Austin, and a home opened. Between 1886 and 1888,113 veterans were admitted to the Texas Confederate Home, and between 1887 and 1953, more than 2,000 ex-Confederates resided there. As these old soldiers died, they were interred in the State Cemetery, where the rows of small, simple stones increased steadily. In time they were joined by their wives, some of whom had spent their last years at the Confederate Woman's Home, which opened at 3710 Cedar Street on June 3, 1908 (Beeman 1986:66-67).

At the same time new interments were increasing in the southeastern portion of the cemetery, where Confederate soldiers rested, a different phenomenon is believed to have taken place in the northeastern acre where Federal soldiers were interred. Beginning in the $1880 \mathrm{~s}$, as western forts and camps closed, the United States Quartermaster Corps initiated a program to remove the bodies of soldiers who had died while in service. In Texas, the cemeteries at more than 30 forts, camps, posts, and outposts were excavated, and the remains were reinterred at the U.S. National Cemetery in San Antonio. Interment records at the cemetery indicate that approximately 46 individuals were moved from Austin to San Antonio where they were reburied with soldiers from military installations such as Forts McKavett, Bliss, Clark, Concho, Richardson, and Davis; camps such as Eagle Pass and Verde, and miscellaneous facilities 'such as Indianola, Galveston, D'Hanis, and Enoch Jones's farm on the Medina River (Fort Sam Houston National Cemetery, Burial Registers n.d.) (see Appendix A).

Interment and reinterment activities during 
the final quarter-century were accompanied by responses to criticisms by both the public and the cemetery superintendent. After the superintendent reported on a number of shortcomings in 1879 , the commissioner of insurance statistics and history hired local contractor Frederic Braun to build $2,000 \mathrm{ft}$ of cedar and cypress fencing, $5 \mathrm{ft}$ high, and two carriage and side footman's gates. The fence was to be finished with three coats of zinc and oil paint; Braun also completed lettering and gilded stars (Braun 1881a, 1881b, 1882). Another improvement was completed in about 1886 when a gate was installed on the west side of the cemetery near the street railway. However, the superintendent continued to complain about the lack of burial guidelines. Luminaries Ashbel Smith, R. O. W. McManus, and William L. Hunter were buried in 1886; Frank W. Johnson in about 1888; H. W. Cook and Andrew J. Dorn between 1888 and 1890; and John Ireland by 1900 . However, the class of persons entitled to burial in the State Cemetery was not defined, so that the superintendent had no rules to follow when granting burial permits (Superintendent of Public Buildings and Grounds 1886:5-6, 1888a:5, 1888b:6-7, 1890:5, 1900:7).

The superintendent also continued to fret about the general condition of the cemetery. Perhaps impressed by the monumental stature of many of the historical luminaries there, he criticized the quality of stone used in the few monuments that had been erected and pointed out that the graves of Frank Johnson and Ashbel Smith had been marked with boards. Some graves had no locating designation at all. He urged the legislature to think of the cemetery as a "State or monumental park," a "beautiful home for the dead." $\mathrm{He}$ pointed out that other states, "with histories far less interesting than ours," were erecting appropriate monuments to their distinguished citizens. He then suggested that the cemetery be "properly laid out with walks and drives" and that massive granite monuments be erected (Superintendent of Public Buildings and Grounds 1888a:5, 1888b:6-7, 1890:5). Response to these suggestions was slow and grudging, however, and it was only in about 1896 that Superintendent John R. Mobley laid off lots and blocks in the cemetery; the following year, state ownership of lot 5, Division B, was affirmed by the sole surviving witnesses to the 1854 agreement between Andrew Jackson Hamilton and the state (Superintendent of Public Buildings and
Grounds 1896:5; Travis County Deed Record 142:436).

\section{1-1919: A Resurgence of Interest}

The first half-century of the history of the State Cemetery had been characterized by grand visions that failed to come to fruition, a lack of sufficient appropriations for maintenance and site improvements, and an absence of guidelines on which to base decisions about interments. In contrast, the first two decades of the twentieth century saw the cemetery achieve a sort of "critical mass" as hundreds of Confederate veterans were buried in a short span of time, famous historical figures continued to be buried in or moved to the site, money was appropriated for several noteworthy monuments, and a governor who loved history made sure adequate funds were available for improvements to the infrastructure at the cemetery.

Several projects captured the public imagination during the early twentieth century. The first of these was the plan to erect a monument over the remains of General Albert Sidney Johnston. A contract was let to Elisabet Ney to sculpt a figure of the deceased Confederate officer; the monument was to be located on a rise overlooking the everincreasing rows of lesser Confederate officers and men whose more-anonymous graves spread out to the east 400 -fold by 1904 . The monument finally was accepted on August 6, 1906 (Austin History Center, Area File-C2170; Superintendent of Public Buildings and Grounds 1905:9-10). Four years later, the House and Senate resurrected an idea from 1852 and made plans to disinter the body of Stephen F. Austin, reinter his remains in the State Cemetery, and erect a monument there, a project that was completed in about 1911. Finally, Joanna Troutman and General John A. Wharton were reinterred in the cemetery, and imposing statues were erected of these two historical figures who faced each other across the narrow road that had been named for Albert Sidney Johnston (McDonald 1911; Muir 1950:17; Steely 1984:33; Superintendent of Public Buildings and Grounds 1902:7, 1905:9-10; Townsend 1910).

The addition of a number of high-profile historical figures to the cemetery after 1900 was accompanied by improvements to the infrastructure of the site. Between 1901 and 1902, driveways and walks were graveled and the perimeter fence 
was painted and repaired. During 1903 and 1904, for a cost of approximately $\$ 2,500.00$, the superintendent built a house for the keeper, filled in a drainage that ran through the middle of the cemetery, installed water pipes and connected them with the city water service, and planted trees, shrubs, and flowers. Between 1907 and 1908, the superintendent constructed cement-block curbing around the Official and Confederate Plats, filled behind the curbs, planted evergreens, and improved the drives, grades, and walls. During the next 2 years, improvements planned included a new iron fence (which appears not to have been built), additional curbing, and gravel for driveways (Superintendent of Public Buildings and Grounds 1902:7, 1905: 9-10, [1908]:6, [1910]:4).

Perhaps the most ambitious improvements occurred during the term of Governor O. B. Colquitt (1910-1915), whose special interests included the Alamo and the San Jacinto Battlefield. He initiated the reinterment of Joanna Troutman and probably encouraged construction of the Austin, Troutman, and Wharton monuments. A government report for the period October 31, 1912, to November 30,1914 , noted that approximately $\$ 5,000$ had been spent to build a new cement-block fence around the cemetery and cement curbs for a driveway to the front entrance, and to complete some grading (Austin American-Statesman, August 12, 1973; State Inspector of Masonry, Public Buildings and Works 1915:7). This last project, which included the installation of the distinctive concrete work uncovered in 1995, was completed by Brown \& Reissig, a short-lived contracting firm comprised of John T. Brown and his brother-in-law, Oscar Reissig. The two men worked together for approximately a year (ca. 1913-1914) and then parted ways, Brown becoming a telephone and telegraph company lineman and Reissig continuing what became a lifetime career as a concrete finisher (Austin City Directory 1914; Reissig 1995; Travis County Civil Minutes 29:479; Travis County Marriage Record 14:300).

It is possible that the distinctive pillars that mark the south entrance of the cemetery also were completed during Governor Colquitt's term. Regardless, the superintendent could justifiably say in 1914 that "the present condition of the State Cemetery is better than it had ever been before. It is well kept, and due regard has been paid to the sacredness of the ground" (Superintendent of
Public Buildings and Grounds 1914:4).

\section{9-1940: The Cemetery Flourishes}

The year 1919 marked a change in supervision of the State Cemetery. The Board of Control assumed responsibility for the site, and for the next two decades, the cemetery flourished. Money became available for site improvements. More importantly, the Board of Control and State Highway Department cooperated with the encouragement of businessman and historian Louis Kemp, whose special interest resulted in heightened public attention as the state approached its centennial.

Some limited work on the cemetery may have been completed in the early 1920s when the Board sought to correct overflow conditions that occurred on a sporadic basis when, water that collected in the central part of the cemetery ran through the southeastern area (Anonymous 1922). However, the major portion of the state's improvement of the cemetery did not occur until later in the 1920 s when interest rekindled in the site as a "city of the illustrious dead" (Dallas Morning News 1925 [no month or day listed]). In 1929, Senate Bill No. 181 called for "the removal of the remains of prominent Texans from present burial grounds to the State Cemetery in Austin, Texas, for the erection of monuments in the State Ce[me]tery, and, in a few instances, erection of monuments at cemeteries where said bodies are now buried." On August 26, the State Board of Control made an agreement with Thurlow B. Weed to furnish all materials and perform all work necessary to carry out the provisions of Senate Bill No. 181 (Walthall 1929), and the project began almost immediately with the removal and reinterment of James Pinckney Henderson, Peter Hansborough Bell, Kenneth L. Anderson, Jesse Billingsley, Jesse Grimes, Oliver Jones, W. B. Scates, Moseley Baker, John A. Greer, Richard Ellis, Hardin R. Runnels, the Reverend James C. Wilson, Robert M. Williamson, and Robert Potter (Texas. Forty-First Legislature 1929a:210-211). These illustrious historical characters were joined later in the year by Captain James Hughes Callahan and Captain Benjamin Franklin Bryant (Texas. Forty-First Legislature 1929b:266-268), in 1931 by David Spangler Kaufman, Davis Thomas, Randal Jones, John W. Bunton, Josiah Wilbarger, and Joel W. Robinson (Texas. Forty-Second Legislature 
1931:213-215), and in 1935 by Sterling C. Robertson, Nestor Clay, James A. Sylvester, William Menefee, Jacob de Cordova, James Chance, and William C. Crawford (Texas. Forty-Fourth Legislature 1935:546-547). By 1935, 28 men and 16 women had been reintered; a year later, the total was 76 (Muir 1950:17, 18).

The reinterment of dead Texas heroes was accompanied by efforts to clear brush from portions of the cemetery (American-Statesman 1936 [no month or day listed]), to plant grass and install a drainage system that would prevent damage from heavy rains, and to level portions of the grounds (Texas State Board of Control [1932]:15). In addition, the state resolved to acknowledge Louis Kemp's leadership in drawing the attention of Texans to their history by reintering Texas heroes and enhancing their reburial location. On February 6, 1930, the State Highway Department designated a new state highway and named it Lou Kemp Avenue. The road was to begin outside the cemetery at the corner of Sixth and Onion Streets and run north to the south or Seventh Street cemetery entrance. It then was to continue north along the old Albert Sidney Johnston Avenue and exit the cemetery grounds at Eleventh Street (Texas. State Highway Department 1930:437).

\section{1-Present}

The two decades between 1920 and 1940 were a period of relatively intense activity at the cemetery, during which its identity as the state's official cemetery-museum had been firmly cemented. For the next half century, however, interest in the site seems to have waned, and the legislature appropriated only the monies needed to maintain the status quo.

Kemp was involved in a campaign during the 1950s to bring additional Texas heroes back to the state for reinterment (Steely 1984:36). Of more concern, however, was the vandalism that had damaged both the grounds and graves. The Board of Control perceived that the masonry wall around the perimeter of the cemetery was inadequate, and board members proposed replacing it with a cyclone fence (Warden 1950). This idea failed to come to fruition, however, and site improvements between 1950 and 1968 consisted instead of improvements to the caretaker's cottage (1950); installation of a sprinkler system, relocation of the
Capitol grounds greenhouse to the cemetery, erection of a flagpole, and construction of new utility, storage, and garage buildings (1960-1962); and replacement of Confederate headstones (1962). Installation of a new iron fence finally occurred between 1968 and 1973 (Jenkins 1972).

One of the more important changes that occurred in the 1950s involved policy. Almost 75 years after an early superintendent had called for a law to "specifically define the class of persons entitled to burial in the grounds" (Superintendent of Public Buildings and Grounds 1879:6), the legislature passed a bill that, for the first time, provided specific authority "for the determination of applicable regulations relating to interment." The State Board of Control then established the regulations, which required that an individual had to be a member or ex-member of the Texas legislature, a Confederate veteran, elected state official, state official appointed by the governor and confirmed by the legislature, individual designated by governor's proclamation or a concurrent resolution of the legislature, or the spouse of anyone meeting these criteria (Burke 1968; The Texas Public Employee 1963:16).

Interest in undertaking major architectural and landscaping work at the State Cemetery began in the early 1990s and resulted in specific recommendations for repairs, maintenance, and site enhancement (Espey, Huston/SME, Inc. n.d.). Availability of ISTEA funding provided an opportunity to develop a cemetery master plan, which was completed in January 1995 (JVR and Associates and Texas Parks and Wildlife Department 1995). Since that date, the General Services Commission, Texas Historical Commission, Texas Department of Transportation, and Texas Parks and Wildlife Department have cooperated to formulate a plan for the further development of the cemetery.

\section{SUMMARY}

The Texas State Cemetery, located on lot 5 , Division B, is situated on undeveloped land that was owned between 1849 and 1854 by Andrew Jackson Hamilton, a member of the Texas Legislature. Following the death of his fellow legislator, General Edward Burleson, Hamilton agreed to make lot 5 available for Burleson's burial, and the legislature resolved to establish a state cemetery and acquired title to the land in 1854 . 
From earliest years, the legislature's intent was both to provide a place of interment for political and military figures and to create a cemetery-museum to which previously interred historic figures would be moved. General acknowledgment of the site as a military cemetery, as well, was expressed in the interments of hundreds of Confederate veterans in the southeastern portion of the site and the setting aside of 1 acre in the northeast corner of lot 5 for use by the federal government if and when soldiers of the Union forces occupying Austin died.

For much of its history, the cemetery was not guided by specific laws concerning burial eligibility. In addition, graves often were indicated with temporary markers; some graves were not marked until a number of years after interment; there was no apparent system to the selection, placement, or orientation of graves; and records were kept and maintained in an erratic fashion. Indeed, the fortunes of the cemetery during the twentieth century appear to have been dependent on the extent to which powerful political figures became personally interested in the site. Governor Colquitt's election brought with it major site improvements (possibly including those in the vicinity of the south entrance) and the addition of a number of major historical figures to the cemetery's inventory. The interest of Louis Kemp between 1926 and 1936 was reflected in more site improvements and reinterments, while Lieutenant Governor Bob Bullock often is credited with spearheading recent enhancement plans.

Increasing interest in the State Cemetery has brought with it improved record keeping concerning the locations and identities of burials and the nature of modifications to the infrastructure. However, historical research and archeological investigations have been necessary to locate and identify burials and site features for which documentation may be lacking in records of the General Services Commission. Title research has confirmed that there is little likelihood of improvements to lot 5, Division B, prior to designation of the tract as a state cemetery in 1851 . On the other hand, historical research has revealed that the northeastern corner of the cemetery was the location of federal interments ca. 1866-1870, while archeological investigations have uncovered the remnants of early landscaping elements at the old south entrance. 



\section{RESULTS OF ARCHEOLOGICAL SURVEY AND SUBSURFACE GEOARCHEOLOGICAL INVESTIGATIONS}

Douglas K. Boyd and Karl W. Kibler

Archeological investigations conducted in the summer of 1995 included (1) a pedestrian survey of the cemetery, and (2) mechanical testing to provide geomorphic data and search for unmarked graves in and adjacent to construction zones. As a result of unanticipated finds during the search for unmarked graves, two additional tasks were completed: (3) hand testing and mapping of buried concrete remains of Albert Sidney Johnston Avenue in the Plaza de los Recuerdos construction zone; and (4) investigation of unmarked graves of Federal soldiers in the Northeast Cenotaph construction zone. Each task is described separately below.

\section{PEDESTRIAN SURVEY}

An initial reconnaissance of the 18-acre cemetery was conducted on 24 April 1995 by Principal Investigator Boyd, and a more-intensive pedestrian survey was conducted on 23 May 1995 by Boyd and Project Geomorphologist Kibler. Because much of the property was covered with grass, pavement, buildings, and graves, standard survey techniques were not employed, and the investigations concentrated on areas where ground exposure was good, particularly in and around proposed construction zones. At the time of the survey, there were no known graves in the undeveloped northern half of the cemetery, and all known burials and reserved plots were located in the southern half.

The survey revealed nothing of significance. Occasional pieces of historic and modern debris (primarily brick fragments, ceramics, glass, and plastic) were found throughout the cemetery, but debris was concentrated in only two areas. Abun- dant materials that obviously had been washed in were scattered along the concrete- and rock-lined drainage in the central portion of the cemetery (see Figure 1). In addition, several discrete concentrations of cultural debris around the highest hill in the undeveloped northeastern quarter represent multiple historic/modern dump episodes. These trash areas generally include gravelly fill that is out of place on the surface but could have been dug up somewhere in the project area. State Cemetery foreman John Sanchez (GSC) stated that the hilltop and northeastern portion of the cemetery had been used for many years as a dump area for excess grave fill and other debris. In addition, he noted that a slight rectangular depression on the north edge of the hillslope (i.e., just north of the area called Observation Hill on Figure 2) was a borrow pit where fill had been removed. Aside from the evidence of disturbance in some areas, the gently rolling nature of the topography of the entire cemetery also suggested that considerable leveling (i.e., filling in of low spots) probably had occurred over the years.

\section{MECHANICAL TESTING AND GEOMORPHIC ASSESSMENT}

The next major task was mechanical testing using a backhoe, followed by a Gradall. Trenching was done in various parts of the cemetery but concentrated primarily on the proposed construction zones (see Figures 2 and 3). Twelve 30-inchwide backhoe trenches were excavated down to sterile, ancient sediments usually encountered at a depth of less than $1 \mathrm{~m}$. The primary objective of the backhoe work was to provide geomorphic information for evaluating the landforms in the 
project area, but the trenches also helped define the nature and extent of modern disturbances. The excavations were closely monitored by the Project Geomorphologist, but no prehistoric or historic cultural materials were encountered.

The subsurface exposures provided by the backhoe allowed for a thorough evaluation of the geomorphic setting of the project area. The cemetery is situated on a high gravel terrace of the Colorado River, which overlies Upper Cretaceous Austin Group chalks and marls (Garner and Young 1981) that outcrop in the southern half of the cemetery where the overlying terrace deposits have been removed through erosion. The terrace is late Pleistocene in age (probably early Wisconsinan, ca. $80,000-50,000$ years B.P.) and highly dissected and eroded in areas. Based on the elevation and composition of the terrace, it most likely represents a Capitol terrace, one of six defined terrace deposits along the Colorado River (Rodda 1970:7).

Four depositional units were observed in the 12 backhoe trenches. The oldest unit is the Austin Group chalks and marls exposed at the southern end of the cemetery and observed in Backhoe Trenches 1, 6, and 8-12. These chalks and marls consist of highly weathered, pale yellow to white, calcareous to extremely calcified clays and silts. The next unit consists of those clasts and sediments comprising the Capitol terrace, which consists of a highly weathered clay, sand, and poorly sorted quartzites, cherts, and other rare metamorphic and igneous rocks. Well-developed $\mathrm{Ck}$ horizons with Stage II to II+ carbonate morphologies that have been enhanced by the dissolution of limestone terrace gravels are common throughout this sedimentary unit. This fill was observed in Backhoe Trenches 2, 4, and 5. The third depositional unit, which is inset into the Capitol terrace unit, consists of highly weathered alluvial and colluvial clays and paludal (marsh) or cienaga (spring or seep) deposits. The age of this fill is estimated to be terminal Pleistocene (ca. 13,000-10,000 years B.P.) based on the morphology of secondary carbonates, the presence of ferromanganese concretions, and the degree of weathering within the fill. The areal extent of this fill is limited to the low-lying areas and natural drainages within the cemetery. Backhoe Trenches $1,3,6-8$, and 12 exhibited the third fill. The fourth and most-recent fill is artificial and consists of a gravelly material sometimes accompanied by historic/modern trash or debris, used in landscaping and leveling within the last century. Archival evidence indicates that filling episodes and landscape work may date to various times, primarily $1903-1904$, the 1920 s, and the 1930 s, while archeological remains indicate that some gully filling dates to the 1940 s and later. Gravelly artificial fill $35-82 \mathrm{~cm}$ thick was observed in all backhoe trenches. Gravelly fill with historic/modern trash was observed primarily in Gradall Trenches 26 and 27 (discussed below).

Backhoe trenching was immediately followed by Gradall trenching in each of the proposed construction zones. Twenty-nine 4-ft-wide Gradall trenches were excavated, with each trench being monitored closely during excavation. As a result of findings in Gradall Trenches 1-7 excavated in the proposed Plaza de los Recuerdos construction zone, Gradall Trenchesi 30 and 31 were subsequently excavated to define the buried features further. Although continuous trenching would have been preferable in most areas, this was impossible because of buried sprinkler lines in most construction areas. The direction of trenching also was dictated in many cases by the presence of buried sprinkler lines and other features.

Based on the trenching results, five important observations were made with respect to prehistoric resources. First, the absence of any lithic artifacts, burned rocks, or other cultural evidence suggests that prehistoric occupations either did not occur in the project area or that such evidence is not preserved (i.e., perhaps having been removed by erosion). Second, no intact sediments of culturally relevant age were observed in the uplands. Third, there is abundant evidence that extensive landscaping and addition of artificial fill occurred throughout the cemetery during the last century. Fourth, intact deposits of culturally relevant age were observed only along the drainages in the lowest, central part of the cemetery, but even the uppermost strata of these alluvial sediments are extensively disturbed and contain historic and modern debris. And fifth, intensive trenching in the alluvial sediments along the drainage suggests that the likelihood of finding any evidence of prehistoric occupations is extremely low. It was concluded that even if prehistoric cultural evidence could be located through more intensive investigations, such efforts would not be warranted because there is little or no chance of isolating, dating, or interpreting meaningful cultural components or 
discrete artifact assemblages.

Historic features and/or cultural materials were found in 16 of the 43 trenches; these results are summarized by individual construction zone in Table 1. Each construction zone (see Figures 2 and 3 ) is discussed separately below.

The proposed Plaza de los Recuerdos construction area was investigated with one backhoe and nine Gradall trenches. Remains of concrete curbs encountered in all of the Gradall trenches were subsequently determined to be remnants of Albert Sidney Johnston Avenue. These features are discussed in detail below.

The proposed construction at the Albert Sidney Johnston Memorial will be limited to expanding the walkway around the structure in all directions. This area was investigated with a single backhoe trench. Nothing was found, and archival data suggest that it is unlikely that there are unmarked graves or historic features in the immediate vicinity.

One backhoe trench and one Gradall trench were placed in the vicinity of the Kemp Memorial. Although additional construction is planned for the area immediately around the Kemp burials, nothing unusual or cultural was found in the trench, and archival records indicate that unmarked burials in the vicinity are unlikely.

Intensive mechanical work, consisting of 2 backhoe and 11 Gradall trenches, was done along

\begin{tabular}{|c|c|c|}
\hline \multicolumn{3}{|c|}{$\begin{array}{c}\text { TABLE } 1 \\
\text { SUMMARY OF BACKHOE AND GRADALL TRENCHING RESULTS } \\
\text { BY PROPOSED CONSTRUCTION ZONE }\end{array}$} \\
\hline Construction Zone & Backhoe/Gradall Trenches & Results/Findings \\
\hline \multirow[b]{2}{*}{ Plaza de los Recuerdos } & BHT 10 & None \\
\hline & GTs $1-7,30$ and 31 & $\begin{array}{l}\text { Concrete curbs and roadwork in all trenches. These features } \\
\text { represent remains of Albert Sidney Johnston Avenue. }\end{array}$ \\
\hline $\begin{array}{l}\text { Albert Sidney Johnston } \\
\text { Memorial }\end{array}$ & BHT 9 & None \\
\hline Kemp Memorial & BHT 11 and GT 9 & None \\
\hline $\begin{array}{l}\text { Memorial Garden, Pond, } \\
\text { and Drainage }\end{array}$ & $\begin{array}{l}\text { BHTs } 6 \text { and } 7 \text {, } \\
\text { GTs } 10-20\end{array}$ & $\begin{array}{l}\text { Few historic/modern bricks in GT } 10 . \text { Nothing in any other } \\
\text { trenches. }\end{array}$ \\
\hline Observation Hilltop & BHT 5 & None \\
\hline $\begin{array}{l}\text { Visitors Center/ } \\
\text { Maintenance Area }\end{array}$ & BHTs 1 and 12, GT 21 & None \\
\hline Mausoleum/Entry Area & BHT 3, GTs 23-28 & $\begin{array}{l}\text { Sparse historic/modern debris noted in GTs } 23,24 \text {, and } 25 \text {. } \\
\text { A burial plot reservation marker also was found in GT } 25 \text {. } \\
\text { Substantial amounts of historic/modern debris, mixed with } \\
\text { gravelly sediments, were encountered in GTs } 26 \text { and } 27 . \\
\text { All artifacts postdate } 1930 \text {. Nothing found in GT } 28 .\end{array}$ \\
\hline Northwest Cenotaph & BHT 2, GT 22 & None \\
\hline Northeast Cenotaph & $\begin{array}{l}\text { GT } 29 \\
\text { (double-wide trench) }\end{array}$ & $\begin{array}{l}\text { Three rectangular soil stains, presumably grave pits, oriented } \\
\text { east-west in a north-south row parallel to the east cemetery } \\
\text { fence. Presumed to be burials of Federal soldiers during } \\
\text { Reconstruction period, 1866-1870. Some historic/modern } \\
\text { (post-1930) debris found in trench fill. }\end{array}$ \\
\hline None & BHTs 4 and 8 , GT 8 & None \\
\hline
\end{tabular}


the current drainage in the proposed Memorial Garden, Pond, and Drainage construction area. Extensive evidence of disturbance was noted in stratigraphic profiles of some of the trenches. No cultural materials were found except for one trench that produced a few isolated bricks that probably were dumped into the drainage. Because it floods periodically, the drainage is an unlikely spot for burials, and there is no archival evidence indicating that unmarked graves might exist anywhere in the current drainage.

A single backhoe trench was excavated in the proposed Observation Hilltop construction area, located on the prominent hilltop that is the highest point in the cemetery. Nothing cultural was found, and archival evidence suggests that it is unlikely that any burials occurred here.

Because of the presence of numerous buildings and buried water and utility lines, only three trenches (two backhoe and one Gradall) could be excavated in the proposed Visitors Center/Maintenance construction area. Extensive disturbance of the sediments was noted, and nothing unusual or cultural was found. Historically, this spot was used for many decades, as it still is today, as a maintenance area. There is no hint in the archival records that any burials ever occurred in the vicinity.

The proposed Mausoleum/Entry construction area was investigated with a series of six Gradall trenches, each oriented east-west, parallel to the northern cemetery fence. Sparse historic/modern debris found in the gravelly fill of Gradall Trenches 23,24 , and 25 may represent materials that were washed into, or were dumped in, low-lying areas. A concrete cylinder with a letter and numbers ("B" over "11-29") crudely incised into one end was found in the fill from Gradall Trench 25 . This $15.5-\mathrm{cm}$-diameter and $31-\mathrm{cm}-$ long cylinder was subsequently identified as a cemetery plot reservation marker. Similar markers were seen on some of the reserved plots in the south half of the cemetery.

Large quantities of historic/modern debris (metal, ceramic, glass, bone, and rubber artifacts) were observed in the fill of Gradall Trenches 26 and 27. While all of the specimens are generally datable to the mid to late twentieth century, three specimens are temporally sensitive. One especially diagnostic artifact is a 1947 Texas license plate. The second specimen is a clear glass bottle base with a ca. 1940s maker's mark of the Maywood Glass Company, accompanied by the embossed number " 46 " that may indicate that the bottle was manufactured in 1946. The third diagnostic artifact is a 1-pint, clear glass liquor bottle with an Anchor-Hocking Glass Corporation maker's mark postdating 1938 (Toulouse 1971:46-48, 357-358). The side of this bottle is embossed with "FEDERAL LAW FORBIDS SALE OR RE-USE OF THIS BOTTLE" that dates the manufacture of the bottle to post-1933 (Olsen 1978:27).

The stratigraphic profiles of Gradall Trenches 26 and 27 revealed that the gravelly sand and historic debris represent borrow materials that were brought in to fill an old gully. This fill was confined to the eastern three-quarters of Gradall Trench 26 and the western one-half of Gradall Trench 27. The diagnostic artifacts indicate that the fill could have been brought in as early as the late 1940 s or as late as the $1950 \mathrm{~s}-1960 \mathrm{~s}$, and the absence of plastic supports this assessment. Consequently, this trash dump is deemed to be of no historical importance.

Nothing cultural was found in the single Gradall and backhoe trenches in the proposed Northwest Cenotaph construction area. Archival evidence indicates that it is unlikely that any historic features or graves exist in this area.

Gradall Trench 29 is a double-wide trench excavated in the proposed Northeast Cenotaph construction zone. Some historic/modern debris (e.g., ceramics, glass, metal, and plastic) was observed in the trench fill, but only one diagnostic artifact was found. It is a cream-slipped stoneware base fragment with a Wallace China Company mark, indicating manufacture by a company that was in business only from 1931 to 1964 (Lehner 1988:498). All of this debris represents twentiethcentury trash and is of no historic or archeological significance.

More importantly, rectangular outlines of three grave pits were encountered in the bottom of Gradall Trench 29 at a depth of ca. 2 to $3 \mathrm{ft}$ below the ground surface. Archival documents indicate that these features represent burials of Federal troops, but subsequent hand testing revealed the graves to be empty. Additional archival research confirmed that numerous burials of Federal troops in Austin had been exhumed and reinterred in San Antonio. The archival and archeological investigations of these unmarked graves are discussed below. 


\section{FEATURES ASSOCIATED WITH ALBERT SIDNEY JOHNSTON} AVENUE

\section{Archeological and Archival Investigations}

The proposed Plaza de los Recuerdos construction area was investigated initially with a series of seven Gradall trenches that exposed intact remains of substantial concrete curbs of an old roadway. Preliminary archival research during the Stage I investigation suggested that the buried concrete features were probably the remains of Albert Sidney Johnston Avenue. A crude handdrawn map of the cemetery, probably dating to the 1920 s, shows a north-south roadway identified as Albert Sidney Johnston Avenue expanding out around a football-shaped plaza in the approximate area where the concrete curbing was found (Figure 7). Although it is not drawn to scale and has many obvious inaccuracies, the location of Albert Sidney Johnston Avenue correlates with the location of the buried features. None of the current cemetery officials had any idea that such substantial concrete features were present in this area.

Gradall Trenches 1-7 were excavated within the paved turnaround encompassing the flagpole in the south-central portion of the cemetery (Figure $8 a$ ). Archeologically, three types of historic features were encountered-concrete curbs, road base sediments, and three discrete square pits. Concrete features were encountered in each trench, and it immediately became apparent that they represented curbs associated with an old roadway. A single intact curb was found in some trenches, while two parallel intact curbs were found in others. The curbs were inset at varying depths into the weathered limestone substrate, and the concrete was poured in place using L-shaped forms. The curbs appeared to be continuous, but vertical impressions marking the joint seams between form sections were clearly visible. All exposed curb sections exhibited a 20 -cm-wide top and expanded out an additional $45 \mathrm{~cm}$ on the bottom toward the inside of the road. Thickness varied from about 30 to $40 \mathrm{~cm}$ from the top of the curb to the bottom part of the L. All curb sections that were examined sloped gently southward, and their tops varied from less than $10 \mathrm{~cm}$ to over $40 \mathrm{~cm}$ in depth below the surface (Figure $8 b, c$ ). Many knowledgeable individuals (e.g., construction workers, historians, architects, and historic restoration professionals) saw these features exposed, and they all were impressed with the quality of the concrete and the concrete work.

Layers of sometimes sporadic, sometimes continuous red clay in the sediment profiles (see Figure $8 b$ ) between curbs in several areas were in sharp contrast to the surrounding sediments. These layers were found at the bottom level of the curbs, sandwiched between the underlying white calcareous clay, marl, and caliche and the overlying dark brown to black clays. Unnatural in this setting, the red clay was definitely brought in, presumably to form a road base. Parallel depressions filled with red clay noted in two trenches are thought to be wheel tracks from vehicle traffic.

The third type of feature found in the Plaza de los Recuerdos construction area was represented by three pit features found in the floor of Gradall Trenches 3 and 6 and in the south wall profile of Gradall Trench 5. The features consisted of uniform concentrations of dark brown clay in the calcareous sediments. The pit edges were sharp, and the features were square in plan view (Figure $8 d$ ). When first encountered, it was speculated that these were pits where large monuments had been set into the ground. This interpretation seems logical given their uniform placement in relation to the old roadway.

The pattern that emerged from the buried concrete curbs in Gradall Trenches 1-7 was generally similar to the outline of the expanded plaza of Albert Sidney Johnston Avenue shown on the historic map (see Figure 7). Using the crude map as a guide, it was speculated that the roadway would continue southward to its old entrance from Seventh Street. Two large cut stone pillars located in the center of the Seventh Street fence marked the location of the old entrance, and hand digging at the north side of the pillar bases uncovered concrete curb remnants heading due north. In addition, it is further speculated that the square pit features found in Gradall Trenches 3, 5, and 6 represent the locations of former similar pillars that once lined the edges of Albert Sidney Johnston Avenue.

When it became apparent that many of the reserved burial plots between Sections A and B (see Figure 1) might fall directly over buried concrete road curbs, cemetery officials requested 


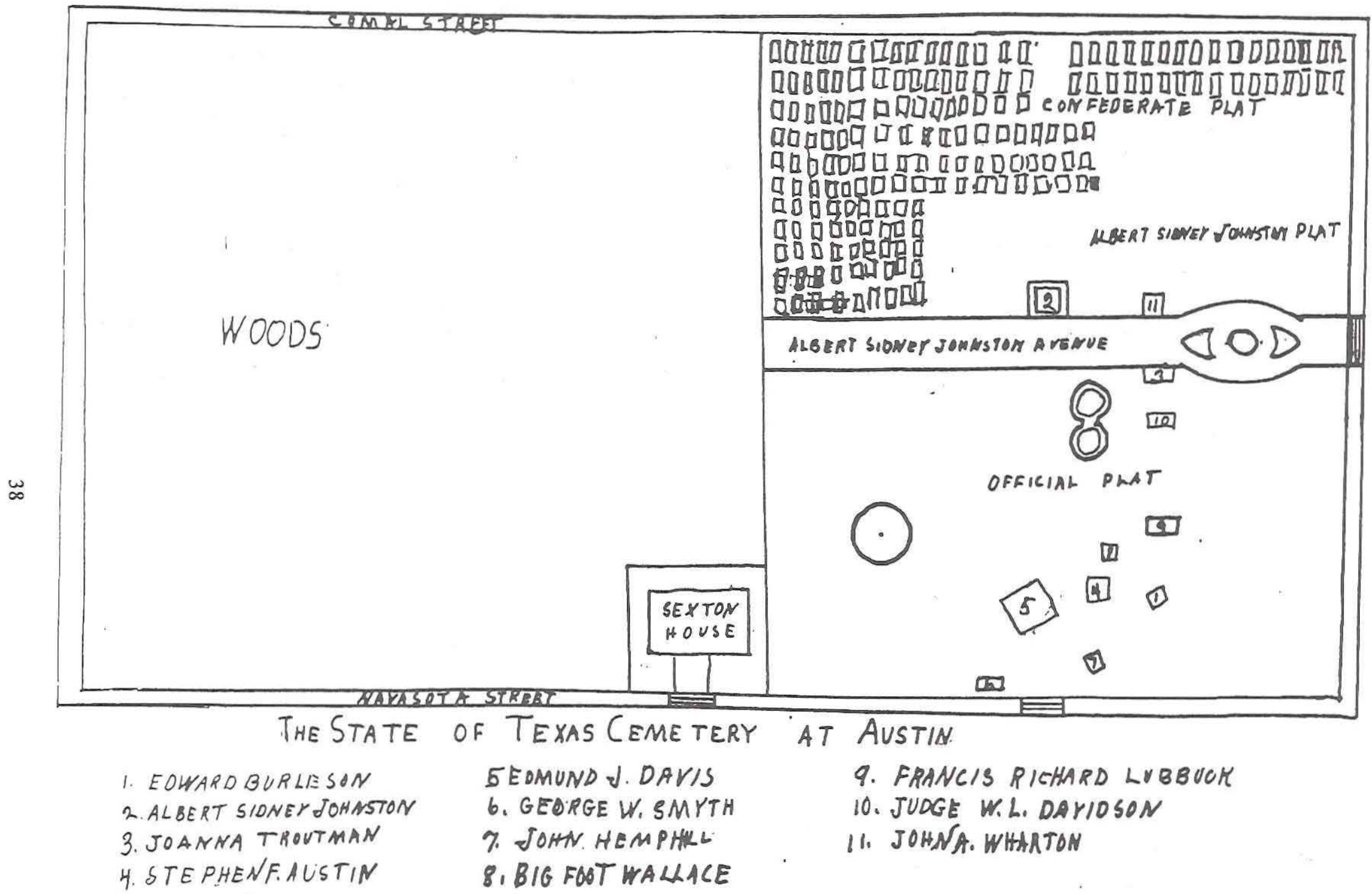

Figure 7. Pre-1928 hand-drawn map entitled "The State of Texas Cemetery at Austin." This map is an attachment to a document dated April 1928 in the Local History Program files at the Texas Historical Commission. It is not known when or by whom the map was drawn. 


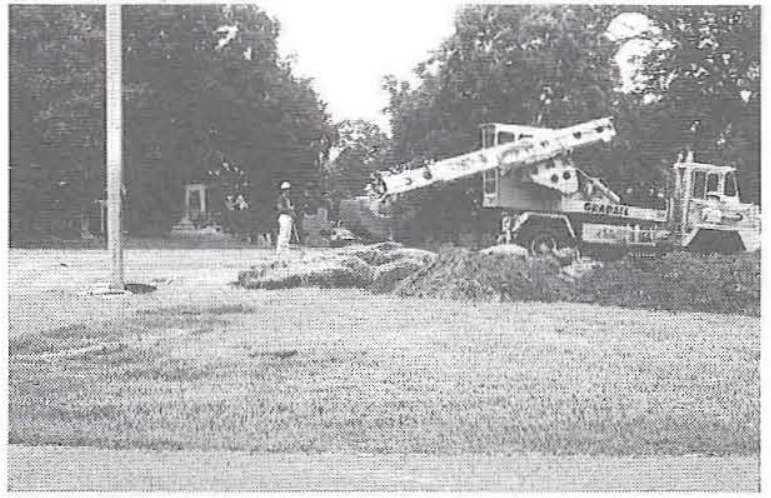

a

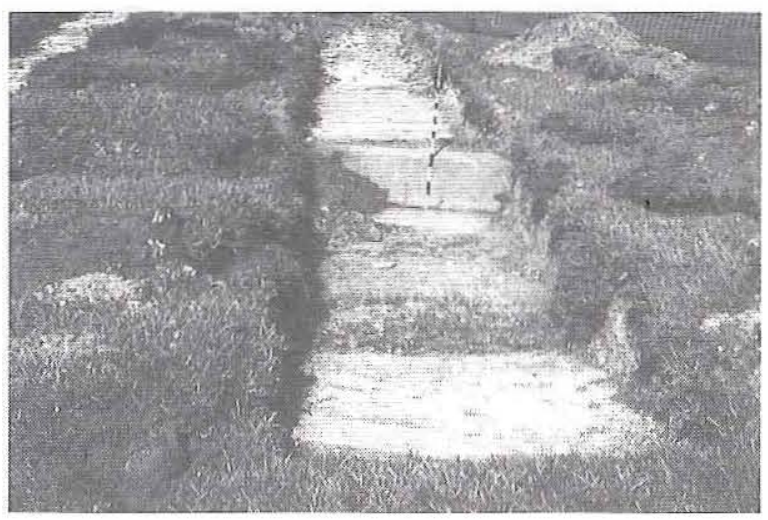

C

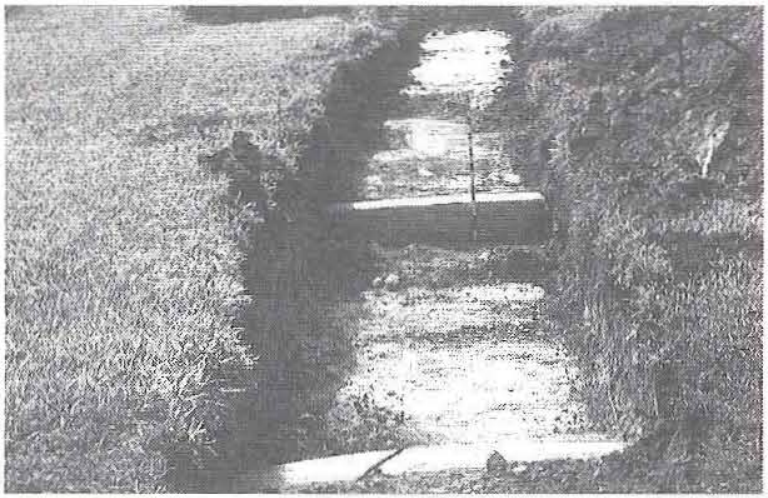

$\mathrm{b}$

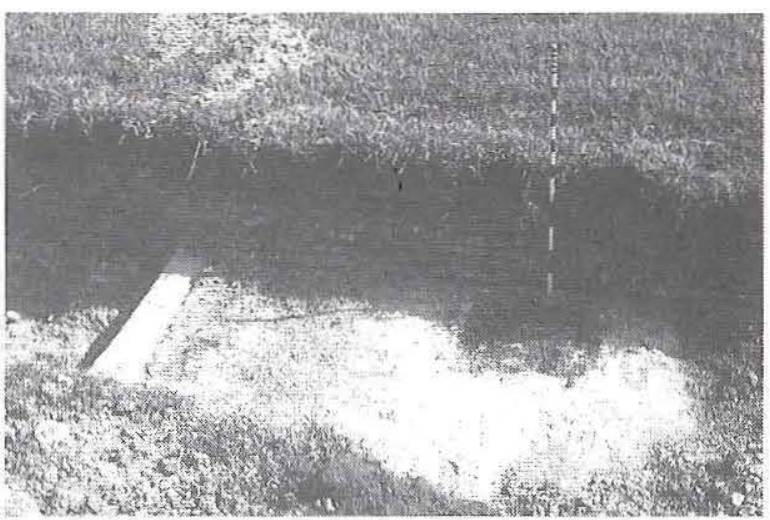

d

Figure 8. Gradall testing and concrete roadway features in the proposed Plaza de los Recuerdos construction area. (a) View north of Gradall testing in progress; $(b)$ view east of Gradall Trench 2 showing interior concrete curb in foreground, exterior concrete curb in background (with $1-\mathrm{m} \mathrm{scale}$ ), and remnant of red clay road base in between; (c) view west of Gradall Trench 6 showing interior and exterior concrete curbs; $(d)$ view south of Gradall Trench 6 showing the exterior curb and the square pit feature (dark stain) outside the roadway.

that additional Gradall testing be done in the area between the old Seventh Street entrance and the paved turnaround. In order to define the location of buried curbs south of the turnaround, Gradall Trenches 30 and 31 were excavated at the point where the southern end of Albert Sidney Johnston Avenue plaza was suspected to be. These trenches quickly located the concrete curbs and even exposed the apex (i.e., the point where the two interior curbs converge) at the southern end of the plaza (Figure 9a). The name of the construction contractor who built the curbs - "BROWN \& REISSIG" over "AUSTIN, TEX."-was stamped into the concrete apex (Figure $9 b$ ).

After Gradall Trenches 30 and 31 were excavated, the pattern of buried concrete curbs emerged, as shown in Figure 10. More-extensive excavations or continuous trenching would have been helpful in defining the patterns, but additional work could not be done without completely removing buried sprinkler lines scattered throughout the area. Some important details, such as the locations of the interior circle and the butt ends of the triangular wings, remain unknown, but the general locations of the buried curbs can be defined. Despite the incompleteness of exposure, a hypothetical reconstruction of the roadway is offered in Figure 11 by interpolating the archeological data (see Figure 10) based on the crude historic outline of the roadway plaza on the hand-drawn map (see Figure 7). This reconstruction is a rough approximation and should not be considered an accurate map of all of the buried features associated with Albert Sidney Johnston Avenue. More archival and/or archeological work would be needed to define precisely the nature and extent of the road- 


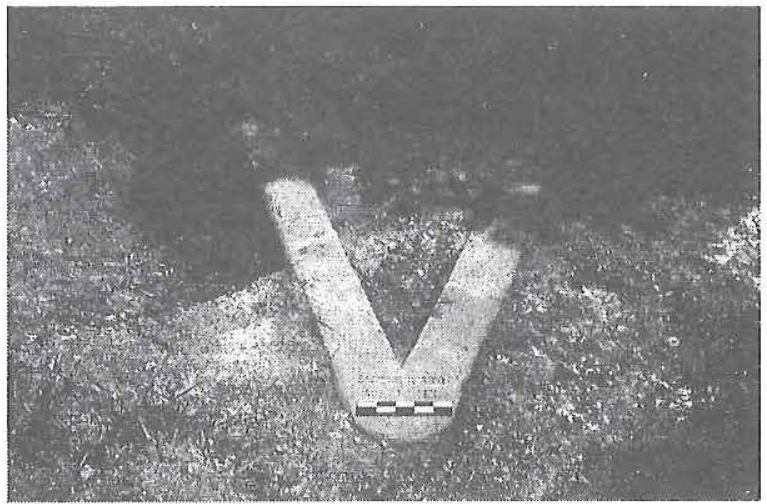

a

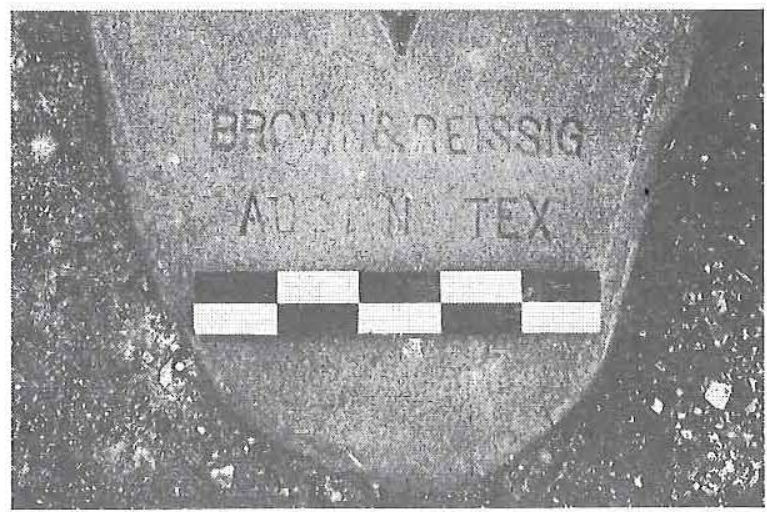

b

Figure 9. Concrete curb feature in Gradall Trench 30. (a) View north of curb at the southern apex of plaza area; $(b)$ close-up of apex showing stamped construction contractor's name- "BROWN \& REISSIG" over "AUSTIN, TEX."

related features in the Plaza de los Recuerdos area. Additional archival research conducted during the Stage II investigations confirmed that the buried concrete features are remnants of the Albert Sidney Johnston Avenue roadwork. Brown \& Reissig was identified as an Austin-based contracting firm that existed for approximately one year around 1913-1914. In addition, a 1914 government report documents the expenditure of $\$ 5,000.00$ between 1912 and 1914 for various cemetery improvements, including cement curbs for a driveway to the front entrance (see Chapter 3). Consequently, it may be concluded that the buried concrete curbs and related features, and the still-standing pillars at the old southern Seventh Street entrance, were built around 1913-1914 as part of a major cemetery renovation done under the 1910-1915 administration of Governor O. B.
Colquitt (see Chapter 3). The avenue was named after the famous Confederate General Albert Sidney Johnston (1803-1862), whose remains had been brought to Austin and reinterred in the cemetery in 1867 (Germany 1995:22). Johnston's grave, complete with a sculptured stone monument by Elisabet Ney and enclosed by a large wroughtiron structure, is located approximately $120 \mathrm{ft}$ due north of Gradall Trench 3.

The concrete features probably remained in use until 1929-1930, when the Texas State Highway Department constructed State Road Spur 165. Now called the Lou Kemp Highway, this new road was to begin outside the cemetery at the corner of Sixth and Onion Streets, extend northward to the Seventh Street cemetery entrance, and then continue north along the old Albert Sidney Johnston Avenue to exit the cemetery grounds at Eleventh Street. As it currently exists, Lou Kemp Highway encompasses only the paved roads within the cemetery boundary. Rather than removing the 1913-1914 roadwork, the sunken Albert Sidney Johnston Avenue was filled in with sediment during the 1929-1930 highway construction phase, effectively raising the level of much of the northsouth corridor through the southern half of the cemetery. It is not known if concrete remains of Albert Sidney Johnston Avenue are preserved beneath the paved roadway that extends north of the turnaround or if the old concrete roadwork was removed from this area.

\section{Summary and Recommendations}

The substantial concrete roadwork and related features of Albert Sidney Johnston Avenue encountered in the Plaza de los Recuerdos construction area have received only cursory examination and documentation. Archeological work has shown that these buried features are intact and in excellent condition. Archival work to date reveals that these features are associated with Governor O. B. Colquitt's cemetery renovation work between 1910 and 1915. Consequently, it appears that the remains of Albert Sidney Johnston Avenue are indeed historically significant.

Since the current construction plans call for the Plaza de los Recuerdos area to be raised (i.e., additional sediments added) rather than excavated, there will be no construction-related impacts to the Albert Sidney Johnston roadwork. Consequently, 


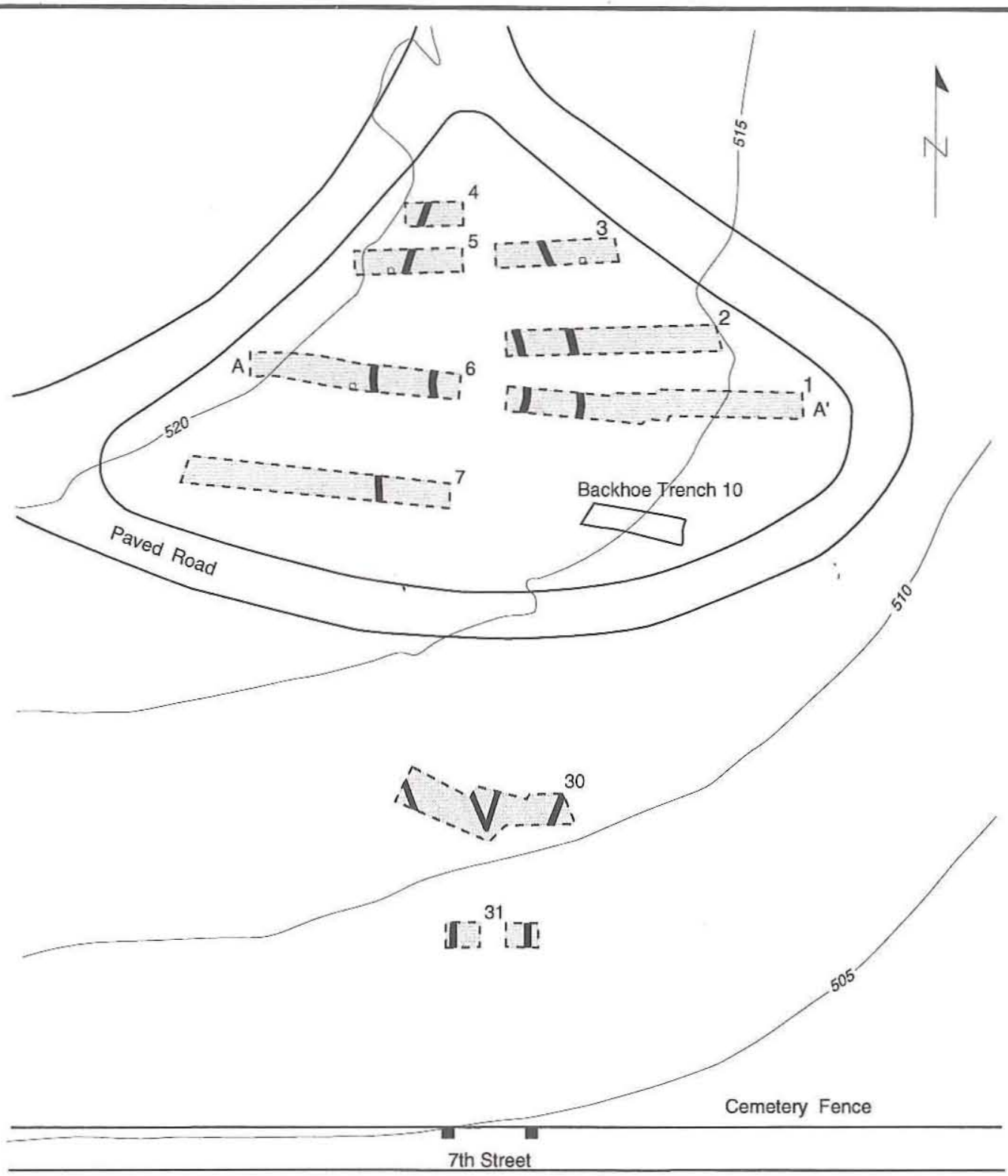

$$
\begin{array}{cl}
\text { L E G E N D } \\
\hdashline-1 \text { Gradall Trench } \\
\square \quad \text { Pit Feature } \\
\square \quad \text { Concrete Curb }
\end{array}
$$

$P \& A I / 96 / B W$

Figure 10. Plan view of the proposed Plaza de los Recuerdos construction area showing the location of Gradall trenches and concrete curbing of Albert Sidney Johnston Avenue. It is based on detailed mapping data compiled by the Texas Parks and Wildlife Department.

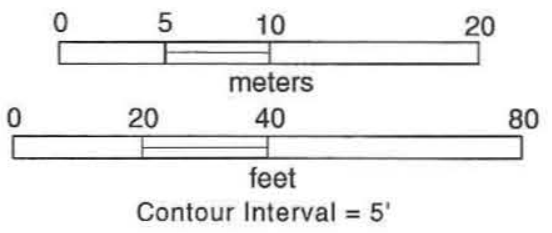

Contour Interval $=5$ 
no archeological or archival work is recommended in conjunction with the cemetery renovation project. It is recommended that all of the buried features be left intact and not altered by any future cemetery actions (such as burials) or construction projects. In the event that any project undertaking may alter or destroy any portions of the roadwork and related features, additional archival work is needed to fully evaluate their historical significance. Furthermore, if any impacts from cemetery actions or future development may occur, additional archeological field investigations also may be necessary to define further the precise locations of the buried roadwork. A simple hand-auger coring devise could be used to trace out the concrete curbs quickly.

Even in the absence of project-related potential impacts, however, additional archival research could be informative from a historical perspective and could provide valuable information for cemetery officials. A thorough examination of the Texas Highway Department records relating to Lou Kemp's cemetery renovation work would be an important first step. It is possible that detailed maps, drawings, descriptions, and/or photographs were made of the roadway before it was modified during the 1929-1930 Highway Department improvements. It also is possible, but less likely, that records pertaining to the original 1913-1914 construction might still exist.

\section{INVESTIGATION OF FEDERAL BURIALS}

\section{Archeological and Archival Investigations}

The proposed Northeast Cenotaph construction area was investigated with a single irregular- shaped, double-wide Gradall trench between a cluster of large trees and the northeast corner cemetery fence. Insignificant historic/modern debris was observed in the trench fill, but three rectangular soil anomalies were immediately recognized as grave pits (Figure 12). Two rectangular pits were completely exposed, and one was partially exposed in the trench. All three were oriented with their long axes east-west, perpendicular to the east cemetery fence, and arranged in a single north-south row roughly parallel with the 


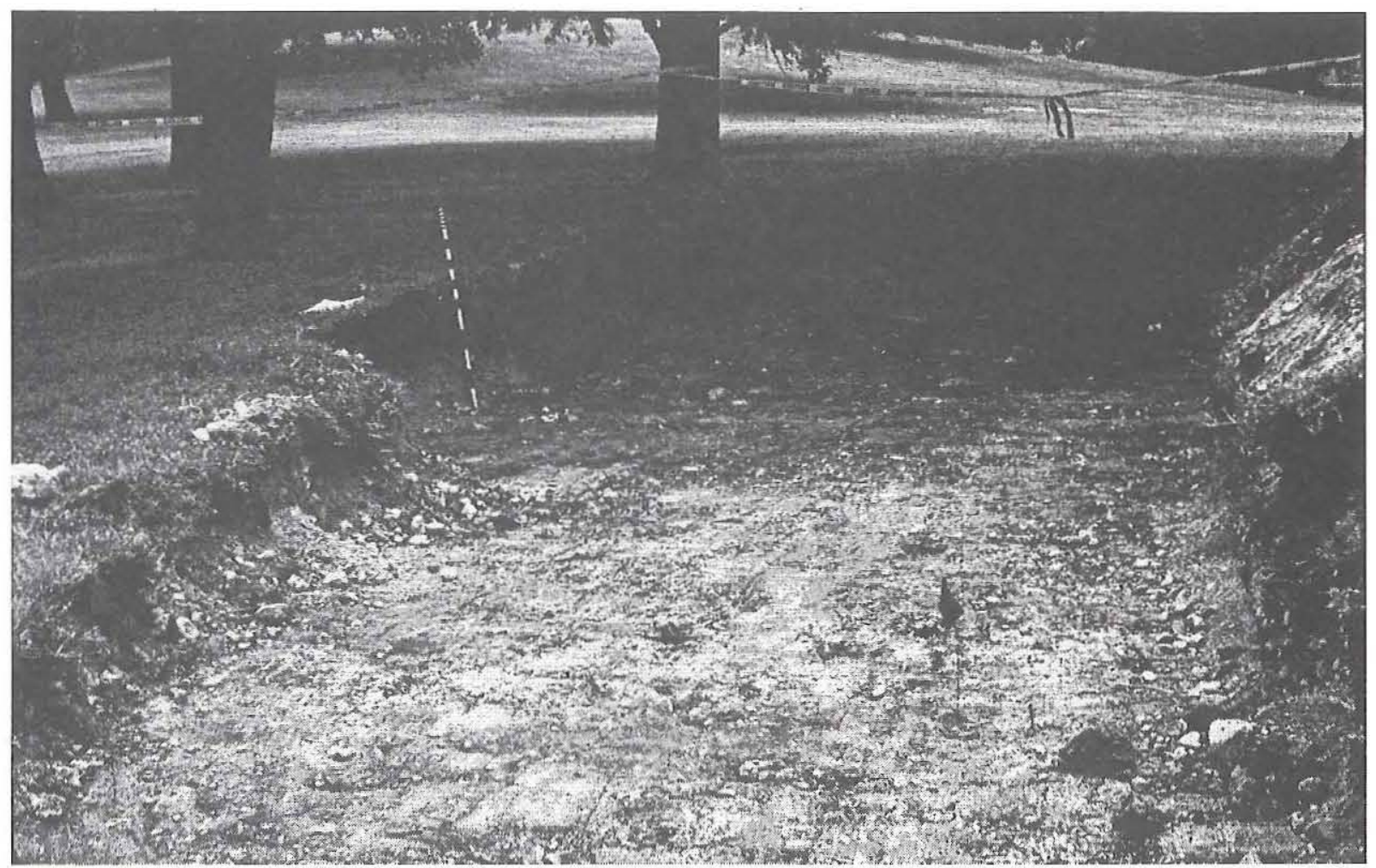

a

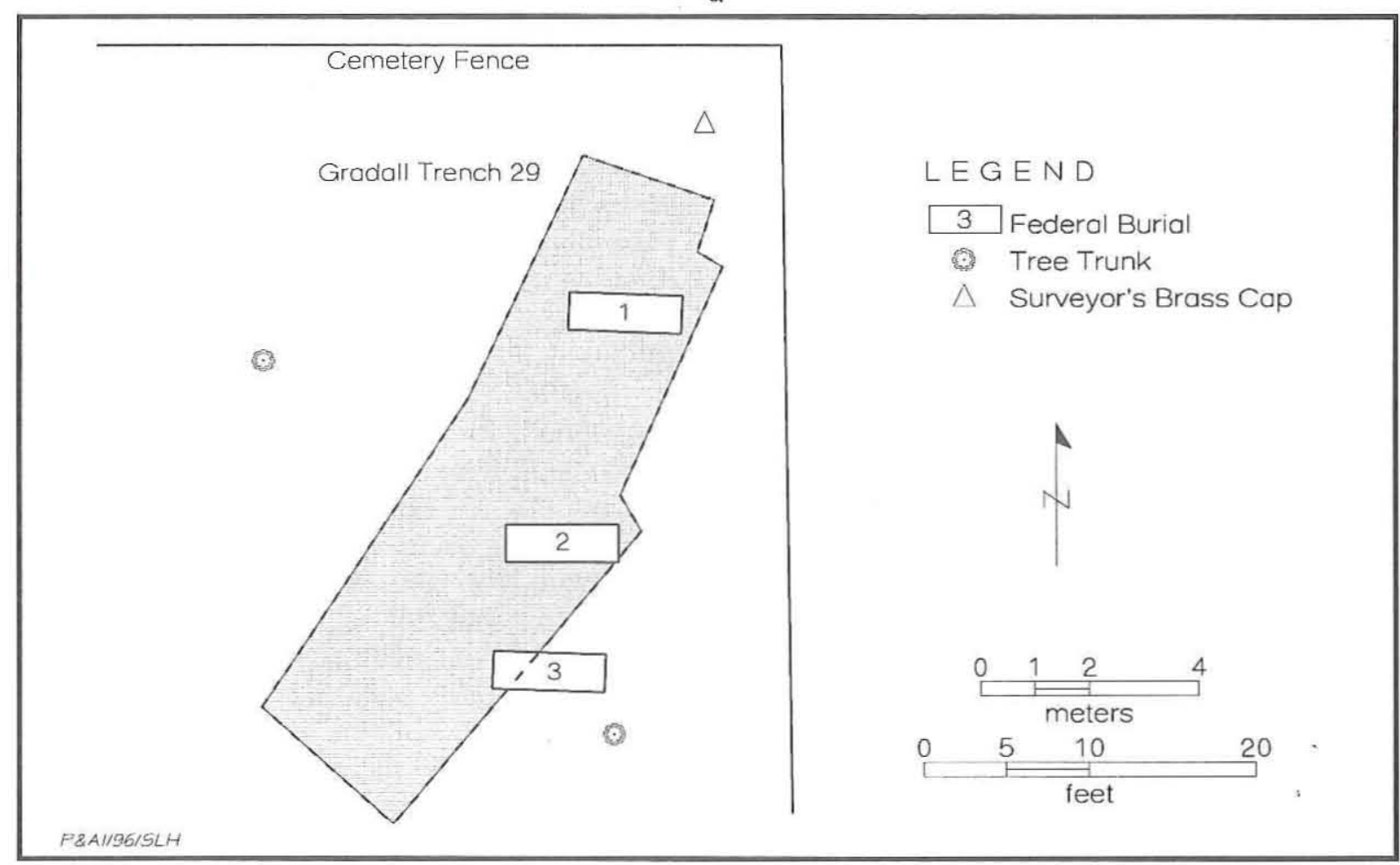

Figure 12. Photograph and plan view of the grave pits exposed in Gradall Trench 29 in the northeast corner Federal burial area. (a) View southwest of excavated trench with Federal Grave 1 in the foreground (pin flag marks west end); (b) plan view showing spatial relationship and orientation of grave pits. 
east fence. Stage I archival research indicated that the three grave pits are located within a 1-acre plot in the northeastern corner of the cemetery that was set aside by the state legislature in 1866 for the interment of Federal troops occupying Austin during the Reconstruction Period (see Chapter 3). Based on this evidence, it was assumed that an unknown number of interments could have occurred in this area between 1866 and 1874, when Reconstruction in Texas came to an end (Webb 1952:II:446-447). Among the historic records found during this first stage of research was an unsubstantiated account mentioning the possibility that the Federal burials in the State Cemetery had been exhumed and reinterred in a National Cemetery in San Antonio. Soon after determining that these features were likely to be Federal burials, Bill Brinkman, Camp Commander of the Sam Houston Camp of Sons of Union Veterans, was notified and invited to visit the site.

Although the archival records indicated a high probability that more graves exist in the northeastern corner of the cemetery (i.e., approximately $70 \times 70$ yards, or $64 \times 64 \mathrm{~m}$ ), the presence of buried sprinkler lines and numerous large trees prevented excavation of additional Gradall trenches or further expansion of Gradall Trench 29. Consequently, the next step was to investigate the known grave pits rather than continue searching for more grave pits.

Federal Graves 1 and 2 were investigated with hand-dug trenches perpendicular to each grave's long axis across the western end (i.e., the foot end) of each grave. When no skeletal remains were encountered in either grave, the hand excavations were expanded and all of the fill inside both graves was carefully troweled and removed. The absence of any human skeletal materials in either grave led to the conclusion that the remains of these Federal soldiers had indeed been removed.

Fairly well preserved remnants of a wooden hexagonal coffin (Figure 13) were found inside the rectangular pit of Federal Grave 1. The rectangular pit measured approximately $256 \times 79 \mathrm{~cm}$ (101 x 31 inches). The coffin inside measured approximately $190 \mathrm{~cm}$ (75 inches) in length and $50 \mathrm{~cm}$ (20 inches) in maximum width, and it tapered to approximately $28 \mathrm{~cm}$ (11 inches) wide at the head (east) and $20 \mathrm{~cm}$ (8 inches) wide at the feet (west). A wood sample and a few corroded nails from the floor of the coffin were collected,

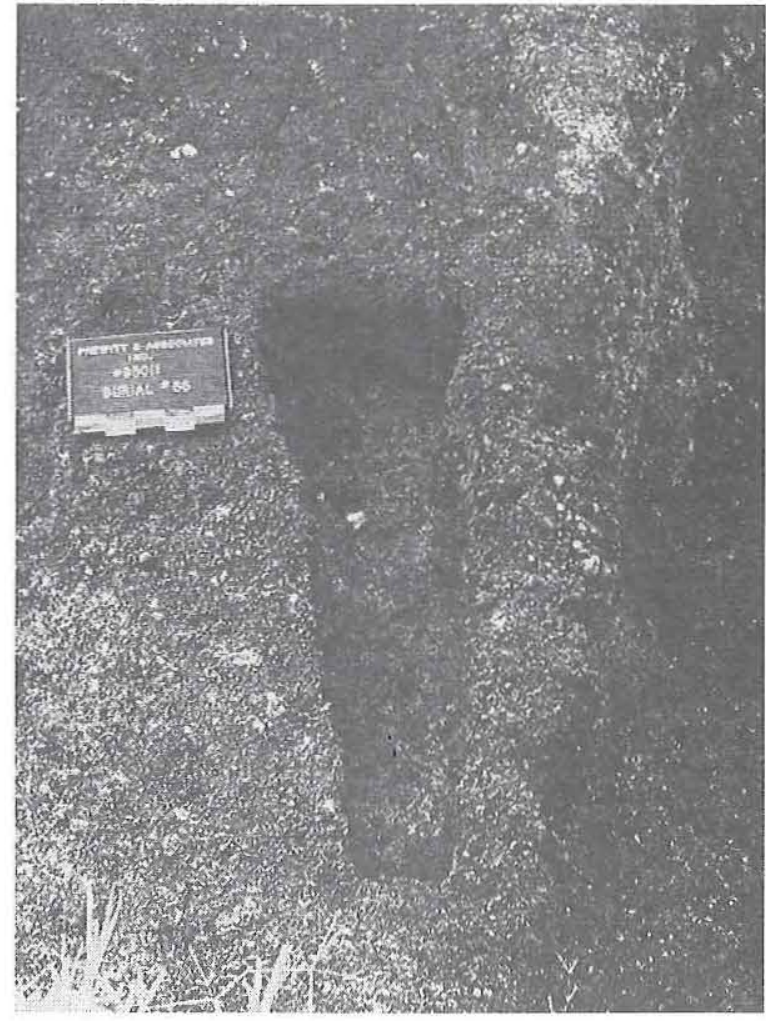

Figure 13. Wooden coffin remnants in Federal Grave 1 (shown in photo with the field designation of Burial 58). View is to the east, and the west half of the fill inside the coffin has been removed.

but no other coffin hardware or personal artifacts were found. The coffin wood was identified as Pinus sp. (hard pine) by J. Philip Dering of the Paleoethnobotany Laboratory at Texas A\&M University.

Federal Grave 2 consisted of a rectangular grave shaft with the faint outline of a hexagonal coffin, head to the east, measuring approximately $198 \mathrm{~cm}$ (78 inches) in length and $59 \mathrm{~cm}(23$ inches) in maximum width. The coffin was discernible as a contrast between the fill and the surrounding sediment rather than as an organic stain from rotted wood. Consequently, it appears that the most of the wooden coffin may have been removed at the time of the disinterment. A single fragment of wood, which almost certainly came from the original coffin, was collected. It also was identified by J. Philip Dering as Pinus sp. (hard pine).

The only artifacts found in the fill of Federal Grave 2, one corroded cut nail and a .54-caliber Spencer rimfire cartridge case, were collected. 
Although found in the grave, their association with the burial is unclear. The Spencer cartridge is particularly interesting because it dates to the right time period. The Spencer repeater had become the preferred carbine by the end of the Civil War, and McChristian (1995:27) notes that Spencers were "issued almost exclusively to the postwar regular army." It may have been thrown into the grave at the time of the original burial or perhaps at the time of disinterment.

After an on-site meeting and consultation with a representative of the Texas Historical Commission's Department of Antiquities Protection, the decision to investigate the third Federal burial was made. Since the grave shaft was only partially exposed by the Gradall, a backhoe was used to remove the overburden from the eastern half of the grave. Most of the fill from the western half of the grave was then hand excavated, but a large mesquite root prevented complete excavation of the east half. Again, no human skeletal remains were recovered. Federal Grave 3 proved to be very similar to Grave 1 in that it consisted of a rectangular pit with a faint outline of a rotted wooden coffin with the head end to the east. The wood was poorly preserved, and no sample was obtained. No other artifacts were observed.

After confirming that the three known grave pits in the Federal burial area were indeed empty, it could then be safely assumed that the rumored exhumation and reinterment had actually occurred. Subsequent archival research during the Stage II investigations was aimed at finding documents confirming that Federal burials had been moved from the cemetery. This additional research also attempted to identify when burials were moved, where they were moved to, how many were moved, and, if possible, whose remains were moved. Project Historian Freeman found historic documents confirming that many burials of Federal soldiers had been moved from Austin to a National Cemetery on Paso Hondo Street in San Antonio (see Appendix A). Established in 1867, the National Cemetery on Paso Hondo preceded San Antonio's Fort Sam Houston National Cemetery. However, all records pertaining to reinterment of soldiers from Austin in the earlier Paso Hondo cemetery were found in burial registers at Fort Sam Houston National Cemetery. These registers indicate that 62 burials in the National Cemetery (Paso Hondo) had been moved there from Austin (see Table 43). The dates of death, and even the names and service records, are unknown for the majority of these soldiers. However, of the 18 burials for which dates of death are known, 13 are soldiers who died between 1865 and 1873 and are known to have been buried originally in Austin. Although the records do not specify that these individuals were buried originally at the State Cemetery, this seems very likely given the fact that a portion of the cemetery was set aside specifically for the burial of Federal soldiers from the large peace-keeping force stationed in Austin during Reconstruction. The fact that 9 of the 13 named individuals mentioned above, and numerous unnamed individuals, had served with the 4 th and 6 th Cavalry units is further evidence that these soldiers were moved from the State Cemetery. Many companies of both of these regiments were stationed in Austin beginning in 1865 and throughout the Reconstruction period (see Chapter 3 ).

What remains most unclear in this scenario is when the National Cemetery reinterments from Austin occurred. While the Fort Sam Houston National Cemetery's register books record the dates of death and original places of burial for many individuals, the dates of reinterment are not recorded (see Figure 50). The current archival information is not sufficient to determine when Federal burials were removed from the State Cemetery, but it may be speculated that this occurred soon after 1880. The United States Quartermaster Corps initiated a burial reinterment program that year and began systematically removing bodies of soldiers from military burial grounds at forts and camps that had been closed (see Chapter 3). It is likely that the removal of Federal Reconstruction burials occurred between 1880 and 1900.

The fact that the Federal soldiers (at least the three whose graves have been found) were buried with their heads to the east is unusual. The significance of this is not yet understood, but this funerary trait is very uncommon for latenineteenth-century Christian burials. Jordan $(1982: 30)$ notes that

Nearly all southern folk cemeteries have the graves aligned on an east-west axis, and burials are made with feet to the east. A Christian symbolism is attached to this practice by most rural folk. The 
east, they say, is the direction of Jerusalem, of the second coming, and archangel Gabriel's horn will sound from that quarter. In order to be facing Christ when they rise from their graves on Judgment Day, the dead must lie with their feet to the east.

Another line of thought among rural Texans and throughout the Southern states is that "feet-to-theeast burial allows the dead to face the rising sun" (Jordan 1982:31). Other researchers have noted that the Christian tradition of feet-to-the-east burial, common throughout the United States, is of British European origin (Jordan 1980).

The primary reason for burying a Christian in any orientation other than feet to the east is because that person had done something bad. Jordan $(1980: 233,1982: 30-31)$ observed that in parts of Europe and in the Southern United States sinners and wrong-doers, especially persons who committed suicide, typically were buried in a north-south alignment. Tradition holds that suicide victims often were buried in a nontraditional face-down position. At least two archeological examples of face-down burials (including one from Texas) are known, but neither can be linked conclusively with a suicide victim (Taylor et al. 1986:42,69). One published account links deliberate face-down burial with several Federal deserters who were executed during the Civil War (Robertson 1984:155, as cited in Taylor et al. 1986:42).

There are at least three alternative explanations for the nontraditional, head-to-the-east burials of these three Federal soldiers, who in all likelihood were buried by other Federal soldiers: (1) the nontraditional burial orientations were simply fortuitous; perhaps the soldiers assigned to burial details were not aware of the Christian preference for feet-to-the-east burial; (2) the nontraditional burial orientations were intentional but were for unknown reasons unrelated to Christian burial traditions; perhaps the U.S. Army chose to bury these soldiers in this manner because, as a temporary occupying force, they knew the State Cemetery was only a temporary burial place; or (3) the nontraditional burials were intentional because these soldiers were perceived as immoral individuals by their own comrades or the U.S. Army. Spatial segregation of individuals within cemeteries along family lines, by ethnic or religious groups, and according to economic status were common practices (Jordan 1982:31-33; Winchell et al. 1992:27-28). Perhaps the three graves that were found were burials of ne'er-do-wells whose graves were intentionally segregated from the rest of the soldiers' burials. In this case, the nontraditional orientation of their coffins would have signified that they were, for whatever reasons, looked down upon by their comrades. None of these interpretations is favored or ruled out by the evidence at hand; however, it would be interesting to know the orientations of other Federal burials at the State Cemetery.

\section{Summary and Recommendations}

Archival evidence indicates that the three empty grave pits in the northeast corner of the cemetery are the original burial locations of Federal Reconstruction soldiers who died in Austin between ca. 1866 and 1874 but whose remains subsequently were removed and reinterred in the first National Cemetery (Paso Hondo) in San Antonio. Burial registers at the Fort Sam Houston National Cemetery indicate that remains of as many as 60 Federal soldiers were reinterred from Austin, and many of these are likely to have been buried originally in the State Cemetery. Thus, an unknown number of graves may exist throughout the northeastern 1-acre tract set aside by the Texas Legislature in 1866 for the burial of Federal soldiers during Reconstruction. The fact that no human remains were found in any of the three investigated graves indicates that the human remains were removed for reburial while some of the coffin remains were left behind. The combined archeological and archival evidence suggests that the Federal government made a serious attempt to remove the remains of all of the Federal troops buried at the State Cemetery. This does not mean that the remains of every soldier buried there were actually moved, and it is quite possible, perhaps even likely, that some burials were missed because they were not marked at the time the disinterments took place.

The proposed work in the Northeast Cenotaph construction zone, which consists of building a small cenotaph and associated walkways, is not likely to impact any unmarked graves. The cenotaph will be located completely within the area investigated by Gradall Trench 29, and there are 
no unmarked graves (other than the three already investigated) in this area. Although the associated walkway covers a larger area and extends across portions of the northeastern 1-acre tract that have not been investigated, its construction will impact only the upper 6 to 8 inches of sediment, and there is little possibility of locating or disturbing unmarked graves at this shallow depth. Thus, no additional work is recommended for the Northeast Cenotaph area in connection with the cemetery renovation construction. However, based on experiences at other historic cemeteries, it would be unusual if all of the burials were actually removed from the northeast corner area, and many may have been missed. Consequently, if any future cemetery actions or proposed construction activities involve subsurface impacts anywhere within the northeastern 1-acre tract (other than the proposed cenotaph), these activities must be coordinated with the Department of Antiquities Protection of the Texas Historical Commission. This is especially true if this northeastern corner is to be opened up for modern burials. In this case, it would be wise to conduct an extensive search for unmarked graves and quickly test each grave to determine if human remains are present. Gradall stripping would be the most efficient method of locating the graves, while a backhoe trench across the lower portion of each grave would immediately determine if human remains are present. 



\section{BURIAL DESCRIPTIONS}

Helen Danzeiser Dockall, Rolando L. Garza, and Kevin E. Stork

\section{INTRODUCTION}

This chapter is intended to provide summary information pertaining to each of the excavated individuals; more-detailed information relating to mortuary and osteological characteristics is provided elsewhere in the report. Casket construction and hardware, as well as personal items and nonassociated artifacts, are discussed in Chapter 6 . Osteological analyses are discussed in Chapter 7. Appendix D provides a detailed skeletal inventory for each individual, and Appendixes $\mathrm{E}$ and $\mathrm{F}$ list the metric and nonmetric skeletal data. Listings of medical disorders are located in Appendix G.

The excavated burials described in this chapter were relocated from the first row of graves in Section $\mathrm{F}$, as well as from the first two rows in the northwest corner of Section D (Figure 14). The burials excavated from Section $\mathrm{F}$ were given the numbers 1 through 46 , corresponding to the Texas State Cemetery plot numbers FA1 through FA46. Burials 47 through 57 originally were located in Section D and correspond with plot numbers DA1 through DA6 and DB1 through DB5. Forty-three of the individuals from Section $\mathrm{F}$ and four from Section D were residents of the Confederate Home for Men in Austin at the time of their deaths and were interred by the home. The Confederate Home was founded in 1887 by the John B. Hood Camp of Confederate Veteran's with the collaboration of the Albert Sidney Johnston Chapter of the Daughters of the Confederacy (Webb 1952:I:391). Private money was raised to buy over
16 acres of land in Austin on which to build a home and associated buildings; disabled and dependent Confederate veterans began using the home in 1891 (Webb 1952:I:391). An amendment to the state constitution in 1893 allowed the legislature to provide for the home by deeding the property to the state; eventually 10 additional acres of land were purchased and a hospital was constructed (Barkley 1963:125; Webb 1952:I:391). Forty of the individuals excavated from Section F died at the home in 1907 or 1908 ; the remaining six died in the 1930s.

Most of the individuals interred in the excavated portion of Section D were not residents of the home, but all of the men were veterans of the Confederate States Army. Most interments in that section took place between 1920 and 1932, but one of the men buried in this section, Dr. John R. Ward, originally was buried in 1884 and reinterred in the State Cemetery in 1958. The latest interment, that of Josephine Walker (Burial 50), occurred in 1951. Burials in Section D tended to be more elaborate, in terms of caskets and casket hardware, than those in Section $F$ since those individuals were interred by family members rather than by the state.

Of particular interest with respect to these burials is the placement of their graves relative to the locations of their headstones and Lou Kemp Highway. Figure 14 shows these spatial relationships and reveals an interesting pattern. Disregarding the headstones for a moment, it is clear that the Section D grave shafts were less-neatly aligned 


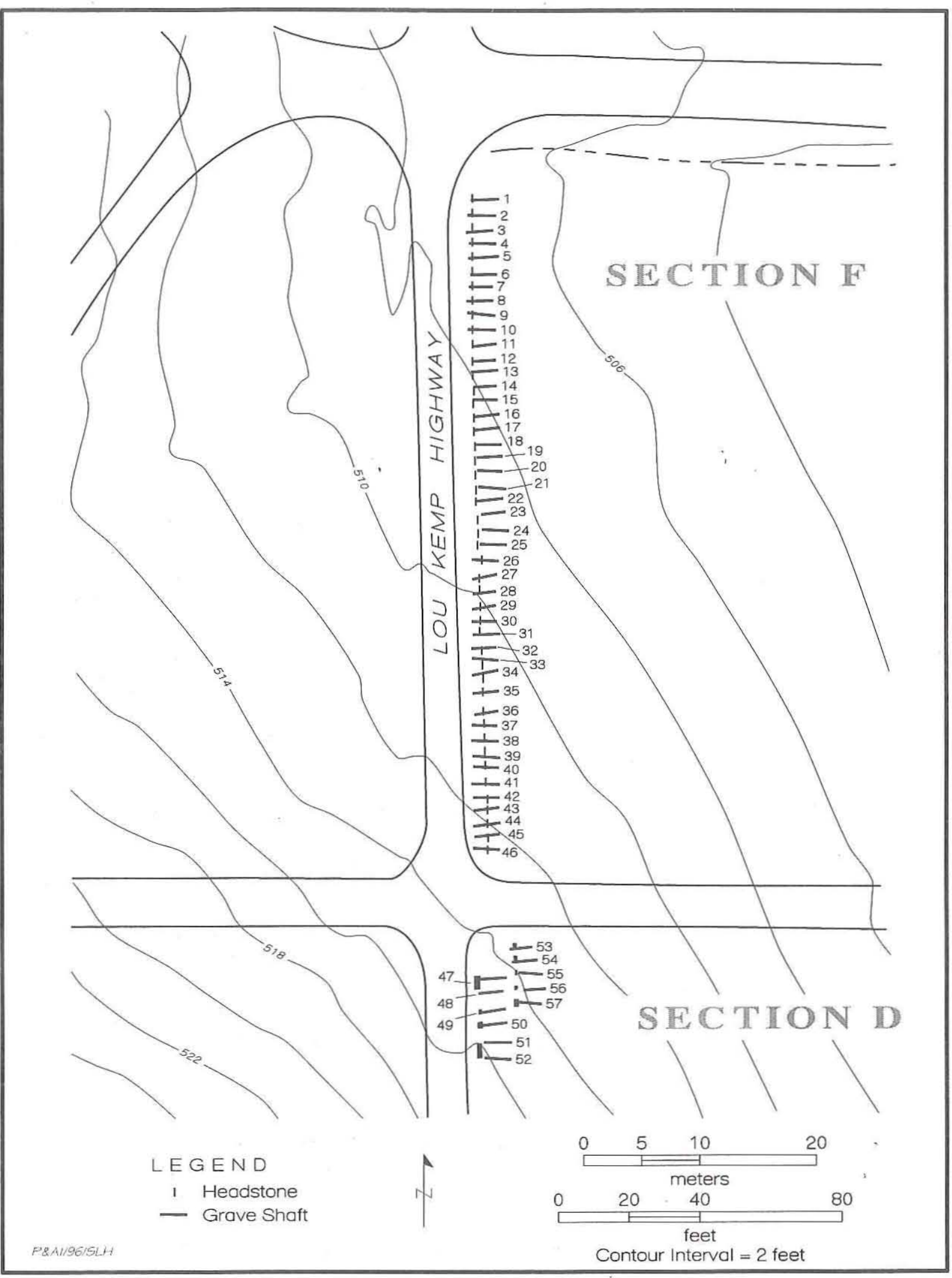

Figure 14. Map of original grave and headstone locations for the 57 excavated burials. 
than those in Section F. Section D interments spanned a period of 67 years with the 11 burials occurring in 1884, 1917, 1920,1923, 1925, 1931/ $1932(n=5)$, and 1951. These burials were not dug in sequence, and the irregular row alignments and skewed grave shaft orientations are probably due to the fact that the graves were dug at different times without precise knowledge of where the adjacent graves were located. The placement of their headstones, however, is relatively ordered, with each stone being located in close proximity to the head of the grave, or graves in the two cases where single stones were used to mark two graves (Burials 47 and 48, and 51 and 52).

In contrast, many of the graves in Section $\mathrm{F}$ were more uniform in their placement relative to each other, although the grave orientations change abruptly in the vicinity of Burials 5-10 and Burials 22-27. These anomalies may be explained by looking at the chronological sequence of burials. The earliest graves in Section F, Row A were the 39 interments dating to 1907 and 1908 (Burials 7 to 46). Starting with Burial 46 at the southern end of the row on 14 October 1907, burials were added in rapid succession and more or less sequentially through Burial 35 on 12 November 1907. The next grave in sequence was Burial 23 on 15 November 1907 , with the intervening 11 grave plots being left empty. The grave shaft of Burial 23 was not aligned precisely with the previous grave shafts, causing many subsequent burials to be skewed as well. The chronological sequence of the burials filling in this gap, all of which occurred between 18 November 1907 and 19 January 1908, was 34, $33,24,32,31,30,29,25,28,26$, and 27 . At this point, the graves were being dug in both directions, and it appears that the gravediggers attempted to straighten out the row as the grave plots were filled in. The grave shafts of Burials 25 and 26 are askew by more than $2 \mathrm{ft}$, and all graves south of Burial 25 are aligned relative to each other while most of the graves north of Burial 26 are aligned relative to each other. Burials 22 to 7 were added in more or less sequential order between 29 January 1908 and 3 June 1908. Burials 6-1 were added to Row A of Section F over 2 decades after the last 1908 grave; Burials 6-2 were dug in 1930 and 1931, and Burial 1 was added in 1939. It appears that the original intent was to avoid locating graves in the low-lying area near the drainage. As Confederate sections of the cemetery began to fill during the early twentieth century (see Chapter 3), burial plots became scarce. By the 1930s, space was at a premium and cemetery officials apparently decided to add more graves near the drainage. The northern limit of burials in Section F was extended during this time by adding five or six grave plots at the north end of each row.

In Section F, the locations of the grave shafts, relative to their headstones and Lou Kemp Highway, also are revealing. All of the 1907 and 1908 burials in Row A predate the 1929-1930 construction of Lou Kemp Highway (see Chapter 3). It is interesting to observe that each of the early burials in the northern half of Row A (i.e., Burials 7-25) had its headstone in close proximity to the head of the grave. Two phenomena are unusual about the southern group (i.e., Burials 26-46): (1) the grave shafts were much closer to the road and proximity to the road increased southward; and (2) the headstones were centered over the graves rather than at or near the head end, and the degree by which the alignment of the headstones was off increased southward. The most likely explanation is that these graves were dug in 1907 and 1908 without reference to an adjacent road, or perhaps in reference to a road that angled more to the southwest than the current road. It also appears likely that the headstones marking Burials 26-46 originally were located at the head end of each grave but were moved to the west just prior to the construction of Lou Kemp Highway in 1929 and 1930.

Investigations of other historic cemeteries have revealed that it is common for headstones or other grave markers to be located in odd orientations relative to the graves they are marking, and many graves lack markers altogether. Some factors that could account for the absence of grave markers are (1) graves were never marked in the first place, (2) graves were marked with wooden markers that subsequently deteriorated, or (3) the theft or accidental removal of grave markers. A few of the factors that may account for grave markers being misoriented relative to grave shafts are (1) markers were added quite some time (even years) after burial when surface evidence of the grave location was obliterated, (2) markers were intentionally moved from their original locations, or (3) markers were accidentally moved (e.g., knocked over) and replaced in the wrong location. 
It has even been observed at some excavated cemeteries, such as the Seven Rivers Cemetery near Carlsbad, New Mexico (Ferguson 1993), for example, that headstones were so far removed from graves that there was no way of knowing exactly which graves the stones marked. In contrast, despite the fact that some headstones may have been moved slightly, the State Cemetery is rather exceptional because each of the 57 burials was marked by a headstone in close proximity to the grave, and the association between graves and grave markers was unquestionable.

Table 2 provides summary information relating to all of the excavated individuals including the person's name, burial number, and Texas State Cemetery plot number. Sex, date of birth, date of death, and age at death also are presented. Headstone type (discussed below) and Confederate States Army service record is documented as well. The information presented in this table and used later in this chapter in the individual burial descriptions came from a variety of sources. Headstones provided, minimally, name and date of death; a service record also usually was recorded on the headstone. Additional information was obtained from records kept by the Confederate Home for Men. A Confederate Home roster (on file at the Center for American History, The University of Texas at Austin) includes information on all residents (called inmates on the roster) who entered the home. It provides place of birth, occupation, more-specific service information, when the person came to Texas, residence in Texas, when they were admitted to the home, and any disabilities they had when entering the home. In addition, the roster states whether the person died in the home or when they were discharged. Furthermore, the doctor at the Confederate Home hospital submitted reports of hospital activities that were published in official annual or biennial reports of the board of directors and superintendent of the Texas Confederate Home. The report published for the period of 1907 and 1908 listed cause of death for many of the excavated individuals (Texas Confederate Home 1908). State of Texas death certificates were obtained for those people who did not die in the home. By using these sources, information pertaining to cause of death was located for all but seven of the individuals.

Pension records, especially useful for those people who had not been admitted to the Confederate Home, were available for those people who joined the Confederate Army while in Texas and later applied for pensions. In total, 23 of the excavated individuals had pension records on file. In general, pension records provided the same types of information as the Confederate Home records. General index cards to the Compiled Service Records of Confederate soldiers provided data on rank, as well as corresponding information on service units. Any discrepancies between these cards and headstone information are noted in the table and in the burial descriptions.

Obituaries and family histories also provided information for all of the individuals interred in Section D. Obituaries were obtained for all 11 of these individuals, while family history also provided information in the cases of George and Emma Kyser (Burials 47 and 48). A family member, Jacqueline Fickel (personal communication 1995), visited the cemetery and provided detailed genealogical information pertaining to the Kysers.

Of the individuals of known rank, 14 were officers and the remainder were privates when they served in the Confederate States Army. Five of the officers were noncommissioned sergeants and corporals, and the others were lieutenants, captains, and one surgeon. The average age of the individuals at the beginning of the Civil War in 1861 was 26.1 years, with the youngest being 14 and the oldest being 47 . When the age data are considered by calculating only the privates, the average age in 1861 was 25.9 , with a range of 14 to 43 years. The average age of officers was 25.1 years, ranging from 18 to 47 . While most of the excavated veterans served in units from Texas $(n=29)$, many served in units outside Texas and settled here after the war. Four men served in Missouri units; three each were from Alabama, Louisiana, and Tennessee; two each were from Georgia, South Carolina, and Virginia; and one each served in Arkansas and North Carolina. In terms of occupations after the war (Table 3), most of the men with known occupations were farmers (37 percent), followed by ranchers/stockmen (12 percent), sales people (10 percent), and carpenters ( 8 percent).

The locations of all burials were marked by headstones at the west (head) end of each grave. However, the majority of the headstones faced the west where they would be visible from Lou Kemp 
TABLE 2

SUMMARY OF HISTORICAL DATA FOR THE 57 INDIVIDUALS WHOSE REMAINS

WERE EXHUMED AND REINTERRED AT THE TEXAS STATE CEMETERY*

\begin{tabular}{|c|c|c|c|c|c|c|c|c|c|}
\hline $\begin{array}{l}\text { Burial } \\
\text { No. }\end{array}$ & $\begin{array}{l}\text { TSC } \\
\text { Plot No. }\end{array}$ & Name & Sex & $\begin{array}{l}\text { Date of } \\
\text { Birth }\end{array}$ & $\begin{array}{l}\text { Date of } \\
\text { Death }\end{array}$ & $\begin{array}{l}\text { Age at } \\
\text { Death }\end{array}$ & $\begin{array}{l}\text { Headstone } \\
\text { Type }\end{array}$ & $\begin{array}{l}\text { Confederate States Army } \\
\text { Rank and Service }\end{array}$ & Other** \\
\hline 1 & FA1 & Guess, Mattie J. & F & $1848(7 / 21)$ & $1939(9 / 24)$ & 91 & 1 & none & $\begin{array}{l}\text { wife of } \\
\text { Z. R. Guess }\end{array}$ \\
\hline 2 & FA2 & Gentry, Samuel & $\mathrm{M}$ & 1837 & $1931(11 / 24)$ & 94 & 2 & $\begin{array}{l}\text { private, Co. E (C), } \\
2 \text { (22) Tenn. Cav. }\end{array}$ & \\
\hline 3 & FA3 & Watkins, Joseph & M & unknown & 1931 & $?$ & 2 & $\begin{array}{l}\text { private, Co. H, Robert Reg. } \\
11 \text { Inf.; Co. A, } 5 \text { Tex. Cav. }\end{array}$ & \\
\hline 4 & FA4 & Rogers, William Everet & M & 1847 & $1931(1 / 2)$ & 83 & 2 & $\begin{array}{l}\text { private, Co. C (A), } \\
2 \text { Mo. Cav. }\end{array}$ & \\
\hline 5 & FA5 & Tiner, Richard A. & $\mathrm{M}$ & 1842 & $1930(12 / 28)$ & 88 & 2 & $\begin{array}{l}\text { sergeant, Co. C, } 31 \text { Tex Cav. } \\
\text { Dismounted }\end{array}$ & \\
\hline 6 & FA6 & Benson, Joseph R. & $\mathrm{M}$ & 1835 & $1930(12 / 26)$ & 95 & 2 & sergeant, Co. I, 15 Tex. Inf. & \\
\hline 8 & FA8 & Wyatt, James Morgan & M & 1814 & $1908(5 / 6)$ & 94 & 1 & $\begin{array}{l}\text { captain, Co. H, Showalter's } \\
\text { Reg. }\end{array}$ & \\
\hline 9 & FA9 & McCulloch, T. J. & $\mathrm{M}$ & 1835 & $1908(5 / 20)$ & 73 & 1 & $\begin{array}{l}\text { unknown, Runnells' Co. A, } \\
1 \mathrm{Va} \text {. Inf. }\end{array}$ & \\
\hline 10 & FA10 & Bates, J. M. & $\mathrm{M}$ & 1836 & $1908(5 / 24)$ & 73 & $\begin{array}{c}1 \\
-\end{array}$ & $\begin{array}{l}\text { unknown, Co. C (L), } \\
9 \text { La. Cav. }\end{array}$ & $\begin{array}{l}\text { age at death } \\
\text { could be } 72\end{array}$ \\
\hline 11 & FA11 & Bott, Fenton A. & M & 1830 & $1908(5 / 3)$ & 78 & 1 & $\begin{array}{l}\text { private, Co. D, } 8 \text { Tex. } \\
\text { Rangers }\end{array}$ & \\
\hline 12 & FA12 & Bernard, Lewis A. & M & 1828 & $1908(5 / 7)$ & 80 & 1 & private, Co. H, $26 \mathrm{La}$. Inf. & \\
\hline
\end{tabular}

*Data compiled from headstone inscriptions, General Services Commission records, Texas Confederate Home records, pension records, death certificates, index cards to Compiled Service Records of Confederate soldiers, newspaper obituaries, and published books.

**Minor discrepancies, such as records indicating death on different days, are not noted; major discrepanies are noted. 


\begin{tabular}{|c|c|c|c|c|c|c|c|c|c|}
\hline \multicolumn{10}{|c|}{ Table 2, continued } \\
\hline 14 & FA14 & Turner, Joseph M. & $\mathrm{M}$ & 1839 & $1908(4 / 14)$ & 68 & 1 & $\begin{array}{l}\text { private, Co. A (H), Young's } \\
\text { Reg., } 12 \text { Tex. Inf. }\end{array}$ & \\
\hline 16 & FA16 & Davenport, J. V. & M & 1840 & $1908(4 / 7)$ & 68 & 1 & private, Co. C, 14 S.C. Inf. & \\
\hline 17 & FA17 & Brock, A. F. & M & 1840 & $1908(2 / 14)$ & 68 & 1 & unknown, Co. C, 2 Tex. Cav. & \\
\hline 18 & FA18 & Ormand, J. B. & M & 1819 & $1908(3 / 10)$ & 89 & -1 & $\begin{array}{l}\text { private, Co. G, Terrell's } \\
\text { Reg., } 37 \text { Tex. Cav. }\end{array}$ & \\
\hline 19 & FA19 & Hogun, James W. & M & 1830 & $1908(3 / 23)$ & 78 & 1 & captain, Co. F, 2 Miss. Cav. & \\
\hline 22 & FA22 & Kelly, Marshall C. & M & 1836 & $1908(1 / 29)$ & 72 & 1 & $\begin{array}{l}\text { lieutenant, Co. E (F), } \\
\text { Ragsdale's Bat., } 32 \text { Tex. Cav. }\end{array}$ & Mason \\
\hline 23 & FA23 & Alexander, J. A. & M & 1835 & $1907(11 / 15)$ & 72 & 1 & private, Co. C, 16 Tex. Cav. & \\
\hline 24 & FA24 & Briggs, Isaac C. & M & 1816 & $1907(11 / 22)$ & 91 & 1 . & $\begin{array}{l}\text { unknown, Co. F, 1st Tenn. } \\
\text { Art. }\end{array}$ & \\
\hline 25 & FA25 & Simmons, James R. & M & 1840 & $1907(12 / 17)$ & 67 & 1 & $\begin{array}{l}\text { private, Co. } \mathrm{K}, 7 \text { Tex. Cav. } \\
(3 \text { Tex. Cav.) }\end{array}$ & \\
\hline 26 & FA26 & Smith, Joshua Francis & M & 1821 & $1908(1 / 7)$ & 87 & 1 & private, Co. C, 21 Tex. Cav. & \\
\hline 27 & FA27 & Porter, John Y. & M & 1818 & $1908(1 / 19)$ & 90 & 1 & $\begin{array}{l}\text { private, Co. D, Wood's Reg., } \\
36 \text { Tex. Cav. }\end{array}$ & \\
\hline
\end{tabular}




\begin{tabular}{|c|c|c|c|c|c|c|c|c|c|}
\hline \multicolumn{10}{|c|}{ Table 2, continued } \\
\hline $\begin{array}{l}\text { Burial } \\
\text { No. }\end{array}$ & $\begin{array}{l}\text { TSC } \\
\text { Plot No. }\end{array}$ & Name & Sex & $\begin{array}{l}\text { Date of } \\
\text { Birth }\end{array}$ & $\begin{array}{l}\text { Date of } \\
\text { Death }\end{array}$ & $\begin{array}{l}\text { Age at } \\
\text { Death }\end{array}$ & $\begin{array}{l}\text { Headstone } \\
\text { Type }\end{array}$ & $\begin{array}{l}\text { Confederate States Army } \\
\text { Rank and Service }\end{array}$ & Other \\
\hline 28 & FA28 & Johnson, James W. & M & 1836 & $1908(1 / 6)$ & 72 & 1 & private, Co. I, 2 Tex. Cav. & \\
\hline 29 & FA29 & Thomas, John P. & $\mathrm{M}$ & 1837 & $1907(12 / 15)$ & 72 & 1 & $\begin{array}{l}\text { private, Co. E (G), } \\
\text { Waul's Leg. }\end{array}$ & $\begin{array}{l}\text { Age at death } \\
\text { could be } 70 \text { or } \\
71\end{array}$ \\
\hline 30 & $\mathrm{FA} 30$ & Trezervant, L. E. & $\mathrm{M}$ & 1833 & $1907(11 / 26)$ & 74 & 1 & captain, Co. I, 26 Tex. Cav. & \\
\hline 31 & $\mathrm{FA} 31$ & Stewart, William H. & M & 1847 & $1907(11 / 25)$ & 60 & 1 & $\begin{array}{l}\text { unknown, Co. F, Wood's } \\
\text { Reg., } 36 \text { Tex. Cav. }\end{array}$ & \\
\hline 32 & FA32 & Adams, John M. & $\mathrm{M}$ & 1839 & $1907(11 / 24)$ & 68 & 1 & $\begin{array}{l}\text { corporal/musician, Co. A, } \\
14 \text { Ark. Inf. }\end{array}$ & \\
\hline 33 & FA33 & Stanley, Stephen L. & $\mathrm{M}$ & 1841 & $1907(11 / 21)$ & 66 & 1 & private, Co. D, 7 Tex. Cav. & \\
\hline 34 & FA34 & Moody, Louis Robert & M & 1830 & $1907(11 / 18)$ & 77 & 1 & unknown, Co. F, 1 S.C. Vol. & \\
\hline 35 & FA35 & Bowdoin, Henry A. & M & 1832 & $1907(11 / 12)$ & 75 & 1 & private, Co. D, $45 \mathrm{Ga}$. Inf. & \\
\hline 36 & FA36 & Walker, John H. & $\mathrm{M}$ & 1847 & $1907(11 / 11)$ & 60 & 1 & corporal, Co. E, 11 N.C. Inf. & \\
\hline 37 & FA37 & Brown, Daniel P. & M & 1832 & $1907(11 / 7)$ & 75 & 1 & private, Co. A, 6 Ala. Inf. & \\
\hline 38 & FA38 & Morgan, J. H. & M & 1828 & $1907(11 / 5)$ & 79 & 1 & unknown, Pyron's 1 Tex. & \\
\hline 39 & FA39 & Starnes, Amos D. & $\mathrm{M}$ & 1836 & $1907(10 / 29)$ & 71 & 1 & $\begin{array}{l}\text { private, Co. G (A), } 1 \text { Ala. } \\
\text { Inf. }\end{array}$ & \\
\hline 40 & FA40 & Jacks, D. R. & $\mathrm{M}$ & 1840 & $1907(10 / 23)$ & 67 & -1 & $\begin{array}{l}\text { ordnance sergeant, Co. F (D), } \\
\text { Waul's Leg. ( } 9 \text { Tex. Inf.) }\end{array}$ & \\
\hline 41 & FA41 & Shry, William & M & 1825 & $1907(10 / 26)$ & 82 & 1 & lieutenant, Co. E, 8 Tex. Inf. & Mason \\
\hline 42 & FA42 & Bird, Albert G. & M & 1829 & $1907(10 / 23)$ & 76 & 1 & unknown, Co. B, 3 Ala. Inf. & $\begin{array}{l}\text { age at death } \\
\text { could be } 77 \\
\text { or } 78\end{array}$ \\
\hline 43 & FA43 & Hagler, C. C. & M & 1834 & $1907(10 / 23)$ & 73 & 1 & private, Co. I, $11 \mathrm{Ga}$. Inf. & \\
\hline
\end{tabular}




\begin{tabular}{|c|c|c|c|c|c|c|c|c|c|}
\hline \multicolumn{10}{|c|}{ Table 2, continued } \\
\hline $\begin{array}{l}\text { Burial } \\
\text { No. }\end{array}$ & $\begin{array}{l}\text { TSC } \\
\text { Plot No. }\end{array}$ & Name & Sex & $\begin{array}{l}\text { Date of } \\
\text { Birth }\end{array}$ & $\begin{array}{l}\text { Date of } \\
\text { Death }\end{array}$ & $\begin{array}{l}\text { Age at } \\
\text { Death }\end{array}$ & $\begin{array}{l}\text { Headstone } \\
\text { Type }\end{array}$ & $\begin{array}{l}\text { Confederate States Army } \\
\text { Rank and Service }\end{array}$ & Other \\
\hline 44 & FA44 & Bowden, John T. & M & 1844 & $1907(10 / 21)$ & 63 & 1 & private, Co. E, 12 Tenn. Inf. & \\
\hline 45 & FA45 & Willis, Jubal & M & 1835 & $1907(10 / 20)$ & 72 & 1 & private, Co. F, 8 Mo. Inf. & \\
\hline 46 & FA46 & Robinson, Andrew M. & M & 1832 & $1907(10 / 14)$ & 75 & 1 & $\begin{array}{l}\text { private, Co. A, Bates' Inf., } \\
13 \text { Tex. Vol. }\end{array}$ & \\
\hline 47 & DA1 & Kyser, George Washington & M & $1845(1 / 21)$ & $1920(5 / 28)$ & 75 & 3 & private, Co. A, 32 Tex. Cav. & Mason \\
\hline 48 & DA2 & Kyser, Emma J. & $\mathrm{F}$ & $1851(1 / 8)$ & $1923(2 / 18)$ & 72 & 3 & none & $\begin{array}{l}\text { wife of } \\
\text { George W. } \\
\text { Kyser }\end{array}$ \\
\hline 49 & DA3 & Walker, George Tulley & M & $1839(7 / 6)$ & $1925(5 / 3)$ & 85 & 2 & $\begin{array}{l}\text { captain (major ?), Co. G, } \\
11 \text { Tex. Inf. }\end{array}$ & \\
\hline 50 & DA4 & Walker, Josephine M. & $\mathrm{F}$ & $1871(12 / 16)$ & $1951(7 / 31)$ & 79 & 4 & none & $\begin{array}{l}\text { wife of } \\
\text { George T. } \\
\text { Walker }\end{array}$ \\
\hline 51 & DA5 & Pannell, Margaret C. & $\mathrm{F}$ & $1849(3 / 7)$ & $1931(4 / 10)$ & 82 & 3 & none & $\begin{array}{l}\text { wife of John } \\
\text { S. Pannell }\end{array}$ \\
\hline 52 & DA6 & Pannell, John S. & M & $1843(5 / 25)$ & $1931(4 / 29)$ & 88 & 3 & captain, unknown & Mason \\
\hline 53 & DB1 & Burleson, Jacob & $\mathrm{M}$ & $1839(5 / 20)$ & $1917(2 / 26)$ & 78 & 5 & $\begin{array}{l}\text { 2nd lieutenant, Co. I, } \\
34 \text { Tex. Cav. }\end{array}$ & $\begin{array}{l}\text { Texas Ranger } \\
\text { (prewar) }\end{array}$ \\
\hline 54 & DB2 & Burleson, Mary Ivy & $\mathrm{F}$ & $1842(10 / 20)$ & $1932(7 / 19)$ & 89 & 6 & none & $\begin{array}{l}\text { wife of Jacob } \\
\text { Burleson }\end{array}$ \\
\hline 55 & DB3 & Bradfield, Louisa A. & $\mathrm{F}$ & 1852 & $1931(6 / 13)$ & 79 & 1 & none & $\begin{array}{l}\text { wife of James } \\
\text { O. Bradfield }\end{array}$ \\
\hline 56 & DB4. & Bradfield, James O. & $\mathrm{M}$ & $1843(12 / 2)$ & $1932(3 / 7)$ & 88 & 2 & private, Co. E, 1 Tex. Inf. & \\
\hline 57 & DB5 & Ward, Dr. John R. & M & $1840(2 / 14)$ & $1884(12 / 11)$ & 44 & 7 & $\begin{array}{l}\text { surgeon, Co. G (F, I), } 11 \text { Va. } \\
\text { Inf. }\end{array}$ & $\begin{array}{l}\text { reinterred } \\
1958(8 / 20)\end{array}$ \\
\hline
\end{tabular}


TABLE 3

OCCUPATIONS OF MEN EXCAVATED FROM THE TEXAS STATE CEMETERY*

\begin{tabular}{|l|c|c|}
\hline Occupation & $\begin{array}{c}\text { Number of } \\
\text { Individuals }\end{array}$ & $\begin{array}{c}\text { Percent of } \\
\text { Individuals }\end{array}$ \\
\hline Blacksmith & 1 & 2.0 \\
Carpenter & 4 & 7.8 \\
Engineer & 1 & 2.0 \\
Farmer & 19 & 37.3 \\
Judge/Attorney & 2 & 3.9 \\
Laborer & 1 & 2.0 \\
Merchant and Other Sales People & 5 & 9.8 \\
Physician/Surgeon & 2 & 3.9 \\
Printer & 2 & 3.9 \\
Rancher, Cattleman, and Stockman & 6 & 11.8 \\
Shoemaker & 1 & 2.0 \\
Sailor & 1 & 2.0 \\
Teacher & 1 & 2.0 \\
Unknown & 5 & 9.8 \\
\hline *Sources: Confederate Home roster, obituaries, pension \\
records, Harwell (1947).
\end{tabular}

in shape and measured (above ground) approximately 8 inches wide by 14.5 inches tall by 2.25 inches thick. Inscriptions on these headstones usually consist of six lines of information that include name, military record, date of death, and age at death. Type 2 markers were used on 12 percent $(n=$ 7) of the burials and apparently represent replacement markers for Type 1 headstones. Also made of white marble, Type 2 markers are rectangular with a canted top. The Southern Cross of Honor is engraved above the textual information on the face of each stone. The markers measure (above ground) approximately 12 inches wide by 18.5 inches high by 4 inches thick. The name is engraved in a semicircular manner as the first line of information, followed by company and regiment information and then by the initials "C.S.A" (Confederate States of America). Type 2 markers provide no infor-

Highway, rather than east (toward the foot end of the grave) as headstones usually are placed. The only exceptions to this were seen on headstones from row DB (Burials 53-57), one headstone in row FA (Burial 24), and one headstone in row DA (Burial 50), which all faced in the traditional easterly direction. In terms of burial position according to traditional southern customs, the husband is usually buried to the right (south) of his wife (Jordan 1982:30). Only five couples could be examined to see if they maintained this traditional placement. Of these, three couples (the Kysers, Walkers, and Bradfields) did not maintain this tradition; rather, the husband was interred to the north of his wife. Jordan (1982:30) notes the existence of this "non-traditional" pattern in approximately one-third of married couples in a given cemetery; in this case, two-thirds of the couples were interred in this less-common position, although the sample size is quite small.

Seven varieties of headstones were used to mark the excavated graves (see Table 2). Only headstone Types 1 and 2 (Figure 15) were used to mark the locations of the 46 burials in Section F. Type 1, the most commonly observed headstone, was used on 74 percent of the graves $(n=42)$. Constructed of white marble, Type 1 is rectangular mation as to the individuals' year of death or age at death.

The Type 2 markers are generically called "V.A. replacement stones" by cemetery personnel. After 1974, the Department of Veterans Affairs took over the veterans grave marker program that formerly had been run by the Department of the Army. According to the Department of Veterans Affairs' Director of Claims Evaluation Service, Office of Memorial Programs (Christine P. Farrell, personal communication 1995), Congress authorized the issuance of headstones for Confederate burial plots in 1906 and the use of the Southern Cross of Honor on Confederate headstones in 1929. The government-issue Type 2 headstones were obtained at the request of family members, State Cemetery officials, or others on behalf of the Confederate veterans, often to replace headstones that were broken or illegible. Since the Southern Cross of Honor was present on all Type 2 stones marking the graves of excavated individuals (see Figure 17), these stones postdate 1929. Archival research suggests that many damaged headstones in the Confederate veterans' Sections D and F were replaced in 1962.

Section D contained headstone Types $3-7$, in addition to one example of Type 1 and two exam- 


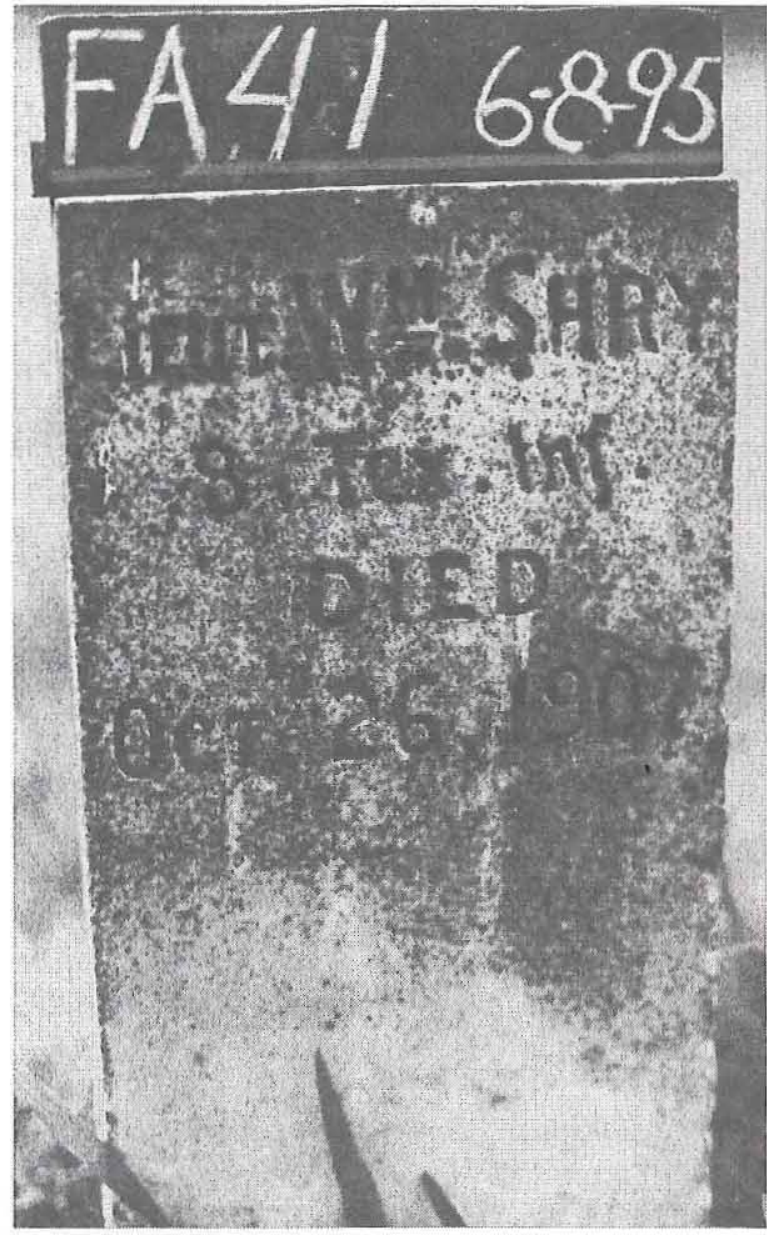

Type 1

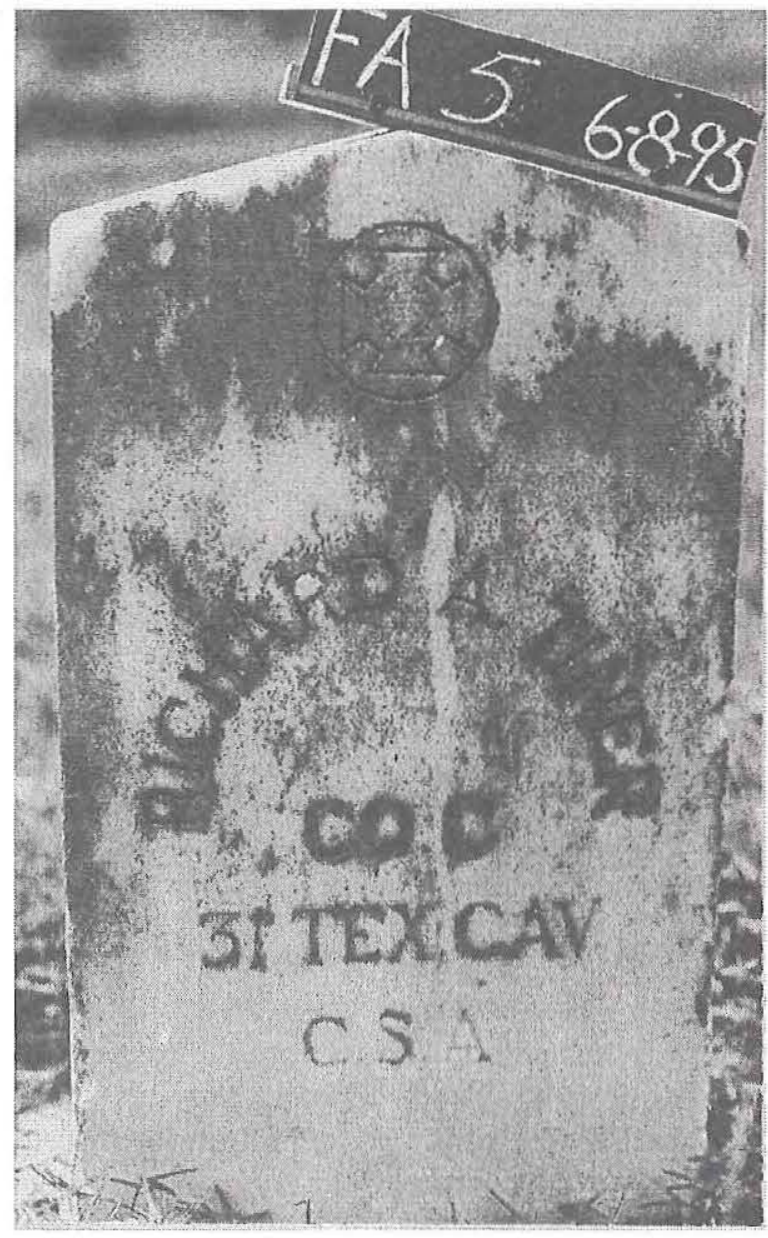

Type 2

Figure 15. Types 1 and 2 headstones from excavated burials in Sections F and D. Photographs courtesy of Texas Parks and Wildlife Department, Force Account.

ples of Type 2 markers. Headstone Type 3 (Figure 16), which marked the graves of the Kysers (Burials 47 and 48) and the Pannells (Burials 51 and 52 ), is a double marker engraved with a Mason's symbol separating the words "MOTHER" and "FATHER" at the top of the stone. The last name is engraved in all capital letters as the last line of text on the marker. The marker on Burials 51 and 52 differed from the other Type 3 stone in that it measures 21 inches high by 37 inches wide, as contrasted with 28 inches high by 37 inches wide. The only other significant difference is the placement of names on the face of the marker. On the Pannells' stone, Margaret Pannell's name is engraved on the left (north) side of the stone, with her husband's on the right (south) side; this pattern is reversed on the Kyser headstone. Both Type 3 markers are of pink or red granite.

All of the other headstone types are represented by just one example. Type 4 is a smoothshouldered variety observed on Burial 50 (see Figure 16). Constructed of white marble, the marker measures 23 inches high by 18 inches wide. The word "MOTHER" is engraved on the superior surface of the stone. The facing surface contains three lines of information: name, date of birth, and date of death. Headstone Types 5 and 6 (Figure 17), marking the Burlesons (Burials 53 and 54), are similar in material and style. Both are of pink granite and have impressed lettering. Type 5 measures 15 by 15 inches; Type 6 measures 14 by 14 inches. Type 5 (Burial 53) has the name "BURLESON" in raised lettering on the superior surface of the marker. The text on the face of the 


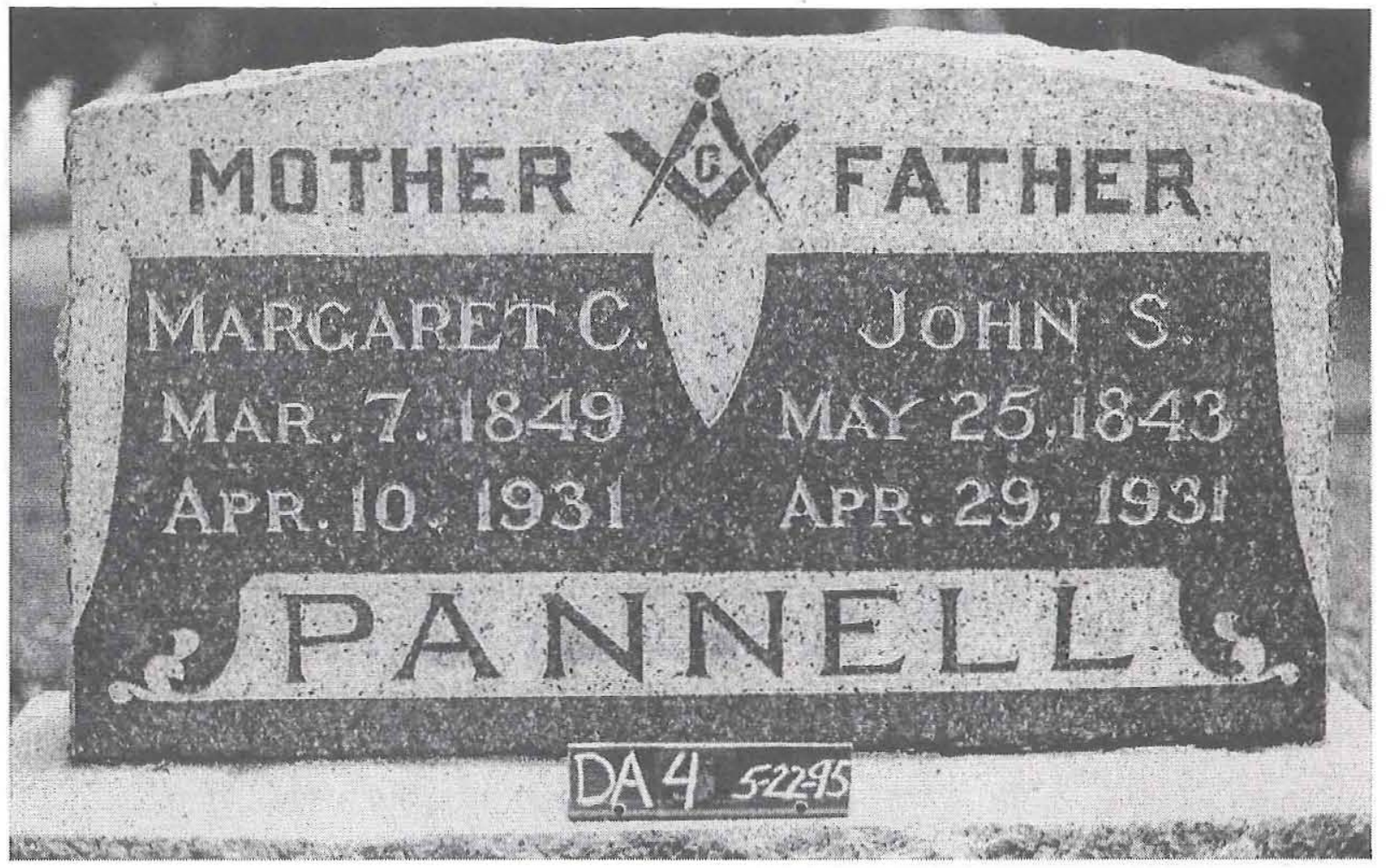

Type 3

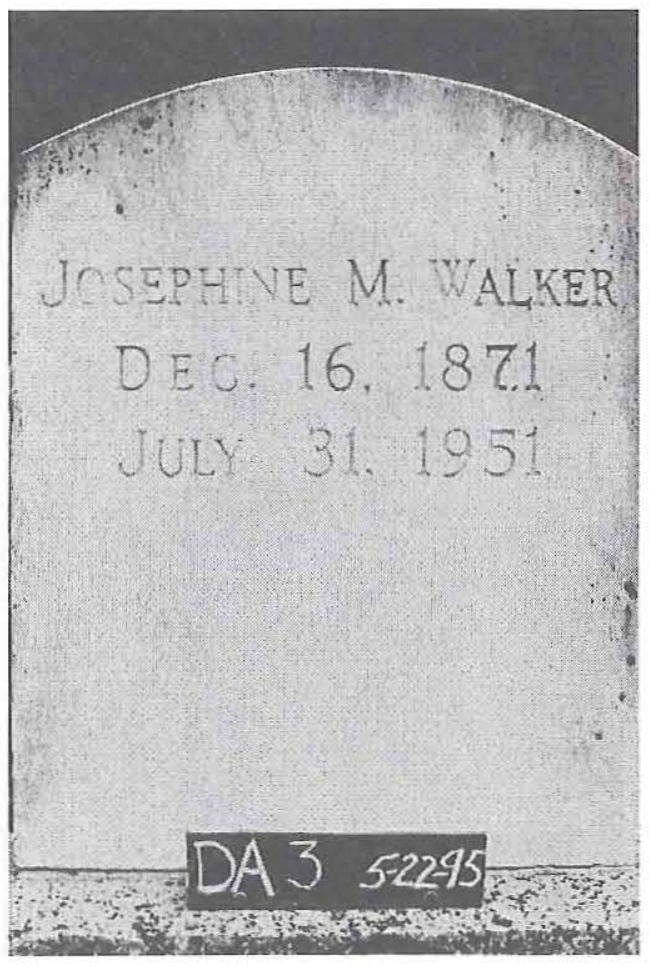

Type 4

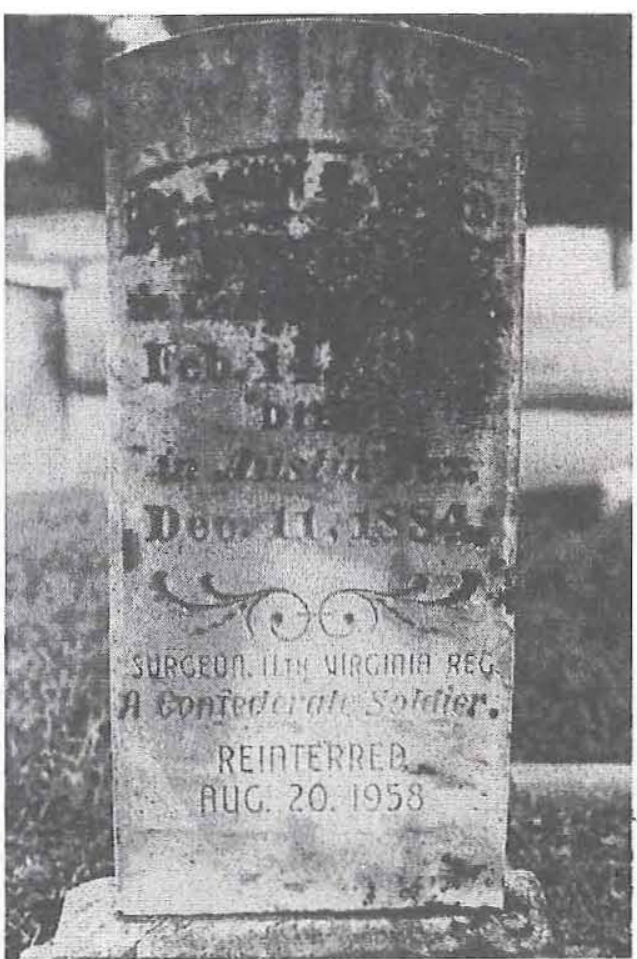

Type 7

Figure 16. Types 3, 4, and 7 headstones from excavated burials in Section D. 
Texas State Cemetery Project

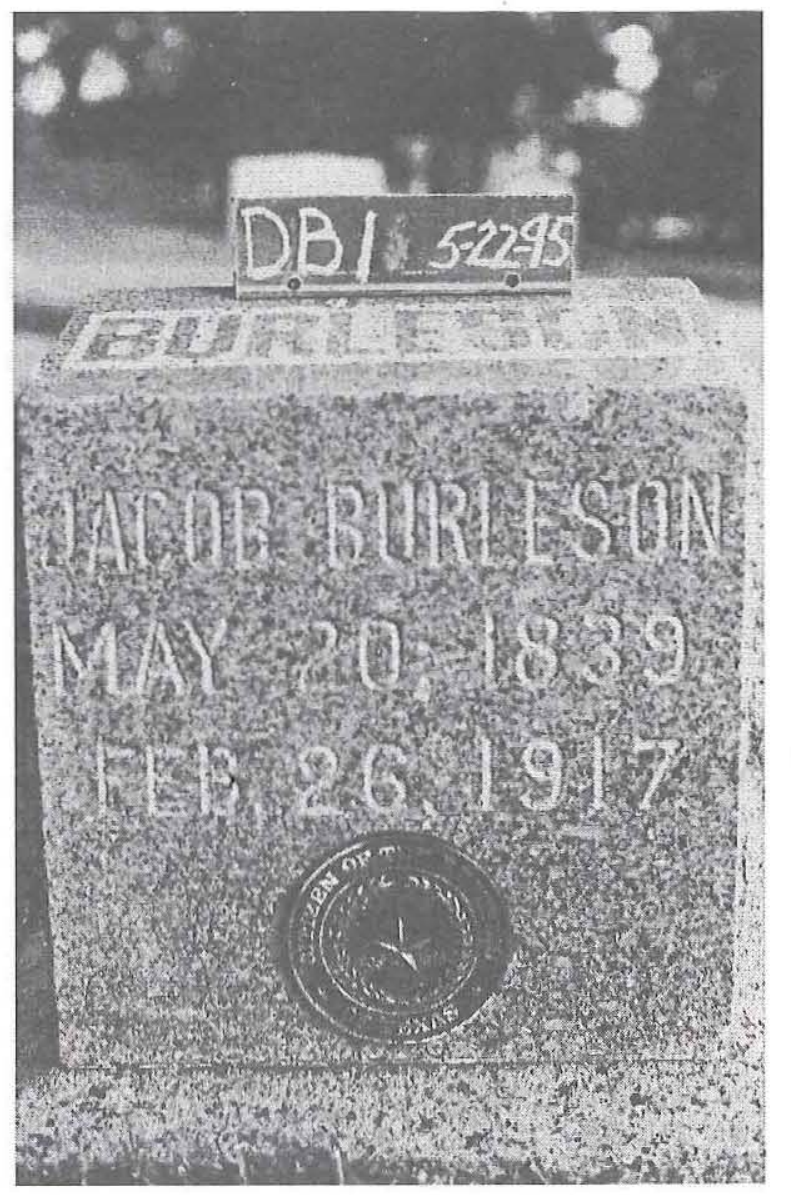

Type 5

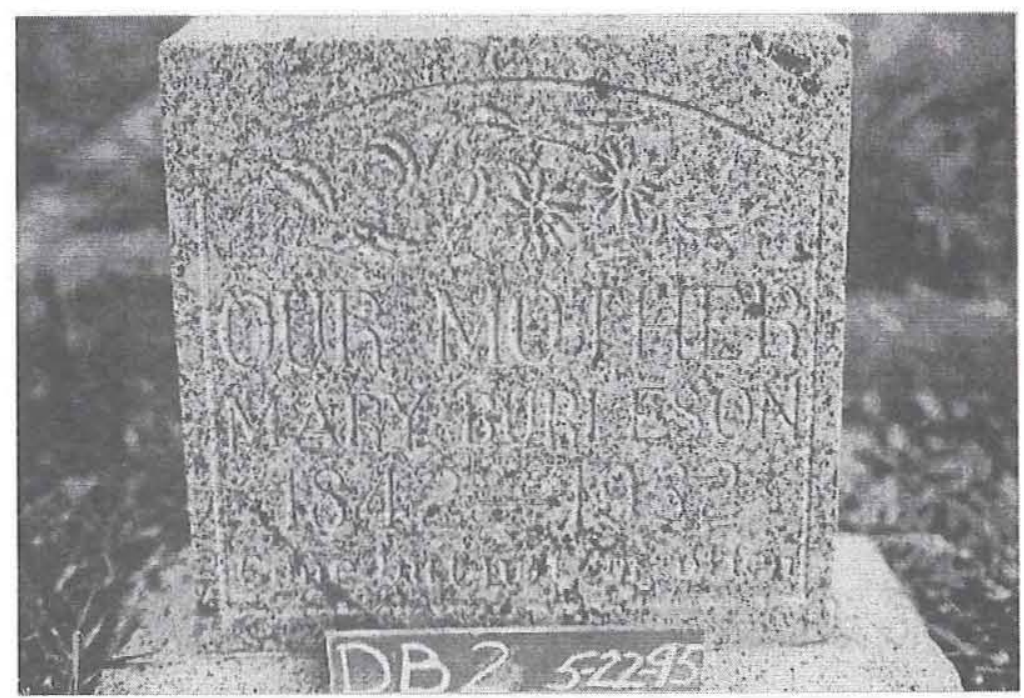

Type 6

Figure 17. Types 5 and 6 headstones from excavated burials in Section D. 
marker is organized into three lines containing name, date of birth, and date of death. In addition, a round bronze plaque reading "Citizen of the Republic of Texas" was added to the face of the stone below the marker text. Type 6 (Burial 54) is inscribed with the words "OUR MOTHER" as the top line of information, followed by "MARY BURLESON," year of birth, year of death, and "Gone but not Forgotten."

A single example of headstone Type 7 was observed on Dr. John R. Ward's grave (Burial 57; see Figure 16). It is a tall rectangular marker (31 by 14 inches) made of white marble. The original engraving contains his name in an arched banner, place and date of birth, place and date of death, and the words "A Confederate Soldier." In 1958, Dr. Ward's coffin was reinterred at the Texas State Cemetery. During this process, additional information was added to his headstone using a different style of lettering than the original text. The new information states, "SURGEON, 11th VIRGINIA REG." and "REINTERRED AUG. 20, 1958."

All of the individuals listed in Table 2 are described in greater detail in the remainder of this chapter. Burial descriptions are presented in an abbreviated subject-oriented format, with individual headings that fall into four major categories: personal history, headstone data, mortuary and cultural characteristics, and osteological characteristics. In general, the personal history section includes data on when and where the individual was born, when he/she came to Texas, military record, admission to the Confederate Home, occupation, disabilities, and cause of death. All information in the personal history sections was obtained from the sources described previously. Because these differ for each individual, specific sources of historical information are listed with each burial description.

Headstone data are summarized by listing the headstone type (as described above; see Figures 15-17) and presenting each inscription as it appears on the stone. Each line of text in the inscription represents a separate line on the stone, and the original capitalization and punctuation are preserved. Symbols that appear on the stones are indicated by the italicized name of the symbol inside brackets. Brackets also are used to enclose portions of inscriptions that are questionable or illegible on the stone and other descriptive comments pertaining to the headstone text.
Information concerning mortuary and cultural characteristics came from the archeological excavation of the burials. Data in this category include a description of the casket and its associated hardware, as well as its orientation (all orientations were read as west of magnetic north). Casket and viewing window dimensions are sometimes approximate due to poor preservation. Casket hardware is discussed by types that are described in Chapter 6. The position and orientation of the body in the casket also are described. Body orientation was determined by a compass reading taken from the articulated vertebral column. Orientations are stated as the direction in which the top of the spinal column points, relative to a $360^{\circ}$ circle. Personal artifacts recovered with an individual also are described in this section. This includes clothing items such as buttons, suspender buckles, and bow ties. Cuff and collar studs and other jewelry, hair combs, and dentures are considered as other personal items. Some casket hardware items, such as Mason's symbols, also are placed into the personal goods section since these artifacts, while actually casket items, reflect more-personal information about each interred individual. The last artifacts listed in this section are ones of a nonpersonal nature, especially items that were located in the grave shaft fill above the casket. In a few cases, artifacts found in caskets are not believed to have been buried intentionally with the individuals, and their occurrence probably is due to postdepositional disturbances. In these cases, the artifacts are discussed under the nonassociated artifacts heading.

The last major heading, osteological characteristics, contains information about preservation and skeletal disorders. The taphonomy section focuses on the condition of the skeletal remains upon exposure. The related inventory section discusses the completeness of each burial. The pathology section is divided into seven categories. The first, degenerative changes, includes all instances of degenerative changes to the skeleton, including appendicular and axial examples. The trauma category pertains primarily to fractures visible on the bones, although bone fusions unrelated to arthritic changes also are discussed in this category. Infectious disorders are discussed next and include any periosteal and sclerotic reactions evidenced on the osteological remains. Neoplasms incorporate any new bone depositions that are not 
arthritic or infectious in nature, consisting primarily of button osteomas. Disorders listed in the metabolic and hematological category consist primarily of porotic hyperostosis, cribra orbitalia, and general cranial thickening. Dental disorders such as caries, linear enamel hypoplasia, antemortem tooth loss, and abscesses are subsumed under the dental category. The last category ("other") is used to discuss enthesophytes and other disorders that do not fit discretely into one of the other categories.

\section{BURIAL DESCRIPTIONS}

\section{Burial 1}

Name: Mattie J. Guess

Date of Death: September 24, 1939 Age at Death: 91 years

Personal History: Born in Mississippi in 1848. Married Zachariah R. Guess of the 40th Mississippi Infantry. Came to Texas in 1903 and resided in Wheellock. Occupation listed as housewife. Admitted to the Confederate Home on October 8, 1930. Her cause of death was listed as bronchopneumonia, with senility as a contributing factor.

Sources of Historical Information: Headstone, General Services Commission records, Confederate Home records, Pension (\#21761, number assigned to pension of her husband, Zachariah Guess), Death Certificate (\#71709).

Headstone Type: $\quad 1$

Headstone Inscription:

$$
\begin{aligned}
& \text { MATTIE J. } \\
& \text { Wife of } \\
& \text { Z. R. GUESS } \\
& 1848-1939
\end{aligned}
$$

\section{Mortuary Characteristics:}

- Casket Description: Wooden casket with ornamental grooving on exterior of casket walls inside an outer box $(206 \times 50 \mathrm{~cm})$.

- Casket Orientation: $270^{\circ}$

- Casket Hardware: 6 Type 10 handles, "At Rest" plaque on casket lid, wood screw with thin rectangular ferrous plate, 2 sets of ferrous hook and eye latches connecting south wall and floor of casket, 6 nails.

- Body Orientation and Position: Extended supine, facing east; orientation of vertebral column indeterminate.

- Arm and Hand Positions: Extended

- Leg Positions: Extended

\section{Cultural Characteristics:}

- Clothing: 2 metal-back loop buttons with a clear celluloid face on top of a cork backing.

- Personal Goods: Mandibular and maxillary dentures.

Nonassociated Artifacts: 4 stoneware fragments found in grave shaft.

\section{Osteological Characteristics:}

Preservation

- Taphonomy: Preservation was good to excellent with a high degree of thoracic tumbling.

- Inventory: Complete skeleton except for many elements of the hands and feet, as well as vertebrae.

Pathology

- Degenerative: Arthritic lipping was noted at the distal end of the left radius and around the articular surface of the right patella. Eburnation was present on the right articular facets of two thoracic vertebrae.

- Traumatic: None

- Infectious: None

- Neoplasm: None

- Metabolic and Hematological: None

- Dental: All teeth were lost antemortem and replaced with a full set of dentures.

- Other: None

\section{Burial 2}

Name: Samuel Gentry

Date of Death: November 24, 1931

Age at Death: 94 years

Personal History: Born in Kentucky in 1837, served in Company E (or C), 2nd (or 22nd) Tennessee Cavalry, Army of Tennessee. Came to Texas in 1882 and lived in the community of Vallyview where he worked as a farmer. Admitted 
to the Confederate Home on December 1, 1929. Cause of death listed as pneumonia with arteriosclerosis as a contributing factor.

Sources of Historical Information: Headstone, General Services Commission records, Confederate Home records, Death Certificate (\#53672).

Headstone Type: $\quad 2$

Headstone Inscription:

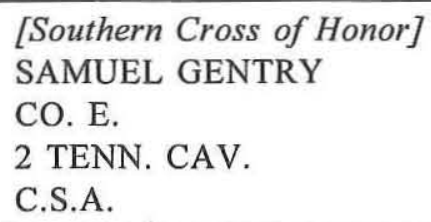

Mortuary Characteristics:

- Casket Description: Well-preserved wooden casket in outer burial box (220 cm long).

- Casket Orientation: $280^{\circ}$

- Casket Hardware: 6 Type 10 handles, 15 nails.

- Body Orientation and Position: Extended supine, facing east; vertebral column $280^{\circ}$.

- Arm and Hand Positions: Arms slightly flexed with left hand over left os coxa and right hand over right os coxa.

- Leg Positions: Extended

Cultural Characteristics:

- Clothing: 2 black two-hole rubber buttons (1 small and 1 large).

- Personal Goods: None

Nonassociated Artifacts: Large $(75 \mathrm{~mm})$ iron hex nut, lip fragment of salt-glazed stoneware bottle, 2 fragments of stoneware.

\section{Osteological Characteristics:}

Preservation

- Taphonomy: Extensive thoracic tumbling, disturbed upper arms.

- Inventory: Complete skeleton except for femur, patella, and tibia of the left leg.

Pathology

- Degenerative: Arthritic lipping was observed at the sternal ends of both clavicles and on the articulating facets of the manubrium. Lipping was also observed on the left humeral head and distal ends of both radii and the right ulna. Two cervical vertebrae and a thoracic vertebra exhibited lipping on the articular facets, and eburnation was apparent on the fovea for the dens on the atlas. Lipping was noted around the right acetabulum and at the distal end of the right tibia and one foot phalanx.

- Traumatic: Well-healed, aligned fractures of the right clavicle and left ulna were noted. The fracture of the ulna was located at the distal one-third of the shaft, while that of the clavicle was located near the sternal end.

- Infectious: None

- Neoplasm: None

- Metabolic and Hematological: None

- Dental: All teeth were lost antemortem.

- Other: None

\section{Burial 3}

Name: Joseph Watkins

Date of Death: 1931

Age at Death: Indeterminate

Personal History: Born in Alabama (date of birth unknown). Came to Texas in 1849 and resided in Gonzales. Served in Company H, Robert Regiment No. 11 Infantry, Ruadl's (?) Brigade, Macken's Division. Detached as a teamster on February 28, 1865. Served in Company A, 5th Texas Cavalry. Pension records note that the cost of casket and robe was not to exceed $\$ 30$. Mr. Watkins did not live in the Confederate Home.

Sources of Historical Information: Headstone, General Services Commission records, Pension (\#32143), index cards of Compiled Service Records.

Headstone Type: 2

Headstone Inscription:

[Southern Cross of Honor] JOSEPH WATKINS

CO. A

5 TEX. CAV.

C.S.A.

Mortuary Characteristics:

- Casket Description: Very poorly preserved 
wooden casket (casket stain measured $212 \times 47 \mathrm{~cm}$ ). Outer box indeterminate.

- Casket Orientation: $287^{\circ}$

- Casket Hardware: 6 Type 10 handles, remnants of a ferrous plaque on top of casket lid, 17 fragments of highly corroded thin ferrous bars that appear to be portions of Type 2 and Type 3 latches, 9 highly corroded nails.

- Body Orientation and Position: Extended supine, facing east; vertebral column $287^{\circ}$.

- Arm and Hand Positions: Right arm flexed with hand on sacrum; left arm extended.

- Leg Positions: Extended

\section{Cultural Characteristics:}

- Clothing: Three large black rubber two-hole buttons and seven small black rubber two-hole buttons were recovered. Two of the large buttons were found next to each forearm. The other large button was on top of the right os coxa. Two of the small buttons were found on the right side of the vertebral column. The five other small buttons were in the pelvic region.

- Personal Goods: Three celluloid collar/cuff studs were recovered, one each on either side of the lower cervical vertebrae and one in association with the right forearm.

Nonassociated Artifact: A triangular small ferrous rod found underneath the cranium appears similar to a file; however, its purpose, as well as its significance in relation to the burial, is unknown.

\section{Osteological Characteristics:}

\section{Preservation}

- Taphonomy: Preservation was fair to good. Drifting had occurred among elements of the feet.

- Inventory: Complete skeleton except for highly fragmented pelvis.

Pathology

- Degenerative: Cervical vertebrae had lipping on the articular facets, osteophytes, and porosity of the vertebral bodies. Lipping was present on thoracic and lumbar vertebral bodies. The right ischium had lipping at the acetabulum. The distal end of the left femur was severely arthritic (in one area the lipping extended by $24 \mathrm{~mm}$ ), probably as a reaction to the wound to the left tibia (see following). Less-severe deposition was noted on the distal end of the right femur. The proximal articular surface of the left tibia showed eburnation. Eburnation, lipping, and porosity were present at the distal end of the right first metatarsal, while the left fifth metatarsal showed only lipping.

- Traumatic: The left tibia (which was severely infected, see following) had a scooped defect on the lateral aspect of the anterior crest, proximal end, that appears to have resulted from a bullet/musket ball glancing off that portion of the crest, rather than going through the shaft.

- Infectious: The right tibia had an area of healed periosteal reaction (ca. $40 \mathrm{~mm}$ in length) at the medial distal portion of the shaft. The left tibia had severe osteitis and periostitis at the proximal end of the shaft (probably as the result of infection of a bullet/musket ball wound). The affected area had highly sclerotic bone with deep vascular impressions and projecting bone spicules. The left fibula in the area corresponding directly to the wound of the left tibia exhibited patches of sclerotic bone deposition.

- Neoplasm: None

- Metabolic and Hematological: None

- Dental: All teeth were lost antemortem.

- Other: None

\section{Burial 4}

\author{
Name: William Everet Rogers \\ Date of Death: January 2, 1931 \\ Age at Death: 83 years
}

Personal History: Born in Mississippi in 1847. Served in Company C (or A), 2nd Missouri Cavalry, Chlaber's (?) Brigade, Forisl's (?) Division, Army of the Trans-Mississippi. Came to Texas in 1874 and settled in Hubbard. Occupation listed as carpenter. Admitted to Confederate Home on November 30, 1926, with a disability listed as old age.

Sources of Historical Information: Headstone, General Services Commission records, Confederate Home records, index cards of Compiled Service Records. 
Headstone Type: 2

Headstone Inscription:

[Southern Cross of Honor]

WILLIAM E. ROGERS

CO. C

2 MO. CAV.

C.S.A.

Mortuary Characteristics:

- Casket Description: Wooden casket (with some red pigment) inside an outer box $(201 \times 57 \mathrm{~cm})$.

- Casket Orientation: $280^{\circ}$

- Casket Hardware: 6 Type 10 handles, highly corroded rectangular ferrous plaque on top of casket lid, 15 fragments of highly corroded ferrous bars that may be portions of Type 2 and Type 3 latches, 1 ferrous corner brace found in northeast corner of the casket or outer box, 17 highly corroded nails.

- Body Orientation and Position: Extended supine, facing east; vertebral column $275^{\circ}$.

- Arm and Hand Positions: Arms slightly flexed with hands on the os coxae.

- Leg Positions: Extended

\section{Cultural Characteristics:}

- Clothing: 2 large black rubber two-hole buttons found on top of thoracic region to the right side of vertebral column, 4 small twohole black rubber buttons found underneath the pelvis.

- Personal Goods: None

\section{Osteological Characteristics:}

Preservation

- Taphonomy: Preservation was good to excellent. Slight drifting of hand and feet elements had occurred.

- Inventory: Complete skeleton with fragmented pelvis.

Pathology

- Degenerative: Moderate to severe lipping was present on the left humeral head and new bone deposition was apparent on the articular surface. The glenoid cavities of both scapulae were lipped and eburnated. Both clavicles had arthritic lipping and porosity at the sternal ends. The right trapezium and first metacarpal exhibited extreme lipping and eburnation. Osteophytes and porosity were present on all cervical bodies. Eburnation was visible on the dens and the fovea for the dens.

- Traumatic: A well-healed depression fracture was present on the right parietal, to the right of lambda.

- Infectious: Sclerotic lesions were identified on the pleural surfaces of three ribs.

- Neoplasm: None

- Metabolic and Hematological: None

- Dental: All teeth were lost antemortem.

- Other: Two ribs have scalloped defects perforating the bone. Large muscle attachments on the clavicles, ulnae, radii, and humeri indicate that Mr. Rogers was robustly muscled in the upper body.

\section{Burial 5}

Name: Richard A. Tiner

Date of Death: December 28, 1930 Age at Death: 88 years

Personal History: Born in Mississippi in 1842, came to Texas in 1851 and resided in Lavernia. Occupation listed as farmer. Served as a Sergeant in Company C, 31st Texas Cavalry Dismounted, Malone's Brigade, Taylor's Division, Army of the Trans-Mississippi. Admitted to Confederate Home on June 14, 1928.

Sources of Historical Information: Headstone, General Services Commission records, Confederate Home records, Pension (\#37225), index cards of Compiled Service Records.

Headstone Type: 2

Headstone Inscription:

[Southern Cross of Honor]

RICHARD A. TINER

CO. C

31 TEX. CAV.

C.S.A.

\section{Mortuary Characteristics:}

- Casket Description: Wooden casket inside an 
outer box $(207 \times 66 \mathrm{~cm})$. Red pigment was noted on the casket.

- Casket Orientation: $280^{\circ}$

- Casket Hardware: 6 Type 10 handles, highly corroded ferrous plaque on top of casket lid, Type 1 latch on the west casket wall, 4 fragments of corroded ferrous bars, possible portions of Type 2 and Type 3 latches, 22 corroded nails.

- Body Orientation and Position: Extended supine, facing east; vertebral column $279^{\circ}$.

- Arm and Hand Positions: Extended

- Leg Positions: Extended

\section{Cultural Characteristics:}

- Clothing: 2 small four-hole shell buttons found on top of thoracic vertebrae, large twohole shell button found on top of sacrum, 2 large black rubber buttons ( 1 on left os coxa and 1 on top of sacrum), 7 small two-hole black rubber buttons ( 2 on top of os coxae, 2 on vertebral column, 2 near left wrist, 1 near right wrist).

- Personal Goods: Celluloid collar stud, cuprous metal cuff link recovered from area of left wrist.

\section{Osteological Characteristics:}

\section{Preservation}

- Taphonomy: Preservation ranged from fair to poor. Drifting of hand and feet elements had occurred. The cranium was disturbed by Gradall excavations during initial exposure.

- Inventory: All facial bones of the skull were missing. The postcranial skeleton was complete with the exception of a fragmented pelvis.

Pathology

- Degenerative: Porosity and lipping was evident at both mandibular condyles and associated articular surfaces. Extreme lipping and eburnation were present at the proximal end of the left first metacarpal. The right first metacarpal and trapezium showed eburnation but no lipping. Three hand phalanges had lipping at the proximal ends. Slight lipping was present on the glenoid cavity of the left scapula. All cervical and thoracic vertebrae evidenced porosity and small osteophytes on the centra.

- Traumatic: None

- Infectious: None
- Neoplasm: None

- Metabolic and Hematological: None

- Dental: All teeth were lost antemortem.

- Other: An enthesophyte was noted at the distal end of the left humerus.

\section{Burial 6}

Name: Joseph R. Benson

Date of Death: December 26, 1930 Age at Death: 95 years

Personal History: Born in South Carolina in 1835. Moved to Texas in 1842, lived in Sonora and worked as a laborer. Served as a sergeant in Company I, 15th Texas Infantry. Cause of death listed as pneumonia, with senility as a contributing cause. Mr. Benson did not reside in the Confederate Home.

Sources of Historical Information: Headstone, Pension (\#25245), Death Certificate (\#60880).

Headstome Type: 2

Headstone Inscription:

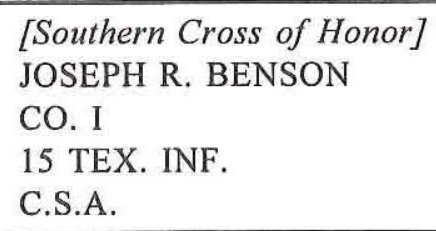

Mortuary Characteristics:

- Casket Description: Badly deteriorated wooden casket $(217 \times 49.5 \mathrm{~cm})$. Lower portion was damaged by heavy equipment.

- Casket Orientation: $280^{\circ}$

- Casket Hardware: 4 Type 10 handles, 2 nails.

- Body Orientation and Position: Extended supine, facing east; orientation of vertebral column unknown.

- Arm and Hand Positions: Arms slightly flexed with left hand over left os coxa and right hand over right os coxa.

- Leg Positions: Indeterminate

\section{Cultural Characteristics:}

- Clothing: Fragments of black cloth, 2 large rubber buttons found along spine, 2 small rubber buttons in each wrist area, 3 small 
rubber buttons in pelvic area, 2 two-hole shell buttons in the thoracic area.

- Personal Goods: Two small celluloid studs found in the upper thoracic area.

\section{Osteological Characteristics:}

Preservation

- Taphonomy: Lower legs were damaged by Gradall. Root disturbance in thoracic and pelvic areas.

- Inventory: Complete skeleton except for fragmented pelvis and missing patella, tibia, and fibula of the left leg, as well as both feet.

Pathology

- Degenerative: All observable phalanges exhibited arthritic lipping at the proximal facets. The right patella had lipping around the articular surface. Both ulnae were lipped at the proximal ends. All observable vertebrae showed osteoarthritis. Eburnation was noted on the dens of the axis. Two cervical vertebrae had osteophytes, as did one thoracic vertebra. Lipping and porosity were observed on the right articular facets of all observable cervical and thoracic vertebrae. Four thoracic vertebral bodies were fused together.

- Traumatic: The left humerus had a healed, aligned fracture immediately distal to the head.

- Infectious: None

- Neoplasm: None

- Metabolic and Hematological: None

- Dental: All teeth lost antemortem.

- Other: Well-developed linea aspera on both femora.

\section{Burial 7}

Name: Patrick Halman West

Date of Death: June 3, 1908

Age at Death: 77 years

Personal History: Born in Kentucky in 1831. Came to Texas in 1847, lived in Waco. Served in Company C, 5th Texas Infantry. Occupation listed as stockman. Admitted to the Confederate Home on May 15, 1904, with a disability listed as rheumatism. Cause of death listed as hemorrhage of the bowels.

Sources of Historical Information: Headstone, Confederate Home records, Pension (\#02860).
Headstone Type: $\quad 1$

Headstone Inscription:

P. H. WEST

Co. C 5 Tex. Inf.

DIED

JUNE 3. 1908

Aged 77 Yrs.

\section{Mortuary Characteristics:}

- Casket Description: Wooden casket (ca. $170 \mathrm{~cm}$ long) was almost completely destroyed by root action from a tree stump $(55 \times 30 \mathrm{~cm})$ at the foot of the casket. Viewing window (ca. $60 \times 20 \mathrm{~cm}$ ) was located in the upper section of the casket.

- Casket Orientation: $282^{\circ}$

- Casket Hardware: 4 Type 1 handles, 3 Type 1 thumbscrews with 3 Type 1 escutcheons, 2 Type 2 thumbscrews with 2 Type 3 escutcheons (associated with viewing window), 2 small cuprous metal tack heads, 13 nail fragments.

- Body Orientation and Position: Extended supine, facing east; orientation of vertebral column unknown.

- Arm and Hand Positions: Arms crossed with left hand over right os coxa and right hand over left os coxa.

- Leg Positions: Indeterminate due to root displacement.

\section{Cultural Characteristics:}

- Clothing: Small glass button recovered from upper torso area.

- Personal Goods: None

\section{Osteological Characteristics:}

Preservation

- Taphonomy: The skeletal remains were very poorly preserved, due in part to extensive root disturbance. Both femora were forced to the left side of the casket by roots. Root action destroyed the pelvic area and the lower legs and feet. The thoracic area under the viewing window had disintegrated and could not be recovered.

- Inventory: The skull was badly fragmented with only the calvarium and mandible present. Bones of the upper body were present, but few 
hand elements and only three vertebrae were present. The lower body was represented only by the femora, right patella, tibiae, and a few foot elements.

Pathology

- Degenerative: The three recovered cervical vertebrae had osteophytes on the superior and inferior surfaces of the centra. The right proximal ulna had lipping at the trochlear process. The right patella had small areas of new bone deposition on the articular surface.

- Traumatic: A well-aligned healed fracture was visible on the midshaft of the right tibia.

- Infectious: None

- Neoplasm: None

- Metabolic and Hematological: None

- Dental: No maxillary dentition was recovered. Eleven mandibular teeth were lost antemortem. The remaining 5 teeth were very worn, but had no disorders.

- Other: None

\section{Burial 8}

Name: James Morgan Wyatt

Date of Death: May 6, 1908

Age at Death: 94 years

Personal History: Born in Kentucky in 1814. Came to Texas in 1839 , served as a captain in Company H, Showalter's Regiment. Lived in Caldwell and worked as a farmer. Admitted to the Confederate Home on April 24, 1901, with disabilities listed as paralysis and old age. Pension records note that he had a "badly deformed" foot. Cause of death listed as senility and effects from a fall.

Sources of Historical Information: Headstone, Confederate Home records, Pension (\#07638).

Headstone Type: 1

Headstone Inscription:

CAPT. J. M. WYATT

Co. H: Showalters Reg

DIED

MAY 6. 1908

Aged 94 Yrs.
Mortuary Characteristics:

- Casket Description: Wooden casket with a viewing window $(40 \times 20 \mathrm{~cm})$ in an outer box $(196 \times 55 \mathrm{~cm})$.

- Casket Orientation: $277^{\circ}$

- Casket Hardware: 6 Type 1 handles, 4 Type 1 thumbscrews with 4 Type 1 escutcheons located at the corners of the casket, 2 Type 2 thumbscrews and 2 Type 3 escutcheons, Type 5 latch, 2 fabric, and 2 decorative tack heads.

- Body Orientation and Position: Extended supine, facing east; orientation of vertebral column indeterminate.

- Arm and Hand Positions: Arms slightly flexed with hands at the os coxae.

- Leg Positions: Extended

\section{Cultural Characteristics:}

- Clothing: 2 leather buttons found in the pelvic area.

- Personal Goods: None

\section{Osteological Characteristics:}

Preservation

- Taphonomy: Skeletal remains were in good condition, except for the thoracic area under the viewing window which had been reduced to powder and the highly fragmented pelvic area. Carpals and hand phalanges were scattered.

- Inventory: The skeleton was complete with the exception of the pelvic area.

Pathology

- Degenerative: Minor arthritic lipping was noted on the proximal ends of the right and left ulna. Lipping and pitting were observed on the articular facets and centra of 6 cervical, 11 thoracic, and 2 lumbar vertebrae but were most severe in the cervicals. Eburnation was present on the fovea for the dens and the dens. The distal end of a proximal hand phalanx was eburnated, and a foot phalanx showed lipping at the distal end.

- Traumatic: None

- Infectious: The left femur had a dense periosteal reaction on the anterior surface that wrapped around the bone to the linea aspera, which was not affected. Active patches of periostitis were noted at the distal end of the bone. The left tibia had periostitis that was 
especially severe on the lateral aspect. The medial aspect of the left fibula evidenced the same reaction. The right femur and tibia showed the same periosteal reaction, but to a lesser degree.

- Neoplasm: None

- Metabolic and Hematological: None

- Dental: Eight maxillary teeth were recovered; one had been lost antemortem. Of the eight maxillary teeth that could be examined, all were very worn, one had a caries, and five had moderate calculus deposits. Only one mandibular tooth was recovered; eight had been lost antemortem. The one that could be examined was worn down to the root and had no apparent disorders.

- Other: Mr. Wyatt was very robustly muscled. The arm and leg bones showed large,roughened muscle attachment sites, especially the linea aspera and humerus above the deltoid tuberosity.

\section{Burial 9}

Name: T. J. McCulloch

Date of Death: May 20, 1908

Age at Death: 73 years

Personal History: Born in Virginia in 1835. Served in Company A, 1st Virginia Infantry, Runnells' Battalion, Jackson's Brigade. Came to Texas in 1867 and resided in Jewett. Occupation listed as physician. Admitted to the Confederate Home on March 1, 1903, with a general disability. Cause of death listed as sclerosis of the liver.

Sources of Historical Information: Headstone, General Services Commission records, Confederate Home records.

Headstone Type: 1

Headstone Inscription:

T. J. McCULLOCH

Runnells Co. A Va. Inf.

DIED

MAY 20, 1908

Aged 73 Yrs.
Mortuary Characteristics:

- Casket Description: Wooden casket inside an outer box $(190 \times 55 \mathrm{~cm})$.

- Casket Orientation: $285^{\circ}$

- Casket Hardware: 6 Type 1 handles, 3 sets of Type 1 thumbscrews with Type 1 escutcheons, thin cuprous star-shaped casket ornament at head end of casket lid, 6 highly corroded fragments of flat ferrous metal bars that are possibly portions of Type 2 and Type 3 latches, 11 nails.

- Body Orientation and Position: Extended supine, facing east; vertebral column $280^{\circ}$.

- Arm and Hand Positions: Right arm flexed with hand on sacrum, left arm crossed with hand on right forearm.

- Leg Positions: Extended

\section{Cultural Characteristics:}

- Clothing: Black fabric bow tie found at neck area.

- Personal Goods: $18 \mathrm{~K}$ gold ring found in association with proximal phalanx of left hand.

\section{Osteological Characteristics:}

\section{Preservation}

- Taphonomy: Preservation was fair to poor. The cranium shifted and was highly fragmented. Mild thoracic tumbling was observed, and the pelvis was very fragmented. Right femur (disarticulated from right tibia and fibula) had rotated $180^{\circ}$ and shifted medially. The left leg had rotated $90^{\circ}$ laterally. Elements of the feet were intermingled. Slight drifting of hand elements had occurred.

- Inventory: Complete skeleton with fragmented thoracic and pelvic areas.

Pathology

- Degenerative: Fovea for dens on atlas showed lipping and eburnation.

- Traumatic: Two ribs had very well healed, well aligned fractures. One fracture appeared to be a greenstick break, while the other was complete. The left fibula had a large callus at the distal end. Broken nose evidenced by misaligned nasals.

- Infectious: Possible ear infection suggested by pitted and remodeled bone just superior to the external auditory meatus. Healed osteitis was noted at the proximal end of the right tibia. 
- Neoplasm: The right lunate had a benign cyst.

- Metabolic and Hematological: None

- Dental: Only four maxillary teeth were recovered, and all had caries and moderate calculus deposits. Interproximal grooving was noted on the mesial and distal aspects of the right second molar, the mesial aspect of both third molars, and the distal area of left third premolar. Six mandibular teeth were found; seven had been lost antemortem. The left third molar had a tin filling, and the left second incisor and right third premolar had caries.

- Other: None

\section{Burial 10}

Name: J. M. Bates

Date of Death: May 24, 1908.

Age at Death: 73 years

Personal History: Born in Virginia in 1836, served in Company C (L), 9th Louisiana Cavalry, Taylor's Brigade. Came to Texas in 1866, occupation listed as merchant, lived in Floresville. Admitted to the Confederate Home on June 7, 1898, with disabilities listed as general and blindness. Cause of death listed as cardiac dropsy.

Sources of Historical Information: Headstone, General Services Commission records, Confederate Home records.

Headstone Type: $\quad 1$

Headstone Inscription:

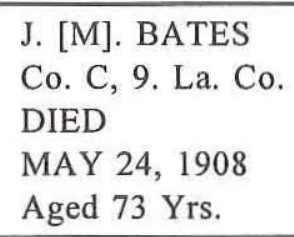

J. [M]. BATES

Co. C, 9. La. Co.

DIED

MAY 24, 1908

Aged 73 Yrs.

Mortuary Characteristics:

- Casket Description: Deteriorated wooden casket (190 cm long).

- Casket Orientation: $276^{\circ}$

- Casket Hardware: 4 Type 2 handles, 2 Type 1 latches and 2 Type 2 latches, fragment of cloth with impression of star decorative tack, 48 nail fragments.
- Body Orientation and Position: Extended supine, facing east; vertebral column $280^{\circ}$.

- Arm and Hand Positions: Left arm was crossed with left hand on right os coxa. Right arm was extended.

- Leg Positions: Extended

Cultural Characteristics:

- Clothing: Small fragments of black cloth.

- Personal Goods: Bone cuff stud, white-metal cross with crown attached to the middle of the casket lid.

\section{Osteological Characteristics:}

Preservation

- Taphonomy: Limbs were in good condition but the thoracic and pelvic areas were badly deteriorated. In general, the left side of the body was more poorly preserved than the right side.

- Inventory: This individual was represented by a fragmented skull missing small facial bones but had a complete postcranial skeleton.

\section{Pathology}

- Degenerative: Temporomandibular joint disorder was present on both temporals. Both humeral heads had new arthritic bone deposition and the corresponding glenoid cavities of the scapulae exhibited lipping. All recovered distal and medial phalanges had arthritic lipping at the proximal facets. All cervical vertebrae had extreme porosity on the centra surfaces, and two had osteophytes projecting off the centra. All articular surfaces were lipped. The fovea for the dens and the dens had severe lipping. Three of the five recovered thoracic vertebrae exhibited porosity and lipping. Both femora had lipping and new bone deposition on the distal articular surfaces, and both patellae had severe lipping at the articular surface, as well as new bone deposition. Three foot phalanges had lipping at the proximal facet.

- Traumatic: None

- Infectious: None

- Neoplasm: None

- Metabolic and Hematological: None

- Dental: The recovered maxillary alveolus revealed that eight teeth had been lost antemortem. Both areas extending from $\mathrm{P}^{4}$ to $\mathrm{M}^{3}$ were not recovered, so the condition of those 
teeth could not be assessed. Nine mandibular teeth were lost antemortem; six were lost postmortem. Only the right canine was recovered, and it showed a slight calculus deposit and a caries.

- Other: The right ulna had an enthesophyte at the coronoid process. Mr. Bates had welldeveloped linea aspera on both femora. Enthesophytes were noted at the soleal line of both tibiae. Both patellae had ossified tendons that extended superiorly. In addition, one proximal foot phalanx exhibited improper ossification; it appears that a tendon next to the phalanx had ossified and fused to the bone.

\section{Burial 11}

Name: Fenton A. Bott

Date of Death: May 3, 1908

Age at Death: 78 years

Personal History: Born in Virginia in 1830. Came to Texas in 1849 and resided in Round Rock. Occupation listed as farmer. Served in Company D, 8th Texas Rangers, Harrison's Brigade (also in Green's Brigade). Admitted to the Confederate Home on May 31, 1906, with a disability listed as old age. Confederate Home records list date of death as May 2, 1908. Cause of death listed as sclerosis of the liver.

Sources of Historical Information: Headstone, General Services Commission records, Confederate Home records, Pension (\#11422), index cards of Compiled Service Records.

Headstone Type: 1

Headstone Inscription:

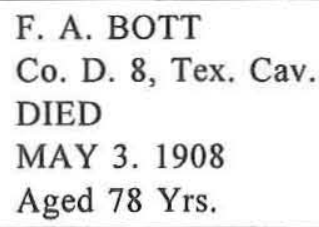

Mortuary Characteristics:

- Casket Description: Highly deteriorated wooden casket (casket stain measures $198 \times 62 \mathrm{~cm}$ ). Outer box indeterminate.
- Casket Orientation: $280^{\circ}$

- Casket Hardware: 4 Type 2 handles, Type 1 caplifter, Type 2 latch, 3 fragments of what appear to be portions of Type 3 latches, 33 highly corroded wire nails.

- Body Orientation and Position: Extended supine, facing east; vertebral column $278^{\circ}$.

- Arm and Hand Positions: Right arm crossed with hand on left os coxa; left arm extended.

- Leg Positions: Extended

\section{Cultural Characteristics:}

- Clothing: Black fabric bow tie found on top of lower cervical vertebrae.

- Personal Goods: 2 bone cuff studs.

\section{Osteological Characteristics:}

\section{Preservation}

- Taphonomy: Skeletal remains were well preserved, but some disarticulation had occurred. The cranium had rolled away from the body, and the mandible was resting on its left side between the cervical vertebrae and the left clavicle. The left humerus was displaced toward the head of the casket. Both legs had rotated $180^{\circ}$, slightly displacing the os coxae. The right tibia had drifted slightly, and feet elements were tumbled.

- Inventory: Complete skeleton.

\section{Pathology}

- Degenerative: Arthritic lipping was observed on both glenoid cavities and at the proximal facets of 16 of the 18 recovered hand phalanges. Both scaphoids exhibited lipping, and a bone spur was present on the distal facet of both first metacarpals. All cervical vertebrae had porosity and lipping on the centra and articular surfaces. The dens had extreme lipping. All thoracic vertebrae showed the same porosity and lipping, and one had a large osteophyte projecting off the anterior aspect of the centrum. Arthritic activity of the lumbar vertebrae was limited to lipping and porosity of the articular surfaces. All seven recovered foot phalanges had lipping at the proximal facets.

- Traumatic: None

- Infectious: Both temporals displayed erosive bone similar to that seen in Burial 9. Both maxillae evidenced active sinusitis as demon- 
strated by extensive periosteal layering of the maxillary chambers.

- Neoplasm: None

- Metabolic and Hematological: None

- Dental: Two maxillary teeth were lost antemortem, and three were lost postmortem. Only five could be examined for disorders. The left canine had two caries. Calculus deposits were moderate to severe on each tooth. The mandibular arcade contained nine observable teeth. Four teeth were lost antemortem, and one was lost postmortem. None of the observable teeth had caries, although the right premolars and the right third molar exhibited linear enamal hypoplasias. Calculus deposits ranged from slight to severe.

- Other: None

\section{Burial 12}

Name: Lewis A. Bernard

Date of Death: May 7, 1908

Age at Death: 80 years

Personal History: Born in Virginia in 1828. Served in Company H, 26th Louisiana Infantry, Shoup's Brigade. Moved to Texas in 1871, occupation listed as printer. Admitted to Confederate Home on December 7, 1907, with rheumatism listed as a disability. Cause of death was listed as chronic gastritis.

Sources of Historical Information: Headstone, General Services Commission records, Confederate Home records, index of Compiled Service Records.

Headstone Type: 1

Headstone Inscription:

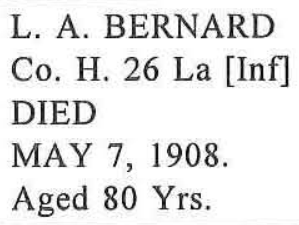

L. A. BERNARD

Co. H. 26 La [Inf]

DIED

MAY 7, 1908.

Aged 80 Yrs.

\section{Mortuary Characteristics:}

- Casket Description: Wooden casket in good condition $(195 \times 55 \times 44 \mathrm{~cm})$. Viewing window $(50 \times 40 \mathrm{~cm})$ had a wooden panel cover- ing the glass.

- Casket Orientation: $283^{\circ}$

- Casket Hardware: 5 Type 1 handles, 2 Type 1 thumbscrews, 2 Type 1 escutcheons, 3 Type 2 thumbscrews with 3 Type 3 escutcheons associated with panel over viewing window.

- Body Orientation and Position: Extended supine, facing east; vertebral column $280^{\circ}$.

- Arm and Hand Positions: Arms were crossed with the left hand on the right os coxa and the right hand on the left os coxa.

- Leg Positions: Extended

\section{Cultural Characteristics:}

- Clothing: Bow tie fragment, small 4-hole shell button.

- Personal Goods: 2 bone cuff studs.

\section{Osteological Characteristics:}

Preservation

- Taphonomy: Burial was in poor condition with the bone under viewing window reduced to stain; this included the thoracic area and the humeri. The legs were well preserved.

- Inventory: Complete skull except for facial bones; complete postcranial skeleton with highly fragmented pelvis.

\section{Pathology}

- Degenerative: Severe temporomandibular joint disorder in the left mandibular joint only. Lipping and pitting are extreme and the condyle is extremely wasted in appearance, especially when compared to the right side. Lipping and porosity were evident in the cervical vertebrae (centra and articular surfaces), and eburnation was apparent on the atlas and axis at the dens articulation. In addition, severe lipping surrounded that articulation. Moderate lipping and porosity were observed on the thoracic and lumbar vertebrae (centra and articular facets). One hand phalanx exhibited lipping at the proximal facet, as did one distal foot phalanx.

- Traumatic: None

- Infectious: Healed osteitis of proximal onethird of left femur.

- Neoplasm: None

- Metabolic and Hematological: None

- Dental: Only three maxillary teeth were recovered. All exhibited caries and moderate 
to severe calculus. The right third molar had a tin filling. Twelve mandibular teeth were recovered; two additional teeth had been lost antemortem. All had extremely severe calculus deposits, and the left third molar had an unfilled caries. An interproximal groove (distal) was noted on the left fourth premolar.

- Other: Proximal end of the right ulna had an enthesophyte, as did both patellae. Strong muscle attachments were noted on the metacarpals of both hands.

\section{Burial 13}

Name: J. F. Hargrove

Date of Death: May 1, 1908

Age at Death: 64 years

Personal History: Born in Georgia in 1844. Served in Company H, 3rd Louisiana Infantry, Army of the Trans-Mississippi. Came to Texas in 1863 and resided in Fort Worth. Occupation listed as farmer. Admitted to the Confederate Home on October 23, 1907, with a disability listed as tropical affliction. Confederate Home records have date of death listed as May 2, 1908. Cause of death listed as cirrhosis of the liver.

Sources of Historical Information: Headstone, General Services Commission records, Confederate Home records, index cards of Compiled Service Records.

\section{Headstone Type: $\quad 1$}

Headstone Inscription:

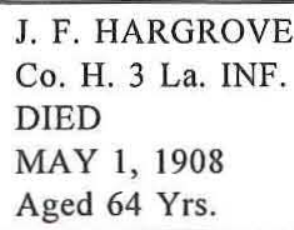

Mortuary Characteristics:

- Casket Description: Highly deteriorated wooden casket (stain measured $203 \times 63 \mathrm{~cm}$ ). Outer box indeterminate.

- Casket Orientation: $280^{\circ}$

- Casket Hardware: 4 Type 2 handles, Type 1 caplifter, 2 Type 2 latches, 2 sets of Type 2 or
Type 3 latches, 2 Type 4 latches, 54 highly corroded wire nails.

- Body Orientation and Position: Extended supine, facing east; vertebral column $295^{\circ}$.

- Arm and Hand Positions: Extended

- Leg Positions: Extended

\section{Cultural Characteristics:}

- Clothing: Four-hole shell button found in upper right region of the thorax, cuprous eyelet found under lower lumbar vertebrae.

- Personal Goods: 2 bone cuff studs.

\section{Osteological Characteristics:}

\section{Preservation}

- Taphonomy: Preservation was fair to poor. The cranium was badly fragmented and had rolled onto the right side resulting in a large curvature of the vertebral column. Postcranial bones were badly fragmented. The distal left ulna had shifted slightly away from the body. The left femur had rotated laterally approximately $90^{\circ}$.

- Inventory: The skull was highly fragmented with facial bones absent. The postcranial skeleton was complete with a fragmented pelvis.

\section{Pathology}

- Degenerative: The left temporomandibular joint showed severe lipping and pitting. Arthritic lipping and porosity were evident on the distal end of the right radius; porosity only was seen at the distal end of the right ulna. The proximal end of the left radius had moderate to severe lipping and pitting. The left clavicle exhibited porosity and lipping at the sternal facet; porosity and lipping were apparent on the acromial facet of the right clavicle. The right lunate and triquetral had lipping and porosity; as did the left lunate and trapezium. In addition, both lunates were eburnated. Three distal hand phalanges had lipping at the proximal facets. Two medial and 1 proximal hand phalange had lipping at the distal ends. One cervical centra fragment had a Schmorl's node, and the dens articulation area showed minor lipping. No other vertebrae showed any signs of osteoarthritis. Both femora had minor lipping at the distal ends.

- Traumatic: None 
- Infectious: None

- Neoplasm: None

- Metabolic and Hematological: Generalized cranial thickening and pitting was apparent on the frontal and parietals.

- Dental: All maxillary and mandibular teeth were lost antemortem.

- Other: Fusion of a medial and a distal foot phalanx.

\section{Burial 14}

Name: Joseph M. Turner

Date of Death: April 14, 1908

Age at Death: 68 years

Personal History: Born in Georgia in 1839. Came to Texas in 1858 and lived in Brownwood with an occupation listed as farmer. Served in Company A (or $\mathrm{H}$ ) of the 12th Texas Infantry, Young's Regiment, discharged from the army in 1862 for an unspecified disability. First admitted to the Confederate Home on November 22, 1902, with disability listed as "aged and feeble" lungs. He was first discharged on July 27, 1903. Readmitted on November 15, 1904, and released at his request on May 20, 1905. Entered the home for the last time on December 1, 1907. Cause of death listed as street car accident.

Sources of Historical Information: Headstone, General Services Commission records, Confederate Home records, Pension (\#12133).

Headstone Type: 1

Headstone Inscription:

J. M. TURNER

Co. A. YOUNGS Reg

DIED

APRIL 14, 1908

Aged 68 Yrs.

Mortuary Characteristics:

- Casket Description: Wooden casket $(170 \times 45 \mathrm{~cm})$ with a viewing window. Constructed with screws instead of nails.

- Casket Orientation: $283^{\circ}$

- Casket Hardware: 6 Type 1 handles, 1 Type
1 thumbscrew and escutcheon, 2 Type 3 escutcheons found near viewing window, 2 cuprous metal domed tacks, 25 iron screws.

- Body Orientation and Position: Extended supine, facing east; vertebral column $281^{\circ}$.

- Arm and Hand Positions: Crossed with right hand over left os coxa and left hand over right os coxa.

- Leg Positions: Extended

Cultural Characteristics:

- Clothing: 4-hole iron button, 2 small clothcovered iron buttons from chest area, 4 small copper eyelets from pelvic area.

- Personal Goods: None

\section{Osteological Characteristics:}

Preservation

- Taphonomy: Burial was well articulated, but the bone under the viewing window was badly fragmented.

- Inventory: Complete skeleton, except for highly fragmented vertebrae and fragmented pelvis.

Pathology

- Degenerative: Temporomandibular joints evidenced lipping and porosity. Right scapula had lipping around the glenoid cavity. The right trapezium and triquetral evidenced arthritic lipping. The triquetral was also eburnated. Right first metacarpal had a large bone spur at the distal end, inferior surface. The axis had lipping, porosity, and eburnation on the inferior articular facets. Only three other vertebrae were complete enough to examine for disorders.

- Traumatic: Healed depression fracture $(8 \times 11 \mathrm{~mm})$ on right frontal boss. The right femoral head was dislocated so that the right acetabulum, as well as the femoral head, had large areas of eburnation with surface porosity and lipping at the superior lateral portion.

- Infectious: None

- Neoplasm: None

- Metabolic and Hematological: None

- Dental: Only five maxillary teeth were recovered; seven had been lost antemortem. The lateral incisors and third molars were congenitally missing. The right canine had a large caries that destroyed the crown of the tooth; 
the left canine had 3 hypoplastic episodes. Very severe calculus deposits were noted on the left second molar. All mandibular teeth were lost antemortem with the exception of the two third molars, which were severely impacted. Both were completely horizontal, with their crowns in a mesial direction.

- Other: Marked linea aspera on both femora.

\section{Burial 15}

Name: John Ferron

Date of Death: April 18, 1908

Age at Death: 85 years

Personal History: Born in Ireland in 1823. Came to Texas in 1846. Residence listed as Galveston and occupation listed as sailor. Served in Company F, 2nd Texas Infantry. Admitted to the Confederate Home on May 7, 1892. Discharged at his request on April 4, 1896. Readmitted to the Confederate Home on February 4, 1898. Disabilities listed as general and old age. Confederate Home records list the date of death as April 10, 1908. Cause of death listed as la grippe (influenza).

Sources of Historical Information: Headstone, General Services Commission records, Confederate Home records.

Headstone Type: 1

Headstone Inscription:

\section{JNO. FERRON \\ DIED \\ APRIL 18. 1908 \\ Aged 85 YRS.}

\section{Mortuary Characteristics:}

- Casket Description: Highly deteriorated wooden casket with an oval viewing window (casket stain measured $195 \times 55 \mathrm{~cm}$; viewing window measured $52 \times 41 \mathrm{~cm}$ ). Outer box indeterminate.

- Casket Orientation: $288^{\circ}$

- Casket Hardware: 6 Type 1 handles, 2 sets of Type 1 thumbscrews and Type 1 escutcheons, 3 sets of Type 2 thumbscrews and Type 3 escutcheons, thin cuprous metal star-shaped ornament, thin cuprous metal oval-shaped ornament (several green stains were noted on casket walls, indicating other ornaments of the same material, but they were too badly deteriorated to define), 38 highly corroded wire nails.

- Body Orientation and Position: Extended supine, facing east; vertebral column $284^{\circ}$.

- Arm and Hand Positions: Right arm slightly crossed with hand on top of sacrum; left arm extended.

- Leg Positions: Extended

\section{Cultural Characteristics:}

- Clothing: 3 cloth-covered iron buttons on top of vertebral column, four-holed shell button on top of upper thoracic vertebrae.

- Personal Goods: White-metal cross with crown emblem attached to the middle of the casket lid.

\section{Osteological Characteristics:}

Preservation

- Taphonomy: Preservation was fair to good except for the cranium and thoracic area which were fragmented by the pressure of the viewing window.

- Inventory: The skull was badly fragmented with facial bones absent. Postcranially, the skeleton was complete with a fragmented pelvis.

\section{Pathology}

- Degenerative: Both clavicles exhibited lipping and pitting of the sternal and acromial ends, but they were more severe on the left side. The glenoid cavity of the left scapula had moderate to severe lipping and porosity, as did the left humeral head. Arthritic bone deposition was observed on the capitulum of the left humerus. The right humeral head had arthritic lipping. Both radii and ulnae had lipping at the proximal and distal ends, but it was more severe on the left side. The right first metacarpal had severe lipping and pitting at the proximal and distal ends. The articulating trapezium had associated lipping and pitting. All left carpals were extremely arthritic. The lunate was so badly deformed by pitting and destruction that it was barely recognizable. Left second metacarpal had lipping on the 
palmar surface. All observable cervical and thoracic vertebrae had lipping and porosity on the centra and articular facets. Moderate to severe lipping occurred on the fovea for the dens on the atlas. The dens of the axis had extreme new bone growth and was eburnated. All five lumbar vertebrae had severe porosity and lipping of both the centra and the articular facets. Both acetabuli had minor lipping.

- Traumatic: A well-healed, aligned fracture was observed on the distal one-third of the left ulna.

- Infectious: None

- Neoplasm: None

- Metabolic and Hematological: None

- Dental: No maxillary teeth were recovered, and all mandibular teeth were lost antemortem.

- Other: None

\section{Burial 16}

Name: J. V. Davenport

Date of Death: April 7, 1908

Age at Death: 68 years

Personal History: Born in South Carolina in 1840 , served in Company C, 14th South Carolina Infantry, McGowan's Brigade. Came to Texas in 1872. Lived in Dallas and worked as a carpenter. Admitted to the Confederate Home on April 7, 1907, with a disability listed as kidney trouble. Progressive paralysis was the listed cause of death.

Sources of Historical Information: Headstone, General Services Commission records, Confederate Home records.

Headstone Type: $\quad 1$

Headstone Inscription:

J. V. DAVENPORT

Co. C. 14 S. C. Inf

DIED

APRIL 7, 1908

Aged 68 YRS

Mortuary Characteristics:

- Casket Description: Poorly preserved wooden casket (ca. $200 \times 44 \mathrm{~cm}$ ).
- Casket Orientation: $286^{\circ}$

- Casket Hardware: 5 Type 1 handles, numerous fragments of cuprous decorations, 22 nail fragments.

- Body Orientation and Position: Extended supine, facing east; vertebral column $280^{\circ}$.

- Arm and Hand Positions: Left arm crossed with hand resting on right os coxa; right arm extended.

- Leg Positions: Extended

\section{Cultural Characteristics:}

- Clothing: 3 cloth-covered iron buttons, 2 copper rivets with heavy coarse fabric in between.

- Personal Goods: None

\section{Osteological Characteristics:}

\section{Preservation}

- Taphonomy: Large tree stump $(30 \times 30 \mathrm{~cm})$ disrupted the casket at the midline. Despite root action, the skeletal remains were in good condition, although a large root had grown around the right femur, and extensive root etching was observed on most elements.

- Inventory: Complete skeleton.

Pathology

- Degenerative: Cervical vertebrae had very minor arthritis; two had slight osteophytes. Thoracic vertebrae all had minor lipping, and seven had small osteophytes. All lumbar vertebrae had severe lipping and small osteophytes. Four left ribs had extreme lipping at the vertebral facet. The ilia had lipping at the auricular surface and porosity and lipping in the acetabuli. Auricular surfaces of the sacrum were lipped. The distal phalanges of the first toe had arthritic lipping.

- Traumatic: One rib had a jagged perforation (ca. $16 \times 12 \mathrm{~mm}$ ) near the sternal end. The rib was split in half and remained disunited in the area of the perforation. It is possible that a shell fragment perforated the rib, which never reunited with the other section. The left fibula had a healed, aligned fracture of the distal end.

- Infectious: Sclerotic bone along the fractured area of the left fibula.

- Neoplasm: None

- Metabolic and Hematological: None 
- Dental: All maxillary and mandibular teeth were lost antemortem.

- Other: Ossified cricoid cartilage. The fifth lumbar vertebra was fused to the sacrum. The left ischium had a sclerotic lump protruding superiorly on the lateral surface.

\section{Burial 17}

Name: A. F. Brock

Date of Death: February 14, 1908 Age at Death: 68 years

Personal History: Born in Missouri in 1840 . Came to Texas in 1857 and resided in Abilene. Occupation listed as farmer. Served in Company C, 2nd Texas Cavalry, W. P. Lane's Brigade. Admitted to the Confederate Home on February 9, 1905. Disability listed as catarrh (inflammation of the mucous membranes, usually those of the nose and throat). Cause of death listed as quick consumption.

Sources of Historical Information: Headstone, General Services Commission records, Confederate Home records.

Headstone Type: 1

Headstone Inscription:

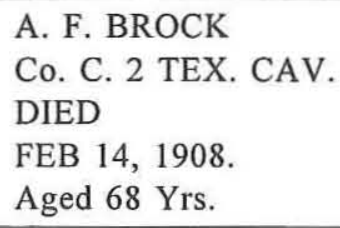

A. F. BROCK

Co. C. 2 TEX. CAV.

DIED

FEB 14, 1908.

Aged 68 Yrs.

Mortuary Characteristics:

- Casket Description: Wooden casket with an oval viewing window (window measured $55 \times 34 \times 0.2 \mathrm{~cm}$ ) inside a rectangular wooden outer box $(198 \times 57 \mathrm{~cm})$.

- Casket Orientation: $285^{\circ}$

- Casket Hardware: 6 Type 3 handles, 4 sets of Type 3 thumbscrews and Type 1 escutcheons, 3 Type 2 thumbscrews, thin cuprous metal star-shaped ornament on top of viewing window panel, green powdery stains from thin cuprous metal ornaments along casket walls, 51 highly corroded wire nails.
- Body Orientation and Position: Extended supine, facing east; vertebral column oriented $285^{\circ}$.

- Arm and Hand Positions: Left arm slightly flexed with the hand on top of sacrum. Right arm crossed with the hand on top of left forearm and left os coxa.

- Leg Positions: Extended

\section{Cultural Characteristics:}

- Clothing: Black fabric bow tie found on top of the upper thoracic vertebrae, a cloth-covered iron button found on the left side of a lumbar vertebrae just above the left os coxa.

- Personal Goods: None

Nonassociated Artifacts: Fragment of milk glass jar sealer found underneath the skull. The nature of its association with the burial is unclear, but there is no evidence of postdepositional disturbance.

\section{Osteological Characteristics:}

Preservation

- Taphonomy: Good preservation with minimal shifting and disarticulation.

- Inventory: Complete skeleton.

Pathology

- Degenerative: Temporomandibular joints had lipping and porosity. Minor lipping and porosity of sternal and acromial facets occurred on the left clavicle. Minor to moderate lipping occurred on cervicals 3-6. One thoracic vertebra had lipping and porosity on the centrum. Lumbars 4 and 5 had moderate to severe lipping and porosity, especially on the inferior surfaces of the centra. Minor to moderate lipping was observed on the first sacral centrum. Minor lipping occurred on the posterior aspect of the left femoral condyles.

- Traumatic: None

- Infectious: None

- Neoplasm: Button osteoma $(5 \times 7 \mathrm{~mm})$ on medial surface of left tibia shaft.

- Metabolic and Hematological: None.

- Dental: Ten maxillary teeth were recovered; 4 were lost antemortem and 2 were lost postmortem. Caries were located on the right fourth premolar and the left canine. Calculus deposits were moderate to severe, and dental 
wear was light to moderate. Eleven mandibular teeth were identified; 2 were lost antemortem. The left first molar had caries. Calculus deposits were moderate to severe. A subperiosteal ossified hematoma was located near the right third molar, in a labial position.

- Other: The distal ends of the left tibia and left fibula had projecting articulating bone spurs, possibly resulting from a pull to the ligament that holds the bones together.

\section{Burial 18}

Name: J. B. Ormand

Date of Death: March 10, 1908

Age at Death: 89 years

Personal History: Born in South Carolina in 1819. Came to Texas in 1850 and resided in Hico in Hamilton County. Occupation listed as farmer. Served in Company G, Terrell's Regiment, 37th Texas Cavalry, Army of the Trans-Mississippi. Admitted to the Confederate Home on January 1, 1904. Discharged at his request on June 9, 1906. Readmitted on August 1, 1906. Disabilities listed as old age and wounds. Cause of death listed as la grippe (influenza).

Sources of Historical Information: Headstone, General Services Commission records, Confederate Home records, index cards of Compiled Service Records.

Headstone Type: 1

Headstone Inscription:

J. B. ORMAND

CO. G. Terrells Reg.

DIED

MARCH 10, 1908

Aged 89 YRS.

\section{Mortuary Characteristics:}

- Casket Description: Wooden casket with an oval viewing window $(52 \times 29 \times 0.2 \mathrm{~cm})$ inside an outer box $(213 \times 56 \mathrm{~cm})$.

- Casket Orientation: $280^{\circ}$

- Casket Hardware: 6 Type 1 handles, 4 sets of Type 3 thumbscrews and Type 1 escutcheons,
2 Type 2 thumbscrews, several remnants of thin cuprous metal ornaments, 74 highly corroded wire nails.

- Body Orientation and Position: Extended supine, facing east; vertebral column $288^{\circ}$.

- Arm and Hand Positions: Right arm slightly flexed with hand on top of sacrum. Left arm crossed with hand on top of right forearm.

- Leg Positions: Extended

\section{Cultural Characteristics:}

- Clothing: 2 cloth-covered iron buttons found on top of lower thoracic and lumbar vertebrae.

- Personal Goods: 2 white-metal dumbbellshaped cuff links.

\section{Osteological Characteristics: \\ Preservation}

- Taphonomy: Preservation was fair to good, although the cranium and vertebral areas were badly fragmented due to the viewing window. Vertebral column was slightly disarticulated in a lateral manner. Some drifting of hand and feet elements had occurred.

- Inventory: The skull was badly fragmented, with loss of smaller facial bones. The postcranial skeleton was complete, with the exception of a highly fragmented pelvis.

Pathology

- Degenerative: The left humeral head and glenoid cavity evidenced arthritic activity. (Arthritic activity in the left hand and shoulder was probably related to the wound described below.) The right humeral head and glenoid cavity also exhibited lipping. The left lunate had lipping, new bone deposition, and eburnation. The left scaphoid, trapezium, and pisiform had lipping as well. Right triquetral had eburnation. All recovered cervical vertebrae had lipping and porosity on the centra and on the articular facets. One thoracic vertebra had minor lipping and porosity in the same areas. Two of the recovered lumbar vertebrae had lipping, and one had a Schmorl's node on its superior surface. The superior surface of the first sacral centrum was lipped. The right acetabulum had severe lipping (extending 10 $\mathrm{mm}$ ) and new bone growth such that the acetabulum was nearly unrecognizable. The right femoral head also had severe arthritic activity 
in terms of lipping and new bone deposition, as did the distal end. The distal end of the left femur had lipping that extended up to $6 \mathrm{~mm}$ from the original articular surface. (See trauma section for an explanation of arthritic activity in the left hip and leg.) Both patellae had lipping around the articular surface, as well as porosity and some new bone deposition.

- Traumatic: A healed, unaligned fracture of the left first metacarpal was present. The distal end of the left radius had fractured very close to the articular surface. The entire distal end of the radius had extremely severe arthritic lipping, which resulted in a malformation of that end of the bone. New bone growth also extended from the radial tuberosity to the radial head. Lipping was observed at the head of the radius. The distal end of the left ulna also was severely malformed due to arthritic activity and new bone deposition. It is believed that the trauma to the left wrist area resulted from some sort of wound, although the cause of the wound is not clear. Right fourth metacarpal also had a well-healed fracture. The left femoral head was completely disarticulated from the shaft due to some sort of trauma. The neck disintegrated and the inferior aspect of the head was covered with rough cortical bone, as was the area where the femoral neck was once located. The areas where the femoral head and the shaft articulated had large areas of eburnation $(35 \times 15 \mathrm{~mm})$. The left femur was extremely arthritic, as described earlier.

- Infectious: A large area of healed periostitis was noted on the proximal one-half of the left fibula shaft, lateral aspect.

- Neoplasm: None

- Metabolic and Hematological: None

- Dental: All maxillary teeth were lost antemortem. Three mandibular teeth were recovered; 12 were lost antemortem. The left canine and lateral incisor had large caries. Calculus deposits were minimal.

- Other: Cyst in left hamate (ca. $8 \mathrm{~mm}$ ).

\section{Burial 19}

Name: James W. Hogun

Date of Death: March 23, 1908

Age at Death: 78 years
Personal History: Born in Alabama in 1830. Served as a captain in Company F, 2nd Mississippi Cavalry, Armstrong's Brigade, Jackson's Division. Came to Texas in 1877 and resided in Port Lavaca. Occupation listed as merchant. Admitted to the Confederate Home on April 12, 1904, with a gunshot wound listed as his disability. Cause of death listed as cirrhosis of the liver.

Sources of Historical Information: Headstone, General Services Commission records, Confederate Home records, index cards of Compiled Service Records.

Headstone Type: 1

\section{Headstone Inscription:}

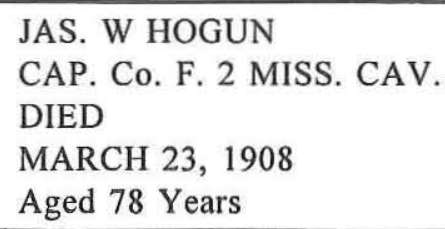

\section{Mortuary Characteristics:}

- Casket Description: Wooden casket $(197 \times 62 \mathrm{~cm})$ with an oval viewing window $(59 \times 35 \times 0.2 \mathrm{~cm})$ in an outer box. Red pigment was noted on casket wood.

- Casket Orientation: $287^{\circ}$

- Casket Hardware: 6 Type 1 handles, 6 sets of Type 1 thumbscrews with Type 1 escutcheons, 2 sets of Type 2 thumbscrews with Type 3 escutcheons, thin cuprous metal star-shaped ornament on top of viewing window panel, 37 highly corroded wire nails.

- Body Orientation and Position: Extended supine, facing east; vertebral column $277^{\circ}$.

- Arm and Hand Positions: Right arm crossed with hand on top of left os coxa. Left arm crossed with hand on top of right forearm and right os coxa.

- Leg Positions: Extended

\section{Cultural Characteristics:}

- Clothing: 2 cuprous metal eyelets, one found under the upper portion of each os coxa.

- Personal Goods: 2 white-metal dumbbellshaped cuff links, a white-metal Masonic emblem on top of casket lid at the midline of Zones $\mathrm{D}$ and $\mathrm{E}$. 


\section{Osteological Characteristics:}

Preservation

- Taphonomy: Preservation was fair to poor. The skull and thoracic regions were highly fragmented due to the presence of a viewing window. Some of the smaller hand and feet elements had drifted slightly.

- Inventory: Skull was missing smaller facial bones; lumbar vertebrae were gone, and the pelvis was extremely fragmented.

\section{Pathology}

- Degenerative: Proximal ends of ulnae exhibited minor lipping. The left capitate had lipping and new bone deposition that marred the inferior facet. Surface porosity and minor lipping were observed on the centra of four cervical vertebrae and five thoracics. The right patella had severe lipping, eșpecially medio-laterally. The proximal facet of the right tibia had arthritic deposition and porosity, as well as small areas of eburnation. The distal end of the right femur showed corresponding changes.

- Traumatic: None

- Infectious: None

- Neoplasm: None

- Metabolic and Hematological: None

- Dental: One maxillary tooth (a right third molar) was recovered. A gross caries had destroyed the crown of the tooth. Four mandibular teeth were located; nine were lost antemortem. The crown of the left second molar was destroyed by a giant caries, and an abscess had developed at the cervical margin.

- Other: The right acetabulum had new bone deposition along the inferio-lateral rim resulting in a wide "ridge" of new bone. The cause of this is unknown.

\section{Burial 20}

Name: Jarrett J. Cromer

Date of Death: February 22, 1908

Age at Death: 80 years

Personal History: Born in Alabama in 1828. Came to Texas in 1856 and resided in Georgetown. Occupation listed as blacksmith. Served in Company E, 35th Texas Cavalry, Brown's Battalion. Admitted to the Confederate Home on June 6, 1904. Discharged at his own request on July 2,
1906. Readmitted to the Confederate Home on February 1, 1907. Disabilities listed as old age, partial paralysis of the left arm, and severe arrhythmia of the heart. Confederate Home records list date of death as February 21, 1908. Causes of death listed as la grippe (influenza) and pneumonia.

Sources of Historical Information: Headstone, General Services Commission records, Confederate Home records, Pension (\#04414), index cards of Compiled Service Records.

Headstone Type: $\quad 1$

\section{Headstone Inscription:}

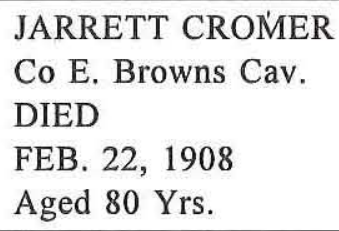

Mortuary Characteristics:

- Casket Description: Wooden casket with an oval viewing window $(52 \times 32 \times 0.2 \mathrm{~cm})$ in an outer box $(197 \times 62 \mathrm{~cm})$.

- Casket Orientation: $285^{\circ}$

- Casket Hardware: 6 Type 3 handles, 4 sets of Type 3 thumbscrews with Type 1 escutcheons, remnants of thin cuprous metal ornaments, star-shaped ornaments on each short wall as well as one on top of the viewing window panel, diamond-shaped ornaments located on the long walls, 88 highly corroded wire nails.

- Body Orientation and Position: Extended supine, facing east; vertebral column $280^{\circ}$.

- Arm and Hand Positions: Right arm extended; left arm slightly flexed with the hand on top of the sacrum.

- Leg Positions: Extended

\section{Cultural Characteristics:}

- Clothing: 2 cloth-covered iron buttons found on top of lower thoracic and lumbar vertebrae.

- Personal Goods: None

Osteological Characteristics:

Preservation

- Taphonomy: Preservation was fair to poor. 
The skull and thoracic regions were highly fragmented due to the viewing window.

- Inventory: The skull was badly fragmented with smaller facial bones missing. The postcranial skeleton was complete except for cervical vertebrae and a fragmented pelvis.

\section{Pathology}

- Degenerative: Both temporomandibular joints had slight porosity.

- Traumatic: The left clavicle had a wellhealed, unaligned fracture at midshaft in which the sternal end of the bone was misplaced in an inferior direction. The right tibia had a healed, aligned fracture approximately onethird of the way from the distal end. A corresponding fracture was observed in the right fibula. The right second metatarsal had a healed fracture at the midshaft. Three right rib shafts had healed aligned fractures.

- Infectious: None

- Neoplasm: None

- Metabolic and Hematological: None

- Dental: Ten maxillary teeth were recovered; one had been lost antemortem. All teeth were very worn, and calculus deposits varied from none on most teeth to very severe on the right second molar. Both canines had caries. In addition, the left canine had a large abscess. Nine mandibular teeth were recovered; six were lost antemortem. Calculus ranged from mild on most teeth to severe deposits on the left fourth premolar.

- Other: Four hand phalanges had small, irregular sclerotic deposits on the dorsal surfaces. The right radius had an enthesophyte at the radial tuberosity; another was noted on the greater trochanter of the left femur. Records listed partial paralysis of the left arm. This was apparent when the dimensions of the left arm were compared to those of the right.

\section{Burial 21}

Name: W. W. Hill

Date of Death: February 19, 1908

Age at Death: 73 years

Personal History: Born in Tennessee in 1835. Came to Texas in 1836 and resided in Blooming Grove. Occupation listed as farmer. Served in Company E (or C), Bates' 11th (or 13th) Texas

Volunteers. First admitted to the Confederate Home on June 19, 1895. Discharged honorably from the home on February 3, 1897. Readmitted to the Confederate Home on March 22, 1898. Discharged honorably on March 30, 1905. Readmitted to the Confederate Home on August 1, 1906. Disabilities listed as sore eyes and rupture. Cause of death listed as la grippe (influenza) and pneumonia.

Sources of Historical Information: Headstone, General Services Commission records, Confederate Home records, Pension (\#20665), index cards of Compiled Service Records.

Headstone Type: 1

Headstone Inscription:

\section{W. W. HILL \\ Co. E Bates Tex. Reg. \\ DIED}

FEB. 191908

Aged 73 Yrs.

\section{Mortuary Characteristics:}

- Casket Description: Wooden casket with an oval viewing window $(54 \times 33 \times 0.22 \mathrm{~cm})$ in an outer box $(194 \times 58 \mathrm{~cm})$.

- Casket Orientation: $282^{\circ}$

- Casket Hardware: 6 Type 3 handles, 4 sets of Type 3 thumbscrews with Type 1 escutcheons, 2 sets of Type 2 thumbscrews with Type 3 escutcheons, remnants of 2 thin cuprous metal star-shaped ornaments (one on top of viewing window panel and the other on top of casket lid at the midline of Zones D and E), several thin cuprous diamond-shaped ornaments, 53 highly corroded wire nails.

- Body Orientation and Position: Extended supine, facing east; vertebral column $267^{\circ}$.

- Arm and Hand Positions: Left arm slightly flexed with hand on top of the left os coxa and femoral head. The right arm is crossed with the hand on top of the left wrist and left os coxa.

- Leg Positions: Extended

Cultural Characteristics:

- Clothing: Possible metal button fragments on 
top of the lower vertebral column.

- Personal Goods: None

Nonassociated Artifacts: Small butchered Bos sp. (probably cow) bone found in the grave shaft.

\section{Osteological Characteristics:}

Preservation

- Taphonomy: Preservation was good. The upper vertebral column and shoulders had shifted to the right. The presence of the viewing window did not have the same adverse effects as seen on many burials. The right os coxa had flipped over $180^{\circ}$. Some drifting of hand and feet elements had occurred.

- Inventory: Complete skeleton.

Pathology

- Degenerative: Mild to moderate arthritic lipping was present on the distal humeri and the proximal ulnae. Lipping was also observed on both glenoid cavities and the right radius. Three of the cervical vertebrae had minor lipping and porosity on the centra. Four of the lower thoracic vertebrae had osteophytes on both the superior and inferior surfaces. Thoracics 11 and 12 had fused together through bridging osteophytes. Three of the lumbar vertebrae had osteophytes on the superior and inferior surfaces. Porosity was present on the surfaces of both acetabuli. Mild lipping was present on the distal ends of both femora. The right patella had moderate lipping on the inferio-lateral aspect and an isolated area of new bone deposition on the articular surface. The left patella had very mild lipping.

- Traumatic: None

- Infectious: Sclerotic lesions were present on the dorsal surfaces of three proximal hand phalanges.

- Neoplasm: None

- Metabolic and Hematological: None

- Dental: Twelve maxillary teeth were recovered, and two were lost antemortem. Calculus deposits were moderate to severe. The right fourth premolar had a caries. Nine mandibular teeth were recovered; seven were lost antemortem. Calculus deposits were moderate to severe.

- Other: Enthesophyte on the proximal end of the right ulna.
Burial 22

Name: Marshall C. Kelly

Date of Death: January 29, 1908

Age at Death: 72 years

Personal History: Born in Alabama in 1836. Moved to Texas in 1850 and resided in San Antonio, occupation listed as farmer/carpenter. Served as a lieutenant in Company E (F), Ragsdale's Battalion of the 32nd Texas Cavalry, Army of the Trans-Mississippi. Admitted to the Confederate Home on January 19, 1907, with an encysted tumor listed as his disability. Pension records stated he suffered from sunstroke, a defective left eye, and a gunshot wound in the muscular junction of the lower leg. Cause of death listed as blood poisoning.

Sources of Historical In formation: Headstone, General Services Commission records, Confederate Home records, Pension (\#04966).

Headstone Type: $\quad 1$

Headstone Inscription:

M. C. KELLY
Co. F. Ragsdale[s] Bat.
DIED

JAN. 29, 1908

Aged 72 Yrs.

Mortuary Characteristics:

- Casket Description: Poorly preserved wooden casket (stain measured $190 \times 58 \mathrm{~cm}$ ).

- Casket Orientation: $275^{\circ}$

- Casket Hardware: 6 Type 7 handles, 4 Type 3 thumbscrews with Type 1 escutcheons, 31 nails.

- Body Orientation and Position: Extended supine, facing east; vertebral column $275^{\circ}$.

- Arm and Hand Positions: Arms were crossed with both hands resting over the right os coxa.

- Leg Positions: Extended

Cultural Characteristics:

- Clothing: 2 metal buttons.

- Personal Goods: Small white-metal Masonic casket ornament recovered from Zone E. 
Osteological Characteristics:

Preservation

- Taphonomy: Skeletal remains were in good condition, but the skull was fragmented; drifting was limited to elements of the feet.

- Inventory: Smaller facial bones and cervical vertebrae were missing, but the rest of the skeleton was complete.

\section{Pathology}

- Degenerative: The right pisiform was extremely arthritic. Three proximal, two medial, and two distal hand phalanges had lipping at the proximal facets. The third right metacarpal had lipping at the distal facet. No vertebral bodies were available for examination, but two neural arches of thoracic vertebrae had lipping and porosity on the inferior articular surfaces. The left talus had an arthritic bone projection at the fibular articulation. Both first metatarsals had marked lipping at the inferior distal surface and eburnation where the sesamoids articulated. Both distal phalanges of the first toe had lipping at the proximal ends.

- Traumatic: The right ulna had a well-healed, aligned fracture at the distal portion of the shaft.

- Infectious: None

- Neoplasm: None

- Metabolic and Hematological: Generalized cranial thickening $(10 \mathrm{~mm})$ was noted on the frontal, parietals, and occipital.

- Dental: Thirteen maxillary teeth were recovered. Mild to moderate calculus deposits were noted. Caries were present on the right third premolar, canine, and both incisors, as well as the left third molar. Abscesses were present on the right third premolar and the right canine. Thirteen mandibular teeth were observed; three were lost postmortem. The right first and second molars exhibited caries. The right first molar also had a cervical abscess.

- Other: None

\section{Burial 23}

Name: J. A. Alexander

Date of Death: November 15, 1907

Age at Death: 72 years

Personal History: Born in Tennessee in 1835, came to Texas in 1862 and lived in Leady. His occupation was listed as cattleman. Served in Company C, 16th Texas Cavalry, Army of Tennessee. Admitted to the Confederate Home on December 12, 1906, with paralysis noted as his disability. Discharged June 13, 1907, and readmitted July 4, 1907. Cause of death listed as cirrhosis of the liver.

Sources of Historical Information: Headstone, General Services Commission records, Confederate Home records.

\section{Headstone Type: 1}

Headstone Inscription:
J. A. ALEXANDER
Co. C. 16 Tex. Cáv.
Died
NOV. 15,1907
Aged 72 Yrs.

\section{Mortuary Characteristics:}

- Casket Description: Poorly preserved wooden casket with only a few remaining fragments of wood (dimensions are indeterminate).

- Casket Orientation: $275^{\circ}$

- Casket Hardware: 4 Type 2 handles, 2 Type 2 latches, 22 nails.

- Body Orientation and Position: Extended supine, facing east; vertebral column $280^{\circ}$.

- Arm and Hand Positions: Left arm was crossed with hand resting on the right os coxa. Right arm was extended.

- Leg Positions: Extended

\section{Cultural Characteristics:}

- Clothing: 3 metal buttons found along vertebral column, 2 snap fasteners.

- Personal Goods: A cloth-covered iron band (93 $\mathrm{mm}$ in diameter) that would have formed a ring was found in the neck region. The function of this item is unknown.

\section{Osteological Characteristics:}

\section{Preservation}

- Taphonomy: Skeletal remains were extremely well preserved and articulated, despite the poor condition of the casket.

- Inventory: Complete burial except for frag- 
mentation of the vertebral column.

\section{Pathology}

- Degenerative: Left temporomandibular joint had lipping and an isolated area of erosion. One thumb had extreme lipping of the distal end of the proximal phalanx and the proximal end of the distal phalanx (which also had surface porosity). The rest of the recovered distal phalanges had very mild lipping. Both of the observable cervical vertebrae had lipping; the atlas had lipping around the fovea, and the axis had lipping at the inferior centrum surface. One of the four observable thoracics had lipping at the costal facet. The right navicular had lipping.

- Traumatic: One right central rib had a healed, greenstick fracture that was slightly misaligned.

- Infectious: The right second, third, and fourth metatarsals had sclerotic bone deposits at the proximal portions of the shafts, especially inferiorly. This was also present on the left third and fourth metatarsals, but to a much lesser degree. The right intermediate cuneiform also had this type of deposition.

- Neoplasm: None

- Metabolic and Hematological: None

- Dental: Seven maxillary teeth were recovered. Both central incisors and canines had one episode of linear enamel hypoplasias. The left fourth premolar had a caries. Nine mandibular teeth were recovered; four were lost antemortem and the lower third molars were missing congenitally. Both canines had two hypoplastic episodes.

- Other: None

\section{Burial 24}

Name: Isaac C. Briggs

Date of Death: November 22, 1907

Age at Death: 91 years

Personal History: Born in Tennessee in 1816, served in Company F, 1st Tennessee Artillery, Forrest's Brigade, Army of Tennessee. Came to Texas in 1887 and lived in Ethel as a farmer. Admitted to the Confederate Home on January 11, 1894 , with his disability listed as ulcers. Causes of death listed as senility and injury from a fall.
Sources of Historical Information: Headstone, General Services Commission records, Confederate Home records.

Headstone Type: 1

Headstone Inscription:
I. C. BRIGGS
Co. F. Tenn. Art.
DIED
NOV. 22, 1907
Aged 91 Yrs.

\section{Mortuary Characteristics:}

- Casket Description: Wooden casket in an outer box (dimensions indeterminate); viewing window (dimensions indeterminate) with wood panel covering.

- Casket Orientation: $275^{\circ}$

- Casket Hardware: 4 Type 2 handles, 4 Type 4 thumbscrews, 2 Type 2 escutcheons, 3 Type 5 thumbscrews with Type 3 escutcheons, 2 star-shaped decorative tacks, 24 nail fragments, corrugated fastener.

- Body Orientation and Position: Extended supine, facing east; orientation of vertebral column indeterminate.

- Arm and Hand Positions: Extended

- Leg Positions: Extended

\section{Cultural Characteristics:}

- Clothing: 1 metal snap fastener.

- Personal Goods: 2 bone cuff studs.

\section{Osteological Characteristics:}

\section{Preservation}

- Taphonomy: Skeletal remains were very poorly preserved; the bone under the glass viewing window consisted of a layer of fine dust. Cranial and postcranial bones were broken and fragmented.

- Inventory: The skull was highly fragmented, and no small facial bones were recovered. The postcranial skeleton also was fragmented; bones of the right forearm, the right clavicle, and all vertebrae except one were missing.

\section{Pathology}

- Degenerative: The left lunate exhibited lipping; the right scaphoid, triquetral, trapezoid, 
and trapezium were lipped and eburnated. The left femur had severe arthritic lipping at the distal end (related to fracture described below). The left patella had minor lipping. The proximal left tibia was eburnated on the articular surface.

- Traumatic: The left femur had a healed, unaligned fracture at midshaft in a dorsoventral direction. The bone overlapped by approximately $4.5 \mathrm{~cm}$, resulting in considerable shortening of the bone.

- Infectious: Healed periostitis at anterior-distal portion of the left femur.

- Neoplasm: None

- Metabolic and Hematological: None

- Dental: Ten maxillary teeth were recovered. Calculus deposits were severe, but no caries were noted. Numerous hypoplastic episodes were recorded on the right and left canine and all incisors. Twelve mandibular teeth were recovered. Calculus deposits were moderate to severe, and no caries were observed. Hypoplastic episodes were noted on both central and lateral incisors.

- Other: None

\section{Burial 25}

Name: James R. Simmons

Date of Death: December 17, 1907

Age at Death: 67 years

Personal History: Born in Kentucky in 1840, moved to Texas in 1859. Lived in Bowie and worked as a carpenter. Records indicate that he served in Company K, 3rd Texas Cavalry, Sibley's Brigade, Army of the Trans-Mississippi, although his headstone says Company K, 7th Texas Cavalry. Admitted to the Confederate Home on December 31,1906 , with his disability listed as bronchitis. Cause of death listed as tuberculosis.

Sources of Historical Information: Headstone, General Services Commission records, Confederate Home records, history of Confederates in New Mexico (Hall 1978:285).

\section{Headstone Type: 1}

Headstone Inscription:

$$
\begin{aligned}
& \text { J. R. SIMMONS } \\
& \text { Co. K. 7. Tex. Cav. } \\
& \text { DIED } \\
& \text { DEC. } 17,1907 \\
& \text { Aged } 67 \text { years }
\end{aligned}
$$

\section{Mortuary Characteristics:}

- Casket Description: Wooden casket $(207$ x 68 $\mathrm{cm}$ ) with viewing window (dimensions indeterminate).

- Casket Orientation: $275^{\circ}$

- Casket Hardware: 4 Type 2 handles (some with remains of gold paint), 2 Type 3 thumbscrews with Type 1 escutcheons, 3 Type 5 thumbscrews, 2 bell-shaped decorative tack heads, elaborate decorative piece from the outer wall of the casket, 18 nails.

- Body Orientation and Position: Extended supine, facing east; vertebral column $275^{\circ}$.

- Arm and Hand Positions: Arms were crossed with left hand on right os coxa and right hand on left os coxa.

- Leg Positions: Extended

\section{Cultural Characteristics:}

- Clothing: 2 metal buttons, fragment of bow tie.

- Personal Goods: 2 bone cuff studs.

\section{Osteological Characteristics: \\ Preservation}

- Taphonomy: The cranium was fragmented; bone under the viewing window was eroded and badly disintegrated.

- Inventory: The skull was highly fragmented, and smaller facial bones were absent; the postcranial skeleton was complete with the exception of most cervical vertebrae and the right patella and fibula.

\section{Pathology}

- Degenerative: Minor lipping was observed on the glenoid cavity of the left scapula and the sternal end of left clavicle. A distal hand phalanx had lipping at the proximal facet. Five of the 11 observable thoracic vertebrae had osteophytes, as did 4 of the 5 lumbars. 
Three lumbar vertebrae had Schmorl's nodes on the superior surface, while one had a node just on the inferior surface. Both proximal and distal phalanges of the first toes had mild lipping.

- Traumatic: None

- Infectious: None

- Neoplasm: None

- Metabolic and Hematological: None

- Dental: Five maxillary teeth were recovered; all had caries. Linear enamal hypoplasias were noted on the left central and lateral incisors (right incisors were not available for observation). Four mandibular teeth were recovered; eight additional teeth were lost antemortem, and four were lost postmortem. All four mandibular teeth had caries, and the left lateral incisor had hypoplasias.

- Other: Enthesophytes were noted at the deltoid area of the right humerus.

\section{Burial 26}

Name: Joshua Francis Smith

Date of Death: January 7, 1908

Age at Death: 87 years

Personal History: Born in Tennessee in 1821, came to Texas in 1857, and lived in Milam County where he worked as a farmer. Served in Company C, 21st Texas Cavalry, Parson's Brigade. Admitted to the Confederate Home on March 3, 1892, with a disability listed as paralysis. Readmitted on April 9, 1901; released at his request on August 6, 1904. Reentered Confederate Home sometime after 1904 and died there in 1908. Pension records show that he was blind. Cause of death listed as apoplexy (stroke).

Sources of Historical Information: Headstone, General Services Commission records, Confederate Home records, Pension (\#06413).

Headstone Type: 1

Headstone Inscription:

J. C. SMITH

CO. C. 21. Tex. Cav.

DIED

JAN. 7, 1908

Aged 87 Yrs.

\section{Mortuary Characteristics:}

- Casket Description: Poorly preserved wooden casket in an outer box. No wood remained of the lower half of the casket, but the grave shaft measured $185 \times 44 \mathrm{~cm}$.

- Casket Orientation: $280^{\circ}$

- Casket Hardware: 4 Type 1 handles, 3 Type 3 thumbscrews with Type 1 escutcheons, 2 Type 5 thumbscrews, one bell-shaped tack, 5 corrugated fasteners. Numerous thin copper decorations were observed but were too fragile to collect intact.

- Body Orientation and Position: Extended supine, facing east; vertebral column $280^{\circ}$.

- Arm and Hand Positions: Arms crossed with left hand on right os coxa and right hand on left os coxa.

- Leg Positions: Extended

\section{Cultural Characteristics:}

- Clothing: 3 iron buttons, cuprous metal snap fastener.

- Personal Goods: None

Nonassociated Artifacts: Dropped-forged, oxidized iron shovel head with a broken handle found in the east end of the shaft fill, approximately $50-70 \mathrm{~cm}$ below the ground surface. The cutting edge of the shovel has a large piece missing.

\section{Osteological Characteristics:}

Preservation

- Taphonomy: Bone was extremely fragile and crumbled when excavated. This condition seemed to result from extensive root damage and insect activity. Thoracic tumbling was noted.

- Inventory: Fragmented skull with missing small facial bones; complete postcranial skeleton.

Pathology

- Degenerative: Minor arthritic lipping was present around the glenoid cavities of both scapulae. Left triquetral and pisiform had eburnation. A distal and a medial hand phalanx had lipping on the proximal facets. Cervicals 3-7 had extreme osteophytes and surface porosity, especially on the inferior surface. All 12 thoracic vertebrae had very minor lipping at the anterior border of the centra. Two lumbar vertebrae had slight 
lipping at the centrum, and three had porosity on the inferior surface of the centra. Two had Schmorl's nodes on the superior surface. The os coxae had lipping at the superior edges of both acetabuli.

- Traumatic: None

- Infectious: None

- Neoplasm: None

- Metabolic and Hematological: None

- Dental: Ten maxillary teeth were recovered. The right first molar, right third premolar, right canine, right lateral incisor, and both central incisors had caries. Calculus deposits were not present on the teeth. Eight mandibular teeth were recovered; seven additional teeth were lost antemortem. The left incisors, right lateral incisor, and right canine had caries. No calculus was present on the mandibular teeth.

- Other: One medial hand phalanx was much shorter than all of the other ones. The right tibia had a bone spur at the latero-distal end that resulted from a pulled ligament.

\section{Burial 27}

Name: John Y. Porter

Date of Death: January 19, 1908

Age at Death: 90 years

Personal History: Born in South Carolina in 1818. Came to Texas in 1854 and resided in Oakville. Occupation listed as farmer. Served in Company D, Wood's Regiment, 36th Texas Cavalry, De Bray's Brigade. Admitted to the Confederate Home on January 5, 1901, with disabilities listed as kidney trouble and blindness. Cause of death listed as senile debility.

Sources of Historical Information: Headstone, General Services Commission records, Confederate Home records, Pension (\#02716), index cards of Compiled Service Records.

Headstone Type: 1

Headstone Inscription:

J. Y. Porter

CO. D. WOOD'S REG.

DIED

JAN. 19, 1908

Aged 90 Yrs.
Mortuary Characteristics:

- Casket Description: Highly deteriorated wooden casket $(198 \times 54 \mathrm{~cm})$ with a straighttopped, oval-shaped viewing window $(51 \times 27 \mathrm{~cm})$. Outer box indeterminate.

- Casket Orientation: $285^{\circ}$

- Casket Hardware: 4 Type 7 handles, 4 sets of Type 3 thumbscrews with Type 1 escutcheons, 3 Type 3 thumbscrews, 4 iron corrugated wood fasteners (one found near each corner), 2 fragmented cuprous diamond-shaped ornaments (one found on each short wall), green powdery stains of other thin cuprous metal ornaments (probably tack heads) noticed on long running walls, 49 highly corroded wire nails, 4 wood screws.

- Body Orientation and Position: Extended supine, facing east; vertebral column $280^{\circ}$.

- Arm and Hand Positions: Extended

- Leg Positions: Extended

\section{Cultural Characteristics:}

- Clothing: Four-hole bone button found on top of left os coxa.

- Personal Goods: None

Nonassociated Artifacts: Brass rim-fire cartridge (possibly .52 caliber) found near the top of the west casket wall in grave shaft fill.

\section{Osteological Characteristics:}

Preservation

- Taphonomy: Preservation was good. Cranium had rolled onto its left side.

- Inventory: Complete skeleton with fragmented skull.

\section{Pathology}

- Degenerative: Both temporomandibular joints had lipping and porosity. Porosity and lipping were observed on the glenoid cavities of both scapulae and on the sternal and acromial facets of both clavicles. The clavicular facets of the sternum showed lipping as well. The humeral heads, distal radii, and proximal ulnae all showed arthritic lipping that was much worse on the right side than on the left. Left lunate had lipping. Three proximal hand phalanges had lipping at the distal ends; five distal hand phalanges had lipping at the proximal ends. The dens had extreme lipping that corresponded with lipping seen on the fovea 
for the dens. One cervical body had porosity and osteophytes. Seven thoracic vertebrae had Schmorl's nodes on the inferior surface. All thoracics had severe (almost bridging) osteophytes. All lumbar vertebrae had moderate lipping and porosity on the centra and on the articular facets. Both acetabuli had moderate lipping, as did both femoral heads. Distal ends of femora also showed lipping. Moderate lipping was present on both patellae. One medial foot phalanx had lipping at the distal end.

- Traumatic: None

- Infectious: Both maxillae evidenced severe healed periostitis, suggestive of sinusitis.

- Neoplasm: None

- Metabolic and Hematological: Cranial thickening $(12 \mathrm{~mm})$ was evident on frontal, parietals, and occipital.

- Dental: Eight maxillary teeth were recovered. The right third molar had a caries. Calculus was only noted on two of these maxillary teeth. Twelve mandibular teeth were recovered; two were lost antemortem and two were lost postmortem. Calculus deposits were mild to moderate. The left two incisors and the right third molar had abscesses. The right third molar was also fractured at the distal portion of the crown prior to death.

- Other: None

\section{Burial 28}

Name: James W. Johnson

Date of Death: January 6, 1908

Age at Death: 72 years

Personal History: Born in Kentucky in 1836, moved to Texas in 1852 and lived in Rockport as a farmer. Served in Company I, 2nd Texas Cavalry, Hobb's Brigade, Kirby Smith's Division, Army of the Trans-Mississippi. Admitted to Confederate Home on January 23, 1895, with disability listed as rheumatism. Cause of death listed as cystitis.

Sources of Historical Information: Headstone, General Services Commission records, Confederate Home records.

Headstone Type: 1
Headstone Inscription:

J. W. JOHNSON
CO. [I] 2 Tex. Cav.
DIED

JAN. [6] 190[?]

Aged 72 Yrs.

Mortuary Characteristics:

- Casket Description: Badly deteriorated wooden casket $(181 \times 52 \mathrm{~cm})$ with a viewing window.

- Casket Orientation: $280^{\circ}$

- Casket Hardware: 4 Type 1 handles, 2 Type 3 thumbscrews with Type 1 escutcheons, Type 5 thumbscrew, 2 diamond-shaped tacks, bellshaped tack, 3 oval-shaped decorations, fragment of a cuprous decorative leaf, 24 nails.

- Body Orientation and Position: Extended supine, facing east; vertebral column $280^{\circ}$.

- Arm and Hand Positions: Arms crossed with left hand over right os coxa and right hand over left os coxa.

- Leg Positions: Extended

Cultural Characteristics:

- Clothing: No artifacts recovered.

- Personal Goods: 2 bone cuff studs.

\section{Osteological Characteristics:}

Preservation

- Taphonomy: Skeletal remains were in poor condition; bone under the viewing window was reduced to fragments and powder.

- Inventory: Complete, but highly fragmented, skeleton.

Pathology

- Degenerative: Lipping was observed at the head of the right humerus. One proximal hand phalanx had lipping at the distal end. One of the three recovered cervical vertebrae had lipping on the inferior surface of the centrum. All thoracics had lipping on the centra. The lumbars were extremely arthritic with osteophytes, porosity, and new bone deposition on the surfaces of the centra. Ribs had arthritis at the vertebral articular facets. Lipping was observed on the centra of the first sacral element. The right patella was lipped along the medial inferior surface. Proximal facets of 
the second and third left metatarsals had areas of localized bone loss.

- Traumatic: None

- Infectious: Active and healed periosteal depositions were noted endocranially along the sagittal suture.

- Neoplasm: None

- Metabolic and Hematological: None

- Dental: Only one maxillary tooth was recovered; nine had been lost antemortem. The left lateral incisor had a gross caries that destroyed the crown of the tooth. All mandibular teeth were lost antemortem.

- Other: None

\section{Burial 29}

Name: John P. Thomas

Date of Death: December 15, 1907

Age at Death: 72 years

Personal History: Born in Alabama in 1837. Served in Company E (or G), Waul's Legion. Discharged on July 29, 1862, at Quintana after obtaining a substitute. Came to Texas in 1868 and resided in Leon County. Occupation listed as farmer. Admitted to the Confederate Home on June 24, 1900, with disabilities listed as kidney trouble and hemorrhaging weak heart. Cause of death listed as "hemorrhage, purpura." Pension records contain a document pertaining to the funerary reimbursement which stated the cost of a casket and burial robe was not to exceed $\$ 30.00$. Confederate Home records indicate that Thomas may have died at 70 or 71 years of age.

Sources of Historical Information: Headstone, General Services Commission records, Confederate Home records, Pension (\#24811), index cards of Compiled Service Records.

Headstone Type: 1

\section{Headstone Inscription:}

J. P. THOMAS
Co. E. Wauls Leg.
DIED
DEC. 15,1907
Aged 72 Yrs.

Co. E. Wauls Leg.

DEC. 15,1907

Aged 72 Yrs.
Mortuary Characteristics:

- Casket Description: Highly deteriorated wooden casket $(190 \times 57 \mathrm{~cm})$ with a straighttopped, oval-shaped viewing window $(47 \times 32 \times 0.2 \mathrm{~cm})$. Yellow or gold pigment noticed on casket wood. Outer box indeterminate.

- Casket Orientation: $285^{\circ}$

- Casket Hardware: 4 Type 2 handles, 4 sets of Type 3 thumbscrews with Type 1 escutcheons, 2 Type 5 thumbscrews. All white-metal hardware found on this casket was painted gold. One thin cuprous diamond-shaped ornament was found on the east wall of casket; remnants of three other thin cuprous metal ornaments noticed along casket walls. Four corrugated iron wood fasteners and 47 corroded wire nails recovered.

- Body Orientation and Position: Extended supine, facing east; vertebral column $285^{\circ}$.

- Arm and Hand Positions: Right arm crossed with hand on top of head of left femur and lower left os coxa. Left arm also slightly crossed with hand on top of sacrum.

- Leg Positions: Extended

\section{Cultural Characteristics:}

- Clothing: Black fabric bow tie found on top of upper thoracic vertebral column.

- Personal Goods: 2 bone cuff studs.

\section{Osteological Characteristics:}

Preservation

- Taphonomy: Preservation was fair to good. The cranium was badly fragmented.

- Inventory: Complete skeleton with fragmented skull and lumbar vertebrae.

\section{Pathology}

- Degenerative: Ulnae had minor lipping on the proximal and distal ends. Schmorl's nodes were observed on four thoracic centra. Right distal femur had minor lipping around the medial condyle. The patella also had lipping. Lipping was noted on the proximal end of the right tibia.

- Traumatic: None

- Infectious: Healed periosteal reaction in the left maxillary sinus chamber, suggesting sinusitis. The right maxillary sinus did not show any periosteal reaction. 
- Neoplasm: None

- Metabolic and Hematological: None

- Dental: All maxillary teeth were recovered, except for the left third molar which was lost prior to death. Almost all teeth had very severe calculus deposits. Caries were noted on four teeth, the right first molar, right third premolar, and the left third and fourth premolars. All mandibular teeth were recovered except the left third molar. Like the maxillary teeth, almost all mandibular teeth had very severe calculus deposits, but none had caries.

- Other: Enthesophyte on the proximal end of the right ulna. Enthesophytes projected superiorly from both tibial tuberosities. Enthesophytes on anterior surfaces of both patellae. The right lateral cuneiform was incompletely fused to the third metatarsal. Fusion was observed only on the plantar surface (cuneiometatarsal coalition).

\section{Burial 30}

Name: L. E. Trezervant

Date of Death: November 26, 1907

Age at Death: 74 years

Personal History: Born in Virginia in 1833, moved to Texas in 1855, lived in Galveston and worked as an attorney-at-law. Served as captain of Company I, 26th Texas Cavalry, De Bray's Brigade. Admitted to the Confederate Home on January 5, 1905, with a disability listed as "disordered nerves." Cause of death listed as heart failure.

Sources of Historical Information: Headstone, General Services Commission records, Confederate Home records.

Headstone Type: 1

Headstone Inscription:

L. E. TREZERVANT
Co. I. 26 Tex. Cav
DIED
NOV. 26.1907
Aged 74 Yrs.

L. E. TREZERVANT

Co. I. 26 Tex. Cav

NOV. 26. 1907

Aged 74 Yrs.
Mortuary Characteristics:

- Casket Description: Badly deteriorated wooden casket (stain measured ca. $183 \times 48 \mathrm{~cm}$ ) with a large viewing window $(50 \times 35 \mathrm{~cm})$.

- Casket Orientation: $280^{\circ}$

- Casket Hardware: 4 Type 2 handles, 3 Type 4 thumbscrews with Type 1 escutcheons, starshaped decorative tack, Type 5 latch, 15 nails.

- Body Orientation and Position: Extended supine, facing east; vertebral column $278^{\circ}$.

- Arm and Hand Positions: Left arm was crossed with hand resting on the right os coxa. Right arm was extended.

- Leg Positions: Extended

\section{Cultural Characteristics:}

- Clothing: Fragments of black cloth were found under the viewing window, including a bow tie.

- Personal Goods: Maxillary dentures. One metal finger ring with central stone of moss agate and floral decoration on the band; a second ring was a plain gold band with the name "Helen" inscribed on the inside. Both rings were found on the fourth finger of the left hand.

- Other: A nail was driven postmortem through the floor of the casket and into the lateral portion of the left calcaneus.

\section{Osteological Characteristics:}

\section{Preservation}

- Taphonomy: The thoracic area had deteriorated due to the viewing window; the remainder of the skeleton was extremely fragile.

- Inventory: Complete skeleton, with some loss of vertebrae and small facial bones.

\section{Pathology}

- Degenerative: The left temporomandibular joint had severe porosity and lipping; the right side had none. The dens had extreme lipping. Two cervical centra had porosity and lipping.

- Traumatic: None

- Infectious: None

- Neoplasm: Button osteoma on the left maxilla, lateral alveolar margin.

- Metabolic and Hematological: None

- Dental: Maxillary dentures. Eight mandibular teeth were recovered; seven were lost antemor- 
tem, and one was lost postmortem. Mild calculus deposits were noted on most of the teeth. Caries were identified on the left incisors, as well as on the right incisors, right canine, and right third premolar.

- Other: Large enthesophyte on deltoid area of the left humerus.

\section{Burial 31}

Name: William H. Stewart

Date of Death: November 25, 1907

Age at Death: 60 years

Personal History: Born in Mississippi in 1847. Served in Company F, Wood's 36th Texas Cavalry Regiment, Writ Adams' Brigade, Forrest's Division, Army of Tennessee. Came to Texas in 1870 and resided in Houston and Cherokee Counties. Occupations listed as engineer and farmer. Admitted to the Confederate Home on October 17, 1907. Disability listed as lung trouble. Cause of death listed as tuberculosis.

Sources of Historical Information: Headstone, General Services Commission records, Confederate Home records, Pension (\#10346).

Headstone Type: 1

Headstone Inscription:
W. H. STEWART
Co. F. Woods Reg.
DIED
NOV. 251907
Aged 60 Yrs.

Mortuary Characteristics:

- Casket Description: Wooden casket with a straight-topped, oval-shaped viewing window $(54 \times 36 \times 0.3 \mathrm{~cm})$ inside an outer box $(213 \times 61 \mathrm{~cm})$. Gold or yellow pigment noted on casket wood.

- Casket Orientation: $280^{\circ}$

- Casket Hardware: 4 Type 2 handles, 3 sets of Type 4 thumbscrews with Type 1 escutcheons, 2 Type 5 thumbscrews, Type 5 latch, 3 corrugated iron wood fasteners found near corners, 37 highly corroded wire nails.
- Body Orientation and Position: Extended supine, facing east; vertebral column $280^{\circ}$.

- Arm and Hand Positions: Extended

- Leg Positions: Extended

\section{Cultural Characteristics:}

- Clothing: A black fabric bow tie with a straight pin attachment was found on top of upper thoracic vertebrae. Three cloth-covered iron buttons were found on top of the vertebral column, from the lower thoracic to the lumbar vertebrae; small four-hole shell button was found in the lower thoracic region just to the right side of the vertebral column; large fourhole shell button was found within the left thoracic area.

- Personal Goods: Bone cuff stud.

\section{Osteological Characteristics:}

\section{Preservation}

- Taphonomy: Preservation was good to fair. The cranium had rolled onto its right side, and the facial area had separated from the rest of the cranium. Drifting was limited to elements of the feet.

- Inventory: Complete but fragmented skull; complete postcranial skeleton.

\section{Pathology}

- Degenerative: Mild lipping and porosity were noted in both temporomandibular joints. The dens had lipping and porosity. One of the cervical bodies also had extreme porosity. Moderate lipping was apparent on the superior articular facets of T12. Mild lipping was present on the inferior surface of L4 and the superior aspect of L5. Mild lipping was noted on the distal left ulna, distal tibiae, proximal right tibia, patellae, and distal femora.

- Traumatic: Healed, aligned fracture of a left rib shaft fragment. Fractured area was located approximately $5 \mathrm{~cm}$ from the sternal facet. The left fifth metacarpal had a well-healed fracture of the shaft near the distal end.

- Infectious: Active periosteal reaction on petrosal portion of both temporals; sclerotic bone deposition on the roof of the maxillae.

- Neoplasm: None

- Metabolic and Hematological: None

- Dental: Fourteen maxillary teeth, some of which had mild calculus deposits, were recov- 
ered. The left lateral incisor and the left third molar had caries. Ten mandibular teeth were recovered; four were lost antemortem, and two were lost postmortem. Calculus deposits were present on some teeth. Caries were observed on both second molars. At one time, the right molar had a tin filling which stained the tooth, but the filling was lost.

- Other: Subperiosteal ossified hematoma on the disto-anterior aspect of the left tibia.

\section{Burial 32}

Name: John M. Adams

Date of Death: November 24, 1907 Age at Death: 68 years

Personal History: Born in Arkansas in 1839, served as a Corporal/Musician in Company A, 14th Arkansas Infantry, Herbert's Brigade. Came to Texas in 1865, lived in San Angelo and worked as a stockman. Admitted to the Confederate Home on March 16, 1907, with a general disability. Cause of death listed as epilepsy.

Sources of Historical Information: Headstone, General Services Commission records, Confederate Home records.

Headstone Type: 1

Headstone Inscription:

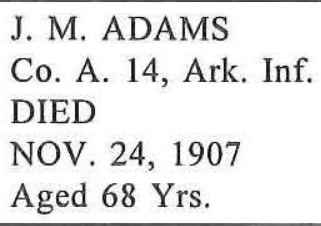

J. M. ADAMS

Co. A. 14, Ark. Inf.

DIED

NOV. 24, 1907

Aged 68 Yrs.

Mortuary Characteristics:

- Casket Description: Wooden casket $(184 \times 50 \mathrm{~cm})$ with a viewing window $(50 \times 30 \mathrm{~cm})$.

- Casket Orientation: $277^{\circ}$

- Casket Hardware: 4 Type 2 handles, 4 Type 4 thumbscrews with Type 2 escutcheons, Type 5 thumbscrew, 27 nail fragments.

- Body Orientation and Position: Extended supine, facing east; vertebral column $280^{\circ}$.

- Arm and Hand Positions: Arms were crossed with left hand on the right os coxa and the right hand on the left os coxa.
- Leg Positions: Extended

\section{Cultural Characteristics:}

- Clothing: 2 metal buttons, cuprous metal straight pin, 3 metal eyelets, bow tie, and fragments of black cloth.

- Personal Goods: 2 bone cuff studs.

- Other: A nail was driven postmortem through the side of the casket and into the left humeral head.

\section{Osteological Characteristics:}

\section{Preservation}

- Taphonomy: The bone was fragile, but remains under the viewing window had not suffered the deterioration seen in other burials. Evidently the loose dry soil in this burial limited the amount of condensation that developed under the glass of the viewing window.

- Inventory: Complete skeleton.

Pathology

- Degenerative: One left rib had lipping at the vertebral facet. One cervical vertebra had lipping on the superior articular facets on the left side. The axis showed lipping on the inferior articular facet of the right side. All five lumbars had osteophytes projecting from the anterior centrum.

- Traumatic: None

- Infectious: None

- Neoplasm: None

- Metabolic and Hematological: None

- Dental: Eight maxillary teeth were recovered; six were lost postmortem. All teeth had moderate calculus deposits, and the left canine had caries. Nine mandibular teeth were recovered; five were lost antemortem, and two were lost postmortem. Most of these teeth had moderate calculus deposits. Caries were identified on both canines. Interproximal grooving was noted on the mesial surface of the left third premolar.

- Other: The medial and distal phalanges of one of the fifth toes had fused together.

\section{Burial 33}

Name: Stephen L. Stanley

Date of Death: November 21, 1907 Age at Death: 66 years

Personal History: Born in Texas in 1841. 
Residence listed as Angelina County, and occupation listed as farmer. Served in Company D, 7th Texas Cavalry, Green's Brigade, Texas Division. First admitted to the Confederate Home on November 6, 1897. Discharged on June 30, 1902. Readmitted on October 22, 1902. Records fail to note a discharge after this date but document a readmittance to the Confederate Home on June 9, 1907 , with disability listed as an ulcer of the leg. His pension record notes, "Sore leg rupture and wounds received in war, badly wounded by bomb shell in hip and thigh. A bad chronic sore on leg suffered with for 30 years." Cause of death listed as blood poisoning.

Sources of Historical Information: Headstone, General Services Commission records, Confederate Home records, Pension (\#09916), index cards of Compiled Service Records.

Headstone Type: $\quad 1$

Headstone Inscription:

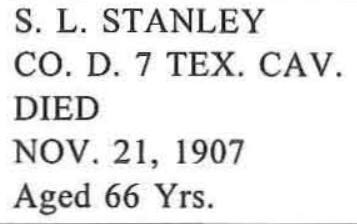

S. L. STANLEY

CO. D. 7 TEX. CAV.

DIED

NOV. 21, 1907

Aged 66 Yrs.

\section{Mortuary Characteristics:}

- Casket Description: Deteriorated wooden casket with a straight-topped, oval-shaped viewing window $(50 \times 32 \mathrm{~cm})$ inside an outer box (stain measures $196 \times 60 \mathrm{~cm}$ ).

- Casket Orientation: $285^{\circ}$

- Casket Hardware: Four Type 2 handles, 4 sets of Type 4 thumbscrews with Type 2 escutcheons, 2 sets of Type 2 thumbscrews with Type 3 escutcheons, Type 5 latch found on the upper left side of the viewing window, ornamental cuprous tack head found on top of casket floor in Zone D or E, 3 corrugated wood fasteners, and 49 corroded nails.

- Body Orientation and Position: Extended supine, facing east; vertebral column $280^{\circ}$.

- Arm and Hand Positions: Arms crossed with hand elements intermixed on the pelvis.

- Leg Positions: Extended

\section{Cultural Characteristics:}

- Clothing: Small four-hole shell button found on top of the first lumbar vertebrae. Two cloth-covered iron buttons found in Zone C. Black fabric bow tie found on top of cervical vertebrae.

- Personal Goods: 2 bone cuff studs.

\section{Osteological Characteristics:}

Preservation

- Taphonomy: Preservation was poor. The skeleton appeared to have shifted against the north wall of the casket. Proximal ends of the left ulna and radius protruded outside the casket stain. Hand elements were intermixed on top of the pelvis, and the lower legs had shifted against each other. Feet elements had drifted.

- Inventory: Complete but fragmented skeleton. Pathology

- Degenerative: Two thoracic vertebrae were fused together on the right side. The area of fusion arose from the center of each centra rather than from the top or bottom. All lumbar vertebrae had porosity and osteophytes on the centra. L1 had a Schmorl's node on the superior surface. Lipping occurred around the surface of the left patella.

- Traumatic: Traumatic injury to the right leg (see next section).

- Infectious: The palate had sclerotic roughening. The right femur had a pulled muscle at the linea aspera that at one time was infected. Severe osteomyelitis affected the right tibia and fibula. The distal end of the right tibia had eight active cloacae; these were also present on the fibula. Florid bone deposits were noted along the entire shafts of both the tibia and fibulae. In some areas, the two bones were fused together. Bone deposition was both active and healed, suggesting that the infection was a chronic condition. The right medial cuneiform was fused to the right first metatarsal. All metatarsals and tarsals of the right foot had sclerotic bone deposition, especially on the superior surfaces.

- Neoplasm: None

- Metabolic and Hematological: Frontals, parietals, and occipital exhibited cranial thickening caused by expansion of the diploë. 
- Dental: Seven maxillary teeth were recovered; eight teeth were lost antemortem. All teeth were very worn and had mild to severe calculus deposits. The right first molar and the left third premolar had caries, and the right third premolar and the left central incisor had apical abscesses. The right central incisor had extreme lingual wear, while the right third premolar had unusual distal wear. Five mandibular teeth were recovered; nine were lost antemortem, and two were lost postmortem. Calculus deposits were moderate and none had caries. The crown of the left fourth premolar appeared to have been broken antemortem.

- Other: Gallstone recovered from right pelvic area. The fifth lumbar vertebra was fused to the sacrum.

\section{Burial 34}

Name: Louis Robert Moody

Date of Death: November 18, 1907 Age at Death: 77 years

Personal History: Born in 1830. Served with Company F, 1st South Carolina Volunteers. Resided in Austin and worked as a merchant. His disabilities were listed as exposure and old age. $\mathrm{He}$ was shot through the jaw during the war and was captured. Mr. Moody never lived in the Confederate Home.

Sources of Historical Information: Headstone, Pension (\#03930).

Headstone Type: 1

Headstone Inscription:

L. R. MOODY

DIED

NOV. 18, 1907.

Mortuary Characteristics:

- Casket Description: Wooden casket that was larger than the others $(210 \times 70 \mathrm{~cm})$; casket ornaments were made of brass instead of white metal.

- Casket Orientation: $280^{\circ}$

- Casket Hardware: 6 Type 2 handles, large brass caplifter (51 mm), brass "At Rest" plaque $(17 \times 9 \mathrm{~cm}), 3$ Type 2 latches.

- Body Orientation and Position: Extended supine, facing east; vertebral column $280^{\circ}$.

- Arm and Hand Positions: Left arm crossed with hand resting on right os coxa; right arm extended.

- Leg Positions: Extended

Cultural Characteristics:

- Clothing: None

- Personal Goods: Brass calla lily decoration attached to casket lid at midline of Zones D and $\mathrm{E}$, bone collar stud, 2 bone cuff studs.

\section{Osteological Characteristics:}

Preservation

- Taphonomy: The skeleton was well articulated, but the bone was in very poor condition due to extensive root action.

- Inventory: Complete, but fragmented, skeleton.

Pathology

- Degenerative: The right temporomandibular joint had porosity. Minor lipping was apparent on the distal right humerus and on the proximal ends of both ulnae. Moderate lipping and porosity were observed on the centra of four cervical vertebrae. Thoracic vertebrae 8-12 were fused together at the centra, as were the first two lumbar. An additional lumbar had moderate to severe centrum lipping. Schmorl's nodes were identified on the inferior surface of $\mathrm{T} 5$ and the inferior and superior surfaces of $\mathrm{T} 6$ and $\mathrm{T} 7$, as well as the superior surface of $\mathrm{T} 8$.

- Traumatic: One left rib fragment had a wellhealed, slightly unaligned fracture.

- Infectious: Two patches of new bone formation were present endocranially on the frontal. One area measured $39 \times 22 \mathrm{~mm}$, and the other measured $8 \times 5 \mathrm{~mm}$. Both areas were surrounded by an irregular, but smooth-floored, ivorylike depression that was circumvented by small ridges of new bone. The floor of the left maxillary sinus chamber had a patch of healed periosteal reaction.

- Neoplasm: None

- Metabolic and Hematological: None

- Dental: Thirteen maxillary teeth were recov- 
ered; the remaining three teeth were lost antemortem. Wear was severe, but calculus deposits were light. Caries were noted on the right first molar and the left canine and third premolar. The right second molar was rotated so that it was oriented mesiodistally rather than bucco-labially. Thirteen mandibular teeth were recovered; the rest were lost prior to death. All teeth were severely worn, but only three had calculus deposits. The right third molar was oriented such that it faced mesiolingually. The second right molar was worn down to two separate roots, one of which had an antemortem chip in it.

- Other: None

\section{Burial 35}

Name: Henry A. Bowdoin

Date of Death: November 12, 1907

Age at Death: 75 years

Personal History: Born in Georgia in 1832. Served in Company D, 45th Georgia Infantry, Thomas' Brigade, A. P. Hill's Division. Came to Texas in 1892 and resided in Houston County. Occupation listed as farmer. Admitted to the Confederate Home on July 6, 1896, and discharged at his request on September 29, 1903. Readmitted to the Confederate Home on October 1, 1904. Disability listed as wound to arm and hand. Cause of death listed as stomach ulceration.

Sources of Historical Information: Headstone, General Services Commission records, Confederate Home records, index cards of Compiled Service Records.

\section{Headstone Type: 1}

Headstone Inscription:

$$
\begin{aligned}
& \text { H. A. BOWDOIN } \\
& \text { Co. D 45, Ga. Inf. } \\
& \text { DIED } \\
& \text { NOV. 12, } 1907 \\
& \text { Aged } 75 \text { Yrs. }
\end{aligned}
$$

\section{Mortuary Characteristics: \\ - Casket Description: Highly deteriorated}

wooden casket $(203 \times 55 \mathrm{~cm})$. Outer box indeterminate.

- Casket Orientation: $282^{\circ}$

- Casket Hardware: 4 Type 5 handles, Type 1 latch, 2 Type 2 latches, 2 Type 3 latches, 2 Type 4 latches found in Zone D, 11 corroded thin ferrous strips recovered throughout casket, 79 highly corroded wire nails.

- Body Orientation and Position: Extended supine, facing east; vertebral column $287^{\circ}$.

- Arm and Hand Positions: Right arm crossed with hand on top of left os coxa; left arm extended.

- Leg Positions: Extended

\section{Cultural Characteristics:}

- Clothing: Four-hole milk glass button found underneath right wrist, on top of left os coxa, cloth-covered iron button found to the left of the vertebral column, black fabric bow tie found on upper thoracic vertebrae.

- Personal Goods: 2 bone cuff studs.

\section{Osteological Characteristics:}

Preservation

- Taphonomy: Preservation was good to fair. The cranium was highly fragmented with collapsing of the facial elements. Drifting was observed in clavicles and patellae. Feet elements, particularly those of the right foot, were distributed around the lower end of the casket.

- Inventory: Complete skeleton

Pathology

- Degenerative: The bone of the left temporomandibular joint was very thin and porous. The right temporomandibular joint was not available for examination; however, the right mandibular condyle showed atrophy of the medial side. Eburnation covered one-third of the right humeral head and the associated glenoid cavity of the humerus. Arthritic lipping was present on the acromial end of the right clavicle. Moderate to severe lipping of the proximal and distal ends of the left first and second metacarpals and associated proximal and distal phalanges was observed. The proximal end of the left first metacarpal was eburnated. The left trapezium was eburnated in a localized area that corresponded to ebur- 
nation on the first metacarpal. The left lunate was severely deformed by new bone deposition, but it is unclear whether this resulted from arthritis or infection. Arthritic lipping and porosity were present on the centra of $\mathrm{C} 3$ through C7. Moderate to severe lipping was observed on the superior surface of the T2 centrum; a large osteophyte projected inferiorly. A Schmorl's node was present on the superior surface of T7. Lumbars 1 and 2 had severe (nearly bridging) osteophytes on the left side only. Bone spurs were present on the proximal surfaces of both tibiae.

- Traumatic: Two left rib fragments had healed greenstick fractures. The proximal end of the right radius and ulna were fused together, and they were fused to the distal humerus. Two proximal hand phalanges were missing their distal articular surfaces and tapered to an end. Small sclerotic bone lesions were noted on these tapered ends. The arthritic involvement described above for the hands, and the tapered proximal phalanges, may have resulted from the injury to arm and hand referred to in Confederate Home records. It should also be noted that, although recovery of hand elements was very complete, the third and fourth fingers of the left hand were not recovered. It is possible that these fingers were lost in an injury, and the only evidence that remains are the tapered distal ends of the remaining proximal phalanges.

- Infectious: Both temporals exhibited thinning and erosion of the petrosal portion, possibly resulting from an ear infection. The condition was more severe in the right ear than the left. The sternum had periosteal deposits (healed) on both the inner and outer surfaces, near costal notches 2 and 3 . Sclerotic bone deposits appeared around the edge of the right humeral head. A sclerotic lesion also was present on the inferior aspect of the right coracoid process.

- Neoplasm: None

- Metabolic and Hematological: Both orbits of the frontal bone exhibited healed cribra orbitalia.

- Dental: All maxillary teeth were lost antemortem. All mandibular teeth also were lost antemortem with the exception of the canines. Both of these teeth had severe calculus depos- its, and the left one had a large caries that perforated the root. An apical abscess also was associated with this tooth.

- Other: Cleft lip was noted on the left maxilla extending from the central incisor to canine area.

Burial 36

Name: John H. Walker

Date of Death: November 11, 1907

Age at Death: 60 years

Personal History: Born in North Carolina in 1847. Served as a corporal in Company E, 11th North Carolina Infantry, Petegrew's Brigade, Heth's Division, Army of Northern Virginia. Came to Texas in 1869 and resided in Eagle Pass. Occupation listed as ranchman. Admitted to the Confederate Home on June 1, 1907, with a disability listed as skull fracture. Causes of death listed as prostatitis and uremia.

Sources of Historical Information: Headstone, General Services Commission records, Confederate Home records, index cards of Compiled Service Records.

Headstone Type: $\quad 1$

\section{Headstone Inscription:}

$$
\begin{aligned}
& \text { J. H. WALKER } \\
& \text { Co E. } 11 \text { N.C. Inf. } \\
& \text { DIED } \\
& \text { NOV. } 11,1907 \\
& \text { Aged } 60 \text { Yrs. }
\end{aligned}
$$

\section{Mortuary Characteristics:}

- Casket Description: Wooden casket inside an outer box $(199 \times 62 \mathrm{~cm})$.

- Casket Orientation: $280^{\circ}$

- Casket Hardware: 4 Type 5 handles, Type 1 latch, 2 Type 2 latches, 2 Type 3 latches, 11 corroded thin ferrous metal strips, 93 highly corroded wire nails.

- Body Orientation and Position: Extended supine, facing east; vertebral column $283^{\circ}$.

- Arm and Hand Positions: Arms crossed with hands on the pelvis. 
- Leg Positions: Extended

Cultural Characteristics:

- Clothing: Cloth-covered iron button on lumbar vertebrae, black fabric bow tie found to the right of the vertebral column.

- Personal Goods: 2 bone cuff studs.

\section{Osteological Characteristics:}

Preservation

- Taphonomy: Preservation was good to excellent, although the cranium was fragmented. Drifting of hand and feet elements had occurred.

- Inventory: Complete skeleton with fragmented skull.

Pathology

- Degenerative: Both temporomandibular joints had slight areas of roughening. Both glenoid cavities of the scapulae had minor lipping. One left and one right rib had a bone spur at the vertebral portion of the shaft. All cervical vertebrae had porosity and lipping of the centra. Also, the dens exhibited extreme arthritic bone deposition. Thoracics 9-11 had small Schmorl's nodes on the inferior and superior surfaces of the centra. Thoracic 12 was fused to L1, which was fused to L2 by a bony bridge spanning the anterior surface of the centra. In addition, the articular facets were fused together. The bodies of T12 and L1 were wedged anteriorly, resulting in kyphosis of the spine. The intervertebral disk of these vertebrae had ossified. Lumbars 3-5 had large osteophytes. The acetabuli had minor lipping, as did both patellae. Lipping was noted on the distal end of a left metatarsal as well as on the proximal articular facets of five foot phalanges.

- Traumatic: The right first rib was dislocated. The Confederate Home records note that he had a fractured skull, but no sign of this was noted osteologically, perhaps due to the fragmentation of the skull. It is also possible that the blow occurred to the posterior right side of the mandible, explaining why all of those teeth were lost antemortem.

- Infectious: None

- Neoplasm: None

- Metabolic and Hematological: None

- Dental: Eleven maxillary teeth were recov- ered; four were lost antemortem. Calculus deposits varied from nonexistent to moderate. No teeth had caries, but one (the right fourth premolar) had an abscess that appeared to have resulted from extreme dental wear. All mandibular teeth were recovered with the exception of the right third premolar through the right third molar, which were lost before death. The expression of calculus was similar to that seen on maxillary teeth, but three teeth had caries (left first and second molars, right canine) and none had abscesses.

- Other: Eight proximal hand phalanges had very large flexor tendon attachments. The right ulna had an enthesophyte at the proximal end.

\section{Burial 37}

Name: Daniel P. Brown

Date of Death: November 7, 1907

Age at Death: 75 years

Personal History: Born in Georgia in 1832, served in Company A, 6th Alabama, Longstreet's Division, Army of Northern Virginia. Came to Texas in 1870 and lived in Newton County where he worked as a farmer. Admitted to the Confederate Home on February 8, 1904, with a disability listed as palsy. Cause of death listed as paralysis agitans.

Sources of Historical Information: Headstone, General Services Commission records, Confederate Home records.

Headstone Type: 1

Headstone Inscription:
D. P. BROWN
Co. A. 6. Ala.
DIED
NOV. 7. 1907
Aged 75 Yrs.

Mortuary Characteristics:

- Casket Description: Very poorly preserved wooden casket $(185 \times 63 \mathrm{~cm})$.

- Casket Orientation: $280^{\circ}$ 
- Casket Hardware: 4 Type 2 handles, 3 Type 2 latches, 19 nails, 1 corrugated fastener.

- Body Orientation and Position: Extended supine, facing east; vertebral column $275^{\circ}$.

- Arm and Hand Positions: Left arm crossed with hand on right os coxa. Right arm extended.

- Leg Positions: Extended

\section{Cultural Characteristics:}

- Clothing: None

- Personal Goods: 2 bone cuff studs.

\section{Osteological Characteristics:}

Preservation

- Taphonomy: Burial had suffered from extensive bioturbation; the thoracic area exhibited extensive displacement as did the legs, with the right fibula disarticulated and the left patella displaced to the area of the right hand. Most bones exhibited root etching.

- Inventory: Highly fragmented skeleton, complete except for lumbar vertebrae and small facial bones.

\section{Pathology}

- Degenerative: Porosity was observed at the sternal end of the right clavicle. The right radius had lipping at the distal end. One right rib had lipping around a vertebral facet. All cervical centra had porosity and slight lipping, as did the only five observable thoracic vertebrae.

- Traumatic: The left first metacarpal had a well-healed fracture at midshaft that resulted in the bone bowing superiorly. One rib shaft had a healed, complete fracture.

- Infectious: The left maxillary sinus chamber had sclerotic lesions suggestive of healed sinusitis. The dorsal surfaces of all hand proximal phalanges and one medial phalanx had small ivorylike sclerotic bone deposits that were deposited in an irregular fashion.

- Neoplasm: None

- Metabolic and Hematological: None

- Dental: Only seven maxillary teeth were recovered. None had calculus, but caries were noted on the right third molar and on the right lateral incisor. In addition, two linear enamel hypoplasias were observed on the right canine. Six mandibular teeth were recovered; seven had been lost antemortem and two were lost postmortem. Five of the six remaining teeth had caries: the left canine and lateral incisor, as well as the right lateral incisor, right canine, and right third premolar. All had moderate calculus deposits.

- Other: The left radius had an enthesophyte at midshaft.

\section{Burial 38}

Name: J. H. Morgan

Date of Death: November 5, 1907 Age at Death: 79 years

Personal History: Born in Virginia in 1828, moved to Texas in 1848, lived in Waco and worked as a farmer. Served in Pyron's Company of the 1st Texas Regiment, Green's Brigade, Walker's Division. Admitted to the Confederate Home on May 14, 1902; disability listed as old age. Cause of death listed as chronic malaria.

Sources of Historical Information: Headstone, General Services Commission records, Confederate Home records.

Headstone Type: 1

\section{Headstone Inscription:}

J. H. MORGAN
Pyron's 1. Tex
DIED
NOV 5, 1907
Aged 79 Yrs.

Mortuary Characteristics:

- Casket Description: Badly deteriorated wooden casket; casket lid and lower half of casket were completely gone (dimensions indeterminate).

- Casket Orientation: $280^{\circ}$

- Casket Hardware: 4 Type 2 handles, 3 Type 2 latches, 3 corrugated fasteners.

- Body Orientation and Position: Extended supine, facing east; vertebral column $275^{\circ}$.

- Arm and Hand Positions: Both arms crossed with hands crossed over the pelvic region.

- Leg Positions: Extended

\section{Cultural Characteristics:}

- Clothing: None 
- Personal Goods: 2 bone cuff studs.

\section{Osteological Characteristics: \\ Preservation}

- Taphonomy: Extensive root activity was noted throughout the burial, with especially negative effects on the skull.

- Inventory: Complete skeleton with a fragmented skull.

\section{Pathology}

- Degenerative: Arthritic pitting and lipping were noted on both humeral heads, as well as on the left distal humerus at the capitular surface. Lipping also was noted on the distal ends of both radii and the proximal ends of both ulnae. Minor arthritic lipping was noted on the distal end of the right second and third metacarpals as well as at the proximal ends of eight phalanges. Roughened bone deposits were noted on the dens of the axis. Minor to moderate lipping, more severe on the left side, was noted on the articular facets of two cervical vertebrae. Single Schmorl's nodes were observed on the inferior surface of the first thoracic centrum and on the superior surface of an undetermined thoracic vertebra. Two Schmorl's nodes were present on the superior surface of the first lumbar centra. Both patellae exhibited small areas of arthritic lipping and pitting. Both tibiae had bone spurs at the proximal ends. Minor arthritic lipping was noted on the following bones of the right foot: calcaneus, navicular, medial and intermediate cuneiforms. The same elements of the left foot had lipping, in addition to the cuboid.

- Traumatic: Both nasal bones were fractured approximately $1 \mathrm{~cm}$ from the superior suture line. One set of proximal and medial phalanges were fused together at a slight curve, possibly due to an old fracture. The right clavicle had a healed greenstick fracture that resulted in anterior-posterior flattening of the shaft. The left clavicle had a well-healed, unaligned fracture that resulted in the left clavicle being much shorter than the right one. Four ribs had aligned, well-healed complete fractures.

- Infectious: The right and left maxillary sinuses had sclerotic bone deposits, suggestive of sinusitis, in large and small patches on the floors and walls of the chambers. Three ribs had patches of healed periostitis on the pleural surfaces.

- Neoplasm: None

- Metabolic and Hematological: None

- Dental: All maxillary teeth were lost antemortem. All mandibular teeth were lost antemortem except for the right canine, third premolar, and second molar. Of these, the right second molar exhibited a caries.

- Other: The right fibula had a small enthesophyte that projected posteriorly, just above the distal articular facet.

Burial 39

Name: Amos D. Starnes

Date of Death: October 29, 1907

Age at Death: 71 years

Personal History: Born in Alabama in 1836. Served in Company G (or A), 1st Alabama Infantry (or Cavalry), Luarle's Brigade, Army of Tennessee. Came to Texas in 1902 and resided in Prairie Hill; occupation listed as printer. Admitted to the Confederate Home on October 12, 1907, with a disability of paralysis. Cause of death also is listed as paralysis.

Sources of Historical Information: Headstone, General Services Commission records, Confederate Home records, index cards of Compiled Service Records.

Headstone Type: 1

Headstone Inscription:
A. D. STARNES
Co. G. 1. Ala. Inf. DIED
OCT. 29, 1907
Aged 71 Yrs.

\section{Mortuary Characteristics:}

- Casket Description: Wooden casket with a canted-oval viewing window $(54 \times 36 \times 0.25 \mathrm{~cm})$ inside an outer box $(223 \times 68 \mathrm{~cm})$.

- Casket Orientation: $280^{\circ}$

- Casket Hardware: 4 Type 2 handles, 4 sets of Type 3 thumbscrews with Type 2 escutcheons, 
2 sets of Type 5 thumbscrews with Type 3 escutcheons, thin cuprous diamond-shaped ornament, several remnants of other thin cuprous metal ornaments, 57 highly corroded wire nails.

- Body Orientation and Position: Extended supine, facing east; vertebral column $280^{\circ}$.

- Arm and Hand Positions: Right arm crossed with hand on top of abdominal area. Left arm extended.

- Leg Positions: Extended

\section{Cultural Characteristics:}

- Clothing: 3 cloth-covered iron buttons found just to the right of the vertebral column. Black fabric bow tie found on top upper thoracic vertebrae.

- Personal Goods: 2 bone cuff studs. .

\section{Osteological Characteristics:}

\section{Preservation}

- Taphonomy: Preservation was good with slight disarticulation. Elements of the right hand were scattered. The distal end of the left femur shifted medially and the right leg rotated laterally $90^{\circ}$. Feet elements were scattered in the lower portion of the casket. A small rodent skeleton found in the casket fill on top of the pelvis obviously was intrusive and accounts for some of the disturbance.

- Inventory: Complete skeleton with fragmented skull missing small facial bones.

\section{Pathology}

- Degenerative: The left mandibular condyle was atrophied, but the left temporomandibular surface was unobservable. Moderate lipping was noted on the glenoid cavities of both scapulae, but it was worse on the right side. Both humeral heads had moderate lipping and porosity. The acromial end of the left clavicle exhibited arthritic porosity. Moderate lipping was observed at the articular facets of all carpals. All right metacarpals exhibited lipping at both the proximal and distal ends. Nine distal hand phalanges had severe arthritic lipping and porosity. In total, 17 hand phalanges were lipped and 3 were eburnated. Moderate to severe lipping and porosity were noted on the centra and articular facets of the third through seventh cervical vertebrae. Lipping was noted on the dens articulation of the first two cervical vertebrae. Two Schmorl's nodes were identified on the inferior aspect of the centrum of the first thoracic vertebra; one was noted on the superior aspect. Two additional Schmorl's nodes were noted on an indeterminate thoracic vertebra. Thoracic vertebra 12 had a small osteophyte that projected superiorly. All lumbar vertebrae had very slight lipping of the centra. Minor lipping and porosity were noted on the medial facet of the right patella, as well as on the distal ends of both femora. All metatarsals had lipping at the distal ends. Three distal foot phalanges, two medial phalanges, and one proximal phalanx had eburnated articular surfaces. One sesamoid of the foot was eburnated.

- Traumatic: The left eye rim had a healed fracture extending from the frontotemporal line to the supraorbital notch. The blow to the head may have resulted in the wasting of the left mandibular condyle (described above).

- Infectious: The left temporal had erosive lesions on the petrosal, possibly indicative of an ear infection; the right temporal was unobservable. The left first rib had osteitis at the sternal end. Sclerotic lesions were noted on the dorsal surfaces of seven hand phalanges.

- Neoplasm: None

- Metabolic and Hematological: None

- Dental: Eight maxillary teeth were recovered; four were lost antemortem. Half of the observable maxillary teeth had caries, but none had abscesses or enamel hypoplasias. Only one (right third molar) had severe calculus deposits. Eleven mandibular teeth were recovered; the remaining five teeth were lost antemortem. Five of the lower teeth had caries, and one (left third premolar) had a cervical abscess. In general, calculus deposits were moderate to severe.

- Other: The right radial tuberosity had an enthesophyte. An ossified tendon projected inferiorly from the anterior surface of the right patella.

\section{Burial 40}

Name: D. R. Jacks

Date of Death: October 23, 1907

Age at Death: 67 years 
Personal History: Born in Georgia in 1840, moved to Texas in 1857. Lived in San Antonio and worked as a clerk. Served as ordnance sergeant for Company F (or D) of Waul's Texas Legion. Admitted to the Confederate Home on July 7, 1903 , with a disability listed as rheumatism.

Sources of Historical Information: Headstone, General Services Commission records, Confederate Home records, Pension (\#09024).

Headstone Type: 1

Headstone Inscription:
D. R. Jacks
Ord. Sgt. Waul's Leg.
DIED
OCT. 23. 1907
Aged 67 Yrs.

Mortuary Characteristics:

- Casket Description: Badly deteriorated wooden casket (193 x $63 \mathrm{~cm})$.

- Casket Orientation: $280^{\circ}$

- Casket Hardware: 4 Type 2 handles, 4 Type 3 thumbscrews with Type 2 escutcheons, 3 oval tin tack heads, 1 diamond tin tack, 1 bellshaped tack, 5 nails.

- Body Orientation and Position: Extended supine, facing east; vertebral column $273^{\circ}$.

- Arm and Hand Positions: Left crossed with hand resting on left os coxa. Right arm extended.

- Leg Positions: Extended

\section{Cultural Characteristics:}

- Clothing: 3 four-hole shell buttons.

- Personal Goods: 2 bone cuff studs.

- Other: A nail had been driven through the casket's side wall and into the distal end of the left tibia (postmortem).

\section{Osteological Characteristics:}

Preservation

- Taphonomy: Thoracic area was highly fragmented and the right radius was disarticulated.

- Inventory: Complete skeleton with fragmented skull missing small facial elements.

Pathology

- Degenerative: Both temporomandibular joints exhibited slight lipping and porosity on the articular surface (mandibular condyles were not present for examination). All recovered medial and distal hand phalanges exhibited arthritic lipping at the proximal facets.

- Traumatic: The dorsal surface of the left second metacarpal had a small piece of metal embedded in it antemortem. While there was bone growth around it, the new bone deposition was not extensive. The left shoulder may have been dislocated, as evidenced by abnormalities at the sternal end and the costoclavicular area of the left clavicle.

- Infectious: The petrosal portion of the left temporal had porous lesions that may have resulted from an ear infection. The petrosal of the right temporal had a milder expression. Sclerotic roughening was observed on the palate. The pleural surfaces of all ribs had healed, plaquelike periosteal depositions.

- Neoplasm: None

- Metabolic and Hematological: None

- Dental: Only one maxillary tooth (left lateral incisor) could be examined; six were lost antemortem and four were lost postmortem. The left lateral incisor was heavily worn and had a large apical abscess; however, no calculus deposits or caries were observed. Only one mandibular tooth (left fourth premolar) could be examined; 10 teeth were lost antemortem, and 4 teeth were lost postmortem. The fourth premolar had very little wear and only mild calculus deposits; however, one linear enamel hypoplasia was noted, and the single tooth had three discrete caries.

- Other: None

\section{Burial 41}

Name: William Shry

Date of Death: October 26, 1907 Age at Death: 82 years

Personal History: Born in Virginia in 1825, came to Texas in 1860 and resided in Montaque County as a farmer. Served as lieutenant in Company E, 8th Texas Infantry. Admitted to the Confederate Home on January 1, 1906, with a disability listed as old age.

Sources of Historical Information: Headstone, 
General Services Commission records, Confederate Home records, index cards of Compiled Service Records.

Headstone Type: 1

Headstone Inscription:

$$
\begin{aligned}
& \text { Lieut. Wm. Shry } \\
& \text { 8, Tex. Inf } \\
& \text { DIED } \\
& \text { OCT. } 26,1907
\end{aligned}
$$

Mortuary Characteristics:

- Casket Description: Badly deteriorated wooden casket (dimensions indeterminate).

- Casket Orientation: $280^{\circ}$

- Casket Hardware: 4 Type 6 handles, 5 corrugated fasteners, 2 diamond-shaped tacks.

- Body Orientation and Position: Extended supine, facing east; vertebral column $280^{\circ}$.

- Arm and Hand Positions: Left arm was extended. Right arm was crossed with hand on left os coxa.

- Leg Positions: Extended

\section{Cultural Characteristics:}

- Clothing: None

- Personal Goods: 2 bone cuff studs, large white-metal Mason's emblem attached to casket lid in Zone D.

\section{Osteological Characteristics:}

\section{Preservation}

- Taphonomy: Poorly preserved skeletal remains. Bone was damaged from root action, both femora had rotated $90^{\circ}$, but the tibiae were in their proper position. The skull, left tibia, and left fibula were badly fragmented.

- Inventory: The skull was badly fragmented and many elements were absent. Many ribs and vertebrae also were not recovered. Most other bones were highly fragmented.

Pathology

- Degenerative: Both temporomandibular joints had extreme lipping on the articular surface, and both mandibular condyles were wasted. Both lunates had minor arthritic lipping. The four recovered medial phalanges had lipping at both facets. Two distal hand phalanges had lipping at the proximal end. One of the three cervical vertebrae available for observation had lipping and porosity of the centra, while two just had lipping. The fovea for the dens on the atlas had extreme lipping around the articular surface. Eight of the 10 observable thoracic vertebrae had slight osteophytic development at the inferior borders of the centra. Three of these also had Schmorl's nodes on the inferior and superior surfaces. All four available lumbar had osteophytes, and three had Schmorl's nodes on both surfaces. Both acetabuli had arthritic lipping, but it was more severe on the left side. The proximal phalange of one of the first toes had eburnation at the distal end.

- Traumatic: The right ulna had a healed, aligned fracture at the distal one-third of the midshaft, evidenced by a large bone callus. One set of proximal and medial hand phalanges demonstrated an "amputation" at the base of the medial phalanx. The small portion of the medial phalanx that remained had fused to the proximal phalanx.

- Infectious: The petrosal region of both temporals had porous lesions suggestive of an ear infection. Cranial pitting on a parietal fragment appeared more reminiscent of a healed infection than porotic hyperostosis.

- Neoplasm: None

- Metabolic and Hematological: None

- Dental: No maxillary teeth were recovered; due to fragmentation, it was impossible to determine whether loss was ante- or postmortem. All mandibular teeth were lost antemortem.

- Other: The left fifth metacarpal had a small bone spur at the proximal end near the articular surface. Three proximal hand phalanges had enlarged flexor tendon attachments.

\section{Burial 42}

Name: Albert G. Bird

Date of Death: October 23, 1907

Age at Death: 76 years

Personal History: Born in Pennsylvania in 1829. Served in Company B, 3rd Alabama Infantry. Came to Texas in 1868 and resided in Navasota as 
a carpenter. Admitted to the Confederate Home on June 20,1895, with a general disability. Cause of death listed as chronic gastritis. In the event of his death, Bird requested that the Confederate Home administrators notify the Philadelphia, Pennsylvania, papers in order to publish his obituary. Confederate Home records indicate that Bird was 77 or 78 years old at death.

Sources of Historical Information: Headstone, General Services Commission records, Confederate Home records, index cards of Compiled Service Records.

Headstone Type: 1

Headstone Inscription:
A. G. BIRD
CO. B. 3. Ala. Inf.
DIED
OCT. 23, 1907
Aged 76 Yrs.

Mortuary Characteristics:

- Casket Description: Wooden casket in an outer box $(217 \times 65 \mathrm{~cm})$.

- Casket Orientation: $285^{\circ}$

- Casket Hardware: 4 Type 2 handles, 4 sets of Type 3 thumbscrews with Type 2 escutcheons, 2 thin cuprous-metal bell-shaped casket ornaments found centered on top of casket ( 1 over the thoracic vertebrae and the other over the knees), 2 larger thin cuprous-metal casket ornaments, 52 corroded wire nails.

- Body Orientation and Position: Extended supine, facing east; vertebral column $285^{\circ}$.

- Arm and Hand Positions: Right arm extended. Left arm slightly flexed with hand on top of sacrum.

- Leg Positions: Extended

\section{Cultural Characteristics:}

- Clothing: 2 cuprous-metal buttons with a 5pointed star on face (one on top of left os coxa and the other along the lower right tibia), fourhole shell button found along vertebral column, cloth-covered iron button found on top a lower thoracic vertebrae.

- Personal Goods: 2 bone cuff studs.

\section{Osteological Characteristics: \\ Preservation}

- Taphonomy: Preservation was fair to poor due to extensive root activity. Cranium was highly fragmented, with the exception of the frontal bone. The upper vertebral column had shifted to the right. Right leg rotated $90^{\circ}$ laterally. Feet elements were intermixed.

- Inventory: The skull was fragmented with missing small facial elements. Fragmentation of the thoracic region made total recovery of the ribs impossible. Although the pelvic area was very fragmented, portions of each element were recoverable.

Pathology

- Degenerative: The distal ends of both humeri showed lipping and some small areas of new bone deposition on the posterior aspect of the right capitulum. Moderate lipping was observed on the proximal and distal surfaces of the radii, with bone spicules occurring on the superior surface of the left distal radius. Moderate lipping was noted at the proximal ends of both ulnae. Both first metacarpals had moderate lipping at the proximal and distal articular facets. In addition, the corresponding proximal and distal phalanges showed lipping. Lipping was observed on the distal end of right metacarpal 3. All evidence for arthritis in the arms was more severe on the left side than the right. Severe arthritic lipping was observed on three of the four recovered cervical centra, as well as on the articular facets. The centrum of $\mathrm{C} 7$ was badly malformed, and the dens of the axis had lipping. Five thoracic vertebrae had osteophytes; three centra had osteophytes on both the superior and inferior surfaces, one osteophyte only occurred on the inferior surface, and one occurred only on the superior surface. The remaining thoracic vertebrae showed moderate lipping of the centra. One thoracic vertebra had a Schmorl's node. Thoracic vertebra 12 and lumbar 1 were fused together by bridging osteophytes on both sides, as were two indeterminate thoracic vertebrae. Moderate lipping was noted on four lumbar vertebrae; two had small osteophytes on the inferior surface of the centrum. Minor lipping was observed on the right patella at the medial aspect of the articular surface. In 
addition, two small areas of new bone deposition were noted on the articular surface of the same bone. Lipping was observed at both tali on the superior articular facet, anterior aspect. Severe lipping, porosity, and new bone deposition were observed on the right and left first metatarsals at the distal ends, as well as on the sesamoids. Corresponding arthritic developments were noted in the associated proximal and distal phalanges. Together, these formed large bunions. Small bone spicules were observed on the distal articular surfaces of the left second and fourth metatarsals, as well as the right second metatarsal. Eburnation was observed on the distal ends of three medial phalanges of the foot.

- Traumatic: A possible healed greenstick fracture of a right rib was observed. The break was located approximately $5 \mathrm{~cm}$ from the vertebral facet. Evidence of a minor muscle pull was observed on the right patella at the superior-anterior surface.

- Infectious: Sclerotic deposits were observed on the dorsal surfaces of six proximal hand phalanges.

- Neoplasm: None

- Metabolic and Hematological: None

- Dental: Only two maxillary teeth were recovered; four were lost antemortem. The recovered teeth (the right third premolar and the right lateral incisor) had severe calculus deposits but no caries, hypoplasias, or abscesses.

- Other: An enthesophyte projected inferiorly from the superior-lateral aspect of the lateral epicondyle of the left humerus.

\section{Burial 43}

Name: C. C. Hagler

Date of Death: October 23, 1907

Age at Death: 73 years

Personal History: Born in Georgia in 1834. Served in Company I, 11th Georgia Infantry, T. Anderson's Brigade, Army of Northern Virginia. Came to Texas in 1878 and resided in Lone Oak, Hunt County, as a farmer. Admitted to the Confederate Home on January 10, 1907, with a general disability. Cause of death listed as cancer.

Sources of Historical Information: Headstone,
General Services Commission records, Confederate Home records, index cards of Compiled Service Records.

Headstone Type: 1

Headstone Inscription:
C. C. HAGLER
Co. I. 11 Geo. Inf.
DIED
OCT. 23. 1907
Aged 73 Yrs.

\section{Mortuary Characteristics:}

- Casket Description: Wooden casket in an outer box $(193 \times 65 . \mathrm{cm})$.

- Casket Orientation: $275^{\circ}$

- Casket Hardware: 4 Type 2 handles, 6 sets of Type 3 thumbscrews with Type 2 escutcheons, remnants of thin cuprous lining tacks, 51 corroded wire nails.

- Body Orientation and Position: Extended supine, facing east; vertebral column $280^{\circ}$.

- Arm and Hand Positions: Arms crossed, with right hand on top of left os coxa and the left hand on top of the right os coxa.

- Leg Positions: Extended

\section{Cultural Characteristics:}

- Clothing: None

- Personal Goods: The metal remnants of a coin purse latch with a 1900 U.S. Indian head penny found in Zone B.

\section{Osteological Characteristics:}

\section{Preservation}

- Taphonomy: Preservation was fair to poor with some disarticulation. The cranium was highly fragmented. Drifting of elements had occurred in the hands and feet regions, and the left patella had been displaced.

- Inventory: Nearly complete but highly fragmented skeleton. Small facial bones, some ribs, some vertebrae, and portions of the pelvis were not recovered.

\section{Pathology}

- Degenerative: Moderate to severe lipping was noted on the distal left humerus, especially in the region of the capitulum. Severe lipping 
with some bone deposition was observed on the inferio-medial aspect of the distal articular surface of the right ulna. Minor lipping was noted at the proximal and distal ends of the left ulna. An eburnated area was noted in the left radius at the superior-lateral aspect of the distal radius. The right radius had lipping at the proximal facet. All five recovered right carpals (scaphoid, lunate, hamate, pisiform, and trapezium) had severe lipping and pitting. The pisiform was malformed due to lipping and new bone deposition. The scaphoid and the lunate both had large eburnated areas. Moderate lipping was observed on the proximal facet of the right first metacarpal, as well as on the distal facets of three right medial phalanges and two right distal ones. The left hamate, scaphoid, trapezium, and trapezoid had moderate lipping. Eburnation was observed on the trapezium and the proximal end of the left first metacarpal, as well as the trapezoid and scaphoid. Lipping was observed on the left first distal hand phalange. All four recovered lumbar vertebrae had lipping of the articular facets. Arthritic pitting was observed on the proximal facet of both first proximal foot phalanges. Lipping, porosity, and new bone deposition were noted on the left calcaneus, talus, and navicular. The talus and navicular were also eburnated where they articulate.

- Traumatic: A large callus was observed at the midshaft of the right fifth metacarpal. The fracture was complete and well aligned.

- Infectious: None

- Neoplasm: None

- Metabolic and Hematological: None

- Dental: Five maxillary teeth were recovered; four were lost antemortem, and one was lost postmortem. Calculus deposits were mild to moderate. The right fourth premolar, right canine, and left lateral incisor had caries. No abscesses or hypoplasias were observed. Six mandibular teeth were observed; three teeth were lost antemortem. Calculus deposits varied from nonexistent to severe. The right central incisor and the right second molar had caries. In addition, a cervical abscess was noted on the right first molar. The right third premolar had an interproximal groove at the distal cervical margin.

- Other: A medial hand phalanx had ossification of a flexor tendon. The tendon ossified and attached to the phalanx. Enthesophytes were observed on the left femur above the medial condyle and at the superior aspect of the left patella.

\section{Burial 44}

Name: John T. Bowden

Date of Death: October 21, 1907

Age at Death: 63 years

Personal History: Born in Tennessee in 1844. Served in Company E, 12th Tennessee Infantry, P. Smith's Brigade, Army of Tennessee. Came to Texas in 1874 and resided in Rice, Navarro County. Occupation listed as farmer. First admitted to the Confederate Home on July 22, 1898, and discharged by order of the Medical Board on August 31, 1899. Readmitted to the Confederate Home on April 29, 1900. Records fail to note his next discharge, but he was readmitted to the Confederate Home on July 1, 1902. Discharged from the Confederate Home on October 31, 1904. A later Confederate Home roster entry documents "Re[illegible] as December 21, 1904 by Order of the Court." Discharged on March 29, 1905. There is no record of his reentering the Confederate Home after this date, but Mr. Bowden died there in 1907. Disabilities listed as wound near spine and hernia. Cause of death listed as uremia.

Sources of Historical Information: Headstone, General Services Commission records, Confederate Home records, index cards of Compiled Service Records.

Headstone Type: $\quad 1$

Headstone Inscription:
J. T. BOWDEN
Co. E. 12. Inf. Tenn. DIED
OCT. 21, 1907
Aged 63 Yrs.

\section{Mortuary Characteristics:}

- Casket Description: Highly deteriorated wooden casket (stain measured 204 x $59 \mathrm{~cm}$ ). 
Outer box indeterminate.

- Casket Orientation: $285^{\circ}$

- Casket Hardware: 6 Type 4 handles, 4 sets of Type 3 thumbscrews with Type 2 escutcheons, thin cuprous diamond-shaped tack head, fragmented remnants of other thin cuprous ornaments, 39 corroded wire nails.

- Body Orientation and Position: Extended supine, facing east; vertebral column $280^{\circ}$.

- Arm and Hand Positions: Extended

- Leg Positions: Extended

Cultural Characteristics:

- Clothing: None

- Personal Goods: Bone cuff stud; white-metal calla lily casket ornament found on top of long axis of casket lid between Zones D and E.

\section{Osteological Characteristics:}

Preservation

- Taphonomy: Preservation was fair to good. The skull was highly fragmented, and the left leg had rotated about $90^{\circ}$ laterally. Elements of the feet were intermixed.

- Inventory: Complete skeleton with fragmented skull missing small facial bones.

\section{Pathology}

- Degenerative: Both humeri had lipping at the proximal ends, and the right humerus had lipping at the distal end as well. The left radius was lipped at the distal end. Both ulnae had lipping at the proximal ends, while the left ulna had lipping at the distal end. Arthritic lipping was observed on the proximal facets of all distal hand phalanges and seven medial phalanges. Minor lipping was present at the dens and the fovea for the dens of the first two cervical vertebrae. Four of the thoracic vertebrae had Schmorl's nodes. All five lumbar vertebrae had very minor lipping at the articular facets. The right acetabulum had moderate lipping, as did the right femoral head. Both tali had lipping at the middle of the superior articular surface.

- Traumatic: None

- Infectious: Three hand phalanges had small sclerotic lesions on the dorsal surface.

- Neoplasm: None

- Metabolic and Hematological: None

- Dental: Ten maxillary teeth were examined; five teeth were lost antemortem. All teeth were heavily worn, and calculus deposits varied from none to severe. Only two teeth (right first molar and second left molar) had caries. Nine mandibular teeth were recovered; the rest were lost prior to death. Calculus was nonexistent to mild. Both central incisors and the right canine had caries, but no teeth had abscesses or enamel hypoplasias.

- Other: Enthesophyte at radial tuberosity of left radius and left patella. The right hamate was missing the hamulus, but the cause of this is unclear.

\section{Burial 45}

Name: Jubal Willis

Date of Death: October 20, 1907

Age at Death: 72 years

Personal History: Born in Missouri in 1835, served in Company H (F), 8th Missouri Infantry, Kirby Smith's Division. Came to Texas in 1862 and lived in Milford as a shoemaker. Admitted to the Confederate Home on June 26, 1902, with a disability listed as hemorrhoids. Cause of death listed as dengue.

Sources of Historical Information: Headstone, General Services Commission records, Confederate Home records.

Headstone Type: 1

Headstone Inscription:
JUBAL WILLIS
CO. F. 8 Mo. Inf.
DIED
OCT. 20, 1907
Aged 72 Yrs.

\section{Mortuary Characteristics:}

- Casket Description: No wood remained from the casket, but there was an oval-shaped viewing window $(55 \times 35 \mathrm{~cm})$.

- Casket Orientation: $280^{\circ}$

- Casket Hardware: 4 Type 6 handles, Type 3 thumbscrew with a Type 2 escutcheon, Type 5 thumbscrew with a Type 3 escutcheon, 16 nail fragments. 
- Body Orientation and Position: Extended supine, facing east; orientation of vertebral column unknown.

- Arm and Hand Positions: Left arm was extended with lower arm slightly bent with hand resting on upper femur. Right arm was extended.

- Leg Positions: Extended

\section{Cultural Characteristics:}

- Clothing: Four-hole copper button.

- Personal Goods: 2 bone cuff studs.

\section{Osteological Characteristics:}

\section{Preservation}

- Taphonomy: The skeletal remains were in very poor condition, and the cancellous bone was extremely eroded. The vertebral column and ribs were reduced to powder; remaining bone was exceedingly fragile, especially cranial elements. The severe nature of this deterioration went beyond what was observed for other burials with viewing windows.

- Inventory: Portions of all elements were present except for small facial bones. Ribs, vertebrae, and elements of the pelvis were so fragmented that they could not be observed for disorders.

\section{Pathology}

- Degenerative: Both scapulae had lipping around the glenoid cavities. The right trapezium had lipping, as did all of the recovered distal hand phalanges. Only two cervical vertebrae could be examined; of these, the dens and the fovea for the dens bore evidence of arthritic lipping. Both first metatarsals had slight lipping at the proximal facets.

- Traumatic: None

- Infectious: Sclerotic roughening of the palate.

- Neoplasm: None

- Metabolic and Hematological: None

- Dental: Twelve maxillary teeth were recovered; three were lost antemortem. Teeth with calculus had moderate deposits. Caries were observed on the right third premolar, right incisors, and left second and third molars. No abscesses or hypoplasias were observed. Eleven mandibular teeth were observed. The left second and third molars were carious. No evidence was seen of calculus, hypoplasias, or abscesses.
- Other: None

\section{Burial 46}

\author{
Name: Andrew M. Robinson \\ Date of Death: October 14, 1907 \\ Age at Death: 75 years
}

Personal History: Born in Texas in 1832; worked as a stockman and resided in Georgetown. Served in Company A, Bates' Battalion, 13th Texas Volunteers. Admitted to the Confederate Home on April 3, 1907, with a disability listed as blindness. On the pension medical examination he stated that he was "crippled in my back," while the physician stated that he was mentally deranged. Cause of death listed as autointoxication.

Sources of Historical In formation: Headstone, General Services Commission records, Confederate Home records, Pension (\#04921).

Headstone Type: 1

Headstone Inscription:
A. M. ROBINSON
Co. A. Bates. Inf.
DIED
OCT. 14,1907
Aged 75 Yrs.

\section{Mortuary Characteristics:}

- Casket Description: Wood from casket (195 x $70 \mathrm{~cm}$ ) had deteriorated; grave shaft dug into the caliche rock $(216 \times 73 \mathrm{~cm})$ was well defined.

- Casket Orientation: $276^{\circ}$

- Casket Hardware: 4 Type 6 handles, 2 Type 2 latches (one each from Zones B and C), 2 Type 3 latches (one each from Zones D and E), Type 4 latch from Zone C, 12 nails.

- Body Orientation and Position: Extended supine, facing east; vertebral column $280^{\circ}$.

- Arm and Hand Positions: Extended with hands slightly bent toward os coxae.

- Leg Positions: Extended

\section{Cultural Characteristics:}

- Clothing: 1 metal button. 
- Personal Goods: 2 bone cuff studs.

Nonassociated Artifacts: A glass flask with "FULL 1/2 PINT" on bottom, broken just above the shoulders, was found in the grave shaft fill above the casket.

\section{Osteological Characteristics:}

\section{Preservation}

- Taphonomy: The skeletal remains were well articulated, but the bone was fragile and some root etching was observed.

- Inventory: Complete skeleton with fragmented pelvis.

\section{Pathology}

- Degenerative: Severe lipping was observed on both glenoid cavities. Porosity was observed on the sternal ends of both clavicles. The left humerus had lipping on the proximal end, and the left radius had lipping at the distal end. Both ulnae had lipping and porosity at the distal ends. The right scaphoid and capitate had lipping. The left lunate was lipped and porous; the left trapezium just had lipping. The proximal end of the right first metacarpal had lipping, as did the distal end. Both first proximal phalanges had lipping at the proximal facets, and one had a large area of eburnation. All medial hand phalanges had lipping at both ends. Two recovered distal hand phalanges had lipping at the proximal facets. All cervical vertebrae had lipping and porosity of the centra, as well as the articular facets. Articular facets on the left side had much more severe expressions of arthritis than did those on the right. The centrum of the twelfth thoracic vertebra had a large osteophyte protruding from the inferior surface in an anterior direction. The remaining thoracics had moderate lipping and porosity at the articular facets and at the rib articulations. These seemed to be worse on the right side of the body. Schmorl's nodes were located on the superior surfaces of two vertebrae. All of the lumbars had extreme osteophytes and L5 had lipping that corresponded with the first sacral body. Three left ribs and four right ones had porosity at the articular surfaces of the heads. The right femur had arthritic lipping at the head and the distal end, and both acetabuli were surrounded by lipping. The right patella had mild lipping around the articular surface.

- Traumatic: The right first and second metatarsals were dislocated anteriorly with both bearing new facets.

- Infectious: The right maxillary sinus chamber had abundant healed periostitis indicative of sinusitis.

- Neoplasm: Both pubii had small bone spicules that protruded from the dorsal and the ventral surfaces, but they were much more abundant on the ventral surface.

- Metabolic and Hematological: None

- Dental: All maxillary and mandibular teeth were lost antemortem.

- Other: Upper body was very well developed.

$$
\begin{gathered}
\text { Burial } 47 \\
\vdots \\
\text { Name: George Washington Kyser } \\
\text { Date of Death: May 28, } 1920 \\
\text { Age at Death: } 75 \text { years }
\end{gathered}
$$

Personal History: Born in Lafayette, Mississippi, on January 21, 1845. Came to Texas with his parents and siblings, arriving in Bastrop on Christmas Eve 1851. The Kyser family remained in Bastrop County for 2 years, then moved to Hays County in 1853. They lived for a few years in Stringtown, a stagecoach stop on the old San Antonio highway just south of San Marcos. In 1858 the family moved to San Marcos. In February 1862 , George W. Kyser enlisted as a private in Company A, 32nd Texas Cavalry (also known as the 36th), Woods Regiment, Confederate Army of the Trans-Mississippi. His company was organized in San Marcos and the regiment was organized in San Antonio. The regiment was on duty in Texas and did not participate in any battles until the Spring of 1864, when it was ordered to Louisiana for the Red River Campaign. They fought almost constantly for 40 to 50 days, starting at Blair's Landing and ending at Yellow Bayou. G. W. Kyser was reported to be within 50 feet of General Tom Green when the general was killed at Blair's Landing. The regiment was disbanded at Houston in May of 1865 . Kyser returned to his home in San Marcos and engaged in farming and stock raising. In 1881, Kyser moved to Luling, Caldwell County, where he was engaged in the livery business until 1888. On February 7, 1882, G. W. Kyser married Emma J. Kirtley, formerly of 
Kentucky. While living in Luling, Kyser served as mayor, alderman, and justice of the peace. In 1888 , Kyser was elected county judge of Caldwell County and relocated to Lockhart, the county seat. Kyser held this office for 20 years. On July 15, 1913, Kyser took the office of the Commissioner of Pensions, appointed by the Governor of Texas, $\mathrm{O}$. B. Colquitt, and served until the end of his term. Of his term in office Kyser stated,

During the 18 months I was Commissioner of Pensions, I placed on the pension roll 8,678 of my old comrades and dear old distressed widows of my dead comrades. This I consider the most patriotic, Christian work I have done in my whole life, and for this work I have the solid endorsement of the Confederate Veteran's Association of Texas which I prize more highly than I would to be governor of Texas [Harwell 1947:98].

Regarding his political and religious persuasions, Kyser stated,

At the age of 17 I became a Confederate soldier and a democrat. This was in 1862 . I cast my first vote that year for Jack Wilcox, a candidate for the Confederate Congress, and from that good day to this, I claim that I have not changed my politics or religion. I am a Jeffersonian Democrat and wish I was good enough to be a good old time golden rule Christian, and could practice the teachings of Jesus Christ when he was on earth among men [Harwell 1947:98].

In regards to the Civil War, Kyser stated,

I believe that the South was right during the great conflict, and after a half century of thought, study and reading of the strife, know I was right, and I am glad to know that out of the great losses we sustained in the unholy and uncalled-for war we as a people saved our honor and still have the South and the principles for which she fought [Austin Statesman 1914:28].

Aside from his political life, Kyser was a member of the Masons, Knight of Pythias, and A.O.U.W. lodges, and he had served as a presiding officer for each of these organizations at one time or another.
He also was a member of the Improved Order of Red Men and Eagles. George W. Kyser died at his home in Austin on Friday, May 28, 1920. Cause of death listed as senile changes.

Sources of Historical Information: Headstone, General Services Commission records, Death Certificate (\#18085), obituary (Austin Statesman 1914), published biography (Harwell 1947).

Headstone Type: $\quad 3$

Headstone Inscription:

FATHER [Mason symbol] MOTHER GEORGE W. EMMA J. MAY 28. $1920 \quad$ FEB. 18,1923 KYSER [name inside banner]

Mortuary Characteristics:

- Casket Description: Wooden casket inside an outer box $(204 \times 55 \mathrm{~cm})$.

- Casket Orientation: $280^{\circ}$

- Casket Hardware: 6 Type 12 handles, Type 4 caplifter, rectangular white-metal plaque (too corroded to determine the inscription), 36 corroded nails.

- Body Orientation and Position: Extended supine, facing east; vertebral column $276^{\circ}$.

- Arm and Hand Positions: Arms crossed with hands on top of the opposing os coxae.

- Leg Positions: Extended

\section{Cultural Characteristics:}

- Clothing: 5 large and 3 small compound buttons with cuprous domed face plates and iron back plates with loop shank attachments (the design stamped on the button faces consists of a Confederate flag, the letters U C V, and 1861-65), 2 disc iron buttons (one found on top of an os coxa), 2 four-hole bone buttons (one found on top of an os coxa).

- Personal Goods: A large Masonic emblem found on top of casket lid on the midline of Zones D and E, maxillary dentures, bone cuff stud found with the left wrist.

\section{Osteological Characteristics:}

\section{Preservation}

- Taphonomy: Preservation was good to excel- 
lent and the body was well articulated. Some slight drifting of left foot elements had occurred.

- Inventory: Complete skeleton.

Pathology

- Degenerative: Arthritic changes were noted at the proximal and distal ends of the right humerus and at the proximal aspect of the left humerus. Minor lipping was noted on the distal ends of the right and left radius. Both glenoid cavities of the scapulae were lipped. The fovea for the dens on the atlas was lipped, but the dens was not available for observation. The third thoracic vertebra through the tenth had fused together. In addition, osteophytes were observed on the inferior surface of $\mathrm{T} 2$ and the inferior and superior surfaces of T11 and T12. Schmorl's nodes were seen on the inferior surfaces of $\mathrm{T} 5$ and $\mathrm{T} 11$ and the superior surfaces of T6 and T12. All five lumbar vertebrae had severe lipping of the centra. An osteophyte was noted on the superior surface of L1. Minor lipping was present on all the superior and inferior articular facets of the lumbar vertebrae. Both acetabuli had lipping around the superior edge. New bone had bridged the sacrum laterally to the right and left os coxa, almost fusing the bone anteriorly. An osteophyte was also observed on the superior articular surface of the first sacral element. Minor lipping was observed on the head of the right femur, as well as at the distal end. The right patella had moderate lipping. Bone spurs were identified at the proximal ends of both tibiae.

- Traumatic: None

- Infectious: None

- Neoplasm: None

- Metabolic and Hematological: None

- Dental: All maxillary teeth were lost antemortem and replaced with maxillary dentures. All mandibular teeth were lost antemortem except for the right canine. This tooth had severe calculus, but no caries, abscess, or enamel hypoplasias.

- Other: Both right and left patellae had ossified tendons projecting superiorly from the anterior surface. A set of medial and distal foot phalanges had fused together.

\section{Burial 48}

Name: Emma J. Kyser

Date of Death: February 18, 1923

Age at Death: 72 years

Personal History: Born in Kentucky on January 8, 1851. She was wife of George W. Kyser (see Burial 47). Cause of death listed as Bright's disease, with influenza as a contributing factor.

Sources of Historicall Information: Headstone, General Services Commission records, Confederate Home records, Death Certificate (\#006[5]442).

Headstone Type: $\quad 3$

Headstone Inscription: 'See description of Burial 47.

Mortuary Characteristics:

- Casket Description: Iron casket (193 x $60 \mathrm{~cm})$ that was slightly oval in shape. The lid was in two sections with a large cross piece in the middle. The upper section could be opened separately, or both sections could be opened together.

- Casket Orientation: $280^{\circ}$

- Casket Hardware: Type 14 (full extension bar) handles, with 2 white-metal lugs on the north and south walls. Single lug short bar handles were located at the head and the foot of the casket. Large white-metal "At Rest" plaque in Zones D and $\mathrm{E}$.

- Body Orientation and Position: Extended supine, facing east; vertebral column $280^{\circ}$.

- Arm and Hand Positions: Crossed with the right hand on the right os coxa and the left hand on the left os coxa.

- Leg Positions: Extended

\section{Cultural Characteristics:}

- Clothing: 1 shell button.

- Personal Goods: Full set of dentures, 2 plastic mock tortoise shell hair combs.

Nonassociated Artifacts: Small ceramic doll's foot, found in the casket in the vicinity of the right hand. The association of this artifact with the 
burial is uncertain.

\section{Osteological Characteristics:}

Preservation

- Taphonomy: Skeletal remains were badly disturbed by root action from numerus small rootlets. The thoracic vertebrae and the feet were subjected to extensive root etching and erosion. Bones that were in direct contact with the iron of the casket were badly eroded. Lower leg bones were displaced.

- Inventory: Complete skull; complete postcranial skeleton.

Pathology

- Degenerative: The left temporomandibular joint exhibited lipping, and the left mandibular condyle was wasted. In addition, the left condyle had severe lipping that projected superiorly and anteriorly. The left first metacarpal had minor lipping around the proximal facet. The fovea for the dens and the dens had extreme lipping. Cervicals 5 and 6 had lipping around the centra and porosity of the inferior centra surface, while C6 had lipping of the superior surface. Eight thoracic centra (T5-T12) had small osteophytes projecting superiorly and inferiorly from the centra.

- Traumatic: None

- Infectious: None

- Neoplasm: None

- Metabolic and Hematological: None

- Dental: All teeth were lost antemortem and replaced with a full set of dentures. The left upper incisor of the maxillary dentures had a small gold filling that was drilled into the false tooth, as if emulating a filling in an original tooth.

- Other: None

\section{Burial 49}

Name: George Tulley Walker

Date of Death: May 3, 1925

Age at Death: 85 years

Personal History: Born in South Carolina in 1839, moved to Texas in 1858 and lived in Llano. Served as lieutenant and captain of Company G, 11th Texas Infantry, Randal's Brigade, Walker's Division, Army of the Trans-Mississippi (obituary says Walker attained the rank of major by the end of the war, but pension record shows his last rank as captain). Worked as a salesman and a caretaker. Admitted to the Confederate Home on December 5, 1911 , with his disability listed as a hernia. Released at his own request on May 28, 1912. Was readmitted to the Confederate Home on June 1, 1916, and released again on September 23, 1918. Cause of death listed as cardio-renal disease.

Headstone Type: 2

Headstone Inscription:

[Southern Cross of Honor]

CAPT.

GEORGE T. WALKER

CO. G

11 TEX. INF.

C.S.A.

Sources of Historical Information: Headstone, General Services Commission records, Confederate Home records, Pension (\#17070), Death Certificate (\#10701).

Mortuary Characteristics:

- Casket Description: Well-preserved wooden casket $(200 \times 58 \mathrm{~cm})$.

- Casket Orientation: $279^{\circ}$

- Casket Hardware: 2 Type 11 (full extension bar) handles with 3 iron lugs on each long side, 2 Type 11 single lug short bar handles at each short end of the casket, "At Rest" plaque found between the legs in Zones D and $E$ just below the pelvic area, 14 nail fragments, 8 corrugated fasteners.

- Body Orientation and Position: Extended supine, facing east; vertebral column $280^{\circ}$.

- Arm and Hand Positions: Extended

- Leg Positions: Extended

Cultural Characteristics:

- Clothing: 2 large four-hole bone buttons from Zone C, 2 small two-hole shell buttons found associated with left wrist area, 1 large twohole shell button, 2 cuprous-metal suspender buckles.

- Personal Goods: Full set of dentures; the upper had a gold bridge spanning the right canine. 
Nonassociated Artifacts: 3 fragments of glass, 1 ceramic fragment located in grave fill.

\section{Osteological Characteristics:}

Preservation

- Taphonomy: The skeletal remains were well preserved and had suffered little from root action. The left femur and tibia had rotated $90^{\circ}$.

- Inventory: Fragmented skull missing small facial elements; complete postcranial skeleton.

Pathology

- Degenerative: The left mandibular condyle had irregular bone deposits on the articular surface; the left temporomandibular articular surface had corresponding lipping and porosity. The left humerus had lipping at the capitulum. The proximal and distal endis of the right and left metacarpals had moderate lipping. The corresponding proximal phalanges had lipping at the distal ends. One of these had a malformed head and eburnation. One medial hand phalanx had eburnation. The left second and third metacarpals had eburnation on the head. Cervicals 4-6 were fused at the centra through osteophyte development. They were also fused at the articular facets. Cervicals 3, 4, and 7 had lipped and pitted centra. Thoracic 1 had severely lipped and pitted articular facets. Three of the middle thoracic vertebrae were fused together at the centra due to osteophyte development on the left side of the bodies. The bottom one of these had Schmorl's nodes at the superior and inferior surfaces. Five thoracics had osteophytes on the right side of the inferior surface of the centra. Four of these also had Schmorl's nodes. Three lumbar vertebrae had Schmorl's nodes, and two others had osteophytes projecting off the inferior surface on the left side. Moderate lipping was observed at the rim of both acetabuli. The distal ends of both femora had minor lipping, especially on the superiorlateral margin. Both patellae had moderate lipping, but the expression seen on the left side was a little more severe. The left patella had an isolated patch of new bone deposition near the center of the articular facet. Both tibiae had bone spurs on the proximal ends. Both first metatarsals had eburnated grooves at the inferior surfaces of the heads. One foot sesa- moid had new bone, lipping, and eburnation.

- Traumatic: None

- Infectious: The left maxillary sinus was filled with several layers of dense sclerotic bone, thickening the bone to 2 to 3 times normal width. The petrosal portion of the left temporal had porous lesions possibly indicative of an ear infection. Three medial hand phalanges and seven proximal hand phalanges had sclerotic lesions on the dorsal surface.

- Neoplasm: None

- Metabolic and Hematological: None

- Dental: All maxillary teeth were lost antemortem, except for the right canine. A set of maxillary dentures was recovered, but a gold bridge spanned the right canine. A space was left in the maxillary dentures for the real third premolar, although it was also lost prior to death. The right canine had moderate wear and a cervical abscess on the lingual side. All mandibular teeth were lost prior to death and replaced with mandibular dentures.

- Other: Both patellae had ossified tendons projecting superiorly off the anterior surface. The right tibia had an enthesophyte at the tibial tuberosity.

\section{Burial 50}

Name: Josephine M. Walker

Date of Death: July 31, 1951

Age at Death: 79 years

Personal History: Born in Nacogdoches on December 16, 1871. Wife of George T. Walker (see Burial 49). Died in the Austin State Hospital of pulmonary tuberculosis.

Sources of Historical Information: Headstone, General Services Commission records, Pension (\#17070, her husband's pension), Death Certificate (\#38290).

Headstone Type: 4

Headstone Inscription:

MOTHER [on top horizontal edge]

JOSEPHINE M. WALKER

DEC. 16,1871

JULY 31,1951 
Mortuary Characteristics:

- Casket Description: Wooden casket in an outer box $(202 \times 60 \mathrm{~cm})$. The casket was constructed using a tongue-and-groove technique. A grayish cotton/wool material located on the casket floor is believed to have functioned as padding material.

- Casket Orientation: $284^{\circ}$

- Casket Hardware: Type 15 handle complex, 4 nails.

- Body Orientation and Position: Extended supine, facing east; vertebral column $270^{\circ}$.

- Arm and Hand Positions: Arms slightly flexed with hands on top of the pelvis.

- Leg Positions: Extended

\section{Cultural Characteristics:}

- Clothing: Thigh-high nylon stockings.

- Personal Goods: Plastic cone-shaped object. The base of the cone had a face like a button with two circular holes. The cone itself was threaded. The diameter of the base was $16 \mathrm{~mm}$, and the object was $17.5 \mathrm{~mm}$ tall. The two holes on the face of the base were roughly $3 \mathrm{~mm}$ deep.

\section{Osteological Characteristics:}

\section{Preservation}

- Taphonomy: Preservation was fair to poor. The cranial and postcranial remains were highly fragmented.

- Inventory: The skull was fragmented and missing portions of larger elements and small facial bones. Many elements of the vertebral column were not present.

Pathology

- Degenerative: The right temporomandibular joint exhibited lipping and porosity. The right mandibular condyle had corresponding changes. The left mandibular condyle also showed lipping and porosity, but the left temporomandibular joint was unavailable for examination. The right humerus had abundant new bone deposition at the proximal head, probably related to the fracture described below. Extreme arthritis and new bone deposition were observed on the posterior aspect of the distal end of the radius, probably related to the break described below. The right first metacarpal was severely lipped at the proximal facet. The right scaphoid, lunate, and pisiform were extremely lipped and covered with new bone deposition. The proximal phalanges of (both thumbs were lipped, but the right one was more severe, especially at the distal end. Five of the nine medial hand phalanges had lipping at both ends, as did three of the six distal phalanges. Only three thoracic vertebrae were available for examination; all had osteophytic development. Both patellae had severe lipping around the margin and porosity at the articular surface.

- Traumatic: The right humerus had an unaligned healed fracture at the proximal end of the neck, displacing the head posteriorly. Because of the fracture, the right humerus measured $307 \mathrm{~mm}$ long as compared to the left humerus which measured $332 \mathrm{~mm}$ long. The right ulna had a well-healed, unaligned break at the distal end of the shaft; the area below the shaft was slightly displaced laterally. The right radius had a well-healed break at the distal end of the radius, which was displaced posteriorly. The right fifth metacarpal was broken at midshaft and displaced in a medial fashion. The right femoral head was separated at the shaft just above the lesser trochanter. Much new bone was deposited in the new articular area. A right rib was broken at the back, near the vertebral facet. A callus was still evident at the break.

- Infectious: None

- Neoplasm: A small button osteoma was observed on the mandible just below the central incisors on the anterior portion of the horizontal ramus.

- Metabolic and Hematological: None

- Dental: Six maxillary teeth were recovered; two teeth were lost antemortem, and two were lost postmortem. Of the teeth that could be examined, only one (the left second molar) had a caries. Twelve mandibular teeth were observed; two were lost antemortem. These teeth had no calculus deposits, no abscesses, no hypoplasias, and no caries. The fourth premolars were molariform in shape, and the central incisors had labial sloping wear.

- Other: A set of right foot medial and distal phalanges was fused together.

\section{Burial 51}

Name: Margaret C. Pannell

Date of Death: April 10, 1931

Age at Death: 82 years 
Persomal History: Born in Mississippi on March 7, 1849. Married to John S. Pannell (see Burial 52). Cause of death listed as angina pectoris.

Sources of Historical Information: Headstone, General Services Commission records, Death Certificate (\#20875), obituary (Austin Statesman, April 11, 1931).

Headstone Type: $\quad 3$

Headstone Inscription:

\section{MOTHER [Masonic Symbol] FATHER MARGARET C. JOHN S. MAR. 7. 1849 MAY 25, 1843 \\ APR. 10. 1931 \\ PANNELL [name inside banner]}

Mortuary Characteristics:

- Casket Description: Metal casket $(202 \times 80 \mathrm{~cm})$ of unusual design, consisting of a lower box with a two-piece vaulted lid. The lid was in two sections that slid onto the bottom box fitting into a lip at the foot of the casket. The lower section could be slid on and the upper left off for viewing, after which the upper section was slid on and bolted into place. An inlay of wood was placed around the top edge of the bottom box.

- Casket Orientation: $278^{\circ}$

- Casket Hardware: A Type 14 three-lug full extension bar handle was located on both long sides of the casket, a single-lug short bar handle was located at each short end. These were similar to other Type 14 handles except that the lug was iron rather then white metal.

- Body Orientation and Position: Extended supine, facing east; vertebral column $275^{\circ}$.

- Arm and Hand Positions: Extended

- Leg Positions: Extended

Cultural Characteristics:

- Clothing: None

- Personal Goods: Plastic mock tortoiseshell hair pin from Zone A, full set of dentures.

\section{Osteological Characteristics:}

Preservation

- Taphonomy: The skeletal remains had suf- fered from extensive root disturbance. Bone that was in contact with the metal of the casket was very eroded.

- Inventory: Major bones of the skull were highly fragmented and facial bones were not preserved. Postcranial remains were preserved with the exception of a few vertebrae and ribs.

\section{Pathology}

- Degenerative: Moderate to severe lipping was observed on the right humeral head; minor to moderate lipping was noted on the left humeral head. The distal articular facets of the left radius were extremely arthritic with lipping and new bone deposition; the distal end of the left ulna also exhibited lipping. These instances of arthritis were related to the fractures described below. Lipping was observed on the left scaphoid, trapezium, lunate, pisiform, and trapezoid. The right scaphoid, trapezoid, lunate, and trapezium were lipped, and eburnation was noted on the trapezoid and trapezium. Eburnation was observed on the heads of right metacarpals 2-4. Lipping was observed at the proximal ends of four proximal hand phalanges. The dens articulation of the atlas and axis had severe lipping and eburnation. The third cervical vertebra had lipping and pitting of the centrum and the left superior articular facet. Three thoracic vertebrae had lipping and porosity on the centra. Six thoracics showed lipping and porosity only on the right side of the centra. All lumbar vertebrae had small osteophytes on the inferior and superior surfaces. Severe lipping and eburnation with grooving were noted on the inferior and superior articular facets of L4 and L5. The right patella had minor lipping. The articular surface of the first sacral element had lipping and porosity of the centra. In addition, the right articular facet was eburnated. Right metatarsals 2 and 3 had extreme arthritic porosity at the proximal facets. The intermediate and lateral right cuneiforms had porosity.

- Traumatic: The left ulna had a well-healed, unaligned fracture at the distal end (approximately $3 \mathrm{~cm}$ from the styloid process). The distal end of the left radius also was fractured. The left scaphoid, trapezium, and trapezoid were fused together.

- Infectious: A healed periosteal reaction was observed on the frontal crest. This appeared 
as striated bone that focused around a central point measuring $25 \times 35 \mathrm{~mm}$. The petrosal portion of the right temporal had healed periostitis at the superior-anterior portion. Perforations were also observed on the petrosal. Sclerotic lesions were noted on the dorsal surface of six proximal hand phalanges.

- Neoplasm: None

- Metabolic and Hematological: None

- Dental: All teeth were lost antemortem and replaced with a full set of dentures.

- Other: None

\section{Burial 52}

Name: John S. Pannell

Date of Death: April 29, 1931

Age at Death: 88 years

Personal History: Born in Mississippi on May 25, 1843 (although his death certificate shows his date of birth as May 20, 1843). Resident of Travis County for approximately 69 years. Member of Onion Creek Masonic Lodge No. 220. Served as a captain in the Confederate Army. Cause of death listed as la grippe (influenza).

Sources of Historical Information: Headstone, Death Certificate (\#20877), obituary (Austin Statesman, April 30, 1931).

\section{Headstone Type: $\quad 3$}

Headstone Inscription: See Burial 51 description.

\section{Mortuary Characteristics:}

- Casket Description: Identical to casket of Burial 51.

- Casket Orientation: $278^{\circ}$

- Casket Hardware: Identical to casket of Burial 51.

- Body Orientation and Position: Extended supine, facing east; orientation of vertebral column indeterminate.

- Arm and Hand Positions: Extended

- Leg Positions: Extended

\section{Cultural Characteristics:}

- Clothing: None

- Personal Goods: None

\section{Osteological Characteristics:}

Preservation

- Taphonomy: Skeletal remains were badly eroded; most of the bone that was in direct contact with metal of the casket was completely gone. This was particularly noted on the right side of the body. This side also had very little fill inside the casket, thus leaving the bones more exposed.

- Inventory: The highly fragmented skull was missing some facial elements, including the left maxilla. The postcranial skeleton was missing some hand elements, two cervical vertebrae, and some foot elements.

\section{Pathology}

- Degenerative: The left clavicle had arthritic pitting and a small eburnated area at the acromial end. Both right and left scapulae had moderate pitting of the glenoid fossae. The right humerus had moderate to severe lipping of the distal end. The capitulum was eburnated. The right radius had moderate to severe lipping of the head and eburnation. The proximal end of the right ulna had moderate lipping of the radial notch. The distal ends of the left radius and ulna were lipped. The left trapezium was extremely arthritic with lipping and new bone deposition. The deposition was so severe that it masked the true shape of the bone. Eburnation with grooving was observed on the left first metacarpal and on the trapezium and trapezoid. The right first metacarpal also had eburnation with grooving. One set of proximal and distal phalanges also had severe eburnation and grooving. The distal ends of three proximal hand phalanges had the same manifestation. Lipping, grooving, and eburnation were noted on the distal head of one proximal hand phalanx. Severe lipping, eburnation, and grooving were observed on the proximal and distal ends of three medial phalanges. Grooving and eburnation only were observed on the distal ends of two medial phalanges. All five of the observable thoracic vertebrae had lipping on the articular facets. Manifestations on the left side were much more severe. Minor lipping was noted on thoracics 1-3. Thoracic vertebrae 4 and 5 were fused at the right side of the centra by bridging osteophytes. Thoracic 3 had eburnation on the superior articular facet on the right 
side. Thoracic 4 had eburnation on the inferior and superior articular facets on the right side, and T5 had eburnation on the superior articular facet on the right side. Minor lipping was observed on the centra of four other thoracic vertebrae. Thoracic 11 had a small osteophyte on the superior centrum surface. The right superior articular facet of the sacrum had moderate lipping. Minor lipping was noted on both acetabuli. Lipping was observed on the femoral head and distal end of the right femur. Minor to moderate lipping of the right patella was observed, especially on the lateral margin. The right tibia exhibited moderate lipping of the lateral articular surface. Moderate lipping was noted on the distal end of the left femur and a small area of new bone was deposited on the lateral condyle. The left patella had lipping, as did the lateral condyle of the left tibia.

- Traumatic: None

- Infectious: None

- Neoplasm: None

- Metabolic and Hematological: None

- Dental: No maxillary teeth were recovered. Six mandibular teeth were recovered; the rest were lost antemortem. Two linear enamel hypoplasias were noted on the left canine and the left lateral incisor.

- Other: None

\section{Burial 53}

Name: Jacob Burleson

Date of Death: February 26, 1917

Age at Death: 78 years

Personal History: Born in Texas in 1839, lived in Webberville and worked as a rancher. Served in the Texas Rangers before the war, served as 2 nd lieutenant in Company I, 34th Texas Cavalry, Green's Brigade. Admitted to the Confederate Home on April 7, 1905, with lung trouble. His pension was rejected because he was an "inmate" of the Confederate Home. The cause of death listed on death certificate is illegible.

Sources of Historical Information: Headstone, General Services Commission records, Confederate Home records, pension records (no number assigned due to rejection), Death Certificate (\#5982).
Headstone Type: $\quad 5$

Headstone Inscription:

\section{BURLESON}

[name inside banner on top horizontal edge]

JACOB BURLESON

MAY 20, 1839

FEB. 26, 1917

Citizen of the Republic of Texas

[on round bronze plaque]

\section{Mortuary Characteristics:}

- Casket Description: Badly deteriorated wooden casket (no measurements were possible); the only wood that remained was a small fragment located under the metal plaque.

- Casket Orientation: $278^{\circ}$

- Casket Hardware: 6 Type 8 handles, 2 Type 3 caplifters, metal plaque, 23 nail fragments, 3 corrugated fasteners.

- Body Orientation and Position: Extended supine, facing east; vertebral column $280^{\circ}$.

- Arm and Hand Positions: Crossed with left hand over the right os coxa and the right hand over the left os coxa.

- Leg Positions: Extended

Cultural Characteristics:

- Clothing: 6 two-hole shell buttons.

- Personal Goods: None

\section{Osteological Characteristics:}

Preservation

- Taphonomy: Skeletal remains had suffered greatly from root action; several bones were disarticulated, particularly the lower legs and feet.

- Inventory: The skull was relatively complete, missing only small facial bones. Postcranial remains were complete with the exception of several vertebrae that were not recovered, rib fragments, and some hand and foot elements.

Pathology

- Degenerative: Both temporomandibular joints had lipping and porosity. The area of the right elbow was severely arthritic. The distal end of the humerus was lipped, and the right radius had extreme lipping, eburnation, and deposi- 
tion at the radial head. Minor lipping was also noted on the distal end of the radius. The proximal end of the ulna was severely lipped with bone deposition in the trochlear area. The distal end had minor lipping. The left elbow had almost the same amount of arthritis as the right side, including eburnation at the capitular surface and the radial head. Both lunates and scaphoids had minor lipping. The proximal hand phalanges of the thumb had lipping at the proximal facets. Five medial and five distal hand phalanges had lipping at the proximal ends. The axis and C3 were fused together at the inferior and superior articular surfaces and at the centra. All cervical vertebrae except the atlas and axis had lipping and porosity of the centra, both superior and inferior. Two thoracic vertebrae had slight lipping of the centra. Two lumbar centra were fused by a large osteophyte on the left side. One lumbar centrum had a large osteophyte on the right side projecting inferiorly from the centrum. The lower body showed no arthritic changes.

- Traumatic: The left parietal had a well-healed large depression fracture located $19 \mathrm{~mm}$ from the sagittal suture near lambda. The depression was oval shaped and measured $45 \times 30 \mathrm{~mm}$. A possible explanation for this fracture could be a blow to the head from a rifle butt or the edge of a saber.

- Infectious: Healed periostitis was present in the frontal sinus, and some sclerotic bone deposition was observed endocranially. This endocranial deposition may be related to the blunt trauma described above. The right zygomatic and maxilla had disorganized bone deposition on the exterior surface, which is probably related to the severe sinus infection noted in the right maxillary chamber, or to the tooth loss and severe resorption of the right alveolus. The left maxilla had a similar deposition, but it was much smaller. Sinusitis was noted in both maxillary chambers, but was much more severe on the right side where the chamber was almost completely full of sclerotic bone depositions. Sclerotic roughening was noted on the palate. Sixteen of the hand phalanges (proximal and medial) had sclerotic deposits on the dorsal surface. Six right ribs had healed periostitis on the pleural surface; this was apparent on one left rib fragment.
This probably would have shown up more frequently, but the ribs were very fragmented.

- Neoplasm: A button osteoma was noted on the inner surface of the mandible above the left mylohyoid foramen.

- Metabolic and Hematological: Healed cribra orbitalia was observed in both eye orbits. Cranial thickening (ca. $15 \mathrm{~mm}$ ) was evident in the frontal, parietals, and temporals.

- Dental: All maxillary teeth were lost antemortem with the exception of the left central incisor, canine, and third molar. All of those teeth had caries, and the central incisor had two hypoplastic defects. Eight mandibular teeth were recovered; the other eight were lost antemortem. The left third molar, left canine, and right lateral incisor had caries. All anterior teeth from the left canine to the right canine had hypoplastic episodes. Four were noted on the canines and two were noted on the incisors. Extreme resorption of the alveolar bone around the anterior teeth had occurred.

- Other: The front distal shafts of both humeri above the capitulum had smooth areas where the radial heads could rest in a hyper-flexed position.

\section{Burial 54}

\author{
Name: Mary Ivy Burleson \\ Date of Death: July 19, 1932 \\ Age at Death: 89 years
}

Personal History: Born in Louisiana in 1842. Married to Jacob Burleson (see Burial 53). Cause of death listed as Pylae-nephrosis with arteriosclerosis as a contributing cause.

Sources of Historical Information: Headstone, General Services Commission records, Death Certificate (\#32262).

Headstone Type: 6

Headstone Inscription:

[Floral Design]

OUR MOTHER

MARY BURLESON

1842-1932

Gone but not Forgotten 
Mortuary Characteristics:

- Casket Description: Wooden casket in an outer box $(200 \times 48 \mathrm{~cm})$.

- Casket Orientation: $280^{\circ}$

- Casket Hardware: Type 9 extension bar handle complex, corroded white-metal plaque with the inscription "Our Mother, Mary Burleson, 1842 to 1932 ," Type 1 latch, 2 Type 2 latches, 2 Type 3 latches, 14 thin ferrous bars, 23 corroded wire nails.

- Body Orientation and Position: Extended supine, facing east; vertebral column $258^{\circ}$.

- Arm and Hand Positions: Extended

- Leg Positions: Extended

\section{Cultural Characteristics:}

- Clothing: 16 domed-disc metal buttons found along the long axis of the body from the thoracic region to below the knees.

- Personal Goods: 1 gold-plated bar pin found on top of upper thoracic vertebrae.

\section{Osteological Characteristics:}

\section{Preservation}

- Taphonomy: Preservation was good to fair. Cranium had rolled slightly backwards. The mandible was disarticulated, fragmented, and in a small pile of cervical vertebrae. The upper vertebral column had shifted to the right displacing the ribs, right scapula, and the distal right humerus. The right arm was pushed up against the casket wall. Some drifting of left hand elements had occurred. The right os coxa had flipped over. The left os coxa had disarticulated from the femur head and drifted slightly down the body. The left tibia and fibula had rotated $90^{\circ}$ laterally. The foot elements were slightly scattered. The main source of disturbance appears to be the growing root system of the nearby tree.

- Inventory: The skull was complete with fragmentation of facial elements. The postcranial skeleton was complete with the exception of most ribs and a few thoracic vertebrae.

\section{Pathology}

- Degenerative: Lipping was noted on the distal right humerus and on both humeral heads. This lipping was more severe on the right side than the left. The glenoid cavity of the left scapula was lipped; the right side was not present for comparison. Minor lipping was noted on the left distal radius. The left lunate had an eburnated surface that articulated with the distal ulna (also eburnated). Minor lipping and new bone deposition were evident on the centra of two cervical vertebrae. Two of the nine thoracic vertebrae recovered had minor lipping on the inferior surface of the centra and one had severe lipping. Three additional thoracic vertebrae had minor lipping on the articular facets. Osteophytes were observed on three lumbar vertebrae. The remaining two vertebrae had lipping of the centra. The acetabulum had minor lipping. Pitting was observed on the right and left distal femora and on the right distal tibia. The proximal surface of both tibiae also had porosity.

- Traumatic: None

- Infectious: None

- Neoplasm: None

- Metabolic and Hematological: None

- Dental: All teeth were lost antemortem.

- Other: Possible osteoporosis based on the light and porous nature of the bone. One set of medial and distal foot phalanges were fused together.

\section{Burial $5 \mathbf{5}$}

Name: Louisa A. Bradfield

Date of Death: June 13, 1931

Age at Death: 79 years

Personal History: Born in Louisiana in 1852. Came to Texas in 1853 and resided in Dallas. Married to James O. Bradfield (see Burial 56). Occupation listed as housewife. Admitted to the Confederate Home on August 1, 1929. Her cause of death was listed as hemiplegia with a contributing cause of death listed as hypertension.

Sources of Historical Information: Headstone, General Services Commission records, Confederate Home records, Death Certificate (\#3[0]946).

Headstone Type: $\quad 1$

Headstone Inscription:
LOUISA A.
Wife of
J. O. BRADFIELD
1852-1931 
Mortuary Characteristics:

- Casket Description: Wooden casket in an outer box $(198 \times 63 \mathrm{~cm})$.

- Casket Orientation: $278^{\circ}$

- Casket Hardware: 6 Type 13 handles, highly oxidized rectangular ferrous metal plaque (too corroded to make out any inscription), Type 1 latch, 2 Type 2 latches, 2 Type 3 latches, 16 corroded wire nails.

- Body Orientation and Position: Semiflexed, supine; the majority of the vertebral column was oriented at $300^{\circ}$.

- Arm and Hand Positions: Arms crossed with hands on top of the opposite os coxa.

- Leg Positions: The left leg was rotated $90^{\circ}$ laterally and extended with a slight flex in the knee. The right leg was rotated $90^{\circ}$ medially with knee flexed $100^{\circ}$, almost touching the north wall of casket.

\section{Cultural Characteristics:}

- Clothing: Two-hole shell button found under the left os coxa, cuprous-metal safety pin found below the left os coxa.

- Personal Goods: Gold ring (presumably a wedding ring) found with left hand.

\section{Osteological Characteristics:}

\section{Preservation}

- Taphonomy: Preservation was fair to poor. The cranium was highly fragmented and crushed. The lower body appeared to have rotated onto its left side. There was a sharp curve in the vertebral column, in the lower thoracic to upper lumbar region.

- Inventory: The skull was fragmented and small facial bones as well as the left maxilla were not recovered. The postcranial skeleton was complete with the exception of a few missing vertebrae.

\section{Pathology}

- Degenerative: Both temporomandibular joints had lipping and new bone deposition, as did both mandibular condyles. The occipital condyles had moderate lipping along the entire surface. The right and left glenoid cavities had severe lipping. The right humeral head was also severely lipped; the left head could not be examined. The proximal facet of the left first metacarpal had minor lipping, while the proximal facet of the right first metacarpal had lipping and eburnation. The right trapezium had corresponding lipping and eburnation. Eight of 10 medial hand phalanges had slight lipping at the proximal facets. Four of the six recovered distal phalanges had lipping. The superior articular (condylar) facets of the atlas were lipped, as was the fovea for the dens. The axis had lipping at the dens, and the other five cervical vertebrae had lipping at the centra and two had porosity of the inferior surface. Two cervical centra had porosity on the superior surface. Six of the eight recovered thoracic vertebrae had lipping on the centra. Two lumbar centra were fused together on the right side. The other two recovered lumbar vertebrae had small osteophytes. The vertebral facet of one right rib had severe lipping and porosity, but the rest of the ribs did not show this. Moderate lipping was observed on the right and left patellae.

- Traumatic: None

- Infectious: Three proximal hand phalanges had sclerotic lesions on the dorsal surfaces. The distal shaft of the left tibia had a patch of healed periostitis.

- Neoplasm: None

- Metabolic and Hematological: The frontal and parietals had cranial thickening (10-12 mm).

- Dental: No maxillary teeth were recovered. All mandibular teeth were lost antemortem.

- Other: The medial and distal phalanges of one toe were fused together.

\section{Burial 56}

\author{
Name: James O. Bradfield
}

Date of Death: March 7, 1932

Age at Death: 88 years

Personal History: Born on December 2, 1843, in Georgia. Moved to Texas in 1852 where he lived in Dallas and worked as a teacher. Served in Company E, 1st Texas Infantry, Hood's Brigade, Army of Northern Virginia. Pension records mistakenly said he had deserted. Several letters, including one from his captain, said that he did not desert, but his pension was never approved. $\mathrm{He}$ was admitted to the Confederate Home on October 25,1912 , with rheumatism. Pension medical exam listed a broken left shoulder, defective hearing, asthma, and chronic kidney problems. Cause of 
death was listed as liver cancer with arterio-sclerosis as a contributing cause.

Sources of Historical Information: Headstone, General Services Commission records, Confederate Home records, pension records (no number assigned because it was rejected), Death Certificate (\#14178).

Headstone Type: $\quad 2$

Headstone Inscription:

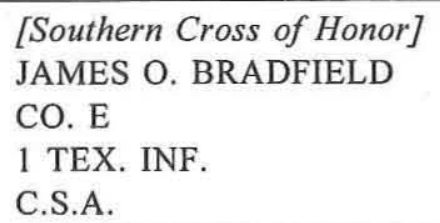

Mortuary Characteristics:

- Casket Description: Casket was totally disintegrated with no wood remaining; no measurements were possible. Other items seem to indicate that this casket was the same as others associated with 1930 s burials.

- Casket Orientation: $280^{\circ}$

- Casket Hardware: 6 Type 10 handles, remains of an iron plaque (no inscription could be discerned), 2 Type 2 latches, 2 Type 3 latches, 13 nail fragments, 5 corrugated fasteners.

- Body Orientation and Position: Extended supine, facing east; vertebral column $280^{\circ}$.

- Arm and Hand Positions: Arms flexed with left hand over the left os coxa and the right hand over the right os coxa.

- Leg Positions: Extended

\section{Cultural Characteristics:}

- Clothing: Four 19-mm rubber buttons (Zone B), three $15-\mathrm{mm}$ rubber buttons (Zone C), three 15-mm shell buttons (Zone B), two 11-mm shell buttons (Zone D)

- Personal Goods: Metal cuff link (Zone C), copper metal stud, 2 celluloid collar studs (Zone A).

\section{Osteological Characteristics: \\ Preservation}

- Taphonomy: Skeletal remains were very poorly preserved; the thoracic area was mostly reduced to powder. Elements of the hands and feet were scattered. Most of the long bones were fragmented, as was the skull.

- Inventory: The skull was highly fragmented; small facial bones and the left maxilla were not recovered. Postcranially, several ribs and vertebrae were missing.

\section{Pathology}

- Degenerative: The left temporomandibular joint had lipping and porosity; the right side just had lipping. Mild lipping was noted on the glenoid cavities of both scapulae. In addition, both scapulae had porosity at the clavicular articulation of the acromion. The acromial ends of both clavicles exhibited corresponding porosity and lipping. The right first metacarpal had severe lipping and porosity. The right trapezium had mild lipping around the surface articulation with the first metacarpal. The left first metacarpal and the left trapezium were lipped, but to a lesser degree than the right. All eight recovered medial hand phalanges and all eight recovered distal phalanges had lipping on the proximal facets. The fovea for the dens and the dens were severely arthritic. The axis and C3 were fused together at the centra and at the inferior and superior articular surfaces. The third cervical vertebra had new bone deposition on the inferior centra surface. The centra of C4-7 had large pores and new bone deposition on both the inferior and superior surfaces. Three thoracic neural arches had lipping and porosity around the inferior and superior articular facets; this was more severe on the left side than the right. Three thoracic centra had osteophytes and porosity on both surfaces. The first sacral centra had severe arthritis with new bone deposition and porosity. The inferior surface of the last lumbar corresponded with this. Both acetabuli had extreme lipping, especially inferiorly. New bone deposition had occurred on the acetabular surface. Both patellae had severe arthritis. One of the six medial foot phalanges had lipping at the proximal facet, as did five of the seven distal phalanges.

- Traumatic: None

- Infectious: Three ribs had healed periostitis on the pleural surface near the sternal end. More may have had this, but they were too frag- 
mented to observe.

- Neoplasm: None

- Metabolic and Hematological: None

- Dental: Only two maxillary teeth (the third molars) were recovered. The right one had three discrete caries and a large apical abscess. The left one had one caries. All mandibular teeth were lost antemortem.

- Other: Enthesophytes projected from the anterior surface of the left patella.

\section{Burial 57}

Name: Dr. John R. Ward

Date of Death: December 11, 1884

Age at Death: 44 years

Personal History: Born in Campbell County, Virginia, on February 14, 1840. On Novemiber 16, 1861 , Dr. Ward was assigned to duty with the 11th Regiment of Virginia Volunteers of the Army of the Potomac (later the Army of Northern Virginia) as an assistant surgeon. On June 22, 1863, he was promoted to surgeon. This is confirmed by a letter dated January 6, 1864, from President Jefferson Davis to the Senate of the Confederate States listing John R. Ward of Virginia among the individuals promoted to surgeon. The letter is from the Journal of the Congress of the Confederate States of America, 1861-1865 (Vol. III), printed 61 years after the end of the Civil War (U.S. FiftyEighth Congress, 2d Session 1904). Records dated to April 18,1864, and August 16, 1864, indicate that Dr. Ward was serving as a medical officer with the 11 th Virginia Infantry stationed at Taboro, North Carolina (on these dates his name appears on two separate reports listing the sick and wounded). On May 7, 1864, Dr. Ward was absent from the Surgical Corps by order of the Medical Director (this record notes that he was sick or wounded at the time). In January 1865 , Dr. Ward was listed as being "On leave of absence, Hd. 2. A. N. Va." (Headquarters 2, Army of Northern Virginia); his name appeared under the heading of "Absent commissioned officers accounted for." A "Prisoner of War" record dated to May 30,1865, was signed by John R. Ward, Surgeon, 11th Regiment of Virginia Infantry at Campbell C. H. (Court House) Virginia. He came to Austin, Texas, around 1871 where he worked in the profession of dentistry. $\mathrm{He}$ abandoned this occupation and moved to the country where he farmed and traded real estate. Dr. Ward amassed a considerable fortune in these activities and died in affluent circumstances. His cause of death was listed as consumption (tuberculosis).

One of Dr. Ward's descendants, Jackie Tomerlin (personal communication 1996) of San Antonio said that her father, John Beretta Ward, compiled extensive research files relating to Dr. Ward. Among the historical records and artifacts possessed by the family are documents indicating that Dr. Ward was a close personal friend of General Robert E. Lee and that Dr. Ward may have served as Lee's personal surgeon for a time. Dr. Ward's remains were reinterred in the Texas State Cemetery in 1958 at the requeșt of John Ward Beretta (then president of the First National Bank of San Antonio).

Sources of Historical Information: Headstone, General Services Commission records, index cards of Compiled Service Records, obituary (Austin Statesman, December 12, 1884), notice of appointment as surgeon (U.S. 58th Congress, 2d Session 1904).

Headstone Type: $\quad 7$

Headstone Inscription:

DR. JOHN R. WARD [name inside banner]
BORN
in Campbell Co. Va.
Feb. $14,1840$.
DIED
in Austin Tex.
Dec. 11,1884
[Scroll design]
SURGEON, 11 th VIRGINIA REG.
A Confederate Soldier
REINTERRED
AUG. 20, 1958

Note: Three lines of block lettering found below the scroll design are of a different style and apparently were added at the time of the 1958 reinterment (i.e., the bottom line and the second and fourth lines from the bottom). 
Mortuary Characteristics:

- Coffin Description: Wrought iron coffin $(207 \times 58 \mathrm{~cm})$ with a viewing window under a pentagonal iron viewing window panel $(70 \times 43 \mathrm{~cm})$ fastened by 3 screws/bolts. There was a rough rectangular hole $(4 \times 2.5 \mathrm{~cm})$ which appeared to have been cut (postmanufacture) into the casket lid about $107 \mathrm{~cm}$ from the west wall and about $17 \mathrm{~cm}$ from the south wall of the casket lid.

- Coffin Orientation: $282^{\circ}$

- Coffin Hardware: 8 Type 16 handles, 28 Type 4 escutcheons with standard dome head screws/bolts.

Cultural and Osteological Characteristics: Because Dr. Ward's coffin was intact and never opened, no additional information was gathered. 


\section{ANALYSIS OF MATERIAL CULTURE}

\section{Helen Danzeiser Dockall}

This chapter describes the material $\cdot$ culture associated with the 57 excavated graves of the Confederate veterans and their spouses. Casket construction and associated hardware are described, as are personal items recovered from the graves. Nonassociated artifacts recovered from the grave shaft or fill (i.e., objects not believed to represent deliberate grave inclusions) are also discussed. Last, intrasite comparisons of variability in mortuary traits, as reflected by caskets and their associated hardware, are made, as are comparisons with other historic cemeteries. Socioeconomic and chronological interpretations of the State Cemetery burial data are considered. When caskets or casket hardware are described, 57 burials are included; however, in discussing personal goods, the sample size is only 56 since the coffin of Burial 57 was not opened.

\section{CASKET DESCRIPTIONS}

All burial receptacles recovered were rectangular caskets, with the exception of one hexagonal coffin (Burial 57) which dates to 1884 but was relocated to the cemetery in 1958 . That the only hexagonal coffin recovered has the earliest date supports archeologically and historically based statements that rectangular burial receptacles date to a later time period than hexagonal coffins. ${ }^{3}$

\footnotetext{
${ }^{3}$ Although not discussed here, Federal soldiers who died while stationed in Austin between ca. 1866 and 1874 were buried in hexagonal coffins (see Chapter 4).
}

Blakely and Beck (1982:188) note that hexagonal coffins are earliest, followed by octagonal and then rectangular caskets. The earliest interment (1891) at the Morgan Chapel Cemetery in Bastrop, Texas, also was placed in a hexagonal coffin (Taylor et al. 1986:43). In general, coffins (represented by hexagonal and octagonal burial cases) gradually were replaced by rectangular caskets in the latter half of the nineteenth century (see Coffin 1976; Earls et al. 1991:12; Farrell 1980; Habenstein and Lamers 1962; Lebo 1988:91; Taylor et al. 1986: 43). Larkin (1988:99) states, "Through the first half of the nineteenth century coffins retained their characteristic and unmistakable shape - flat-sided, with a tapering hexagonal profile that fit the body."

All but four of the excavated caskets were constructed of wood (93 percent); the remaining four were metal. Thirty-nine wood samples from Sections D and F were submitted to J. Philip Dering of the Paleoethnobotany Laboratory at Texas A\&M University. Of these samples, 23 are from caskets, 8 are from outer boxes, and 7 are from either the casket or the outer box. As can be seen in Table 4, most of the caskets $(n=17)$ and outer boxes $(n=6)$ were constructed of hard pine, but bald cypress, maple, spruce, yellow poplar, and juniper also are represented. Historically, pine was a favored wood for coffins because it was easy to work (Larkin 1988:99).

All of the wood types identified were used as casket construction material at other historic cemeteries. For instance, wood identifications made by J. Philip Dering on caskets from the 
TABLE 4

IDENTIFICATION OF WOOD SAMPLES FROM BURIALS

\begin{tabular}{|c|c|c|c|c|}
\hline $\begin{array}{l}\text { Burial/ } \\
\text { Sample No. }\end{array}$ & $\begin{array}{l}\text { Year of } \\
\text { Death }\end{array}$ & Context of Sample & Taxon & $\begin{array}{l}\text { Common } \\
\text { Name* }\end{array}$ \\
\hline $\begin{array}{l}1 \mathrm{a} \\
1 \mathrm{~b}\end{array}$ & 1939 & $\begin{array}{l}\text { Casket } \\
\text { Outer box }\end{array}$ & $\begin{array}{l}\text { Taxodium distichum } \\
\text { Pinus sp. }\end{array}$ & $\begin{array}{l}\text { Bald Cypress } \\
\text { Hard Pine }\end{array}$ \\
\hline 2 & 1931 & Casket & $\begin{array}{l}\text { Indeterminate softwood, } \\
\text { possibly Juniperus sp. } \\
\text { or Taxodium sp. }\end{array}$ & $\begin{array}{l}\text { Juniper or } \\
\text { Bald Cypress }\end{array}$ \\
\hline $\begin{array}{l}4 \mathrm{a} \\
4 \mathrm{~b}\end{array}$ & 1930 & $\begin{array}{l}\text { Casket } \\
\text { Outer box }\end{array}$ & $\begin{array}{l}\text { Acer sp. } \\
\text { Pinus sp. }\end{array}$ & $\begin{array}{l}\text { Maple } \\
\text { Hard Pine }\end{array}$ \\
\hline $\begin{array}{l}5 \mathrm{a} \\
5 \mathrm{~b}\end{array}$ & 1930 & $\begin{array}{l}\text { Casket } \\
\text { Outer box }\end{array}$ & $\begin{array}{l}\text { Picea sp. } \\
\text { Pinus sp. }\end{array}$ & $\begin{array}{l}\text { Spruce } \\
\text { Hard Pine }\end{array}$ \\
\hline $\begin{array}{l}8 \mathrm{a} \\
8 \mathrm{~b}\end{array}$ & 1908 & $\begin{array}{l}\text { Casket } \\
\text { Outer box }\end{array}$ & $\begin{array}{l}\text { Pinus sp. } \\
\text { Acer sp. }\end{array}$ & $\begin{array}{l}\text { Hard Pine } \\
\text { Maple }\end{array}$ \\
\hline 9 & 1908 & Indeterminate (casket?) & Pinus sp. & Hard Pine \\
\hline 10 & 1908 & Indeterminate & Pinus sp. & Hard Pine \\
\hline 11 & 1908 & Indeterminate (casket?) & Pinus sp. & Hard Pine \\
\hline 12 & 1908 & Casket & Pinus sp. & Hard Pine \\
\hline 13 & 1908 & Indeterminate & Indeterminate softwood & \\
\hline 14 & 1908 & Indeterminate & Pinus sp. & Hard Pine \\
\hline 18 & 1908 & Casket & Pinus sp. & Hard Pine \\
\hline 19 & 1908 & Indeterminate (outer box?) & Pinus sp. & Hard Pine \\
\hline 20 & 1908 & Indeterminate (casket?) & Pinus sp. & Hard Pine \\
\hline 23 & 1907 & Wood from core of bar handle & Pinus sp. & Hard Pine \\
\hline 24 & 1907 & Indeterminate & Pinus sp. & Hard Pine \\
\hline 25 & 1907 & Indeterminate & Pinus sp. & Hard Pine \\
\hline 27 & 1908 & Indeterminate (casket?) & Pinus sp. & Hard Pine \\
\hline 28 & 1908 & Indeterminate & Pinus sp. & Hard Pine \\
\hline 29 & 1907 & Indeterminate & Pinus sp. & Hard Pine \\
\hline 30 & 1907 & Indeterminate & Pinus sp. & Hard Pine \\
\hline $\begin{array}{l}31 \mathrm{a} \\
31 \mathrm{~b}\end{array}$ & 1907 & $\begin{array}{l}\text { Casket } \\
\text { Outer box }\end{array}$ & $\begin{array}{l}\text { Populus sp. } \\
\text { Pinus sp. }\end{array}$ & $\begin{array}{l}\text { Yellow Poplar } \\
\text { Hard Pine }\end{array}$ \\
\hline 32 & 1907 & Casket? & Pinus sp. & Hard Pine \\
\hline 33 & 1907 & Indeterminate (outer box?) & Pinus sp. & Hard Pine \\
\hline
\end{tabular}




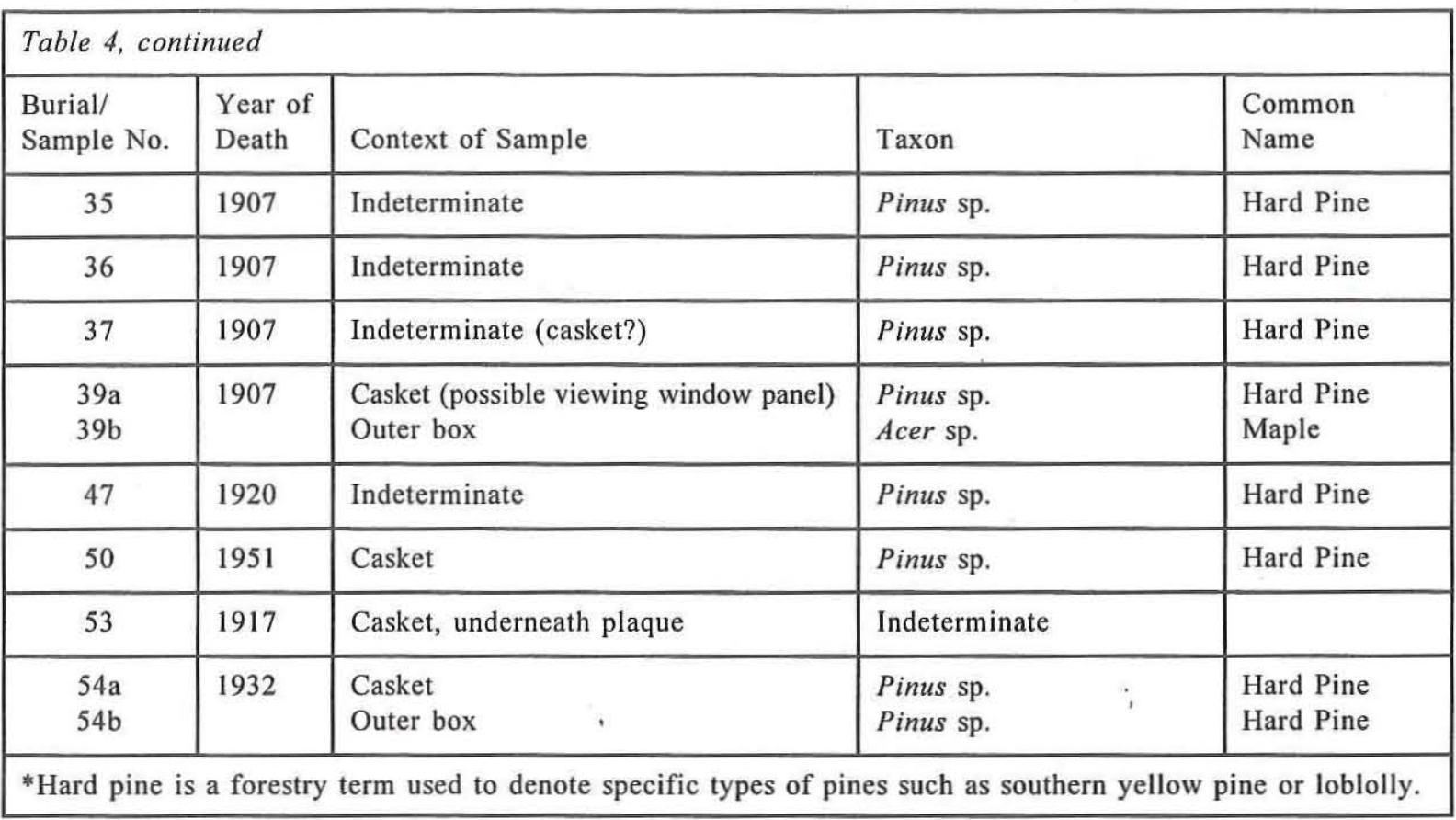

Phillips Memorial Cemetery (Powell and Dockall 1996a) showed that several caskets were constructed of hard pine, while one was fabricated from bald cypress and another was identified as Salicaceae (of which yellow poplar is a member). However, the Phillips Cemetery also had caskets constructed of ash (Fraxinus sp.) and possibly persimmon (Diospyros virginiana), both wood types not identified at the State Cemetery. Outer boxes from the Phillips Cemetery were all constructed from hard pine. Identifiable wood analyzed from coffins at the Morgan Chapel Cemetery showed that caskets were constructed of softwood Pinus sp. (pine), hardwood Prunus sp. (cherry), or indeterminate hardwood (Holloway 1986:Table 6). Coffin wood from the Laredo Cemetery was identified as southern yellow pine (Pinus sp.), spruce (Picea sp.), or cedar (Juniperus sp. or Thuja sp.) (Rogers and McReynolds 1981:87). Samples from four coffins recovered from the Boothill Cemetery in Texas showed that two were constructed of yellow pine, one was white pine, and one was yellow poplar (Earls and Lintz 1991: 95-96). In addition, one coffin from the Coffey Cemetery (Texas) was identified as southern yellow pine (Earls and Lintz 1991:116). Wood samples from caskets recovered from the Uxbridge Almshouse Cemetery in Massachusetts documented that the majority were pine, but pine and yellowpoplar, yellow-poplar, and possibly chestnut also were used (Hansen 1991:Table 27).

The dimensions of the excavated caskets are displayed in Table 5. Average length is $198.5 \mathrm{~cm}$ and average width is $58.6 \mathrm{~cm}$. Average dimensions of only the wooden caskets are $198.3 \times 57.5 \mathrm{~cm}$. The metal caskets are larger and average $201 \times 69.5 \mathrm{~cm}$. All wooden caskets were constructed with the grain running parallel to the long axis and do not appear to have been of a made-tofit nature. Table 6 shows casket length, with an associated stature estimate, for each burial. It can be seen that 18 individuals were at least $30 \mathrm{~cm}$ shorter than their wooden casket length. Furthermore, two individuals (Burials 39 and 42, both males) were buried in wooden caskets that were over $50 \mathrm{~cm}$ longer than their estimated statures. There are no examples of individuals being forced into a casket that was too small for them, as has been identified at some other historic cemeteries (see Bell 1991:264). The discrepancies between casket length and estimated stature at death suggest that these caskets were mass produced. HackerNorton and Trinkley (1984:7) suggest that massproduced caskets did not become popular in rural areas of the South until the 1920s; information from the State Cemetery suggests that this accep- 
TABLE 5

CASKET DIMENSIONS

\begin{tabular}{|c|c|c|c|c|c|}
\hline Burial No. & Length $(\mathrm{cm})$ & Width $(\mathrm{cm})$ & Burial No. & Length $(\mathrm{cm})$ & Width $(\mathrm{cm})$ \\
\hline 1 & 206 & 50 & 30 & 183 & ca. 48 \\
\hline 2 & 220 & - & 31 & 213 & 61 \\
\hline 3 & 212 & 47 & 32 & 184 & 50 \\
\hline 4 & 201 & 57 & 33 & 196 & 60 \\
\hline 5 & 207 & 66 & 34 & 210 & 70 \\
\hline 6 & 217 & 49.5 & 35 & 203 & 55 \\
\hline 7 & ca. 170 & - & 36 & 199 & 62 \\
\hline 8 & 196 & 55 & 37 & 185 & 63 \\
\hline 9 & 190 & 55 & 38 & - & - \\
\hline 10 & 190 & . & 39 & $223^{\prime}$ & 68 \\
\hline 11 & 198 & 62 & 40 & 193 & 63 \\
\hline 12 & 195 & 55 & 41 & - & - \\
\hline 13 & 203 & 63 & 42 & 217 & 65 \\
\hline 14 & 170 & 45 & 43 & 193 & 65 \\
\hline 15 & 195 & 55 & 44 & 204 & 59 \\
\hline 16 & 200 & 44 & 45 & - & - \\
\hline 17 & 198 & 57 & 46 & 195 & 70 \\
\hline 18 & 213 & 56 & 47 & 204 & 55 \\
\hline 19 & 197 & 62 & $48 *$ & 193 & 60 \\
\hline 20 & 197 & 62 & 49 & 200 & 58 \\
\hline 21 & 194 & 58 & 50 & 202 & 60 \\
\hline 22 & 190 & 58 & $51^{*}$ & 202 & 80 \\
\hline 23 & - & - & $52 *$ & 202 & 80 \\
\hline 24 & - & - & 53 & - & - \\
\hline 25 & 207 & 68 & 54 & 200 & 48 \\
\hline 26 & 185 & 44 & 55 & 198 & 63 \\
\hline 27 & 198 & 54 & 56 & - & - \\
\hline 28 & 181 & ca. 52 & $57^{*}$ & 207 & 58 \\
\hline 29 & 190 & 57 & \multicolumn{3}{|l|}{${ }^{*}$ Metal caskets } \\
\hline $\begin{array}{l}\text { Wood only } \\
\text { Metal only } \\
\text { Combined }\end{array}$ & $\begin{array}{l}\text { Leng } \\
\bar{x}=19 \\
\bar{x}=20 \\
\bar{x}=19\end{array}$ & $\begin{array}{l}\sigma=11 \\
\sigma=5 . \\
\sigma=11 .\end{array}$ & $\begin{array}{l}\frac{\text { Width }}{=57.5} \\
\bar{x}=69.5 \\
\bar{x}=68.6 \\
\bar{x}=58.0\end{array}$ & $\begin{array}{lr}\sigma= & 6.9 \\
\sigma= & 12.2 \\
\sigma= & 8.1\end{array}$ & \\
\hline
\end{tabular}




\begin{tabular}{|c|c|c|c|c|c|}
\hline \multicolumn{6}{|c|}{$\begin{array}{c}\text { TABLE } 6 \\
\text { COMPARISON OF CASKET LENGTH TO ESTIMATED STATURE }\end{array}$} \\
\hline Burial No. & $\begin{array}{l}\text { Casket } \\
\text { Length }(\mathrm{cm})\end{array}$ & $\begin{array}{l}\text { Estimated } \\
\text { Stature }(\mathrm{cm})\end{array}$ & Burial No. & $\begin{array}{l}\text { Casket } \\
\text { Length }(\mathrm{cm})\end{array}$ & $\begin{array}{l}\text { Estimated } \\
\text { Stature }(\mathrm{cm})\end{array}$ \\
\hline 1 & 206 & - & 29 & 190 & 179.2 \\
\hline 2 & 220 & - & 30 & 183 & 169.4 \\
\hline 3 & 212 & 177.4 & 31 & 213 & 181.5 \\
\hline 4 & 201 & 173.3 & 32 & 184 & 169.7 \\
\hline 5 & 207 & 176.0 & 33 & 196 & 179.8 \\
\hline 6 & 217 & 184.1 & 34 & 210 & 179.5 \\
\hline 7 & ca. 170 & - & 35 & 203 & 173.8 \\
\hline 8 & 196 & 177.7 & 36 & 199 & 165.2 \\
\hline 9 & 190 & '- & 37 & 185 & 170.3 \\
\hline 10 & 190 & 175.6 & 38 & - & 175.6 \\
\hline 11 & 198 & 174.9 & 39 & 223 & 162.0 \\
\hline 12 & 195 & 172.0 & 40 & 193 & 172.8 \\
\hline 13 & 203 & 173.7 & 41 & - & 160.9 \\
\hline 14 & 170 & 163.7 & 42 & 217 & 165.0 \\
\hline 15 & 195 & 162.7 & 43 & 193 & 178.4 \\
\hline 16 & ca. 200 & 182.2 & 44 & 204 & 171.3 \\
\hline 17 & 198 & 169.2 & 45 & - & 174.0 \\
\hline 18 & 213 & 174.5 & 46 & 195 & 163.6 \\
\hline 19 & 197 & 174.6 & 47 & 204 & 169.3 \\
\hline 20 & 197 & 165.3 & $48^{*}$ & 193 & 153.2 \\
\hline 21 & 194 & 165.7 & 49 & 200 & 171.7 \\
\hline 22 & 190 & 176.2 & 50 & 202 & 167.0 \\
\hline 23 & - & 166.5 & $51^{*}$ & 202 & 152.4 \\
\hline 24 & - & 170.3 & $52^{*}$ & 202 & 175.3 \\
\hline 25 & 207 & 174.8 & 53 & - & 170.1 \\
\hline 26 & 185 & 167.6 & 54 & 200 & 158.4 \\
\hline 27 & 198 & 171.4 & 55 & 198 & 158.3 \\
\hline 28 & 181 & 165.0 & 56 & - & 166.0 \\
\hline
\end{tabular}


tance began earlier, at least by 1907 , in urban areas.

All of the metal burial containers (i.e., a metal coffin from Burial 57 and three metal caskets from Burials 48, 51, and 52) were recovered from Section D. Two were associated with women and two with men; all date to the 1920 s and 1930s except for one 1884 interment. The caskets recovered from Burials 48,51 , and 52 appeared to have been constructed from sheet iron. In all cases, the lids had collapsed into the main portion of the casket and soil had invaded the interior portion, just as in the wooden caskets. The casket used to inter Mrs. Kyser (Burial 48) had a twosectioned flat lid with a large cross piece in the center of the lid. The metal caskets associated with the Pannells (Burials 51 and 52) were identical (Figure 18). Each had a two-sectioned vaulted lid with both sections designed to slide from the head along the lipped upper edges of the casket walls. The construction of this casket would have permitted placing just the lower half of the lid on the casket while leaving the upper portion off for viewing of the deceased. No evidence of paint was observed.

The coffin associated with Dr. John Ward (Burial 57) was the most elaborate burial receptacle (Figures 19 and 20). It was constructed of cast or wrought iron and was still intact, in spite of its having been buried since 1884 (i.e., for 111 years) and moved in 1958. Because the coffin had thick iron walls that had not deteriorated to the extent of others in the cemetery, it was removed intact. The coffin was hexagonal in shape, and the sides tapered in toward the bottom. The lid had ornamental tiers, and a viewing window (still intact) was inset into the upper portion of the lid. This window was covered by an intact wrought iron panel that was fastened by three bolts/screws. A roughly rectangular opening $(4 \times 2.5 \mathrm{~cm})$ in the

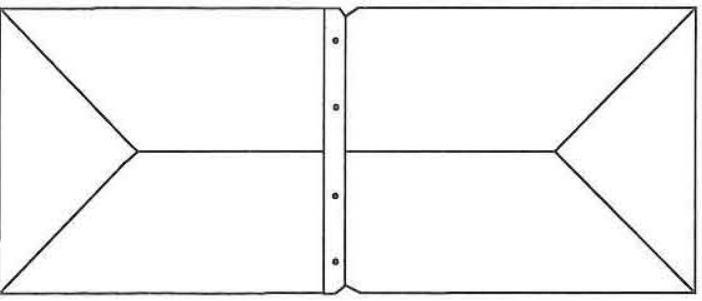

Two-Part Top Section
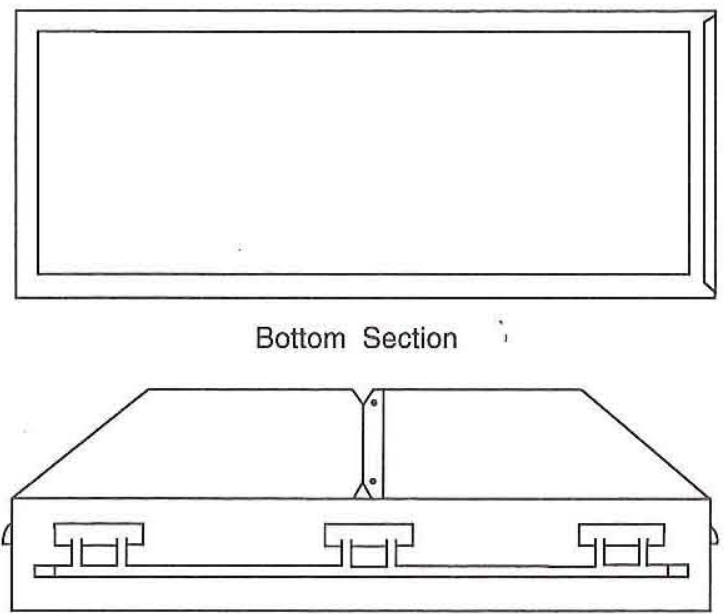

Side Profile

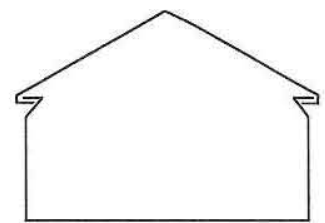

Cross Section

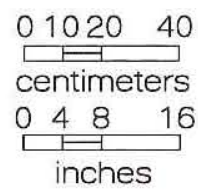

$P \& A I / 96 / B W$

Figure 18. Metal casket associated with Burials 51 and 52.

right side of the lid near the hand area (see Figure 20) was not part of the original fabrication of the coffin. A possible explanation is that for some reason the people responsible for Dr. Ward's original relocation to the State Cemetery in 1958 might have cut a hole into his coffin lid, although it is hard to imagine why this would have been done, and it is not clear why the hole was located in the area of the right hand. Had the original crew wanted to look into the coffin for some reason, they could have either opened the viewing window panel or cut a larger hole into a different region of the lid. It is obvious that they were not attempting to drain accumulated water from the coffin, because had that been the desired effect, 


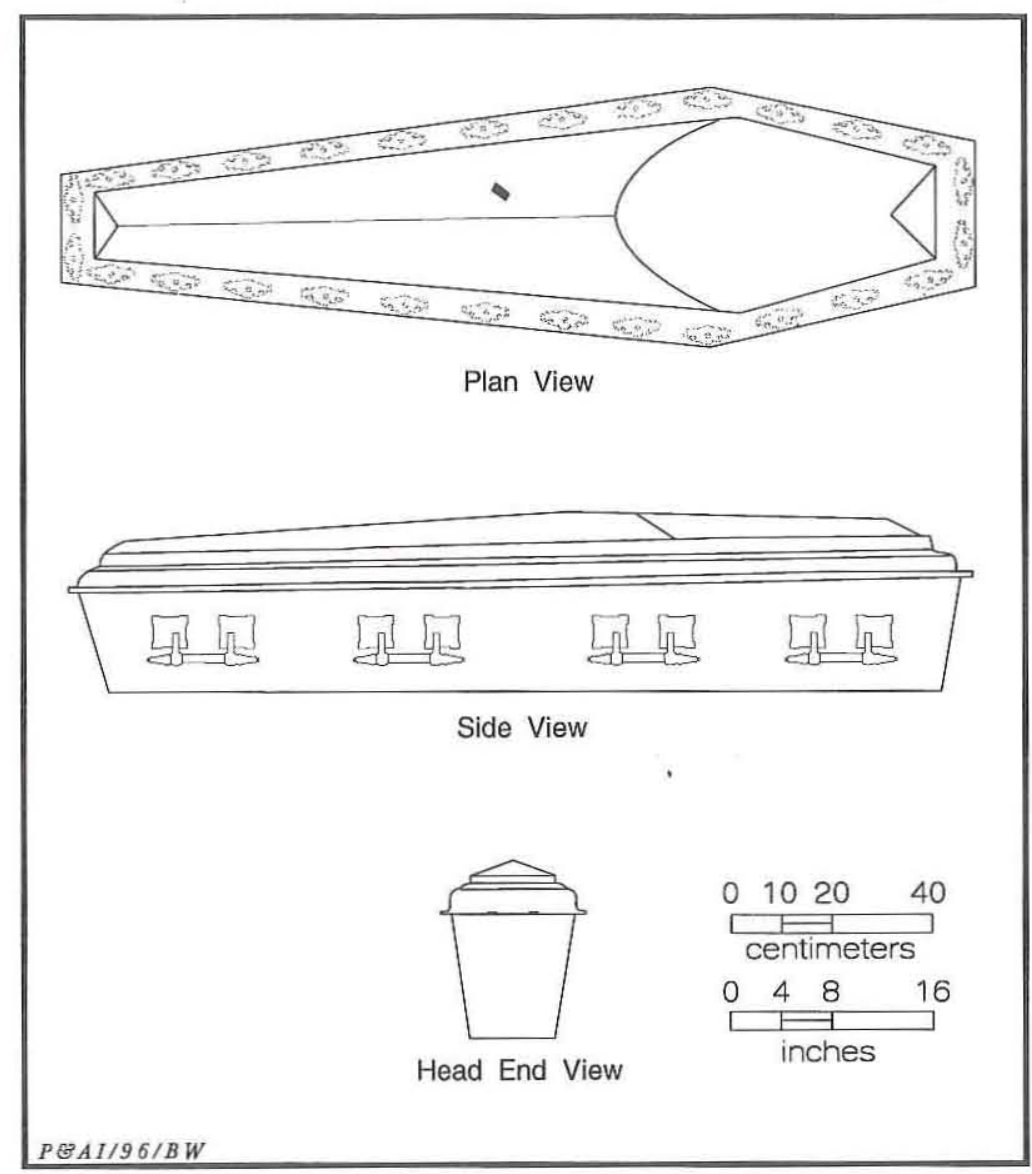

Figure 19. Metal coffin associated with Burial 57.

accommodated a life saving device that was added to the coffin after its manufacture. This device may have been removed in 1958 when the casket was relocated to the State Cemetery.

\section{Outer Boxes}

It is not uncommon for caskets to be placed into an outer box to protect the casket when it is shipped and to protect it from overburden when it is buried. Until the 1870 s, this outer box was buried simply as a means of disposing of it (Habenstein and Lamers 1962:302), although it came to serve the same function as a metal or cement vault. Further support for the idea that the caskets at the State Cemetery were mass produced may be found in the presence of outer boxes at the site, if these outer boxes were used as shipping containers as well as burial vaults (see Powell and Dockall 1996b). Twenty-three (40.4 percent) of the 57 burials excavated contained

they would have cut the hole into the coffin bottom, not the lid.

A second possible explanation for the hole in Dr. Ward's coffin relates to life-saving devices that were used most commonly during the late $1880 \mathrm{~s}$ (see Habenstein and Lamers 1962). These devices were purchased by some individuals to insure that they (or their loved ones) were not accidentally buried while still alive. One such device, invented in 1868 , ". . . consisted of a square tube, containing a ladder and a cord, one end of which was to be placed in the hand of the person laid in the coffin, while the other extended up to a bell on the top of the tube which was attached to the head of the coffin" (Habenstein and Lamers 1962:288). At least two other life signal devices, patented just 2 years before Dr. Ward's death, also were operated through hand movements, rather than speaking tubes (see Habenstein and Lamers 1962). It is possible that the rectangular shape cut into the right hand area of Dr. Ward's coffin lid originally evidence of outer boxes; in 10 cases ( 17.5 percent), the presence of an outer box was indeterminate. The outer box recovered from Burial 19 provides the best evidence of the method of construction. The top and bottom were manufactured from numerous transverse planks that were perpendicular to the long axis and direction of wood grain of the casket. The lid of the box with Burial 19 had two narrow longitudinal strips nailed to the tops of the planks. The outer boxes associated with these burials seem to have been of a simpler construction than the late-nineteenth-century boxes illustrated in Habenstein and Lamers (1962:Figure 26). Those boxes, constructed of cedar, chestnut, oak, and mahogany, had tops that appear to have been one complete sheet of wood, and the corners had protective, decorative braces.

\section{Decorative Paint and Grooving}

Remnants of paint pigment were observed on 


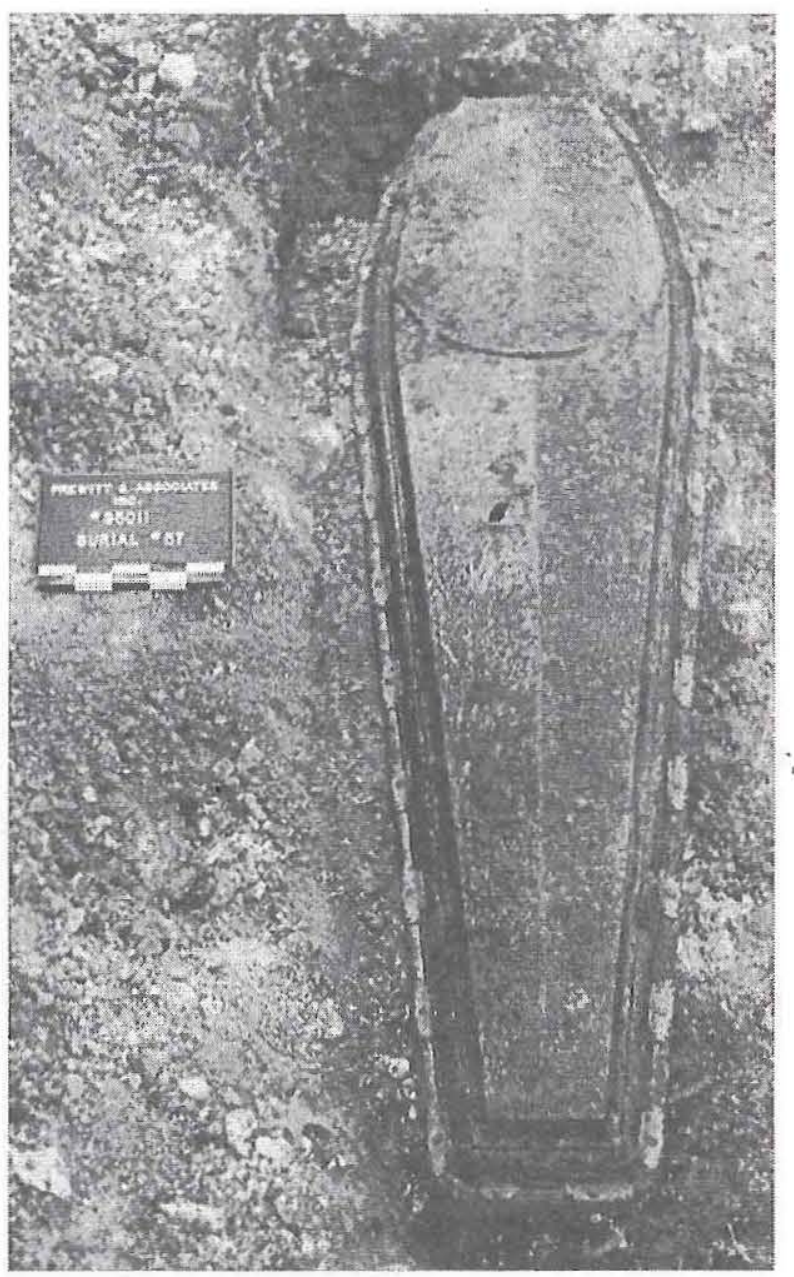

a

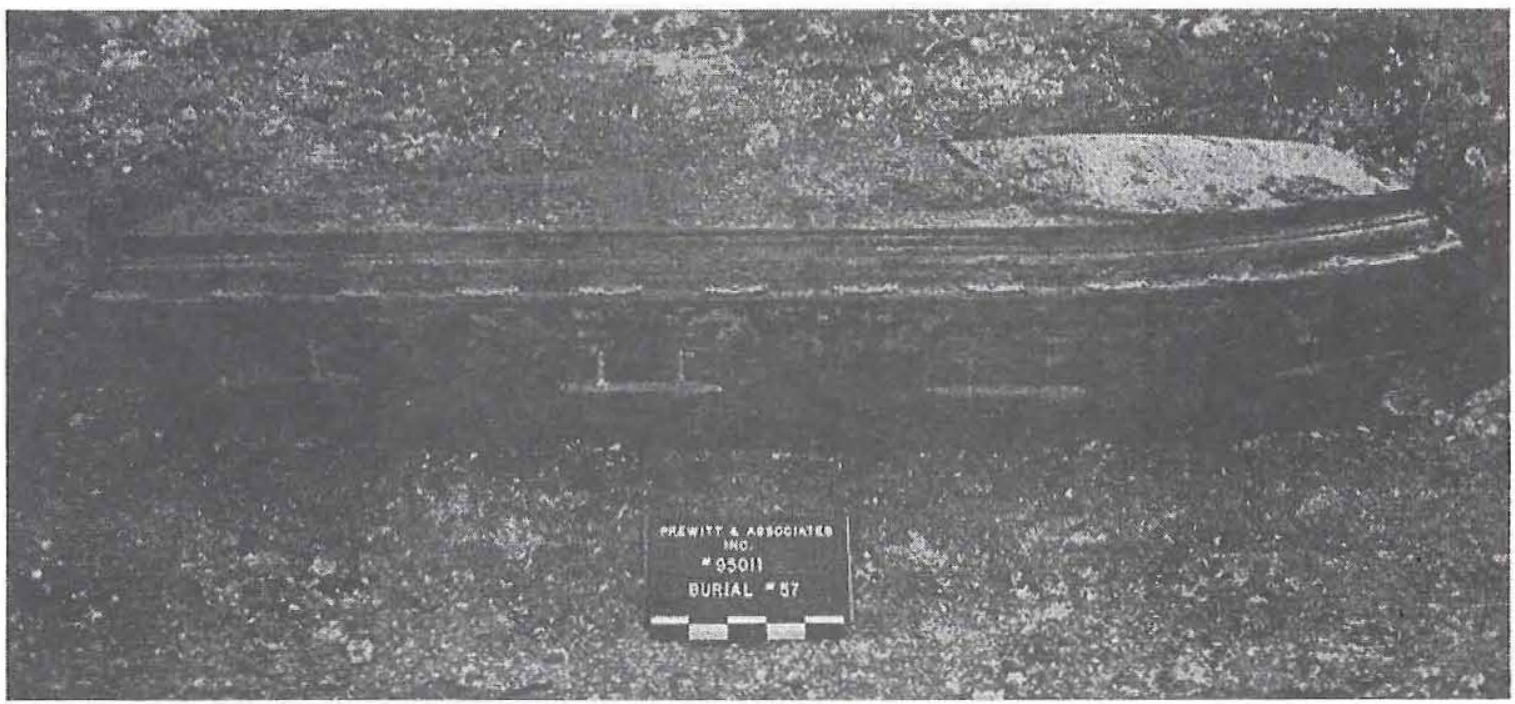

b

Figure 20. Top (a) and side $(b)$ views of metal coffin of Burial 57 in situ. 
caskets associated with five burials ( 8.8 percent). Burials 4, 5, and 19 all showed evidenced of red pigment; these burials had outer boxes as well as caskets. In the cases of Burials 5 and 19, it appears that the pigment was on the casket itself; however, it is not clear if the pigment on Burial 4 was associated with the casket or the outer box. Yellow/gold pigment was noted with Burials 29 and 31. The paint with Burial 29 seems to have been on the interior of the casket, but the paint with Burial 31 appears to have been on the casket lid. Ornamental grooves were noted only on the exterior casket walls of Burial 1, belonging to a woman interred in 1939. Burial receptacles with evidence of paint have been recovered from a number of other cemeteries, including Cedar Grove (Rose 1985), Phillips (Powell and Dockall 1996a), Laredo (McReynolds 1981), Morgan Chapel (Taylor et al. 1986), and Boothill (O'Neill et al. 1991). In all likelihood, the low frequency of observed decorative paint and grooving on caskets from the State Cemetery reflects relatively poor preservation of the wood and metal surfaces rather than limited use of painted coffins.

\section{Padding}

Only one burial yielded any evidence of padding. A gray cotton/wool material was observed on the casket floor of Burial 50, a female buried in 1951 . This padding probably originally was covered with a piece of fabric. Paddings composed of pine shavings (Pinus taeda) were recovered from five burials at the Phillips Memorial Cemetery (Powell and Dockall 1996a). Wood shavings also were used as padding in burials at the First African Baptist Church Cemetery (Parrington and Roberts 1990:Figure 9.5), while grass or hay was used to line a few coffins from the Uxbridge Almshouse Burial Ground (Bell 1991:280-281). As mentioned above for decorative paint and grooves, the limited evidence for the use of padding inside caskets at the State Cemetery is probably due to poor preservation.

\section{CASKET HARDWARE}

The excavations yielded a variety of mortuary hardware, consisting primarily of casket handles, thumbscrews, escutcheons, caplifters, and plaques. All distinct varieties of these items were assigned type numbers in the field. This facilitated note taking and record keeping since subsequent recovery of an already known type could be discussed by type number. This section describes the types of mortuary hardware associated with each burial. Unless otherwise specified, all casket hardware was made of white metal, which is "any of several types of lead or tin based metals and in coffin hardware was probably lead based" (Hacker-Norton and Trinkley 1984:11). Terminology used in this section follows Hacker-Norton and Trinkley (1984). The various types of casket hardware associated with each burial are summarized in Table 7. When applicable, comparisons of hardware from the State Cemetery are made with hardware found at other historic cemeteries for which published data are available. The Freedman's Cemetery, a recently excavated large African-American cemetery in Dallas, yielded a large casket hardware data set. However, this information is not yet published so it is not used here as a comparative data set.

\section{Viewing Windows}

Viewing windows were associated with the upper portions of container lids in 22 of the 57 burials (38.6 percent; see Table 7). One style of viewing window was associated with the 1884 coffin, while five styles were associated only with 1907 and 1908 wooden caskets (Table 8, Figure 21). Although the intact 1884 casket was not opened, its viewing window is presumed to be approximately the same size and shape as the sealed shield-shaped pentagonal panel covering it (see Figure 19). If so, then it would have been the largest of all of the viewing windows.

The 21 viewing windows on 1907 and 1908 wooden caskets were quite varied, but it should be noted that exact sizes and shapes were difficult to determine in most cases. All viewing windows were broken in place, probably when the casket lids collapsed down into the box. In a few cases, the glass fragments approximated the configuration of the original window, but more commonly the fragments were scattered. Consequently, the excavators often had to approximate the dimensions and outline of the viewing windows. Because of this, the relative outlines and sizes of glass windows shown in Figure 21 are considered approximations of the various styles and should not 


\begin{tabular}{|c|c|c|c|c|c|c|c|c|c|c|c|c|}
\hline & & & & & & $\begin{array}{r}\text { TABLE } \\
\text { SKET HA }\end{array}$ & $\begin{array}{l}\text { E } 7 \\
\text { RDWARE }\end{array}$ & & & & & \\
\hline $\begin{array}{l}\text { Burial } \\
\text { No. }\end{array}$ & $\begin{array}{l}\text { Date of } \\
\text { Burial }\end{array}$ & $\begin{array}{l}\text { Viewing } \\
\text { Window }\end{array}$ & $\begin{array}{l}\text { Handle } \\
\text { Type }\end{array}$ & $\begin{array}{l}\text { Escutcheon } \\
\text { Type }\end{array}$ & $\begin{array}{l}\text { Thumbscrew } \\
\text { Type }\end{array}$ & $\begin{array}{l}\text { Latch } \\
\text { Type }\end{array}$ & $\begin{array}{l}\text { Caplifter } \\
\text { Type }\end{array}$ & Plaque & $\begin{array}{l}\text { No. of } \\
\text { Decorative } \\
\text { Ornaments }\end{array}$ & $\begin{array}{l}\text { No. of } \\
\text { Tack Heads }\end{array}$ & $\begin{array}{l}\text { No. of } \\
\text { Nails/(Screws) }\end{array}$ & $\begin{array}{l}\text { No. of } \\
\text { Corrugated } \\
\text { Fasteners }\end{array}$ \\
\hline 1 & 1939 & & 10 & & & & & $x$ & & & 6 & \\
\hline 2 & 1931 & & 10 & & & & & & & & 15 & \\
\hline 3 & 1931 & & 10 & & & 2,3 & & $\mathrm{x}$ & & & 9 & \\
\hline 4 & 1931 & & 10 & & & $2,3 ?$ & & $\mathrm{x}$ & & & 17 & \\
\hline 5 & 1930 & & 10 & & & $1,2,3 ?$ & & $\mathrm{x}$ & & & 22 & \\
\hline 6 & 1930 & & 10 & & & & & & & & 2 & \\
\hline 7 & 1908 & $\mathrm{x}$ & 1 & 1,3 & 1,2 & & & & & 2 & 13 & \\
\hline 8 & 1908 & $\mathrm{x}$ & 1 & 1,3 & 1,2 & 5 & & & & 4 & & \\
\hline 9 & 1908 & & 1 & 1 & 1 & $2,3 ?$ & & & 1 & & 11 & \\
\hline 10 & 1908 & & 2 & & & 1,2 & & & & 1 & 48 & \\
\hline 11 & 1908 & & 2 & & & 2,3 & 1 & & & & 33 & \\
\hline 12 & 1908 & $\mathrm{x}$ & 1 & 1,3 & 1,2 & & & & & & & \\
\hline 13 & 1908 & & 2 & & & $2,2 / 3,4$ & 1 & & & & 54 & \\
\hline 14 & 1908 & $x$ & 1 & 1,3 & 1 & & & & $\therefore$ & 2 & (25) & \\
\hline 15 & 1908 & $\mathrm{x}$ & 1 & 1,3 & 1,2 & & & & 1 & $\mathrm{x}$ & 38 & \\
\hline 16 & 1908 & & 1 & & & & & & & 1 & 22 & \\
\hline 17 & 1908 & $\mathrm{x}$ & 3 & 1 & 3,2 & & & & $\mathrm{x}$ & & 51 & \\
\hline 18 & 1908 & $x$ & 1 & 1 & 3,2 & & & & & $x$ & 74 & \\
\hline
\end{tabular}




\begin{tabular}{|c|c|c|c|c|c|c|c|c|c|c|c|c|}
\hline \multicolumn{13}{|c|}{ Table 7, continued } \\
\hline $\begin{array}{l}\text { Burial } \\
\text { No. }\end{array}$ & $\begin{array}{l}\text { Date of } \\
\text { Burial }\end{array}$ & $\begin{array}{l}\text { Viewing } \\
\text { Window }\end{array}$ & \begin{tabular}{|l} 
Handle \\
Type
\end{tabular} & $\begin{array}{l}\text { Escutcheon } \\
\text { Type }\end{array}$ & $\begin{array}{l}\text { Thumbscrew } \\
\text { Type }\end{array}$ & $\begin{array}{l}\text { Latch } \\
\text { Type }\end{array}$ & $\begin{array}{l}\text { Caplifter } \\
\text { Type }\end{array}$ & Plaque & $\begin{array}{l}\text { No. of } \\
\text { Decorative } \\
\text { Ornaments }\end{array}$ & $\begin{array}{l}\text { No. of } \\
\text { Tack Heads }\end{array}$ & $\begin{array}{l}\text { No. of } \\
\text { Nails/(Screws) }\end{array}$ & $\begin{array}{l}\text { No. of } \\
\text { Corrugated } \\
\text { Fasteners }\end{array}$ \\
\hline 19 & 1908 & $x$ & 1 & 1,3 & 1,2 & & & & 1 & & 37 & \\
\hline 20 & 1908 & $\mathrm{x}$ & 3 & 1 & 3 & & & & 3 & $\mathrm{x}$ & 88 & \\
\hline 21 & 1908 & $\mathrm{x}$ & 3 & 1,3 & 3,2 & & & & 2 & $x$ & 53 & \\
\hline 22 & 1908 & & 7 & 1 & 3 & & & & & & 31 & \\
\hline 23 & 1907 & & 2 & & & 2 & & & & & 22 & \\
\hline 24 & 1907 & $\mathrm{x}$ & 2 & 2,3 & 4,5 & & & & & 2 & 24 & 1 \\
\hline 25 & 1907 & $\mathrm{x}$ & 2 & 1 & 3,5 & & & & 1 & 2 & 18 & \\
\hline 26 & 1908 & 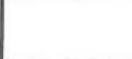 & 1 & 1 & 3,5 & & & & & $x$ & & 5 \\
\hline 28 & 1908 & $x$ & 1 & 1 & 3,5 & & & & & 7 & 24 & \\
\hline 29 & 1907 & $\mathrm{x}$ & 2 & 1 & 3,5 & & & & & 4 & 47 & 4 \\
\hline 30 & 1907 & $x$ & 2 & 1 & 4 & 5 & & & & 1 & 15 & \\
\hline 31 & 1907 & $\mathrm{x}$ & 2 & 1 & 4,5 & 5 & & & & & 37 & 3 \\
\hline 32 & 1907 & $\mathrm{x}$ & 2 & 2 & 4,5 & & & & & & 27 & \\
\hline 33 & 1907 & $x$ & 2 & 2,3 & 4,2 & 5 & & &.- & 1 & 49 & 3 \\
\hline 34 & 1907 & & 2 & & & 2 & 2 & $\mathrm{x}$ & & & 19 & \\
\hline 35 & 1907 & & 5 & & & $1,2,3,4$ & & & & & 79 & \\
\hline 36 & 1907 & & 5 & & & $1,2,3$ & & & & & 93 & \\
\hline 37 & 1907 & . & 2 & & & 2 & & & & & 19 & 1 \\
\hline
\end{tabular}




\begin{tabular}{|c|c|c|c|c|c|c|c|c|c|c|c|c|}
\hline \multicolumn{13}{|c|}{ Table 7, continued } \\
\hline $\begin{array}{l}\text { Burial } \\
\text { No. }\end{array}$ & $\begin{array}{l}\text { Date of } \\
\text { Burial }\end{array}$ & $\begin{array}{l}\text { Viewing } \\
\text { Window }\end{array}$ & $\begin{array}{l}\text { Handle } \\
\text { Type }\end{array}$ & $\begin{array}{l}\text { Escutcheon } \\
\text { Type }\end{array}$ & $\begin{array}{l}\text { Thumbscrew } \\
\text { Type }\end{array}$ & $\begin{array}{l}\text { Latch } \\
\text { Type }\end{array}$ & $\begin{array}{l}\text { Caplifter } \\
\text { Type }\end{array}$ & Plaque & $\begin{array}{l}\text { No. of } \\
\text { Decorative } \\
\text { Ornaments }\end{array}$ & $\begin{array}{l}\text { No. of } \\
\text { Tack Heads }\end{array}$ & $\begin{array}{l}\text { No. of } \\
\text { Nails/(Screws) }\end{array}$ & $\begin{array}{l}\text { No. of } \\
\text { Corrugated } \\
\text { Fasteners }\end{array}$ \\
\hline 38 & 1907 & & 2 & & & 2 & & & & & & 3 \\
\hline 39 & 1907 & $\mathrm{x}$ & 2 & 2,3 & 3,5 & & & & 1 & $\mathrm{x}$ & 57 & \\
\hline 40 & 1907 & & 2 & 2 & 3 & & & & & 5 & 5 & \\
\hline 41 & 1907 & & 6 & & & & & & & & & 5 \\
\hline 42 & 1907 & & 2 & 2 & 3 & & & & 2 & 2 & 52 & \\
\hline 43 & 1907 & & 2 & 2 & 3 & & & & & $\mathrm{x}$ & 51 & \\
\hline 44 & 1907 & & 4 & 2 & 3 & & & & & $\mathrm{x}$ & 39 & \\
\hline 45 & 1907 & $\mathrm{x}$ & 6 & 2,3 & 3,5 & & & & & & 16 & \\
\hline 46 & 1907 & & 6 & & & $2,3,4$ & & & & & 12 & \\
\hline 47 & 1920 & & 12 & & & & 4 & $\mathrm{x}$ & & & 36 & \\
\hline 48 & 1923 & & 14 & & & & & $\mathrm{x}$ & & & & \\
\hline 49 & 1925 & & 11 & & & & & $\mathrm{x}$ & & & 14 & 8 \\
\hline 50 & 1951 & & 15 & & & & & & & & 4 & \\
\hline 51 & 1931 & & 14 & & & & & & & & & \\
\hline 52 & 1931 & & 14 & & & & & & .. & & & \\
\hline 53 & 1917 & & 8 & & & & 3 & $\mathrm{x}$ & & & 23 & 3 \\
\hline 54 & 1932 & & 9 & & & $1,2,3$ & & $\mathrm{x}$ & & & 23 & \\
\hline 55 & 1931 & & 13 & & & $1,2,3$ & & $\mathrm{x}$ & & & 16 & \\
\hline 56 & 1932 & . & 10 & & & 2,3 & & $\mathrm{x}$ & & & 13 & 5 \\
\hline 57 & 1884 & $\mathrm{x}$ & 16 & 4 & & & & & & & & \\
\hline
\end{tabular}




\begin{tabular}{|c|c|c|c|c|c|c|c|}
\hline \multicolumn{8}{|c|}{$\begin{array}{c}\text { TABLE } 8 \\
\text { VIEWING WINDOWS }\end{array}$} \\
\hline Burial No. & Small Oval & Large Oval & Rectangle & Cut Oval & Cut/Canted Oval & Shield & Unknown \\
\hline $\begin{array}{c}7 \\
8 \\
12 \\
14 \\
15 \\
17 \\
18 \\
19 \\
20 \\
21 \\
24 \\
25 \\
27 \\
28 \\
29 \\
30 \\
31 \\
32 \\
33 \\
39 \\
45 \\
57^{*}\end{array}$ & $\begin{array}{c}\mathrm{x} \\
\mathrm{x} \\
\mathrm{x}\end{array}$ & $\begin{array}{l}\mathrm{x} \\
\mathrm{x} \\
\mathrm{x} \\
\mathrm{x} \\
\mathrm{x} \\
\mathrm{x}\end{array}$ & $\mathrm{x}$ & $\begin{array}{l}\mathrm{x} \\
\mathrm{x}\end{array}$ & $\begin{array}{l}x \\
x\end{array}$ & $\mathrm{x}$ & $\begin{array}{l}x \\
x \\
\\
\\
x\end{array}$ \\
\hline $\begin{array}{l}\text { No. of } \\
\text { Occurrences }\end{array}$ & 5 & 7 & 1 & 3 & 2 & 1 & 3 \\
\hline
\end{tabular}

be considered well-defined types.

The most common styles of 1907-1908 viewing windows were the small (ca. $40 \times 20 \mathrm{~cm}$ ) and large (ca. $55 \times 34 \mathrm{~cm}$ ) ovals observed in 12 of the 21 caskets (57.1 percent). Two viewing window styles basically were variations of ovals. Called a cut oval and a canted/cut oval, these styles were observed on five caskets (23.8 percent). The cut ovals were approximately the same size (ca. $54 \times 36 \mathrm{~cm}$ ) or slightly smaller (ca. $50 \times 32 \mathrm{~cm}$ ) than the larger plain ovals, while the cut/canted ovals were the same size (ca. $54 \times 36 \mathrm{~cm}$ ) and very slightly smaller (ca. $47 \times 32 \mathrm{~cm}$ ). A plain rectangular (ca. $60 \times 20 \mathrm{~cm}$ ) viewing window was present on only one casket (4.8 percent), and only three viewing windows (14.3 percent) were so disturbed that they could not be assigned to a general style. Viewing windows have been observed at many other historic cemeteries, including
Cedar Grove (Rose 1985), Morgan Chapel (Taylor et al. 1986), Tucker (Lebo 1988), Laredo (McReynolds 1981), Boothill (O'Neill et al. 1991), and Uxbridge (Bell 1991).

\section{Casket Handles}

Sixteen types of casket handles were recovered. All caskets had double lug swing bail, double lug short bar, or extension bar handles with single lugs. The typical pattern of handle placement consisted of two or three handles on each long wall. Twenty-four of 51 caskets $^{4}$ (47.1 percent) had a total of six handles, while 26 (51.0 percent) had only four handles. A single coffin, dating to 1884 , deviated from the typical patterns

${ }^{4}$ Excludes caskets with extension bar handles. 


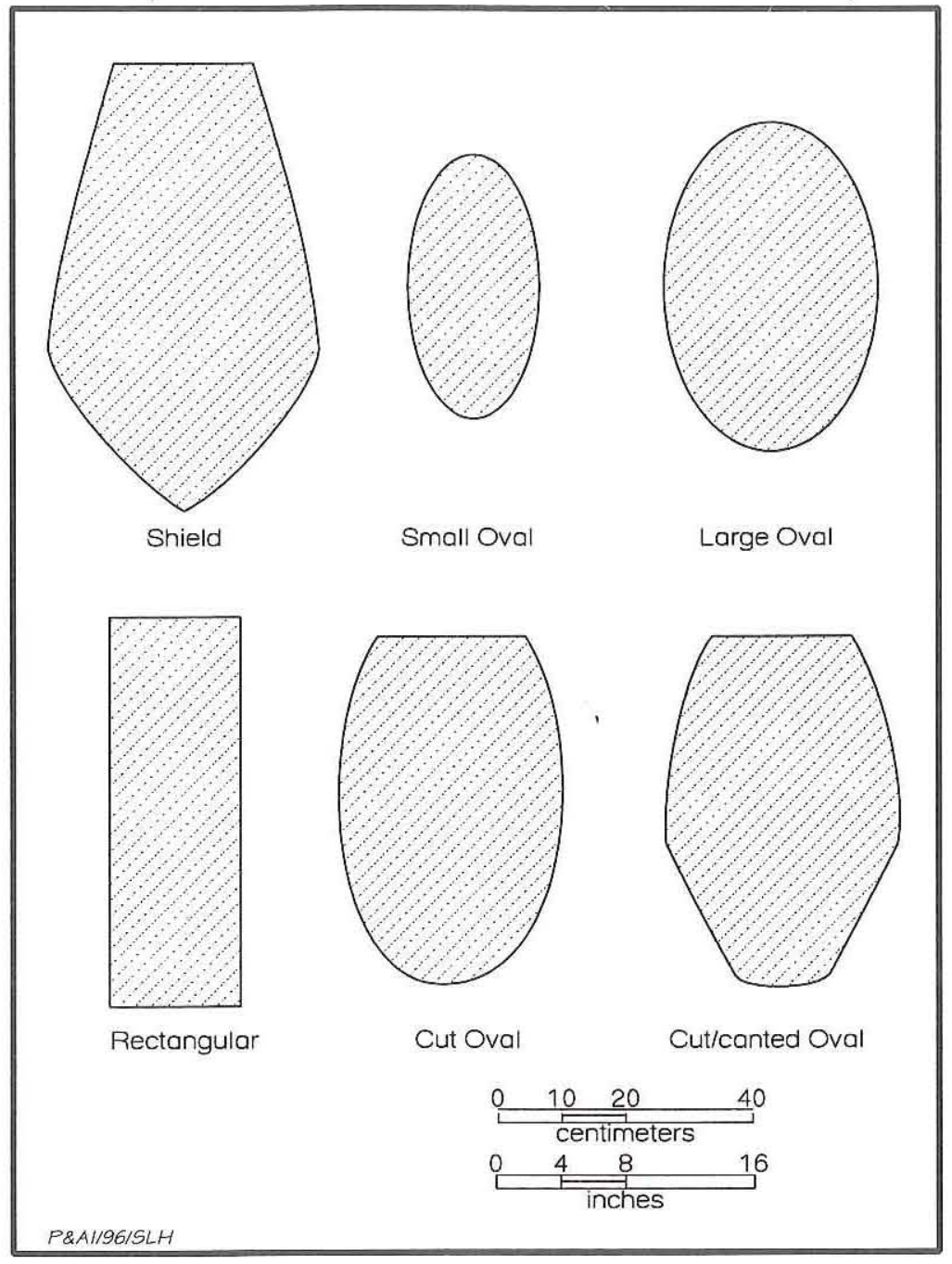

Figure 21. Viewing window styles.

and had eight handles. The casket handle types defined for the State Cemetery, categorized by handle form, are as follows: double lug swing bail (Types 1, 3, 4, and 7); double lug short bar (Types $2,5,6,8,12,12,13$, and 16), and extension bar with single lug (Types 9, 11, 14, and 15). Each of these handle forms is discussed in more detail below.

The number of handles per casket is generally associated with handle type. For instance, in all cases except one (Burial 34), Type 2 handles were placed in sets of four on a casket. In all cases except three, Type 1 handles were seen in sets of six. Types $3,4,8,10,12$, and 13 were seen in sets of six, while Types 5 and 6 were used in sets of four. However, Type 7 (seen in only two burials) was used once as six handles and once as four. The eight handles on the 1884 iron coffin were all Type 16 , a handle type not observed on any caskets.

Seventeen of the burials (29.8 percent) had double lug swing bail handles of four varieties (Types 1, 3, 4, and 7; Figure 22). Type 1 handles, with a death's head motif, were the most frequently recovered swing bails; 11 of the 17 burials (64.7 percent) with swing bails had this particular variety. These handles measured $19 \mathrm{~cm}$ long from lug to lug and $8 \mathrm{~cm}$ high. The death's head motif commonly was used on headstones in Colonial American graveyards, remaining one of the most dominant design forms through the eighteenth century (Dethlefsen and Deetz 1966; Sloane 1991). The figure served to remind cemetery visitors of the inevitability of death, as well as suggesting that they live devout and faithful lives (Sloane 1991: 22). Only three burials had Type 3 swing bails with an oak leaf/ acorn motif, which measured $22 \mathrm{~cm}$ long and $8.5 \mathrm{~cm}$ high. One set of Type 4 swing bails with a scalloped design $(20 \mathrm{~cm}$ long and $8 \mathrm{~cm}$ high) was recovered. Only two had Type 7 floral pattern handles measuring $19.2 \mathrm{~cm}$ long and $8.2 \mathrm{~cm}$ high.

Double lug short bars were the most commonly seen casket handles as 34 of the 57 burials (59.6 percent) bore this style. Eight varieties of double lug short bars were documented from the excavated graves (Figures 23 and 24); of these, Type 2 was the most common (18 of 34 burials; 52.9 percent), and a complete handle measured $26.5 \mathrm{~cm}$ long by $8.6 \mathrm{~cm}$ high. At least two sets of Type 2 handles (Burials 23 and 46) documented a rope-style bar that originally was covered in cloth, along with painted lugs. The other caskets with Type 2 handles had bars that had wood in the center and were surrounded by a plain-design ferrous sheet. Type 10 was the next most fre- 

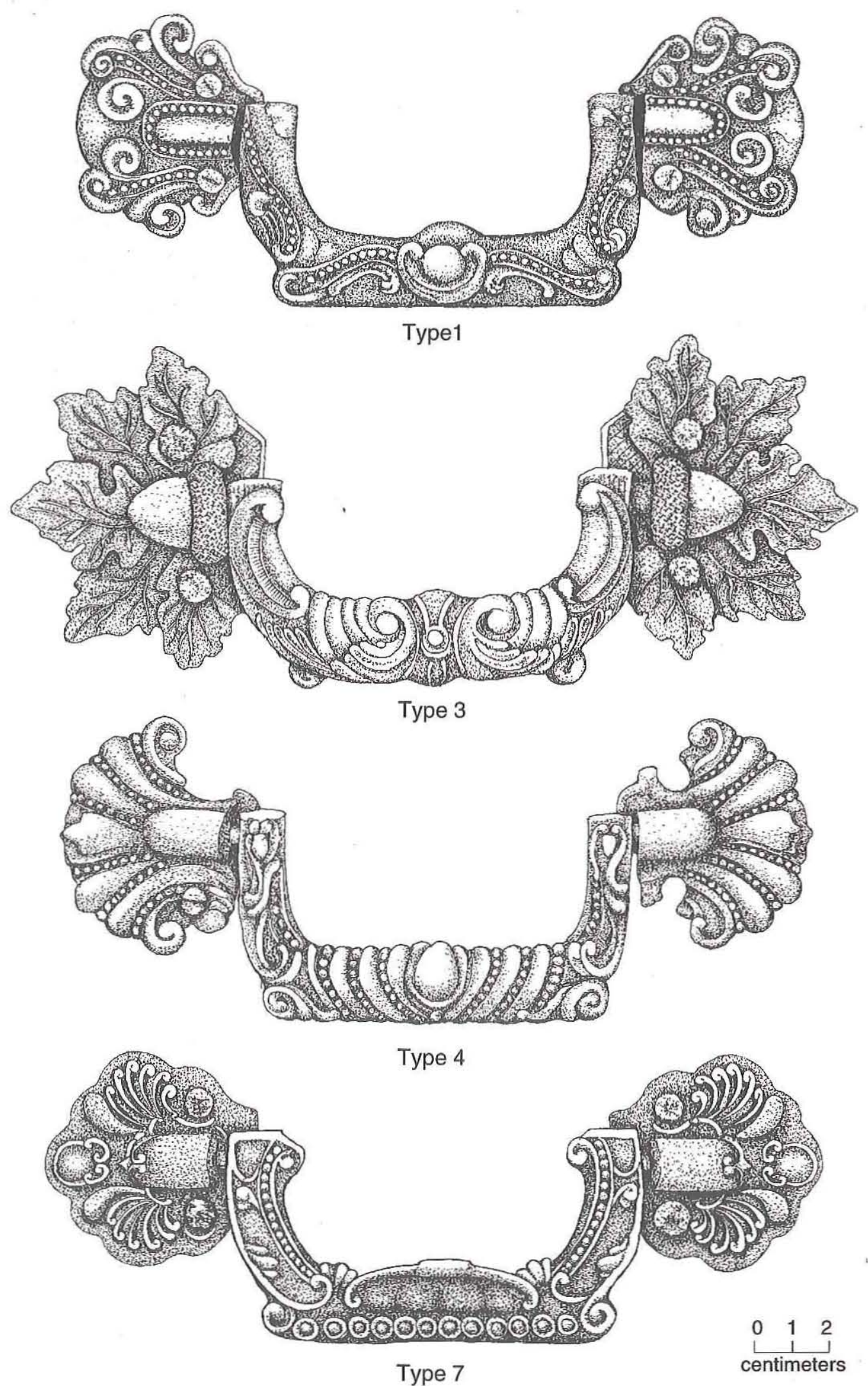

Figure 22. Types of swing bail handles. 

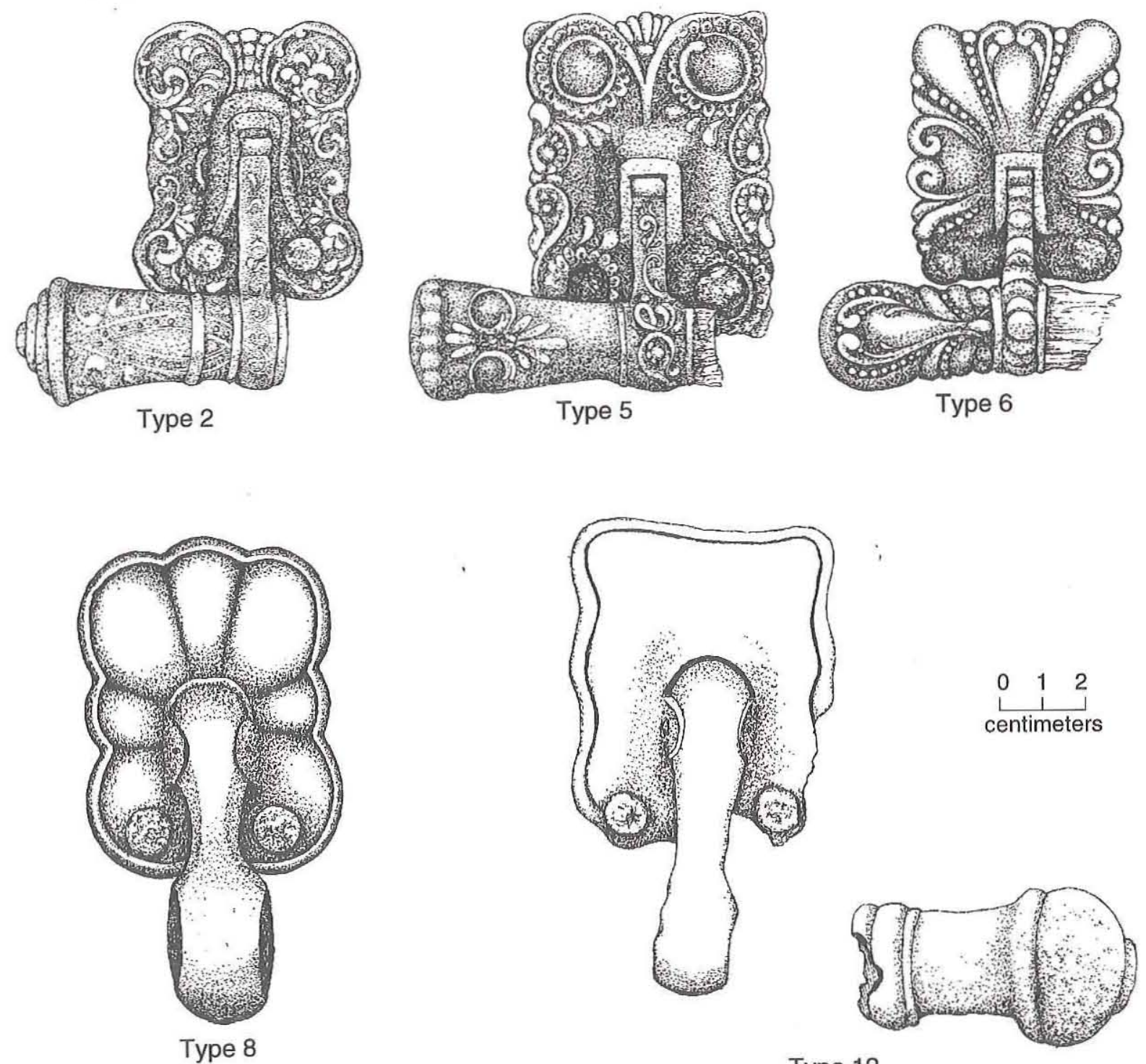

Type 12

Figure 23. Single lugs from double lug short bar handles.

quently observed type $(n=7)$, and a complete handle measured $32 \mathrm{~cm}$ long by $12 \mathrm{~cm}$ high. It was unusual because the handle was made of iron instead of white metal, and it was restricted to burials from the 1930s. Because the handle was fabricated of iron, it was not as well preserved as other handles and some details may have been obscured by the presence of rust. Type 6 was observed on three burials, and Type 5 was found on two. The Type 5 handles have squarish floral lugs, and the complete handle measures approximately $28 \mathrm{~cm}$ long by $9 \mathrm{~cm}$ high. The bar is a wooden core surrounded by metal. The Type 6 handles have square lugs with beaded and scrolled designs, each measuring $5 \times 6 \mathrm{~cm}$; no complete handle measurement was possible since the wooden bar was missing. Types $8,12,13$, and 16 were seen in one burial each. Type 8 is unusual because the lugs (each measured $6 \times 1 \mathrm{~cm}$ ) were chrome plated over white metal while the bar was iron over a wooden core. Type 12 lugs (each measured $7.5 \times 6.3 \mathrm{~cm}$ ) of white metal are similar in style to but simpler in design than Type 8. The Type 13 lug (31 cm long by $12 \mathrm{~cm}$ high) is very similar to Type 10 in that it is also iron and was observed only on a 1930 s burial; the difference is limited to 


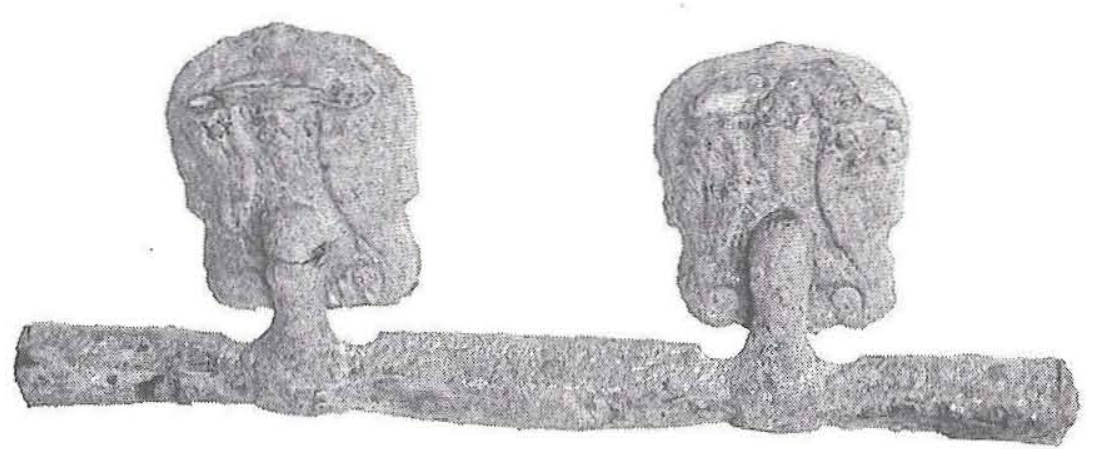

Type 10

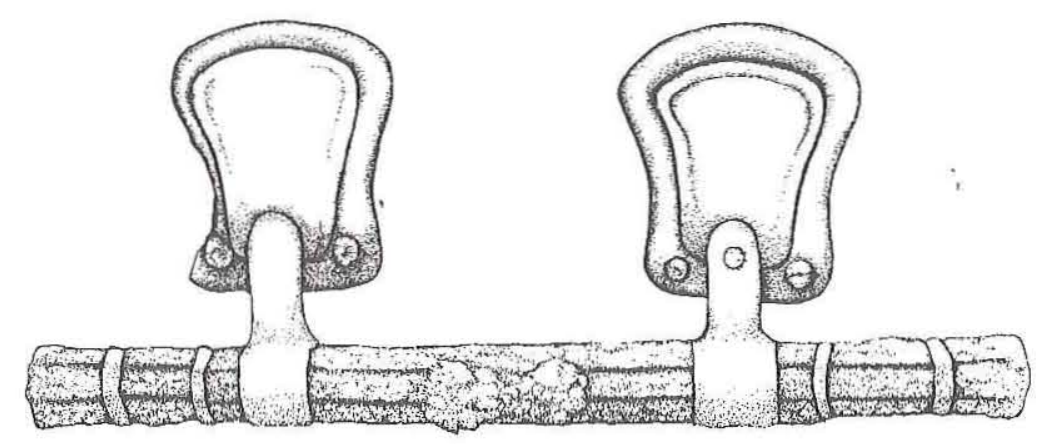

Type 13

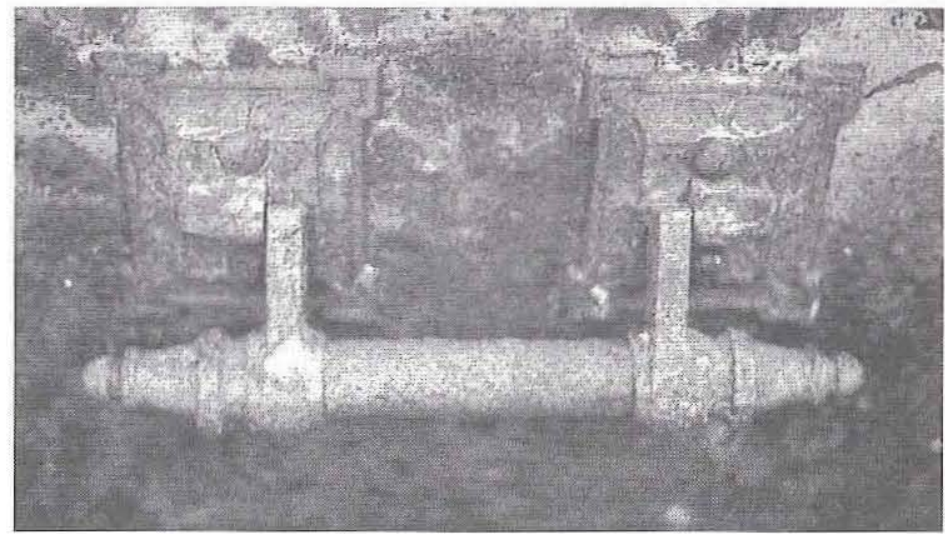

Type 16

012

centimeters

Figure 24. Double lug short bar handles.

a slightly different design style on the lug. The Type 16 white-metal handles are unlike any of the others and date to a much earlier time (1884). They were very well preserved and had a shorter overall dimension than other handles seen at the site (complete handle measured $24 \times 11 \mathrm{~cm}$ ).

Four types of extension bar handles were recorded on six burials, all from Section D. These 
types were found on three of the metal caskets and three wooden ones. Type 9 (Figure 25) was attached to the wooden casket of Burial 54. A single handle bar extending the entire length of the casket was attached to each long wall by three art deco-style single lugs (each lug measured $18.6 \times 9.4 \mathrm{~cm}$ ); short bar handles, attached by identical single lugs, were present on both short ends of the casket. The bar was ferrous metal, but the lugs and caps of the handles were white metal. White paint remnants were noted on the lugs. The backs of these lugs bear an inscription denoting the model number and manufacturer:

\section{4,400 \\ SARGENT \& CO NEW HAVEN CONN USA}

Type 11 extension bar handles were recovered from the wooden casket of Burial 49 (Figure 26). Like Type 9, long metal bars extending the length of the casket on each side were attached by three lugs, and identical lug handles were present on each short end. The lugs (each $17 \times 9.3 \mathrm{~cm}$ ) were manufactured of poor-quality iron that was badly deteriorated. The bars were square in shape and had a wooden core surrounded by metal; caps were white metal covered with silver paint.

Type 14 handles (see Figure 25) had the same placement as the other extension bars, with three single lugs on each long side wall and single lugs on the short walls. This handle type was found on three metal caskets (Burials 48, 51, and 52). However, the lugs had a scrolled design along the edges and were constructed of white metal on Burial 48 , while they were less ornately decorated and made of iron on Burials 51 and 52. Type 14 lugs measure $18.1 \times 9 \mathrm{~cm}$.

Type 15 handles were the most elaborate extension bars identified and were associated with the most recent interment (Burial 50; 1951) in the excavated portion of the cemetery (see Figure 26). The handle complex was manufactured from a lightweight metal and completely surrounded the wooden casket. Four corner lugs, one lug on the center of each short wall, and three lugs on each long axis served to attach the complex to the casket. The two short bars and two long bars connected to each other at each corner lug, forming a continuous handle that circumscribed the casket. Each side wall lug measured $15.5 \times 14.1 \mathrm{~cm}$.
Some of the handle types seen at the State Cemetery also have been observed at other cemeteries in Texas and other southern states. Type 1 death's head handles (see Figure 22), for example, also were recovered from the Cedar Grove (Rose 1985:Figure 19) and Phillips Memorial (Powell and Dockall 1996a:Figure 6.15) Cemeteries. In addition, they are present in the Calhoun collection examined by Hacker-Norton and Trinkley (1984: Figure $11 \mathrm{~A})$. The Type 2 handle style was observed at the Tucker Cemetery (Lebo 1988: Figure 14F); Type 3 also was seen at the Phillips Memorial Cemetery (Powell and Dockall 1996a). The Type 4 handle was recovered from the Cedar Grove Cemetery (Rose 1985:Figure 41) and is present in the Calhoun collection (Hacker-Norton and Trinkley 1984:Figure 11 B). The Type 6 handles described here are the same as those illustrated in Hacker-Norton and Trinkley (1984: Figure $5 \mathrm{D}$ ) from the Calhoun collection. In addition, handle Types 10 and 13 were very similar to the handle illustrated in Figure $5 \mathrm{~B}$ in HackerNorton and Trinkley (1984).

\section{Escutcheons and Thumbscrews}

Escutcheons are decorative metal plates through which thumbscrews or bolts pass in order to attach casket lids or viewing window covers to casket bodies. Twenty-nine ( 50.9 percent) of the excavated graves had escutcheons of some variety (see Table 7), and all were manufactured from white metal. All recovered escutcheons (Figure 27) functioned either as part of a casket lid fastener complex (Types 1,2, and 4) or as part of viewing window panel fasteners (Type 3 ). Type 1 was most common (65.5 percent of all burials with escutcheons had this type). These plates were crosshatched and measured $63 \times 23 \mathrm{~mm}$. Type 2, with a floral motif, was observed on nine caskets ( 31.0 percent) and measured $74 \times 24 \mathrm{~mm}$. Type 3 escutcheons were smaller than the others $(40 \times 17 \mathrm{~mm})$ and were used to fasten down the viewing window panel. This type was noted on 11 caskets (37.9 percent of those with escutcheons), all of which also had viewing windows. Type 4 escutcheons, seen only on the iron coffin of Burial 57 (John Ward), are unusual in that 28 were used to attach the coffin lid (see Figure 20), while all other escutcheons used to fasten a casket lid numbered no more than 4 per casket. Furthermore, 

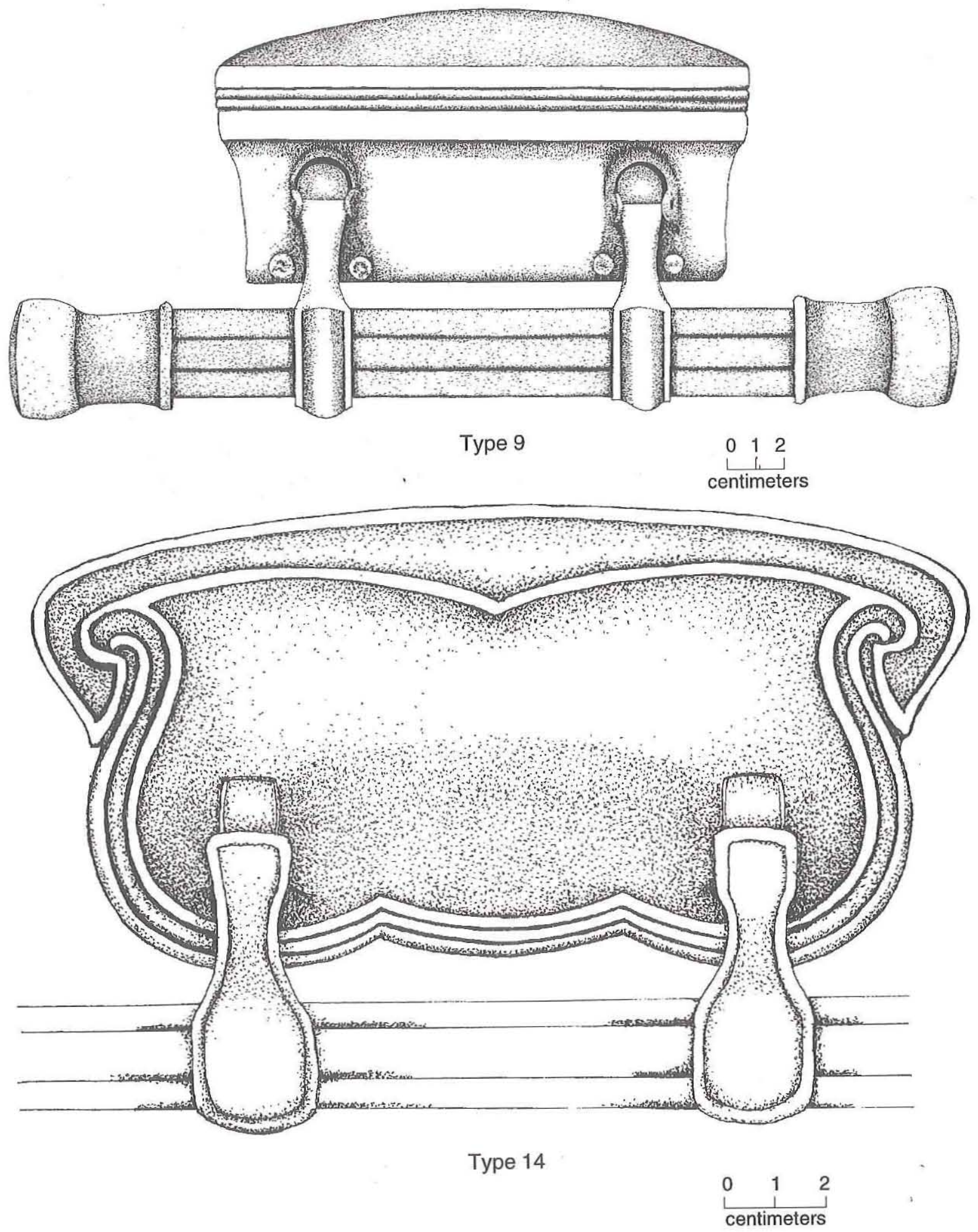

Figure 25. Type 9 and Type 14 single lug extension bar handles. 


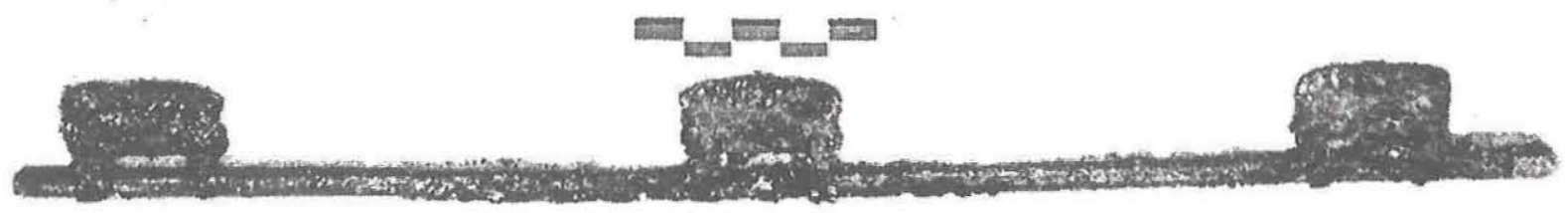

Type 11

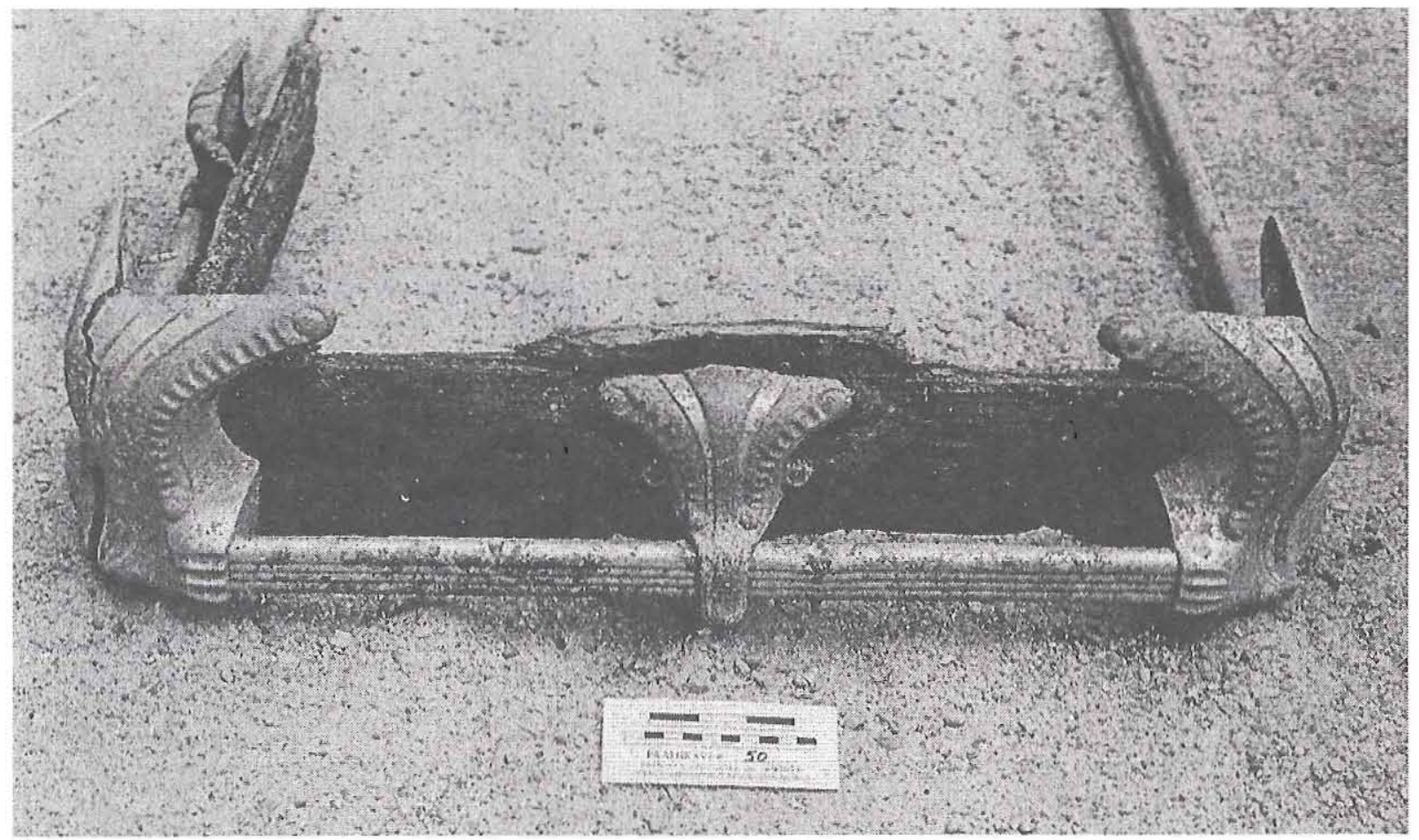

Type 15

Figure 26. Type 11 and Type 15 extension bar handles.

all escutcheons were associated with thumbscrews, except Type 4 which was used with plain screws.

Thumbscrews are screws with decorative heads, often matching the decorations on escutcheons, used to attach casket lids and viewing window covers. Five styles of thumbscrews were recovered from 28 graves (Figure 28). Escutcheons and thumbscrews were sold separately, or as matched sets (Hacker-Norton and Trinkley 1984: 30). Thumbscrew Types 1,3 , and 4 were associated with escutcheon Type 1, while Types 3 and 4 were associated with escutcheon Type 2 . Thumbscrew Types 2 and 5 were used only with escutcheon Type 3, for fastening the viewing window panel. Type 1 had a hatched patten $(31 \times 25 \mathrm{~mm})$ and was observed on 25 percent of the burials that had thumbscrews; Type $3(32 \times 26 \mathrm{~mm})$ had a floral motif and was the most common thumbscrew type (57.1 percent). Type 4 had a three-leaf clover design with the words "AT REST" in raised lettering $(35 \times 33 \mathrm{~mm})$. This type was seen on almost 18 percent of the caskets bearing thumbscrews. Thumbscrew Type 2 was smaller $(20 \times 16 \mathrm{~mm})$ with a round shell-like design, while Type $5(23 \times 18 \mathrm{~mm})$ was fan shaped. Of these small thumbscrews, both types were observed on 32.1 percent of the caskets (nine each).

None of the burials dating after 1908 had escutcheons or thumbscrews. Of the burials dating to 1907 and 1908, 28 of 40 (70 percent) had them. The earliest interment with escutcheons dates to 1884 , but, as mentioned earlier, it did not have corresponding thumbscrews. Escutcheon Type 2 was limited to burials dating to 1907 , while escutcheon Types 1 and 3 were found with both 1907 and 1908 burials. Thumbscrew Type 4 ("AT 

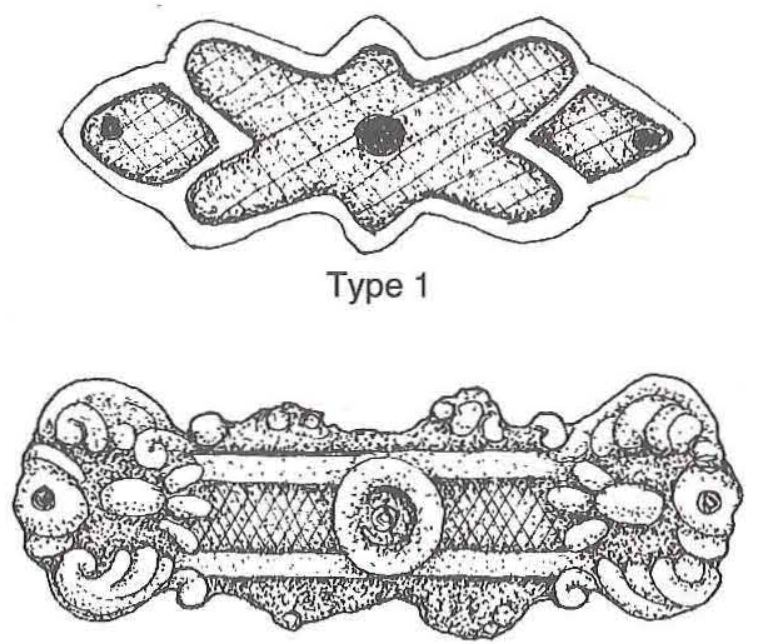

Type 2

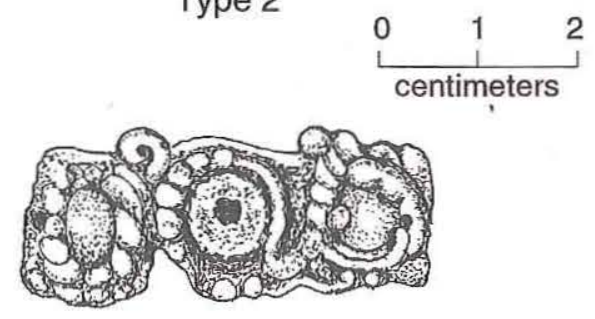

Type 3

Figure 27. Escutcheons.

REST") was documented only with 1907 burials, while Types 1 and 3 were used both in 1907 and 1908 interments. Thumbscrew Types 2 and 5 (for viewing window panels) also were found exclusively with 1907 and 1908 burials.

Identical styles of thumbscrews and escutcheons were observed at the Phillips Memorial and Cedar Grove Cemeteries. Escutcheons that match Types 1 and 2 were recovered from Cedar Grove (Rose 1985:Figures 20 and 42), as were thumbscrews that correspond with our Types 1,2 , and 3 (Rose 1985:Figures 42, 44, and 20). Three burials recovered from Phillips had thumbscrews that are identical to the Type 3 thumbscrews described here (Powell and Dockall 1996a:Figure 8.3). In addition, the Type 2 and Type 3 escutcheons match Figures $14 \mathrm{FF}$ and $14 \mathrm{KK}$, respectively, in HackerNorton and Trinkley (1984).

\section{Latches}

Five types of latches used for attaching the casket or outer box lid were recovered from 21 graves (36.8 percent) (see Table 7; Figure 29). All latches were of ferrous metal and occurred in many different combinations. Type $1(33 \times 35 \mathrm{~mm})$ was found on only six caskets and was usually located at the head end of the lid. Type 2 latches $(100 \mathrm{x}$ $21 \mathrm{~mm}$ ) were the most frequently recovered $(77.3$ percent of all caskets with latches had this variety). These were located along the long walls of the casket at the head end. Type 3 latches $(68 \times 21 \mathrm{~mm})$ also were located on the long walls, but at the foot end; these were recorded on 12 burials (57.1 percent) and were always associated with Type 2 latches. Type 4 latches $(39 \times 14 \mathrm{~mm})$ were only recovered from the long walls of three caskets, all of which also had latch Types 2 and 3. Type 5 (ca. $77 \times 18 \mathrm{~mm}$ ) latches were observed on four caskets (Burials 8, 30,31, and 33) and were never associated with other latches. They were, however, associated with 1907/1908 caskets bearing viewing windows. It appears that Type 5 latches were used to hold the viewing window cover in place.

Latch Types 1, 2, and 3 seem to have formed a latch complex on several of the burials. For instance, Burials 3, 35, 36, 54, and 55 each have all three latch types on the lid. As mentioned earlier, latch Types 2 and 3 were associated in 12 cases and Type 4 was seen with Types 2 and 3 in all three cases in which it was observed. Type 5, used for viewing windows rather than fastening the casket lid, is the only type that was not found consistently in association with other types.

It is not possible to determine unequivocally if Types 1, 2, 3, and 4 latches were associated with casket lids or outer box lids, but it seems likely that they were used to attach the casket lids. Four burials $(10,23,34$, and 46$)$ with latches did not even have outer boxes, and in an additional five cases $(3,11,13,35$, and 56$)$, outer boxes were indeterminate. Furthermore, with the exception of Burial 9, none of the caskets bearing latches other than Type 5 had escutcheons or thumbscrews used for fastening the casket lid. Therefore, it seems likely that latch Types 1, 2, 3, and 4 substituted in some cases for thumbscrews and escutcheons.

In addition to the five previously described latch types, a hook-and-eye latch complex was observed on Burial 1. This system consisted of eye rings attached to the long wall of the casket and a hook projection fastened to the floor. Two of these latches were found on the floor of the casket - one at the foot end and one at the middle; it is possible that a third latch at the head was missed during excavation. It is not certain what 


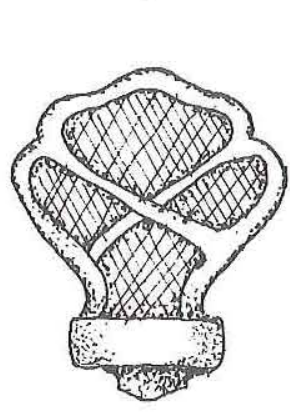

Type 1

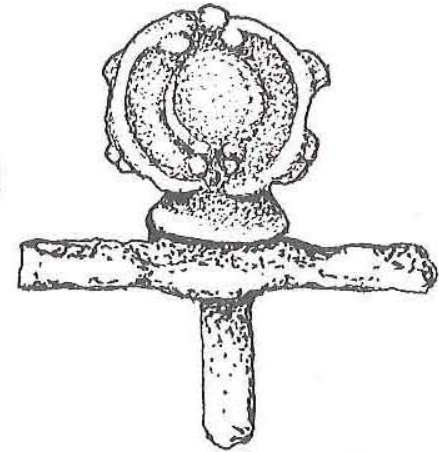

Type 2

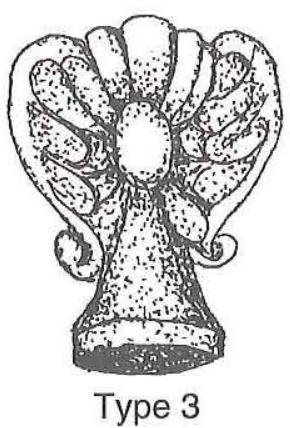

Type 3

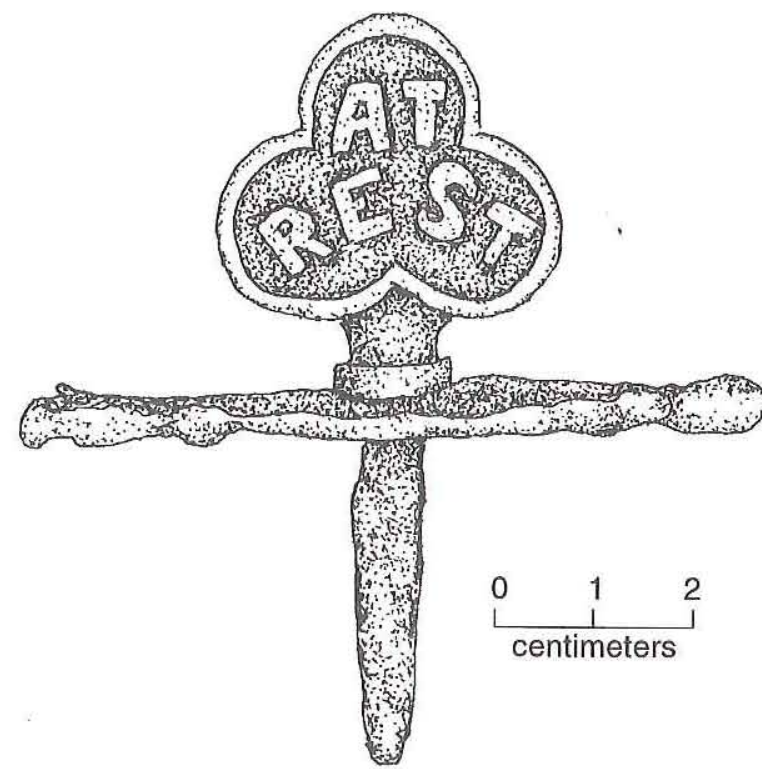

Type 4

Figure 28. Thumbscrews.

function(s) these latches served; perhaps they were used to secure a removable side wall that enhanced viewing of the body.

\section{Caplifters}

Caplifters are knoblike handles used to lift the upper half of a divided casket lid for viewing the body (Hacker-Norton and Trinkley 1984:11). Four styles of caplifters were recovered from five (8.8 percent) of the burials (see Table 7; Figure 30), which would indicate that at least these five caskets had divided casket lids that allowed for viewing (in addition to the caskets with viewing windows described above). All caplifters were white metal with the exception of the Type 2 caplifter associated with
Burial 34 that was manufactured of brass. The Type 1 caplifters were small $(28 \mathrm{~mm}$ in diameter and $28 \mathrm{~mm}$ high) Tiffany lamp-shaped knobs. Type 2 was much larger $(51 \times 38 \mathrm{~mm})$ with a scrolled and beaded design. At least one caplifter identical in design to Type 2 was recovered from the Cedar Grove Cemetery (Rose 1985: Figure 69); this style was also identified in the Calhoun collection (Hacker-Norton and Trinkley 1984:Figure $13 \mathrm{~K})$. The Type 3 caplifter $(40 \times 22 \mathrm{~mm})$ was flat with beads around the circumference. Type 4 was a very plain design $(41 \times 23 \mathrm{~mm})$. None of the caplifters were associated with viewing windows, and their placement on the upper portion of the casket lid (above the upper thoracic region of the body) indicates that they were used with divided casket lids that could be opened for viewing of the deceased. The Type 1 and 2 caplifters were found only with 1907 and 1908 interments, while Type 3 dates to 1917 and Type 4 dates to 1920 .

\section{Plaques}

Decorative plaques were recovered from the center of the casket lids of 12 burials; only one was interred in 1907, and all the others date between 1907 and 1934 (see Table 7). Of the interments dating to the 1930s, 7 of 11 (63.6 percent) had some form of plaque. All three of the 1920 s burials contained plaques, as did the one 1917 burial. Seven plaques were not legible; of these, five were made of iron and the other two were white metal. Of the plaques that were legible, four were inscribed with "At Rest" (Figure 31). The first of these, a 212-x-10-mm rectangle found with Burial 1, was fabricated from an indeterminate metal and originally was covered with gold paint. An "At Rest" plaque $(170 \times 90 \mathrm{~mm})$ recovered from Burial 34 was unlike all the other plaques because it was made of brass and had ornately scalloped edges 


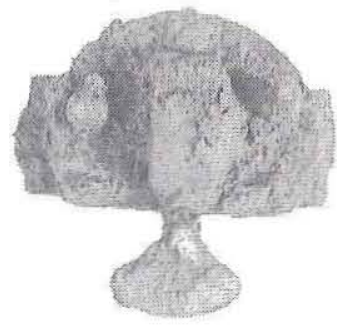

Type 1
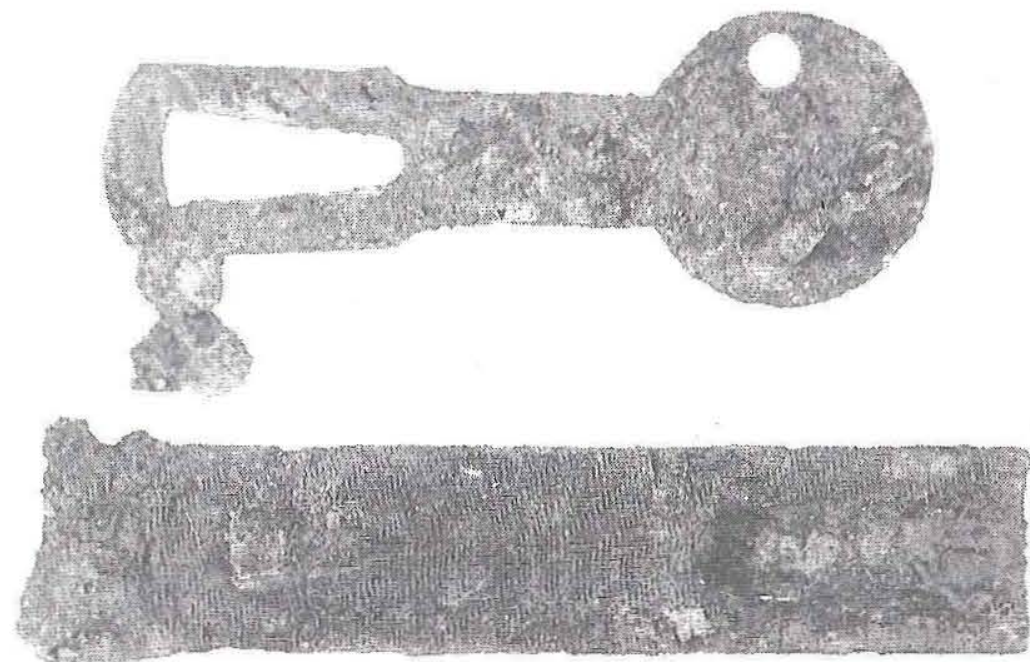
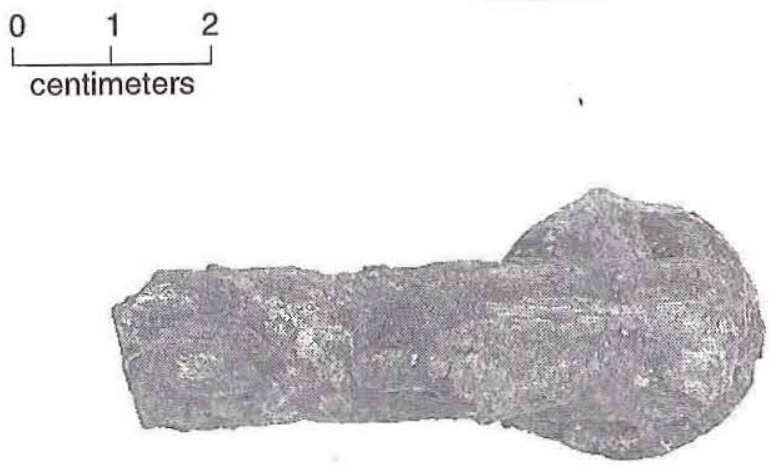

Type 3

\section{Type 2 ;}
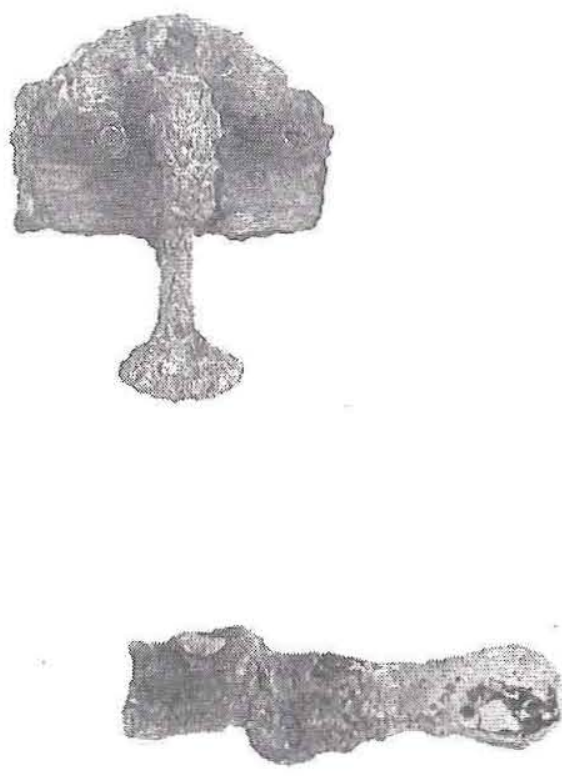

Type 5

Type 4

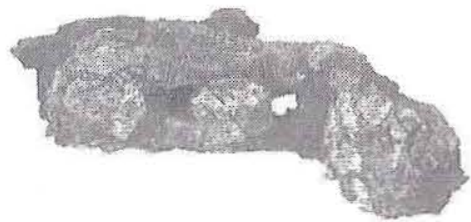

Figure 29. Latches.

with a scroll border decoration. Burial 48 yielded an oval "At Rest" plate made of white metal $(250 \times 95 \mathrm{~mm})$ that had been painted silver, and Burial 49 contained a similar oval plaque, although the lettering style was different. The only legible casket plaque that did not read "At Rest" contained the words "Our Mother, Mary Burleson, 1842-1932" and was recovered from Burial 54.
The plate was white metal and measured approximately 193 x $92 \mathrm{~mm}$. Plaques bearing the inscriptions "At Rest," "Mother," "Our Darling," and other phrases have been recovered from numerous historic cemeteries, including Phillips (Powell and Dockall 1996a), Cedar Grove (Rose 1985), Morgan Chapel (Taylor et al. 1986), and Tucker (Lebo 1988). 

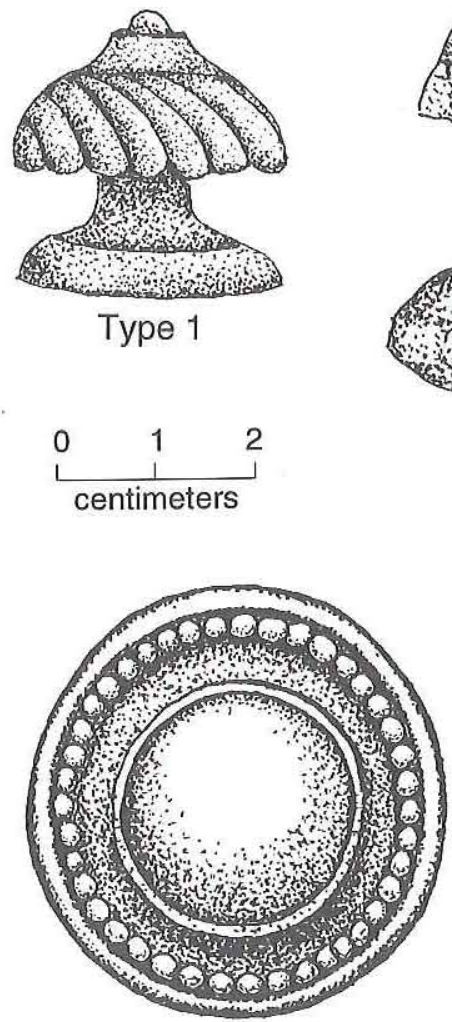

Type 3

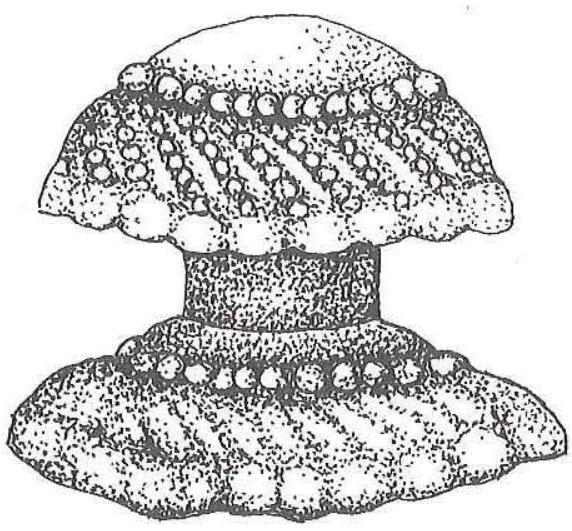

Type 2

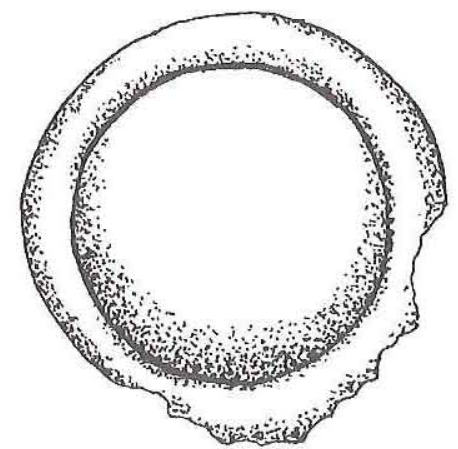

Type 4

floral center piece remained since the outer oval area was extremely fragile and frequently was not preserved. All of these were seen on the casket walls. A total of 11 six-sided star tacks, measuring $30 \times 30 \mathrm{~mm}$, were recovered with eight caskets; in four of these cases (Burials 9, 15, 17, and 19), the tack was found on top of the casket lid. In the other cases (Burials 10, 16, 20, and 21), the stars were located on the casket walls; one tack was found with a fragment of black cloth preserved beneath it. One casket (Burial 24) had two three-dimensional stars. iSeven bell-shaped tacks $(15 \times 25 \mathrm{~mm})$ were recovered from five graves (Burials 25, 26, 28,40 , and 42) and sometimes were associated with the viewing window panel, although they would not have been strong enough to serve as caplifters. At least 11 diamond-shaped tacks $(50 \times 26 \mathrm{~mm})$ with a dome in the middle were noted within seven caskets (Burials 20, 27, 28, 29, 39, 40, and 44). Multiple-pointed

\section{Decorative Ornaments/Tacks}

Decorative tacks recovered from caskets usually were placed on the outer surface of the casket, possibly to cover coffin nails (HackerNorton and Trinkley 1984:11). Because these items are all made of cuprous metal, they are extremely fragile. Caskets probably had decorative ornaments/tacks more often than shown by archeological evidence. Twenty-six (45.6 percent) of the caskets had decorative tacks (see Table 7), and all were from the 1907 or 1908 burials in Section F; no interments dating to a later time period exhibited these items.

Eight types of tacks were documented (Figure 32). Three types were observed on the outside of the casket; two of these (six-sided star and bellshaped tacks) occasionally were observed inside the casket as well. Eleven floral/oval tacks $(29 \times 24 \mathrm{~mm})$ were recovered from five caskets (Burials 7, 8, 15, 28, and 40). Often only the decorative tacks (dimensions indeterminate) were seen in two cases (Burials 30 and 33). Only one casket (Burial 28) yielded a portion of a decorative tack that originally had been shaped as a leaf; the veins of the leaf were clearly visible in the recovered fragment. Five caskets (Burials 8, 14, 18, 26, and 43) produced a number of plain dome-shaped tacks $(17 \times 8 \mathrm{~mm})$. In addition, one intricately designed decorative ornament was located on the outer casket wall of Burial 25 (Figure 33).

The floral/oval decorative studs recovered are identical to those illustrated from the Calhoun collection in Hacker-Norton and Trinkley (1984: Figure $13 \mathrm{~B}$ ). The diamond-shaped studs are also similar to those illustrated in Hacker-Norton and Trinkley (1984:Figure 13 E-J). These diamond studs have also been recovered from the Phillips Memorial Cemetery (Powell and Dockall 1996a) and the Laredo Cemetery (McReynolds 1981: Figure 7C). A leaf-shaped stud similar or identical to the one found with Burial 28 was noted at the 

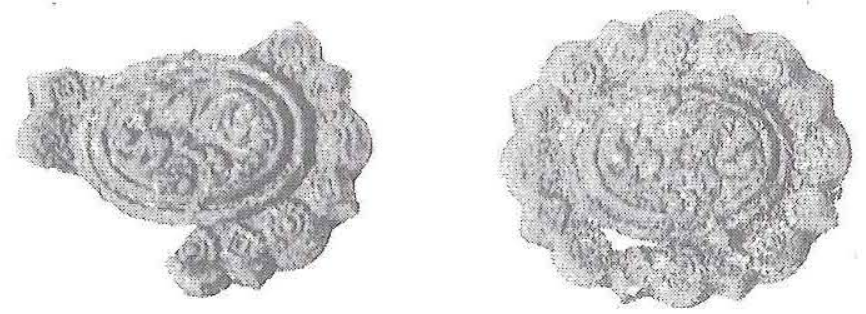

a
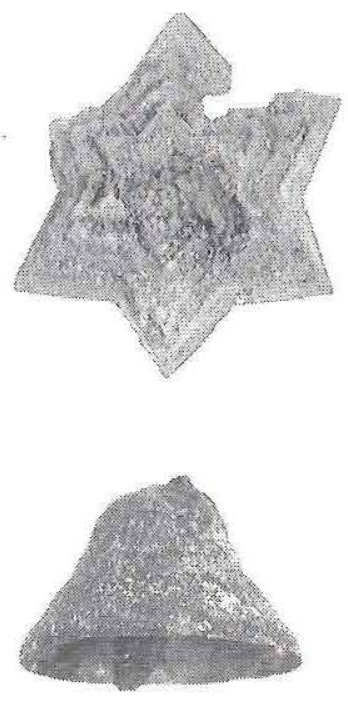

C

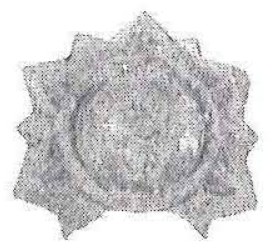

e

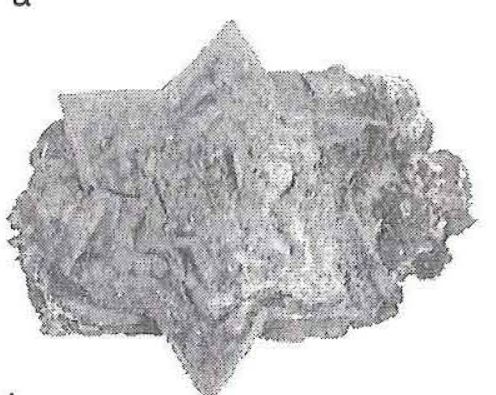

b
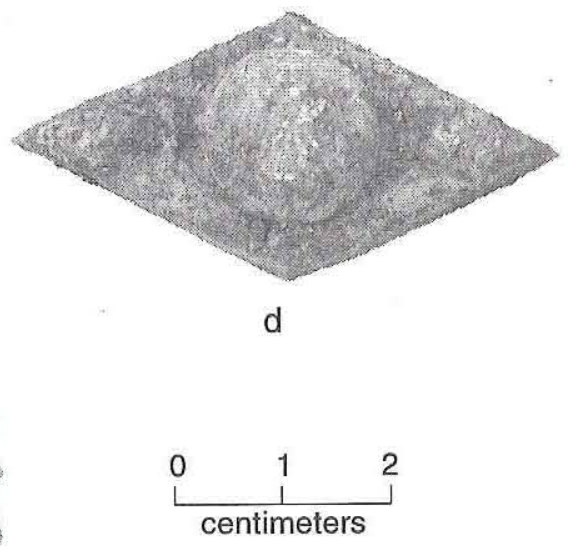

Figure 32. Decorative tacks. (a) Floral/oval; (b) three-dimensional star; $(c)$ bell shaped; $(d)$ diamond shaped; $(e)$ multiple pointed.

evidenced by interior tacks.

\section{Nails/Screws/ \\ Corrugated \\ Fasteners}

Nails, screws, and/or corrugated fasteners commonly were used in the construction of wooden caskets. Wire nails were recovered from all wooden caskets except six; no nails were recovered from metal caskets (see Table 7). The absence of nails in five of the six wooden caskets is probably related to recovery or recording errors rather than a real absence of nails for construction. The sixth casket (Burial 14) apparently was constructed with 25 screws instead of nails. The only other screws associated with casket construction were used in conjunction with nails in Burial 27. Small $(30 \times 16 \mathrm{~mm})$ corrugated metal fasteners used to attach adjoining pieces of wood were recovered from 12 of the wooden caskets (see Table 7). The fact that corrugated fasteners were recovered from burials without outer boxes suggests that the fasteners were used in the manufacture of the casket itself. However, four other burials with corrugated fasteners had outer boxes, and four were indeterminate; in

Morgan Chapel Cemetery (Taylor et al. 1986: Figure 6).

Only one burial (Burial 10) yielded definite evidence of a fabric lining, and another (Burial 30) was possibly lined based on a fragment of yellow/ brown fabric found on the casket wall. In addition to these burials, a reasonable assessment of the percentage of lined caskets can be made based on the presence of tacks recovered from interior casket walls of at least 21 burials. The other five caskets producing decorative tacks/ornaments had tacks on the outer surface of the casket only. Minimally, almost 40 percent of the 53 wooden caskets excavated from the cemetery were lined, as these cases, the fasteners may have been used either on the outer box or on the casket. The most recent casket (Burial 50; 1951) was constructed using a tongue-and-groove method to join the walls at each corner. Only four nails were used in the construction of this well- preserved casket.

\section{PERSONAL ITEMS}

The presence of personal items within a grave reflects a number of cultural and noncultural factors, including affluence and burial customs. In addition, excavation procedures and taphonomic processes affect the recovery, and hence the inter- 

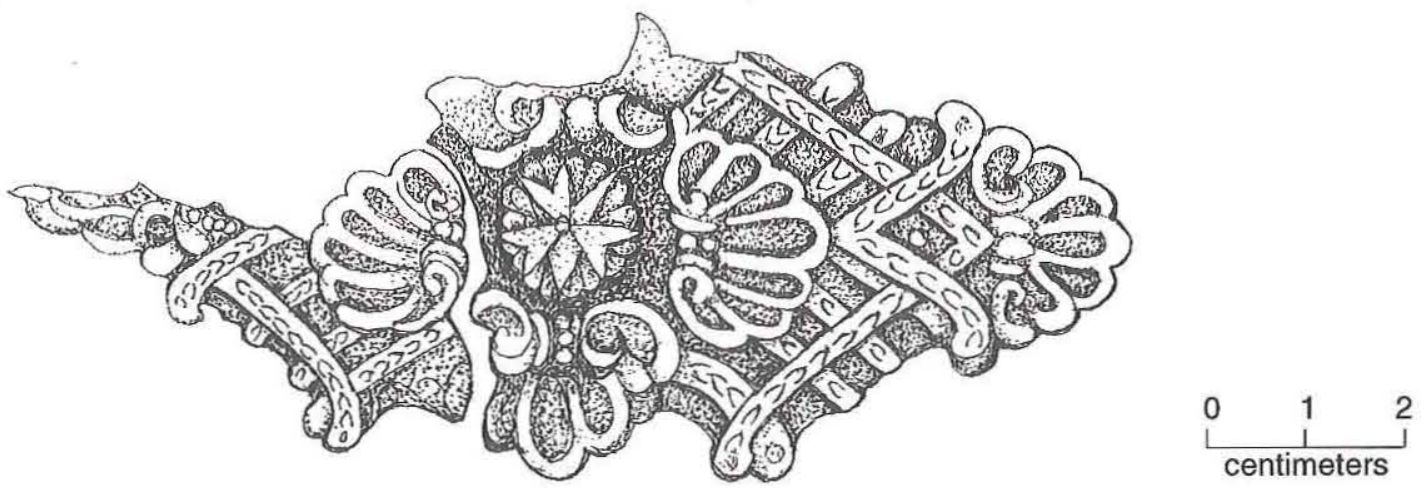

Figure 33. Decorative ornament recovered from Burial 25 .

pretation, of personal goods (see Schiffer 1987). Excavation of the burials at the State Cemetery yielded numerous personal items. Most consisted of clothing items (e.g., buttons and bow ties), jewelry (e.g., collar studs and cuff links), and religious and organizational symbols. This section addresses those items of a personal nature recovered from the burials; all of these items were reburied with the individuals, with the exception of two "United Confederate Veterans" buttons collected from Burial 47 with permission of relatives of the deceased.

\section{Personal Casket Hardware}

Although the specimens described in this section technically can be called casket hardware, they are considered personal items because of the individualized nature of the objects and the information they impart about the deceased. Eight burials produced personalized casket hardware (Table 9), all of which were decorative ornaments that originally were fastened to the midline of casket lids. White-metal Mason's symbols were recovered with Burials 19, 22, 41, and 47 (Figure 34). Two of these were large (103 x $102 \mathrm{~mm})$ and two were small $(55 \times 61 \mathrm{~mm})$, with the primary difference being that the compass and square of the smaller Mason's symbol are of a simpler design than are those of the larger Mason's symbol.

Two white-metal crosses $(155 \times 92 \mathrm{~mm})$ were recovered from Burials 10 and 15; both had intricate floral designs with an ornate crown that appears to wrap diagonally around the junction of the long and short arms of the cross (Figure 35). Similar floral cross and crown symbols were recovered from the Laredo Cemetery (McReynolds
1981:Figure 16 A), but they have straight edges at the ends of the cross pieces rather than rounded ends as observed on the State Cemetery examples. In addition, the name' of the maker $\left(\mathrm{W}^{\mathrm{M}}\right.$ SMITH[']S PATTERN) was present on the back of the cross recovered from the Laredo Cemetery. In religious iconography, a Latin cross whose surface is decorated with floral patterns is called "a Cross Adorned," while the crown probably represents "the crown of life." In this particular case, the combination of cross and crown may signify "entrance to heaven by way of the cross" and eternal life (Webber 1938:79, 108, 364, 365).

Burials 34 and 44 had calla lily ornaments. The ornament found with Burial 34 (see Figure 35) was made of brass and measured $185 \times 90 \mathrm{~mm}$. The lily found with Burial 44 was smaller $(104 \times 54 \mathrm{~mm})$ and fabricated of white metal rather than brass. It is possible that a similar lily was recovered from the former Wesleyan Methodist Church Cemetery in Ontario (ca. 1821-1900), but all that was noted was that the decorative object was "a partial piece showing the stem and leaves of what seems to be a tulip type flower" (Kogon and Mayer 1995:142). No dimensions were provided, and the piece was not illustrated, so it is impossible to tell if it was identical to those recovered from the State Cemetery. Jordan (1982: 28 ) notes that it is common to find lilies growing in Texas cemeteries, and Webber (1938:79) states that the Easter lily is "a common and extremely popular symbol of our Lord's Resurrection."

\section{Clothing}

Clothing items were the personal goods most frequently recovered. Only 11 burials (19.6 


\begin{tabular}{|c|c|c|c|c|c|c|c|c|c|c|c|c|c|}
\hline \multicolumn{14}{|c|}{$\begin{array}{c}\text { TABLE } 9 \\
\text { PERSONAL GOODS ASSOCIATED WITH THE EXCAVATED INDIVIDUALS }\end{array}$} \\
\hline $\begin{array}{l}\text { Burial } \\
\text { No. }\end{array}$ & $\begin{array}{l}\text { Date of } \\
\text { Burial }\end{array}$ & $\begin{array}{l}\text { Personal } \\
\text { Casket } \\
\text { Hardware }\end{array}$ & $\begin{array}{l}\text { Bow } \\
\text { Ties }\end{array}$ & Buttons & $\begin{array}{l}\text { Suspender } \\
\text { Buckle }\end{array}$ & Eyelet & $\begin{array}{l}\text { Rivet/ } \\
\text { Snap }\end{array}$ & $\begin{array}{l}\text { Finger } \\
\text { Rings }\end{array}$ & $\begin{array}{l}\text { Hair } \\
\text { Combs }\end{array}$ & $\begin{array}{l}\text { Cuff } \\
\text { Links }\end{array}$ & $\begin{array}{l}\text { Celluloid } \\
\text { Collar } \\
\text { Studs }\end{array}$ & Dentures & Other \\
\hline 1 & 1939 & & & 2 miscellaneous & & & & & & & & $\mathrm{x}$ & \\
\hline 2 & 1931 & & & 2 rubber & & & & & & & & & \\
\hline 3 & 1931 & & & 10 rubber & & & & & & & $3^{*}$ & & \\
\hline 4 & 1931 & & & 6 rubber & & & & & & & & & \\
\hline 5 & 1930 & & & 9 rubber, 3 shell & & & & & & 1 metal & 1 & & \\
\hline 6 & 1930 & & & 9 rubber, 2 shell & & & & & - & & 2 & & \\
\hline 7 & 1908 & & & 1 miscellaneous & & & & & & & & & \\
\hline 8 & 1908 & & & 2 leather & & & & & & & & & \\
\hline 9 & 1908 & & $\mathrm{x}$ & & & & & 1 & & & & & \\
\hline 10 & 1908 & $\mathrm{x}$ & & & & & & & & 1 bone & & & \\
\hline 11 & 1908 & & $\mathrm{x}$ & & & & & & & 2 bone & & & \\
\hline 12 & 1908 & & $\mathrm{x}$ & 1 shell & & & & & & 2 bone & & & \\
\hline 13 & 1908 & & & 1 shell & & 1 & & & & 2 bone & & & \\
\hline 14 & 1908 & & & 2 metal & & 4 & & & & & & & \\
\hline 15 & 1908 & $\mathrm{x}$ & & 1 shell, 3 metal & & & & & & & & & \\
\hline 16 & 1908 & & & 3 metal & & & 2 & & & & & & \\
\hline 17 & 1908 & & $\mathrm{x}$ & 1 metal & & & & & & & & & \\
\hline
\end{tabular}




\begin{tabular}{|c|c|c|c|c|c|c|c|c|c|c|c|c|c|}
\hline \multicolumn{14}{|c|}{ Table 9, continued } \\
\hline $\begin{array}{l}\text { Burial } \\
\text { No. }\end{array}$ & $\begin{array}{l}\text { Date of } \\
\text { Burial }\end{array}$ & \begin{tabular}{|l} 
Personal \\
Casket \\
Hardware
\end{tabular} & $\begin{array}{l}\text { Bow } \\
\text { Ties }\end{array}$ & Buttons & $\begin{array}{l}\text { Suspender } \\
\text { Buckle }\end{array}$ & Eyelet & $\begin{array}{l}\text { Rivet/ } \\
\text { Snap }\end{array}$ & $\begin{array}{l}\text { Finger } \\
\text { Rings }\end{array}$ & $\begin{array}{l}\text { Hair } \\
\text { Combs }\end{array}$ & $\begin{array}{l}\text { Cuff } \\
\text { Links }\end{array}$ & $\begin{array}{l}\text { Celluloid } \\
\text { Collar } \\
\text { Studs }\end{array}$ & Dentures & Other \\
\hline 18 & 1908 & & & 2 metal & & & & & & 2 metal & & & \\
\hline 19 & 1908 & $\mathrm{x}$ & & & 2 & & & & & 2 metal & & & \\
\hline 20 & 1908 & & & 2 metal & & & & & & & & & \\
\hline 21 & 1908 & & & metal (\# unknown) & & & & & & & & & \\
\hline 22 & 1908 & $\mathrm{x}$ & & 2 metal & & & & & & & & & \\
\hline 23 & 1907 & & & 3 metal & & & 2 & & & & & & \\
\hline 24 & 1907 & & & & & & 1 & & & 2 bone & & & \\
\hline 25 & 1907 & & $\mathrm{x}$ & 2 metal & & & & & & 2 bone & & & \\
\hline 26 & 1908 & & & 3 metal & & & 1 & & & & & & \\
\hline 27 & 1908 & & & 1 miscellaneous & & & & & & & & & \\
\hline 28 & 1908 & & & & & & & & & 2 bone & & & \\
\hline 29 & 1907 & & $\mathrm{x}$ & & & & & & & 2 bone & & & \\
\hline 30 & 1907 & & $\mathrm{x}$ & & & & & 2 & & & & $\mathrm{x}$ & \\
\hline 31 & 1907 & & $\mathrm{x}$ & 2 shell, 3 metal & & & & & & 1 bone & & & \\
\hline 32 & 1907 & & $\mathrm{x}$ & 2 metal & & 3 & & &. & 2 bone & & & \\
\hline 33 & 1907 & & $\mathrm{x}$ & 1 shell, 2 metal & & & & & & 2 bone & & & \\
\hline 34 & 1907 & $\mathrm{x}$ & & & & & & & & 2 bone & & & \\
\hline 35 & 1907 & . & $\mathrm{x}$ & $\begin{array}{l}1 \text { metal, } \\
1 \text { miscellaneous }\end{array}$ & & & & & & 2 bone & & & \\
\hline 36 & 1907 & & & 1 metal & & & & & & 2 bone & & & \\
\hline
\end{tabular}




\begin{tabular}{|c|c|c|c|c|c|c|c|c|c|c|c|c|c|}
\hline \multicolumn{14}{|c|}{ Table 9, continued } \\
\hline $\begin{array}{l}\text { Burial } \\
\text { No. }\end{array}$ & $\begin{array}{l}\text { Date of } \\
\text { Burial }\end{array}$ & $\begin{array}{l}\text { Personal } \\
\text { Casket } \\
\text { Hardware }\end{array}$ & $\begin{array}{l}\text { Bow } \\
\text { Ties }\end{array}$ & Buttons & $\begin{array}{l}\text { Suspender } \\
\text { Buckle }\end{array}$ & Eyelet & $\begin{array}{l}\text { Rivet/ } \\
\text { Snap }\end{array}$ & $\begin{array}{l}\text { Finger } \\
\text { Rings }\end{array}$ & $\begin{array}{l}\text { Hair } \\
\text { Combs }\end{array}$ & $\begin{array}{l}\text { Cuff } \\
\text { Links }\end{array}$ & $\begin{array}{l}\text { Celluloid } \\
\text { Collar } \\
\text { Studs }\end{array}$ & Dentures & Other \\
\hline 37 & 1907 & & & & & & & & & 2 bone & & & \\
\hline 38 & 1907 & & & & & & & & & 2 bone & & & \\
\hline 39 & 1907 & & $\mathrm{x}$ & 3 metal & & & & & & 2 bone & & & \\
\hline 40 & 1907 & & & 3 shell & & & & & & 2 bone & & & \\
\hline 41 & 1907 & $\mathrm{x}$ & & & & & & & & 2 bone & & & \\
\hline 42 & 1907 & & & 1 shell, 3 metal & & & & & & 2 bone & & & \\
\hline 43 & 1907 & & & & & & & & - & & & & coin purse \\
\hline 44 & 1907 & $\mathrm{x}$ & & & & & & & & 1 bone & & & \\
\hline 45 & 1907 & & & 1 metal & & & & & & 2 bone & & & \\
\hline 46 & 1907 & & & 1 metal & & & & & & 2 bone & & & \\
\hline 47 & 1920 & $\mathrm{x}$ & & $\begin{array}{l}10 \text { metal, } \\
2 \text { miscellaneous }\end{array}$ & & & & & & 1 bone & & $\mathrm{x}$ & \\
\hline 48 & 1923 & & & 1 shell & & & & & 2 & & & $\mathrm{x}$ & \\
\hline 49 & 1925 & & & $\begin{array}{l}3 \text { shell, } \\
2 \text { miscellaneous }\end{array}$ & 2 & & & & & & & $\mathrm{x}$ & \\
\hline 50 & 1951 & & & & & & & & & & & & thigh-high nylons \\
\hline 51 & 1931 & & & & & & & & $1^{-}$ & & & $\mathrm{x}$ & \\
\hline 53 & 1917 & & & 6 shell & & & & & & & & & \\
\hline 54 & 1932 & & & 16 metal & & & & & & & & & bar pin \\
\hline 55 & 1931 & & & 1 shell & & & & 1 & & & & & safety pin \\
\hline 56 & 1932 & ' & & 7 rubber, 5 shell & & & & & & 1 metal & 2 & & copper stud* \\
\hline
\end{tabular}




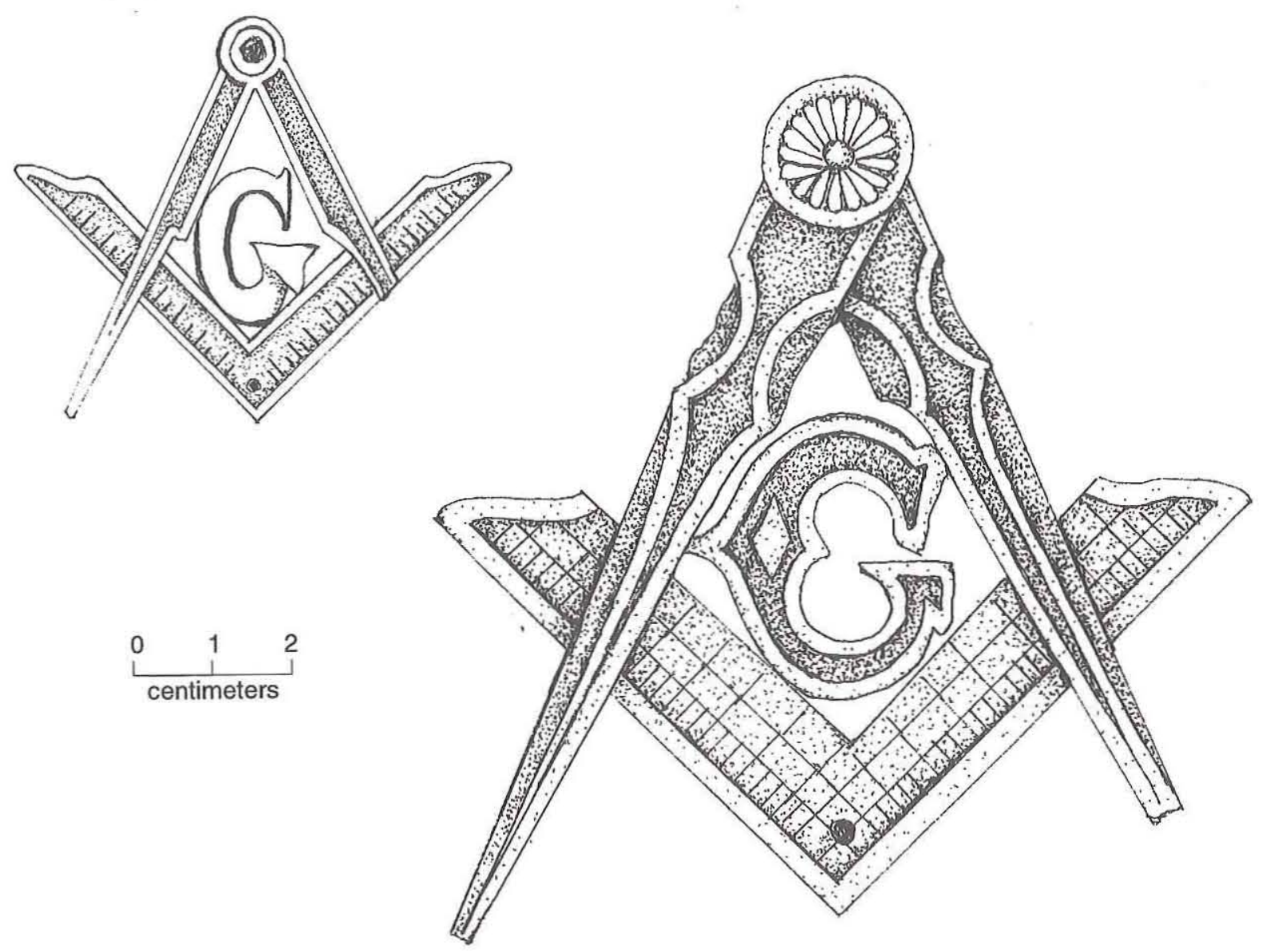

Figure 34. Mason's symbol casket lid ornaments.

percent) did not yield some sort of clothing remains (Burials 10, 19, 28, 32, 37, 38, 41, 43, 44, 51 , and 52 ), as defined by fabric remnants, bow ties, buttons, suspender buckles, eyelets, rivets, or snaps.

\section{Bow Ties and Other Fabric Remnants}

Bow ties were recovered with 12 of the 40 men (30 percent) interred in 1907-1908 (see Table 9). All of these were identical in style and made of a black fabric with a very tight satin weave, but they fastened to the shirt in a variety of ways. In one case, a straight pin that had been used to attach the bow tie to the shirt was recovered (Burial 31); in another instance, a copper clasp was attached to the back of the tie (Burial 12). The tie recovered from Burial 29 had a button attachment. Although the fabric was not identified positively, the bow ties most likely were made of silk or some imitation silklike material. Silk was the most common material from which bow ties were made around the turn of the century, as indicated by Sears, Roebuck and Company catalogues from 1897, 1902, and 1908 (Sears, Roebuck and Company, Inc. 1971, 1976, 1993). Whatever the material, the 1907-1908 bow ties were better preserved than all other types of fabric.

Fragments of a jacket were recovered from the torso area of Burial 32. Fragments of brown cloth, probably representing a dress, were recovered from Burial 54. No other type of cloth fabric fragments were recovered, with the exception of a few cloth remnants on some metal buttons.

\section{Buttons}

Many buttons, including rubber, shell, bone, leather, and metal varieties, were identified (Figure $36)$. Buttons were noted with 39 of the 56 analyzed individuals (69.6 percent; see Table 9). Metal buttons were most common, observed in 22 

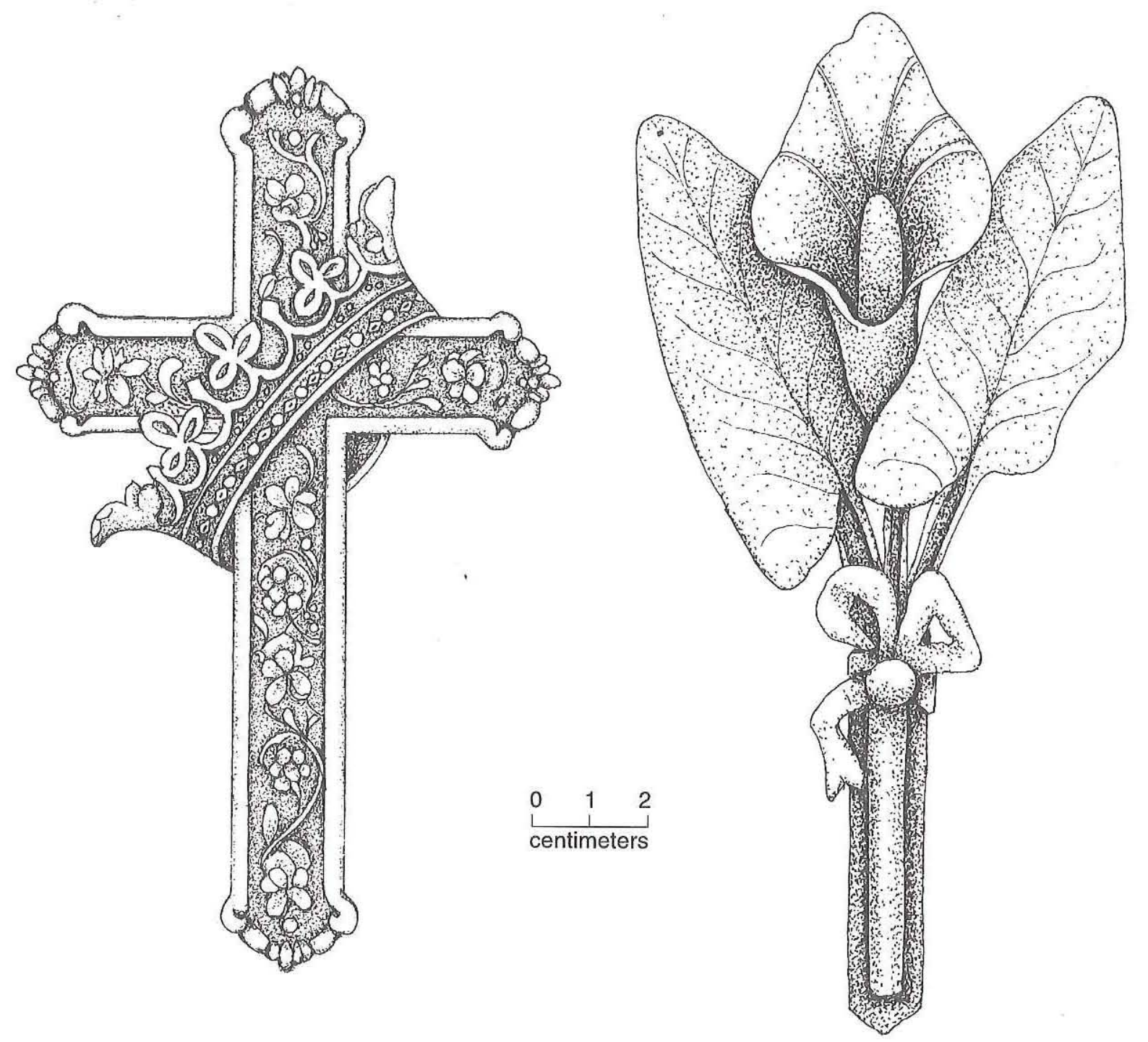

Figure 35. Cross and calla lily casket lid ornaments.

burials (39.3 percent). Two burials, a female interred in the 1930s and a male interred in the 1920 s, had metal buttons; all other examples of metal buttons were observed on the 1907 and 1908 burials. Twenty of the 40 men interred in 1907 or 1908 had metal buttons. These dome-shaped buttons were $14 \mathrm{~mm}$ in diameter, and some had black cloth remnants adhering to them. The attachments were not recovered on all specimens, but when they were recovered, they were loop attachments. The buttons were always recovered from the lower thoracic to upper lumbar vertebrae area and apparently functioned as suit coat buttons. Most of the buttons were recovered from the left side of the vertebral column, as would be expected if they came from a man's buttoned jacket.

The metal buttons from a 1920 interment differed from the 1907 and 1908 burials. Eight domed metal buttons - five large $(23 \mathrm{~mm})$ and three small $(15 \mathrm{~mm})$-were recovered in an alternating pattern along the vertebral column of Burial 47 (Mr. Kyser). These buttons had the letters "U C V" (United Confederate Veterans), the Stars and Bars Confederate battle flag, and "1861-65" printed on the face (Figure 37). These buttons could have been used on a jacket and/or a vest. That Mr. Kyser was buried in clothing sporting buttons of the United Confederate Veterans organization is notable because he served as State Commissioner of Pensions for Confederate 

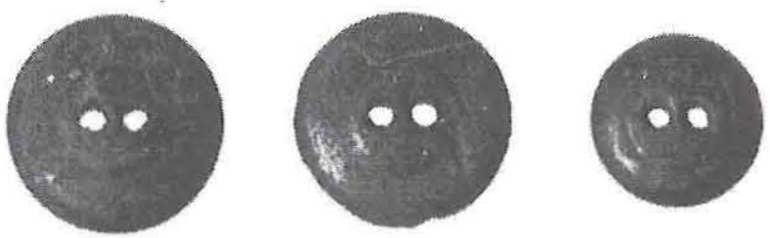

a

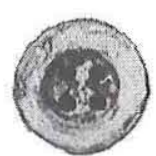

b

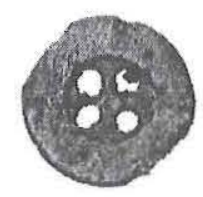

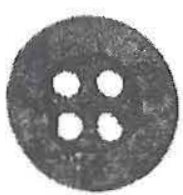

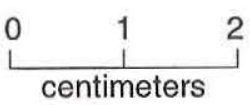

Figure 36. Varieties of buttons. (a) Rubber; $(b)$ shell; $(c)$ bone; $(d)$ metal with a star imprint.

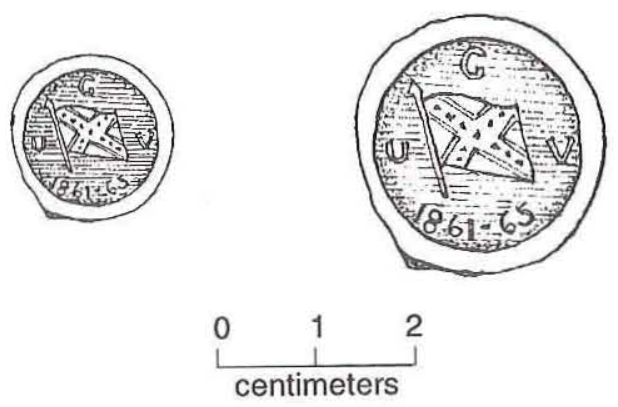

Figure 37. United Confederate Veterans buttons from Burial 47.

Veterans in 1913-1915. Mr. Kyser obviously was proud of his postwar service helping Confederate veterans (see Chapter 5). In addition, two $20-\mathrm{mm}$ metal buttons were recovered from the top of each os coxa. It is possible that these were trouser buttons used to fasten suspenders.

Two metal buttons $(16 \mathrm{~mm})$ recovered from Burial 42 had a five-pointed star on the face and a loop attachment on the back (see Figure 36d). These seem originally to have been in the pelvic area of the burial. The only other metal buttons were from the 1932 interment of Mrs. Burleson (Burial 54). Sixteen domed buttons $(16 \mathrm{~mm}$ in diameter) with loop attachments were recovered from the midline of her skeleton to below the knees. They appear to have served as fasteners on the front of a dress.

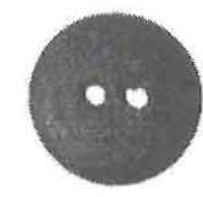

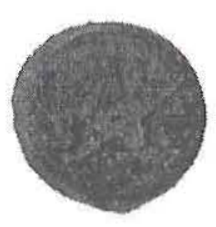

d
Rubber buttons were observed only in the 1930s burials (Burials 2, 3, 4, 5, 6, and 56; see Table 9). These were black with a two-hole concave face covered with fine linear striations or crosshatch marks that may have been intended to emulate fabric. The large ones measured approximately $18-20 \mathrm{~mm}$ in diameter, while the small ones were approximately $15 \mathrm{~mm}$. Intraburial placement suggests that these buttons (large or small) adorned sleeves of coat jackets. In addition, these small and large buttons were recovered in the pelvic area where they may have been used to fasten pants. A few were found along the vertebral column and may have been used on shirts, vests, or jackets.

Shell buttons of the two- and four-hole varieties were recovered from 14 burials (see Table 9), spanning all years of interment. These were very fragile and often fell apart when touched. Due to their fragile nature, it is likely that the number of recovered buttons is not an accurate reflection of the number that originally existed. This is especially true of those with only one shell button. Large shell buttons measured $15 \mathrm{~mm}$ in diameter, while small ones were $11 \mathrm{~mm}$. In general, the small buttons were four-holed and the large twoholed, but this was not true in every case. The majority were recovered from the vertebral area and may represent shirt buttons. In one case (Burial 49), the buttons were located near the wrist and may have been used to fasten shirt cuffs. In general, these types of buttons were numerous and inexpensive (Fink and Ditzler 1993:55). Two leather buttons ( $16 \mathrm{~mm}$ in diameter) were found in the pelvic region of Burial 8 .

Miscellaneous buttons were made of celluloid, glass, and bone (see Table 9). Two celluloid dress buttons, $22 \mathrm{~mm}$ in diameter and $4 \mathrm{~mm}$ high, were recovered from the abdomenal area of Burial 1, a woman interred in 1939 . They had a metal back with a single loop for attachment. A clear celluloid tortoiseshell shield covered a piece of cork (or corklike material) sandwiched between the front and back. Celluloid button popularity was at its 
peak from the late 1870 s to the 1930 s (Fink and Ditzler 1993:61). A fragment of a two-hole glass button with a crosshatched design was recovered from the torso area of Burial 8. One four-hole milk glass button, $16.5 \mathrm{~mm}$ in diameter, was found under the right wrist on top of the pelvis of Burial 35. A four-hole bone button ( $18 \mathrm{~mm}$ in diameter) was recovered from the top of the left side of the pelvis of Burial 27, and two identically styled buttons $(14 \mathrm{~mm})$ were recovered from the top of each os coxa of Burial 47 (Mr. Kyser). The bone buttons recovered from these two burials had a raised outer edge and a depressed center where the holes were drilled. Two bone buttons $(17 \mathrm{~mm}$ in diameter) recovered from Burial 49 also had four holes, but they did not have the raised edge. These were located in the thoracic area next to the vertebral column.

\section{Miscellaneous Clothing Items}

Several other clothing items were recovered, including suspender buckles, eyelets, rivets, snaps, and a pair of nylons (see Table 9). Two copper suspender buckles, measuring $33 \times 18 \mathrm{~mm}$, were located on the right side of the pelvis of Burial 49. Eyelets were recovered from Burials 13, 14, and 32. These 8-mm-diameter eyelets were made of copper. The eyelets with Burials 13 and 14 were found in the pelvic area, presumably associated with trousers. Snaps were found with Burials 23, 24 , and 26. The snap identified in Burial 26 was found in the pelvic area and measured $15 \mathrm{~mm}$ in diameter by $6 \mathrm{~mm}$ thick. Two rivets with large heads $(13 \mathrm{~mm})$ were recovered from the lower portion of Burial 16. Fragments of a heavy and coarse cloth remained within the rivets. A wellpreserved pair of thigh-high nylons was recovered from Burial 50, an interment that occurred in 1951. One rusted safety pin was found with Burial 55 beneath the pelvis on the left side.

\section{Jewelry}

Jewelry is defined here as any item of adornment of a personal nature and includes finger rings, decorative pins, cuff links, collar studs, and hair combs. These items were relatively common, being recovered from 36 of the 56 excavated graves (64.3 percent).

\section{Rings and Bar Pin}

Gold rings were recovered from three individuals - two males and a female (see Table 9). One was an attorney, one was a doctor, and one was the wife of a teacher. Mr. McCulloch (Burial 9) was interred in 1908 with a gold wedding band bearing an imprint of " $18 \mathrm{~K}$ " within the band. The ring had an exterior diameter of $16 \mathrm{~mm}$ and an interior one of $15 \mathrm{~mm}$; the band was $4 \mathrm{~mm}$ wide. Plain 18-carat gold wedding bands of a comparable size were sold through Sears, Roebuck and Company catalogues for $\$ 2.00$ in 1897 (Sears, Roebuck and Company 1976:n.p.), and the price had changed little by 1908 when they offered the same ring for $\$ 1.99$ (Sears, Roebuck and Company 1971:311).

Mr. Trezervant (Burial 30) was buried with two rings, both on the ring finger of his left hand. One was a plain wedding band, made of a gold and cuprous material, with an outside diameter of $19 \mathrm{~mm}$ and an inner one of $18 \mathrm{~mm}$. The name "Helen" was inscribed in a script fashion inside the band. The other ring had a flat-cut moss agate stone set into the band; it had an outer dimension of $19 \mathrm{~mm}$ and an inner one of $17 \mathrm{~mm}$. The moss agate stone set into the band was oval in shape and measured $17 \times 12 \mathrm{~mm}$. Small flowers were engraved on both sides of the band at the top of the ring.

The only other wedding band was recovered on the left hand of Mrs. Bradfield (Burial 55). It had an outer diameter of $17 \mathrm{~mm}$, an inner diameter of $14 \mathrm{~mm}$, and a band width of $4.5 \mathrm{~mm}$. No inscriptions or markings were present.

Mrs. Burleson (Burial 54) was interred in 1931 with a bar pin attached by a straight pin closure (Figure $38 a$ ) in the right upper torso area. The pin was gold plated and measured $50 \times 5 \mathrm{~mm}$ with a triangular and floral motif engraved on the face. Fragments of a dark cloth still adhered to the pin closure. Similar bar pins were available for sale in the 1922-1923 Montgomery Ward catalog (reprinted 1969) ranging in price from 89 cents to $\$ 2.12$.

\section{Hair Combs}

Two women were buried with hair combs (see Table 9). Two plastic hair combs were recovered from the head region of Burial 48 (Emma Kyser). These combs were a mock tortoiseshell style that 

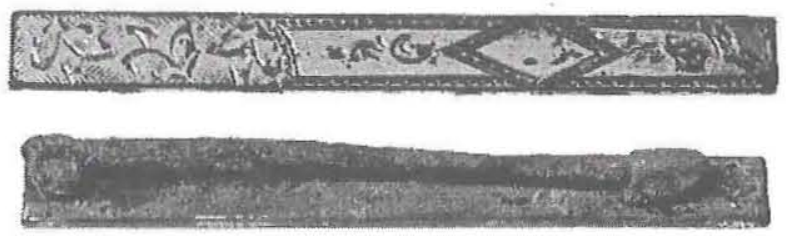

a
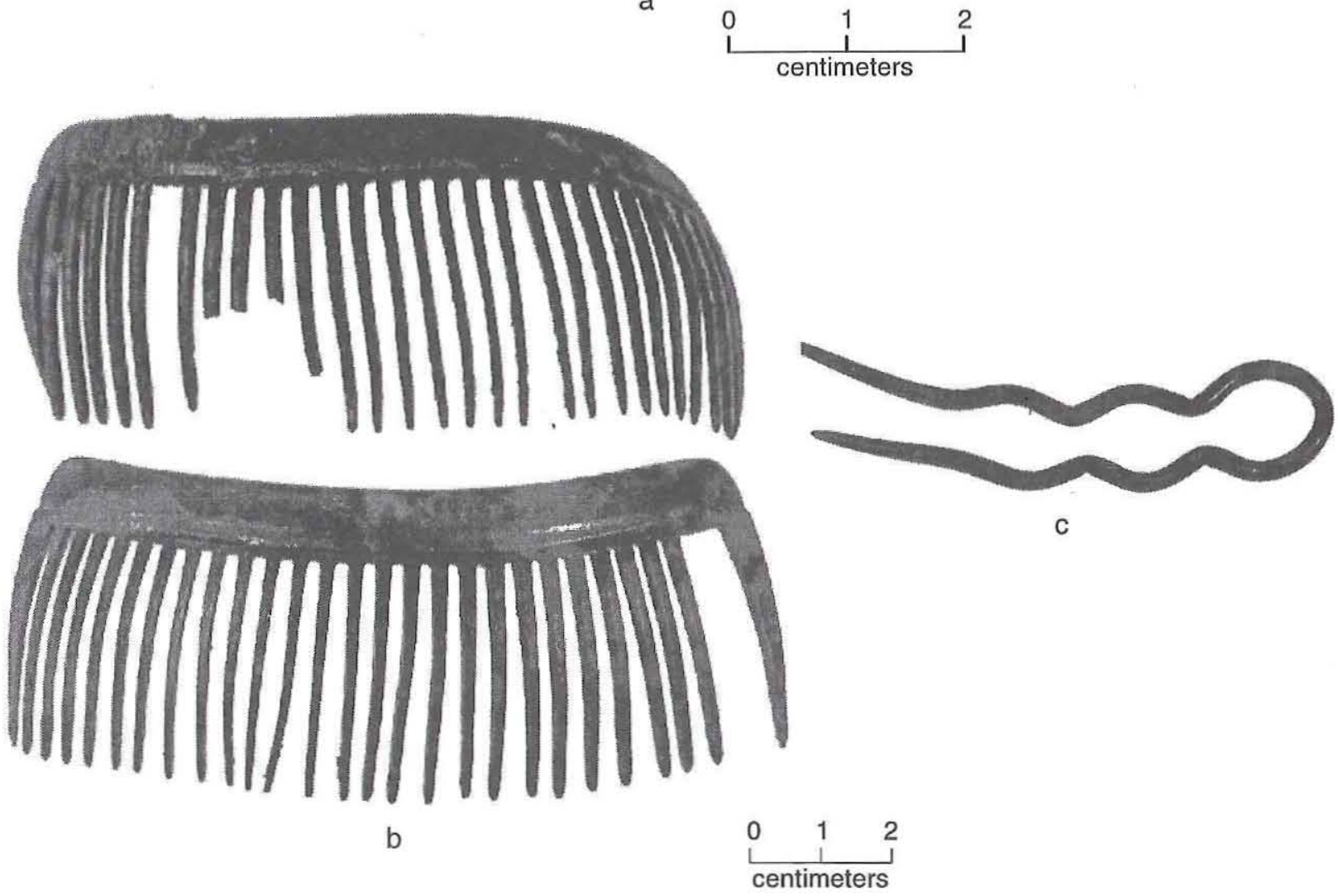

Figure 38. Bar pin and hair combs. (a) Front and back views of bar pin from Burial 54; (b) hair combs from Burial 48; (c) hair comb from Burial 51.

measured $109 \times 41 \mathrm{~mm}$ (Figure $38 b$ ). Multiple teeth ran the length of each comb and may have interlocked when worn together. Another mock tortoiseshell hair comb of a different style was recovered from Burial 51 (Margaret Pannell). This comb measured $69 \times 17 \mathrm{~mm}$ and was a U-shaped tuck style (Figure $38 \mathrm{c}$ ). Hair combs of a similar style appear in the 1922-1923 Montgomery Ward (1969:349) catalog; the back combs (item number $45 \mathrm{C} 8516$ ) could be purchased for 30 cents each, and decorated tuck combs (item number 45C 8535) cost 52 cents a pair.

\section{Cuff Links}

Cuff links were recovered from 29 of the 50 analyzed male burials (58 percent). Of these, all but four were from 1907 or 1908 interments (see Table 9). All cuff links were fabricated of metal, bone, or celluloid. Twenty-four of the 29 sets of cuff links ( 82.8 percent) were made of bone and were identical in style and size $(18 \times 10 \mathrm{~mm})$ (Figure 39a). They were constructed of two separate pieces - a highly polished dome-shaped upper portion and a separate stud that fit into the bottom of the other piece. Bone cuff links were limited to the 1907 or 1908 interments with the exception of one 1920 burial.

Four sets of metal cuff links were observed (see Table 9). Two sets occurred with 1908 interments (Burials 18 and 19), one set was from a 1930 burial (Burial 5), and one dated to 1932 


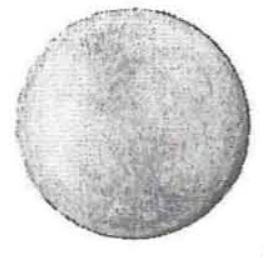

a
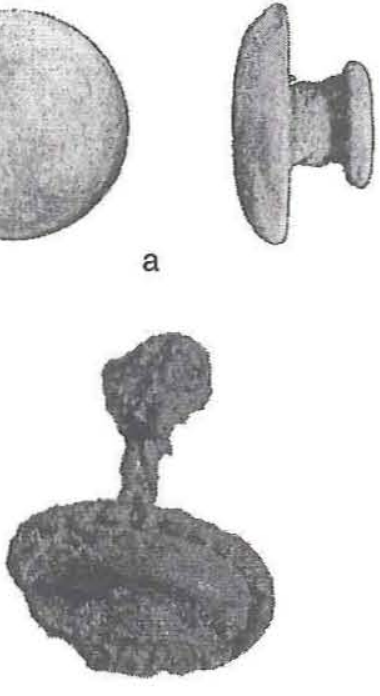

C

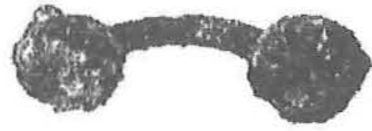

b

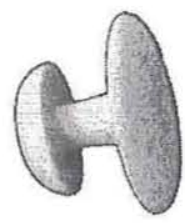

d

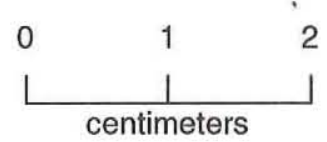

Figure 39. Cuff links and collar studs. (a) Top and side views of bone cuff link; $(b)$ dumbbell-shaped metal cuff link; $(c)$ oval metal cuff link; $(d)$ celluloid collar stud.

(Burial 56). The cuff links found with Burials 18 and 19 were probably made of white metal and were $22.5 \mathrm{~mm}$ in length. These links were shaped like curved dumbbells with little round balls at each end (Figure 39b). The metal cuff links recovered from Burials 5 and 56 were identical, each with an oval-shaped face and beaded edges, measuring approximately $16 \times 11 \mathrm{~mm}$ (Figure $39 c$ ). One probable cuff link was made of celluloid and was recovered from Burial 3 (Joseph Watkins). It was identical to the celluloid collar studs described below but was identified as a cuff stud based on its location near the man's arms. Mr. Watkins had two collar studs that were identical to this possible cuff link. It is possible that the item was normally used as a collar stud, but functioned as a cuff link in this case. The cuff links recovered probably were used on sleeves of jackets and/or shirts.

\section{Collar Studs}

Collar studs were recovered with four men (Burials 3, 5, 6, and 56), all of whom were interred in the 1930s (see Table 9; Figure 39d). All

were celluloid studs constructed as one solid piece. They measured $12 \mathrm{~mm}$ in diameter and $10 \mathrm{~mm}$ high. In addition, a copper stud of an indeterminate purpose was recovered from the thoracic area of Burial 56, which also contained two definite collar studs. This stud measured $14 \mathrm{~mm}$ in diameter and $11 \mathrm{~mm}$ high. Like the celluloid studs, this was one piece and had a depressed center. It is unclear whether this copper stud was used as a third collar stud or if it was a cuff link since another metal cuff link was recovered (mentioned above).

\section{Dentures}

Dentures were recovered from six individuals (see Table 9; Figure 40). All of these were full (maxillary and mandibular) sets with the exception of one maxillary denture (Burial 47). One of the 1907 interments (Burial 30) contained dentures; all other examples date to the 1920s and 1930s. The portion of the dentures representing soft tissue (the palate and alveolus) were composed of vulcanized rubber, while the teeth were made of porcelain. From 1855 to the 1930 s, vulcanized rubber was the best denture material that could be produced and was the primary material used for denture manufacture (Peyton 1975:213). Because vulcanized rubber was inexpensive and easy to mold, the use of vulcanite with porcelain teeth was the standard for making dentures (Hagman 1979: 25; Peyton 1975:213). While this material was the best available, there were some disadvantages to it, including inadequate aesthetic quality, and varying color, taste, and odor (Peyton 1975:213). The artificial teeth in the dentures were all identical in terms of shape and size, as if the teeth were all made from a single mold. Artificial upper and lower third molars were not represented in the dental appliances. Several teeth in a few sets of dentures had suffered postmortem damage. For instance, the right incisors, canine, and premolars of the maxillary dentures from Burial 47 were damaged. The dentures with Burial 48 (Mrs. 

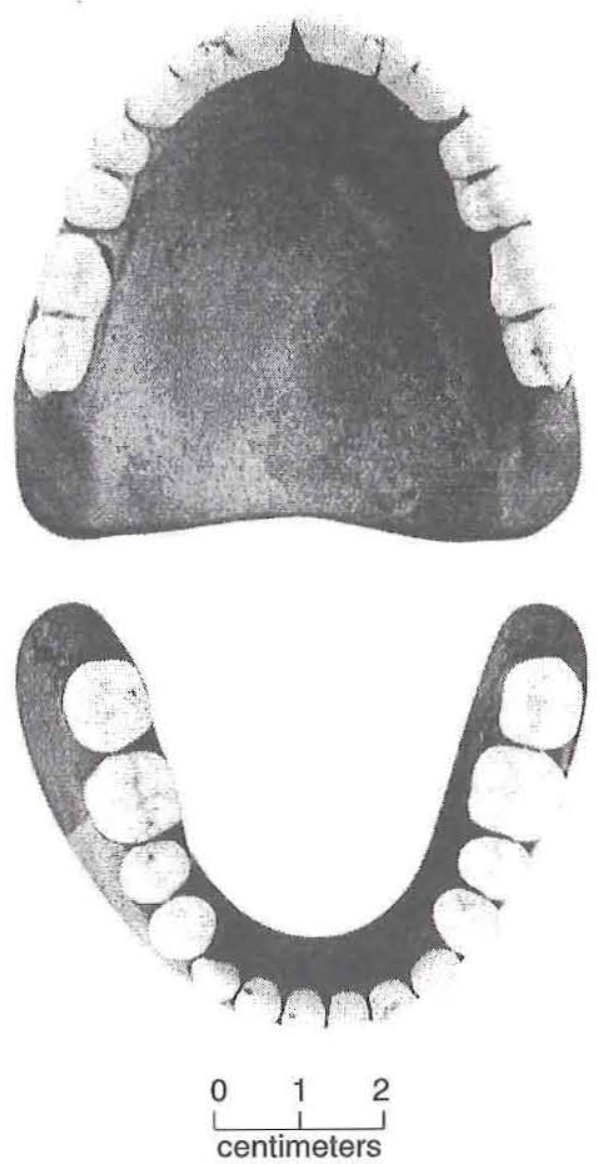

Figure 40. Maxillary and mandibular dentures.

Kyser) were unusual because a gold filling had been drilled into an upper central incisor. The filling may have been placed in the tooth in an effort to emulate a filling in the original tooth, thus making the artificial teeth appear more realistic. The maxillary dentures found with Burial 49 were unusual in that they were constructed with a gap to surround the original right canine and right third premolar. A gold bridge spanned the canine as if to anchor the dentures to it.

\section{Miscellaneous Personal Items}

A few personal items could not be classified under one of the previous headings. A small cream-colored plastic object was recovered from the pelvic area of Burial 50 (Josephine Walker), a 1951 interment. This object measures $16 \mathrm{~mm}$ in diameter and $17.5 \mathrm{~mm}$ high; the face is shaped like a button and the base is funnel shaped and threaded (Figure 41).

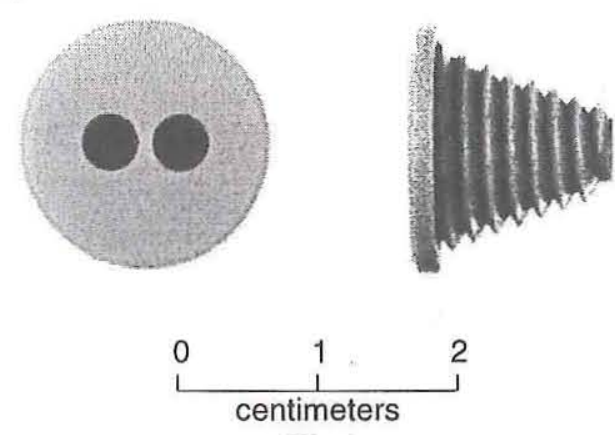

Figure 41. Side and top views of trocar button from Burial 50.

Although it was first thought that this object might represent some sort of medical or gynecological device (e.g., a pessary), gynecologists who were consulted did not recognize it (Dr. Lamar McNew, personal communication 1995; Dr. Randy Smith, personal communication 1995). Subsequent to our attempts to identify this specimen, Texas Parks and Wildlife Department archeologist Art Black (personal communication 1996) identified it as part of a drain plug used by morticians during the embalming process. The identification of this object was confirmed by a mortician from the Callaway-Jones Funeral Home of Bryan, Texas (Mike Jones, personal communication 1996). It is called a "trocar button" (informally known as a "second belly button") and is used to plug an incision left during the embalming process. Plastic trocar buttons probably came into use during the late 1940s and are a good temporal indicator when found in a burial. Not all post-1940s burials will have trocar buttons, however, because they never totally replaced the use of sutures to close embalming incisions.

Burial 43 (C. C. Hagler) was interred in 1907 with a coin purse that contained a penny. The purse (Figure $42 a$ ) was represented only by a metal rim with a three-ball pressure clasp found in the upper right thoracic area. Some fabric was still attached to the metal. Immediately adjacent to the metal portion of the coin purse was a badly corroded copper Indian head penny with a 1900 date. Similar coin purses were observed in a 1922-1923 Montgomery Ward (1969:318) catalog for 23 cents (item number 47C 3850). An item of an indeterminate function was located in the neck region of J. A. Alexander (Burial 23). This object was a circular piece of metal (ca. $93 \mathrm{~mm}$ in diameter and 


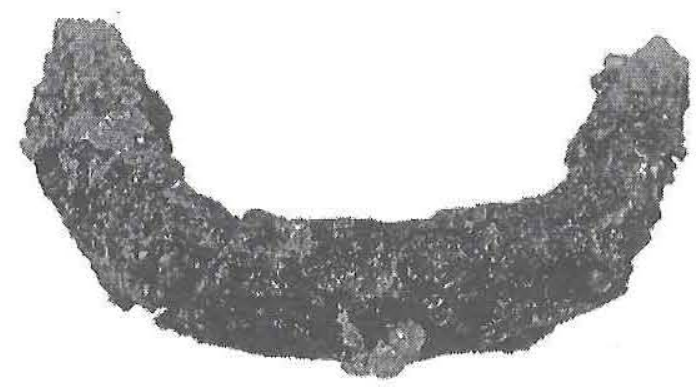

a
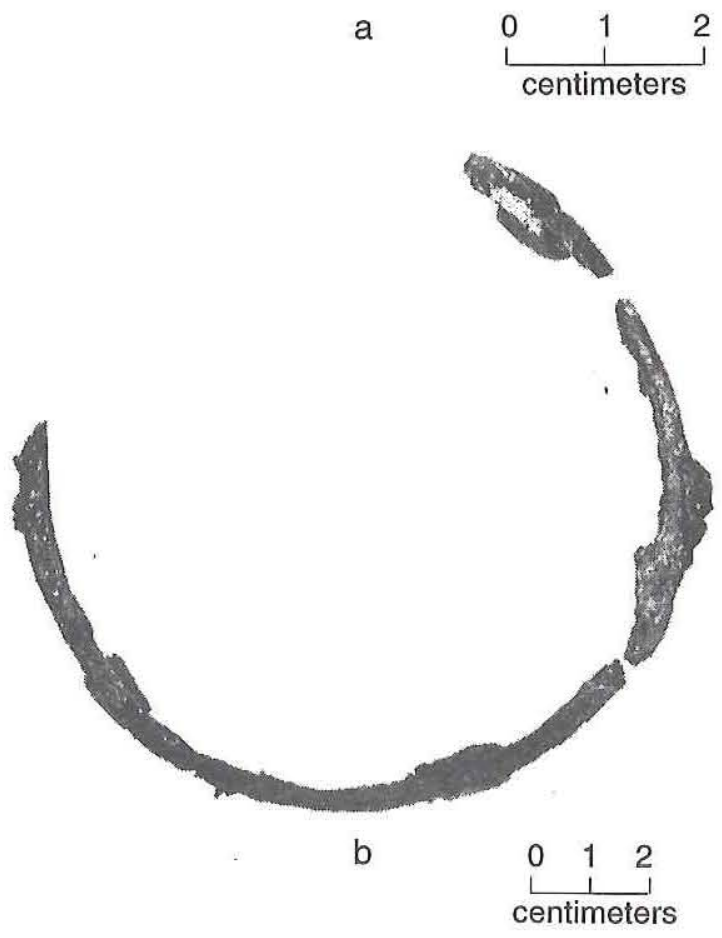

Figure 42. Miscellaneous personal items. (a) Metal remnants of a coin purse from Burial 43.; $(b)$ unidentified cloth-covered metal object from Burial 23.

$3 \mathrm{~mm}$ in thickness) covered by a thick fabric with a chevron-style weave (Figure $42 b$ ). It is unclear what this object is, but it may have encircled an item made of perishable material. Nothing similar to this item was identified in any of the other graves. It is not known if this specimen represents an unassociated intrusion into the casket, a medical device, or some type of personal object.

\section{NONASSOCIATED ARTIFACTS}

Several artifacts not classifiable as casket hardware, decorations, or personal items were recovered from the grave fill of 13 burials (Table 10). In all cases, these items are considered to be unassociated with the original burial event, although some were recovered from the fill within the casket. Four small stoneware sherds were recovered from the fill of Burial 1. A ceramic bottle lip fragment ( $23 \mathrm{~mm}$ wide) with a salt-type yellow glaze was found immediately below the casket lid of Burial 2. In addition, two fragments of stoneware with a white glaze were recovered from the shaft fill of Burial 2. A small ceramic/ porcelain doll's foot was located in the hand area of Emma Kyser (Burial 48), and one ceramic sherd was recovered from the fill of Burial 49. The doll's foot in the casket of Burial 48 measured $18 \mathrm{~mm}$ long and was broken just above the ankle area. The foot was unpainted and the molding seam was visible.

Several metal artifacts were noted, including a large iron hex nut in the fill above the casket of Burial 2. This corroded hex nut measured $75 \mathrm{~mm}$ long and wide and $20 \mathrm{~mm}$ thick. A triangular metal rod similar to a three-cornered file was recovered under the skull in Burial 3. This object measured $123 \mathrm{~mm}$ long by $9 \mathrm{~mm}$ wide and $9 \mathrm{~mm}$ thick. A broken and heavily oxidized iron shovel head $(48.6 \times 17.6 \mathrm{~cm})$ was found in the eastern end of the grave fill associated with Burial 26 . The artifact consisted of the shovel blade with a damaged cutting edge and the bent tubular shaft into which a wooden handle would have attached. The spent casing of a .52-caliber Spencer rimfire cartridge was found in the upper grave shaft fill of Burial 27 on top of the west casket wall.

Three bottle glass fragments were found in the fill of Burial 49 and one $1 / 2$-pint clear glass flask was located in the grave shaft fill of Burial 46. This flask was $80 \mathrm{~mm}$ wide and of an indeterminate height since the neck was broken. Side seams were observed, and "FULL 1/2 PINT" was printed on the bottom surface. A fragment of a milk glass jar sealer was found below the skull in Burial 17. Butchered cow bones were found in the fill of Burials 21 and 34.

In many of these cases, the artifacts found in grave shaft fill are probably fortuitous. Since the cemetery had already been in use for over 50 years at the time of these interments, it is likely that some small metal objects, broken glass, and ceramic sherds were scattered about the grounds and were introduced accidentally into the grave shaft fill. A few of the other artifacts may have been thrown into the grave pits intentionally, but they 


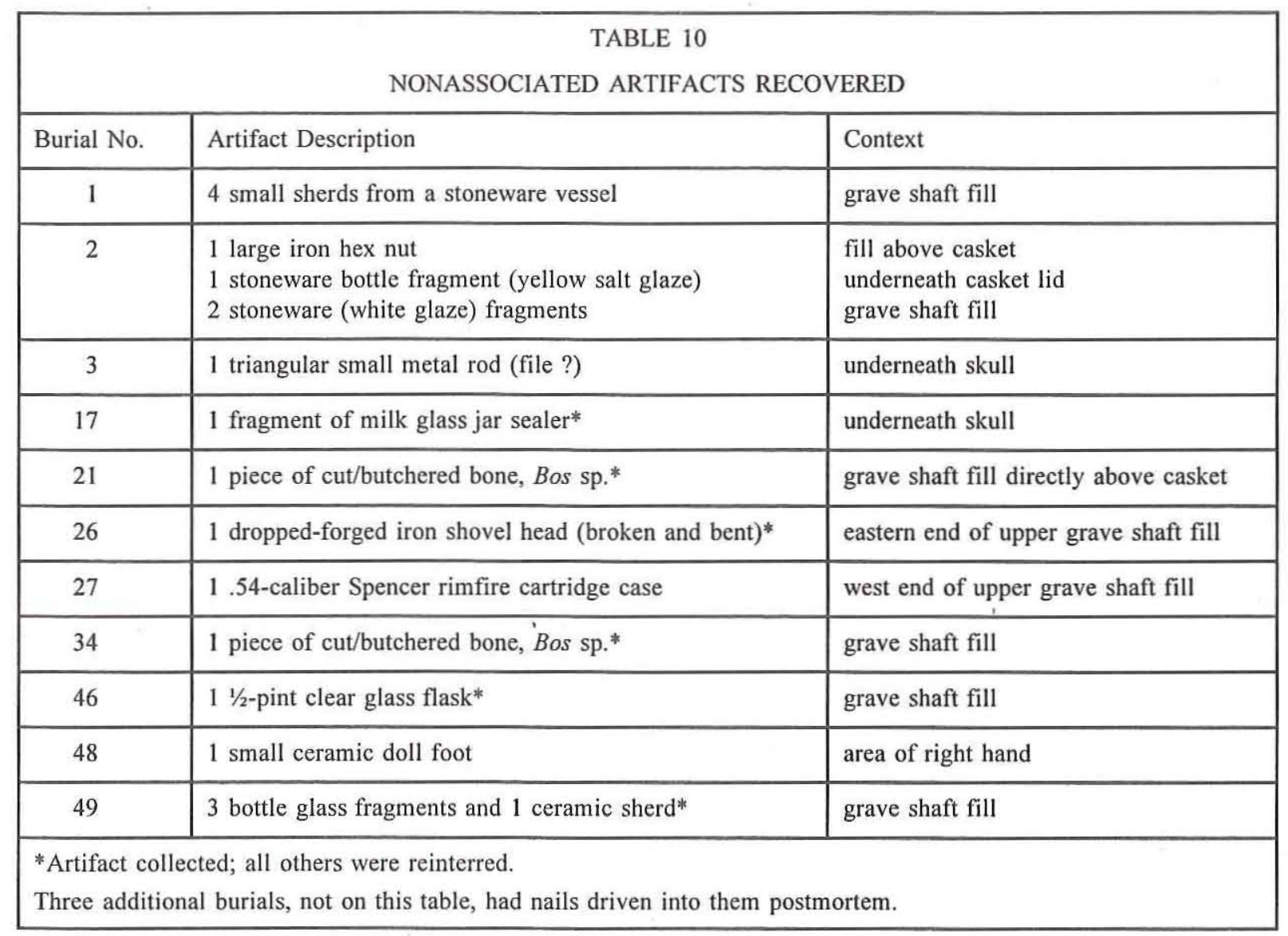

are not directly associated with the burials. The broken and bent shovel head, for example, may have been damaged while in use and discarded into the pit by the gravediggers. The butchered cow bones could represent discarded remnants of gravediggers' meals. Although the presence of a nearly complete $1 / 2$-pint flask, presumably a liquor bottle, in the fill of Burial 46 could be accidental, the bottle may have been discarded by gravediggers. Or, perhaps the bottle represents a final offering by one of the deceased's comrades.

Interpretation of some of the artifacts found inside caskets is even more problematic. Although these could represent postburial intrusions (e.g., carried in by rodents), there is no evidence for such and other explanations are possible. Perhaps the broken doll's foot found in Burial 48 had simply been left in the woman's dress when she was buried. The two artifacts found directly beneath the skulls in Burials 3 (a metal rod) and 17 (a fragment of a glass jar seal) are not likely to have been intrusive. No definitive explanations can be offered, but it is possible that these objects were used in an expedient manner by morticians preparing the bodies for burial (e.g., as props under their heads or to hold hair or clothing in place).

All nonassociated artifacts found inside caskets were reinterred with the other burial remains. Most of the nonassociated artifacts found in grave shaft fill also were reinterred, but a few of the more interesting specimens were collected (see Table 10). In addition to the nonassociated artifacts listed in Table 10, three burials contained bodies that had nails driven into them postmortem. That these events occurred after death was clearly demonstrated osteologically by the absence of new, remodeled bone surrounding the point of entry. Burial 30 (L. E. Treservant) contained a nail that had been driven through the floor of the casket into the lateral portion of the man's left calcaneus (i.e., his heel). A nail embedded in the left humeral head of Burial 32 (John M. Adams) had been driven through the left casket side wall and 
into his shoulder. Burial 40 (D. R. Jacks) had a nail through the distal end of his left tibia; it also had been driven through a casket side wall. It is unclear why these nails were driven into the bodies of these individuals, but it seems unlikely that their occurrence was accidental. Since casket construction and installation of hardware presumably would have been done before the bodies were placed into the containers, perhaps additional nails were added to repair caskets or add ornamentation; this too seems unlikely, however, given the locations of the nails (i.e., the floor and low on side walls) and the absence of associated ornaments. It also is hard to imagine a scenario where caskets containing bodies might be moved in such a manner and with sufficient force that the nails were driven fortuitously through the wood and into bones. If not accidental, one plausible explanation is that the nails were used intentionally by morticians attempting to hold limbs in particular positions when preparing the bodies for display. This explanation is possible for Burial 32 since the casket had a viewing window and it was the left shoulder that was nailed down. It also could explain the nail in the left ankle of Burial 40 because the casket had no viewing window and the full body would have been viewed with the lid removed. This explanation is less satisfactory for Burial 30 , however, since the casket had a viewing window but it was the left foot that was nailed down. Nailing the foot down probably would not have been necessary unless the body was viewed open casket despite the viewing window.

\section{INTERPRETATIONS OF MATERIAL CULTURE}

Funeral expenses of all of the 46 individuals interred in Section F, with the exception of 3 (Burial 3, Mr. Watkins; Burial 6, Mr. Benson; and Burial 34, Mr. Moody), were paid by the Confederate Home for Men with funding allocated by the State of Texas. In addition, 4 of the 11 individuals (Burials 49, 53, 55, and 56) buried in Section D died while living in the Confederate Home for Men, and their burials were subsidized by the state through the Confederate Home. That two of the people residing in the Confederate Home for Men at the time of their deaths were women (Burials 1 and 55) is not unusual. Most women, particularly widows, lived in a separate Confederate home for women (Webb 1952:I:192), but some veterans' wives were allowed to live with them at the mens' home (Roberts 1930). Mortuary expenses of the remaining people in Section D were covered by family members. Temporally, the excavated burials in Section D occurred at a later date than most of those in Section F. Excavated Section D interments date from 1917 to 1951, with the exception of Dr. Ward (Burial 57), who originally was interred at a different cemetery in 1884 and subsequently was relocated to the State Cemetery in 1958. Most Section F burials took place in 1907 or 1908 , except for six burials that date to the 1930s. Because of these economic and temporal differences, the burial data may be used to infer mortuary behavior and the socioeconomic status of the Confederate veterans interred by the Confederate Home for Men. These interpretations are based both on comparisons among the 57 burials as well as by comparing the State Cemetery burial data with that from other historic cemeteries, both in and outside Texas.

\section{Intrasite Comparisons}

\section{Socioeconomic Analysis}

Perhaps the most significant information to be attained from the excavations relates to the quality of the burials of the former Confederate soldiers. Because the vast majority of these individuals (82.5 percent) were wards of the state at the time of their death, it was anticipated prior to the excavations that these people would have been buried in inexpensive boxes. Excavated historic burials of poor persons in other cemeteries suggested that this would be the case. For instance, at the cemetery associated with the Uxbridge Almshouse, 58 percent of the coffins analyzed had no hardware whatsoever (Bell 1991:279). The remaining 42 percent were "decorated" only with coffin screws, tacks, and hinges (Bell 1991). No examples of coffin handles, thumbscrews, escutcheons, plaques, or decorative studs were noted, and only two coffins (6.5 percent) had viewing windows. At the Highland Park institutional cemetery, most people were interred singly in simple undecorated pine boxes, but four coffins had two individuals each (Lanphear 1988:63; Rosenberg-Naparsteck 1985:14). Also, sometimes more than one coffin was observed in a designated grave plot (Lanphear 
1988:63; Rosenberg-Naparsteck 1985:15). Only one of 296 coffins had a glass viewing window (Rosenberg-Naparsteck 1985:14).

The excavations at the State Cemetery, however, yielded evidence indicating that the 47 individuals whose funerals were paid for by the Confederate Home for Men were buried in nicely constructed and elaborately decorated caskets. All caskets were decorated with handles, and many had thumbscrews, escutcheons, and decorative studs. In addition, three of the caskets provided by the Confederate Home had caplifters indicating that they had divided lids, and 21 caskets had viewing windows. Caskets with viewing windows were more expensive than those without (Blakely and Beck 1982:188). In addition, five of the subsidized interments had plaques on the casket lids (interestingly, none of these were associated with the 1907-1908 burials). Records associated with two men (Burials 3 and 29) indicate that $\$ 30.00$ was set aside for each of their caskets. In addition, the 1904 annual report of the Confederate Home (Texas Confederate Home 1904) indicates that money was set aside from each budget to pay for the burial of Confederate Home residents. Setting aside money to insure the respectful interment of veterans appears not to have been unusual. Veterans who died in Chicago around 1918, for example, were allocated $\$ 35.00-\$ 50.00$ per burial, while those in New York were allocated $\$ 50.00$ per burial (Hoffman 1919).

In spite of some variability (especially in terms of viewing windows and plaques), the caskets used to inter the people from the Confederate Home seem to exhibit some general uniformity. From this, a pattern to the mortuary behavior pertaining to Confederate Home interments can be surmised. For example, all caskets seem to have been mass manufactured rather than made to fit (see above), and many were placed into outer boxes. In addition, certain handle styles were used repeatedly for Confederate Home burials dating to 1907 and 1908. For instance, handle Types 1 and 2 were used on 28 (71.8 percent) of the early Confederate Home burials. All handle types were double lug short bars or swing bails, with the exception of one set of extension bar handles. Only two styles of escutcheons were used as part of the casket lid fasteners, and only three types of thumbscrews were employed as casket lid fasteners. Of the 1930 Confederate Home interments, only one casket handle type was used, and no thumbscrews and escutcheons were used on these caskets.

In addition to standardization of funerary hardware, many of the men seem to have been interred in identical suits. Evidence for this includes the fact that identical black (possibly silk) bow ties were recovered from 12 (30.8 percent) of the 1907-1908 Confederate Home interments. Identical bone cuff studs were observed on 22 ( 56.4 percent) of the men interred by the Confederate Home. Also, identical metal buttons were found with 20 (51.3 percent) of the men, and identical shell buttons were found in 7 (17.9 percent) of these 1907-1908 burials. The consistency of button types among burials and their patterning within individual burials suggest that these men were interred wearing the same, or very similar, single-breasted suits. Records from the Confederate Home for Men verify that suits were provided to wards of the home (Roberts 1930:60; Texas Confederate Home 1904), and residents probably were interred wearing these state-provided suits. The six men interred by the home after 1908 did not show this degree of standardization in clothing. However, identical rubber buttons and shell buttons were recovered from four of their caskets.

No evidence of shoes was recovered with any of the individuals. This is not surprising, as it was common for individuals to be buried without shoes. At the Phillips Memorial Cemetery, no shoes were recovered, and local funeral directors explained that it is often difficult to place shoes on the decedent's feet (Powell and Dockall 1995:351). Shoes were recovered infrequently with individuals from Cedar Grove (Rose 1985), 41DT104 (Lebo 1988), and 41DT105 (Winchell et al. 1992). No shoes were recovered from the Morgan Chapel Cemetery (Taylor et al. 1986:45).

During the course of excavating the 19071908 interments, one burial (Burial 34, Louis R. Moody) differed significantly from the other interments in terms of casket construction and hardware. First, Mr. Moody's casket was much larger than the other wooden caskets $(210 \times 70 \mathrm{~cm})$. Second, all casket ornaments adorning his burial receptacle were made of brass rather than white metal. Third, his was the only one of the 19071908 caskets to have six Type 2 handles rather than four. Fourth, the caplifter on his casket was 
much larger than all other caplifters, and it was the only brass one recovered. Fifth, his casket was the only one to have a brass "At Rest" plaque. Last, his was the only casket with a large brass calla lily ornament attached to the lid (one other person had a calla lily, but it was much smaller and not brass). Subsequent archival research documented that while Mr. Moody was a Confederate veteran, he never lived in the Confederate Home for Men. How he came to be interred in the middle of a row of individuals who all died while in the Confederate Home is unclear. It is possible that he was somehow connected with the administration of the home, but this has not been verified with historical records. There is no evidence that two other men (Mr. Watkins, Burial 3, and Mr. Benson, Burial 6) interred in Section F in 1930 and 1931 ever lived at the Confederate Home, but their caskets were not distinctly different from those of the other men.

The seven people from Section D who were not buried by the Confederate Home (Burials 47, $48,50-52,54$, and 57) were interred in caskets that were markedly different from those of Confederate Home burials in Section F. In particular, these Section D interments appear to have had greater wealth expended on their burials than those in Section F. Most notably, all of the extension bar handles recovered, with the exception of one set, were from these burials. Five of the seven Section D burials had extension bars on their caskets, which are more expensive handle types than swing bails and short bars (see Hacker-Norton and Trinkley 1984:50). For example, in 1877, Paxson, Comfort, and Co. sold extension bar handles for $\$ 4.13$ wholesale, compared to $\$ 0.28$ for a silverplated metal handle (Hacker-Norton and Trinkley 1984:Table 5). Four metal handles could be purchased at a wholesale price of $\$ 1.12$, while six would cost $\$ 1.68$; either choice was significantly less expensive than extension bars. In 1956, steel extension bars could be obtained for $\$ 5.77$ and antimonial lead ones cost $\$ 11.44$; short bar handles cost $\$ 0.63$ each and swing bails cost $\$ 0.43$ (Hacker-Norton and Trinkley 1984:Table 6). Therefore, extension bars still cost more than even six of the more expensive short bar handles (wholesale cost $\$ 3.78$ ) or six double lug swing bails (cost $\$ 2.58$ ). One of the Section D individuals lacking extension bar handles (Dr. Ward, Burial 57) had eight double lug short bars rather than the typical four or six.

All four metal caskets, ranging in date from 1884 to 1931, came from burials in Section D. Metal caskets have always been significantly more expensive than wooden caskets. Even in 1854, the wholesale price of a metal casket was listed at $\$ 20.50$ (Habenstein and Lamers 1962:269).

Personal goods recovered from Section D also suggest greater wealth. For instance, six sets of dentures were recovered. Of these, three sets were found with people in Section D who were not residing at the Confederate Home at the time of their death, and three sets were recovered from people who were living at the home. Although the sample is small, this means that almost 43 percent of the people living independent of the home at the time of their death had dentures, an expensive health item, compared to, only 6.5 percent of those people interred by the home (including those people in Section D who died while living at the home).

In addition to personal goods and casket hardware, the interments in Section D also differed in headstone type. As described in Chapter 5, all headstones of the Section $F$ individuals were of two types, one of which was issued by the Department of the Army to people who served their country in the military. With the exception of three headstones (one Type 1 belonging to Louisa Bradfield and two Type 2 stones belonging to James Bradfield and George Walker), none of the markers associated with the other Section D interments were issued by the Department of the Army. The remaining markers were of a more individual, and more expensive, nature. Interestingly, Bell (1990:69) noted: "Because grave markers are on display to a community for longer than coffins, the symbolic representation of differential status is more permanently communicated through grave markers than through extravagant burial containers." All of these factors suggest a greater wealth for the individuals who were not wards of the Confederate Home for Men at the time of their death. This is certainly not an unexpected finding given that most men entered the Confederate Home because they could no longer care for themselves.

Bell (1990:54-55) noted that archeological interpretations relating socioeconomic status to coffin decorations need to be re-evaluated since mass-produced casket hardware is inexpensive and was used by many different socioeconomic classes. 
This assessment was based in part on the fact that 45 percent of the caskets from the Uxbridge Burial Ground were decorated with hinges and/or coffin tacks and screws. He argued that mass-produced items are "symbolic of apparent wealth," but should not be used confidently as an absolute indication of socioeconomic status (Bell 1990:55, 72). An intrasite comparison of burials from the State Cemetery, however, is not intended to determine real socioeconomic status of those individuals interred by the Confederate Home versus those who were not. Rather, the goal of such an analysis is to examine how, and with what degree of respect, these interments took place.

Archeological analyses of burial data suggest that those men and women whose burials were subsidized by the State of Texas through the Confederate Home were not interred in the same fashion as those people whose burials were paid for by their families. However, the nature of their interments still indicates a certain degree of status relating to their burials. Casket hardware can be used to reflect either real or apparent status (See Hacker-Norton and Trinkley 1984:51). Apparent status is suggested by the use of less-expensive mortuary furniture to adorn a casket, while real status is indicated by more-expensive items. Hacker-Norton and Trinkley (1984:51) note that apparent status was reflected by the use of short bar or swing bail handles, decorative studs, and stamped metal plates; extension bar handles, caplifters, and heavy plaques were reflective of real status. They further state that "regardless of the type or style, handles were the most expensive items used in trimming a coffin. All of the other items combined, including thumbscrews, escutchions [sic], caplifters, screws, coffin tacks, studs, and the coffin plate, would rarely cost more than the four to six handles" (Hacker-Norton and Trinkley 1984:50). Furthermore, the reduction of handles from six to four would "account for significant savings" (Hacker-Norton and Trinkley 1984:50). This statement may be especially telling in analyzing the casket hardware assemblage of the Section F Confederate Home interments since fully 60.5 percent of the caskets in this row $(n=43)$ had only four handles; 55.3 percent of all Confederate Home interments $(n=47)$, including those in Section D, had only four handles. All of the caskets in Section $\mathrm{F}$ had short bar or swing bail handles rather than extension bars. Most were decorated with thumbscrews, escutcheons, and decorative studs. While the four Confederate Home burials from Section D differ from those of Section F in terms of casket hardware, apparent status rather than real status is still reflected in the choice of mortuary objects. Only one burial (Burial 49) had extension bar handles; the rest had iron double lug short bars. Furthermore, the caskets lack additional decorative objects suggestive of real status. This information, taken together, suggests that the caskets associated with Confederate Home interments are reflective of apparent, rather than real, status. However, the fact that 21 ( 44.7 percent) of the 47 Confederate Home interments (Sections D and F) had caskets with viewing windows seems more suggestive of real status. In addition, six of these men had casket lids decorated with Mason's symbols, calla lilies, and crosses, while six burials also had casket plaques. These additional decorative objects are more suggestive of real, rather than apparent, status. However, it is not known whether these items were purchased by the Confederate Home or if family members or fraternal societies provided additional money for the burial of these particular individuals.

A conservative interpretation of the Confederate Home burials suggests that the burials of these men and women reflect "apparent" status bestowed upon them in the form of nicely decorated caskets, with (minimally) swing bail or short bar handles, casket lid fasteners, and decorative studs. The Confederate Home also may have purchased caskets with viewing windows in some cases, but this is not unequivocal since it is feasible that family members may have helped with the funeral expenses. At the Uxbridge Almshouse, individuals were interred at the "lowest possible cost," as typified by the minimal coffin decorations (Bell 1990:60). Since the people interred by the Confederate Home were wards of the state in a technical sense, it would not have been surprising for them also to have been interred at minimal cost, i.e., in plain coffins with nails only. That their caskets had at least handles, thumbscrews, escutcheons, and decorative studs suggests that they were considered worthy of expense, and presumably indicates a sense of respect on the part of those responsible for their interment.

In addition to trying to determine the relative status of these individuals, a comparison was made 
of the casket quality of people who once had a job indicative of a high socioeconomic status (such as doctors, attorneys, and merchants) as compared to people with more-common labor-oriented jobs (such as farmers and ranchers). Because of sample size disparity (for instance, only two doctors and one attorney were buried in the excavated portion of the cemetery), this could not be achieved on a systematic basis. However, of those people living at the Confederate Home at the time of their death, 11 had once been employed in professional occupations, while 33 were more labor oriented. Of these, the people from professional occupations were interred in caskets identical to those in labororiented fields. Exceptions to this were seen with two merchants, Burials 9 and 19. One had a white-metal cross attached to his casket lid, and the other had a Mason symbol on the casket lid. The only other exception was noted on Burial 49 (a salesman) whose casket had extension bar handles. Six of these professionals had caskets with viewing windows, but so did 15 people from the more-labor-oriented jobs. The fact that no pattern was discerned among the caskets belonging to laborers and professionals is not surprising given that all were residents of the Confederate Home at the time of their death and most likely did not have the monetary means to support themselves.

As described above, the caskets of people in Section D who were not residents of the Confederate Home at the time of death were markedly different. Unfortunately, only three men fit this description, and only two had known occupations (judge and doctor). Of these two men, the surgeon (Burial 57) was interred in an elaborate wrought or cast metal coffin with 8 handles and 28 escutcheons, while the judge (Burial 47) was buried in a wooden casket with six double lug short bar handles and a divided lid. Two of the three men in Section $\mathrm{F}$ not associated with the Confederate Home were buried in caskets that were basically identical to all the others in that row. It is interesting to note, though, that the most elaborate casket (Burial 34) in Section F was associated with a merchant who had not been a resident of the Confederate Home for Men. This casket, described earlier, was notable for the presence of brass rather than white-metal hardware, as well as the presence of a calla lily ornament and an "At Rest" plaque.

In summary, casket analyses document two interesting trends in terms of socioeconomic status and occupation. First, regardless of their occupational status earlier in their lives, those men residing in the Confederate Home at the time of their deaths were all buried in virtually identical caskets. Second, regarding those veterans who lived independent of the home, there is a correlation between occupational status and the elaborateness of their caskets. However, this is based on a very small number of individuals of known occupation $(n=4)$.

\section{Chronological Analysis}

The burial data can also be analyzed from a temporal perspective to support interpretations of changing mortuary patterns during the early nineteenth century. Swing bail casket handles tended to be more common prior to $1880-1890$, when a shift to the more frequent use of short bars was observed (Hacker-Norton and Trinkley 1984:44). Short bars were very popular from 1880 to 1920 , but extension bars became more popular by 1912 (Hacker-Norton and Trinkley 1984:44). Because dates of interment are known for all of the caskets, this assemblage is a good one for testing this statement of stylistic trends. Excluding the only burial that occurred prior to 1907 , i.e., the 1884 iron coffin, swing bail handles were observed on 30.4 percent of all caskets (17 of 56) and all examples dated to 1907 or 1908 . Short bar handles were the most commonly observed casket handle type (58.9 percent, or 33 of 56). They were observed on 23 of the 1907 and 1908 burials, in addition to 10 burials dating to the 1910 s, 1920s, and 1930s. Extension bar handles were relatively uncommon, being noted on only 8.9 percent of the caskets ( 5 of 56). Although extension bar handles had been in use from at least the 1870s (see Hacker-Norton and Trinkley 1984:45), the earliest set observed dates to 1923. All others date from 1925 to 1951 . Therefore, casket handles recovered from the State Cemetery do support the expected temporal pattern (Figure 43).

One other interesting stylistic trend pertaining to casket handles involves metal types. The vast majority of the handles observed were manufactured from white metal. However, all of the Type 10 and Type 13 handles, which were seen only on burials dating to the $1930 \mathrm{~s}$, were constructed of iron, a less expensive material. It is possible that 


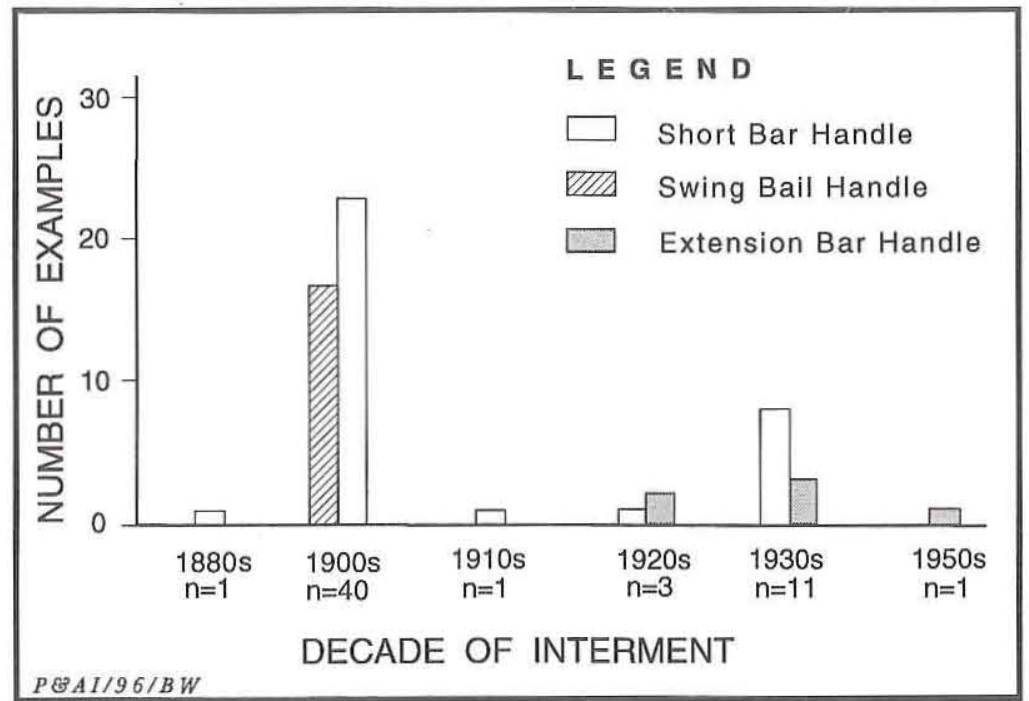

Figure 43. Relative frequency of occurrence of, swing bail, short bar, and extension bar handles in the excavated burials.

the use of iron as a casket handle material in the 1930s was a concession made to the Depression, which was occurring at the time.

Patents for glass viewing windows date between 1860 and 1900 (Blakely and Beck 1982:188, citing Kline and Kline n.d.). However, at least one earlier patent, dating to 1867 , has been located by James Davidson (personal communication 1996). All windows noted in this sample occurred only on 1907 and 1908 caskets, with the exception of one case associated with an 1884 coffin. Four cemeteries-Morgan Chapel, 41DT104, Boothill, and Uxbridge - had some viewing windows that could be dated firmly. Of the viewing windows on caskets from these sites, none postdated 1904. This suggests that viewing windows declined in popularity during the early 1900 s and that the caskets used to bury Confederate Home veterans were already out of style.

Decorative tacks or studs were noted on 45.6 percent of the burials, and all cases were limited to 1907 and 1908 interments. Hacker-Norton and Trinkley (1984:49) suggested that, by the turn of the century, decorative studs were no longer popular in the funeral industry and their use after this date probably corresponded with rural cemeteries and the inexpensive nature of the items. That no studs postdating 1908 were recovered supports the contention that they became less popular at the turn of the century. The presence of studs on the 1907-1908 burials of people from the Confederate
Home during a period of time when studs were declining in popularity may reflect a desire of funeral home directors to rid their stock of a less-popular item. The inexpensive but decorative nature of these objects made them well suited to the adornment of these state-subsidized caskets. Lastly, no escutcheons or thumbscrews were present on caskets postdating 1908, although thumbscrew manufacture persisted at least through the 1960s (see HackerNorton and Trinkley 1984:46). The coffin dating to 1884 had 28 escutcheons that were associated with screws rather than thumbscrews. A perusal of casket hardware catalogs dating to 1865 and 1871 suggests that plain coffin screws were used with escutcheons until they were supplanted by thumbscrews (Hacker-Norton and Trinkley 1984:30).

Temporally, there are several primary differences between the 1907-1908 interments and the later ones. The earlier burials had thumbscrews and escutcheons which were not observed on later burials. Handle types were limited to swing bails and short bars. Furthermore, only these early burials had viewing windows. Later burials had short bar and extension bar handles; lids were fastened with latches rather than escutcheons and thumbscrews. Plaques were recovered most frequently from burials dating to the 1930s.

\section{Intersite Comparisons}

This section compares mortuary features of the State Cemetery with burial evidence from other historic cemeteries. Most of the cemeteries composing the comparative sample are from Texas, although some are from Arkansas, Oklahoma, Massachusetts, and South Carolina. All of the sites date from the late 1800 s to the mid 1900 s, with the earliest one dating 1831-1872 and the most recent dating ca. 1880-1942. The Cedar Grove cemetery was an African-American burial ground in Arkansas that dated from 1890 to 1927 (Rose 1985); the Phillips Memorial Cemetery was also an African-American cemetery that was 
essentially coeval with Cedar Grove, dating from the late 1800s to 1927 (Dockall et al. 1996). The Mount Pleasant Cemetery (38CH778), located in South Carolina, contained the remains of ante- and postbellum African-Americans (Trinkley and Hacker-Norton 1984). Sites 41DT104 and 41DT105 both represent family cemeteries from Delta County, Texas; 41DT104 dates from approximately 1880 to 1942 , and 41DT105 dates from the 1850 s to the late 1870 s or early 1880 s (Lebo 1988 ; Winchell et al. 1992). The Morgan Chapel Cemetery, located in Bastrop County, Texas, dates 1891-1937 (Taylor et al. 1986). The Laredo Cemetery, in southern Texas, dates from the 1890s to the 1920s (McReynolds 1981). The Boothill and Coffey Cemeteries, located in Coleman and Concho Counties, contained the remains of pioneer Texans who died between 1870 and 1885 (Earls et al. 1991). The Morgan, Yarbrough, and Bryne Cemeteries, dating ca. 1860 to 1913 , were located in McMullen County, Texas, and represent family burial grounds (Fox 1984). The McGee Creek cemeteries represent the burial grounds of Choctaw families in Oklahoma dating 1899-1924 (Ferguson 1983). The last comparative sample is the Uxbridge Almshouse burial ground which contained the remains of paupers interred in Uxbridge, Massachusetts, between the years 1831 and 1872 (Elia and Wesolowsky 1991).

These sites provide critical points of comparison in terms of time, population composition, location, and type of burial ground. There is one significant way in which the State Cemetery differs from all of the comparative samples. The sample composing this cemetery consisted only of the remains of elderly individuals; no young adults or children are represented in the burial assemblage. Since children's graves generally are minimally decorated when compared to those of adults (see Hacker-Norton and Trinkley 1984; Rose 1985; Trinkley and Hacker-Norton 1984), this factor may have affected the overall percentage of decorative items observed at sites with funerary hardware, especially at sites such as Cedar Grove with a high percentage of infant and child deaths (51.3 percent; Rose and Santeford 1985). This is far less likely to be a factor in cemeteries like Phillips, in which only 4.6 percent of the burial population was composed of subadults (Dockall et al. 1996). This also is not likely to be a factor in the Morgan Chapel Cemetery, in which 61.9 percent of the burials were infants, but all except one had ornate hardware and several had viewing windows (Taylor et al. 1986).

Many factors affect the elaboration of a casket in terms of handles, thumbscrews, escutcheons, viewing windows, and other mortuary hardware items. The time in which the cemetery was in use is one factor that can affect the mortuary assemblage since certain hardware types were used more commonly during different periods of time. For instance, casket handles, thumbscrews, and escutcheons become more popular after 1860 (see Kogon and Mayer 1995). All of the comparative data sets are generally contemporaneous, minimizing the effects of temporal differences, with the exception of the Uxbridge Almshouse Burial Ground. This cemetery is earlier than the rest, so temporal differences may be an issue here. In addition to temporal factors, popularity, local availability, and wholesale purchasing techniques also affect the elaboration of a burial container (Hacker-Norton and Trinkley 1984:44). Finally, relative wealth of the family or the presence of fraternal societies or religious groups that raise or provide money for interment also must be considered (see Bell 1990; Earls 1991).

The effects of these factors on the burial assemblages being considered here are purely speculative, but it is important to acknowledge that all of these elements interact to create the recovered mortuary assemblage. Given this, a comparison of the State Cemetery mortuary assemblage with the sites described above shows several interesting trends (Table 11). For example, the State Cemetery has the highest percentage of caskets (98.2 percent) rather than coffins, followed by the Morgan Chapel Cemetery ( 81.0 percent). This is especially interesting since the Morgan Chapel Cemetery is arguably the most similar, and therefore the best comparison, in terms of date and geographic proximity. Four metal casket/coffins were recovered from the State Cemetery; only one other site (41DT104) yielded a metal casket, which dated to 1942 (Lebo 1988:91). In terms of viewing windows, the State Cemetery and Morgan Chapel have virtually the same percentage, at 38.6 percent and 38.1 percent, respectively. This is followed closely by $41 \mathrm{DT} 104$ at 31.3 percent; all other examples from the comparative cemeteries lag far behind at 10 percent and less. The Morgan Chapel Cemetery had the most frequent evidence 
for paint on burial receptacles (33.3 percent), followed by 41DT104, Phillips, Cedar Grove, and then the State Cemetery. The State Cemetery is the only one in which all burial receptacles exhibited casket handles; 90.5 percent of the caskets at the Morgan Chapel Cemetery had handles. The only two caskets without handles at Morgan Chapel belonged to infants (Taylor et al 1986). The State Cemetery also had the highest number of burials with escutcheons ( 50.9 percent), followed by the African-American Cedar Grove (46.8 percent) and Phillips ( 38.3 percent) Cemeteries. In terms of thumbscrews, the Morgan Chapel Cemetery had the highest number of graves evidencing them (66.7 percent), followed by the State Cemetery sample (49.1 percent), and then Cedar Grove (46.8 percent) and 41DT104 (43.8 percent). The most frequent occurrence of caplifters was noted at 41DT104 (18.8 percent), followed by Phillips (10.6 percent) and Cedar Grove (10.1 percent). The frequency at Cedar Grove may actually be higher than this; caplifters in this report were not designated as such by name, so this figure was determined based on recognizing caplifters in report illustrations and burial descriptions. Only 8.8 percent of the caskets from the State Cemetery had caplifters, a frequency almost identical to that at the much earlier Boothill and Coffey Cemeteries. The most common occurrence of casket plaques was noted at the Morgan Chapel Cemetery (57.1 percent), followed by Cedar Grove (29.1 percent) and the State Cemetery (21.1 percent).

The highest number of burials with decorative or lining tacks was noted at 41DT105 (81.3 percent), followed by Morgan Chapel at 76.2 percent. The Boothill/Coffey, Cedar Grove, Texas State, and Uxbridge Almshouse Cemeteries all exhibit similar frequencies of caskets recovered with decorative or lining tacks, ranging between 45.2 and 53.8 percent. That so many tacks were recovered from 41DT105, a site notable for its lack of ornamentation, may be related to recovery processes. This was the only cemetery, other than Cedar Grove, that underwent a water-screening process. The grave fill from only two of the other comparative sets (Boothill/Coffey and Uxbridge) underwent dry screening. Given the small nature of these items, it is likely that many were missed in excavations where fill was not screened.

The burial assemblage from the State Cemetery appears to be most similar to two assemblages from other Texas cemeteries - Morgan Chapel and 41DT104. All three date from the late nineteenth to the early to mid twentieth century, but the latter two burial grounds represent family cemeteries. In spite of the contemporaneity of these sites, the temporal factor is not believed to be the sole explanation for their similarities. Several other excavated cemeteries date to approximately the same time period but do not show the same degree of ornamentation. The degree of similarity between the Morgan Chapel and 41DT104 cemeteries can be explained since they were both burial grounds of unimpoverished families. That the State Cemetery burials are most similar to these family burial plots may reflect, at least in part, the support of groups such as the United Daughters of the Confederacy (who played an active role in the lives of these veterans at the Confederate Home for Men) and their desire to emulate a familylike interment ceremony. The Confederate Home residents were not buried at the State Cemetery alone or as paupers; they were buried in the presence of friends with a certain degree of accompanying ritual which may have simulated the burial of a family member.

The State Cemetery burials also are similar to the burials recovered from the African-American Cedar Grove and Phillips Memorial Cemeteries in some respects. Some hardware styles recovered at the State Cemetery are identical to ones from Phillips and Cedar Grove, but the frequencies of these items differ. Both of these cemeteries are contemporaneous with the excavated burials at the State Cemetery. Furthermore, fraternal societies are known to have played roles in the funeral ceremonies of individuals interred at both of the comparative cemeteries (Dockall et al. 1996; Watkins 1985).

The mortuary assemblage from the State Cemetery differs most drastically from burials at 41DT105, a rural family cemetery ( 1850 s to 1870 s or 1880s) in Delta County which is virtually devoid of hardware. Burials from the Boothill/ Coffey and Morgan/Yarbrough/Bryne Cemeteries are quite different from those recovered from the State Cemetery in terms of material culture. With the exception of one burial from the Boothill Cemetery, burial receptacles from all of these cemeteries lack any sort of hardware. These sites, however, contained the remains of early settlers on the periphery of Texas civilization; thus, it may 
TABLE 11

COMPARISONS OF TYPES AND FREQUENCIES OF CASKET HARDWARE FROM

THE TEXAS STATE CEMETERY AND OTHER HISTORIC CEMETERIES

\begin{tabular}{|c|c|c|c|c|c|c|c|c|c|c|c|c|}
\hline & $\begin{array}{l}\text { Texas } \\
\text { State } \\
1884- \\
1951\end{array}$ & $\begin{array}{l}\text { Morgan } \\
\text { Chapel } \\
1891- \\
1937\end{array}$ & $\begin{array}{l}\text { Cedar } \\
\text { Grove } \\
1890- \\
1927\end{array}$ & $\begin{array}{l}\text { Phillips } \\
\text { Memorial } \\
\text { late } 1800 \text { s- } \\
1927\end{array}$ & $\begin{array}{l}\text { 41DT104 } \\
1880- \\
1942\end{array}$ & $\begin{array}{l}\text { 41DT105 } \\
1850 \mathrm{~s} \text { to } \\
1870 \mathrm{~s} \text { or } \\
1880 \mathrm{~s}\end{array}$ & $\begin{array}{l}\text { Laredo } \\
1890 \mathrm{~s}- \\
1920 \mathrm{~s}\end{array}$ & $\begin{array}{l}\text { Boothill/1 } \\
\text { Coffey } \\
1870- \\
1885\end{array}$ & $\begin{array}{l}\text { Morgan/ } \\
\text { Yarbrough/ } \\
\text { Bryne } \\
1860-1913\end{array}$ & \begin{tabular}{|l} 
Uxbridge \\
$1831-$ \\
1872
\end{tabular} & $\begin{array}{l}\text { McGee } \\
\text { Creek } \\
1899- \\
1924\end{array}$ & $\begin{array}{l}38 \mathrm{CH} 778 \\
1860 \mathrm{~s}- \\
1920 \mathrm{~s}\end{array}$ \\
\hline Number of Graves & 57 & 21 & 79 & $53^{*}$ & 16 & 16 & 22 & 13 & 31 & 31 & 11 & 37 \\
\hline Casket Characteristics & $\# \%$ & $\# / \%$ & $\# / \%$ & $\# / \%$ & $\# / \%$ & $\# \%$ & $\# / \%$ & $\# / \%$ & $\# / \%$ & $\# \%$ & $\# / \%$ & $\# / \%$ \\
\hline Rectangular Caskets & $56 / 98.2$ & $17 / 81.0$ & $33 / 41.8$ & $26 / 49.1$ & $5 / 31.3$ & $1 / 6.3$ & 0 & $3 / 23.1$ & $4 / 12.9$ & $2 / 6.5$ & - & 0 \\
\hline Coffins & $1 / 1.8$ & $4 / 19.0$ & $36 / 45.6$ & $17 / 32.1$ & $2 / 12.5$ & $15 / 93.8$ & $19 / 86.4$ & $9 / 69.2$ & $27 / 87.1$ & $25 / 80.6$ & - & $37 / 100$ \\
\hline Metal Caskets & $4 / 7.0$ & 0 & 0 & 0 & $1 / 6.3$ & 0 & 0 & 0 & 0 & 0 & 0 & 0 \\
\hline Outer Boxes & $23 / 40.4$ & $4 / 19.0$ & $20 / 25.3$ & $38 / 80.9$ & 0 & 0 & 0 & 0 & $1 / 3.2$ & 0 & 0 & - \\
\hline Paint & $5 / 8.8$ & $7 / 33.3$ & $11 / 13.9$ & $7 / 14.9$ & $3 / 18.8$ & 0 & $2 / 9.1$ & $1 / 7.7$ & 0 & - & $2 / 18.2$ & - \\
\hline $\begin{array}{l}\text { Casket Handles } \\
\text { Type } 1 \\
\text { Type } 2 \\
\text { Type } 3 \\
\text { Type } 4 \\
\text { Type } 5 \\
\text { Type } 6 \\
\text { Type } 7 \\
\text { Type } 8 \\
\text { Type 9 } \\
\text { Type } 10 \\
\text { Type } 11 \\
\text { Type } 12 \\
\text { Type } 13 \\
\text { Type } 14 \\
\text { Type } 15 \\
\text { Type } 16\end{array}$ & \begin{tabular}{|c}
$57 / 100$ \\
11 \\
18 \\
3 \\
1 \\
2 \\
3 \\
2 \\
1 \\
1 \\
7 \\
1 \\
1 \\
1 \\
3 \\
1 \\
1
\end{tabular} & $19 / 90.5$ & $\begin{array}{c}39 / 49.4 \\
\mathrm{x} \\
\mathrm{x}\end{array}$ & $\begin{array}{c}41 / 87.2 \\
x \\
x\end{array}$ & $\begin{array}{c}10 / 62.5 \\
x\end{array}$ & 0 & $4 / 18.2$ & $1 / 7.7$ & 0 & 0 & $1 / 9.1$ & $3 / 8.1$ \\
\hline
\end{tabular}




\begin{tabular}{|c|c|c|c|c|c|c|c|c|c|c|c|c|}
\hline \multicolumn{13}{|l|}{ Table 11, continued } \\
\hline & $\begin{array}{l}\text { Texas } \\
\text { State } \\
1884- \\
1951\end{array}$ & $\begin{array}{l}\text { Morgan } \\
\text { Chapel } \\
1891- \\
1937\end{array}$ & $\begin{array}{l}\text { Cedar } \\
\text { Grove } \\
1890- \\
1927\end{array}$ & $\begin{array}{l}\text { Phillips } \\
\text { Memorial } \\
\text { late 1800s- } \\
1927\end{array}$ & $\begin{array}{l}41 \mathrm{DT} 104 \\
1880- \\
1942\end{array}$ & $\begin{array}{l}41 \mathrm{DT} 105 \\
1850 \mathrm{~s} \text { to } \\
1870 \mathrm{~s} \text { or } \\
1880 \mathrm{~s}\end{array}$ & $\begin{array}{l}\text { Laredo } \\
1890 \text { s- } \\
1920 \text { s }\end{array}$ & \begin{tabular}{|l} 
Boothill// \\
Coffey \\
$1870-$ \\
1885
\end{tabular} & $\begin{array}{l}\text { Morgan/ } \\
\text { Yarbrough/ } \\
\text { Bryne } \\
1860-1913\end{array}$ & $\begin{array}{l}\text { Uxbridge } \\
1831- \\
1872\end{array}$ & $\begin{array}{l}\text { McGee } \\
\text { Creek } \\
1899- \\
1924\end{array}$ & $\begin{array}{l}38 \mathrm{CH} 778 \\
1860 \mathrm{~s}- \\
1920 \mathrm{~s}\end{array}$ \\
\hline Casket Characteristics & $\# / \%$ & $\# \%$ & $\# / \%$ & $\# / \%$ & $\# / \%$ & $\# / \%$ & $\# / \%$ & $H / \%$ & $\# / \%$ & $\# / \%$ & $\# / \%$ & $\# / \%$ \\
\hline $\begin{array}{c}\text { Escutcheons } \\
\text { Type } 1 \\
\text { Type } 2 \\
\text { Type } 3 \\
\text { Type } 4\end{array}$ & $\begin{array}{c}29 / 50.9 \\
19 \\
9 \\
11 \\
1\end{array}$ & - & $\begin{array}{c}37 / 46.8 * * \\
\mathrm{x} \\
\mathrm{x}\end{array}$ & $18 / 38.3$ & $5 / 31.3$ & 0 & $5 / 22.7$ & - & 0 & 0 & $2 / 18.2$ & $1 / 2.7$ \\
\hline $\begin{array}{l}\text { Thumbscrews } \\
\text { Type } 1 \\
\text { Type } 2 \\
\text { Type } 3 \\
\text { Type } 4 \\
\text { Type } 5\end{array}$ & $\begin{array}{c}28 / 49.1 \\
7 \\
9 \\
16 \\
5 \\
9\end{array}$ & $14 / 66.7$ & $37 / 46.8$ & $13 / 27.7$ & $7 / 43.8$ & 0 & $5 / 22.7$ & $1 / 7.7$ & 0 & 0 & $1 / 9.1$ & $3 / 8.1$ \\
\hline Viewing Windows & $22 / 38.6$ & $8 / 38.1$ & $8 / 10.1$ & 0 & $5 / 31.3$ & 0 & $1 / 4.5$ & $1 / 7.7$ & 0 & $2 / 6.5$ & 0 & 0 \\
\hline $\begin{array}{c}\text { Caplifters } \\
\text { Type } 1 \\
\text { Type } 2 \\
\text { Type } 3 \\
\text { Type } 4\end{array}$ & $\begin{array}{c}5 / 8.8 \\
2 \\
1 \\
1 \\
1\end{array}$ & - & $8 / 10.1$ & $5 / 10.6$ & $3 / 18.8$ & 0 & 0 & $1 / 7.7$ & 0 & 0 & 0 & 0 \\
\hline Plaques & $12 / 21.1$ & $12 / 57.1$ & $23 / 29.1$ & $5 / 10.6$ & $1 / 6.3$ & 0 & 0 & 0 & 0 & 0 & 0 & $1 / 2.7$ \\
\hline Decorative/Lining Tacks & $26 / 45.6$ & $16 / 76.2$ & $39 / 49.4$ & $4 / 8.5$ & $3 / 18.8$ & $13 / 81.3$ & $4 / 18.2$ & $7 / 53.8$ & $2 / 6.5$ & $14 / 45.2$ & 0 & $6 / 16.2$ \\
\hline \multicolumn{13}{|c|}{$\begin{array}{l}\text { **Thumbscrews and escutcheons at Cedar Grove were referred to as casket lid fasteners; they were not discussed separately, so it is assumed that the number } \\
\text { of thumbscrews and escutcheons are the same. }\end{array}$} \\
\hline \multicolumn{13}{|c|}{$\begin{array}{l}\text { References: Morgan Chapel (Taylor et al. 1986); Cedar Grove (Rose 1985); Phillips Memorial (Dockall et al. 1996); 41DT104 (Lebo 1988); } \\
\text { 41DT105 (Winchell et al. 1992); Laredo (McReynolds 1981); Boothill/Coffey (Earls et al. 1991); Morgan/Yarbrough/Bryne (Fox 1984); } \\
\text { Uxbridge (Elia and Wesolowsky 1991); McGee Creek (Ferguson 1983); 38CH778 (Trinkley and Hacker-Norton 1984). }\end{array}$} \\
\hline
\end{tabular}


have been much more difficult to obtain casket hardware in these remote areas. Last, the State Cemetery materials are very different from the assemblage recovered from the Uxbridge Almshouse Burial Ground in Massachusetts, a cemetery that contained only two rectangular caskets and no hardware except for tacks, hinges, and screws. This difference may be related to the earlier date of the Uxbridge cemetery at 1831-1872, or it may be related to the fact that the individuals interred at that site were socially marginal paupers who did not have the funds for elaborate interments.

\section{SUMMARY}

An analysis of the material culture associated with excavations at the Texas State Cemetery has provided valuable information about the burial of Confederate veterans at the beginning of this century. Since the majority of the excavated individuals were wards of the Confederate Home for Men in Austin at the time of their deaths, information pertaining to the Confederate Home itself was valuable in interpreting their burials. Analyses of caskets, casket hardware, and personal goods suggest that great care and respect were taken when interring these individuals. All individuals were interred singly in caskets decorated with handles, thumbscrews, and escutcheons; many also had viewing windows and plaques. The degree of ornamentation could represent real or apparent status, or it may be more a reflection of the time in which they were buried. However, since most of the individuals were residents of the Confederate Home when they died, it is doubtful that the burials provided for them at state expense are representative of real status. However, comparisons with other cemeteries suggest that care was taken to display apparent status. This seems especially fitting given these men's positions as heroes of the Confederate States Army in the eyes of most Southerners. Those responsible for the interment of these men demonstrated this by providing fairly elaborate burial containers, even if some of the caskets only had four handles and no viewing windows. Bell (1991:279) notes that the citizens of Uxbridge, Massachusetts, made a "minimally decent" effort to inter the paupers associated with their almshouse. Archeological evidence retrieved from the State Cemetery indicates that a more than minimally decent effort was made to inter these veterans of the Confederate States Army. It would have been just as easy, and less expensive, to inter these men in plain caskets with no handles or decorations (reminiscent of the caskets seen at 41DT105), held together only by undecorated screws and tacks. That this was not done suggests that care was taken during the original interments and that a certain degree of ritual was associated with the burials. Analysis of the funerary material culture indicates that a great deal of significance was placed by the living on the burials of these men. The quality of these caskets was appropriate for burials within the State Cemetery, a unique burial ground set aside for people of particular importance to the history of Texas. The current renovation of the Texas State Cemetery can be viewed as a further reflection of the significance that society has placed on these individuals. 


\section{ANALYSIS OF OSTEOLOGICAL REMAINS}

Helen Danzeiser Dockall and Joan E. Baker

The osteological analysis of the sample provided by excavations at the State Cemetery is unique because the majority of the individuals were Civil War veterans who died in the early to mid 1900s when they were in their sixth decade of life and older. Since the analysis of each individual had to be completed by the end of the day on which it was exhumed, time spent examining each person's skeletal remains was quite limited. However, because this sample is so unusual in terms of population type and demography, a concerted effort was made to collect as much data as possible, given the time limitations. Information collected includes a thorough skeletal inventory, 31 cranial measurements, 43 postcranial measurements, and 33 cranial and postcranial nonmetric traits. In addition, disorders present on the dental and skeletal remains were documented. To maximize the future use of this information by other researchers, most of the recorded data were based on the recommendations made in Standards for Data Collection from Human Skeletal Remains (Buikstra and Ubelaker 1994). Furthermore, rather than presenting just the summary information in tables, all skeletal data are presented in Appendixes D through $\mathrm{G}$ (following the style presented in Rose 1985). The data displayed in these appendixes list the skeletal information obtained from each individual, facilitating research on an individual level.

Given the nature of these samples, particular research questions were considered. Primarily, these consisted of determining the frequency of battle wounds observed in the sample, as well as studying skeletal changes that occur with aging. Because historical documents were available regarding cause of death, it also was possible to examine the rate of positive correlation between observed skeletal changes and reason for death.

Throughout this chapter, the distinction between the burial population and the skeletal sample is important. The burial population consists of 57 individuals whose remains were exhumed. Because one intact coffin was not opened, the skeletal sample consists of 56 individuals whose skeletal remains actually were analyzed. Unless otherwise stated, the State Cemetery "sample" refers specifically to the skeletal sample. The original osteological data forms filled out in the field laboratory for each of the 56 analyzed individuals are included in the project records curated at Texas State Cemetery.

All burials were dug down into the dark clayey sediments that were, with only minor exceptions, very homogeneous. Despite the fact that the burial sediments appeared homogeneous and bone preservation was generally good for all excavated burials, some differential preservation was observed. Differential preservation is mentioned later in this chapter as having been a factor accounting for the low numbers of observations of some skeletal traits, particularly traits associated with vertebrae, fragile facial bones, and other thinwalled bones that tend to weather rapidly. In order to test whether minor differences in sediment composition could have affected bone preservation, 
four samples of grave fill sediment were taken from inside the caskets of Burials 17, 26, 45, and 46. Analysis revealed that all of these samples were alkaline with $\mathrm{pH}$ values of 8.0. Thus, it appears that differential soil $\mathrm{pH}$ was not a significant factor affecting bone preservation. Since the depositional character of the sediments is so homogeneous, it is unlikely that other sedimentological or pedogenic characteristics are responsible for differential bone preservation.

Skeletal age, or the number of years between the date of burial (presumed to be the year of death) and 1995, was considered as a possible factor affecting bone preservation. The skeletal sample consists of remains that had been interred for a minimum of 44 years to a maximum of 88 years and can be divided into three basic age categories. The oldest remains, buried for 87 to 88 years, were those of the 40 persons who died in 1907 and 1908. The skeletal remains from 15 burials of individuals who died between 1917 and 1939 were buried between 56 and 78 years. At the other end of the scale, the remains of a single individual who died in 1951 were buried for only 44 years. Although the sample is quite variable in this respect, no absolute correlation between age of burial and degree of bone preservation can be made. In fact, some of the best-preserved bones were associated with the oldest burials while a few of the younger burials contained examples of moderate to poorly preserved bone.

After ruling out sediment characteristics and skeletal age, it may be concluded that at least four other factors probably did have some affect on bone preservation. These are depth of burial (below the ground surface), soil moisture and the frequency of wetting/drying, the nature and condition of the burial container, and the presence of tree roots. While not quantified in any rigorous manner, observations and general interpretations relating to these factors are offered below.

Depth of burial, measured as centimeters below the ground surface from the base of the headstone to the top of the casket, was a factor affecting bone preservation. All of the graves were dug into dark clayey sediments that overlie Austin chalk (see Chapter 4). For Burials 1-46 in Row A, Section F, the depth of burial ranged from $150 \mathrm{~cm}$ to the top of the deepest casket (Burial 21) to only $85 \mathrm{~cm}$ to the top of the shallowest casket (Burial 44). Although there is considerable varia- tion between individual graves, burials generally were deepest in the central portion of Row A (i.e., Burials 15-30) and shallower both downslope (north) and upslope (south) from there. However, the seven shallowest graves (Burials 38, 40, 41, 42, 44,45 , and 46), each $100 \mathrm{~cm}$ deep or less, all clustered in one area upslope. The reason these graves were shallower is obvious since this is the only area where the bottoms of the grave pits were dug down to the level of, or slightly into, the underlying Austin chalk. The gravediggers simply quit digging upon hitting the harder stratum.

The relationship between depth of burial and bone preservation was not strong, and it appears that other factors may have been more significant. It generally was observed, however, that the deeper burials contained better-preserved bones while the shallower burials tended to have poorly preserved bones. Some of the worst bone preservation was observed in some of the shallow burials in the southern end of Row A, Section F (i.e., Burials 31-46). Nawrocki (1995:58-61) observed the same phenomenon for historic graves at a latenineteenth-century institutional cemetery in New York. Using quantified data on bone condition, this study concluded that "depth below surface is an important environmental taphonomic variable influencing the overall preservation of human skeletal remains" (Nawrocki 1995:61). Three specific factors were suggested as accounting for poorer bone preservation in shallower burials: increased freeze-thaw activity, increased biological (i.e., plant and animal) activity, and differential soil chemistry (i.e., pH levels vary slightly with depth).

Soil moisture is considered to be a factor that affected bone preservation in one area. Burials 1-3 were the lowest on the slope and, hence, were closer to the small drainage that extends from west to east along the north side of Section F. Because of their relative proximity to the drainage, it appears that the sediments in this area are subject to more-frequent wetting and drying and probably stay wetter for longer periods of time. When the burial excavations began, the sediments in Burials 1-3 were noticeably wetter than were the sediments in the adjacent graves. Bone preservation also appeared to be worse in these graves, especially the epiphyseal ends of long bones, vertebrae, and os coxae. Although differential soil moisture also may have been a factor adversely affecting 
bone preservation in other burials upslope, it was not as obvious as it was for the lowest burials.

The nature of the casket enclosing the skeletal remains had a significant impact on bone preservation in many cases. It was observed during the excavations that the worst preserved bones were found, almost invariably, underneath the broken glass viewing windows on caskets dating to the 1907-1908 period. Bones found under the glass, particularly facial bones, vertebrae, and ribs, were in poor condition. This phenomenon was probably related to accelerated deterioration caused by moisture trapped underneath the glass. In many cases, the area underneath glass viewing windows was much wetter than any other areas. Aside from the viewing windows, however, there did not seem to be any correlation between bone preservation and the use of metal vs. wooden caskets. Preservation of skeletal remains recovered from the three metal caskets (Burials 48, 51, and 52) was good, but there were many examples of equally well preserved skeletal remains associated with wooden caskets. It was generally observed, however, that the bones that were in direct contact with metal casket walls were poorly preserved.

The presence of tree roots and rootlets resulted in postdepositional disturbances and increased bone deterioration in several cases. When larger roots were present, bone placement ranged from minimal dislocation to complete disarticulation of large portions of the body. When rootlets were ubiquitious, bone preservation was generally poorer, ranging from minimal root etching to severe scarring and complete deterioration.

Of all the factors listed above, the excavators agreed that viewing windows and tree roots had the most significant adverse affects on bone preservation. In the case-by-case descriptions of bone taphonomy within each burial (see Chapter 5), these are the most commonly noted factors directly associated with poorly preserved skeletal remains. Two other factors that may directly correlate with differential bone preservation are body size and age at death. The field observations are not conclusive and no attempt was made to systematically analyze these variables, but the gracile bones of smaller individuals and the thinner bones of older people (due to age-progressive bone loss) probably were more susceptible to the various causes of bone deterioration.

\section{DEMOGRAPHIC DATA}

All demographic information was obtained from headstones and other written documents, such as pension records and the Confederate Home rosters (see Chapter 5). Sex assessments were made in the field laboratory using standard osteological nonmetric and metric techniques (see Chapter 2 for details). In general, visual assessment of a suite of qualitative secondary sexual characteristics used for determining sex produced correct results. However, nine individuals would have been assigned an indeterminate sex, and three known males would have been incorrectly sexed as females based on cranial and pelvic criteria. For instance, on one of these males, all available cranial traits (frontal bossing, parietal bossing, mastoid process, muscle markings, occipital area, eye rim, supraorbital torus, chin shape, and palate shape) except for gonial eversion suggested a female. As far as the pelvis was concerned, the sciatic notch was relatively narrow and no preauricular sulcus was observed; no other pelvic traits could be examined. Although qualitative features were feminine in form, discriminate function analysis of the talus indicated a male sex, as did the femoral head diameter.

For the sample as a whole, discriminate function analyses of the talus and calcaneus (described in Chapter 2) designated the incorrect sex only for three individuals. In two cases, males were incorrectly assessed as females based on the talus (although measurements on their calcanei produced male results), and in one case a female was miscalculated as a male (based on both the talus and the calcaneus). Dimensions of the femoral head diameter were consistently accurate in determining sex when a $45-\mathrm{mm}$ sectioning point (based on Stewart 1979) was applied. Only two men had femoral head measurements that were below the sectioning point, and no females had a measurement greater than $43 \mathrm{~mm}$ (Appendix E). Femoral head measurements were available on 36 people and only incorrectly estimated sex on two; therefore, a 94.4 percent accuracy rate can be assigned this technique based on the excavated sample. This percentage is very close to the 93 percent accuracy rate noted by Stewart (1979) when he used this technique on the Terry collection.

Due to time constraints, standard aging tech- 
niques could not be tested using this sample of individuals of known age. However, it was apparent that the ectocranial suture closure method would not have accurately assessed the ages of people composing this sample. Many of the people in their 80 s and 90 s had sutures that would have been assessed as representing 30-40 year olds, while some 60 year olds had sutures that were completely obliterated. Some researchers (McKern and Stewart 1957; Powers 1962; Singer 1953) note that the closure of cranial sutures could not be reliably used to indicate age. McKern and Stewart (1957:37) feel that, "So erratic is the onset and progress of closure that an adequate series will provide just about any pattern at any age level." Powers (1962:54) notes that on a sample of 271 individuals of known age, ages produced by suture closure were very different from the known age composition. Furthermore, she found that ". . . anyone over 68 years gives completely unreliable results" (Powers 1962:54). However, others have stressed that cranial suture closure can be used as general age indicator which produces very broad age categories (Masset 1989; Meindl and Lovejoy 1985; Nemeskeri et al. 1960, cited in Iscan and Loth 1989). Certainly, the method would not have given precise, accurate results on this sample. Unfortunately, there was not time to systematically test the method by determining age using suture closure and then comparing the results with known age at death.

\section{Sex}

Of the 57 people in the burial population, 51 were male. The fact that only six women were present is an artifact of the burial place. The State Cemetery is reserved for Confederate veterans, governors, judges, and state officials, as well as their spouses. The six women analyzed in this sample were all wives of Confederate soldiers. The obvious skewing of the sex ratio must be considered when interpreting the following data. For the skeletal sample of 56 individuals, males account for 89 percent $(n=50)$ of the total.

\section{Age}

The youngest individual in the burial population was 44 years old, while the oldest was 95 . Because the coffin of the 44 year old (Burial 57,
Dr. John Ward) was moved intact, his skeletal remains were not analyzed. For the skeletal population, the 55 individuals of known age range from 60 to 95 years. The average age at death for the sample is 77.3. The average age at death for the 6 females is 82.0 , and for the 49 males it is 76.7. Figure 44 illustrates the percentage of analyzed individuals present in each 10-year age range. Almost 45 percent of the individuals of known age from the pooled male and female sample were placed in the 70-79-year range, followed by ca. 23 percent in the 80-89-year range. One-fifth of the total sample were 60 to 69 years old at the time of death, while almost 11 percent were 90 years old or older.

\section{SKELETAL METRICS \\ Cranial Metrics}

A series of 31 measurements were taken on each individual when possible (Appendix E). Due to differential preservation, sample sizes for each measurement fluctuate greatly, with the smallest sample sizes observed on measurements of the fragile facial area. Sample sizes were highest on the sturdy frontal bone and mandible. Averages and standard deviations for each measurement, divided into males and females, are presented in Table 12. Cranial indices were calculated and are presented in Table 13. These indices indicate that the individuals composing the sample were mesocranic with high skulls. Their noses were narrow, and males had wide eye orbits, while females were mesoconchic. The Confederate veterans from the State Cemetery differ markedly from the comparative samples in orbital and maxillo-alveolar indices, having wider eye orbits and a narrower palate than the other samples (Table 14). The women excavated from the State Cemetery are similar to those at the Harvie cemetery in having lower skulls (breadth to height) than the females composing the Colonial and modern samples. In all other indices, however, male and females from the State Cemetery have similar cranial metric values when compared to the other samples.

\section{Postcranial Metrics}

A set of postcranial measurements was taken on each analyzed individual (Appendix E). Due to 


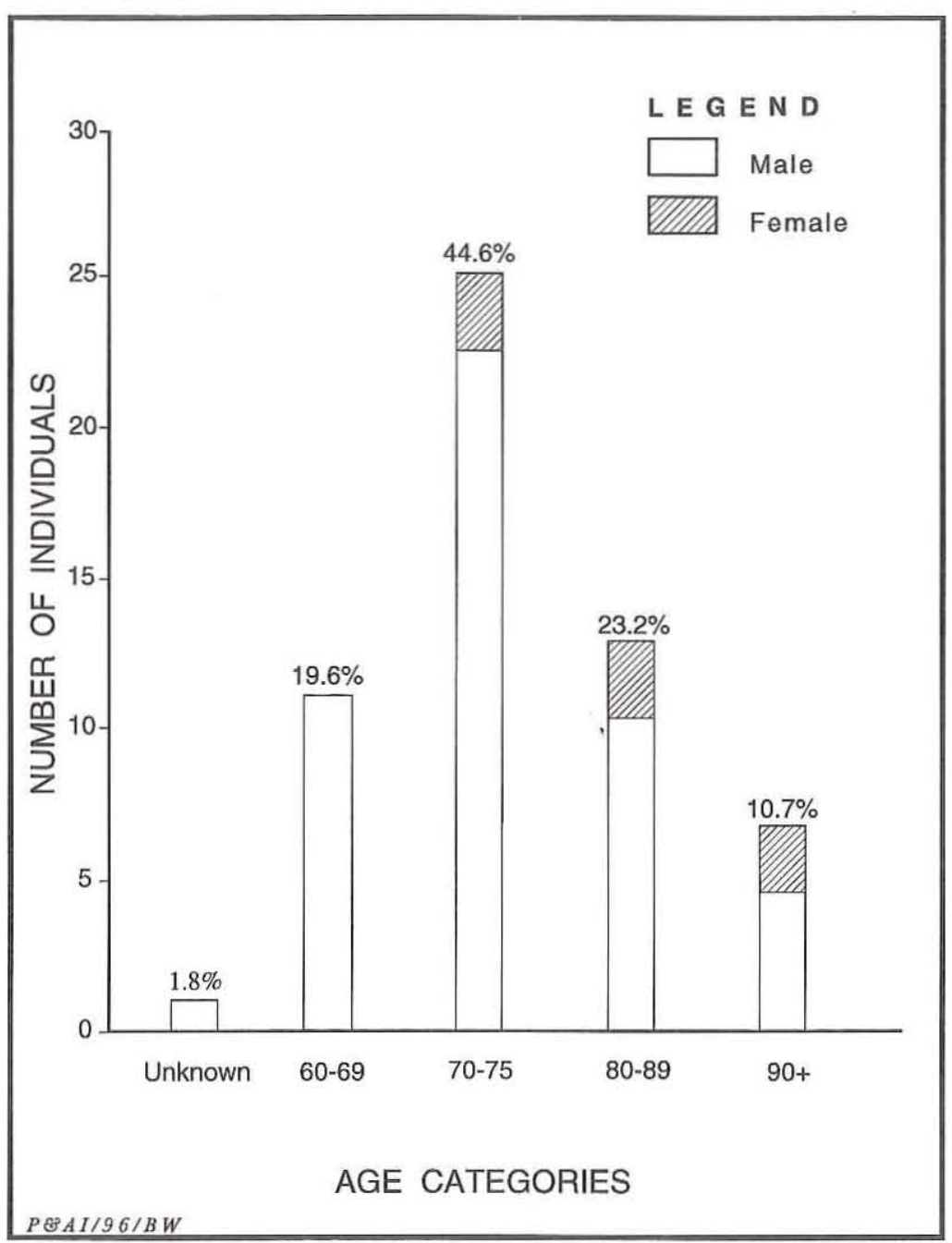

Figure 44. Demographic composition of the burial population from the Texas State Cemetery.

differences in skeletal preservation, not all measurements could be assessed for each individual. Table 15 displays the average and standard deviation of each measurement for males and females. Scapula maximum height was on the original list of measurements to take but is not presented here because no individuals had scapulae complete enough for this measurement. Postcranial indices for males and females are presented in Tables 13 and 16. Meric indices fall into the eurymeric range, and cnemic indices fall into the mesocnemic and eurycnemic ranges. Both of these indices suggest a roundness, rather than a flattening, of the long bones. This is especially noticeable when the males are compared to males from the Harvie Cemetery, as well as the Colonial sample (see
Table 16). Both of the latter samples had much broader, flatter femora. The females from the State Cemetery also had flatter femora than those of the comparative samples (see Table 16).

Stature was estimated using Trotter and Gleser's (1952) formulae, as presented in Bass (1987:Tables 4 and 5). Because all of these individuals were over the age of 30 years at the time of death, a standard age correction factor $(0.06 \mathrm{~cm}$ for each year over 30; Bass 1987:23) was applied to each person's stature estimate. For the one individual of an unknown age (Burial 3), age at death was assumed to be 65 years. Male stature ranged from $160.88 \mathrm{~cm}$ (approximately $5 \mathrm{ft} 2$ inches) to $184.1 \mathrm{~cm}$ (approximately $5 \mathrm{ft} 11$ inches) with an average of $171.89 \mathrm{~cm}$ (approximately $5 \mathrm{ft} 7$ inches). Female stature ranged from $153.23 \mathrm{~cm}$ (approximately $4 \mathrm{ft} 11$ inches) to $167.0 \mathrm{~cm}$ (approximately $5 \mathrm{ft} 5$ inches) with an average of $157.86 \mathrm{~cm}(5 \mathrm{ft} 1$ inch). The height correction factor considers only intervertebral differences that occur as one ages; it does not assess stature loss due to collapsed vertebrae and stooped individuals (see Wesolowsky 1991:237). Therefore, the stature at age of death for some of the individuals analyzed here is probably overestimated. For comparative purposes, stature also was estimated without the age correction factor to provide an idea of the maximum height of these individuals. This uncorrected stature also makes the State Cemetery sample more comparable to other skeletal samples characterized by significantly lower average ages at death.

Both the corrected and uncorrected average stature estimates for the State Cemetery sample, as well as for comparative samples, are listed in Table 17. Only the males from the Uxbridge (stature was calculated only for those individuals 40 years of age and over), Belleview, and Harvie 
TABLE 12

CRANIAL METRICS (mm) FOR THE SKELETAL SAMPLE

\begin{tabular}{|c|c|c|c|c|c|c|}
\hline \multirow[b]{2}{*}{ Measurement } & \multicolumn{3}{|c|}{ Males } & \multicolumn{3}{|c|}{ Females } \\
\hline & $\mathrm{N}$ & $\bar{x}$ & SD & $\mathrm{N}$ & $\bar{x}$ & SD \\
\hline Maximum length & 13 & 184.46 & 13.00 & 3 & 179.00 & 8.72 \\
\hline Maximum width & 13 & 143.31 & 5.23 & 3 & 138.00 & 1.73 \\
\hline Biauricular breadth & 10 & 141.70 & 6.60 & 3 & 134.00 & 3.61 \\
\hline Minimum frontal breadth & 24 & 100.21 & 4.59 & 3 & 95.33 & 1.53 \\
\hline Frontal chord & 25 & 115.84 & 3.77 & 3 & 113.33 & 1.53 \\
\hline Basion-bregma height & 7 & 143.43 & 4.65 & 2 & 126.50 & 2.12 \\
\hline Basion-nasion length & 6 & 107.83 & 18.44 & 2 & 95.50 & 0.71 \\
\hline Basion-prosthion length & 1 & 94.00 & - & - & - & - \\
\hline Upper facial height & 2 & 68.50 & 0.71 & - & - & - \\
\hline Upper facial breadth & 14 & 108.07 & 4.78 & 3 & 99.67 & 2.08 \\
\hline Biorbital breadth & 7 & 100.71 & 4.19 & 3 & 92.00 & 3.00 \\
\hline Interorbital breadth & 4 & 21.25 & 3.20 & 1 & 17.00 & - \\
\hline Orbital height & .4 & 36.25 & 1.89 & 1 & 33.00 & - \\
\hline Orbital width & 4 & 46.75 & 2.75 & 1 & 38.00 & - \\
\hline Nasal height & 2 & 56.50 & 2.12 & - & - & - \\
\hline Nasal breath & 3 & 23.67 & 2.52 & - & - & - \\
\hline Maxillo-alveolar length & 3 & 51.33 & 5.51 & - & - & - \\
\hline Maxillo-alveolar breadth & 1 & 58.00 & - & - & - & - \\
\hline Parietal chord & 17 & 119.59 & 12.39 & 3 & 111.67 & 2.89 \\
\hline Occipital chord & 10 & 105.30 & 7.92 & 3 & 96.67 & 8.50 \\
\hline Foramen magnum length & 7 & 38.57 & 3.26 & 2 & 37.50 & 0.71 \\
\hline Foramen magnum width & 6 & 31.83 & 3.87 & 2 & 31.00 & - \\
\hline Mandible length & 9 & 105.33 & 6.22 & 2 & 111.00 & 8.49 \\
\hline Bicondylar breadth & 10 & 124.90 & 4.63 & 1 & 116.00 & - \\
\hline Ascending ramus height & 31 & 62.26 & 5.28 & 2 & 59.00 & 2.83 \\
\hline Chin height & 23 & 28.48 & 3.38 & 1 & 31.00 & - \\
\hline Height of mandible body & 25 & 29.80 & 3.83 & 1 & 28.00 & - \\
\hline Breadth of mandible body & 29 & 11.86 & 1.71 & 1 & 12.00 & - \\
\hline Bigonial breadth & 23 & 103.43 & 5.34 & 2 & 97.50 & 6.36 \\
\hline Minimum ramus breadth & 37 & 31.41 & 3.68 & 5 & 27.40 & 4.16 \\
\hline Maximum ramus breadth & 31 & 41.84 & 4.51 & 4 & 37.25 & 1.26 \\
\hline
\end{tabular}

Cemeteries had a lower average height than the corrected stature for males from the State Cemetery. The average stature of 21-year-old West Point cadets in the mid to late 1800 s was virtually identical to that of the estimated stature (corrected) of men excavated from the State Cemetery. In general, all stature estimates cluster closely together. The uncorrected stature estimate for males from the State Cemetery is almost identical to the uncorrected stature estimates for five males from the Boothill and Coffey Cemeteries (all ranging in age from their mid to late 40 s to mid 70s). As far as females are concerned, the average (corrected) stature for the females from the State Cemetery compares favorably to the stature of Colonial to Civil War women, but it is much lower than that provided by the Uxbridge Almshouse sample. (Like the males, only females over 40 years were incorporated into the average stature estimate of women interred at Uxbridge.) The uncorrected age stature estimate of the women from the State Cemetery compares closely to all of the estimates, with the exception of Uxbridge.

Because stature reflects growth, and growth is affected by stress, height is frequently used as an indicator of overall health conditions during the growth process (see Brauer 1982; Stini 1979; Tobias 1972). The stature estimates of people 
TABLE 13

SKELETAL INDICES FOR THE SKELETAL SAMPLE

\begin{tabular}{|l|r|l|c|l|}
\hline \multirow{2}{*}{ Skeletal Indices } & \multicolumn{2}{|c|}{ Males } & \multicolumn{2}{|c|}{ Females } \\
\cline { 2 - 5 } & Value & Description & Value & Description \\
\hline Cranial & & & & \\
Cranial & 77.69 & mesocranic & 77.09 & mesocranic \\
Length-height & 77.76 & hypsicranic & 70.67 & orthocranic \\
Breadth-height & 100.08 & acrocranic & 91.67 & tapeinocranic \\
Fronto-parietal & 69.93 & metriometopic & 69.08 & metriometopic \\
Nasal & 41.89 & leptorhinnic & - & - \\
Orbital & 77.54 & chamaeconchic & 6.84 & mesoconchic \\
Maxillo-alveolar & 112.99 & mesuranic & - & - \\
\hline Postcranial & & & & \\
Brachial & 74.45 & - & 79.97 & - \\
Caliber & 16.95 & - & 17.00 & - \\
Femur Robusticity & 12.81 & - & 12.49 & - \\
Meric & 90.37 & eurymeric & 98.21 & eurymeric \\
Pilastric & 105.86 & - & 100.00 & - \\
Cnemic & 69.43 & mesochemic & 83.09 & eurymeric \\
Crural & 81.11 & - & 82.82 & - \\
\hline
\end{tabular}

TABLE 14

COMPARISON OF CRANIAL INDICES FOR THE TEXAS STATE CEMETERY AND OTHER SKELETAL SAMPLES

\begin{tabular}{|l|c|c|c|c|c|}
\hline Cranial Indices & $\begin{array}{c}\text { TSC } \\
50 \text { males } \\
5 \text { females }\end{array}$ & $\begin{array}{c}\text { Harvie } \\
5 \text { males } \\
4 \text { females }\end{array}$ & $\begin{array}{c}\text { Colonial } \\
35 \text { males } \\
9 \text { females }\end{array}$ & $\begin{array}{c}\text { Modern } \\
92 \text { males } \\
57 \text { females }\end{array}$ & $\begin{array}{c}\text { Boothill } \\
4 \text { males } \\
0 \text { females }\end{array}$ \\
\hline Males & & & & & \\
Cranial & 77.69 & 71.80 & 76.00 & 76.90 & 71.09 \\
Length-height & 77.76 & 69.85 & 73.78 & 74.30 & - \\
Breadth-height & 100.08 & 97.23 & 97.25 & 96.66 & - \\
Fronto-parietal & 69.93 & 71.00 & 68.80 & 67.60 & - \\
Nasal & 41.89 & 42.42 & 45.50 & 46.00 & 45.69 \\
Orbital & 77.54 & 85.25 & 86.50 & 83.90 & 81.42 \\
Maxillo-alveolar & 112.99 & 120.41 & 117.80 & 121.20 & - \\
\hline Females & & & & & \\
Cranial & 77.09 & 77.30 & 73.80 & 77.10 & - \\
Length-height & 70.67 & 71.56 & 72.49 & 74.79 & - \\
Breadth-height & 91.67 & 92.54 & 98.34 & 97.16 & - \\
Fronto-parietal & 69.08 & 65.80 & 69.20 & 67.80 & - \\
Nasal & - & 43.43 & - & 45.20 & - \\
Orbital & 86.84 & 85.90 & - & 86.30 & - \\
Maxillo-alveolar & - & 124.74 & - & 116.40 & - \\
\hline
\end{tabular}

NOTE: Because of differential preservation, it was not possible to measure all indices for all individuals in each sample.

${ }^{1}$ Lazenby et al. $1991 ;{ }^{2}$ Angel $1976 ;{ }^{3}$ Gill 1991 
TABLE 15

POSTCRANIAL METRICS (mm) FOR THE SKELETAL SAMPLE

\begin{tabular}{|c|c|c|c|c|c|c|}
\hline \multirow[b]{2}{*}{ Measurement } & \multicolumn{3}{|c|}{ Males } & \multicolumn{3}{|c|}{ Females } \\
\hline & $\mathrm{N}$ & $\bar{x}$ & SD & $\mathrm{N}$ & $\bar{x}$ & SD \\
\hline $\begin{array}{l}\text { Humerus } \\
\text { Maximum length } \\
\text { Maximum diameter } \\
\text { Minimum diameter } \\
\text { Vertical maximum diameter } \\
\text { Transverse diameter } \\
\text { Biepicondylar width }\end{array}$ & $\begin{array}{l}32 \\
46 \\
46 \\
32 \\
31 \\
43\end{array}$ & $\begin{array}{r}336.19 \\
23.82 \\
20.22 \\
50.25 \\
44.87 \\
65.28\end{array}$ & $\begin{array}{r}18.07 \\
2.10 \\
1.76 \\
2.64 \\
2.32 \\
3.48\end{array}$ & $\begin{array}{l}4 \\
5 \\
5 \\
4 \\
3 \\
5\end{array}$ & $\begin{array}{r}269.25 \\
19.80 \\
16.60 \\
41.75 \\
38.00 \\
51.20\end{array}$ & $\begin{array}{r}23.95 \\
0.45 \\
1.82 \\
2.75 \\
1.73 \\
1.79\end{array}$ \\
\hline $\begin{array}{l}\text { Radius } \\
\text { Maximum length } \\
\text { Anterior-posterior diameter } \\
\text { Medio-lateral diameter }\end{array}$ & $\begin{array}{l}35 \\
41 \\
41\end{array}$ & $\begin{array}{r}250.31 \\
13.32 \\
16.72\end{array}$ & $\begin{array}{r}13.61 \\
1.43 \\
1.81\end{array}$ & $\begin{array}{l}3 \\
3 \\
3\end{array}$ & $\begin{array}{r}215.33 \\
12.67 \\
11.00\end{array}$ & $\begin{array}{l}8.08 \\
2.31 \\
2.65\end{array}$ \\
\hline $\begin{array}{l}\text { Ulna } \\
\text { Maximum length } \\
\text { Minimum Circumference } \\
\text { Anterior-posterior diameter } \\
\text { Medio-lateral diameter } \\
\text { Physiological length }\end{array}$ & $\begin{array}{l}33 \\
35 \\
38 \\
38 \\
33\end{array}$ & $\begin{array}{r}269.10 \\
40.80 \\
14.95 \\
17.61 \\
240.64\end{array}$ & $\begin{array}{r}14.36 \\
2.90 \\
1.89 \\
2.14 \\
13.30\end{array}$ & $\begin{array}{l}2 \\
2 \\
3 \\
3 \\
1\end{array}$ & $\begin{array}{r}233.50 \\
34.50 \\
10.00 \\
14.33 \\
203.00\end{array}$ & $\begin{array}{l}6.36 \\
0.71 \\
- \\
1.53 \\
-\end{array}$ \\
\hline $\begin{array}{l}\text { Femur } \\
\text { Maximum length } \\
\text { Bicondylar length } \\
\text { Midshaft circumference } \\
\text { Anterior-posterior diameter } \\
\text { Transverse diameter } \\
\text { Head diameter } \\
\text { Bicondylar width } \\
\text { Anterior-posterior subtrochanteric } \\
\text { Medio-lateral subtrochanteric }\end{array}$ & $\begin{array}{l}22 \\
17 \\
30 \\
30 \\
30 \\
32 \\
18 \\
35 \\
35\end{array}$ & $\begin{array}{r}471.18 \\
466.06 \\
93.87 \\
30.70 \\
29.00 \\
48.81 \\
85.72 \\
30.03 \\
33.23\end{array}$ & $\begin{array}{r}26.56 \\
27.61 \\
5.95 \\
2.74 \\
1.88 \\
2.47 \\
2.99 \\
2.46 \\
2.84\end{array}$ & $\begin{array}{l}2 \\
1 \\
3 \\
3 \\
3 \\
4 \\
2 \\
4 \\
4\end{array}$ & $\begin{array}{r}404.50 \\
411.00 \\
80.67 \\
25.67 \\
25.67 \\
41.00 \\
70.50 \\
27.50 \\
28.00\end{array}$ & $\begin{array}{l}13.44 \\
- \\
2.52 \\
2.52 \\
2.31 \\
1.83 \\
0.71 \\
0.58 \\
2.45\end{array}$ \\
\hline $\begin{array}{l}\text { Tibia } \\
\text { Maximum length } \\
\text { Circumference at nutrient foramen } \\
\text { Anterior-posterior diameter } \\
\text { Medio-lateral diameter } \\
\text { Proximal epiphyseal breadth } \\
\text { Distal epiphyseal breadth }\end{array}$ & $\begin{array}{l}28 \\
40 \\
40 \\
40 \\
22 \\
35\end{array}$ & $\begin{array}{r}382.18 \\
98.68 \\
36.08 \\
25.05 \\
79.86 \\
47.49\end{array}$ & $\begin{array}{r}22.29 \\
6.46 \\
3.32 \\
2.26 \\
3.04 \\
3.16\end{array}$ & $\begin{array}{l}3 \\
5 \\
5 \\
5 \\
3 \\
4\end{array}$ & $\begin{array}{r}335.00 \\
85.60 \\
27.20 \\
22.60 \\
66.67 \\
41.50\end{array}$ & $\begin{array}{r}10.54 \\
7.13 \\
3.35 \\
2.51 \\
2.52 \\
3.11\end{array}$ \\
\hline $\begin{array}{l}\text { Fibula } \\
\text { Maximum length } \\
\text { Maximum diameter }\end{array}$ & $\begin{array}{l}15 \\
21\end{array}$ & $\begin{array}{r}379.93 \\
14.67\end{array}$ & $\begin{array}{r}35.66 \\
2.59\end{array}$ & - & - & - \\
\hline $\begin{array}{l}\text { Scapula } \\
\text { Maximum breadth }\end{array}$ & 3 & 111.33 & 1.53 & 2 & 93.00 & 5.66 \\
\hline $\begin{array}{l}\text { Clavicle } \\
\text { Maximum length } \\
\text { Anterior diameter } \\
\text { Superior diameter }\end{array}$ & $\begin{array}{l}23 \\
30 \\
30\end{array}$ & $\begin{array}{r}149.83 \\
13.13 \\
10.97\end{array}$ & $\begin{array}{r}10.51 \\
2.02 \\
1.40\end{array}$ & $\begin{array}{l}4 \\
4 \\
4\end{array}$ & $\begin{array}{r}140.75 \\
10.00 \\
8.25\end{array}$ & $\begin{array}{r}13.60 \\
1.15 \\
0.50\end{array}$ \\
\hline
\end{tabular}




\begin{tabular}{|l|c|c|c|c|c|c|}
\hline \multirow{2}{*}{ Table 15, continued } & \multicolumn{7}{|c|}{ Males } & \multicolumn{3}{c|}{ Females } \\
\cline { 2 - 7 } Measurement & $\mathrm{N}$ & $\overline{\times}$ & $\mathrm{SD}$ & $\mathrm{N}$ & $\bar{x}$ & $\mathrm{SD}$ \\
\hline Os Coxa & & & & & & \\
Maximum height & 7 & 227.14 & 7.31 & - & - & - \\
Maximum width & 1 & 157.00 & - & - & - & - \\
Ischial length & 2 & 94.50 & 3.54 & - & - & - \\
Pubis length & 2 & 87.00 & 2.83 & - & - & - \\
\hline Sacrum & & & & & & \\
Anterior length & 2 & 123.50 & 9.19 & 1 & 108.00 & - \\
Anterior superior breadth & 2 & 108.00 & 13.00 & 1 & 119.00 & - \\
Maximum tramsverse diameter & 2 & 50.33 & 2.31 & 1 & 46.00 & - \\
\hline Stature & 47 & 171.89 & 5.76 & 5 & 157.86 & 5.82 \\
& & $5,7 "$ & $2.27 "$ & & $57^{\prime \prime}$ & $2.29 "$ \\
\hline
\end{tabular}

excavated from the State Cemetery, especially males, appear to reflect childhoods that were not adversely affected by a lack of calories and nutrients or undue stress. Komlos (1987), based on anthropometric stature of living West Point cadets recorded in the mid to late 1800 s, suggested that in the antebellum period, especially after 1830, stature declined due to a reduced meat production caused in part by an increase in population growth. He noted that farmers and blue collar laborers were affected the most. Calorie and protein levels did not meet earlier, more-abundant levels until 1870 . Because the majority of individuals in this sample were actively growing during this period of nutritional decline, estimated stature might be expected to follow the trend noted in West Point cadets. Although a temporal comparison cannot be made with the skeletal sample from the State Cemetery due to its small size, the fact that the overall stature average (uncorrected for age) compares favorably to Colonial and modern stature averages suggests healthy growth during childhood rather than a restricted diet.

Komlos (1987:920) noted that growth was further disrupted during the Civil War. The effects of the Civil War on stature should be particularly notable in individuals who entered service in the war prior to the end of their growth period, as increased activity levels and decreased food intake would be expected to stunt growth. This idea was tested on males from the State Cemetery by estimating stature of those individuals who were 18 years old and younger in 1861 and comparing it to the stature of individuals older than 18 years (and presumably finished growing) at the start of the war. Eight males ranged in age from 14 to 18 years at the beginning of the war, while 39 were over 18 years. The average maximum attained stature for the younger people who were still growing during the Civil War was $174.5 \mathrm{~cm}$ (s.d. $=5.2$ ), while the average stature for the older men was $174.7 \mathrm{~cm}($ s.d. $=6.0)$. The similarity of these numbers may reflect several factors. It is possible that a difference in stature existed but is masked by the smaller sample size of people less than 18 years old in 1861. It also is possible, though unlikely, that a food disparity did not exist for these particular troops, so that their overall growth was not adversely affected. It is more likely that the stature of the boys less than 18 years old at the start of the Civil War was affected negatively by inadequate food intake and increased energy expenditures. However, once the war ended and they returned to civilian life, they experienced catch-up growth (increased growth rates and/or a longer period of growth) which allowed them to reach their genetic potential in height.

\section{NONMETRIC TRAITS}

Nonmetric trait analysis included data collection on a total of 33 cranial and postcranial nonmetric traits. These traits were chosen on the basis of recommendations presented in Standards for 


\begin{tabular}{|c|c|c|c|c|}
\hline $\mathrm{COM}$ & $\begin{array}{l}N \text { OF POST } \\
\text { XAS STAT }\end{array}$ & $\begin{array}{l}\text { TABLE } 16 \\
\text { INDICES F } \\
\text { RY WITH }\end{array}$ & $\begin{array}{l}\text { AND FEMAI } \\
\text { LETAL SAM }\end{array}$ & \\
\hline Postcranial Indices & $\begin{array}{c}\text { TSC } \\
50 \text { males } \\
5 \text { females }\end{array}$ & $\begin{array}{c}\text { Harvie }^{1} \\
5 \text { males } \\
4 \text { females }\end{array}$ & $\begin{array}{l}\text { Colonial }^{2} \\
35 \text { males } \\
9 \text { females }\end{array}$ & $\begin{array}{c}\text { Modern }^{2} \\
92 \text { males } \\
57 \text { females }\end{array}$ \\
\hline $\begin{array}{l}\text { Males } \\
\text { Brachial } \\
\text { Femur Robusticity } \\
\text { Platymeric } \\
\text { Pilastric } \\
\text { Platycnemic } \\
\text { Crural }\end{array}$ & $\begin{array}{r}74.45 \\
12.81 \\
90.37 \\
105.86 \\
69.43 \\
81.11\end{array}$ & $\begin{array}{r}72.60 \\
12.78 \\
81.40 \\
104.50 \\
74.20 \\
83.50\end{array}$ & $\begin{array}{r}73.70 \\
12.50 \\
85.30 \\
107.60 \\
69.50 \\
82.10\end{array}$ & $\begin{array}{r}75.30 \\
12.70 \\
87.60 \\
111.00 \\
70.20 \\
82.20\end{array}$ \\
\hline $\begin{array}{l}\text { Females } \\
\text { Brachial } \\
\text { Femur Robusticity } \\
\text { Platymeric } \\
\text { Pilastric } \\
\text { Platycnemic } \\
\text { Crural }\end{array}$ & $\begin{array}{l}79.97 \\
12.49 \\
98.21 \\
100.0 \\
83.09 \\
82.82\end{array}$ & $\begin{array}{l}75.90 \\
12.85 \\
83.40 \\
99.20 \\
76.10 \\
84.50\end{array}$ & $\begin{array}{r}- \\
12.30 \\
84.80 \\
104.80 \\
72.00 \\
82.20\end{array}$ & $\begin{array}{r}74.00 \\
12.00 \\
86.60 \\
108.90 \\
69.50 \\
82.60\end{array}$ \\
\hline
\end{tabular}

TABLE 17

COMPARISON OF STATURE $(\mathrm{cm})$ OF INDIVIDUALS FROM THE TEXAS STATE CEMETERY WITH OTHER HISTORIC SAMPLES

\begin{tabular}{|c|c|c|c|c|c|c|c|}
\hline \multirow[b]{2}{*}{ Sample } & \multicolumn{3}{|c|}{ Males } & \multicolumn{3}{|c|}{ Females } & \multirow{2}{*}{$\begin{array}{l}\text { Comparative } \\
\text { Sample Source }\end{array}$} \\
\hline & $\mathrm{N}$ & Stature & SD & $\mathrm{N}$ & Stature & SD & \\
\hline TSC (corrected for age) & 47 & 171.89 & 5.76 & 5 & 157.86 & 5.82 & - \\
\hline TSC (not corrected for age) & 47 & 174.67 & 5.79 & 5 & 160.90 & 5.91 & - \\
\hline Colonial U.S. & 21 & 173.40 & - & 7 & 159.80 & - & Angel 1976 \\
\hline Modern U.S. & 70 & 174.10 & $5.60^{1}$ & 46 & 163.60 & $4.30^{1}$ & Angel 1976 \\
\hline West Point cadets ${ }^{2}$ & 334 & 171.90 & - & - & - & - & Komlos 1987 \\
\hline Fort Laurens & 15 & 173.50 & 7.91 & - & - & - & Sciulli and Gramly 1988 \\
\hline Highland Park & 84 & 172.60 & 5.49 & 59 & 160.00 & 6.00 & Steegmann 1991 \\
\hline Uxbridge $^{3}$ & 8 & 169.38 & 4.59 & 7 & 165.07 & 9.96 & Wesolowsky 1991 \\
\hline Boothill and Coffey ${ }^{3}$ & 5 & 174.37 & 5.17 & - & - & - & Gill 1991 \\
\hline Belleview & - & 170.30 & - & - & 162.00 & - & Rathbun and Scurry 1991 \\
\hline Cross & - & 175.00 & - & - & 163.00 & - & Larsen et al. 1995 \\
\hline Harvie & - & 170.80 & - & - & 161.00 & - & Lazenby et al. 1991 \\
\hline
\end{tabular}


Data Collection from Human Skeletal Remains (Buikstra and Ubelaker 1994). Rather than present in-depth discussions of the nonmetric traits and their importance to osteological research, only highlights of the analysis are presented. Researchers interested in detailed information about particular nonmetric traits are referred to Buikstra and Ubelaker (1994), Hauser and DeStefano (1989), Barnes (1994), Berry and Berry (1967), and ElNajjar and McWilliams (1978). Nonmetric trait data for the State Cemetery skeletal sample are presented in Appendix F.

While the original data collection proceeded using methods given in Standards (Buikstra and Ubelaker 1994), some categories listed for particular traits were collapsed into more-general groupings, while others were entirely discarded. This was done for ease of data computation and presentation; researchers interested in examining the data as originally collected are referred to Appendix C for a copy of the original Standards form used for field data collection and to Appendix $\mathrm{F}$ for nonmetric trait data on specific individuals. Completed data following the Standards format may be obtained from the original osteological data forms that were filled out for each burial and are curated at the Texas State Cemetery.

Many researchers have noted that a number of traits tend to occur more frequently in one sex than another. Because of the skewed demography of this sample (i.e., with a male/female ratio of 8.5 to 1), no sex-based comparisons are made here. However, the State Cemetery sample of males only $(n=50)$ is sufficiently large for comparison with male-only skeletal samples. In the following discussions, comparative data occasionally are presented as a side incidence, in which the number of observations of the trait is divided by the number of analyzed sides of the skull.

\section{Axial Nonmetric Traits}

Only three axial (i.e., unsided, nonvariable) nonmetric traits were analyzed; all of these were cranial traits. The first is the bregmatic bone. In an analysis of 100 adult European males, no bregmatic ossicles were found (Hauser and DeStefano 1989:88). Only one bregmatic bone was seen in the State Cemetery sample, yielding a frequency of 2.9 percent. This frequency may be somewhat inflated in that the sample size for observation of this trait was rather small $(n=34)$.

The sagittal ossicle, seen in 8 individuals, or 38.1 percent of the sample $(n=21)$, also is more frequent than expected. Hauser and DeStefano (1989:91) reported sagittal ossicles in only 3 percent of their male European sample. To put this in perspective, Cosseddu et al. (1979, in Hauser and DeStefano 1989:94-95) reported a maximum frequency of sagittal bones as 23.6 percent, seen in a population of Sardinian Italians. A breakdown of the Sardinian sample by sex, however, shows a frequency of 32.9 percent among males, which is closer to the frequency and sample composition seen in the State Cemetery sample. This unusually high frequency again may be due in part to sampling error $(n=21)$. On the other hand, it is important to remember that this frequency may be an underestimate as well, due to the advanced ages of these individuals and the corresponding tendency towards sutural obliteration. Fragmentation of the skeletal elements also may have contributed to an underestimation. Of course, it is possible that the high frequency of sagittal ossicles reported for this sample is an accurate reflection of the trait's occurrence among this population.

The third axial trait, the apical bone, is notable not for its frequency but for its absence. Hauser and DeStefano (1989:91) list a 17 percent incidence of apical bones among European adult males. Corruccini (1974) found apical ossicles in 10.1 percent of European-Americans. Obviously, the complete absence of this trait in the skeletal sample is unexpected. This deviation from the expected frequency may be attributed to cranial suture obliteration associated with old age or taphonomic fragmentation, both of which may have obscured the visibility of this trait.

\section{Bilateral Nonmetric Traits}

Ten bilateral nonmetric discrete traits are presented in Table 18. Of these, two (supraorbital notches and lambdoid ossicles) fall into the expected ranges for European and European-Àmerican populations. For reasons of methodological incompatibility or lack of research, no comparative data were available for ossicles in the occipitomastoid suture.

The occurrence of parietal foramina, present in 76.2 percent of the skeletal sample, falls within 
TABLE 18

BILATERAL NONMETRIC TRAITS IN THE SKELETAL SAMPLE

\begin{tabular}{|c|c|c|c|c|c|c|c|c|c|c|}
\hline \multirow[b]{3}{*}{ Trait* } & \multicolumn{2}{|c|}{$\mathrm{N}$} & \multicolumn{4}{|c|}{ Present } & \multicolumn{4}{|c|}{ Absent } \\
\hline & \multirow[b]{2}{*}{ Left } & \multirow[b]{2}{*}{ Right } & \multicolumn{2}{|c|}{ Left } & \multicolumn{2}{|c|}{ Right } & \multicolumn{2}{|c|}{ Left } & \multicolumn{2}{|c|}{ Right } \\
\hline & & & \# & $\%$ & $\#$ & $\%$ & $\#$ & $\%$ & $\#$ & $\%$ \\
\hline \multirow[t]{2}{*}{ Supraorbital Notch } & 42 & 41 & 33 & 78.6 & 30 & 73.2 & 9 & 21.4 & 11 & 26.8 \\
\hline & 39 & 38 & 31 & 79.5 & 28 & 73.7 & 8 & 20.5 & 10 & 26.3 \\
\hline \multirow[t]{2}{*}{ Parietal Foramen } & 41 & 42 & 23 & 56.1 & 30 & 71.4 & 18 & 43.9 & 12 & 28.6 \\
\hline & 37 & 38 & 22 & 59.5 & 28 & 73.7 & 15 & 40.5 & 10 & 26.3 \\
\hline \multirow[t]{2}{*}{ Coronal Ossicle } & 31 & 32 & 4 & 12.9 & 2 & 6.3 & 27 & 87.1 & 30 & 93.8 \\
\hline & 29 & 30 & 4 & 13.8 & 2 & 6.7 & 25 & 86.2 & 28 & 93.3 \\
\hline \multirow[t]{2}{*}{ Lambdoid Ossicle } & 15 & 17 & 8 & 53.3 & 10 & 58.8 & 7 & 46.7 & 7 & 41.2 \\
\hline & 14 & 16 & 8 & 57.1 & 10 & 62.5 & 6 & 42.9 & 6 & 37.5 \\
\hline \multirow[t]{2}{*}{ Asterionic Ossicle } & 18 & 16 & 6 & 33.3 & 5 & 31.3 & 12 & 66.7 & 11 & 68.8 \\
\hline & 17 & 15 & 6 & 35.3 & 5 & 33.3 & 11 & 64.7 & 10 & 66.7 \\
\hline \multirow{2}{*}{$\begin{array}{l}\text { Occipito-Mastoid } \\
\text { Ossicle }\end{array}$} & 22 & 22 & 2 & 9.1 & 2 & 9.1 & 20 & 90.9 & 20 & 90.9 \\
\hline & 20 & 20 & 2 & 10.0 & 2 & 10.0 & 18 & 90.0 & 18 & 90.0 \\
\hline \multirow{2}{*}{$\begin{array}{l}\text { Parietal Notch } \\
\text { Bone }\end{array}$} & 26 & 24 & 2 & 7.7 & 3 & 12.5 & 24 & 92.3 & 21 & 87.5 \\
\hline & 23 & 21 & 2 & 8.7 & 3 & 14.3 & 21 & 91.3 & 18 & 85.7 \\
\hline \multirow{2}{*}{$\begin{array}{l}\text { Tympanic } \\
\text { Dehiscence }\end{array}$} & 42 & 43 & 1 & 2.4 & 0 & 0.0 & 41 & 97.6 & 43 & 100.0 \\
\hline & 39 & 39 & 1 & 2.6 & 0 & 0.0 & 38 & 97.4 & 39 & 100.0 \\
\hline \multirow[t]{2}{*}{ Mandibular Torus } & 48 & 51 & 16 & 33.3 & 20 & 39.2 & 32 & 66.7 & 31 & 60.8 \\
\hline & 44 & 46 & 15 & 34.1 & 19 & 41.3 & 29 & 65.9 & 27 & 58.7 \\
\hline \multirow[t]{2}{*}{ Septal Aperture } & 55 & 52 & 3 & 5.4 & 1 & 1.9 & 52 & 94.5 & 51 & 98.1 \\
\hline & 49 & 47 & 2 & 4.1 & 0 & 0.0 & 47 & 95.9 & 47 & 100.0 \\
\hline
\end{tabular}

the expected range of occurrence for individuals. The per-side incidence of the trait, however, is higher than anticipated, with rates of 71.4 percent on the right and 56.1 percent on the left. Hauser and DeStefano (1989:82) recorded positive expression of parietal foramina in a sample of European males as 57 percent on the right and 45 percent on the left.

The frequency of coronal ossicles in the skeletal sample is somewhat larger than expected, particularly on the left side (12.9 percent, $\mathrm{n}=31)$. On an individual basis, coronal ossicles were found 
in 15.6 percent $(n=32)$ of the sample, calculated by dividing the total number of positive expressions, regardless of side, by the number of individuals in which the trait could be observed. In comparison, this trait is seen in 7.5 percent of Dutch individuals and in only 0.1 percent of a sample of European-Americans; worldwide frequencies of this trait hover between 3 and 10 percent (Hauser and DeStefano 1989:92-93).

Asterionic ossicles were far more frequent than expected, with a per-side occurrence of 32.4 percent (calculated by dividing the total number of positive expressions by the number of sides on which the trait could be observed). Corruccini (1974) found a per-side incidence of 10.9 percent among a European-American population. In contrast, parietal notch bones were much less common than anticipated, with this trait occurring only about half as frequently as expected at the State Cemetery. Hauser and DeStefano's (1989: 209) research on a European population recorded these bones in 28 percent (right side) and 23 percent (left side) of crania. The low frequency in the State Cemetery sample may be due to a relative lack of articulated skulls and the fragmentary nature of much of the cranial material.

Another trait, the epipteric bone, is not presented in the table due to a lack of data. The absence of epipteric bones is notable because the absence of this trait has not been noted in previously studied populations (see Hauser and DeStefano 1989:214-215 for a summary of previous research). Corruccini (1974) calculated a 12.9 percent occurrence of epipteric bones among modern European-Americans. The lack of epipteric bones among the State Cemetery sample is most likely an artifact of sampling error and/or poor skeletal preservation.

Tympanic dehiscence, as defined by Standards, was noted in a single individual. This trait occurred as a small foramen on the anterior aspect of the left tympanic plate, posterior to the mandibular fossa. Corruccini (1974) noted a 23 percent side incidence of this trait in a European-American population. Population frequencies range between 0 percent and 67 percent (Hauser and DeStefano 1989:146-147), so while the frequency of this trait in the State Cemetery sample is low, it is not necessarily unusual.

Mandibular tori occurred more frequently in the State Cemetery sample (39.2 percent of indi- viduals) than in Corruccini's (1974) EuropeanAmerican population (23.7 percent of individuals). This difference may be due to disparate data collection, since Corruccini analyzed the trait as an axial one, while Standards recommends the collection of data on a bilateral basis. In addition, the modified coding system used here for statistical analysis collapses trace, slight, moderate, and marked categories into a single category noting only presence or absence.

Unilateral septal apertures were seen in 7.3 percent of individuals in the State Cemetery sample, but no bilateral expression of this trait was apparent. Trotter (1934:218) found septal apertures in 8.5 percent of a sample of EuropeanAmericans. Trotter (1934:218) also noted that European-American females display septal apertures nearly 70 percent more often than males; this higher frequency has sometimes been used as an aid in indicating the sex of an individual. In the Texas State Cemetery sample, this trait occurred in 2 of the 50 males (4 percent) and 2 of the 6 females (33.3 percent).

\section{Nonmetric Traits of Variable Expression}

Data collected for nonmetric traits that vary in both presence and degree of completeness are presented in Table 19. Of these variably expressed traits, comparative data were not available for divided hypoglossal canal, foramen spinosum incomplete, pterygo-spinous bridge, pterygo-alar bridge, accessory transverse foramen, or posterior atlas bridging. The rate of metopic sutures among the skeletal sample was nearly identical to the expected frequency using Hauser and DeStefano's (1989) European sample.

Some notable differences were found in the frequency of mylohyoid bridging. In their sample of adult male Europeans, Hauser and DeStefano (1989:235) found partial mylohyoid bridges in 16 percent (right) and 20 percent (left) of individuals, while no complete bridges were observed. While the combined occurrence of this trait (partial plus complete) is similar for the State Cemetery and European samples, the breakdown of variation in the mylohyoid bridge is distinctly different, with a majority of complete bridges occurring in the cemetery sample.

A second set of nonmetric traits that typically 
TABLE 19

NONMETRIC TRAITS OF VARIABLE EXPRESSION (I) IN THE SKELETAL SAMPLE

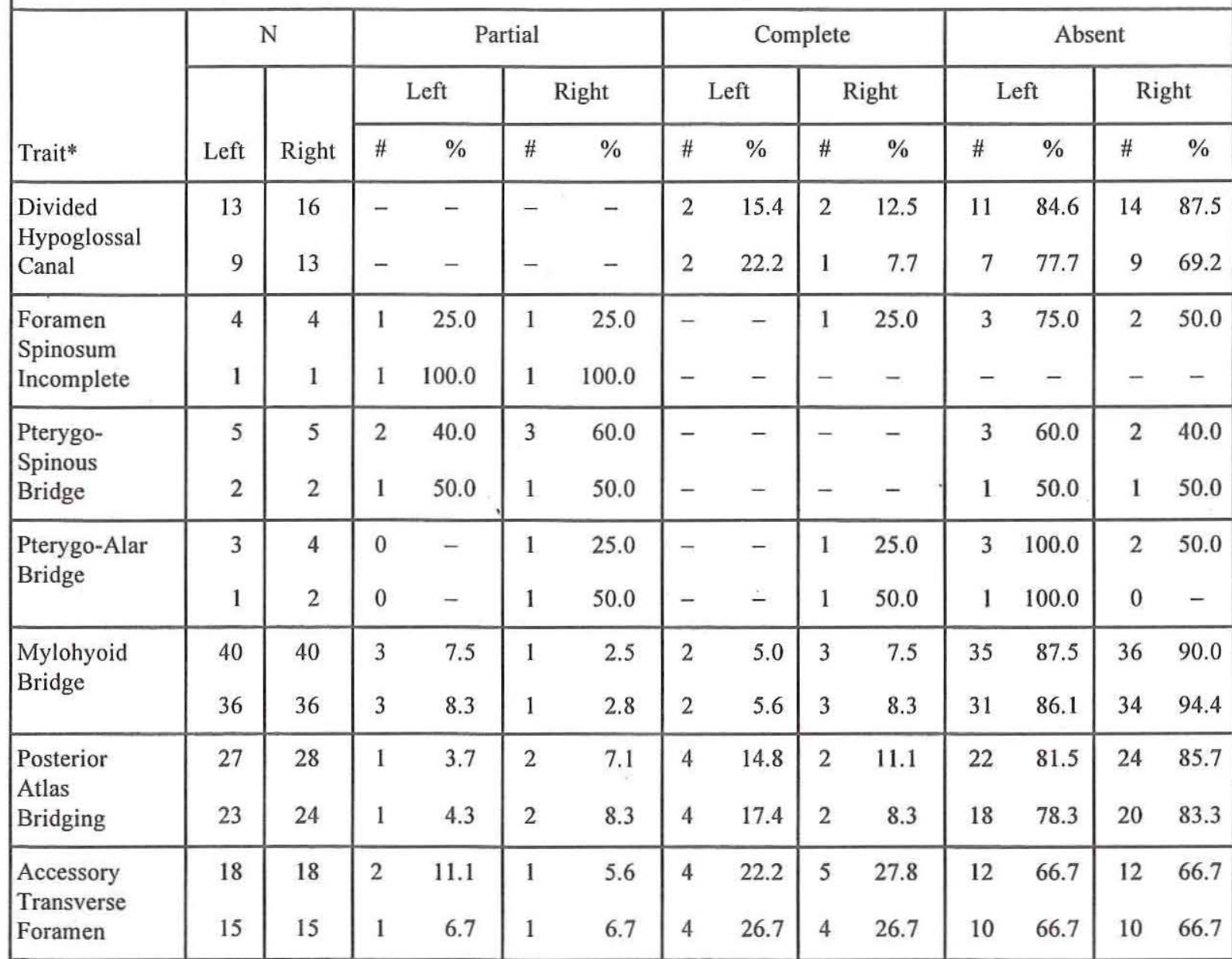

*For each trait, the top row of data is from the total skeletal sample $(\mathrm{N}=56)$ and the bottom row of data is from males only $(n=50)$. Percentage totals may not add up to 100 due to rounding.

vary in terms of number present is shown in Table 20. Comparative data are not presented for zygofacial foramina, mastoid foramina, or supraorbital foramina due to methodological dissimilarities in the available data sets. The frequencies of mental foramina and infraorbital foramina met expected rates among European samples (see Hauser and DeStefano 1989:232-233, 74).

\section{Other Nonmetric Variation}

During analysis, a number of skeletal anomalies other than those coded in the Standards forms were noted. These generally were recorded on the skeletal inventory or pathology forms, since no codes were available for these traits. Harrison (1972:204) pointed out that only 40 percent of individuals yield vertebral radiographs conforming to the "accepted normal pattern of development," so it is not surprising that most of the variation occurred in the vertebral column. In addition, nonmetric traits were also noted in the skull, hand, and foot.

\section{Cranial Nonmetric Traits}

Burial 15 (John Ferron) exhibited a number of large well-marked supernumerary foramina in the frontal bone (two on the right side, four on the left side). These are referred to as supratrochlear or 
TABLE 20

NONMETRIC TRAITS OF VARIABLE EXPRESSION (II) IN THE SKELETAL SAMPLE

\begin{tabular}{|c|c|c|c|c|c|c|c|c|c|c|c|c|c|c|}
\hline \multirow[b]{3}{*}{ Trait* } & \multicolumn{2}{|c|}{$\mathrm{N}$} & \multicolumn{4}{|c|}{ Single } & \multicolumn{4}{|c|}{ Multiple } & \multicolumn{4}{|c|}{ Absent } \\
\hline & \multirow[b]{2}{*}{ Left } & \multirow[b]{2}{*}{ Right } & \multicolumn{2}{|c|}{ Left } & \multicolumn{2}{|c|}{ Right } & \multicolumn{2}{|c|}{ Left } & \multicolumn{2}{|c|}{ Right } & \multicolumn{2}{|c|}{ Left } & \multicolumn{2}{|c|}{ Right } \\
\hline & & & \# & $\%$ & \# & $\%$ & \# & $\%$ & \# & $\%$ & \# & $\%$ & $\#$ & $\%$ \\
\hline \multirow{2}{*}{$\begin{array}{l}\text { Supraorbital } \\
\text { Foramen }\end{array}$} & 41 & 41 & 13 & 31.7 & 8 & 19.5 & 6 & 14.6 & 8 & 19.5 & 22 & 53.7 & 25 & 60.9 \\
\hline & 38 & 37 & 11 & 28.9 & 7 & 18.9 & 6 & 15.8 & 7 & 18.9 & 21 & 55.3 & 23 & 62.2 \\
\hline \multirow{2}{*}{$\begin{array}{l}\text { Infraorbital } \\
\text { Foramen }\end{array}$} & 13 & 13 & - & - & 1 & 7.7 & 1 & 7.7 & 1 & 7.7 & 12 & 92.3 & 11 & 84.6 \\
\hline & 12 & 13 & - & - & 1 & 7.7 & 1 & 8.3 & 1 & 7.7 & 11 & 91.7 & 11 & 84.6 \\
\hline \multirow{2}{*}{$\begin{array}{l}\text { Zygofacial } \\
\text { Foramen }\end{array}$} & 40 & 46 & 13 & 32.5 & 16 & 34.8 & 25 & 62.5 & 24 & 52.2 & 2 & 5.0 & 6 & 13.0 \\
\hline & 37 & 40 & 12 & 32.4 & 13 & 32.5 & 23 & 62.5 & 22 & 55.0 . & 2 & 5.4 & 5 & 12.5 \\
\hline \multirow{2}{*}{$\begin{array}{l}\text { Mastoid } \\
\text { Foramen }\end{array}$} & 52 & 51 & 20 & 38.5 & 23 & 45.1 & 14 & 26.9 & 8 & 15.7 & 18 & 34.6 & 20 & 39.2 \\
\hline & 48 & 46 & 19 & 39.6 & 21 & 45.7 & 14 & 29.2 & 8 & 17.4 & 15 & 31.3 & 17 & 37.0 \\
\hline \multirow{2}{*}{$\begin{array}{l}\text { Mental } \\
\text { Foramen }\end{array}$} & 49 & 50 & 49 & 100.0 & 47 & 94.0 & - & - & 1 & 2.0 & - & - & 2 & 4.0 \\
\hline & 46 & 45 & 46 & 100.0 & 43 & 95.6 & - & - & 1 & 2.2 & - & - & 1 & 2.2 \\
\hline
\end{tabular}

*For each trait, the top row of data is from the total skeletal sample $(\mathrm{N}=56)$ and the bottom row of data is from males only $(n=50)$. Percentage totals may not add up to 100 due to rounding.

frontal foramina, and their expression is probably a result of differing nerve and vessel morphologies (e.g., bifurcation) (Hauser and DeStefano 1989: 50-55). Comparative data are not available for this trait because of researchers' differing nomenclatures and scoring schemes. Mr. Ferron also had a large posteriorly directed foramen in the central portion of the left superior orbital wall. No discussion of this particular trait was found in the literature, but it may be similar in nature to the ethmoidal foramina discussed in Hauser and DeStefano (1989:58-63). The notable distinction between the ethmoidal foramina and that seen in Mr. Ferron is that the latter was clearly located on the frontal bone rather than the ethmoid.

An os japonicum was observed on Burial 19 (James Hogun). This accessory suture was located only on the left zygomatic and took the form described as a "single transverse (inferior) suture" (Hauser and DeStefano 1989:224). In their sample of 100 European males, Hauser and DeStefano (1989:223) found one incidence of bilateral simple transverse sutures of the zygomatic; it is unclear whether this suture appeared inferiorally or superiorally. In addition, they found one unilateral occurrence of an oblique complete simple suture. The State Cemetery sample is comparable, then, to the expected frequencies for this trait.

\section{Nonmetric Traits of the Hand and Foot}

A single anomaly of the hand was discovered. Burial 26 (Joshua Smith) had brachydactyly, exhibited as an unusually short medial phalanx in one hand (side indeterminate). Brachydactyly has several manifestations, including shortened metacarpals or metatarsals and/or short phalanges (Loveland and Gregg 1988). Short phalanges may occur as an anatomic variant or as a result of a number of genetic syndromes (see Loveland and Gregg 1988:Table 1). It is not immediately clear if this particular case was due to nonmetric variation or was pathological in nature. One example 
of a condition linked with brachydactyly is symphalangism, which is an autosomal dominant condition characterized by short and fused phalanges coupled with carpal/tarsal coalitions, brachydactylism, fusions of the cervical vertebrae, and hearing loss (Gaal et al. 1988:783-785; Loveland and Gregg 1988). Mr. Smith's short phalanx was unfused and perfectly formed, but it was approximately half the size of a normal phalange. In addition, all three phalanges associated with that finger were noted to be articulated in the ground, and all of the other recovered phalanges were normal in length and morphology. Thus, the lack of other irregular bone formation in Mr. Smith's hands and neck suggests that he was not suffering from this condition. Instead, the brachydactyly seen in this case is probably an anatomical variant.

Fusion of the medial and distal phalanges of the small toes was noted in five cases: Burial 32 (J. M. Adams), Burial 47 (George W. Kyser), Burial 50 (Josephine Walker), Burial 54 (Mary Burleson), and Burial 55 (Louisa Bradfield). While joint fusion is typically reflective of injury or inflammation, fusion of the fifth toe phalanges occurs in 37 percent of modern individuals (Sarrafian 1983:83, 101-102). This high frequency suggests that this particular kind of joint fusion may be due to normal variation rather than pathological processes.

Burial 29 (J. P. Thomas) exhibited a synostosis or coalition between the third (lateral) cuneiform and the third metatarsal of the right foot. The synostosis occurred on the plantar (inferior) aspect and involved approximately one-third of the joint surface. This location and degree of cunciometatarsal coalition are typical of this condition; this trait is not believed to be related to disease and is probably a form of individual variation (Sarrafian 1983:100). Synostosis of the third cuneiform and third metatarsal typically occurs in 2 percent of feet (Sarrafian 1983:100), a frequency which is nearly matched by the 1.8 percent in the State Cemetery sample.

\section{Vertebral Column Nonmetric Variations}

Burial 27 (John Porter) and Burial 39 (Amos Starnes) both had a supernumerary or sixth lumbar vertebrae. Numerical variation in the presacral vertebrae is not unusual, particularly where the anomaly is an excess segment (Barnes 1994:78). This development of extra vertebral segments is particularly common in the lumbar region, occurring in a minimum of 2.25 percent of modern individuals (Bornstein and Peterson 1966:141; but see Barnes 1994:79 for criticism of their methodology). The frequency of six lumbar vertebrae for the total State Cemetery sample is similar, with an incidence of 3.6 percent. This frequency may be underestimated due to the highly fragmented nature of the vertebral elements of many of these individuals.

Along the same lines, transitional vertebrae were found in one individual, Burial 52 (John S. Pannell). Transitional vertebrae occur due to segmental border shifts, in which vertebrae in the transitional zones (e.g., lumbosacral border) take on the properties of the vertebrae above or below the border (Barnes 1994). This process can increase or decrease the number of vertebrae in a given region while the total number of vertebrae in the column remain unchanged (Barnes 1994:78-80; Steele and Bramblett 1988:113). The shift of vertebral characteristics generally involves the transverse processes and apophyseal joints, and may occur bi- or unilaterally (Barnes 1994:78-80). In Mr. Pannell's case, vertebral preservation was excellent, which allowed specific data about this transition to be recorded. Mr. Pannell displayed cranial shifting at the thoracolumbar region. The eleventh thoracic assumed the characteristics of a typical twelfth, with the superior facets oriented in a coronal plane and the inferior articular surfaces oriented in a sagittal plane (Steele and Bramblett 1988:120). The twelfth thoracic had taken on the appearance of a lumbar vertebra, with both superior and inferior articular surfaces showing the curved shape typical of lumbars.

In two cases, Burial 16 (J. V. Davenport) and Burial 33 (Stephen Stanley), the fifth lumbar vertebra was fused to the sacrum. This fusion has significance for the health of the affected individuals, since it may cause back pain, progressive scoliosis, and sciatica (Barnes 1994:110). This cranial shifting of the lumbosacral border may occur in 8 to 11 percent of the population (Trotter and Peterson 1966 in Steele and Bramblett 1988: 129).

Two more individuals, Henry Bowdoin (Burial 35) and J. H. Walker (Burial 36), had sacra with extra segments. The six sacral elements of these 
individuals had the appearance of normal sacral segments. Since both Mr. Walker and $\mathrm{Mr}$. Bowdoin had the normal complement of pre-sacral vertebrae, these cases probably do not represent cases of complete cranial shifting or sacralization of the sixth lumbar vertebra (see Harrison 1972:98; Jamieson 1937:121; Mann and Murphy 1990:71), which in effect would have combined both processes discussed above. Since the coccyx was recovered in Burial 36, the six-segmented sacrum should not be confused with the fusion of the first coccygeal element to the sacrum, a trait which may occur in up to 50 percent of modern populations (Jamieson 1937:121; Steele and Bramblett 1988: 129). These sacra probably represent normal variation, since Gray (1974:49) and Harrison (1972:98) note that variations of the sacrum may include four or six elements.

Costal facets for lumbar ribs were noted on Mr. Starnes's (Burial 39) first lumbar segment, although the lumbar ribs themselves were not identified. This anomaly may occur on the lumbar or thoracic vertebrae and typically is associated with caudal shifting, in which the first lumbar takes on thoracic characteristics (Barnes 1994:105, 110). Interestingly, an associated caudal shift was not noted in Mr. Starnes, who also had 6 lumbar segments (as discussed above) and 12 thoracic vertebrae. No comparative data are available for this particular combination of traits, although lumbar ribs by themselves occur rarely (see Steele and Bramblett 1988:125-126). Lumbar ribs have medical significance, since many affected individuals will experience pain or tenderness in this region of the back (Barnes 1994:105).

\section{INDICATORS OF HEALTH}

The type, frequency, and distribution of dental and skeletal disorders yields critical information relating to health and occupation. The sample from the State Cemetery is particularly valuable because it represents long-lived survivors of a war. Osteologically, little is known about men who participated in wars, and even less is known of those who survived for decades after the event. Analysis of individuals from the State Cemetery allows us to fill this void. All skeletal material recovered was carefully cleaned and then examined for any evidence of medical disorders. Due to time limitations, all examinations were strictly at the macroscopic level, and no radiographs could be taken.

\section{Dental Disorders}

Dental disorders can provide information on the diet, behavior, and stress experienced by individuals. This section presents dental information such as antemortem tooth loss rates, caries, abscesses, alveolar resorption, and linear enamel hypoplasias. All disorders are described both on an individual basis and using a tooth count method, and most are described in terms of male, female, and pooled samples. In addition to these disorders, typical and atypical wear patterns and fractured teeth observed in the sample also are considered. Dental disorders associated with specific individuals are presented in Appendix G.

\section{Antemortem Tooth Loss}

The loss of teeth prior to death can occur for many different reasons, including extreme dental wear, severe alveolar resorption, abscesses, and caries (Lukacs 1989:271). Because these causes are age cumulative, it was expected that the sample would evidence high antemortem tooth loss rates. Subsequent analysis supported this supposition. When the rate of tooth loss prior to death was calculated for each individual based on the number of observable teeth, it was noted that 26.8 percent $(n=15)$ of the sample showed antemortem loss of all observable teeth (Table 21). Over 14 percent $(n=8)$ had lost between 75 and 99 percent of all observable teeth prior to death. Over half (55.4 percent, $n=31$ ) of all individuals had lost more than 50 percent of their observable teeth prior to death. Only two individuals in the sample documented no cases of antemortem tooth loss. When viewed in terms of sex, all but one of the six females had lost 100 percent of their observable teeth. The antemortem loss rate was much lower for the remaining female at 16.7 percent.

Table 22 presents data on antemortem tooth loss broken down into 10-year age increments. Notably, complete edentulism (100 percent tooth loss) occurs in all age categories, but the rate of loss is highest in the 90- to 99-year age group, where 57 percent, or 4 of the individuals in this age range $(n=7)$, experienced 100 percent tooth loss. For all analyzed individuals, the highest 
TABLE 21

ANTEMORTEM TOOTH LOSS IN THE SKELETAL SAMPLE

\begin{tabular}{|c|c|c|c|c|c|c|c|}
\hline $\begin{array}{l}\text { Burial } \\
\text { No. }\end{array}$ & $\begin{array}{l}\text { No. } \\
\text { Observable }\end{array}$ & $\begin{array}{l}\text { No. Lost } \\
\text { Antemortem }\end{array}$ & $\begin{array}{l}\% \text { Lost } \\
\text { Antemortem }\end{array}$ & $\begin{array}{l}\text { Burial } \\
\text { No. }\end{array}$ & $\begin{array}{l}\text { No. } \\
\text { Observable }\end{array}$ & $\begin{array}{l}\text { No. Lost } \\
\text { Antemortem }\end{array}$ & $\begin{array}{l}\% \text { Lost } \\
\text { Antemortem }\end{array}$ \\
\hline 1 & 32 & 32 & 100.0 & 29 & 32 & 2 & 6.3 \\
\hline 2 & 30 & 30 & 100.0 & 30 & 32 & 23 & 71.9 \\
\hline 3 & 27 & 27 & 100.0 & 31 & 30 & 3 & 10.0 \\
\hline 4 & 30 & 20 & 100.0 & 32 & 30 & 5 & 16.7 \\
\hline 5 & 24 & 24 & 100.0 & 33 & 31 & 17 & 54.8 \\
\hline 6 & 32 & 32 & 100.0 & 34 & 32 & 6 & 18.0 \\
\hline 7 & 16 & 11 & 68.8 & 35 & 30 & 28 & 93.3 \\
\hline 8 & 26 & 9 & 34.6 & 36 & 31 & 9 & 29.0 \\
\hline 9 & 20 & 7 & 35.0 & 37 & 23 & 7 & 30.4 \\
\hline 10 & 24 & 17 & 70.8 & 38 & 30 & 27 & 90.0 \\
\hline 11 & 25 & 6 & 24.0 & 39 & 28 & 9 & 32.1 \\
\hline 12 & 17 & 2 & 11.8 & 40 & 26 & 16 & 61.5 \\
\hline 13 & 26 & 26 & 100.0 & 41 & 16 & 16 & 100.0 \\
\hline 14 & 28 & 21 & .75 .0 & 42 & 21 & '19 & 90.5 \\
\hline 15 & 16 & 16 & 100.0 & 43 & 20 & 7 & 35.0 \\
\hline 16 & 32 & 32 & 100.0 & 44 & 31 & 12 & 35.0 \\
\hline 17 & 29 & 6 & 20.7 & 45 & 26 & 3 & 38.7 \\
\hline 18 & 22 & 9 & 86.4 & 46 & 32 & 32 & 11.5 \\
\hline 19 & 14 & 9 & 64.3 & 47 & 32 & 31 & 100.0 \\
\hline 20 & 26 & 7 & 26.9 & 48 & 32 & 32 & 96.9 \\
\hline 21 & 30 & 9 & 30.0 & 49 & 32 & 31 & 100.0 \\
\hline 22 & 26 & 0 & - & 50 & 24 & 4 & 96.9 \\
\hline 23 & 21 & 4 & 19.0 & 51 & 32 & 32 & 16.7 \\
\hline 24 & 22 & 0 & - & 52 & 16 & 10 & 100.0 \\
\hline 25 & 21 & 8 & 38.1 & 53 & 32 & 21 & 65.2 \\
\hline 26 & 26 & 7 & 26.9 & 54 & 32 & 32 & 65.6 \\
\hline 27 & 24 & 2 & 8.3 & 55 & 16 & 16 & 100.0 \\
\hline 28 & 19 & 1 & 5.3 & 56 & 18 & 16 & 100.0 \\
\hline
\end{tabular}

TABLE 22

ANTEMORTEM TOOTH LOSS BY AGE IN THE SKELETAL SAMPLE

\begin{tabular}{|c|c|c|c|c|c|c|c|c|c|c|c|c|c|c|}
\hline \multirow{2}{*}{$\begin{array}{l}\text { Age in } \\
\text { Years }\end{array}$} & \multicolumn{2}{|c|}{ Totals } & \multicolumn{2}{|c|}{$0 \%$} & \multicolumn{2}{|c|}{$1-24 \%$} & \multicolumn{2}{|c|}{$25-49 \%$} & \multicolumn{2}{|c|}{$50-74 \%$} & \multicolumn{2}{|c|}{$75-99 \%$} & \multicolumn{2}{|c|}{$100 \%$} \\
\hline & \# & $\%$ & $\#$ & $\%$ & $\#$ & $\%$ & \# & $\%$ & $\#$ & $\%$ & $\#$ & $\%$ & $\#$ & $\%$ \\
\hline $60-69$ & 11 & 19.6 & - & - & 3 & 5.4 & 3 & 5.4 & 2 & 3.6 & 1 & 1.8 & 2 & 3.6 \\
\hline 70-79 & 24 & 42.9 & 1 & 1.8 & 6 & 10.7 & 5 & 8.9 & 5 & 8.9 & 4 & 7.1 & 3 & 5.4 \\
\hline $80-89$ & 13 & 23.2 & - & - & 2 & 3.6 & 2 & 3.6 & 1 & 1.8 & 3 & 5.4 & 5 & 8.9 \\
\hline $90-99$ & 7 & 12.5 & 1 & 1.8 & 1 & 1.8 & 1 & 1.8 & - & - & - & - & 4 & 7.1 \\
\hline Unknown & 1 & 1.8 & - & - & - & - & - & - & - & - & - & - & 1 & 1.8 \\
\hline Totals: & 56 & 100.0 & 2 & 3.6 & 12 & 21.5 & 11 & 19.7 & 8 & 14.3 & 8 & 14.3 & 15 & 26.8 \\
\hline
\end{tabular}


overall frequency of edentulism (8.9 percent) is found among the $80-89$ year olds. It should be noted that nearly 61 percent of all individuals in the sample were under the age of 80 years, with almost 43 percent being between the ages of 70 and 79 years; this uneven age distribution may be influencing the analysis. Since individual cell sizes in Table 22 are quite small, patterns in agecumulative loss become more evident when the sample is viewed in terms of two groups: age 60 to 79 years and age 80 to 99 years. Complete edentulism in the 80 to 99 year olds made up 16 percent of the total sample, but edentulous 60 to 79 year olds represent only 10 percent of the sample. At the other end of the spectrum, it becomes evident that younger individuals (age 60-79 years) were nearly three times more likely (16.1 percent, or 9 individuals) to have a loss rate of only 1 to 24 percent when compared' to the older group (5.4 percent, or 3 individuals).

The frequency of antemortem tooth loss also was calculated based on the number of observable teeth per tooth type (i.e., incisor, canine, premolar, and molar). These data were determined for the pooled sample, as well as females and males separately. Table 23 illustrates an extremely high rate of premortem tooth loss. In looking at the entire dental arcade for the pooled sample, no tooth type had fewer than 45 percent of all observable teeth lost prior to death. Seventy-two percent of all observable molars were lost antemortem. Molar loss rates were consistently higher than for any other tooth type, although all tooth types exhibited unusually high loss rates.

Sledzik and Moore-Jansen (1991) provide data on the antemortem tooth loss rate for Confederate and Federal soldiers who died in battle (see Table 23). The average age at death for individuals in their sample was 27.1 years, with a range from 18 to 45 years. Because their sample was composed of both Union and Confederate soldiers who died in battles all over the United States, it cannot be directly compared to the State Cemetery data set. However, if it is accepted as representative of general rates of antemortem tooth loss for troops during the Civil War, then it illustrates that the high degree of loss observed here, as expected, is largely the result of increasing age.

\begin{tabular}{|c|c|c|c|c|c|c|c|c|}
\hline \multicolumn{9}{|c|}{$\begin{array}{l}\text { ANTEMORTEM TOOTH LOSS RATES PER TOOTH TYPE FOR THE } \\
\text { TEXAS STATE CEMETERY AND CIVIL WAR SKELETAL SAMPLES }\end{array}$} \\
\hline & & ample & & & & & & Var* \\
\hline Tooth Type & \# & \% Lost & \# & $\%$ Lost & \# & $\%$ Lost & \# & \% Lost \\
\hline $\begin{array}{l}\text { Maxillary } \\
\text { Incisors } \\
\text { Canines } \\
\text { Premolars } \\
\text { Molars }\end{array}$ & $\begin{array}{r}172 \\
86 \\
155 \\
184\end{array}$ & $\begin{array}{l}54.1 \\
50.0 \\
58.1 \\
60.3\end{array}$ & $\begin{array}{r}18 \\
9 \\
20 \\
27\end{array}$ & $\begin{array}{l}88.9 \\
88.9 \\
85.0 \\
92.6\end{array}$ & $\begin{array}{r}154 \\
77 \\
135 \\
157\end{array}$ & $\begin{array}{l}50.0 \\
45.5 \\
54.1 \\
54.8\end{array}$ & $\begin{array}{r}38 \\
27 \\
98 \\
185\end{array}$ & $\begin{array}{r}10.5 \\
7.4 \\
18.4 \\
27.4\end{array}$ \\
\hline $\begin{array}{l}\text { Mandibular } \\
\text { Incisors } \\
\text { Canines } \\
\text { Premolars } \\
\text { Molars }\end{array}$ & $\begin{array}{l}216 \\
108 \\
218 \\
307\end{array}$ & $\begin{array}{l}53.2 \\
42.6 \\
59.2 \\
79.5\end{array}$ & $\begin{array}{l}24 \\
12 \\
24 \\
36\end{array}$ & $\begin{array}{l}83.3 \\
83.3 \\
83.3 \\
88.9\end{array}$ & $\begin{array}{r}192 \\
96 \\
194 \\
271\end{array}$ & $\begin{array}{l}49.5 \\
37.5 \\
56.2 \\
80.8\end{array}$ & $\begin{array}{r}5 \\
7 \\
16 \\
30\end{array}$ & $\begin{array}{l}\overline{28.6} \\
\overline{43.3}\end{array}$ \\
\hline $\begin{array}{l}\text { Total Dention } \\
\text { Incisors } \\
\text { Canines } \\
\text { Premolars } \\
\text { Molars }\end{array}$ & $\begin{array}{l}388 \\
194 \\
373 \\
491\end{array}$ & $\begin{array}{l}53.6 \\
45.9 \\
58.7 \\
72.3\end{array}$ & $\begin{array}{l}42 \\
21 \\
44 \\
63\end{array}$ & $\begin{array}{l}85.7 \\
85.7 \\
84.1 \\
90.5\end{array}$ & $\begin{array}{l}346 \\
173 \\
329 \\
428\end{array}$ & $\begin{array}{l}49.7 \\
41.0 \\
55.3 \\
69.6\end{array}$ & $\begin{array}{r}43 \\
34 \\
114 \\
215\end{array}$ & $\begin{array}{r}9.3 \\
11.8 \\
15.8 \\
29.8\end{array}$ \\
\hline
\end{tabular}


The oral health status of a modern sample $(n=650)$ of people living in Department of Veterans Affairs nursing home facilities was studied by Weyant et al. (1993). The mean age of this sample was 71.8 years, similar to the mean age of people from the State Cemetery. Like the State Cemetery, the majority of the people composing the Department of Veterans Affairs nursing home sample were white males (Weyant et al. 1993: Table 1). Of their sample, 51 percent of the individuals were edentulous (Weyant et al. 1993: 230 ), compared to approximately 25 percent of people analyzed from the State Cemetery. The different frequencies noted between the two groups are probably the result of disparate sample sizes. It also should be noted that when compared to noninstitutional, nonveteran, modern samples, the nursing home group has higher rates of edentulism (Weyant et al. 1993:232). The comparative data provided by the nursing home facilities support the age-progressive nature of antemortem tooth loss.

\section{Wear}

The degree of dental wear was coded following the method established in Smith (1984). Dental wear is the natural result of dental occlusion and behavioral activities and is not a disorder, but its degree may affect the frequency or severity of other dental disorders, such as caries and abscesses. In addition, severe dental wear can cause difficulties observing disorders such as linear enamel hypoplasias. The degree of wear can be used to indicate the amount of abrasive activities occurring on a tooth and most frequently is used to reflect diet. Because the amount of wear is positively correlated with increasing age, one would expect this sample to show relatively high rates of wear.

Tables 24 and 25 document the degree of dental wear observed on all maxillary and mandibular teeth for the pooled and males-only samples. It should be noted that sample sizes are small due to the high degree of antemortem tooth loss. Severity of dental wear in the pooled sample ranged from a low of 2.7 (moderate to full cusp removal with some dentin exposure) on the maxillary third molars to a high of 6.0 on the mandibular second molars (coalesced areas of dentin with an enamel ring surrounding the tooth). When the teeth were categorized into types for the pooled sample, wear on the maxillary teeth was notably less severe on posterior teeth, especially the

\begin{tabular}{|c|c|c|c|c|}
\hline \multicolumn{5}{|c|}{$\begin{array}{c}\text { TABLE } 24 \\
\text { DEGREE OF DENTAL WEAR IN THE } \\
\text { SKELETAL SAMPLE }\end{array}$} \\
\hline \multirow[b]{2}{*}{ Tooth Type } & \multicolumn{2}{|c|}{ Pooled Sample } & \multicolumn{2}{|c|}{ Males Only } \\
\hline & $\mathrm{N}$ & $\begin{array}{l}\text { Wear } \\
\text { Score }\end{array}$ & $\mathrm{N}$ & $\begin{array}{l}\text { Wear } \\
\text { Score }\end{array}$ \\
\hline Maxillary & & & & \\
\hline $\mathrm{M}^{3}$ & 24 & 2.7 & 24 & 2.7 \\
\hline $\mathrm{M}^{2}$ & 23 & 3.7 & 23 & 3.7 \\
\hline $\mathrm{M}^{1}$ & 19 & 5.3 & 18 & 5.2 \\
\hline $\mathrm{P}^{4}$ & 28 & 4.7 & 26 & 4.6 \\
\hline $\mathrm{P}^{3}$ & 32 & 5.7 & 31 & 5.7 \\
\hline $\mathrm{C}^{-}$ & 37 & 5.7 & 36 & 5.7 \\
\hline$I^{2}$ & 30 & 5.6 & 30 & 5.6 \\
\hline $\mathrm{I}^{1}$ & 32 & 5.8 & 32 & 5.8 \\
\hline Mandibular & & ' & & \\
\hline $\mathrm{M}_{3}$ & 18 & 4.3 & 18 & 4.3 \\
\hline $\mathrm{M}_{2}$ & 20 & 6.0 & 20 & 6.0 \\
\hline$M_{1}^{2}$ & 13 & 4.8 & 11 & 4.9 \\
\hline $\mathrm{P}_{4}$ & 34 & 4.8 & 32 & 4.9 \\
\hline $\mathrm{P}_{3}$ & 49 & 4.9 & 47 & 5.0 \\
\hline $\mathrm{C}$ & 56 & 4.9 & 54 & 5.0 \\
\hline $\mathrm{I}_{2}$ & 45 & 4.7 & 43 & 4.8 \\
\hline $\mathrm{I}_{1}$ & 33 & 5.2 & 31 & 5.2 \\
\hline
\end{tabular}

molars. However, the degree of wear on mandibular teeth was relatively even. Because only one female had teeth that could be examined for wear, the scores for males only are virtually identical to that of the pooled sample. The dental wear scores for the only female with observable teeth (Burial 50) are provided in Appendix G, as are the dental wear scores for all males.

Only four of the individuals analyzed here had unusual wear patterns. Burials 14 and 36 had mesiolingual wear facets on the right and left upper canines, respectively. The right upper third premolar of Burial 33 had extreme distal wear, while the right upper central incisor had extreme lingual wear. Both lower central incisors of Burial 50 had labial sloping wear. These wear patterns most likely can be attributed to pipe smoking or repeated use of the teeth as tools.

\section{Alveolar Resorption}

Resorption of the alveolus results both from 


\begin{tabular}{|l|c|c|c|c|}
\hline \multicolumn{5}{|c|}{ TABLE 25 } \\
DEGREE OF DENTAL WEAR PER TOOTH \\
TYPE IN THE SKELETAL SAMPLE
\end{tabular}

gingival inflammation (periodontal disease) and from normal aging processes (Lukacs 1989:271).

Resorption was examined on all teeth still in the alveolus and coded as slight (1-3 mm), moderate $(4-5 \mathrm{~mm})$, or severe $(>5 \mathrm{~mm})$. All of the examined teeth had some degree of resorption (Table 26, Appendix G). Teeth exhibiting only slight resorption were more uncommon than teeth with moderate to severe resorption. On the maxillary teeth, most examples of severe resorption were identified on the posterior teeth (fourth premolar and molars). This is not true of the mandibular teeth, which show similar degrees of resorption around anterior and posterior teeth. Six individuals (Burials 20, 21, 32, 33, 43, and 53) ranging in age from 66 to 80 years were notable for severe resorption of several teeth, usually the anterior ones.

\section{Hypercementosis}

Hypercementosis results from excessive deposits of cementum on the root of a tooth. It is most commonly attributed to severe alveolar resorption, abscesses, or wear and occurs as a mechanism to aid in maintaining the tooth in its socket (see Comuzzie and Steele 1989:13). All teeth in this sample with observable roots were examined for hypercementosis on a presence/ absence basis. Although 56 individuals were analyzed, their high antemortem tooth loss rate, combined with generally good preservation of mandibles and maxillae, resulted in small sample sizes of teeth observable for this trait. Only 35 of the excavated individuals had roots that could be examined for signs of hypercementosis; of these, 11 people (31.4 percent, 10 males and 1 female) had examples (Appendix G).

Maxillary teeth had higher frequencies of hypercementosis when compared to mandibular teeth (Tables 27 and 28). In both dental arcades, posterior teeth had higher rates of excessive cementum than did the anterior teeth. The lowest frequencies were noted in the incisors, especially the lateral incisors which documented no cases of hypercementosis.

\section{Calculus}

Calculus (mineralized plaque) was recorded when observed on the surface of teeth. The presence of calculus on a tooth may inflame the gingival tissues and result in resorption of the surrounding alveolar bone (Lukacs 1989:267). Deposits were coded following Rose (1985) as mild (isolated areas of deposition), moderate (coalesced deposits), and severe (three-dimensional depositions). Table 29 documents the high rate of calculus that occurred on the analyzed individuals. Frequencies ranged from a low of 51.2 percent of observed maxillary canines to a high of 89.5 percent on mandibular third molars.

The examination of calculus deposits by tooth type (Table 30), demonstrated that mandibular anterior teeth were more commonly affected by calculus than were maxillary anterior teeth. However, maxillary posterior teeth (premolars and molars) were more commonly affected by calculus than were mandibular ones. Because calculus tends to deposit on the lingual surfaces of mandibular incisors and the buccal surfaces of maxillary molars, due to their placement near the ducts of salivary glands (Cawson 1970 in Hillson 1986: 302 ), this slightly increased frequency is not surprising. Of the 40 individuals with observable teeth, only 4 had no dental calculus (10 percent, see Appendix G) and only 1 individual (Burial 12, Mr. Bernard) had occlusal calculus (covering the maxillary left third molar). The occlusal calculus observed on Mr. Bernard was not due to a lack of 


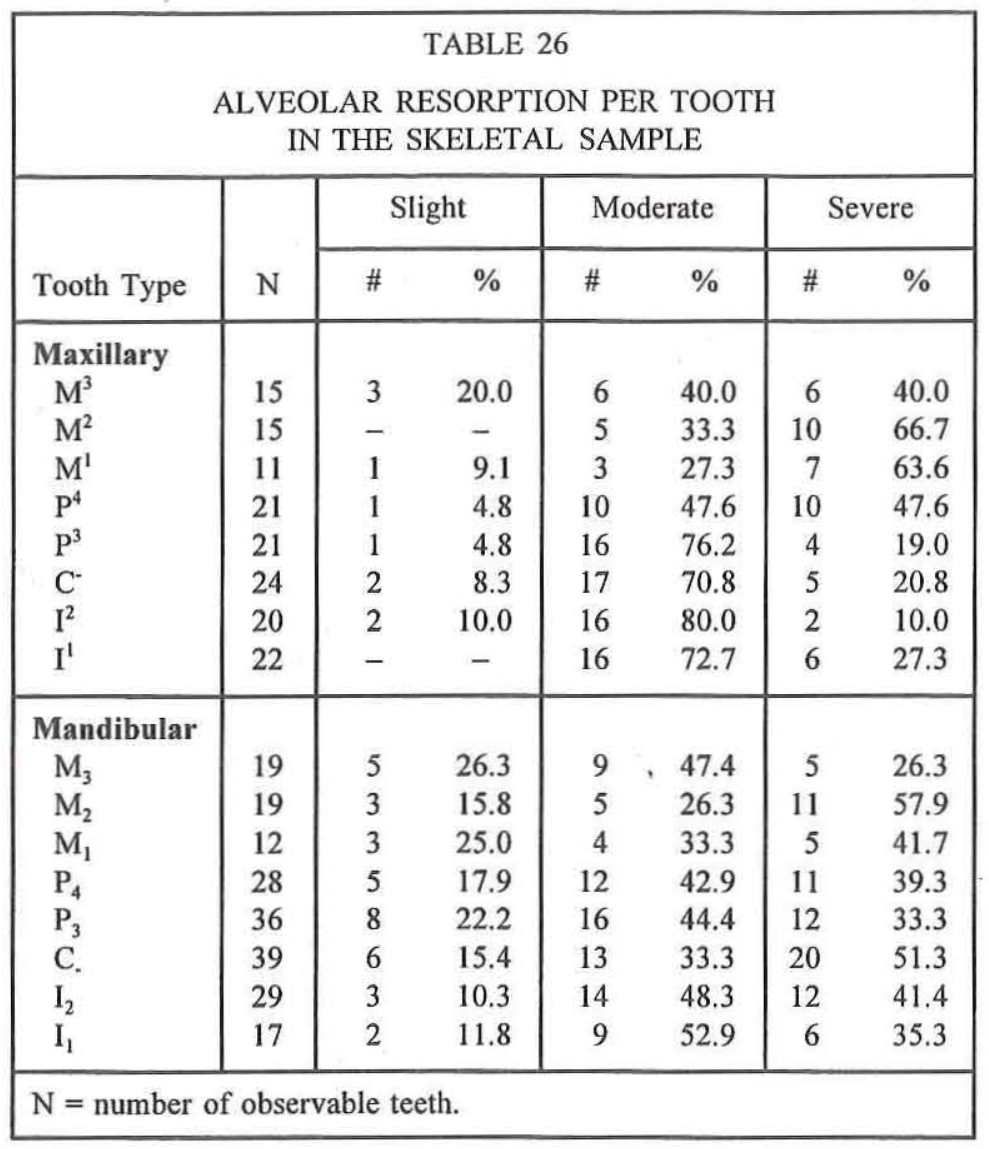

large). In addition, notes were made of any fillings. Information pertaining to caries type is located in Appendix G.

Thirty-four of 41 (82.9 percent) examined individuals with teeth had at least one caries. The modern sample from the Department of Veterans Affairs nursing home care units (described earlier) had a higher caries frequency of 93 percent (Weyant et al. 1993:230). However, the caries frequency at the State Cemetery was much higher than the frequency of 45 percent recorded at Cedar Grove, a historic AfricanAmerican cemetery in Arkansas dating to roughly the same time period, and was higher than the 51 percent recorded for a skeletal sample from a Monroe County (New York) institutional cemetery dating 1826-1863 (Lanphear 1988:Table 37). Only one female from the State Cemetery had observable teeth, and she did evidence dental caries; the remaining 33 individuals were male (see Appendix G). In total,

the corresponding lower third molar and would suggest that Mr. Bernard's left third molars were not occluding. Severe temporomandibular joint disorder was observed on the left side of his jaw only. Lipping and porosity were noted in the temporal glenoid fossa, and wasting of the mandibular condyle had occurred. This temporomandibular joint disorder must have prevented full occlusion of at least the third molars.

\section{Caries}

Dental caries occur when bacteria in plaque destroys the enamel and dentin (Lukacs 1989:263; Ortner and Putschar 1985:438). Because high caries rates usually result from diets rich in sticky foods composed of simple sugars (Powell 1985: 314 ), the frequency of dental caries in a sample is a good indicator of diet. All observable teeth were examined for carious lesions. Each caries was described in terms of type (occlusal, interproximal, buccal, lingual, or gross), location (crown, root, cervical margin), and size (small, medium, or
141 caries were noted on 130 teeth; 14 teeth had 2 caries and 2 teeth had 3 caries. The average number of dental caries per dental arcade was 3.5 , determined on the male portion of the sample only. Using 2.0 as the separation point between a low and a high carbohydrate diet (see Rose et al. 1984), this caries rate suggests a high carbohydrate diet. At 3.5 caries per person, the State Cemetery rate is much higher than the 1.45 caries per person recorded at 41DT105, a rural Anglo-American cemetery in Texas that dated from the 1850 s to 1880s (Winchell et al. 1995:161). The caries per person rate at Belleview, a South Carolina plantation dating 1738-1756 was 2.2 (Rathbun and Scurry 1991:Table 10-4). It should be noted that the caries rate observed in the State Cemetery sample is probably severely underestimated due to the high antemortem tooth loss. Many of the teeth lost prior to death may have had caries that were extensive enough to have resulted in tooth loss.

Table 31 shows the percentage of each tooth that bore evidence of carious lesions. Caries were noted on each tooth, ranging from a low of 2.9 
TABLE 27

HYPERCEMENTOSIS PER TOOTH IN THE SKELETAL SAMPLE

\begin{tabular}{|l|c|c|c|}
\hline Tooth Type & \# Observed & \# Affected & Percent \\
\hline Maxillary & & & \\
$\mathrm{M}^{3}$ & 22 & 4 & 18.2 \\
$\mathrm{M}^{2}$ & 18 & 3 & 16.7 \\
$\mathrm{M}^{1}$ & 14 & 3 & 21.4 \\
$\mathrm{P}^{4}$ & 11 & 2 & 18.2 \\
$\mathrm{P}^{3}$ & 11 & 2 & 18.2 \\
$\mathrm{C}^{-}$ & 19 & 2 & 10.5 \\
$\mathrm{I}^{2}$ & 14 & 0 & - \\
$\mathrm{I}^{1}$ & 18 & 1 & 5.6 \\
\hline $\mathrm{Mandibular}^{2}$ & & & \\
$\mathrm{M}_{3}$ & 8 & 1 & 12.5 \\
$\mathrm{M}_{2}$ & 6 & 1 & 16.7 \\
$\mathrm{M}_{1}$ & 4 & 0 & - \\
$\mathrm{P}_{4}$ & 11 & 1 & 9.1 \\
$\mathrm{P}_{3}$ & 15 & 1 & 6.7 \\
$\mathrm{C}_{.}$ & 22 & 1 & 4.5 \\
$\mathrm{I}_{2}$ & 20 & 0 & - \\
$\mathrm{I}_{1}$ & 19 & 1 & 5.3 \\
\hline
\end{tabular}

\begin{tabular}{|l|rr|rr|}
\hline \multicolumn{5}{|c|}{ TABLE 28 } \\
PERCENT OF HYPERCEMENTOSIS \\
PER TOOTH TYPE IN THE \\
SKELETAL SAMPLE \\
\hline \multirow{4}{*}{ Tooth Type } & \multicolumn{2}{|c|}{ Maxillary } & \multicolumn{2}{c|}{ Mandibular } \\
\cline { 2 - 5 } & $\#$ & $\%$ & $\#$ & $\%$ \\
\hline Incisors & 32 & 3.1 & 39 & 2.6 \\
Canine & 19 & 10.5 & 22 & 4.5 \\
Premolars & 22 & 18.2 & 26 & 7.7 \\
Molars & 54 & 18.5 & 18 & 11.1 \\
\hline \# = number of observable teeth. \\
\hline
\end{tabular}

percent for the lower fourth premolar, to a high of 57.7 percent for the upper third molars. When examined by tooth type and dental arcade, teeth of the maxillary dental arcade tended to show a higher caries frequency (Table 32). As expected given their larger occlusal surface and more-complex cusp structure, molars had the highest frequency of caries. Interestingly, when the caries rates of the Confederate veterans from this cemetery are compared to those of the Civil War battle- field casualties described by Sledzik and MooreJansen (1991:Table 2), some tooth types have similar caries frequencies, in spite of the large difference in average age at death. This is especially true of maxillary premolars and mandibular canines (see Table 32). However, significant rate differences were seen in the other tooth categories, especially lower premolars.

The frequency of varying caries types/locations is displayed by tooth in Table 33. The majority of caries ( 30.5 percent) were located on the mesial and distal cervical margins, while 25.5 percent were located on the interproximal margins of the crown. An almost equal percentage of caries occurred on the occlusal and smooth surfaces of the tooth. The lower frequencies of caries on smooth surfaces are not unexpected because these surfaces are easier to keep clean than interproximal and cervical ones (Powell 1985:316). The lower frequency of occlusal caries may be the result of intentional cleaning of this surface, or food abrasion. Over 17 percent of the documented caries were gross, preventing the exact location of the beginning lesion prior to the extreme destruction of the crown.

Of all of the carious teeth observed in these individuals, few examples of dental fillings were observed. Only five individuals (12.2 percent of the analyzed individuals with teeth; 10 percent of the males) yielded evidence of maxillary and mandibular fillings (one each in Burials 9, 12, 31, 48, and 56). All of the people bearing fillings were male with the exception of one female. Three of the fillings were tin, while the remaining two were gold. The gold filling observed in Burial 48 (Emma Kyser) was especially unusual because it was placed into the left central incisor in a set of maxillary dentures. It is possible that this filling was drilled into the artificial tooth in an effort to emulate a filling that was present in the original tooth. All other fillings were observed on molars (three on the third molar and one on the first molar). During the Civil War period, in general, gold was the most frequently used filling material, but tin fillings were used when the caries was especially large (Dammann 1984:16). Sledzik and Moore-Jansen (1991:218) noted that of the military samples they examined (i.e., samples from the War of 1812, the Civil War, and the Indian Wars of the late 1800s), only the Civil War troops had fillings. They observed 4 individuals out of 49 with fillings 
TABLE 29

DEGREE OF CALCULUS PER TOOTH IN THE SKELETAL SAMPLE

\begin{tabular}{|c|c|c|c|c|c|c|c|c|}
\hline \multirow[b]{2}{*}{ Tooth Type } & \multirow[b]{2}{*}{$\mathrm{N}$} & \multicolumn{2}{|c|}{ Mild } & \multicolumn{2}{|c|}{ Moderate } & \multicolumn{2}{|c|}{ Severe } & \multirow{2}{*}{$\begin{array}{c}\text { Totals } \\
\%\end{array}$} \\
\hline & & $\#$ & $\%$ & \# & $\%$ & $\#$ & $\%$ & \\
\hline Maxillary & & & & & & & & \\
\hline $\mathrm{M}^{3}$ & 25 & 6 & 24.0 & 9 & 36.0 & 7 & 28.0 & 88.0 \\
\hline $\mathrm{M}^{2}$ & 23 & 2 & 8.7 & 6 & 26.1 & 11 & 47.8 & 82.6 \\
\hline $\mathrm{M}^{1}$ & 19 & 1 & 5.3 & 3 & 15.8 & 8 & 42.1 & 63.2 \\
\hline $\mathrm{P}^{4}$ & 30 & 8 & 26.7 & 6 & 20.0 & 5 & 16.7 & 63.3 \\
\hline $\mathrm{P}^{3}$ & 33 & 5 & 15.2 & 11 & 33.3 & 3 & 9.1 & 57.6 \\
\hline $\mathrm{C}^{-}$ & 41 & 4 & 9.8 & 13 & 31.7 & 4 & 9.8 & 51.2 \\
\hline $\mathrm{I}^{2}$ & 31 & 6 & 19.4 & 8 & 25.8 & 4 & 12.9 & 58.1 \\
\hline$I^{1}$ & 33 & 8 & 24.2 & 6 & 18.2 & 5 & 15.2 & 57.6 \\
\hline Mandibular & & & & & & & & \\
\hline $\mathrm{M}_{3}$ & 19 & 1 & 5.3 & 8 & $A 2.1$ & 8 & 42.1 & 89.5 \\
\hline $\mathrm{M}_{2}$ & 20 & 3 & 15.0 & 7 & 35.0 & 3 & 15.0 & 65.0 \\
\hline $\mathrm{M}_{1}$ & 15 & 3 & 20.0 & 3 & 20.0 & 3 & 20.0 & 60.0 \\
\hline $\mathrm{P}_{4}$ & 36 & 6 & 16.7 & 7 & 19.4 & 6 & 16.7 & 52.8 \\
\hline $\mathrm{P}_{3}$ & 49 & 9 & 18.4 & 8 & 16.3 & 9 & 18.4 & 53.1 \\
\hline C. & 55 & 11 & 20.0 & 18 & 32.7 & 11 & 20.0 & 72.7 \\
\hline $\mathrm{I}_{2}$ & 45 & 12 & 26.7 & 8 & 17.8 & 12 & 26.7 & 71.1 \\
\hline $\mathrm{I}_{1}$ & 33 & 10 & 30.3 & 5 & 15.2 & 6 & 18.2 & 63.6 \\
\hline
\end{tabular}

TABLE 30

PERCENT OF CALCULUS PER TOOTH TYPE IN THE SKELETAL SAMPLE

\begin{tabular}{|l|cc|cc|}
\hline \multirow{2}{*}{ Tooth Type } & \multicolumn{2}{|c|}{ Maxillary } & \multicolumn{2}{c|}{ Mandibular } \\
\cline { 2 - 5 } & $\#$ & $\%$ & $\#$ & $\%$ \\
\hline Incisors & 64 & 57.8 & 78 & 67.9 \\
Canine & 41 & 51.2 & 55 & 72.7 \\
Premolars & 63 & 60.3 & 85 & 52.9 \\
Molars & 67 & 79.1 & 54 & 72.2 \\
\hline \multirow{2}{*}{$\#=$ number of observable teeth. } \\
\hline
\end{tabular}

$(\mathrm{n}=6)$ comprising 8.2 percent of the Civil War samples. Their observations of filled teeth are very similar to those noted for the Confederate veterans studied here. The Weir family cemetery, containing the remains of an Anglo-American family interred in Manassas, Virginia, between the 1830 s and 1907, had a very high frequency of dental fillings (Little et al. 1992). Over 50 percent of the caries observed in that sample were filled with gold or gold and an amalgam (Little et al. 1992: 407). Because of the way the data are presented, it is not clear how many individuals had carious teeth that had been filled.

\section{Abscesses}

Abscesses result from caries or extreme dental wear and occur when the pulp chamber becomes exposed and infected. Abscesses are typically classified into two types based on their location; examples ioccurring at the root of the tooth are called periapical, or apical, abscesses, while those occurring at the cervical margin of the tooth are referred to as alveolar, periodontal, or cervical abscesses. These types of abscesses may occur on either the buccal or the lingual surface of the alveolus, although all but one of the examples in the sample were on the buccal surface. Care was taken to code only those openings in the alveolus that showed smooth remodeling of the defect. Defects with jagged edges were assumed to be taphonomic in nature and were not coded.

Fourteen of the 50 males (28 percent; no abscesses were observed on the females) with observable alveoli had at least one dental abscess, yielding a total of 19 observable abscesses (Appen$\operatorname{dix} \mathrm{G})$. Of these, 11 were apical and 8 were alveolar. Abscess frequency per tooth is displayed in Table 34, and frequency per tooth type is displayed in Table 35. The tooth with the highest abscess occurrence was the maxillary canine at 3.7 percent; the maxillary first molar and the mandibular fourth premolar both had no examples (see Table 34). When the data were examined by tooth type, canines had the most frequent occurrences of abscesses, and maxillary teeth, in general, showed slightly higher rates of abscessing than did mandibular ones (see Table 35). Overall, abscess rates were very low, which is surprising given the 
TABLE 31

FREQUENCIES OF CARIES PER TOOTH IN THE SKELETAL SAMPLE

\begin{tabular}{|l|c|r|r|}
\hline Tooth Type & \# Observed & \# Affected & Percent \\
\hline Maxillary & & & \\
$\mathrm{M}^{3}$ & 26 & 15 & 57.7 \\
$\mathrm{M}^{2}$ & 24 & 5 & 20.8 \\
$\mathrm{M}^{1}$ & 19 & 7 & 36.8 \\
$\mathrm{P}^{4}$ & 29 & 6 & 20.7 \\
$\mathrm{P}^{3}$ & 34 & 9 & 26.5 \\
$\mathrm{C}^{-}$ & 41 & 8 & 19.5 \\
$\mathrm{I}^{2}$ & 33 & 8 & 24.2 \\
$\mathrm{I}^{1}$ & 33 & 8 & 24.2 \\
\hline $\mathrm{Mandibular}^{2}$ & & & \\
$\mathrm{M}_{3}$ & 15 & 4 & 26.7 \\
$\mathrm{M}_{2}$ & 21 & 9 & 42.9 \\
$\mathrm{M}_{1}$ & 15 & 4 & 26.7 \\
$\mathrm{P}_{4}$ & 34 & 1 & 2.9 \\
$\mathrm{P}_{3}$ & 50 & 6 & 12.0 \\
$\mathrm{C}_{\text {. }}$ & 57 & 14 & 24.6 \\
$\mathrm{I}_{2}$ & 46 & 10 & 21.7 \\
$\mathrm{I}_{1}$ & 34 & 7 & 20.6 \\
\hline
\end{tabular}

average age of the individuals in this sample and the high rates of caries. The low abscess rate may be suggestive of dental maintenance in terms of tooth extractions prior to pulp exposure. Also, many abscessed teeth may have been lost long before death occurred and remodeled to the point that no visible signs of the abscess were left at the time of the person's death.

\section{Interproximal Grooves}

Only five people (Burials 9, 12, 32, 43, and 45) showed interproximal grooving on teeth. This grooving is usually associated with the practice of frequent probing between the teeth with a small instrument, and is often practiced as a mechanism to reduce the pain of adjacent caries. Four of these individuals had grooves on the third or fourth lower premolar and two had grooves on both the upper second and third molars. One individual had seven teeth that exhibited interproximal grooving: right lower second molar, left and right lower third molars, lower third premolar, right second and third upper molars, and left upper third molar. Each tooth exhibiting grooving was associated with another carious tooth, with the exception of one

\begin{tabular}{|l|c|c|c|}
\hline \multicolumn{4}{|c|}{ TABLE 32} \\
COMPARISON OF PERCENTAGES OF CARIES \\
PER TOOTH TYPE IN THE TEXAS STATE \\
CEMETERY AND CIVIL WAR \\
SKELETAL SAMPLES \\
\hline Tooth Type & Pooled & Males Only & Civil War* \\
\hline Maxillary & & & 10.5 \\
Incisors & 24.2 & 24.2 & 7.4 \\
Canine & 19.5 & 20.0 & 18.4 \\
Premolars & 23.8 & 25.0 & 27.4 \\
Molars & 39.3 & 38.8 & - \\
\hline Mandibular & \multicolumn{3}{|c|}{28.6} \\
Incisors & 21.3 & 22.4 & - \\
Canine & 24.6 & 25.5 & 43.3 \\
Premolars & 8.3 & 8.8 & 34.7 \\
Molars & 33.3 & $;$ & \\
\hline *Data taken from Sledzik and Moore-Jansen \\
(1991:Table 2).
\end{tabular}

tooth in which the neighboring tooth was not present and one case in which the tooth was present but no caries were observed.

\section{Linear Enamel Hypoplasia}

Linear enamel hypoplasias (LEH) are horizontal areas of deficient enamel that can be observed on the crown of a tooth. Many other types of enamel hypoplasias can occur, but only linear examples were recorded in this sample. LEH are general, nonspecific indicators of stresses that occur during childhood (from 5 months in utero until 7 years and from approximately 10 to 16 years) as tooth enamel is being formed (Goodman et al. 1984:25-27; Skinner and Goodman 1992: 163). Any sort of stressor (nutritional, infectious, traumatic, psychological, etc) can result in LEH development if it results in a disruption of the normal growth process. Due to time constraints, only the presence or absence of LEH and the number of occurrences per tooth were noted. It was not possible to measure the distance of each hypoplastic defect from the cemento-enamel junction.

Ten (all males) of the 40 individuals with observable teeth ( 25 percent) had at least one tooth with LEH (Appendix G). This frequency is significantly lower than the rate of 73 percent of indi- 


\begin{tabular}{|c|c|c|c|c|c|c|c|c|}
\hline \multirow[b]{3}{*}{ Tooth Type } & \multicolumn{7}{|c|}{$\begin{array}{l}\text { TABLE } 33 \\
\text { ES TYPES/LOCATIONS PER TOOTH } \\
\text { SKELETAL SAMPLE }\end{array}$} & \\
\hline & \multicolumn{8}{|c|}{ Caries Type/Location* } \\
\hline & 1 & 2 & 3 & 4 & 5 & 6 & 7 & 8 \\
\hline $\begin{array}{l}\text { Maxillary } \\
\mathrm{M}^{3} \\
\mathrm{M}^{2} \\
\mathrm{M}^{1} \\
\mathrm{P}^{4} \\
\mathrm{P}^{3} \\
\mathrm{C}^{-} \\
\mathrm{I}^{2} \\
\mathrm{I}^{1}\end{array}$ & $\begin{array}{l}6 \\
- \\
2 \\
- \\
1 \\
- \\
- \\
-\end{array}$ & $\begin{array}{l}- \\
1 \\
3 \\
- \\
1 \\
1 \\
2 \\
1\end{array}$ & $\begin{array}{l}2 \\
- \\
- \\
5 \\
- \\
- \\
2 \\
4\end{array}$ & $\begin{array}{l}4 \\
- \\
- \\
- \\
- \\
2 \\
- \\
1\end{array}$ & $\begin{array}{l}3 \\
1 \\
- \\
- \\
- \\
- \\
- \\
1\end{array}$ & $\begin{array}{l}4 \\
2 \\
2 \\
- \\
2 \\
2 \\
- \\
1\end{array}$ & $\begin{array}{l}1 \\
- \\
- \\
1 \\
2 \\
1 \\
3 \\
-\end{array}$ & $\begin{array}{l}1 \\
1 \\
- \\
- \\
4 \\
4 \\
3 \\
1\end{array}$ \\
\hline $\begin{array}{l}\text { Mandibular } \\
\mathrm{M}_{3} \\
\mathrm{M}_{2} \\
\mathrm{M}_{1} \\
\mathrm{P}_{4} \\
\mathrm{P}_{3} \\
\mathrm{C}_{.} \\
\mathrm{I}_{2} \\
\mathrm{I}_{1}\end{array}$ & $\begin{array}{c}2 \\
3 \\
2 \\
- \\
1 \\
- \\
1 \\
-\end{array}$ & $\begin{array}{l}1 \\
- \\
- \\
1 \\
- \\
1 \\
2 \\
2\end{array}$ & $\begin{array}{l}\overline{1} \\
\overline{1} \\
2 \\
\overline{2} \\
1 \\
1\end{array}$ & $\begin{array}{l}1 \\
1 \\
- \\
- \\
1 \\
3 \\
- \\
-\end{array}$ & $\begin{array}{l}- \\
1 \\
- \\
- \\
- \\
- \\
- \\
-\end{array}$ & $\begin{array}{l}- \\
2 \\
- \\
- \\
1 \\
4 \\
4 \\
2\end{array}$ & $\begin{array}{l}- \\
1 \\
1 \\
- \\
2 \\
1 \\
3 \\
1\end{array}$ & $\begin{array}{l}- \\
2 \\
1 \\
- \\
2 \\
3 \\
1 \\
2\end{array}$ \\
\hline Totals: & 18 & 16 & 20 & 13 & 6 & 26 & 17 & 25 \\
\hline Percents: & 12.8 & & & & & & & 17.7 \\
\hline
\end{tabular}

viduals with LEH at the Monroe County institutional cemetery (Lanphear 1988:Table 43). Fiftysix percent of the adults analyzed from 41DT105, a rural cemetery in Texas dating to the mid to late 1800s, had at least one LEH (Rose 1992:143). Seven people from the State Cemetery had three or fewer teeth per arcade with hypoplasias, while three people had six or higher. The number of hypoplasias per tooth is shown in Table 36 . No LEH were observed on the maxillary premolars and molars. Most hypoplastic events noted on the anterior maxillary teeth were single or double occurrences; only two teeth had three or more episodes (see Table 36). All mandibular tooth types, with the exception of the first and second molars, evidenced at least one LEH. Only the canine and lateral incisor exhibited three or more episodes. The overall frequency of observed hypoplasia per tooth ranged from a low of 2 percent (mandibular third premolar) to a high of 21.4 percent of the upper central incisors. When viewed by tooth type, approximately 17 percent of the observed maxillary incisors and canines had at least one hypoplasia (Table 37). Mandibular incisors and canines also had much higher rates of LEH than did the premolars and molars.

\section{Congenitally Missing Teeth}

The congenital absence of teeth was noted on only two individuals. The lateral maxillary incisors and the maxillary third molars were missing from Burial 13. In addition, the mandibular third molars were congenitally absent from Burial 23 . Hypodontia tends to be most common in third molars followed in frequency by the lateral maxillary incisors (Ortner and Putschar 1985:446, 450), as observed here. 


\begin{tabular}{|l|c|c|c|}
\hline \multicolumn{5}{|c|}{ TABLE 34 } \\
\hline \multicolumn{4}{|c|}{ FREQUENCY OF DENTAL ABSCESSES } \\
IN THE SKELETAL SAMPLE \\
\hline Tooth Type & \# Observed & \# Affected & Percent \\
\hline Maxillary & & & \\
$\mathrm{M}^{3}$ & 48 & 1 & 2.1 \\
$\mathrm{M}^{2}$ & 49 & 1 & 2.0 \\
$\mathrm{M}^{1}$ & 60 & - & - \\
$\mathrm{P}^{4}$ & 70 & 1 & 1.4 \\
$\mathrm{P}^{3}$ & 80 & 2 & 2.5 \\
$\mathrm{C}^{-}$ & 81 & 3 & 3.7 \\
$\mathrm{I}^{2}$ & 80 & 1 & 1.3 \\
$\mathrm{I}^{1}$ & 80 & 1 & 1.3 \\
\hline $\mathrm{Mandibular}^{1}$ & & & \\
$\mathrm{M}_{3}$ & 94 & 1 & 1.1 \\
$\mathrm{M}_{2}$ & 102 & 1 & 1.0 \\
$\mathrm{M}_{1}$ & 105 & 2 & 1.9 \\
$\mathrm{P}_{4}$ & 106 & - & - \\
$\mathrm{P}_{3}$ & 103 & 1 & 1.0 \\
$\mathrm{C}_{.}$ & 104 & 2 & 1.9 \\
$\mathrm{I}_{2}$ & 104 & 1 & 1.0 \\
$\mathrm{I}_{1}$ & 100 & 1 & 1.0 \\
\hline
\end{tabular}

\begin{tabular}{|l|rc|cc|}
\hline \multicolumn{5}{|c|}{ TABLE 35 } \\
PERCENT OF DENTAL ABSCESSES \\
PER TOOTH TYPE IN THE \\
SKELETAL SAMPLE \\
\hline \multirow{4}{*}{ Tooth Type } & $\#$ & $\%$ & $\#$ & $\%$ \\
\cline { 2 - 5 } & Maxillary & Mandibular \\
\hline Incisors & 160 & 1.3 & 204 & 1.0 \\
Canine & 81 & 3.7 & 104 & 1.9 \\
Premolars & 150 & 2.0 & 209 & 0.5 \\
Molars & 157 & 1.3 & 301 & 1.3 \\
\hline \# = number of observable teeth. \\
\hline
\end{tabular}

\section{Tooth Fractures}

Fracturing of the teeth was noted on five individuals, all males (Burials 12, 14, 27, 33, and 34 ), and was identified based on the smooth appearance of the fractured area. Ortner and Putschar (1985:452) noted that in modern samples tooth fractures frequently result from car accidents, sports injuries, or child's play. Given the nature of this sample, the possibilities of tooth fracturing due to combat should be considered. Pindborg (1970:277, in Ortner and Putschar 1985:452) noted that the upper central incisors are the most commonly fractured teeth. This was not the case in this sample, as all fractured teeth were posterior ones. The third molar was involved in three cases and the second molar in one. In addition, a left fourth premolar was fractured. The third molars were all fractured at the crown; the second molar was fractured at the mesial portion of the root. The entire crown of the left fourth premolar of Burial 33 (Mr. Stanley) was broken off at the root. This is particularly interesting given that a common dental practice of the day involved breaking a carious crown off and leaving the root(s) (Dammann 1984:15).

\section{Skeletal Disorders}

Degenerative joint disorders, infections, trauma, metabolic/hematological disorders, and neoplasms noted on the skeletal remains are described in this section. Disorders are discussed in terms of frequency for the male, female, and pooled samples. Skeletal disorder data are presented in Appendix G.

\section{Degenerative Joint Disease}

Degenerative joint disease (DJD) is the most common disorder to affect the articular surfaces of bone (Ortner and Putschar 1985:419). All available joint surfaces were examined for signs of lipping, porosity, eburnation, or new bone deposition on the joint surface. The occurrence of DJD was extremely high, as would be expected with any sample composed of people of such advanced years. Every individual in the sample exhibited appendicular and/or axial degenerative changes.

With the exception of three individuals (Burials 9, 20, and 30), everyone showed appendicular arthritic changes. The most frequent occurrences were observed in the knees, shoulders, and hands, followed by the hips, elbows, and feet (Table 38). The ankle and articulations of the claviclès were observed least frequently. Heine (1926, as cited in Ortner and Putschar 1985), in a sample composed of modern autopsied individuals, noted that DJD affected the knee most frequently (39.4 percent of 90 year olds examined), followed by the big toe, hip, shoulder, elbow, and then the clavicular facets. 


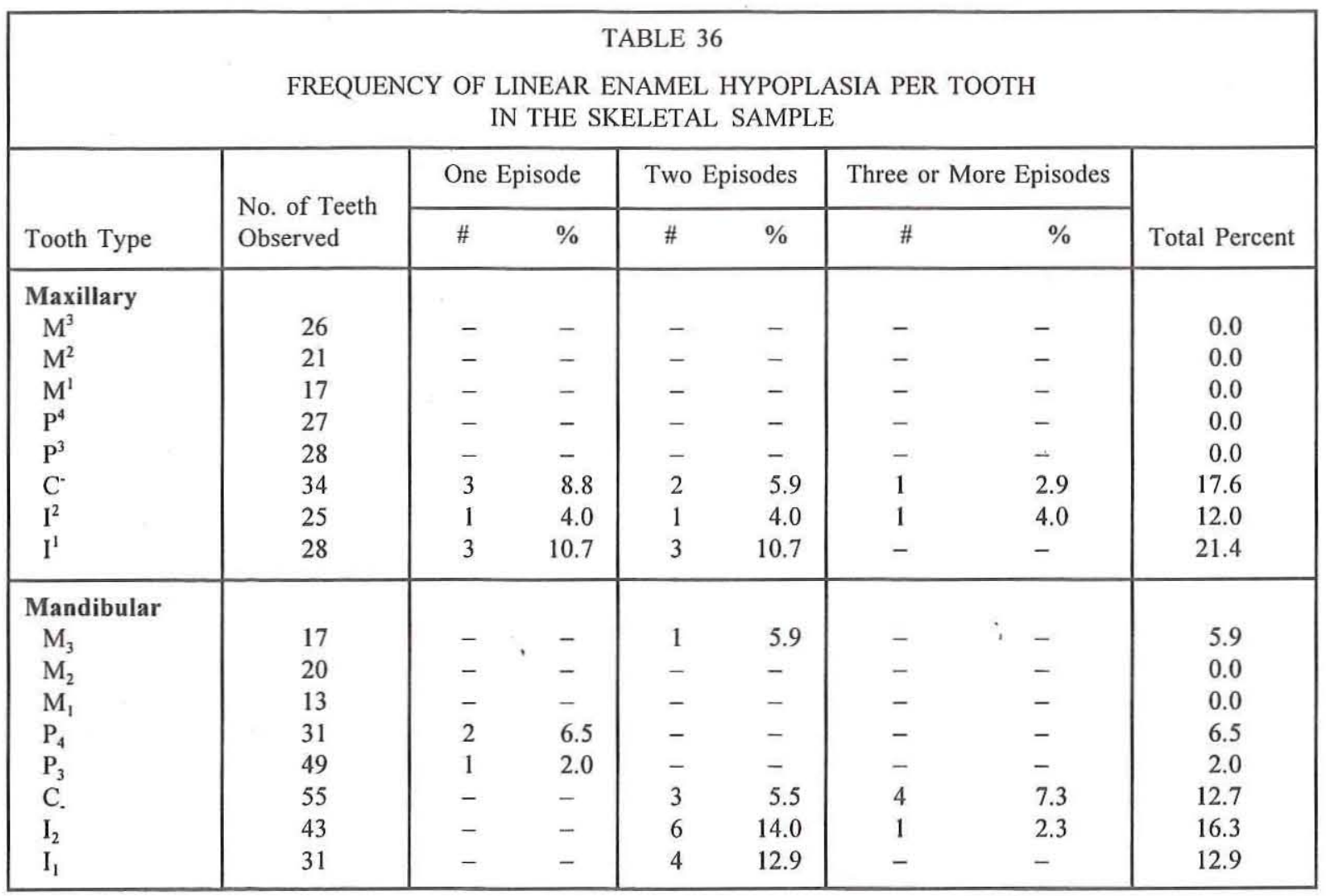

TABLE 37

PERCENT OF LINEAR ENAMEL HYPOPLASIAS PER TOOTH TYPE IN THE SKELETAL SAMPLE

\begin{tabular}{|l|cr|rr|}
\hline \multirow{2}{*}{ Tooth Type } & \multicolumn{2}{|c|}{ Maxillary } & \multicolumn{2}{c|}{ Mandibular } \\
\cline { 2 - 5 } & $\#$ & $\%$ & $\#$ & $\%$ \\
\hline Incisors & 53 & 17.0 & 74 & 14.9 \\
Canine & 34 & 17.6 & 55 & 16.3 \\
Premolars & 55 & 0.0 & 80 & 3.8 \\
Molars & 64 & 0.0 & 50 & 2.0 \\
\hline \# = number of observable teeth. \\
\hline
\end{tabular}

The frequencies that Heine noted are significantly lower than those observed in the cemetery sample, with the exception of the acromio-clavicular joint. In addition, the order of involvement of the foot, hip, and shoulder differs. The extremely high rates of arthritis noted in the State Cemetery sample may result in part from the fact that most of these men had occupations that involved hard physical labor (such as farmer, rancher, blacksmith, etc., see Table 3).

Of the examples of degenerative arthritis observed, only a few cases could be definitively associated with a traumatic event (see Table 38 ). Eighteen percent of degenerative changes to the wrist were the result of fractures or wounds. Less than 10 percent of the arthritic changes in the shoulder were the result of injuries to the arms. Changes to the joints of hands and elbows resulted from trauma in less than 7 percent of the individuals. Like the wrist, almost 18 percent of arthritic signs observed in the hip could be traced to some wound to the leg, as could 9 percent of changes to the knee region. Only one case ( 9 percent) of an injury to the ankle seemed to have either initiated or exacerbated degeneration of that joint. Joint fusion relating to appendicular arthritis also was rare, as it was observed in only two of the analyzed individuals. Burial 35 (Mr. Bowdoin) had a ankylosed proximal radius and ulna, which had fused to the distal end of the humerus. This fusion almost definitely is related to a wound to his arm noted in his Confederate Home roster, with 
TABLE 38

DEGENERATIVE JOINT DISORDER OF THE APPENDICULAR SKELETON IN THE SAMPLE

\begin{tabular}{|c|c|c|c|c|c|}
\hline \multirow[b]{2}{*}{ Joint } & \multirow[b]{2}{*}{ Burial Numbers } & \multicolumn{2}{|c|}{ Affected Individuals } & \multicolumn{2}{|c|}{ Trauma Related } \\
\hline & & \# & $\%$ & \# & $\%$ \\
\hline Shoulder & $\begin{array}{l}2,3,4,5,10,11,14,15,18^{*}, 21,25,26,27,28 \\
32,35^{*}, 36,38,39,41,44,45,46,47,50^{*}, 51 \\
52,53,54,55,56\end{array}$ & 28 & 55.36 & 3 & 9.68 \\
\hline Wrist & $\begin{array}{l}1,2,3,5,13,15^{*}, 18^{*}, 19,22^{*}, 24,26,29,31 \\
35^{*}, 37,38,39,40,41,42,43,44,45,46,47 \\
49,50^{*}, 51^{*}, 52,53,54,55,56\end{array}$ & 27 & 53.93 & 6 & 18.18 \\
\hline Hands & $\begin{array}{l}3,4,5,6,8,10,11,12,13,14,15,22,23,25 \\
27,28,38,39,40,41,42,43,44,45,46,48,49 \\
50^{*}, 51^{*}, 53,55,56\end{array}$ & 30 & 57.14 & 2 & 6.25 \\
\hline Elbow & $\begin{array}{l}4,6,7,8,13,15,19,21,27,29,34,35^{*}, 38,40 \\
42,43,44,47,49,52,53,54\end{array}$ & 21 & 39.29 & 1 & 4.55 \\
\hline $\begin{array}{l}\text { Acromio- } \\
\text { clavicular }\end{array}$ & $13,15,17,35,39,52,56$ & 7 & 12.5 & - & - \\
\hline Sternoclavicular & $\begin{array}{l}2,4,13,15,17,23,25,27,40,41,46,49,53 \text {, } \\
55\end{array}$ & 14 & 25.0 & - & -- \\
\hline Hip & $\begin{array}{l}2,3^{*}, 4,12,14^{*}, 15,16,18^{*}, 21,26,27,28,36 \\
41,44,46,47,49,50^{*}, 52,53,55,56\end{array}$ & 19 & 41.07 & 4 & 17.39 \\
\hline Knee & $\begin{array}{l}1,3 *, 4,5,6,7,10,13,15,1718^{*}, 19,21,24^{*} \\
27,28,29,31,33,35,36,38,39,41,46,47,49 \\
51,52,53,54,55,56\end{array}$ & 30 & 58.93 & 3 & 9.09 \\
\hline Ankle & $2,18,22,23,31,38,39,42,43,44,50^{*}$ & 10 & 19.64 & 1 & 9.09 \\
\hline Feet & $\begin{array}{l}2,3,8,10,11,12,16,22,25,27,28,36,39,41, \\
42,43,45,49,51,56\end{array}$ & 20 & 35.71 & - & - \\
\hline
\end{tabular}

arthritic changes incidental to the injury. Several left carpals (scaphoid, trapezium, and trapezoid) of Burial 51 had fused together as well, which may be related to a fracture of the distal end of the left radius.

Degenerative changes in the axial skeleton were observed in the skull and vertebral column. Changes in the skull were limited to one person with lipping of the occipital condyles and lipping and porosity of the temporomandibular joint noted on the mandibular condyles and/or glenoid fossa of 46 percent $(n=26)$ of the individuals analyzed. Three of the females were affected by temporo- mandibular joint disorder (TMJ), as were 23 of the males. Changes in this joint appeared to be the result of "wear and tear" rather than trauma related. Individuals over the age of 40 years typically show changes in this joint, first in terms of disintegrating cartilage, followed by skeletal manifestations (Alexandersen 1967:586). That the rate of TMJ was so high is not unexpected, given that the average age at death for people composing this sample was 77.3 years. The average age at death for individuals exhibiting TMJ was 75.9 years. In comparison, five older adults (71-98 years old) were recovered from the Harvie family 
cemetery. Of these, four ( 80 percent) evidenced temporomandibular degeneration (Keenleyside and Clark-Wilson 1991:34). The higher percentage of individuals with TMJ at the Harvie cemetery is probably a reflection of the reduced sample size rather than increased stress to the joint.

Vertebral osteoarthritis, represented by marginal lipping, porosity, and osteophytosis, was observed on the apophyseal and/or amphiarthrodial joints of all but five individuals (Burials 20, 24, 29, 45 and 50; Appendix G). Preservation was so poor that only a few vertebrae could be recovered from Burials 24, 45, and 50. Osteophytosis of the vertebral bodies was observed on 51.8 percent $(\mathrm{n}=29)$ of the examined individuals (5 females and 24 males; Appendix G). In some cases, the osteophytes were severe enough to bridge the centra (spinal osteophytosis). Bridging osteophytes were observed in 10 of the males, but no females were affected. In most cases, the osteophytes formed over the intervertebral disk space, which was still intact. However, a few instances were observed in which degeneration had progressed to the stage in which the disk was completely destroyed and the centra ankylosed. The lower thoracic vertebrae were affected most frequently, followed by the cervical vertebrae and then the lumbar. Seven men had four or fewer vertebrae fused together; the remaining men had six or more fused vertebrae. In addition to having vertebrae fused at the centra, four of the Confederate veterans (Burials 36, 49, 53, and 56) exhibited severe degenerative joint disease of the associated apophyseal joints, resulting in ankylosis.

Burial 47 (George Kyser) exhibited fusion of the vertebral bodies of T3-T10, in addition to fusion of the sacrum to the ilia (Figure 45). Because ankylosing spondylitis usually begins with bilateral fusion of the sacrum to the os coxae and is "practically pathognomic" of the disorder (Steinbock 1976:296, 298), this was initially suspected. However, vertebral fusion was unilateral and did not affect the apophyseal joints, as often happens in ankylosing spondylitis. In addition, no other peripheral joints were affected. For all of these reasons, a diagnosis of ankylosing spondylitis was not considered. However, it is possible that Mr. Kyser suffered from diffuse idiopathic skeletal hyperostosis (DISH), which usually affects middle-aged and elderly males (Resnick 1995:1465). Diagnosis of this disorder requires flowing ossification along the anterolateral borders of a minimum of four contiguous vertebral bodies, preservation of the intervertebral space between the affected vertebrae, and absence of apophyseal joint fusion (Resnick 1995). In addition, Utsinger (1985) noted that ossification of the quadriceps tendon to the patella is another criterion of diagnosis. Sacroiliac fusion, with formation of bony bridges (as seen in Mr. Kyser), also has been associated with DISH. Rogers et al. (1985:118) noted that DISH can result in fusion of the upper third of the sacrum to the os coxae. Resnick (1995:1471) also noted that sacroiliac fusion tended to predominate in the upper area of the joint. In addition, DISH sometimes manifests as hyperostosis of the atlanto-occipital joint (Resnick 1995:1469). Mr. Kyser was the only analyzed individual who showed new bone deposition along the occipital condyles of his skull. Because Mr. Kyser met all of the criteria mentioned above, we believe that he suffered from DISH.

In addition to Mr. Kyser, Mr. Walker (Burial 49) also may have exhibited signs of DISH. Cervical vertebrae 4-6 were fused, as were three thoracic vertebrae. The cervicals were fused around the entire centra and at the apophyseal joints. Involvement of the cervical vertebrae is not unusual with DISH. In a study of 21 men with DISH, Resnick et al. (1975:517) noted that 16 showed cervical fusion, most frequently C4-C7. However, the apophyseal fusion of these vertebrae suggests an etiology other than DISH, especially since Utsinger (1985:329) considers it as a means to exclude the diagnosis of DISH. Mr. Walker's thoracic vertebrae were fused anteriolaterally, and the intervertebral spaces were not involved. In addition, both patellae exhibited ossification of the quadriceps tendon and the right tibial tuberosity exhibited hyperostosis along its superior margin, which also is suggestive of DISH (Resnick 1995: 1475; Utsinger 1985:338). Finally, both Mr. Walker and Mr. Kyser had projecting spines on the proximal surface of the tibiae, a trait typical of people affected by DISH (Resnick 1995:1475). Given all of these characteristics, it is likely that Mr. Walker suffered from DISH, and that the apophyseal fusion of his cervicals resulted from degenerative changes. If DISH is accepted as the diagnosis for the above two men, then 3.6 percent of the people analyzed yielded evidence of the disorder, which falls into the range of affected 
Figure 45. Fused thoracic vertebrae (T3-T10), Burial 47.

skeletons ( 2.0 to 3.7 percent) recorded by Rogers et al. (1985). In terms of symptoms, DISH is relatively benign, especially compared to vertebral disorders such as ankylosing spondylitis. The primary symptom is spinal stiffness that is most severe in the morning and evening, alleviating during the day. This stiffness is aggravated by physical inactivity, cold, and wet weather, and appendicular joint pain (especially of the heel, elbow, and knee) is not unusual (Utsinger 1985: 330,332 ).

Schmorl's nodes result from the herniation of the intervertebral disk and usually are caused by load-bearing stresses on the spinal column (Schmorl and Junghanns 1971:158-159). They most frequently affect thoracic and lumbar vertebrae and are common in people over the age of 40 years (Ortner and Putschar 1985:421). Given the age of people composing the State Cemetery sample and the fact that many of the men engaged in the hard labor of farming and ranching, it is surprising that only 32 percent $(n=18$, all male) of the analyzed individuals showed these lesions. Schmorl noted the existence of these nodes on 38 percent of the spines he examined (Schmorl and Junghanns 1971:164); unfortunately, the average age of individuals composing his sample is not known. The lower than expected frequency of Schmorl's nodes observed on the Confederate veterans is not likely to be the result of poor preservation of the vertebral column; viewing windows frequently resulted in extremely poor skeletal preservation, but this affected only a few individuals. The 18 men bearing lesions exhibited a total of 55 nodes. Of these, only 1 was cervical, 44 were thoracic, and 10 were lumbar. The major- ity of the examples could not be identified to the specific vertebrae on which they occurred; however, at least one node was identified on each thoracic vertebra from $\mathrm{T} 5$ through T12, and on lumbar 1 .

In some cases, arthritis of the apophyseal joints was severe enough to result in eburnation. The vast majority of vertebral eburnation was noted at the dens articulation of the axis and atlas vertebrae. At least nine people showed large eburnated areas at those points of articulation. Only one person (Burial 51, Margaret Pannell) evidenced eburnation and associated grooves on the lumbar vertebrae (L4 and L5). In addition, the inferior and superior articular surfaces of T3, T4, T5, and two indeterminate thoracics were eburnated.

In general, arthritis rates for this sample were quite high. However, several of the analyzed men were notable for their very mild cases of arthritis (Burials 9, 17, 20, 30, 32, 37, and 40). These men ranged in age from 68 to 80 years. Three of the men had been employed in jobs that would not be expected to produce a lot of stress to the joints; one was a physician, one was a clerk, and one was an attorney. However, the remaining four were employed in jobs that required great physical labor; two were farmers, one was a stockman, and one was a blacksmith. That these men would show so little evidence of arthritis is surprising.

\section{Periostitis/Osteitis}

Periostitis (an inflammation of the periosteum surrounding a bone) and osteitis (inflammation of the bone) are frequently used as general indicators of stress. These reactions are commonly the result of infections or trauma. Periosteal reactions were identified on the basis of plaques or striated areas of deposition occurring along a bone, while osteitis was identified based on abnormal swelling of a bone, with striations or plaques. Evidence for periostitis or osteitis was recognized in 32 of the 56 analyzed individuals (57.1 percent, Appendix G). Most individuals documented healed osteitis or periostitis, although 12 had lesions that were in an active state at the time of death (Table 39). The skull was the most frequent location of perios- 


\begin{tabular}{|l|l|l|l|l|}
\hline \multicolumn{5}{|c|}{ PERIOSTITIS/OSTEITIS IN THE SKELETAL SAMPLE* } \\
\hline & $\begin{array}{l}\text { Healed } \\
\text { Osteitis }\end{array}$ & $\begin{array}{l}\text { Healed } \\
\text { Periostitis }\end{array}$ & $\begin{array}{l}\text { Active } \\
\text { Osteitis }\end{array}$ & $\begin{array}{l}\text { Active } \\
\text { Periostitis }\end{array}$ \\
\hline Skull & 9,11 & $\begin{array}{l}27,28,29,31,33, \\
34,37,38,40,45,\end{array}$ & - & $\begin{array}{l}11,28,31,34, \\
35,39,40,41, \\
46,49,51,53,\end{array}$ \\
\hline Ribs & 39 & $38,40,56$ & - & - \\
\hline Hand & - & $20,21,37,39,42$, & - & - \\
\hline Phalanges & & $44,49,51,53,55$ & & \\
\hline Fumerus, left & - & 6 & - & - \\
\hline Femur, left & 12 & 8,24 & - & 8 \\
\hline Tibia, left & 3 & $3,8,55$ & - & 8 \\
\hline Tibia, right & 9,33 & $3,8,33$ & 33 & 8,33 \\
\hline Fibula, left & - & $8,16,18$ & - & 8 \\
\hline Fibula, right & 33 & 3,33 & 33 & 33 \\
\hline Foot, right & - & 33 & - & - \\
\hline *Numbers refer to Burials. & 8,33 & & \\
\hline
\end{tabular}

Porous lesions were noted on the petrosal portion of the temporals of seven individuals (only one of whom also had sinusitis). The lesions were all of an erosive nature and were located on the superior-posterior aspect of the petrosal, above the groove for the superior petrous sinus (Figure 46). It is believed that these lesions are indicative of ear infections (otitis media). Singer (1961, in McKenzie and Brothwell 1967:469) noted similar lesions on a Stone Age specimen, describing them as "an irregular large eroded area." Loveland et al. (1990:150) described an adult male with erosive changes on the medial surface of both temporals indicative of intracranial involvement that resulted from a chronic middle ear infection. Unfortunately, no photographs were published of this specimen so it is impossible to see how well it matches the examples from the State Cemetery.

titis due primarily to the occurrence of maxillary sinusitis and porous temporal lesions that are believed to be indicative of an ear infection.

Eight individuals (14.3 percent) bore evidence of sinusitis, in both active and healed conditions. One case of sinusitis was severe enough to obstruct one of the maxillary sinus chambers almost completely. In modern samples, bone reactions to sinusitis are rare and when they occur are the result of neglect of the disorder (Tovi et al. 1992: 426). These lesions develop when osteoblasts are stimulated by microorganisms such as Staphylococcus, Streptococcus, or Actinomyces (Tovi et al. 1992:428). Maxillary sinusitis may result from viral infections, such as the common cold, and recurring episodes of acute cases may lead to chronic sinusitis (Boocock et al. 1995:266-267). Other factors that might induce sinusitis include inadequate housing, overcrowding, malnutrition, pollutants, and overall poor health (Boocock et al. 1995:267).
Contemporary medical research also suggests that these erosive areas may be due to middle ear infections (see Goycoolea and Jung 1991; Meyerhoff et al. 1978). That almost 13 percent of the State Cemetery individuals showed skeletal evidence for ear infections seems rather high. However, Shambaugh and Girgis (1991:1343) noted that "acute otitis media . . . occupied the major and almost exclusive attention and concern of physicians in the otologic sphere until the advent of specific antimicrobial therapy in the mid1930s." Furthermore, the nature of the thin bone in that region "makes every infection of the middle ear capable of intracranial extension" (Shambaugh and Girgis 1991:1343). Prior to antibiotics, it is estimated that 2.3 percent of acute or chronic otitis media cases resulted in intracranial involvement (Goycoolea and Jung 1991:1382).

After the skull, lesions of the legs were most common, and the majority of these lesions were healed. Two individuals (Burials 8 and 33) had 
Figure 46. Erosive lesions perforating the temporal bone of Burial 35. Note the destruction of the petrosal portion and the squamous.

chronic long-term infections of the lower legs. Mr. Wyatt (Burial 8) had a dense periosteal reaction on the distal ends of his femora. Less remodeled bone deposition was visible on his tibiae and the left fibula. Mr. Stanley's (Burial 33) right tibia and fibula documented the only case of osteomyelitis identified on the excavated individuals. Several cloacae were observed on the distal end of the tibia and fibula. The bones, which were greatly expanded in size, were covered with poorly organized sclerotic and woven bone. The fibula and tibia had ankylosed at several locations along the shaft. In addition, the distal end of his right femur had a healed infection, and every element of his right foot had sclerotic depositions on the superior surfaces. Mr. Stanley's infection was entirely unilateral, and obviously of a chronic nature. Subsequent to the analysis, we located records which indicated that his leg had been wounded during the war and that his infection had persisted approximately 40 years. Mr. Stanley's cause of death was listed in the Confederate Home roster as blood poisoning.

Sclerotic lesions were noted on the proximal and medial hand phalanges of 10 people (17.9 percent) (see Table 39). These lesions, noted on both males and females, were always found on the dorsal surfaces of the phalanges and were small and tapered in shape. Although the etiology of these lesions is unknown, they may have resulted from some low-grade trauma to the fingers that caused the periosteum to separate in small areas from the surrounding bone. Interestingly, all of the men with evidence of these sclerotic areas had occupations that involved heavy manual labor (such as farmers, ranchers, blacksmith, and carpenter), except for one salesman. Yuen et al. (1992) suggested that the term "proliferative periosteal processes of phalanges" be applied to a number of different periosteal reactions observed on phalanges. Specifically, they stated, "Common to all of these lesions is an initial stimulus, often related to trauma, that leads to hemorrhagic subperiosteal proliferation which then matures. If the reaction remains contained within the periosteum, a localized fusiform periostitis develops in which the underlying cortex remains intact in the early stages" (Yuen et al. 1992:301). This description matches the lesions noted on the phalanges of the 10 individuals from the State Cemetery; therefore, they can be considered to represent proliferative periosteal processes.

\section{Trauma}

Fractures, dislocations, and wounds observed in the sample are discussed in this section (Appendix G). Twenty-three people (21 males and 2 females) bore evidence of fractures, both aligned and unaligned; 10 people had more than one fractured bone, 5 had two different fractures, and the other 5 had four to eight broken bones. Fractures occurred in all major bones of the body, but ribs were the most commonly broken with nine cases recorded among the 23 people (Table 40 ). It should be noted that this actually underestimates the number of broken ribs because each individual with rib fractures was counted as one case, even if a person had up to four broken ribs. Ulnae were the next most commonly recovered broken bone. All breaks occurred at the distal portion of the shaft (parry fractures), and two were associated with broken radii as well. Elements of the hands often were broken as was the clavicle. Four men had cranial depression fractures, two to the frontal 


\begin{tabular}{|l|c|r|r|}
\hline \multicolumn{4}{|c|}{ TABLE 40} \\
FREQUENCY OF BONE FRACTURES \\
IN THE SKELETAL SAMPLE \\
\hline Element & Number & Percent & Percent \\
& Affected & of Cases & Affected \\
\hline Skull & 4 & 9.1 & 7.1 \\
Nose & 2 & 4.5 & 3.6 \\
Clavicle & 4 & 9.1 & 7.1 \\
Humerus & 2 & 4.5 & 3.6 \\
Ulna & 6 & 13.6 & 10.7 \\
Radius & 3 & 6.8 & 5.4 \\
Ribs & 9 & 20.5 & 16.1 \\
Femur & 3 & 6.8 & 5.4 \\
Tibia & 2 & 4.5 & 3.6 \\
Fibula & 3 & 6.8 & 5.4 \\
Hands & 5 & 11.4 & 8.9 \\
Feet & 1 & 2.3 & 1.8 \\
\hline
\end{tabular}

and two to the parietal bones. The nasals were broken in two other men.

Several individuals were notable for the number of fractures recorded on their skeletal remains. Burial 20 (Jarred Cromer) had a broken left clavicle, right tibia and fibula, right second metatarsal, and three ribs. Although it is impossible to assign a specific cause to these breaks, it should be noted that he worked as a blacksmith and these particular breaks may be occupationally related. Burial 38 (J. H. Morgan) had eight broken bones: both nasal bones, both clavicles, and four ribs. These may have resulted from his work as a farmer; it is also possible to explain the broken nose and ribs through combative activities, although it is difficult to explain the breaks to both clavicles in this manner.

One woman (Burial 50, Josephine Walker) had six broken bones, all occurring on the right side of her body. Her humerus was broken at the head and severely displaced in a posterior direction. Both the radius and ulna were displaced posteriorly at the distal ends, and the right fifth metacarpal was fractured at the midshaft. Mrs. Walker's right femoral head was disarticulated at the shaft above the lesser trochanter, and one right rib was broken near the vertebral end. It was not possible to determine if all of these breaks occurred at the same time, although it is tempting to surmise that the broken arm bones were all part of the same event because they were all displaced in the same direction. Mrs. Walker's bones did not seem to be lighter or more fragile than bones from other individuals, suggesting that osteoporosis was not a factor in the fractures. However, Seeley et al. (1991:842) noted, “. . . most fractures in elderly white women, including those of the wrist, foot, humerus, hip (perhaps only in the intertrochanteric region), rib, toe, leg, pelvis, hand, clavicle, and vertebral body, are significantly related to reduced appendicular bone mass ( $\mathrm{P}<.05$ for all values)" (emphasis added). Therefore, Mrs. Walker may have suffered from a reduction in bone mass, but this decrease was not apparent macroscopically.

Because Mrs. Walker's cause of death was listed as pulmonary tuberculosis, the possibility that the femoral head separation resulted from tuberculosis must be considered. Second to vertebrae, the hip is the most common area of skeletal involvement (Ortner and Putschar 1985:150). Most tuberculosis cases involving this region begin in childhood; although rare, it is possible to see onset even after the age of 50 years (Ortner and Putschar 1985:150). The femoral neck can be a focus of infection and may be destroyed. Destruction of the bone may be so extensive as to alter the shape of the acetabulum. Unfortunately, Mrs. Walker's pelvis was highly fragmented, making the identification of skeletal changes in that region impossible. Because the femoral head had separated above the lesser trochanter with no associated changes of the femoral head, it seems more likely that this destruction resulted from a process other than tuberculosis. Furthermore, no evidence of skeletal tuberculosis was noted on any other elements, although the vertebral column (the most likely area to be affected) was too fragmented to yield evidence of disorders.

Many of the fractures observed in this sample may have occurred as a direct result of combat and may date to wounds received during the Civil War. The depression fractures of the skulls are especially likely to have resulted from combat. The most unusual of these depressions, long and roughly oval in shape, may have resulted from a rifle butt blow to the top of the skull. In addition, the breaks to the distal ends of the ulnae observed in four of the men are typical of those that occur when a protective motion is made with the forearm (parry fractures). None of these fractures can be identified unequivocally as Civil War combat injuries, however.

Only four individuals, all men, bore evidence 
of dislocations. Burial 14 had a subluxation of the right hip that resulted in a large eburnated area and bone deposition. The first rib of Burial 36 was dislocated, and a probable dislocation of the left clavicle of Burial 40 was noted. Burial 46 evidenced an anterior dislocation of right metatarsals I and II with both bearing new articulating facets.

Five men bore skeletal evidence of trauma that could definitively be attributed to wounds, three of which were probably war related. Burial 3 (Joseph Watkins) suffered a projectile wound to the left tibia. It appears that a round metal projectile, possibly a musket ball, glanced off the anterior crest of his tibia in a lateral direction. On the other hand, the wound may have been created by a conoidal minié ball. These generally were .58caliber bullets fired from rifled muskets, which were ubiquitous throughout the war (Lewis 1959). When entering the body at full speed, these projectiles typically left smooth, round, bullet-sized holes where they passed through bone (Johnson 1917: 252). Whatever the projectile, Mr. Watkins's wound was recognized by a large, well-rounded, smooth-walled defect to the anterior crest. The proximal end of the tibia had extensive and wellhealed osteitis and periostitis. Pension records for Mr. Watkins make no note of this injury, however, and no records from the Confederate Home for Men were available for him.

Mr. Davenport (Burial 16) had a large defect on an unidentified rib that appears to have resulted from a shell fragment (or canister round) that pierced the bone near the sternal end (Figure 47). The rib is clearly separated at the area of the large, smooth-walled perforation, and the other portion of the rib articulates with it, although the portions are not fused. The projectile seems to have pierced the rib without disrupting the superior and inferior borders of the bone and left "claw-like" projections of bone surrounding the opening. This is not a lytic lesion, and no other areas similar to it were located on the remaining ribs.

The Confederate Home records for Henry Bowdoin (Burial 35) noted a wound to the arm and hand. Skeletally, the proximal ends of $\mathrm{Mr}$. Bowdoin's right radius and ulna were fused together and fused to the distal end of the humerus. This probably resulted from the wound referred to in historic documents. Some injury to the arm may have caused fractures to those bones, with subsequent fusion. In addition to the arm injury,
Figure 47. Result of wound to rib of Burial 16. The adjoining rib position is not illustrated.

analysis revealed that the proximal phalanges of the left third and fourth fingers were missing the distal articular surfaces and were tapered at the ends. The associated medial and distal phalanges were not recovered. If the injuries occurred at the same time, this pattern would suggest that $\mathrm{Mr}$. Bowdoin had his left hand on his right elbow at the time that he was injured.

The injuries noted on Burials 40 and 41 were the result of wounds, broadly defined, but one was definitely not war related and one is equivocal. D. R. Jacks (Burial 40) had a small piece of unidentifiable metal embedded in the posteriosuperior aspect of the left second metacarpal. This injury does not seem to have resulted from the war because, although bone growth was apparent, it was not extensive. Had the injury occurred during the war, bone growth would have surrounded and encased the embedded metal. William Shry (Burial 41) had a nonmedical amputation of one of his medial hand phalanges. The phalanx, which was fused to the proximal phalanx, had been severed just above the proximal articular surface and was tapered at the end. It is impossible to say whether this injury occurred before or after the Civil War, or if it was a battle-related injury.

\section{Metabolic/Hematological Disorders}

Porotic hyperostosis and cribra orbitalia are skeletal changes that are seen in individuals suffering from iron deficiency anemia. When a person is lacking iron, more red blood cells are produced, thus expanding marrow cavities. This expansion can be recognized by porous lesions occurring on the cranial vault. Increasing evidence suggests that those lesions visible on adult crania resulted from 
childhood bouts with anemia (Stuart-Macadam 1989:217). Only six people $(n=10.71$ percent, five males and one female) from the State Cemetery evidenced porotic hyperostosis, cribra orbitalia, or cranial thickening associated with expansion of the diploë (Appendix G). This suggests that most of the excavated individuals had adequate iron intakes and absorption as children.

In a sample as elderly as this one, it would be expected that the rates of osteoporosis should be high. However, only two individuals had dramatic bone loss suggestive of osteoporosis. One 75-yearold male (Burial 35) had light and porous bones, especially the sternum and ribs. A 90-year-old female (Burial 54) had extremely light long bones, as well as fragile and light os coxae. That these particular bones were affected fits the pattern expected with osteoporosis as bone loss usually occurs first in the vertebrae, sternum, ribs, and pelvis, followed by the long bones (Steinbock 1976:260). Because inactivity can increase the rate of osteoporosis (Steinbock 1976:260), perhaps many of the people in this sample continued to be physically active, even into their old age.

\section{Neoplasms}

Neoplasm refers to an abnormal formation of tissue (bone, in this case), and can be either benign or malignant. Eight people (14.3 percent, one female and seven males) had neoplastic growth (Appendix G). Button osteomas (small benign tumors) were noted on four individuals. They occurred on the medial surface of a tibia shaft, on the lateral alveolar margin of a maxilla, on the horizontal mandibular ramus below the central incisors, and on the inner surface of the mandible above the mylohyoid foramen.

Ossified subperiosteal hematomas were located on two individuals. One case, measuring $25 \times 7$ $\mathrm{mm}$, was observed on the distal end of a tibia (Burial 31), while the other example occurred on the lingual portion of a mandible near the third molar (Burial 17). Hematomas may result from trauma or from nutritional deficiencies of vitamin C (scurvy). Scurvy, which was common during the Civil War (Steiner 1968; Stuart-Macadam 1989:205), is difficult to assess in archeological samples. Wells (1964) felt that edentulous mandibles associated with subperiosteal hemorrhages provided adequate evidence for scurvy. The fact that both of the men with hematomas had relatively complete dental arcades with only moderate dental resorption (in spite of their ages -60 and 68 years old) certainly does nothing to support a diagnosis of scurvy. Also, only 10 percent of adults with scurvy develop subperiosteal hematomas (Stuart-Macadam 1989:203). However, the presence of a hematoma along the gum line is suspicious since this is a frequent location for hematomas in individuals suffering from scurvy (Stuart-Macadam 1989:203). Neither of the affected individuals showed a full suite of characteristics that could be considered diagnostic of scurvy, such as periosteal reaction and antemortem loss of anterior teeth (see Ortner and Putschar 1985; Stuart-Macadam 1989). Therefore, it is best to consider these subperiosteal hemorrhages of an unknown etiology but probably trauma induced.

Evidence of small cysts was observed in the carpals of two individuals. One right lunate (from Burial 9) had a small round, smooth-walled defect that extended into the cancellous portion of the bone. A left hamate recovered from Burial 18 had a similar lesion that was approximately $8 \mathrm{~mm}$ in size. These cysts may have been intraosseous ganglion cysts which, although rare, have been documented to affect both the lunate and the hamate (Fealy and Lineaweaver 1995:215). Intraosseous ganglion cysts are penetrating lesions that result in wrist pain (Fealy and Lineaweaver 1995). Differential diagnoses include osteoarthritic cysts, post-traumatic cysts, or simple bone cysts (see Tham and Ireland 1992:429).

The last neoplastic growth identified was very unusual. Both pubii of Burial 46 (Mr. Robinson), a 75-year-old man, had small spicular bone growths on the dorsal and ventral surfaces, but they were more numerous on the ventral surface (Figure 48). The new bone growth was both abundant and sturdy, and no evidence for other neoplasms was noted elsewhere on his skeleton. Pension and Confederate Home records offer no clues as to what may have caused this bone growth. It is possible that Mr. Robinson was affected by prostate cancer, which frequently is seen in older males. Prostate cancer metastasizes to bone frequently and shows osteoblastic, rather than osteolytic, lesions (Cumming et al. 1990:411; Dearnaley 1994:780; Grayhack and Grayhack 1992:2; Ortner and Putschar 1985:394). The majority of men affected by prostate cancer have 
Figure 48. Ventral surfaces of pubii from Burial 46 showing neoplastic growths on the anterior and posterior aspects.

bony metastases at the time of their death, and the pubis-ischium area shows metastases in 78 percent of modern cases documenting skeletal involvement (Karr 1992:24). Data suggest that prostate cancer is now the second most frequent type of cancer observed in American males, and the likelihood of getting prostate cancer increases with age (Karr 1992:17, 20). The incidence rate for males developing prostrate cancer, based on modern AngloAmericans in Mr. Robinson's age group, is 809.3 per 100,000 males compared to 24.1 for men aged 50-54 years (Karr 1992:Table 5). Autopsies of males have indicated that $30-50$ percent (this percentage increases with advanced age) of males who died of other causes had prostrate cancer at the time of the their death (Karr 1992:17). The osteoblastic nature of the lesions on Mr. Robinson's pubii, his sex, and his age support a diagnosis of prostate cancer. However, other reasons for this neoplastic growth cannot be discounted.

\section{Enthesophytes and Improper Ossification}

Enthesophytes are new bone formations at areas of tendinous and ligament attachments resulting from increased muscle size. They are usually associated with activity level and age (Mann and Murphy 1990). Twenty-two (39 percent, all males) of the sample had enthesophytes on the upper or lower body (Appendix G). Most cases were observed on the linea aspera of the femora, followed by the deltoid area of the humerus, the olecranon process of the ulna, and the patella (Table 41).

\begin{tabular}{|l|l|}
\hline \multicolumn{2}{|c|}{ TABLE 41 } \\
\multicolumn{2}{|c|}{ ENTHESOPHYTES AND IMPROPER } \\
OSSIFICATION IN THE \\
SKELETAL SAMPLE \\
\hline Condition/Localtion & Burial Numbers \\
\hline Enthesophytes & \\
Humerus & $5,8,25,30,39,42$ \\
Ulna & $10,12,21,29,36,39$ \\
Radius & $20,39,44$ \\
Hand & 23,41 \\
Rib & 36, \\
Femur & $6,8,10,14,20,33,39,43$ \\
Patella & $12,29,42,43,44,56$ \\
Tibia & $10,29,38,39,49$ \\
Fibula & 38,39 \\
\hline Improper & \\
Ossification & $10,39,47,49$, \\
Patella & 43 \\
Hand Phalange & 10 \\
Foot Phalange &
\end{tabular}

Any skeletal elements with tendons fused to them were placed into the improper ossification section. This was seen in only six men; four had quadriceps tendons that had ossified to the patella (see Table 41). Mann and Murphy (1990:120) noted that this condition is more common in people over the age of 60 years and may be indicative of diffuse idiopathic skeletal hyperostosis (DISH). Two of the individuals with ossified quadriceps tendons (Burials 47 and 49) are good candidates for DISH, as described above. The only otherimproper ossifications observed in the sample were seen in a medial hand phalanx and a proximal foot phalanx of two separate individuals (Burials 10 and 43; Figure 49). Both of these elements appeared to have a tendon fused to the lateral side of the length of the bone.

\section{Other}

Several other medical disorders that do not fit into the previous categories were noted. A cleft lip was observed on the maxilla of Burial 35 (Mr. 
Figure 49. Improper ossification of a toe phalanx from Burial 10.

Bowdoin). Cleft lip is a developmental defect which affects the soft tissue of the lip as well as the skeletal alveolar margin of the maxilla and can be unilateral or bilateral (Barnes 1994; Yetter 1992). Teeth adjacent to the cleft are usually missing or malformed. Frequency of occurrence ranges from 0.8 to 2.7 cases per 1,000 births, and the exact etiology is unknown (Yetter 1992:1214). In Mr. Bowdoin's case, the cleft lip affected the left maxilla from the region of the central incisor to the canine. The area was triangular in shape with rounded margins that angled superiorly towards the nasal cavity. In addition to being indented, the surrounding alveolar bone was thinner than that seen in cases of normal antemortem tooth loss. Agenesis of the teeth from the left central incisor to the left canine was noted.

Twenty-two (39.2 percent) individuals had ossified cartilage. Since this ossification is an agerelated phenomenon, this rate is not surprising. All ossification of cartilage that was seen came from the throat and rib area. Thyroid cartilage was the most frequently ossified material, followed by cartilage from the thoracic area. Fourteen individuals ranging in age from 60 through 89 years had ossified thyroid cartilage, and all were in Stage 9 ossification (very advanced) as described in Loth and Iscan (1989:122). One man had ossified cricoid cartilage, and five had unidentified ossified throat cartilage. Three men had ossified rib cartilage, and two had unidentified ossified objects in the vertebral area.

One lytic lesion of indeterminate etiology was observed on two ribs of Burial 4 (William Rogers). The defects are scalloped and perforated the bone. Three of his other ribs bore evidence of sclerotic lesions. Burial 44 (John Bowden) had a right hamate that was missing the hamulus. The surface which should have had the hamulus was covered by irregular sclerotic bone. The cause of this condition is unknown. His other hamate was normal.

A gallstone was found in the right pelvic area of Burial 33 (Mr. Stanley). This ossified object was approximately $2 \mathrm{~cm}$ in length and had many convolutions. The surface was billowy and granular, and the overall shape was disorganized. The gallstone was similar in appearance to some illustrated by Kalser (1985:Figure 189-1). Gallstone disease is a very common disorder and in many cases is asymptomatic. When symptoms are present they are usually manifested as upper abdominal pain occurring after meals and lasting from 1 to 24 hours (Diehl et al. 1990:29).

\section{COMPARISON OF WRITTEN RECORDS WITH SKELETAL EVIDENCE}

Death certificates and records kept by the surgeon at the Confederate Home for Men yielded cause of death information for 49 people in this sample. Table 42 provides cause of death for each of these individuals; however, the total number of individuals listed is greater than 49 because a few people had two causes of death listed. The most frequently known causes of death were la grippe (influenza), tuberculosis, and pneumonia (each occurring at a rate of 8.3 percent). This was followed by kidney problems and paralysis (both at 6.7 percent) and cirrhosis, heart problems, and stomach problems (5.0 percent each). All other listed causes of death affected only one or two people in the sample.

Several of the listed causes of death theoretically could leave skeletal evidence of their existence (i.e., tuberculosis, paralysis, cancer, and street car accident). However, very few of the documented causes of death could be established from changes to the skeletal remains. For instance, Burial 33 (Mr. Stanley) died of blood poisoning which is not unexpected given the active case of osteomyelitis affecting him when he died. However, Burial 22 (Mr. Kelly) also had blood poisoning as the listed cause of death, but no skeletal evidence suggestive of this was observed. Two men died of cancer, but the bone was not affected in either case. Of the five people who died of 


\begin{tabular}{|c|c|c|}
\hline \multicolumn{3}{|c|}{$\begin{array}{c}\text { PRIMARY CAUSE OF DEATH AS LISTED } \\
\text { IN THE } 1908 \text { SURGEON'S REPORT FOR } \\
\text { THE CONFEDERATE HOME AND ON } \\
\text { DEATH CERTIFICATES }{ }^{1}\end{array}$} \\
\hline Cause of Death & \# Individuals ${ }^{2}$ & $\%$ of Individuals \\
\hline $\begin{array}{l}\text { Blood poisoning } \\
\text { Cancer } \\
\text { Cardio-renal disease } \\
\text { Cirrhosis } \\
\text { Cystitis } \\
\text { Dengue } \\
\text { Effects from a fall } \\
\text { Epilepsy } \\
\text { Heart problems } \\
\text { Hemorrhage } \\
\text { Intoxication } \\
\text { Kidney problems }{ }^{3} \\
\text { La grippe (influenza) } \\
\text { Malaria } \\
\text { Paralysis } \\
\text { Pneumonia } \\
\text { Prostatitis } \\
\text { Sclerosis of the liver } \\
\text { Senility } \\
\text { Stomach problems } \\
\text { Street car accident } \\
\text { Stroke } \\
\text { Tuberculosis/Consumption } \\
\text { Unknown }\end{array}$ & $\begin{array}{l}2 \\
2 \\
1 \\
3 \\
1 \\
1 \\
2 \\
1 \\
3 \\
2 \\
1 \\
4 \\
5 \\
1 \\
4 \\
5 \\
1 \\
2 \\
2 \\
3 \\
1 \\
1 \\
5 \\
7 \\
\end{array}$ & $\begin{array}{r}3.3 \\
3.3 \\
1.7 \\
5.0 \\
1.7 \\
1.7 \\
3.3 \\
1.7 \\
5.0 \\
3.3 \\
1.7 \\
6.7 \\
8.3 \\
1.7 \\
6.7 \\
8.3 \\
1.7 \\
3.3 \\
3.3 \\
5.0 \\
1.7 \\
1.7 \\
8.3 \\
11.7 \\
\end{array}$ \\
\hline \multicolumn{3}{|c|}{$\begin{array}{l}\text { 'Surgeon's report is from a biennial report on the Texa } \\
\text { Confederate Home (1908) that spans the period from } \\
31 \text { August } 1906 \text { to } 31 \text { August } 1908 \text {. }\end{array}$} \\
\hline $\begin{array}{l}{ }^{2} \text { The total number of indivi } \\
\text { of people excavated becaus } \\
\text { listed. } \\
{ }^{3} \text { Includes nephrosis and Brig } \\
{ }^{4} \text { Includes paralysis agitans a } \\
{ }_{5}^{5} \text { Includes gastritis and stom }\end{array}$ & $\begin{array}{l}\text { sums to greater } \\
\text { me people had t } \\
\text { disease } \\
\text { emiplegia } \\
\text { alcers }\end{array}$ & $\begin{array}{l}\text { than the number } \\
\text { causes of death }\end{array}$ \\
\hline
\end{tabular}

involvement (Steinbock 1976:175). The rate of skeletal involvement for cancer is much higher, with nearly two-thirds of all cases metastasizing to the skeleton (Steinbock 1976:385). The fact that the two people who were known to have died of cancer failed to show skeletal involvement may be due to random statistical chance or to fast-acting carcinomas that resulted in death before the skeleton could be affected. Only one of the four people who died of paralysis showed any skeletal evidence of the disorder, suggesting that the others had late onset.

Thirteen of the excavated Confederate veterans had evidence of violent wounds. Of these, the wounds of five men were documented only in written records, and six were recognized only through the skeletal evidence. Only two men had wounds that were visible skeletally and confirmed in written pension or Confederate Home records. Burials 19, 22, 34,36 , and 44 all had wounds that were noted in written records, but were not observed on bone. Records for Burial 19 (Mr. Hogun) noted a gunshot wound but did not specify the location of the wound. Since it was not observed on the bone, it can be assumed that this was a soft-tissue wound. Pension records noted that Mr. Kelly (Burial 22) received a gunshot wound to a "muscular junction of the lower leg," but, as is suggested by the written statement, the injury was not visible osteologically. Pension records also noted that Mr. Moody tuberculosis, only four were analyzed and none showed skeletal involvement. Of these five, only one was so poorly preserved that the vertebrae (the most frequent locus for tubercular involvement of the skeleton) could not be examined. That the people who died of tuberculosis showed no skeletal involvement is not unusual since the majority of people with this disease never have skeletal involvement. Of people infected by Mycobacterium tuberculosis, only 5 to 7 percent ever exhibit bone
(Burial 34) was shot in the jaw, but there was no skeletal evidence on the recovered mandible and maxillae (which were complete) of this occurrence. Antemortem breaks of the lower second molars were observed and were so severe that just the two root clusters remained of the teeth. The lingual side of the roots of the left second molar were covered by new bone deposition. However, these teeth fractures could have been caused by a number of factors and cannot be directly attributed to 
the gunshot to the jaw. The lack of skeletal evidence for this wound, while surprising, is not without precedent. Johnson (1917:222-223) relates the story of a man who was shot through the cheek without showing bony evidence of injury. The lack of massive bony trauma was attributed to the fact that the man had his mouth open when the injury occurred, allowing the projectile to bypass the teeth and bone of the mouth. It is possible, then, that the bullet that hit Mr. Moody simply passed through the soft tissues of the mouth and face. Historic records documented that Mr. Walker (Burial 36) suffered from a skull fracture. However, the postmortem fragmentation of his cranial elements was so extreme that any head wound was unrecognizable. A wound near the spine was described in Confederate Home records for Mr. Bowden (Burial 44). That no osteological evidence for it exists is not surprising since the description seems to indicate a soft tissue wound.

Burials 3, 4, 14, 16, 39, and 53 exhibited skeletal evidence for violent injuries, but neither pension nor Confederate Home records mention the injuries. A gunshot wound, with well-healed osteitis, was noted on the tibia of Mr. Watkins (Burial 3). Veterans Rogers, Turner, Starnes, and Burleson (Burials 4, 14, 39, 53) had well-healed depression fractures to their frontals or parietals. Mr. Davenport (Burial 16) had a wound to a rib, presumably caused by a metal projectile of some sort that pierced the bone and caused disunion of the shaft. It is possible that none of these wounds were recorded as disabilities in the pension or Confederate Home records because they were so well healed that they were no longer debilitating or noticeable.

Only Mr. Stanley and Mr. Bowdoin (Burials 33 and 35 , respectively) had wounds that were visible osteologically and also noted in written records. Mr. Stanley had a severe case of osteomyelitis that affected his right tibia and fibula. In addition, the distal end of his right femur had a moderate periosteal reaction. Interestingly, $\mathrm{Mr}$. Stanley's pension record (see Chapter 5) notes that his injuries consisted of a "sore leg rupture and wounds received in war, badly wounded by bomb shell in hip and thigh. A bad chronic sore on leg suffered with for 30 years." If the bombshell injured his hip and thigh, then why is it his tibia and fibula that show evidence of a wound? Two possibilities exist: (1) the person who noted the injury could have recorded it incorrectly; or (2) the bombshell did injure his hip and thigh (explaining the reactive bone observed on his femur) but also affected his lower leg. Confederate Home records noted that Mr. Bowdoin had a wound to the arm and hand. This injury was evident osteologically by fusion of the elbow of the right arm and missing middle fingers on the left hand. It is possible that Mr. Bowdoin's left hand was resting on his right elbow at the time he was wounded. Two fingers may have been severed at the time of injury, and a comminuted fracture of the elbow region probably was the cause of the joint ankylosis.

\section{MEDICAL CARE}

The State Cemetery, sample provides a rare opportunity for examining the osteological evidence for medical care during the Civil War and postwar eras. Perhaps the age distribution of the sample makes the most powerful statement about the health care available to these individuals. It is unlikely that Civil War-era populations experienced fewer medical problems than modern populations, so the fact that the average age of death for these veterans was 77.3 years provides the strongest testimony to their health and, by extension, their health care. The discussion that follows gives some general observations about expectations for the sample, as well as the pertinent results of analysis. These observations are followed by a number of case studies, which are intended to demonstrate ways of assessing medical care using osteological and documentary sources.

Standard medical procedures of the time were quite primitive, leading to the perception that certain elements of injury and ensuing medical treatment will be visible. Popular conceptions of Civil War medicine are based on fact, since "[t]he most common surgical procedure of the war was amputation. It was the accepted medical treatment in the 1860 s for a gunshot wound to an extremity" (Dammann 1983:1). Nearly 30,000 limb amputations were performed on Union soldiers during the Civil War, with an average mortality of 25 percent (Dammann 1983:1; Johnson 1917:255). Similar figures probably apply to Confederate forces, so the lack of amputations in the State Cemetery sample (with the possible exception of William Shry's finger) is surprising. The absence of 
amputations may be due to several factors. Considering the advanced age of the men, it is possible that amputees generally died at an earlier age due to stress associated with the loss of a limb. To test this hypothesis, future research on Civil War samples should examine the relationship between average age at death and the frequency of amputations. Alternatively, sampling error may have played a part in the lack of amputations.

The recovery of a number of metal projectiles (e.g., bullets) would not have been unexpected in this sample, since LaGarde (1916:159) noted a tendency for "the old leaden projectiles" to lodge themselves within the body. This was not evident in the State Cemetery sample, however. Despite several documented bullet wounds, no bullets were recovered. This may be due to the Civil War doctors' efficient use of bullet detectors and probes to remove the projectile when possible (in cases where amputation of a limb was not necessary). Alternatively, it may be that projectiles passed completely through the body.

Evidence for dental care was apparent in this sample. As described earlier in this chapter, several of the excavated individuals had fillings in their teeth. A total of six individuals had dentures (three males, three females); all but one of these had full dentures (maxillary and mandibular). All of the dentures appeared to be based on a standardized design in terms of tooth size and morphology; however, two individuals had dentures reflecting some departures from the standard. George Walker (Burial 49), for example, had full mandibular dentures and partial maxillary dentures. The partial maxillary dentures were anchored by means of a gold band which fit around an existing canine. Emma Kyser (Burial 48) had a gold filling inserted into an incisor on a maxillary denture, probably an attempt to replicate a filling in the original tooth. In addition, one individual had a tooth that had been broken off at the crown, possibly reflecting the dental practice of removing a carious crown by breaking it off (Dammann 1984:15). Another common dental practice, that of extracting troublesome teeth, cannot be clearly defined in this sample because intentional extractions cannot be distinguished from accidental or traumatic loss. In any case, it appears that many individuals in this sample had access to professional dental care. While a lack of proper personal care of the teeth may have led to the loss of teeth in many individu- als, these examples demonstrate that dentistry techniques for coping with common dental problems were available.

At least one case of probable refusal of medical treatment is present in Burial 33 (Stephen L. Stanley). Confederate Home records noted that he was "badly wounded by [a] bomb shell in [the] hip and thigh" and that he had "a bad chronic sore on leg suffered with for 30 years" upon his arrival at the home in 1897. This chronic sore was seen in the skeleton as osteomyelitis. By the time he died in 1907, his leg had been infected for 40 years. Mr. Stanley probably represents an unusual case, since amputation was the prescribed treatment for severe gunshot and projectile wounds. An 1861 Sanitary Commission Report on the Subject of Amputation stated:

In army practice, attempts to save a limb which might be perfectly successful in civil life, cannot be made. Especially in this case in compound gunshot fractures of the thigh, bullet wounds of the knee joint and similar injuries to the leg, in which, at first sight, amputation may not seem necessary. Under such circumstances attempts to preserve the limb will be followed by extreme local and constitutional disturbance. Conservative surgery is here in error; in order to save life, the limb must be sacrificed [Dammann 1983:1].

This suggests that either the primary medical treatment (at the time of the injury) was in error according to prevailing medical sentiment, or that Mr. Stanley refused the most appropriate treatment (amputation) in an effort to save his leg. Because of the long-standing nature of his infection, it is likely that this treatment was suggested to $\mathrm{Mr}$. Stanley later in his life as well. For whatever reasons, this operation did not take place. While this infection (blood poisoning) eventually killed him, we cannot ignore the fact that Mr. Stanley lived with the infection for 40 years before succumbing to it. Mr. Stanley's long life probably is due to his sturdy constitution, rather than to any medical treatments that he received or refused.

The case of I. C. Briggs (Burial 24) provides interesting insight into medical treatment of potentially disabling fractures. Mr. Briggs had a fracture of the left femur that healed with a dorso- 
ventral displacement of the shaft. This displacement resulted in a left leg that was nearly 2 inches shorter than the right leg. A fracture of this nature could have been set easily even during the nineteenth century. The severe displacement of the shaft fragments indicates either that the fracture was not properly set or that it was set in alignment but became dislodged due to subsequent movement of the leg. This second alternative is perhaps the most interesting. Confederate Home records list Mr. Briggs's occupation as farmer, so perhaps the demanding work required in farming caused him to return to work earlier than medically advisable, thus reinjuring his leg and causing displacement of the femur shaft. In any case, no mention of this injury was made in Mr. Briggs's Confederate Home records. The doctor(s) who examined Mr. Briggs almost certainly were aware of this condition, but it may not have been mentioned in their records because it was a well-healed injury to which Mr. Briggs had adapted. His adaptation to the shorter leg is supported by the presence of morphological change seen in the right femur. This change may be related to a shift in requirements placed on the musculature of the right leg as a form of compensation. The fact that the left leg was never rebroken and properly set is interesting in that this, too, could have been accomplished during this time period. Perhaps the leg was never reset because Mr. Briggs did not regard his injury as a disability, much less a problem that needed to be corrected.

Immobilization was the treatment of choice for some gunshot wounds. For example, LaGarde (1916:140) noted that early medics treated fractured arms (i.e., those fractured by impact of a bullet) by binding them to the body. This may well have been the preferred treatment in place when Henry A. Bowdoin (Burial 35) received a "wound to the arm." The elbow joint (right distal humerus, proximal radius, and proximal ulna) showed complete fusion in a flexed position. The wound had been stabilized in such a way that the palmar surface of Mr. Bowdoin's hand faced upwards (i.e., was supinated or directed cranially). The ankylosis of the elbow in this unusual position may well have resulted from a hurriedly splinted wound or from concern over displacement of bone fragments resulting from a comminuted fracture. This painful displacement of fragments would have resulted from the crossing over of the proximal ulna and radius when the arm is pronated. The fact that the arm was not reset into a more natural position (such as with the palmar surface of the hand directed dorsally or in a pronated position) may have resulted from another recommended treatment. According to LaGarde (1916:141),

Immobilization in all bone lesions . . . should invariably be practiced, and especially so after lesion from the armored bullets. These hard projectiles ... have a tendency to perforate or gutter a bone without causing complete fracture. . . . Such an injury should be treated by permanent fixation at once and it should not be handled unnecessarily. . . . [W] hen the overlying support gives way from jolting, jarring or undue handling, fracture takes place.'

Although this treatment was recommended in 1916, it probably does not represent a view significantly different from that of standard battlefield medical care of the mid nineteenth to early twentieth centuries. Later medical authorities (ca. World War I) advocated pronation of the forearm joint as the proper position for immobilization (LaGarde 1916:163).

During the Civil War, fatalities due to gunshot wounds of the spine increased as the wound got closer to the skull; that is, wounds of the cervical vertebrae were fatal 25 percent more often than lumbar injuries. Spinal fractures during the war occurred with a relative frequency of 0.26 percent. This low frequency was due to the low velocity of the lead bullets in use. In addition, the position of the spine at the rear of the body offered a measure of relative protection, in that bullets entering the front of the torso typically spent their energy before reaching the spinal column (LaGarde 1916: 214-215). This explanation of the rarity of spinal fractures during the Civil War provides some insight into the invisibility of the spinal injury in Burial 44 (John T. Bowden), who had a "wound near spine." It is not known for certain whether this wound was caused by a bullet, but it seems likely since 90 percent of Civil War wounds were caused by gunshots (Johnson 1917:252). In this case, the fact that no bullet was recovered may be evidence of medical intervention in and of itself. LaGarde (1916:242) noted, "Projectiles imbedded in lung tissue and against the spine are best let 
alone." The absence of the bullet, then, may indicate that either the bullet was never lodged in the body (e.g., passed through) or that it was removed at some time after the injury.

\section{SUMMARY AND CONCLUSIONS}

This chapter has described skeletal characteristics observed in 56 individuals excavated from the Texas State Cemetery. ${ }^{5}$ Interpretations based on skeletal lesions, especially interpretations related to health, must be made carefully because not all stressful events are recorded skeletally. Only those that occur for a long period of time or are traumatic in nature are likely to appear on bone. Some disorders never affect bone (such as most viral infections), and others, like tuberculosis and cancer, may be manifested skeletally, but not in all cases. Therefore, readers should realize that many of the disorders discussed in this chapter actually underestimate the frequency at which the disorders actually occurred in a population. Given this note of caution, individuals excavated from the State Cemetery appear to have been raised in a relatively nonstressful environment. Stature estimates indicate that their health was good as they were growing, as do low linear enamel hypoplasia and porotic hyperostosis rates. Furthermore, the fact that these individuals survived as long as they did (average age at death for the 55 individuals of known age in the burial sample was 77.3 years) suggests that they were relatively well adapted compared to other Civil War veterans who died much earlier. Health declined primarily due to war-related and other traumatic injuries and general age-progressive changes such as arthritis. Caries and antemortem tooth loss rates were also both very high, in part due to poor dental hygiene. The caries rate is indicative of a high carbohydrate, sucrose diet.

Unlike typical "poorhouse" populations, such as the Monroe County institutional cemetery (Lanphear 1988) and the Uxbridge Almshouse (Cook 1991), there is no reason to believe that the individuals who spent their final years at the Confederate Home for Men represent a morestressed part of a population or a "socially

\footnotetext{
${ }^{5}$ Dr. Ward's intact metal coffin was never opened, so his skeletal remains were not analyzed.
}

marginal" subset of a population. Indeed, to many people, they were heroes and deserving of more respect than others. It was for this reason that facilities such as the Confederate Home for Men were established. None of these people were raised in a poorhouse environment; all seem to have been independent of the state until they were very old. Even though they died as wards of the state, there is nothing to indicate that as a segment of a population they were universally poor. Many of them may have come to live in the home because they outlived other relatives or had relatives who could not afford to support them as they got older. In addition, some may have chosen to enter the home for the medical benefits provided by a doctor and nurses maintained at the Confederate Home for Men.

The State Cemetery sample also provides some interesting insight into medical practices of the Civil War and post-Civil War eras. As is frequently the case with scientific inquiry, not all expectations were met. No amputations were encountered among this sample, an occurrence that probably is due to sampling error. Metal projectiles also were conspicuously absent from this sample, although some evidence is available for gunshot and possible gunshot wounds. The lack of bullets may be a reflection of the popular Civil War operation involving excision of the metal fragments. Alternatively, the absence of projectiles could be due to the nature of the wounds themselves. Dental care and the consequences of a lack of dental hygiene were readily apparent in the number of metal fillings and dentures recovered. The treatment of fractures seems to have changed little over time. While immobilization of fractures is and was the desired treatment, the full cooperation of the patient has a great deal of bearing on the success of the therapy. Interestingly, this sample yielded information on the apparent refusal of medical treatment as well.

A significant amount of information can be gained from skeletal samples by examining both overall frequencies of highly visible medical treatments (e.g., fillings) and the more subtle implications that can be drawn from individual case studies. This approach can be most successful when used in conjunction with historical research. Although this particular technique is not often used with skeletal remains, this limited exercise serves as an example of the data that can and should be 
drawn from other samples.

The opportunity to analyze skeletal material of known age and sex, with the support of historical records providing disability and cause of death information, is particularly valuable. Historical records pertaining to health are especially interesting because they provide information that often is not apparent on skeletal remains. That so few of the historical records provided information that matched what was observed skeletally is not due to an inadequacy in record keeping or in the skeletal analysis but is an artifact of the different mediums. Records were made by physicians, nurses, or admittance personnel who based their diagnoses on soft-tissue symptoms. The data available to the osteologists were obviously of a more limited nature, since many disorders do not affect skeletal remains. Furthermore, the osteologists were able to discern more-subtle osteological changes that would not have been apparent to medical practitioners at the time.

Analysis of people of known age and sex is also important to osteologists because it provides a way to test accepted osteological methods.
Unfortunately, given the time frame in which these individuals were excavated, we were not able to take full advantage of this situation. However, it did serve as a way to demonstrate dramatically what we had learned in textbooks about the scope of limitations of skeletal analyses. For instance, as discussed earlier, had the demographic data of these individuals not been known, the sex of several individuals would have been misidentified, and there is no doubt that the average age at death of this sample would have been underestimated by as much as 20 years. The age underestimation is due in part to the fact that assessing ages of people whose growth has stopped is very difficult and is based on more-variable, less-obvious skeletal changes (Iscan and Loth 1989:23). Also, most osteological aging techniques currently in use were developed using remains' of people who died at a much younger age than those composing this sample. Active knowledge of the limitations of osteological analyses serves as a way to make more-realistic statements about the populations we study. 
drawn from other samples.

The opportunity to analyze skeletal material of known age and sex, with the support of historical records providing disability and cause of death information, is particularly valuable. Historical records pertaining to health are especially interesting because they provide information that often is not apparent on skeletal remains. That so few of the historical records provided information that matched what was observed skeletally is not due to an inadequacy in record keeping or in the skeletal analysis but is an artifact of the different mediums. Records were made by physicians, nurses, or admittance personnel who based their diagnoses on soft-tissue symptoms. The data available to the osteologists were obviously of a more limited nature, since many disorders do not affect skeletal remains. Furthermore, the osteologists were able to discern more-subtle osteological changes that would not have been apparent to medical practitioners at the time.

Analysis of people of known age and sex is also important to osteologists because it provides a way to test accepted osteological methods.
Unfortunately, given the time frame in which these individuals were excavated, we were not able to take full advantage of this situation. However, it did serve as a way to demonstrate dramatically what we had learned in textbooks about the scope of limitations of skeletal analyses. For instance, as discussed earlier, had the demographic data of these individuals not been known, the sex of several individuals would have been misidentified, and there is no doubt that the average age at death of this sample would have been underestimated by as much as 20 years. The age underestimation is due in part to the fact that assessing ages of people whose growth has stopped is very difficult and is based on more-variable, less-obvious skeletal changes (Iscan and Loth 1989:23). Also, most osteological aging techniques currently in use were developed using remains' of people who died at a much younger age than those composing this sample. Active knowledge of the limitations of osteological analyses serves as a way to make more-realistic statements about the populations we study. 


\section{SUMIMARY AND CONCLUSIONS}

Helen Danzeiser Dockall

Extensive renovations currently under.way at the Texas State Cemetery, co-sponsored by the General Services Commission and the Texas Parks and Wildlife Department, include the addition of a visitors interpretive center, maintenance facilities, a memorial garden/pool/walkway complex, a mausoleum, a plaza, cenotaphs, and other improvements. These renovations endeavor to promote the historical importance of the cemetery and the people buried within it, as well as to increase public visitation. As part of this renovation, Prewitt and Associates, Inc. (PAI), was contracted as archeological consultant to conduct several specific tasks. These tasks included archival research, pedestrian survey, subsurface investigations (including geoarcheological testing, a search for unmarked graves, and documentation and testing of newly discovered historic features), and the excavation of 57 historic graves of Confederate veterans and spouses.

The importance of the State Cemetery is apparent in its uniqueness as the only burial ground in the United States established exclusively for interment of state dignitaries and heroes. Established in 1851 with the burial of General Edward Burleson, the cemetery has since seen the interment of many people who played vital roles in the history of Texas. The original intent in creating this cemetery was to provide a place of burial for people of political and military importance, as well as to create a cemetery-museum. During the first few decades of the cemetery's history, some graves were unmarked, monuments were few, landscaping was lacking, and record keeping was erratic. The decades of neglect came to an end in the early 1900 s, however, as the state began to take a more active role in managing and improving the cemetery. Money was appropriated for the building of monuments, the relocation and interment of historical figures, and landscaping. Two of the primary people responsible for the increased interest in the State Cemetery were Governor O. B. Colquitt and businessman-historian Lou Kemp. During his administation between 1910 and 1915, Colquitt spearheaded the reinterments of Joanna Troutman and Stephen F. Austin to the state burial ground and allocated funding for the addition of a cement fence around the cemetery and interior roadwork. In the late 1920 s and early 1930 s, Kemp, for whom State Road Spur 165 within the cemetery is named, was responsible for relocating many more important Texans to the cemetery and for extensive construction to enhance its beauty. The need to "specifically define the class of persons entitled to burial in the ground" was recognized before the turn of the century, but no such policy was formally established until the 1950s. The current policy specifies that an individual interred within the cemetery must be either a current or ex-member of the Texas Legislature, a Confederate veteran, an elected or appointed state official, an individual specified by a governor's proclamation, or the spouse of someone buried in the cemetery. The renovations in progress are a continuation of the desire to transform the cemetery into something more than an ordinary burial 
ground; the current work reflects the vision of the site as a repository of Texas history and a tool for public education and awareness.

Archeological investigations conducted by PAI included hand testing of historic features discovered during mechanical testing in proposed construction areas. The most important finds in these areas were the discoveries of extensive concrete features in the Plaza de los Recuerdos construction zone and three unmarked graves in the Northeast Cenotaph construction zone. Examination of historic records and archeological remains confirms that the concrete features buried in the southern half of the cemetery are remnants of Albert Sidney Johnston Avenue. Built by Brown \& Reissig, a construction firm that was in business only for a brief time during 1913 and 1914, this roadwork apparently was done under contract with the State of Texas during Governor Colquitt's administration. The roadway probably remained in use until 1929-1930, when the State Highway Department buried intact the old concrete-curbed roadway to raise the area during construction of Lou Kemp Highway. The buried remains of Albert Sidney Johnston Avenue remain intact and will not be altered by the current renovation work (which calls for the addition of fill in this area rather than excavation).

The three unmarked graves in the northeastern corner of the cemetery were identified as rectangular outlines in a Gradall trench. Hand excavation of these graves revealed remnants of wooden coffins but yielded no human skeletal remains, personal goods, or casket hardware. Archival research found records documenting that the northeastern 1-acre tract within the cemetery was set aside by the state legislature in 1866 for burial of Federal troops who died in Austin during Reconstruction. The graves were empty because the remains of these soldiers were disinterred and relocated to a National Cemetery in San Antonio, Texas. Athough the date of their removal has not been confirmed, the United State Army was active in relocating soldiers' burials from cemeteries at abandoned military posts after 1880 and through the first quarter of the twentieth century.

The most intensive work effort of PAI's archeological investigations consisted of the excavation and relocation of 57 historic graves. All of the burials that were moved originally were located adjacent to the current roadway and comprised the first row of graves along the western edge of Section $\mathrm{F}$ and the first two rows of graves in the northwest corner of Section D. These particular graves had to be relocated because the renovation plan called for roadway improvements and landscaping to provide a buffer zone separating the burial areas from vehicular traffic. The burial exhumations were conducted using standard archeological techniques to insure the respectful treatment of the remains. For each grave, the remains of the burial container (e.g., casket hardware and wood remnants) and all human skeletal remains and personal artifacts were documented and examined in situ, removed to an on-site field laboratory for more-complete analysis, and then placed into specially constructed reburial boxes. The remains recovered from each grave were placed into a reburial box by the end of the same day they were excavated. All reburial boxes were stored on-site in a locked storage vault until they were reinterred in their new locations in Section D on 31 July and 7 August 1995.

The burial sample is exceptional in that so much is known about each individual. All 57 graves were marked with headstones that provide some basic demographic information (e.g., name, date of death, and usually date of birth or age at death) along with a military service record for most of the Confederate veterans (i.e., the regiment and unit with which the individual served usually is shown, and rank is noted in some cases). Archival research provided supplemental information corroborating the headstone data in most cases and filling in unknown details in other cases. Additional information, such as postwar place of residence and occupation, general health conditions, and specific ailments, was documented for the majority of the veterans (i.e., those who lived at the Confederate Home for Men in Austin when they died). Other information was obtained through various sources such as cemetery records kept by the state's General Services Commission, service records of Confederate States Army soldiers, veterans' pension records, newspaper obituaries, and published family histories or personal biographies. When all lines of historic evidence are considered, this burial sample is extremely well documented, especially when compared with published data for other historic burial and cemetery relocations. Names and dates of death are known for all 57 individuals, while the year of 
birth and age at death are known for all but one. Some information relating to Confederate States Army service is known for all but one of the Confederate veterans. In addition, concise personal histories are available for a few of these individuals.

Compared with burial samples from other excavated historic cemeteries, the State Cemetery sample $(n=57)$ is unusual because it is comprised entirely of older people who were Confederate veterans $(n=51)$ or spouses of Confederate veterans $(n=6)$. Unlike the burial samples from most family, community, or institutional (e.g., poorhouse) cemeteries that are reported in the archeological literature, the State Cemetery sample represents a unique segment of the population rather than a broad cross section of society. Except for one 44-year-old man whose remains were not analyzed because they were in a sealed iron coffin (i.e., the 1884 burial mentioned below), the individuals comprising the skeletal sample $(n=56)$ range from 60 to 95 years of age at death. Consequently, the State Cemetery sample is the only reported historic cemetery skeletal sample comprised entirely of people older than 60 years of age.

The temporal distribution of the interments also is unusual. The dates of death (and interment) for the 57 relocated individuals span a 67-year period, but the majority fall into two groups dating to the first half of the twentieth century. Of the 57 burials, the earliest dates to 1884 , although this individual was reinterred (still in his original sealed iron coffin) in the State Cemetery in 1958. The latest burial dates to 1951. All other burials date between 1907 and 1939, with the largest number dating to $1907-1908(\mathrm{n}=40)$, a single burial dating to 1917 , and a second group dating to the 1920s and 1930s $(n=14)$. Because of this distribution, the mortuary data are particularly useful for analyzing temporal changes in funerary traditions and attitudes toward death as manifested in casket construction and hardware, burial clothing, and personal goods. In addition, the bioarcheological data are useful for addressing temporal research questions (e.g., changing patterns of health care and disease frequency within populations).

The 57 excavated graves were oriented in an east-west direction, as are all the graves throughout the State Cemetery. Body placement followed the traditional Christian style of placing the head to the west and feet to the east. Grave markers were located at the head of each burial, but, instead of being oriented with the text facing east (i.e., toward the feet) as markers are commonly placed, the majority (48 of 55 stones) were oriented with the text facing west. This apparently was intentional so that the headstones faced the road. All of the markers associated with excavated graves in Section $F(n=46)$ are of only two varieties, designated as Types 1 and 2. Type 1 headstones are rectangular white marble markers with inscriptions generally composed of four lines of information that include the individual's name, military service record (i.e., regiment and unit), date of death, and age at death. Type 2 markers are larger marble stones with a canted top inscribed with a Southern Cross of Honor, above the text. This style of marker was issued after 1929 specifically for use on Confederate veteran burials. Information inscribed into each stone is limited to the individual's name, military service record, and the initials "C.S.A." (Confederate States of America).

The nine markers associated with the 11 excavated graves in Section D are more varied than those of Section F. These markers include one Type 1 and two Type 2 headstones, but the rest are of five styles. Two couples have identical single headstones manufactured from pink granite emblazoned with the family name, a Mason's symbol, and separate text entries under the headings of "FATHER" and "MOTHER" (Type 3). Another couple has separate headstones constructed of pink granite (Types 5 and 6). These markers are similar in size but contain different styles of engraving, and the man's marker has a bronze plaque on the front identifying him as a "Citizen of the Republic of Texas." The last two markers from Section D (Types 4 and 7) are manufactured from white marble. The most of elaborate of these is associated with the 1884 burial/1958 reinterment. This stone's original inscription lists the individual's name, place and date of birth, and place and date of death, followed by "A Confederate Soldier." Three additional lines of text, noting the man's Confederate service record as a Surgeon with the 11 th Virginia Regiment and the date of the reinterment, apparently were added in a different style of engraving in 1958.

The excavations revealed that, with the exception of the elaborate 1884 metal coffin, all others 
had been interred in decorated caskets made of wood $(n=53)$ or metal $(n=3)$. Most of the wooden burial receptacles were manufactured from hard pine, although a few were constructed of bald cypress, maple, or yellow poplar. At least 40 percent of the wooden caskets were set into outer boxes that served the same function as metal or concrete vaults. Comparison of individuals' stature estimates to casket length suggests that these receptacles were mass produced rather than made to fit. The presence of outer boxes may support this contention if they functioned as shipping containers in addition to vaults.

Caskets usually were decorated with four to six short bar or swing bail handles, although a few caskets had extension bar handles. Escutcheons with thumbscrews commonly were recovered from caskets, as were decorative studs. Several styles of metal casket plaques, most engraved with the words "At Rest," were recovered. More-specialized decorative hardware observed on eight caskets included two intricately designed crosses, two metal calla lilies, and four white-metal Mason's symbols. Caplifters on several caskets implied that they had divided lids in which the upper panel could be opened for viewing. In addition to these caskets, almost 40 percent had viewing windows in the casket lid.

In terms of personal goods associated with the individuals, 92.9 percent of the burials contained evidence of clothing (e.g., buttons, bow ties, and suspender buckles) and jewelry (e.g., rings, cuff links, and collar studs). Buttons often were manufactured from metal, rubber, bone, and shell. The placement of buttons and the presence of bow ties on many of the males suggest that they were interred wearing suits. Many of these individuals had identical bone cuff links and celluloid collar studs. Button number and position, as well as the preservation of some fabric (generally only fragments but also including a complete pair of nylon stockings) suggests that the females were wearing dresses when they were buried. Only three people wore wedding bands, and one of these individuals also had a moss agate ring. Two women were buried with hair combs, and one of these had a bar pin attached to the front of her dress. Vulcanized rubber dentures with porcelain teeth were recovered with six of the excavated individuals.

As mentioned above, the material culture associated with the burials is useful for temporal comparisons. In particular, mortuary traits evident in the large sample of $1907-1908$ burials $(n=40)$ are distinctive from the later group of 1920 s and 1930 s burials $(n=14)$. Supporting expected temporal trends, swing bail handles were placed on some 1907-1908 caskets but were not as common as double lug short bars. Examples of extension bar handles were limited to burials postdating 1923. Other than one 1884 example, viewing windows were observed only on burials occurring in 1907 and 1908. The limited temporal distribution of viewing windows also was noted at four other historic cemeteries in which no burial receptacles with viewing glass postdated 1904. Decorative studs were observed only on the 1907-1908 interments, supporting observations that these items declined in frequency at the turn of the century (see Hacker-Norton and Trinkley 1984). Lastly, no escutcheons and thumbscrews were observed on burials after 1908, although these items were manufactured after this date. The association of screws, rather than thumbscrews, with escutcheons recovered from the 1884 burial suggests that thumbscrews had not supplanted nondecorative screws by that date.

Another unusual characteristic of the State Cemetery burial sample, when compared to other historic burial samples, is that two socioeconomic groups are represented among the 57 individuals. The majority of the individuals $(n=47,82.5$ percent) had lived in the Confederate Home for Men in Austin in their later years, and most of these people died at the home. Established in 1887 by the John B. Hood Camp of Confederate Veterans, in cooperation with the Albert Sidney Johnston Chapter of the Daughters of the Confederacy, the home served as a facility to care for disabled and/or dependent Confederate veterans (Webb 1952:I:391). In 1893, the state legislature took responsibility for the home and the people living there. In addition to food and lodging, residents of the home also received medical care. Even their burials were subsidized by the state. Although the exact amount of money available for each person's interment is not known with certainty, records pertaining to two men suggest that $\$ 30.00$ was allocated to each interment in 1907 .

Historic evidence suggests that most of the individuals who lived at the home were rather poor and had no viable means of supporting themselves, while those individuals who never lived in the 
Confederate Home $(\mathrm{n}=11)$ should represent a higher socioeconomic group. Comparative analysis of the burial data generally supports this socioeconomic division. The plain headstones associated with the Confederate Home burials were certainly less expensive (and many probably were obtained at no cost from the Federal government) than were the more elaborate types of headstones associated with non-home burials. In addition, the mortuary and personal artifacts (e.g., casket hardware, clothing, and jewelry) associated with Confederate Home burials are indicative of a slightly lower economic status than is the material culture associated with their non-home counterparts. Despite this distinction, archeological evidence indicates the individuals who died at the Confederate Home were not buried as paupers. They were interred in nicely constructed caskets with handles, thumbscrews, escutcheons, and decorative studs. Many of these caskets had viewing windows, caplifters, and decorative plaques. In addition, a few had other decorative white-metal ornaments. The men apparently were buried wearing similar styles of single-breasted suits. Burial evidence suggests that these people were buried with respect, despite the fact that technically they were wards of the state.

Excluding the 1884 burial, only 10 of the people did not reside in the Confederate Home for Men. These individuals were buried in caskets that were markedly different than those of the people who died while residing at the Confederate Home. For instance, all extension bar handles, with the exception of one, were identified on these burials. In addition, the only metal burial cases recovered were associated with these people. Price lists from casket hardware catalogs indicate that extension bar handles were more expensive than swing bail and short bar handles, and metal caskets were known to retail for a much higher price than wooden caskets. Personal goods recovered from these burials, along with their more-elaborate headstone styles (described previously), also are indicative of greater wealth for people whose burials were not subsidized by the state.

Osteologically, the skeletal sample $(\mathrm{n}=56)$ is unique because of its demographic composition. All of the analyzed individuals were survivors of the Civil War who were in their sixth decade of life or over; the oldest died at 95 years of age. Of these people, 64 percent $(n=36)$ died between 60 and 79 years of age, 23 percent $(n=13)$ died between the ages of 80 and 89 , and 11 percent $(n=6)$ died between the ages of 90 and 95 . The age at death is unknown for only 1 of the 56 people ( $<2$ percent) whose remains were analyzed. The average age at death of analyzed individuals of known age was 77.3 years, meaning that this sample has one of the highest, if not the highest, mean age at death of the archeologically excavated historic burial samples discussed in this report.

Because of the unusual composition of this sample, and in spite of time limitations, an effort was made to attain as much osteological data as possible. Stature estimates indicate that at the time of death, males were approximately $5 \mathrm{ft} 7$ inches, while females were $5 \mathrm{ft} 1$ inch. These stature estimates suggest that the analyzed individuals had childhoods that were not marred by inadequate nutrition or severe stress. The relatively low frequency of linear enamel hypoplasias (childhood dental defects) also supports this assessment. In addition, only 10 percent of the individuals evidenced porotic hyperostosis or cribra orbitalia, lesions which often are associated with nutritional or other stresses during childhood.

An analysis of dental disorders illustrates that most adverse changes were the result of general age-progressive changes. For instance, antemortem tooth loss rates were extremely high. More than one-quarter of all analyzed individuals had lost all observable teeth prior to death, while an additional 14 percent had lost $75-90$ percent of all observable teeth antemortem. Only two of the analyzed individuals exhibited no tooth loss prior to death. Dental caries, resulting from bacteria in plaque that destroys enamel and dentin, were very common. Almost 83 percent of people composing this sample had at least one caries. The average number of dental caries per mouth was 3.5. The dental caries frequency almost certainly was higher than these calculated figures because caries, and subsequent abscessing, are frequent causes of antemortem tooth loss. Much of the antemortem tooth loss observed in these individuals probably resulted from caries.

An examination of the skeletal remains for medical disorders revealed very frequent occurrences of degenerative joint disease. Every individual exhibited degenerative changes on appendicular joints and/or vertebrae. The most common locations of appendicular changes were the knees, shoulders, hands, hips, elbows, and feet. Vertebral 
osteoarthritis was observed on all but 5 individuals, and bridging osteophytes were noted on 10 men. Eburnation of the atlas/axis articulation also was common, and Schmorl's nodes (resulting from a herniation of the disk) were seen on 32 percent of the sample. The very high rates of arthritis observed are not unexpected given the advanced ages and the fact that many of these men were employed in physically demanding occupations such as farming and ranching.

Periostitis and osteitis can result from infection or trauma and are often used as indicators of stress. Almost 60 percent of the individuals bore some evidence for this type of skeletal change, mostly in a healed state. Many cases of this bone reaction were seen on the maxillary sinuses, characteristic of sinusitis. Following the skull, lesions of the leg were the next most common. Twenty-three people had evidence of fractures, with 10 of these having more than one broken bone. All major bones in the body exhibited signs of fractures, but ribs were the most commonly broken, followed by bones of the forearm. Breaks in these areas are often the result of combative maneuvers, and these examples may have occurred during the Civil War. In addition to these fractures, four men had cranial depressions that probably resulted from violent blows to the head. Three additional men bore evidence of wounds that were almost definitely war related-one had a gunshot wound to his tibia, another had a wound of an indeterminate nature to a rib, and the third had a gunshot wound to his elbow and hand.

Some historic documents, primarily veterans' pension and Confederate Home records, provided information on disabilities and cause of death for many of the individuals. Many of these conditions did not correspond with the skeletal evidence, but this should not be viewed as deficiencies of either historical records or skeletal analyses. Records kept by medical personnel reflect soft tissue changes that are not apparent to bioarcheologists, while bioarcheologists can see skeletal changes that were not apparent to people observing only soft tissue changes.

The high average age at death indicates that these people were relatively healthy compared to Civil War veterans who died at a much earlier age. This high mean age at death certainly reflects considerable sample bias (i.e., much of the sample was drawn from a population comprised of people who were too old to take care of themselves), but the fact that they lived so long also indicates that these individuals may have been in better overall health, received better medical care, or perhaps simply were luckier than many of their contemporaries. Evidence suggests that these individuals had relatively healthy childhoods and that health declined primarily due to age-progressive changes such as arthritis or to war-related and other traumatic lesions. Although their dental health seems to have been generally poor, based on high caries and antemortem tooth loss rates, this probably resulted from a combination of old age and the inadequate dental hygiene practices of the time. That several individuals had dentures indicates that these people received adequate dental care. It should be stressed that, although most of the people came to be wards of the state, they are not representative of "poorhouse" populations that typically exhibit evidence of poor health, poor health care, and pauper's funerals. Based on the bioarcheological evidence, there is no reason to think that the people excavated from the State Cemetery embodied a more stressed part of the population. Based on the archeological evidence, it is clear that these people did not represent a "socially marginal" segment of the population, but received simple yet honorable burials befitting their status as respected Confederate veterans and heroes.

The archeological and archival investigations conducted at the State Cemetery in 1995 have provided a concise historical perspective for understanding the state's most prominent burial ground. Archeological and bioarcheological analyses of the burial remains of 57 Confederate veterans and spouses, along with historical evidence, have yielded valuable information about the lives and deaths of these people. The Texas State Cemetery Renovation Project, and its co-sponsors - the Texas Parks and Wildlife Department and the General Services Commission-seek to expand upon this knowledge and make it more available to the public. Once neglected and in "deplorable" condition prior to 1900 , the past century has seen a steady rise in the status of the now-revered burial ground. The nineteenth-century visionaries who saw its potential as a cemeterymuseum, a link "to the great and glorious past history" of Texas, a "State or monumental park," and a "beautiful home for the dead" would be proud. The renovations of the 1990 s promise to make the Texas State Cemetery a place of pride for the twenty-first century. 


\section{REFERENCES CITED}

Acsadi, G. and J. Nemeskeri

1970 History of Human Life Span and Mortality. Akademiai Kiado, Budapest.

Alexandersen, $\mathrm{V}$.

1967 The Pathology of the Jaws and the T'emporomandibular Joint. In Diseases in Antiquity: A Survey of the Diseases, Injuries, and Surgery of Early Populations, edited by D. Brothwell and A. T. Sandison, pp. 551-595. Charles C. Thomas, Springfield, Illinois.

American-Statesman (newspaper clippings on file at General Services Commission, Austin)

Angel, J. Lawrence

1976 Colonial to Modern Skeletal Change in the U.S.A. American Journal of Physical Anthropology 45:723-736.

Anonymous

1922 Unsigned letter to the State Board of Control, Austin, Texas, October 19, 1922, in the files of Janice Hughes, General Services Commissioner, Austin, Texas.

Austin American-Statesman

Austin City Directories, 1895-1965

Austin History Center

Area Files

Austin Statesman

Barkley, Mary Starr

1963 History of Travis County and Austin, 18391899. Austin Printing Company, Austin.

Barnes, Ethne

1994 Developmental Defects of the Axial Skeleton in Paleopathology. University Press of Colorado, Niwot.

Bass, William M.

1987 Human Osteology; A Laboratory and Field Manual. 3rd ed. Special Publication No. 2. Missouri Archaeological Society, Columbia.

Beeman, Cynthia J.

1986 The Texas Confederate Home and the Confederate Woman's Home. Stirpes XXVI (June):66-67.

Bell, Edward L.

1990 The Historical Archaeology of Mortuary Behavior: Coffin Hardware from Uxbridge, Massachusetts. Historical Archaeology 24: 54-78.

1991 Artifacts from the Almshouse Burial Ground. In Archaeological Excavations at the Uxbridge Almshouse Burial Ground in Uxbridge, Massachusetts, edited by Ricardo J. Elia and Al B. Wesolowsky, pp. 254-283. BAR International Series 564

Berry, A. Caroline, and R. J. Berry

1967 Epigenetic Variation in the Human Cranium. Journal of Anatomy 101(2):361-379.

Blakely, Robert L., and Lane A. Beck

1982 Bioarchaeology in the Urban Context. In Archaeology of Urban America: The Search for Pattern and Process, edited by Roy S. Dickens, pp. 175-207. Academic Prèss, New York.

Boocock, Phillip A., Charlotte A. Roberts, and Keith Manchester

1995 Prevalence of Maxillary Sinusitis in Leprous Individuals from a Medieval Leprosy Hospital. 
International Journal of Leprosy 63:265-268.

Bornstein, Philipp E., and Roy R. Peterson

1966 Numerical Variation of the Presacral Vertebral Column in Three Populations Groups in North America. American Journal of Physical Anthropology 25:139-146.

Brauer, Gerhard W.

1982 Size, Sexual Dimorphism, and Secular Trend: Indicators of Subclinical Malnutrition? In Sexual Dimorphism in Homo sapiens: A Question of Size, edited by R. L. Hall, pp. 245-259. Praeger, New York.

Braun, Fred

1881a Contract for cemetery fence, A. W. Spaight, Commissioner, Fred Braun, contractor. In the files of Janice Hughes, General Services Commission, Austin, Texas.

1881b Fred Braun Contractor for Cemetery Fence, August 20, 1881. In the files of Janice Hughes, General Services Commission, Austin, Texas.

1882 Contractor bill from Fred Braun, Carpenter and Builder for the State of Texas, January 13,1882, Austin, Texas. In the files of Janice Hughes, General Services Commission, Austin, Texas.

Buikstra, Jane E., and Douglas H. Ubelaker (editors)

1994 Standards for Data Collection from Human Skeletal Remains. Research Series No. 44. Arkansas Archeological Survey, Fayetteville.

Burke, William J.

1968 Letter from William J. Burke, Austin, Texas, to Mrs. Patricia Morrison, Austin, Texas, April 9, 1968. Copy in the files of Janice Hughes, General Services Commission, Austin, Texas.

Carter, Emily Suzanne, and Crystal Sasse Ragsdale

1976 Biegel Settlement: Historical Sites Research, Fayette Power Project, Fayette County, Texas. Research Report No. 59. Texas Archeological Survey, The University of Texas at Austin.

Cawson, R. A.

1970 Essentials of Dental Surgery and Pathology. 2nd ed. Churchill Livingstone, Edinburgh.

Coffin, Margaret M.

1976 Death in Early America. Thomas Nelson, Nashville.
Comuzzie, Anthony G., and D. Gentry Steele

1989 Enlarged Occlusal Surfaces on First Molars Due to Severe Attrition and Hypercementosis: Examples from Prehistoric Coastal Populations of Texas. American Journal of Physical Anthropology 78:9-15.

Cook, Lauren J.

1991 The Uxbridge Poor Farm in the Documentary Record. In Archaeological Excavations at the Uxbridge Almshouse Burial Ground in Uxbridge Massachusetts, edited by R. J. Elia and A. B. Wesolowsky, pp. 40-81. BAR International Series 564. British Archaeological Reports, Oxford.

Corruccini, Robert S.

1974 An Examination of the Meaning of Cranial Discrete Traits for Human Skeletal Biological Studies. American Journal of Physical Anthropology 40:425-446.

Cosseddu, G. G., G. Floris, and G. Vona

1979 Sex and Side Differences in the Minor Nonmetrical Cranial Variants. Journal of Human Evolution 8:685-692.

Cumming, J., N. Hacking, J. Fairhurst, D. Ackery, and J. D. Jenkins

1990 Distribution of Bony Metastases in Prostatic Carcinoma. British Journal of Urology 66(4):411-414.

\section{Daily Democratic Statesman}

Dallas Morning News (newspaper clippings on file at General Services Commission, Austin)

Dammann, Gordon E.

1983 Pictorial Encyclopedia of Civil War Medical Instruments and Equipment, Volume I. Pictorial Histories Publishing, Missoula, Montana.

1984 Dental Care during the Civil War. Illinois Dental Journal 53(1):12-17.

Dearnaley, D. P.

1994 Cancer of the Prostrate. British Medical Journal 308:780-784.

Deming, Joan, Marion M. Almy, Janet S. Matthews, and Steven H. Koski

1993 Report on the Excavation of $8 L L 1758$ as Contained within the Proposed U.S. 41 Business Right-of-Way on Fowler Street Between First and Second Streets in the City of Fort 
Myers, Lee County, Florida. Prepared for Florida Department of Transportation. Archaeological Consultants, Inc. Sarasota, Florida.

Dethlefsen, Edwin, and James Deetz

1966 Death's Heads, Cherubs, and Willow Trees: Experimental Archaeology in Colonial Cemeteries. American Antiquity 31(4):502-510.

Diehl, Andrew K., Nancy J. Sugarek, and Knox H. Todd 1990 Clinical Evaluations for Gallstone Disease: Usefulness of Symptoms and Signs in Diagnosis. American Journal of Medicine 89: 29-33.

Dockall, Helen D.

1996 Reconstruction of Site Events. In Home Hereafter: An Archaeological and Bioarchaeological Analysis of an Historic African-American Cemetery (4IGVI25), by H. D. Dockall, J. F. Powell, and D. G. Steele. Report No. 5. Center for Environmental Archaeology, Texas A\&M University, College Station.

Dockall, Helen Danzeiser, and D. Gentry Steele

1995 The Phillips Memorial Cemetery. Cultural Resources Management News and Views 7(1):11-12.

Dockall, Helen D., Joseph F. Powell, and D. Gentry Steele

1996 Home Hereafter: An Archaeological and Bioarchaeological Analysis of an Historic African-American Cemetery (41GV125). Report No. 5. Center for Environmental Archaeology, Texas A\&M University, College Station.

Earls, Amy C.

1991 Archival and Oral History. In Investigations of Historic Cemeteries at O. H. Ivie Reservoir, Coleman, Concho, and Runnels Counties, Texas, by Amy C. Earls, Christopher R. Lintz, George W. Gill, Patrick L. O'Neill, and W. Nicholas Trierweiler, pp. 145-172. Technical Report No. 403. Mariah Associates, Inc., Austin.

Earls, Amy C., and Christopher R. Lintz

1991 Artifact Analysis. In Investigations of Historic Cemeteries at O. H. Ivie Reservoir, Coleman, Concho, and Runnels Counties, Texas, by Amy C. Earls, Christopher R. Lintz, George W. Gill, Patrick L. O'Neill, and W. Nicholas Trierweiler, pp. 95-123. Technical Report No. 403. Mariah Associates, Inc., Austin.

Earls, Amy C., Christopher R. Lintz, George W. Gill, Patrick L. O'Neill, and W. Nicholas Trierweiler

1991 Investigations of Historic Cemeteries at O. $H$. Ivie Reservoir, Coleman, Concho, and Runnels Counties, Texas. Technical Report No. 403. Mariah Associates, Inc., Austin.

Elia, Ricard J., and Al B. Wesolowsky

1991 Archeological Excavations at the Uxbridge Almshouse Burial Ground in Uxbridge, Massachusetts. BAR International Series 564. British Archaeological Reports, Oxford.

El-Najjar, Mahmoud Y., and K. Richard McWilliams

1978 Forensic Anthropology: The Structure, Morphology, and Variation of Human Bone and Dentition. Charles C. Thomas Publisher, Springfield, Illinois.

Espey, Huston/SME, Inc.

n.d. Project Analysis: Construction, Repairs/ Renovations for Fiscal Years 1992-1993, Project ID No. 88, General Site Repairs, State Cemetery Grounds, Austin, Texas. Espey, Huston/SME, Inc., Austin, Texas.

Farrell, James J.

1980 Inventing the American Way of Death, 1830-1920. Temple University Press, Philadelphia.

Fealy, Michael J., and William Lineaweaver

1995 Intraosseous Ganglion Cyst of the Scaphoid. Annals of Plastic Surgery 34(2):215-217.

Ferguson, Bobbie

1983 Final Report on the McGee Creek Cemetery Relocations, Atoka County, Oklahoma. McGee Creek Project. Bureau of Reclamation, Farris, Oklahoma.

1993 ". . . and they laid them to rest in the little plot beside the Pecos": Final Report on the Relocation of Old Seven Rivers Cemetery, Eddy County, New Mexico. 2 vols. United States Bureau of Reclamation, Denver Office.

Fink, Nancy, and Maryalice Ditzler

1993 Buttons: The Collector's Guide to Selecting, Restoring, and Enjoying New and Vintage Buttons. Running Press, Philadelphia. 
Fort Sam Houston National Cemetery

n.d. Burial Registers. Registers in the office of the director, Fort Sam Houston National Cemetery, Fort Sam Houston, Texas.

Fox, Anne A.

1984 A Study of Five Historic Cemeteries at Choke Canyon Reservoir, Live Oak and McMullen Counties, Texas. Choke Canyon Series Vol. 9. Center for Archeological Research, The University of Texas at San Antonio.

Gaal, Stephen A., James R. Doyle, and Ivar J. Larsen 1988 Symphalangism in Hawaii: A Study of Three Distinct Ethnic Pedigrees. The Journal of Hand Surgery 13A(5):783-787.

Gammel, H. P. N. (compiler and arranger)

1898 The Laws of Texas, 1822-1897, vols. III, V, and VI. The Gammel Book Company, Austin.

Garner, L. E., and K. P. Young

1976 Environmental Geology of the Austin Area: An Aid to Urban Planning. Report of Investigations No. 86. Bureau of Economic Geology, The University of Texas at Austin.

Germany, Lisa

1995 Historic Walking Tours: Texas State Cemetery. Edited by Julie Strong. Historic Landmark Commission, Austin Convention and Visitors Bureau, Austin, Texas.

Gill, George W.

1991 Physical Anthropology. In Investigations of Historic Cemeteries at O. H. Ivie Reservoir, Coleman, Concho, and Runnels Counties, Texas, by A. C. Earls, C. R. Lintz, G. W. Gill, P. L. O'Neill, and W. N. Trierweiler, pp. 125-144. Technical Report No. 403. Mariah Associates, Inc., Austin.

Goldstein, Lynne

1995 Politics, Law, Pragmatics, and Human Burial Excavations: An Example from Northern California. In Bodies of Evidence: Reconstructing History through Skeletal Analysis, edited by A. L. Grauer, pp. 3-17. WileyLiss, New York.

Goodman, Alan H., Debra L. Martin, George J. Armelagos, and George Clark

1984 Indications of Stress from Bone and Teeth. In Paleopathology and the Origins of Agriculture, edited by M. N. Cohen and G. J.
Armelagos, pp. 13-49. Academic Press, New York.

Goycoolea, Marcos V., and Timothy T. K. Jung

1991 Complications of Suppurative Otitis Media. In Otolaryngology, Volume II: Otology and Neuro-otology, edited by M. M. Paparella, D. A. Shumrick, J. L. Gluckman, and W. L. Myerhoff, pp. 1381-1403. 3rd ed. W. B. Saunders Co., Philadelphia.

Grauer, Anne L. (editor)

1995 Bodies of Evidence: Reconstructing History through Skeletal Analysis. Wiley-Liss, Inc., New York.

Gray, Henry

1974 Anatomy, Descriptive and Surgical. First published 1901. Edited by T. Pickering Pick and Robert Howden. Running Press, Philadelphia.

Grayhack, John T., and Grayhack, John J.

1992 Clinical Dilemmas and Problems in Assessing Prostatic Metastasis to Bone: The Scientific Challenge. In Prostate Cancer and Bone Metastasis, edited by J. P. Karr and H. Yamanaka, pp. 1-5. Advances in Experimental Medicine and Biology 324. Plenum Press, New York.

Guendling, Randall, Murray K. Marks, Jerome C. Rose, and Lawrence G. Santeford

1985 Methodology. In Gone to a Better Land: A Biohistory of a Rural Black Cemetery in the Post-Reconstruction South, edited by J. C. Rose, pp. 26-38. Research Series No. 25. Arkansas Archeological Survey, Fayetteville.

Habenstein, Robert W., and William M. Lamers

1962 The History of American Funeral Directing. Rev. ed. Bulfin Printers, Milwaukee, Wisconsin.

Hacker-Norton, Debi, and Michael Trinkley

1984 Remember Man Thou Art Dust: Coffin Hardware of the Early Twentieth Century. Research Series 2. Chicora Foundation, Inc., Columbia, South Carolina.

Hagman, Harry C.

1979 The History of Dentures, Part III. Dental Laboratory Review 54(4):22-26.

Hall, Martin Hardwick

1978 The Confederate Army of New Mexico. Presidial Press, Austin. 
Hansen, Julie

1991 Analysis of Coffin Wood. In Archaeological Excavations at the Uxbridge Almshouse Burial Ground in Uxbridge, Massachusetts, edited by Ricardo J. Elia and Al B. Wesolowsky, pp. 370-375. BAR International Series 564. British Archaeological Reports, Oxford.

Harrington, S. P. M.

1993 Bones and Bureaucrats: New York's Great Cemetery Imbroglio. Archaeology 46(2): 28-38.

Harrison, R. J.

1972 Bones. In Cunningham's Textbook of Anatomy, edited by G. J. Romanes. 11th ed. Oxford University Press, London.

Harwell, Thomas Fletcher

1947 Eighty Years Under the Stars and Bars, Including Biographic Sketches of 100 Confederate Soldiers I Have Known. N.p., Kyle, Texas.

Hauser, G., and G. F. DeStefano

1989 Epigenetic Variants of the Human Skull. E. Schwizerbart'sche Verlagsbuchhandlung, Stuttgart.

Heine, J.

1926 Uber die Arthritis Deformans. Virchow's Archiv fur Pathologische Anatomie und Physiologieund fur Klinische Medizin 260: 521-663.

Henderson, Jerry

1995 Freedman's Cemetery. Cultural Resources Management News and Views 7(1):11-12.

Hillson, Simon

1986 Teeth. Cambridge University Press, New York.

Hoffman, Frederick L.

1919 Pauper Burials and the Interment of the Dead in Large Cities. Prudential Press, Newark, New Jersey.

Holloway, Richard G.

1986 Analysis of Wood Remains from the Morgan Chapel Cemetery, 41BP200. In Archaeological Investigations at Morgan Chapel Cemetery (41BP200), A Historic Cemetery in Bastrop County, Texas, by Anna J. Taylor, Anne A. Fox, and I. Waynne Cox, pp. 73-76.
Archaeological Survey Report No. 146. Center for Archaeological Research, The University of Texas at San Antonio.

Iscan, Mehmet Y., and Susan R. Loth

1989 Osteological Manifestations of Age in the Adult. In Reconstruction of Life from the Skeleton, edited by M. Y. Iscan and K. A. R. Kennedy, pp. 23-40. Alan R. Liss, New York.

Jackson, Kenneth T., and Camilo José Vergara

1989 Silent Cities: The Evolution of the American Cemetery. Princeton Architectural Press, New York.

Jamieson, E. B.

1937 Osteology. In Cunningham's Text-Book of Anatomy, edited by J. C. Brash and E. B. Jamieson, pp. 89; 318 . Humphrey Milford, Oxford University Press, New York.

Jenkins, Robert A.

1972 Inter-departmental memorandum from Robert A. Jenkins to Homer A. Foerster, September 14, 1972. Copy in the files of Janice Hughes, General Services Commission, Austin, Texas.

Johnson, Charles B.

1917 Muskets and Medicine, or Army Life in the Sixties. F. A. Davis Company, Philadelphia.

Jordan, Terry G.

1980 The Roses So Red and the Lilies So Fair: Southern Folk Cemeteries in Texas. Southwestern Historical Quarterly 13(3):227-258.

1982 Texas Graveyards: A Cultural Legacy. University of Texas Press, Austin.

JVR and Associates and Texas Parks and Wildlife Department

1995 Texas State Cemetery Master Plan. [JVR and Associates, Austin.]

Kalser, M. H.

1985 Cholelithiasis: Clinical Aspects. In Gastroenterology, Volume 6: Biliary Tract and Pancreas, edited by J. E. Berk, W. S. Haubrich, M. H. Kalser, J. L. A. Roth, and F. Schaffner, pp. 3619-3642. W. B. Saunders Company, Philadelphia.

Karr, James P.

1992 Prostate Cancer in the United States and 
Japan. In Prostate Cancer and Bone Metastasis, edited by J. P. Karr and H. Yamanaka, pp. 17-27. Advances in Experimental Medicine and Biology 324. Plenum Press, New York.

Keenleyside, Anne, and Elizabeth Clark-Wilson

1991 Skeletal Pathology. In The Links that Bind: The Harvie Family Nineteenth Century Burying Ground, edited by S. Saunders and R. Lazenby, pp. 29-40. Occasional Papers in Northeastern Archaeology No. 5. Copetown Press, Dundas, Ontario.

Kline, K., and J. Kline

n.d. The Meaning and Value of the Casket. Brochure of the Casket Manufacturers Association of America, Evanston, Illinois.

Kogon, Stephen L., and Robert G. Mayer

1995 Analyses of Coffin Hardware from Unmarked Burials, Former Wesleyan Methodist Church Cemetery, Weston, Ontario. North American Archaeologist 16(2):133-162.

Komlos, John

1987 The Height and Weight of West Point Cadets: Dietary Change in Antebellum America. Journal of Economic History XLVII(4):897-927.

LaGarde, Louis A.

1916 Gunshot Injuries: How They Are Inflicted, Their Complications, and Treatment. 2nd ed. William Wood and Company, New York.

Lanphear, Kim M.

1988 Health and Mortality in a Nineteenth Century Poorhouse. Ph.D. dissertation, State University of New York at Albany.

Larkin, Jack

1988 The Reshaping of Everyday Life, 1790-1840. Harper and Row, Publishers, New York.

Larsen, Clark S., Joseph Craig, Leslie E. Sering, Margaret J. Schoeninger, Katherine F. Russell, Dale L. Hutchinson, and Matthew A. Williamson

1995 Cross Homestead: Life and Death on the Midwestern Frontier. In Bodies of Evidence: Reconstructing History through Skeletal Analysis, edited by A. L. Grauer, pp. 139-159. Wiley-Liss, Inc., New York.

Lazenby, Richard, Shelley Saunders, Rebecca Southern, Tracy Rogers, and Linda Gibbs

1991 Descriptive Osteology. In The Links That Bind:
The Harvie Family Nineteenth Century Burying Ground, edited by S. Saunders and R. Lazenby, pp. 21-28. Occasional Papers in Northeastern Archaeology No. 5. Copetown Press, Dundas, Ontario.

Lebo, Susan

1988 An Archaeological and Bioarchaeological Perspective: The Tucker (41DT104) and Sinclair (41DT105) Cemeteries of Delta County, Texas. Institute of Applied Sciences, University of North Texas, Denton.

Lehner, Lois

1988 Lehner's Encyclopedia of U.S. Marks on Pottery, Porcelain, and Clay. Collector Books. Schroeder Publishing Company, Inc., Paducah, Kentucky.

Lewis, Berkeley

1959 Notes on Ammunition of the American Civil War. American Ordnance Association, Washington, D.C.

Little, Barbara J., Kim M. Lanphear, and Douglas W. Owsley

1992 Mortuary Display and Status in a NineteenthCentury Anglo-American Cemetery in Manassas, Virginia. American Antiquity 57(3):397-418.

Loth, Susan R., and Mehmet Y. Iscan

1989 Morphological Assessment of Age in the Adult: The Thoracic Region. In Age Markers in the Human Skeleton, edited by M. Y. Iscan, pp. 105-135. Charles C. Thomas, Springfield, Illinois.

Loveland, Carol J., and John B. Gregg

1988 Brachydactyly in a Prehistoric Texas Skeleton. Plains Anthropologist 33(121):399-404.

Loveland, Carol J., Lorna C. Pierce, and John B. Gregg 1990 Ancient Temporal Bone Osteopathology. Annals of Otolology, Rhinology, and Laryngology 99:146-154.

Lukacs, John R.

1989 Dental Paleopathology: Methods for-Reconstructing Dietary Patterns. In Reconstruction of Life from the Skeleton, edited by M. Y. Iscan and K. A. R. Kennedy, pp. 261-286. Alan R. Liss, Inc., New York.

Lundy, John K.

1988 A Report on the Use of Fully's Anatomical 
Method to Estimate Stature in Military Skeletal Remains. Journal of Forensic Sciences 33(2):534-539.

Mann, Robert W., and Sean P. Murphy

1990 Regional Atlas of Bone Disease: A Guide to Pathologic and Normal Variation in the Human Skeleton. Charles C. Thomas, Springfield, Illinois.

Massett, Claude

1989 Age Estimation on the Basis of Cranial Sutures. In Age Markers in the Human Skeleton, edited by M. Y. Iscan, pp. 71-103. Charles C. Thomas, Springfield, Illinois.

McChristian, Douglas C.

1995 The U.S. Army in the West, 1870-1880: Uniforms, Weapons, and Equipment. University of Oklahoma Press, Norman.

McDonald, C. C.

1911 General Laws, The State of Texas, Thirtysecond Legislature, Regular Session Convened January 10, 1911, and Adjourned March 31, 1911. Austin Printing Co., Austin, Texas.

McKenzie, William, and Don Brothwell

1967 Disease in the Ear Region. In Diseases in Antiquity: A Survey of the Diseases, Injuries, and Surgery of Early Populations, edited by D. Brothwell and A. T. Sandison, pp. 464473. Charles C. Thomas, Springfield, Illinois.

McKern, T. W., and T. D. Stewart

1957 Skeletal Age Changes in Young American Males: Analysed from the Standpoint of Age Identification. Technical Report No. EP-45. Environmental Protection Research Division, Quartermaster Research and Development Center, U.S. Army, Natick, Maine.

McReynolds, Mary Jane

1981 Archeological Investigations at the Laredo Cemetery Site (4IWB22), Webb County, Texas. Reports of Investigations No. 11. Prewitt and Associates, Inc., Austin.

Meindl, Richard S., and C. Owen Lovejoy

1985 Ectocranial Suture Closure: A Revised Method for the Determination of Skeletal Age at Death Based on the Lateral-Anterior Sutures. American Journal of Physical Anthropology 68:57-66.
Meyerhoff, William L., Chong S. Kim, and Michael M. Paparella

1978 Pathology of Chronic Otitis Media. Annals of Otology, Rhinology, and Laryngology 87:749-760.

Montgomery Ward

19691922 Montgomery Ward Catalogue. Reprint edited by Hal L. Cohen. H. C. Publishers, New York.

Muir, Andrew Forest

1950 State Cemetery. Texas Parade (September): 16-18.

Murray, Elizabeth A., and Anthony J. Perzigian

1995 A Glimpse of Early Nineteenth Century Cincinnati as Viewed from Potter's Field: An Exercise in Problem Solving. In Bodies of Evidence: Reconstructing History Through Skeletal Analysis, edited by Anne L. Grauer, pp. 173-184. Wiley-Liss, Inc., New York.

Nawrocki, Stephen P.

1995 Taphonomic Processes in Historic Cemeteries. In Bodies of Evidence: Reconstructing History Through Skeletal Analysis, edited by Anne L. Grauer, pp. 49-66. Wiley-Liss, Inc., New York.

Nemeskeri, J., L. Harsanyi, and G. Acsadi

1960 Methoden zur Diagnose des Lebensalters von Skelettfunden. Anthropologie Anz 24:70-95.

Olsen, John W.

1978 A Study of Chinese Ceramics Excavated in Tucson. The Kiva 4(1):1-50.

O’Neill, Patrick L., Christopher R. Lintz, and Amy C. Earls

1991 Description of Cemeteries, Features, and Burials. In Investigations of Historic Cemeteries at O. H. Ivie Reservoir, Coleman, Concho, and Runnels Counties, Texas, by Amy C. Earls, Christopher R. Lintz, George W. Gill, Patrick L. O’Neill, and W. Nicholas Trierweiler, pp. 29-94. Technical Report No. 403. Mariah Associates, Inc., Austin.

Ortner, Donald J., and Walter G. J. Putschar

1985 Identification of Pathological Conditions in Human Skeletal Remains. Smithsonian Institution Press, Washington, D.C.

Parrington, Michael, and Daniel G. Roberts 1990 Demographic, Cultural, and Bioanthropologi- 
cal Aspects of a Nineteenth-Century Free Black Population in Philadelphia, Pennsylvania. In A Life in Science: Papers in Honor of J. Lawrence Angel, edited by J. E. Buikstra, pp. 138-170. Center for American Archaeology, Kampsville, Illinois.

Peyton, Floyd A.

1975 History of Resins in Dentistry. Dental Clinics of North America 19(2):211-222.

Pindborg, J. J.

1970 Pathology of the Dental Hard Tissues. W. B. Saunders Company, Philadelphia.

Powell, Joseph F., and Helen D. Dockall

1996a Mortuary Characteristics at the Phillips Memorial Cemetery. In Home Hereafter: An Archaeological and Bioarchaeological Analysis of an Historic African-American Cemetery (41GV125), by H. D. Dockall, J. F. Powell, and D. G. Steele. Report No. 5. Center for Environmental Archaeology, Texas A\&M University, College Station.

1996b Temporal Aspects of Mortuary Features and Material Culture. In Home Hereafter: An Archaeological and Bioarchaeological Analysis of an Historic African-American Cemetery (41GV125), by H. D. Dockall, J. F. Powell, and D. G. Steele. Report No. 5. Center for Environmental Archaeology, Texas A\&M University, College Station.

Powell, Leah C.

1996 Traditional Narratives and Oral History. In Home Hereafter: An Archaeological and Bioarchaeological Analysis of an Historic African-American Cemetery (4IGV125), by H. D. Dockall, J. F. Powell, and D. G. Steele. Report No. 5. Center for Environmental Archaeology, Texas A\&M University, College Station.

Powell, Leah Carson, and Helen Danzeiser Dockall

1995 Folk Narratives and Archaeology: An African-American Cemetery in Texas. Journal of Field Archaeology 22(3):349-353.

Powell, Mary L.

1985 The Analysis of Dental Wear and Caries for Dietary Reconstruction. In The Analysis of Prehistoric Diets, edited by R. I. Gilbert, Jr., and J. H. Mielke, pp. 307-338. New York, Academic Press.
Powers, R.

1962 The Disparity Between Known Age and Age as Estimated by Cranial Suture Closure. Man 62(84):52-54.

Ragon, Michel

1983 The Space of Death: A Study of Funerary Architecture, Decoration, and Urbanism. Translated by Alan Sheridan. University Press of Virginia, Charlottesville.

Rathbun, Ted A., and James D. Scurry

1991 Status and Health in Colonial South Carolina: Belleview Plantation, 1738-1756. In What Mean These Bones?: Studies in Southeastern Bioarchaeology, edited by M. L. Powell, P. S. Bridges, and A. M. W. Mires, pp. 148164. University of Alabama Press, Tuscaloosa.

Reissig, Marcella (Mrs. Oscar)

1995 Telephone conversation between Marcella Reissig and Martha Doty Freeman, August 27, 1995, Austin, Texas.

Resnick, Donald

1995 Diagnosis of Bone and Joint Disorders, Volume 3. 3rd ed. W. B. Saunders Company, Philadelphia.

Resnick, Donald, Stephen R. Shaul, and Jon M. Robins 1975 Diffuse Idiopathic Skeletal Hyperostosis (DISH): Forestier's Disease with Extraspinal Manifestations. Radiology 115:513-524.

Richter, William L.

1987 The Army in Texas During Reconstruction, 1865-1870. Texas A\&M University Press, College Station, Texas.

Roberts, Ben

1930 From the Confederate Home. Frontier Times $8(2): 60-61$.

Robertson, J. I., Jr.

1984 Tenting Tonight: The Soldier's Life. TimeLife Books Series, The Civil War. Time-Life Books, Alexandria, Virginia.

Rodda, Peter U.

1970 Geology of the Austin West Quadrangle, Travis County, Texas. Bureau of Economic Geology, The University of Texas at Austin. 
Rogers, Ken E., and Mary Jane McReynolds

1981 Identification of Wood Used in Coffin Construction, the Laredo Cemetery Site. In Archeological Investigations at the Laredo Cemetery Site (41WB22), Webb County, Texas. Reports of Investigations No. 11. Prewitt and Associates, Inc., Austin.

Rogers, Juliet, Iain Watt, and Paul Dieppe

1985 Palaeopathology of Spinal Osteophytosis, Vertebral Ankylosis, Ankylosing Spondylitis, and Vertebral Hyperostosis. Annals of the Rheumatic Diseases 44:113-120.

Rose, Jerome C.

1992 Bioanthropological Patterns. In Bioanthropological Investigation of Nineteenth Century Burials at Site 41DT105, by F. Winchell, J. C. Rose, and R. W. Moir, pp. 139-148. Archaeology Research Program, Department of Anthropology, Southern Methodist University, Dallas.

Rose, Jerome C. (editor)

1985 Gone to a Better Land: A Biohistory of a Rural Black Cemetery in the Post-Reconstruction South. Research Series No. 25. Arkansas Archeological Survey, Fayetteville.

Rose, Jerome C., and Lawrence G. Santeford

1985 Burial Interpretation. In Gone to a Better Land: A Biohistory of a Rural Black Cemetery in the Post-Reconstruction South, edited by Jerome C. Rose, pp. 130-145. Research Series No. 25. Arkansas Archeological Survey, Fayetteville.

Rose, Jerome C., Barbara A. Burnett, Michael S. Nassaney, and Mark W. Blaeuer

1984 Paleopathology and the Origins of Maize Agriculture in the Lower Mississippi Valley and Caddoan Culture Areas. In Paleopathology and the Origins of Agriculture, edited by M. N. Cohen and G. J. Armelagos, pp. 393-424. Academic Press, New York.

Rosenberg-Naparsteck, R.

1985 Life and Death in Nineteenth Century Rochester. Rochester History 1055:2-23.

Sarrafian, Shahan K.

1983 Anatomy of the Foot and Ankle. J. B. Lippincott Company, Philadelphia.

Schiffer, Michael B.

1987 Formation Processes of the Archaeological
Record. University of New Mexico Press, Albuquerque.

Schmorl, Georg, and Herbert Junghanns

1971 The Human Spine in Health and Disease. 2nd American ed., translated and edited by E. F. Besemann. Grune and Stratton, New York.

Schuetz, Mardith K.

1974 The Dating of the Chapel at Mission San Juan Capistrano. Special Report No. 12. Texas Historical Commission, Austin.

Sciulli, Paul W., and Richard M. Gramly

1989 Analysis of the Ft. Laurens, Ohio, Skeletal Sample. American Journal of Physical Anthropology 80:11-24.

Sears, Roebuck and Company

1971 Sears, Roebuck and Co. 1908 Catalogue No. 117: The Great Price Maker. Reprint edited by Joseph J. Schroeder, Jr. Digest Books, Inc., Northfield, Illinois.

19761897 Sears Roebuck Catalogue. Reprint edited by Fred L. Israel. Chelsea House Publishers, New York.

1993 The 1902 Edition of the Sears, Roebuck Catalogue. Reprint. Gramercy Books, New York.

Seeley, Dana G., Warren S. Browner, Michael C. Nevitt, Harry K. Genant, Jean C. Scott, and Steven R. Cummings

1991 Which Fractures are Associated with Low Appendicular Bone Mass in Elderly Women? Annals of Internal Medicine 115(11):837-842.

Shambaugh, George E., and Tawfik F. Girgis

1991 Acute Otitis Media and Mastoiditis. In Otolaryngology, Volume II: Otology and Neurootology, edited by M. M. Paparella, D. A. Shumrick, J. L. Gluckman, and W. L. Myerhoff, pp. 1343-1348. 3rd ed. W. B. Saunders Co., Philadelphia.

Singer, R.

1953 Estimation of Age from Cranial Suture Closure: A Report on its Unreliability. Journal of Forensic Medicine 1:52-59.

1961 Pathology in the Temporal Bone of the Boskop Skull. The South African Archaeological Bulletin 16:103. 
Skinner, Mark, and Alan H. Goodman

1992 Anthropological Uses of Developmental Defects of Enamel. In Skeletal Biology of Past Peoples: Research Methods, edited by S. R. Saunders and M. A. Katzenberg, pp. 153-174. Wiley-Liss, Inc., New York.

Sledzik, Paul S., and Peer H. Moore-Jansen

1991 Dental Disease in Nineteenth Century Military Skeletal Samples. In Advances in Dental Anthropology, edited by Mark A. Kelley and Clark S. Larsen, pp. 215-224. Wiley-Liss, Inc., New York.

Sloane, David Charles

1991 The Last Great Necessity: Cemeteries in American History. John Hopkins University Press, Baltimore.

Smith, B. Holly

1984 Patterns of Molar Wear in Hunter-Ġatherers and Agriculturalists. American Journal of Physical Anthropology 63(1):39-56.

State Inspector of Masonry, Public Buildings and Works 1915 Report of State Inspector of Masonry, Public Buildings and Works, October 31, 1912, to November 30, 1914. Von Boeckmann-Jones Co., Printers, Austin, Texas.

Steegmann, A. Theodore

1991 Stature in an Early Mid-19th Century Poorhouse Population: Highland Park, Rochester, New York. American Journal of Physical Anthropology 85:261-268.

Steele, D. Gentry

1976 The Estimation of Sex on the Basis of the Talus and Calcaneus. American Journal of Physical Anthropology 45:581-588.

Steele, D. Gentry, and Claud A. Bramblett

1988 The Anatomy and Biology of the Human Skeleton. Texas A\&M University Press, College Station.

Steely, Jim

1984 Monuments for the Living. Texas Highways 31 (August):32-37.

Steinbock, R. Ted

1976 Paleopathological Diagnosis and Interpretation: Bone Diseases in Ancient Human Populations. Charles C. Thomas, Springfield, Illinois.
Steiner, Paul E.

1968 Disease in the Civil War: Natural Biological Warfare in 1861-1865. Charles C. Thomas, Springfield, Illinois.

Stewart, T. Dale

1979 Essentials of Forensic Anthropology Especially as Developed in the United States. Charles C. Thomas, Springfield, Illinois.

Stini, William A.

1979 Adaptive Strategies of Human Populations under Nutritional Stress. In Physiological and Morphological Adaptation and Evolution, edited by W. A. Stini, pp. 387-407. Mouton Publishers, New York.

Stuart-Macadam, Patricia L.

1989 Nutritional Deficiency Diseases: A Survey of Scurvy, Rickets, and Iron Deficiency Anemia. In Reconstruction of Life from the Skeleton, edited by M. Y. Iscan and K. A. R. Kennedy, pp. 201-222. Alan R. Liss, Inc., New York.

Superintendent of Public Buildings and Grounds

1879 Report of the Superintendent of Public Buildings and Grounds of the State of Texas. January 1, 1879. A. H. Belo \& Co., State Printers, Galveston, Texas.

1886 Biennial Report of the Superintendent of Public Buildings and Grounds, December 1 , 1886. State Printing Office, Austin, Texas.

1888a Report of the Superintendent of Public Buildings and Grounds, April 16, 1888. State Printing Office, Austin, Texas.

1888b Report of the Superintendent of Public Buildings and Grounds, December 1, 1888. State Printing Office, Austin, Texas.

1890 Report of the Superintendent of Public Buildings and Grounds, December 1, 1890. State Printing Office, Austin, Texas.

1896 Report of Superintendent of Public Buildings and Grounds, Austin, November 1, 1896. Ben C. Jones \& Co., State Printers, Austin, Texas.

1900 Report of the Superintendent of Public Buildings and Grounds, December 1, 1890. State Printing Office, Austin, Texas. 
1902 Biennial Report of the Superintendent of Public Buildings and Grounds, Austin, Texas, For Two Years Ending August 31, 1902. Von Boeckmann, Schutze \& Co., State Printers, Austin, Texas.

1905 Biennial Report of the Superintendent of Public Buildings and Grounds, Austin, Texas, For Two Years Ending August 31, 1904. The State Printing Office, Austin, Texas.

[1908] Biennial Report of the Superintendent of Public Buildings and Grounds, Austin, Texas, For Two Years Ending August 31, 1908. Austin Printing Company, Austin, Texas.

[1910] Biennial Report of the Superintendent of Public Buildings and Grounds, Austin, Texas, For Two Years Ending August 31, 1910. Austin Printing Company, Austin, Tẹas.

1914 Biennial Report of the Superintendent of Public Buildings and Grounds For Two Years Ending August 31, 1914. Von BoeckmannJones Co., Austin, Texas.

Taylor, Anna J., Anne A. Fox, and I. Wayne Cox 1986 Archaeological Investigations at Morgan Chapel Cemetery (41BP200), A Historic Cemetery in Bastrop County, Texas. Archaeological Survey Report No. 146. Center for Archaeological Research, The University of Texas at San Antonio.

Texas Confederate Home

1904 Annual Report of the Board of Managers and Superintendent of the Texas Confederate Home for the Year Ending August 31, 1904. Von Boeckmann-Jones Company, Austin.

1908 Biennial Report of the Board of Managers of the Texas Confederate Home for the Two Years Ending August 31, 1908. Von Boeckmann-Jones Company, Austin.

Texas. Fourth Legislature

1851 Journal of the Senate of the State of Texas. No. 17. Texas State Archives, Austin.

1852 Joint Resolution No. 17, passed January 15, 1852. Box 100-1465, Record Group 100, Texas State Library and Archives, Austin, Texas.

Texas. Forty-First Legislature

1929a Appropriation made by the Forty-First Legislature, Second called session. Copy in the files of Janice Hughes, State Building, State Building Commission, Austin, Texas.

1929b Appropriation made by the Forty-First Legislature, Fifth Called session. Copy in the files of Janice Hughes, State Building, State Building Commission, Austin, Texas.

Texas. Forty-Second Legislature

1931 Appropriation made by the Forty-Second Legislature, Regular Session. Copy in the files of Janice Hughes, State Building, State Building Commission, Austin, Texas.

Texas. Forty-Fourth Legislature

1935 Appropriation made by the Forty-Fourth Legislature, Regular Session. Copy in the files of Janice Hughes, State Building, State Building Commission, Austin, Texas.

Texas. General Land Office

1849a City of Austin File \#386.

1849b Patent Record, Out Lots Austin 2.

Texas Historical Commission

Local History Program Files

Texas. House of Representatives

1852 Journal of the House of Representatives of the State of Texas: Fourth Legislature. Cushney \& Hampton, "State Gazette" Office, Austin, Texas.

Texas Public Employee, The

1963 The Stones of the Great Lie on a Hillside Near Downtown Austin. The Texas Public Employee (March):4-5, 16.

Texas State Board of Control

[1932] Sixth Biennial Report of the Texas State Board of Control for the Biennium Ended August 31, 1932. Knape Printing Co., Austin, Texas. Incomplete copy on file at General Services Commission, Austin.

Texas. State Comptroller

1851 Ad valorem tax records, Travis County.

Texas State Gazette, The

Texas. State Highway Department

1930 Minutes of the Board of the State Highway Department, February 26, 1930. Copy in the files of Janice Hughes, State Building, State Building Commission, Austin, Texas. 
Tham, S., and D. C. R. Ireland

1992 Intraosseous Ganglion Cyst of the Lunate: Diagnosis and Management. Journal of Hand Surgery, British Volume 17(4):429-432.

Tobias, Phillip V.

1972 Growth and Stature in Southern African Populations. In Human Biology of Environmental Change, edited by D. J. M. Vorster, pp. 96-104. International Biological Programme, London.

Toulouse, Julian Harrison

1971 Bottle Makers and Their Marks. Thomas Nelson, Inc., New York.

Tovi, Ferit, Daniel Benharroch, Albert Gatot, and Yanku Hertzanu

1992 Osteoblastic Osteitis of the Maxillary Sinus. Laryngoscope 102:426-430.

Townsend, W. B.

1910 General and Special Laws of the State of Texas Passed by the Thirty-First Legislature at its Third Called Session Convened July 19, 1910, and Adjourned August 17, 1910, and at Its Fourth Called Session Convened August 18, 1910, and Adjourned September 10, 1910. Von Boeckmann-Jones Co., Printers, Austin, Texas.

Travis County

Civil Minutes

Deed Records

Marriage Records

Trinkley, Michael, and Debi Hacker-Norton

1984 Analysis of Coffin Hardware from $38 \mathrm{CH} 778$, Charleston County, South Carolina. Research Series 3. Chicora Foundation, Columbia, South Carolina.

Trotter, Mildred

1934 Septal Apertures in the Humerus of American Whites and Negroes. American Journal of Physical Anthropology 19(2):213-227.

Trotter, Mildred, and Goldine C. Gleser

1952 Estimation of Stature from Long Bones of American Whites and Negroes. American Journal of Physical Anthropology 10:463514.

Trotter, Mildred, and Roy R. Peterson

1966 Osteology. In Morris' Human Anatomy: A
Complete Systematic Treatise, edited by B. J. Anson, pp. 133-315. 12th ed. McGraw-Hill, New York.

U.S. Fifty-Eighth Congress, 2d Session

1904 Senate Document No. 234. Government Printing Office, Washington, D.C.

Utsinger, P. D.

1985 Diffuse Idiopathic Skeletal Hyperostosis. Clinics in Rheumatic Diseases 11(2):325-351.

Walthall, R. B.

1929 Contract between R. B. Walthall, Chairman, State Board of Control, and Thurlow B. Weed, Austin, Texas, August 26, 1929. In Box 1991/16-96, Texas State Library and Archives, Austin.

Warden, T. B.

1950 Letter from T. B. Warden, June 7, 1950, to L. W. Kemp, Houston, Texas. Copy in the files of Janice Hughes, State Building, State Building Commission, Austin, Texas.

Watkins, Beverly

1985 Historical Background. In Gone to a Better Land: A Biohistory of a Rural Black Cemetery in the Post-Reconstruction South. Research Series No. 25. Arkansas Archeological Survey, Fayetteville.

Webb, Walter Prescott (editor-in-chief)

1952 The Handbook of Texas, vols. I and II. Texas State Historical Association, Austin.

Webber, F. R.

1938 Church Symbolism: An Explanation of the More Important Symbols of the Old and New Testament, the Primitive, the Mediaeval and the Modern Church. 2nd ed. J. H. Jansen, Cleveland.

Wells, C.

1964 Bones, Bodies, and Disease. Thames and Hudson, London.

Weslowsky, Al B.

1991 The Osteology of the Uxbridge Paupers. In Archaeological Excavations at the Uxbridge Almshouse Burial Ground in Uxbridge Massachusetts, edited by R. J. Elia and A. B. Wesolowsky, pp. 230-253. BAR International Series 564. British Archaeological Reports, Oxford. 
Weyant, R. J., J. A. Jones, M. Hobbins, L. C. Niessen, R. Adelson, and R. R. Rhyne

1993 Oral Health Staus of a Long-Term Care, Veteran Population. Community Dentistry and Oral Epidemiology 21:227-233.

Winchell, Frank, Jerome C. Rose, and Randall W. Moir 1992 Bioarcheological Investigations of Nineteenth Century Burials at Site 41DT105: Cultural Resource Studies for Cooper Lake, Delta County, Texas. Archaeological Research Program, Department of Anthropology, Southern Methodist University.

1995 Health and Hard Times: A Case Study From the Middle to Late Nineteenth Century in East Texas. Chapter 10 in Bodies of Evidence: Reconstructing History through Skeletal Analysis, edited by Anne L. Grauer, pp. 161-172. Wiley-Liss, Inc., New York.

Yetter, Joseph F.

1992 Cleft Lip and Palate. American Family Physician 46:1211-1221.

Yuen, Michael, Lawrence Friedman, William Orr, and W. Peter Cockshott

1992 Proliferative Periosteal Processes of Phalanges: A Unitary Hypothesis. Skeletal Radiology 21:301-303. 
APPENDIX A: Federal Interments in the Texas State Cemetery

Martha Doty Freeman 

Stage I historical research identified documents indicating that 1 acre in the northeastern portion of the State Cemetery had been set aside for the burial of Federal troops after November 9, 1866. Archeological evidence confirmed that burials had occurred within the 1-acre plot, and also revealed that the burial pits uncovered in 1995 had been emptied of their contents (see Chapter 4).

Stage II historical research focused on several issues. One was confirmation of Federal burials in the State Cemetery, a second was identification of the location to which the burials were reinterred, and a third was identification of the individuals whose remains had once been in the Federal plot.

A preliminary investigation led the historian to San Antonio, where she contacted Mr. Alvin J. Sander, Assistant Director of the Fort Sam Houston National Cemetery. The cemetery presently in use is located within Fort Sam Houston adjacent to Harry Wurzbach Road. However, this facility had been preceded by another national cemetery, which was established in 1867 on Paso Hondo. Burial registers in the offices of the Fort Sam Houston National Cemetery enumerated interments in the 1867 national cemetery. Of relevance to the Phase II investigations, the burial registers also enumerated the many reinterments from more than 40 forts, camps, posts, and miscellaneous sites in Texas, New Mexico, Arizona, Indian Territory (Oklahoma), and the Philippine Islands.

The earliest of the registers that recorded activity in Austin listed 18 reinterments by name and 27 reinterments whose identities were unknown. The rank and regiment for each soldier were listed, where known, and the location of reinterment within the National Cemetery indicated (Figure 50). Comparison of the listings within each register resulted in the identification of some previously unidentified burials; confirmation that most of the soldiers had served with the 4th or 6th Cavalry units, both of which were stationed in Austin after 1865; the addition of some death dates; and the identification of the area of reinterment within the National Cemetery (Table 43). A register kept during the twentieth century indicated that the original Section 5 had been redesignated Section C, and plotting of the gravesites on a map copied from the collections of the Environmental Branch at Fort Sam Houston revealed that they were clustered in the eastern portion of Section $\mathrm{C}$ (Figure 51). Some reinterments from Austin also were made to Sections A, B, D, and F.

Reinterment activities at large, historically significant western posts such as Concho and Davis were recorded in the National Cemetery registers in detail. Indeed, notations for these forts indicate the date when the Quartermaster Corps began to exhume bodies and the date when they reinterred the bodies in San Antonio. Unfortunately, records for burials in Austin are less precise, with the registers usually indicating only that the event occurred in Austin or the vicinity of the city. As a result, it is not possible to determine which of the reinterments were made from the State Cemetery since Federal troops were buried at other locations as well. During the winter of 1866, for example, ill troops under Custer's command were hospitalized in a two-story house at 2310 San Gabriel, Austin. Those; who died were buried nearby on the west side of Shoal Creek. Some years later, all but one of the graves were exhumed ${ }^{6}$ and the bodies removed to the National Cemetery. Even today, Oakwood Cemetery contains several graves of "unknown soldiers" (Janet Fish, personal communication 1995) whose headstones display the distinctive shield similar to those on the headstones of former members of the 4th and 6th Cavalries in the San Antonio National Cemetery.

Stage II investigations of the Federal burial site in the State Cemetery yielded further information about the history of the 1-acre reserve. Based on this information, it is possible to conclude that soldiers in the 4th and 6th Cavalries in Austin were buried in that city after the state legislature set aside the acre plot. Some years later, the Quartermaster Corps exhumed approximately 62 burials from Austin and reburied the remains at the National Cemetery on Paso Hondo Street in San Antonio. However, at this point, records do not indicate which of those burials were taken from the State Cemetery. Furthermore, the fact that reinterments were not always complete leaves open the question of whether or not the Quartermaster Corps was able to identify and remove the contents of all graves in the 1-acre reserve.

\footnotetext{
${ }^{6}$ According to Janet Fish (personal communication 1995), those in charge of the exhumations overlooked one burial, which washed out into Shoal Creek during the 1900 flood.
} 


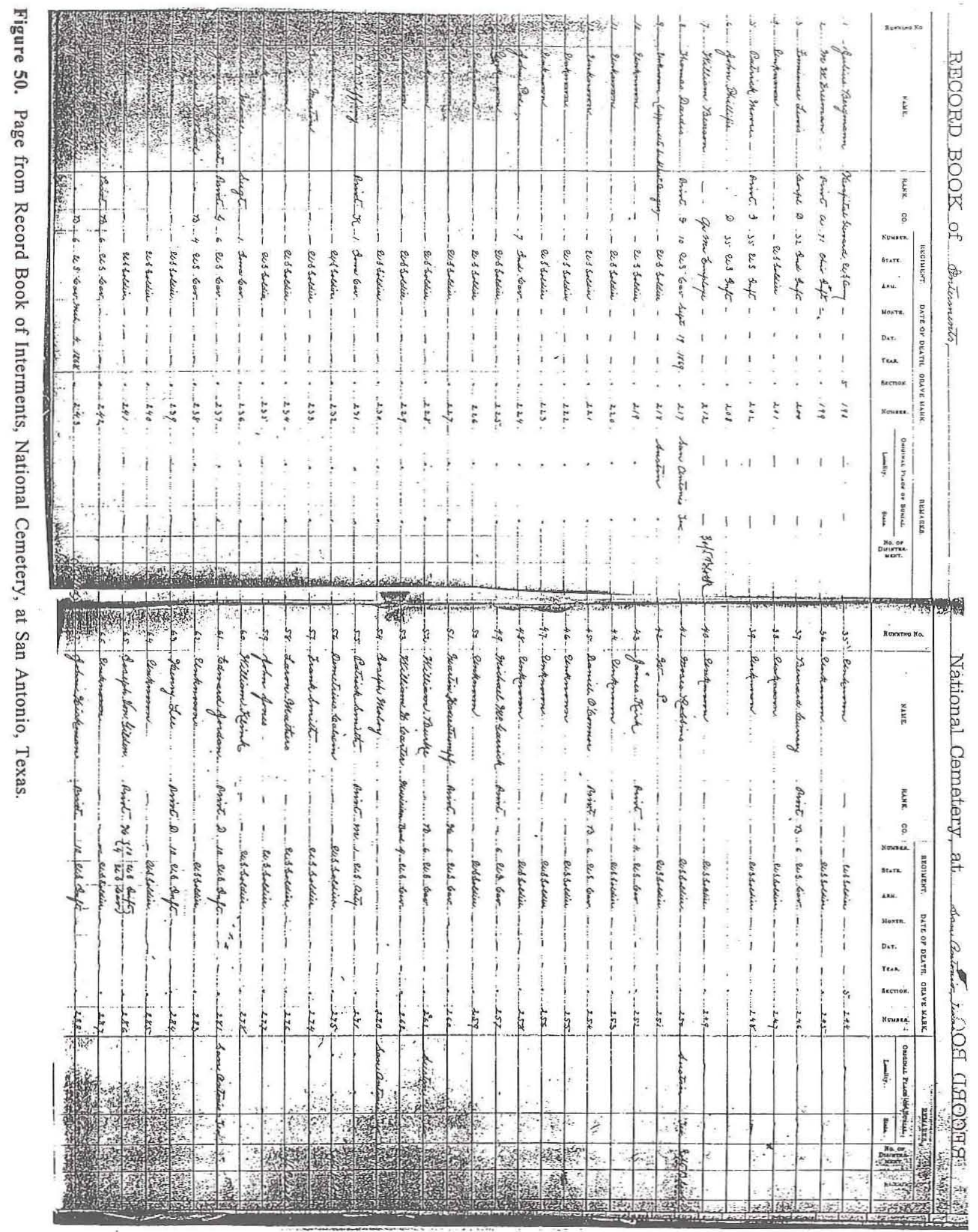




\begin{tabular}{|c|c|c|c|c|}
\hline REINTERMENT & $\begin{array}{l}\text { S FROM AUSTIN, TEXAS } \\
\text { (PASO HONDO }\end{array}$ & $\begin{array}{l}\text { ABLE } 43 \\
\text { N THE UNITED STATES } \\
\text { AN ANTONIO, TEXAS* }\end{array}$ & NATIONAL CE & METERY \\
\hline Name & Rank, Company & Date of Death & Grave Mark & $\begin{array}{l}\text { Original Place } \\
\text { of Burial }\end{array}$ \\
\hline $\begin{array}{l}\text { Robert Foote Sellers, } \\
\text { son of Captain Sellers }\end{array}$ &,- 10th U.S. Infantry & April 16,1873 & $\begin{array}{l}\text { A, no. } 369 \\
\text { [also no. 1] }\end{array}$ & Austin \\
\hline $\begin{array}{l}\text { Adele Hall, daughter } \\
\text { of Lt. R. T. Hall, } \\
\text { Quartermaster }\end{array}$ & -, 1st U.S. Artillery & $\begin{array}{l}\text { February 18, } 1900 \\
\text { [also February 2,1900] }\end{array}$ & $\begin{array}{l}\text { A, no. 1255 } \\
\text { [also no. 73] }\end{array}$ & Austin \\
\hline Unknown & officer, U.S. Army & - & [A], no. 294 & Austin \\
\hline $\begin{array}{l}\text { James C. Callahan** } \\
\text { (also Callehan) }\end{array}$ & $\begin{array}{l}\text { 1st lieutenant, 4th } \\
\text { Regiment, U.S. Cavalry }\end{array}$ & March 25, 1870 & $\begin{array}{l}\text { A, no. } 296 \\
\text { [also no. } 78 \text { ] }\end{array}$ & Austin \\
\hline John O. Cummins & clerk, C. S. Dept. & - & [A], no.. 265 & Austin \\
\hline $\begin{array}{l}\text { Euphan Reynolds, } \\
\text { daughter of General } \\
\text { J. J. Reynolds }\end{array}$ & - & July 28, 1869 & $\begin{array}{l}\text { A, no. 267 } \\
\text { [also no. 67] }\end{array}$ & Austin \\
\hline $\begin{array}{l}\text { Albert Burgess } \\
\text { (supposed to be) }\end{array}$ & U.S. soldier & - & C, no. 278 & Austin \\
\hline G. W. Flint & $\begin{array}{l}\text { 1st sergeant, Co. K, } \\
\text { 13th Wisconsin Infantry }\end{array}$ & - & B, no. 87 & Austin \\
\hline G. W. Flint $[s i c]$ & sergeant, U.S. Army & - & B, no. 143 & Austin \\
\hline John Hannon & $\begin{array}{l}\text { private, Co. A, } \\
\text { 6th U.S. Cavalry }\end{array}$ & - & B, no. 172 & Austin \\
\hline John A. Huber & $\begin{array}{l}\text { private, Co. C, } \\
\text { 13th Wisconsin Infantry }\end{array}$ & - & $\begin{array}{l}\text { B, no. } 150 \\
\text { [also no. 190] }\end{array}$ & Austin \\
\hline J.A.H. & U.S. soldier & - & [B], no. 156 & Austin \\
\hline Arthur L. Hall & $\begin{array}{l}\text { private, 6th Battery, } \\
\text { U.S. Artillery }\end{array}$ & January 7, 1906 & F, no. 1033 & $\begin{array}{l}\text { Austin, Tex., } \\
\text { on march to } \\
\text { Fort Sam } \\
\text { Houston }\end{array}$ \\
\hline E. E. Richards & $\begin{array}{l}\text { private, Co. A, } \\
\text { 51st Indiana Infantry }\end{array}$ & August 22, 1865 & B, no. 59 & [Austin?] \\
\hline Moses Robbins & -, U.S. Army & - & C, no. 256 & Austin \\
\hline $\begin{array}{l}\text { Byron Rodgers, } \\
\text { colored }\end{array}$ & recruit, unassigned & December 28, 1876 & D, no. 774 & [Austin?]. \\
\hline \multicolumn{5}{|c|}{$\begin{array}{l}\text { *Compiled from Registers 1-3, United States National Cemetery (Fort Sam Houston) } \\
\text { **According to the Weekly State Journal (March 31, 1870, p. 6), "Brevet Major" Callahan was killed by two } \\
\text { recently assigned recruits near the sutler store. Callahan had ordered the men back to camp. An argument } \\
\text { ensued and one recruit hit Callahan on the head with a board that had a nail in one end. The newspaper } \\
\text { described the funeral but failed to identify the place of interment. }\end{array}$} \\
\hline
\end{tabular}




\begin{tabular}{|c|c|c|c|c|}
\hline \multicolumn{5}{|l|}{ Table 43 , continued } \\
\hline Name & Rank, Company & Date of Death & Grave Mark & $\begin{array}{l}\text { Original Place } \\
\text { of Burial }\end{array}$ \\
\hline O. B. Tiffany & $\begin{array}{l}\text { private, Co. K, 1st } \\
\text { Regiment, Iowa Cavalry }\end{array}$ & November 5,1865 & C, no. 212 & Austin \\
\hline John Tobin & $\begin{array}{l}\text { private, Co. B, } \\
\text { 6th U.S. Cavalry }\end{array}$ & - & B, no. 176 & Austin \\
\hline Theodore N. Wood & $\begin{array}{l}\text { private, Co. B, } \\
\text { 4th U.S. Cavalry }\end{array}$ & September 3, 1868 & C, no. 200 & Austin \\
\hline Alexander N. Shipley & $\begin{array}{l}\text { lieutenant colonel and } \\
\text { quartermaster, U.S.A. }\end{array}$ & November 15, 1904 & $\begin{array}{l}\text { A, no. } 1443 \\
\text { [also no. 170] }\end{array}$ & Austin \\
\hline Henry Frayer & $\begin{array}{l}\text { private, Co. C, } \\
6 \text { th U.S. Cavalry }\end{array}$ & - & B, no. 183 & Austin \\
\hline John Poe & $\begin{array}{l}\text { private, Co. E, } \\
\text { 7th Indiana Cavalry . }\end{array}$ & November 3,1865 & C, no. 218 & Austin \\
\hline Isaac Martin & -, U.S. soldier & - & C, no. 207 & Austin \\
\hline Oscar Moore & sergeant, 1st Iowa Cavalry & - & C, no. 205 & Austin \\
\hline James Pendergrast & $\begin{array}{l}\text { private, Co. G, } \\
\text { 6th U. S. Cavalry }\end{array}$ & November 8,1865 & C, no. 202 & Austin \\
\hline George B. Bader & $\begin{array}{l}\text { private, Co. B, } \\
\text { 6th U.S. Cavalry }\end{array}$ & - & - & Austin \\
\hline James McDonough & $\begin{array}{l}\text { private, Co. B, } \\
\text { 6th U.S. Cavalry }\end{array}$ & March 4, 1868 & C, no. 196 & Austin \\
\hline Bernard Currey*** & $\begin{array}{l}\text { private, Co. B, } \\
\text { 6th U.S. Cavalry }\end{array}$ & August 23, [1868] & C, no. 193 & Austin \\
\hline W. P. & U.S. soldier & - & - & Austin \\
\hline James Kirk & private, 4th U.S. Cavalry & - & C, no. 254 & Austin \\
\hline Daniel O'Connor*** & $\begin{array}{l}\text { private, Co. B, } \\
\text { 6th U.S. Cavalry }\end{array}$ & August 23,1868 & C, no. 253 & Austin \\
\hline Michael McGarrick & private, 6th U.S. Cavalry & - & C, no. 250 & Austin \\
\hline $\begin{array}{l}\text { Martin Haverstrumpf } \\
\text { (also Haberstumpf) }\end{array}$ & $\begin{array}{l}\text { private, Co. H, } \\
\text { 6th U.S. Cavalry }\end{array}$ & November 12, 1866 & C, no. 248 & Austin \\
\hline William Burke & $\begin{array}{l}\text { private, Co. B, } \\
6 \text { th U.S. Cavalry }\end{array}$ & March 31, 1867 & C, no. 247 & Austin \\
\hline William H. Carter & musician, 4th U.S. Cavalry & July 4, 1870 & C, no. 246 & Austin . \\
\hline 27 unknowns & & & & 2 \\
\hline $\begin{array}{l}\text { ***According to the } h \\
\text { detachment led by } \\
\text { Mr. Maguire about } \\
\text { detachment and she } \\
\text { location. }\end{array}$ & $\begin{array}{l}\text { kly Austin Republican (Aug } \\
\text { Howe that left Austin "in } \\
\text { miles northwest of Austin, } \\
\text { Currey and O'Connor, who }\end{array}$ & $\begin{array}{l}26,1868, \text { p. 2), Cur } \\
\text { suit of some despera } \\
\text { mounted, and approa } \\
\text { re buried on August }\end{array}$ & $\begin{array}{l}\text { Ind O'Connor we } \\
\text { "They arrived } \\
\text { the house. Mag } \\
\text { ike Callahan, at }\end{array}$ & $\begin{array}{l}\text { part of a } \\
\text { the house of a } \\
\text { re fired on the } \\
\text { unidentified }\end{array}$ \\
\hline
\end{tabular}




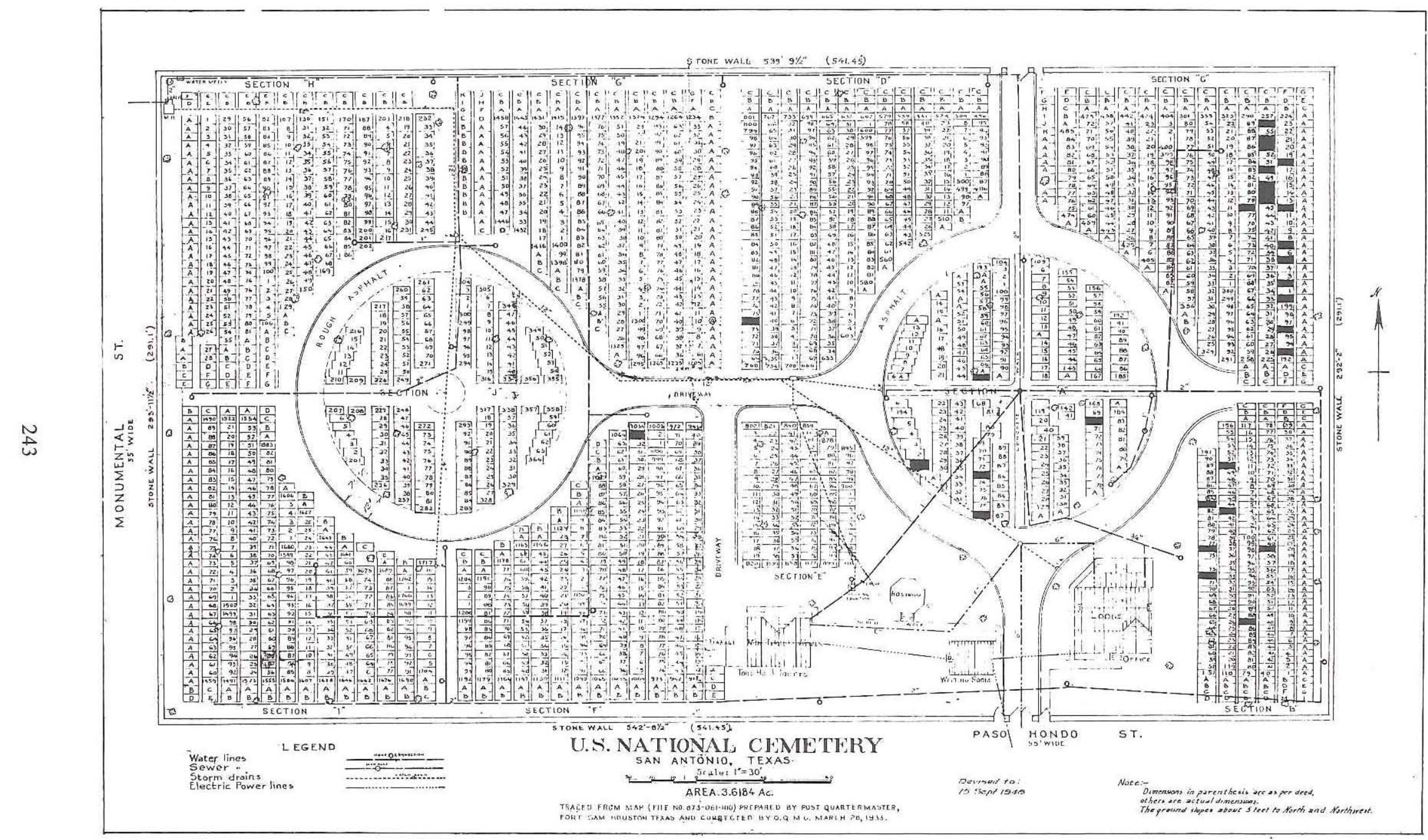

Figure 51. Plat of U.S. National Cemetery, San Antonio, Texas (Paso Hondo Street). From the collections of Fort Sam Houston.

Blackened plots denote locations where Federal soldiers from Austin are interred. 
APPENDIX B: Backhoe Trench Profile Descriptions

Karl W. Kibler 

The profiles of the backhoe trenches are divided into zones, a more-neutral term that allows both soil horizons and depositional units to be described under the same terms. Descriptions for each zone include depth below the surface, thickness, and a field estimation of color and texture. The frequency of inclusions, such as gravels and concretions, is described as few $(<2$ percent), common (2-20 percent), and many ( $>20$ percent). Interpretations concerning soil horizons, depositional processes, and age estimates also were made. Soil horizon classifications follow the guidelines of Birkeland (1984). Relative locations of backhoe trenches within the project area are shown in Figure 2, and interpretations of geomorphic data are presented in Chapter 4 .

Backhoe Trench 1

0-62 cm Artificial gravelly fill.

62-93 cm Yellowish brown clay, few siliceous gravels, terminal Pleistocene? alluvium and colluvium.

93-154+ cm Pale yellow calcareous clay, Upper Cretaceous Austin Group. :

\section{Backhoe Trench 2}

0-50 cm Artificial gravelly fill.

$50-88 \mathrm{~cm} \quad$ Reddish yellow mottled clay, 2Bt soil horizon formed on Capitol terrace deposit.

$88-135 \mathrm{~cm} \quad$ Reddish yellow mottled clay, many $\mathrm{CaCO}_{3}$ nodules, many siliceous gravels, $2 \mathrm{Ck}$ soil horizon formed on Capitol terrace deposit.

135-185+ cm Red sandy clay, many $\mathrm{CaCO}_{3}$ nodules, many siliceous gravels, $2 \mathrm{Ck} 2$ soil horizon formed on Capitol terrace deposit.

Backhoe Trench 3

0-82 cm Artificial gravelly fill.

82-104 cm Yellowish brown clay, many siliceous gravels, many ferromanganese concretions, 2Bsc soil horizon formed on terminal Pleistocene? alluvium.

104-164+ cm Mottled yellowish brown and gray sandy clay, many small siliceous gravels, many ferromanganese concretions, common small $\mathrm{CaCO}_{3}$ nodules, $2 \mathrm{Cksc}$ soil horizon formed on terminal Pleistocene? alluvium.

\section{Backhoe Trench 4}

0-62 cm Artificial gravelly fill.

62-143+ cm Red clay, many siliceous gravels that increase in frequency and size with depth, many $\mathrm{CaCO}_{3}$ nodules that increase in frequency with depth, 2Btk soil horizon formed on Capitol terrace deposit. 
Backhoe Trench 5

0-49 $\mathrm{cm} \quad$ Artificial gravelly fill.

49-124+ $\mathrm{cm} \quad \mathrm{Red}$ sandy clay, many siliceous gravels, many $\mathrm{CaCO}_{3}$ nodules, $2 \mathrm{Ck}$ soil horizon formed on Capitol terrace deposit.

\section{$\underline{\text { Backhoe Trench } 6}$}

$0-38 \mathrm{~cm} \quad$ Artificial gravelly fill.

38-110 cm Mottled yellowish brown and gray sandy clay, many siliceous gravels, many $\mathrm{CaCO}_{3}$ nodules, terminal Pleistocene? alluvium and colluvium.

110-128+ cm Pale yellow calcareous clay, Upper Cretaceous Austin Group.

Backhoe Trench 7

$0-53 \mathrm{~cm} \quad$ Artificial gravelly fill.

53-109 cm Dark gray clay, few siliceous gravels, many $\mathrm{CaCO}_{3}$ nodules, many ferromanganese concretions, terminal Pleistocene? alluvium and cienaga.

109-129+ cm Olive gray sandy clay, many $\mathrm{CaCO}_{3}$ nodules, common siliceous gravels, terminal Pleistocene? alluvium and cienaga.

Backhoe Trench 8

0-78 cm Artificial gravelly fill.

78-108 cm Brown clay loam, many $\mathrm{CaCO}_{3}$ nodules, common siliceous gravels, common manganese concretions, terminal Pleistocene? alluvium and colluvium.

108-146+ $\mathrm{cm}$ Yellowish brown clay, common siliceous gravels, many $\mathrm{CaCO}_{3}$ nodules, Upper Cretaceous Austin Group.

\section{Backhoe Trench 9}

$0-35 \mathrm{~cm} \quad$ Artificial gravelly fill.

35-79+ cm Pale yellow to white extremely calcified clay, Upper Cretaceous Austin Group.

Backhoe Trench 10

0-44 cm Artificial gravelly fill.

44-72+ $\mathrm{cm} \quad$ Pale yellow to white extremely calcified clay, Upper Cretaceous Austin Group. 


\section{Backhoe Trench 11}

0-47 cm Artificial gravelly fill.

47-143+ cm Pale yellow to white extremely calcified clay, Upper Cretaceous Austin Group.

Backhoe Trench 12

0-54 cm Artificial gravelly fill.

54-103 cm Yellowish brown clay, common siliceous gravels, many $\mathrm{CaCO}_{3}$ nodules, terminal Pleistocene? alluvium and colluvium.

103-124+ cm Pale yellow to white extremely calcified clay, Upper Cretaceous Austin Group.

\section{REFERENCE CITED}

Birkeland, Peter W.

1984 Soils and Geomorphology. Oxford University Press, Oxford. 

APPENDIX C: Archeological and Osteological Data Forms 
In conjunction with the excavation of historic burials at the Texas State Cemetery, three forms were used to facilitate data collection in the field and laboratory (see Chapter 2 for an in-depth discussion of data recording methods). During and immediately following the excavation of each burial, a six-page burial excavation form was filled out by the archeologists who did the excavation. This form, which includes a scaled sketch map, was used to document the intraburial proveniences and relationships of the burial container and its associated artifacts (i.e., casket hardware) and the skeletal remains and associated artifacts (i.e., clothing, jewelry, and other personal artifacts). This detailed locational and contextual information is augmented by black-and-white prints and color slides of each burial.

In the laboratory, two other forms were used to record analysis data. A one-page artifact identification form was filled out by the archeologists for each artifact or set of identical artifacts recovered from each burial (e.g., only one form was filled out for four identical casket handles). This form provides precise proveniences, as well as detailed descriptions of each artifact, and a record of all corresponding photographs. In addition, a 13-page osteology data form was completed by the Project Osteologist or her assistant. This form consists of (in order):
- 2 pages devoted to a detailed skeletal inventory

- 1 page of observations on skeletal disorders or pathological conditions (a separate list describing each disorder in more detail also was maintained)

- 2 pages of nonmetric and metric data for assessing an individual's sex

- 1 page of nonmetric data for assessing an individual's age

- 1 page listing all nonmetric biological affinity traits

- 2 pages of cranial and postcranial metric data

- 2 pages of cranial and postcranial nonmetric data

- 2 pages devoted to a dental inventory and dental disorders

All of the burial data analyzed in this report are recorded on these forms; the original field and lab forms for each burial will be curated at the State Cemetery after completion of the renovation work. The three data forms used for the State Cemetery project are presented in this appendix. 
Burial No.

Recorder:

No. of Individuals:

Unit Coordinates (SW):

\section{Grave Shaft}

Soil Type:

Grave Fill

Soil Type:

Color:

Color:

Casket Lid

Wood:

Wood/Glass:

Metal:

Indeterminate:

Other:

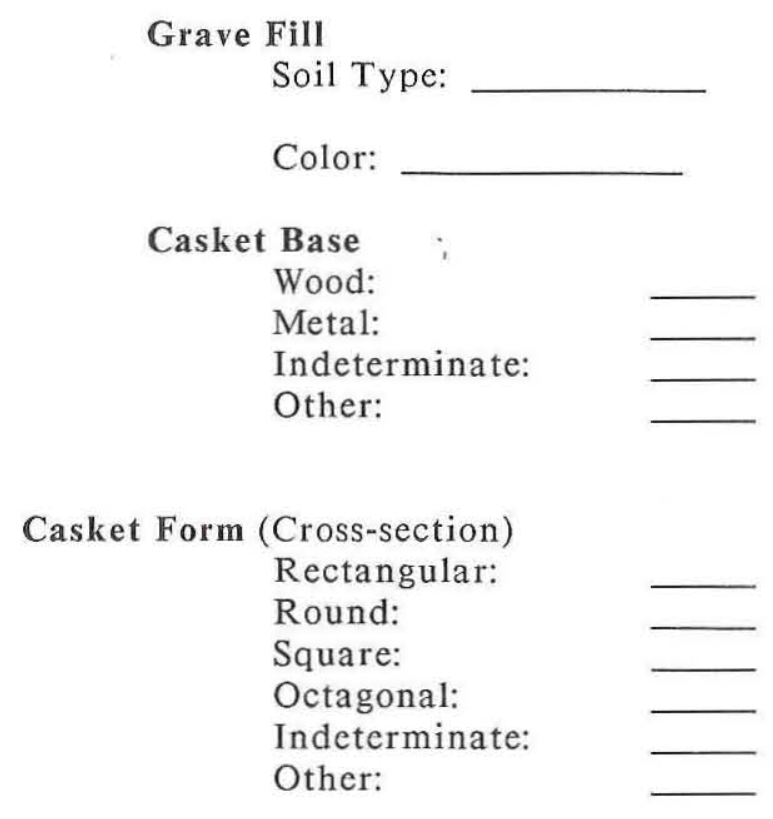

Orientation of Long Axis:

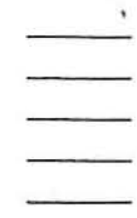

Wood:

Metal:

Indeterminate:

Other:

Casket Form (Plan)

Rectangular:

Tapered to head:

Tapered to feet:

Diamond:

Indeterminate:

Other:

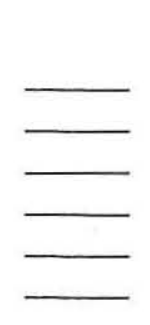

Rectangular:

Round:

Square:

Indeterminate:

Other:

Orientation of Short Axis:

Length of Long Axis (cm):

Length of Short Axis (cm):

Description of Casket and Artifacts: 
Burial No.

Page 2 of 6

Disposal

Primary:

Secondary:

Cremation:

Burial Position

Extended:

Semi-flexed:

Indeterminate:

Other:

Arm Location Left
Extended:
Folded:
Crossed:

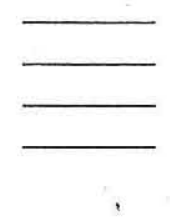

Orientation of Spine:

Description of Burial Position:

\section{Disturbance}

Articulated:

Disturbed:

Indeterminate:

Body Deposition

Supine (Back):

Prone (Front):

Right:

Lef $t$ :

Indeterminate:

Other:

\begin{abstract}
Hands
Over R. Os Coxa:

Over L. Os Coxa:

Over R. shoulder:

Over L. shoulder:

At R. side:

At L. side:

Over/near R. face:

Over/near L. face:

Indeterminate:
\end{abstract}

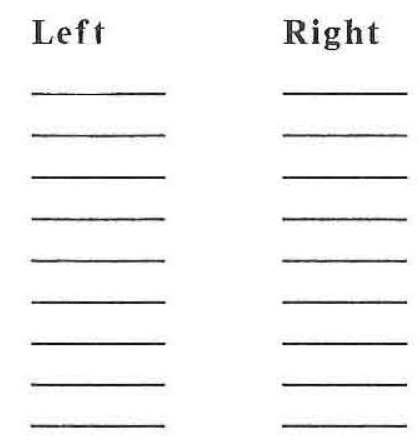

(E or W) Facing (N,S,E,W): 
Burial No.

\begin{tabular}{|c|c|c|c|c|c|}
\hline & \multicolumn{5}{|c|}{ ZONE } \\
\hline GRAVE GOOD & A & B & $\mathbf{C}$ & D & $\mathbf{E}$ \\
\hline \multicolumn{6}{|l|}{ Personal Item } \\
\hline \multicolumn{6}{|l|}{ Glass Button } \\
\hline \multicolumn{6}{|l|}{ Bone Button } \\
\hline \multicolumn{6}{|l|}{ Shell Button } \\
\hline \multicolumn{6}{|l|}{ Porcelain Button } \\
\hline \multicolumn{6}{|l|}{ Metal Button } \\
\hline \multicolumn{6}{|l|}{ Synthetic Button } \\
\hline \multicolumn{6}{|l|}{ Stud } \\
\hline \multicolumn{6}{|l|}{ Straight Pin } \\
\hline \multicolumn{6}{|l|}{ Safety Pin } \\
\hline \multicolumn{6}{|l|}{ Snap Fastener } \\
\hline \multicolumn{6}{|l|}{ Metal Cuff Link } \\
\hline \multicolumn{6}{|l|}{ Metal Pin Jewelry } \\
\hline \multicolumn{6}{|l|}{ Metal Finger Ring } \\
\hline \multicolumn{6}{|l|}{ Metal Earring } \\
\hline \multicolumn{6}{|l|}{ Glass Bead } \\
\hline \multicolumn{6}{|l|}{ Suspender Buckle } \\
\hline \multicolumn{6}{|c|}{ Shoe Leather Fragment } \\
\hline \multicolumn{6}{|l|}{ Eyelet } \\
\hline \multicolumn{6}{|l|}{ Fabric } \\
\hline Dental Appliance & & & & & - \\
\hline $\mathrm{Comb}$ & & & & & . \\
\hline \multicolumn{6}{|l|}{ Coin } \\
\hline Other & & & & & \\
\hline
\end{tabular}


Burial No.

Page 4 of 6

\begin{tabular}{||l|l|l|l|l|l||}
\hline \multicolumn{5}{|c|}{ ZONE } \\
\hline MORTUARY HARDWARE & A & B & C & D & E \\
\hline Casket Handle & & & & & \\
\hline Casket Lid Fastener & & & & & \\
\hline Receptacle Lid Fastencr & & & & & \\
\hline Iron Band & & & & $;$ & \\
\hline Casket Ornament & & & & & \\
\hline Unidentified Metal & & & & & \\
\hline Coffin Wood Fragment & & & & & \\
\hline Plaque & & & & & \\
\hline Diamond Tack & & & & & \\
\hline Nail & & & & & \\
\hline Lining Tack & & & & & \\
\hline Screw & & & & & \\
\hline Corrugated Fastener & & & & & \\
\hline Viewing Window Glass & & & & & \\
\hline Decorator Tack & & & & & \\
\hline Coffin Fabric & & & & & \\
\hline Other Metal & & & & & \\
\hline Other & & & & & \\
\hline
\end{tabular}


Burial No.

\begin{tabular}{||l|l|l|l|l|l||}
\hline \multicolumn{5}{||c||}{ ZONE } \\
\hline $\begin{array}{l}\text { OTHER MISCELLANEOUS } \\
\text { ARTIFACTS }\end{array}$ & A & B & C & D & E \\
\hline Window Glass & & & & & \\
\hline Bottle Glass & & & & & \\
\hline Ceramics & & & & & \\
\hline Pop-top Tabs & & & & & \\
\hline Metal Can & & & & & \\
\hline Metal (non-casket) & & & & & \\
\hline Other Wood Fragment & & & & & \\
\hline Porcelain & & & & & \\
\hline Brick Fragments & & & & & \\
\hline Cement/Mortar Fragment & & & & & \\
\hline Headstone Fragment & & & & & \\
\hline
\end{tabular}

\begin{tabular}{||l|c|c|c|c|c||}
\hline \multicolumn{7}{|c|}{ ZONE } \\
\hline ORGANIC & A & B & C & D & E \\
\hline Human Hair & & & & & \\
\hline Human Tissue & & & & & \\
\hline Animal Bone & & & & & \\
\hline Seeds & & & & & \\
\hline Nuts & & & & & \\
\hline Other & & & & & \\
\hline
\end{tabular}

Pollen Sample, Grave Fill

Pollen Sample, Sacrum/Pelvis:
Field Sack Number:

Ficld Sack Number: 
Burial No.

Page 6 of 6

\section{Plan View}

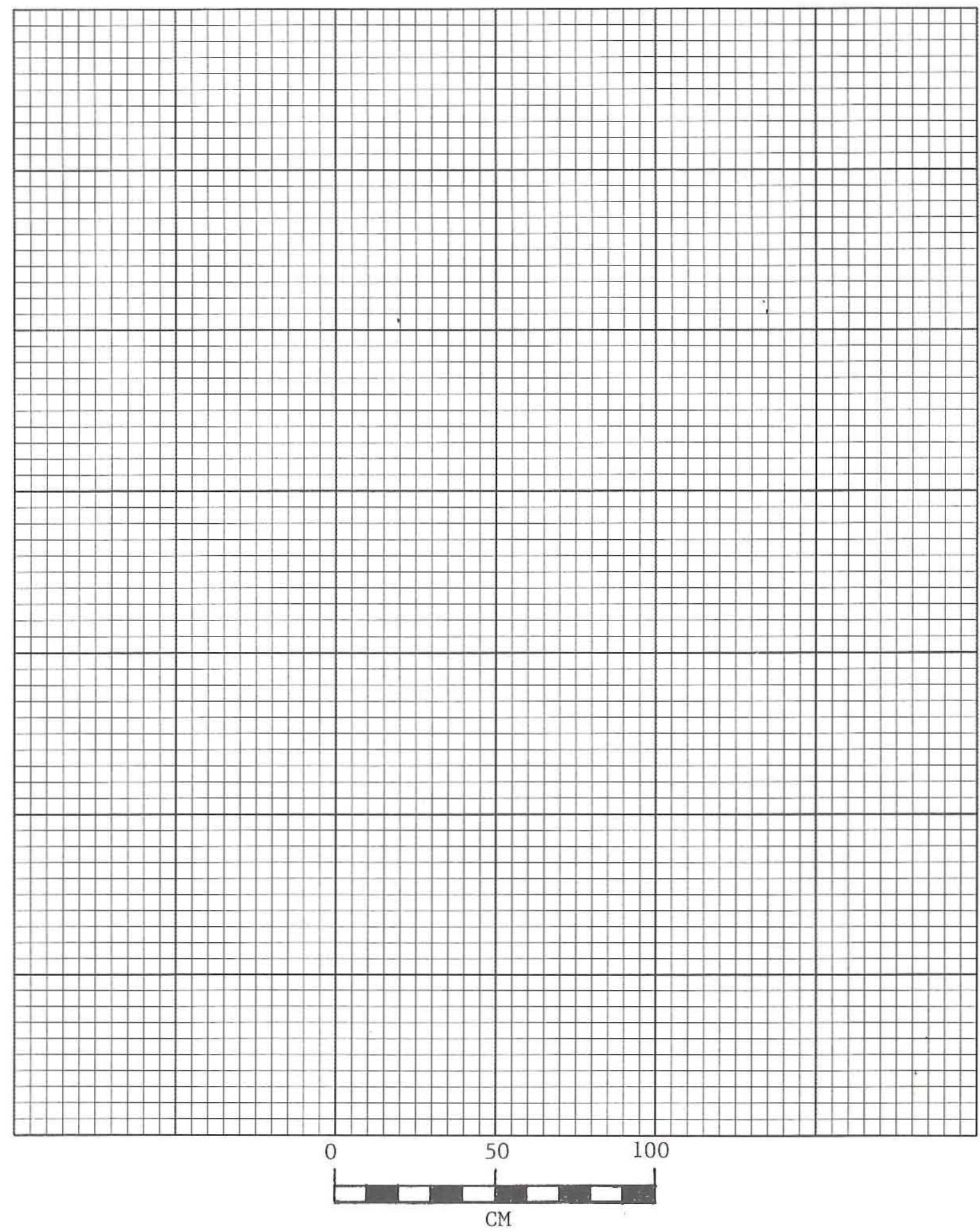


TEXAS STATE CEMETERY RENOVATION PROJECT

Prewitt \& Associates, Inc.-Project \# 95011

ARTIFACT FIELD IDENTIFICATION FORM
P\&AI GRAVE \#

Page of

DATE
ARTIFACT TYPE:

NUMBER OF ARTIFACTS OF THIS TYPE:

MATERIAL TYPE:

$\square$ Iron $\square$ Glass

$\square$ Brass/Bronze/Copper

$\square$ Tin

$\square$ Lead

$\square$ Other metal:

Maximum Width (mm)

Maximum Thickness (mm)

ARTIFACT DESCRIPTION:

\begin{tabular}{l} 
GRAVE ZONE (circle one): \\
\begin{tabular}{|c|c|c|c|c|c|c|c|}
\hline Shaft Fill & A & B & C & D & E & All Zones & Unknown \\
\hline
\end{tabular} \\
\hline
\end{tabular}

LOCATION OF ARTIFACTS WITHIN GRAVE:

PHOTOGRAPHS:

B\&W- Roll \#
Frame \#'s

COLOR- Roll \#

Frame \#'s

ARTIFACT SKETCH (if none, indicate why) 
Burial No.

Recorder:
Date:

Page 1 of 13

\begin{tabular}{|c|c|c|c|c|c|c|}
\hline \multirow[b]{2}{*}{ ELEMENT } & \multicolumn{3}{|c|}{ Left } & \multicolumn{3}{|c|}{ Right } \\
\hline & Cond. & Path1 & Path2 & Cond. & Path1 & Path2 \\
\hline Frontal & & & & $\mathrm{XXXXX}$ & $\mathrm{XXXX}$ & $\mathrm{XXXX}$ \\
\hline \multicolumn{7}{|l|}{ Parietal } \\
\hline \multicolumn{7}{|l|}{ Temporal } \\
\hline Occipital & & & & $\mathrm{XXXXX}$ & $\mathrm{XXXX}$ & $\mathrm{XXXX}$ \\
\hline Sphenoid & & & & $\mathrm{XXXXX}$ & $\mathrm{XXXX}$ & $\mathrm{XXXX}$ \\
\hline \multicolumn{7}{|l|}{ Nasal } \\
\hline \multicolumn{7}{|l|}{ Zygomatic } \\
\hline \multicolumn{7}{|l|}{ Lacrimal } \\
\hline \multicolumn{7}{|l|}{ Maxilla } \\
\hline \multicolumn{7}{|l|}{ Palatine } \\
\hline \multicolumn{7}{|l|}{ Maxillary teeth (number) } \\
\hline \multicolumn{7}{|l|}{ Mandibular teeth (number) } \\
\hline \multicolumn{7}{|l|}{ Mandible } \\
\hline \multicolumn{7}{|l|}{ Clavicle } \\
\hline \multicolumn{7}{|l|}{ Scapula } \\
\hline \multicolumn{7}{|l|}{ Sternum } \\
\hline Ribs (number, cond.) & I & 1 & I & 1 & 1 & 1 \\
\hline \multicolumn{7}{|l|}{ Humerus } \\
\hline \multicolumn{7}{|l|}{ Radius } \\
\hline \multicolumn{7}{|l|}{ Ulna } \\
\hline Carpals (number, cond.) & 1 & l & 1 & 1 & I & 1 \\
\hline $\begin{array}{l}\text { Metacarpals } \\
\text { (number, condition) }\end{array}$ & 1 & l & / & l & 1 & l \\
\hline Phalanges (number) & & & & XXXXX & XXXX & XXXX \\
\hline
\end{tabular}


Burial No.

Skeletal Inventory, cont.

\begin{tabular}{|c|c|c|c|c|c|c|}
\hline \multirow[b]{2}{*}{ ELEMENT } & \multicolumn{3}{|c|}{ Left } & \multicolumn{3}{|c|}{ Right } \\
\hline & Cond. & Path1 & Path2 & Cond. & Path1 & Path2 \\
\hline $\begin{array}{l}\text { Cervical Vertebrac } \\
\text { (number, condition) }\end{array}$ & / & l & / & $\mathrm{XXXXX}$ & $\mathrm{XXXX}$ & $\mathrm{XXXX}$ \\
\hline $\begin{array}{l}\text { Thoracic Vertebrae } \\
\text { (number, condition) }\end{array}$ & / & / & / & $\mathrm{XXXXX}$ & $\mathrm{XXXX}$ & $\mathrm{XXXX}$ \\
\hline $\begin{array}{l}\text { Lumbar Vertebrac } \\
\text { (number, condition) }\end{array}$ & / & l & 1 & $\mathrm{XXXXX}$ & $\mathrm{XXXX}$ & $\mathrm{XXXX}$ \\
\hline Sacrum & & & & $\mathrm{XXXXX}$ & $\mathrm{XXXX}$ & $\mathrm{XXXX}$ \\
\hline Ilium & ' & & & & & \\
\hline \multicolumn{7}{|l|}{ Ischium } \\
\hline \multicolumn{7}{|l|}{ Pubis } \\
\hline \multicolumn{7}{|l|}{ Femur } \\
\hline \multicolumn{7}{|l|}{ Patella } \\
\hline \multicolumn{7}{|l|}{ Tibia } \\
\hline \multicolumn{7}{|l|}{ Fibula } \\
\hline $\begin{array}{l}\text { Metatarsals } \\
\text { (number, condition) }\end{array}$ & / & / & I & / & l & I \\
\hline Tarsals (number, condition) & 1 & 1 & 1 & 1 & I & 1 \\
\hline Phalanges (number, cond.) & l & I & / & $\mathrm{XXXXX}$ & $\mathrm{XXXX}$ & $\mathrm{XXXX}$ \\
\hline
\end{tabular}


Burial No.

Date:

Recorder:

Page 3 of 13

Pathology Diagnosis

(check where applicable)

Infectious Disease

Local Periostitis/Osteitis

Systemic Perio./Osteitis

Treponematosis

Tuberculosis

Other Infection
Trauma

Fracture

Violence

Medical Trauma

Dislocation

Other Trauma:
Degenerative Disease

Degenerative Joint Disease

Osteoarthritis

Rheumatoid Arthritis

Enthesophytosis

Metabolic and Hematological Disease

Generalized Anemia

Other Anemia

(Specify):

Gout

Acromegaly

Scurvy

Rickets

Osteogenic Disorder

(Specify):

\section{Neoplasm}

Osteosarcoma

Chondrosarcoma

Osteoma

Other Neoplasm:

Developmental Disorder

Cleft Palate

Cong. Dysplasia

Other Malformation

(Specify):

Comments: 
Burial No.

Date:

Recorder:

Page 4 of 13

$"-"$ = female, $"+"$ = male

Non-Metric Sex Assessment

\begin{tabular}{|c|c|c|}
\hline $\begin{array}{l}\text { CRANIAL } \\
\text { OBSERVATIONS }\end{array}$ & $\begin{array}{l}\text { SEX } \\
-\end{array}$ & COMMENTS: \\
\hline Forehead & 21012 & \\
\hline Mastoid Process & 21012 & \\
\hline Muscle Markings & 21012 & \\
\hline Occipital area & 21012 & \\
\hline Eye orbit shape & 21012 & \\
\hline Eye rim & 21012 & ; \\
\hline Supraorbital torus & 21012 & \\
\hline Parietal bossing & 21012 & \\
\hline Chin shape & 21012 & \\
\hline Gonial eversion & 21012 & \\
\hline Palate shape & 21012 & \\
\hline PELVIC OBSERVATIONS & 21012 & \\
\hline Sciatic notch & 21012 & \\
\hline Preauricular sulcus & 21012 & \\
\hline Iliac blade & 21012 & \\
\hline Pubic shape & 21012 & \\
\hline Subpubic angle & 21012 & \\
\hline Ventral arc & 21012 & \\
\hline Dorsal pits & 21012 & \\
\hline TOTAL SCORE & & \\
\hline
\end{tabular}


Burial No,

Date:

Recorder:

$\longrightarrow$

$r:$

Page 5 of 13

Metric Sex Assessment

TALUS- R OR L

Maximum length: _ $\mathrm{mm}$

Maximum width: $\mathrm{mm}$

Body height: $\mathrm{mm}$

Max. length trochlea $\mathrm{mm}$

Max. width trochlea $\mathrm{mm}$

Discriminant function number:

Score:

Sex: Male

Female

CALCANEUS- R OR L

Body height:

$\longrightarrow \mathrm{mm}$

Discriminant function number:

Score:

Sex: Male

Female

Comments: 
Burial No.

Date:

Recorder:

Non-Metric Age Assessment

Gilbert-McKern-Stewart Scores

Component II (Ventral):

Component III (Rim):

Component I (Dorsal):

Total Score:

Estimated Age: $\pm$

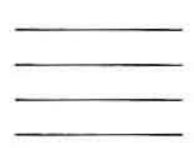

Suchey-Brooks Score

Component:

Grade:

Estimated Age:

Auricular Surface Morphology

Surface Granularity:

Billowing:

Apex Distinctiveness:

Retro-Auricular Activity:

Marginal Lipping:

Estimated Age:

$\pm$

Comments: 
Burial No.

Date:

Recorder:

Page 7 of 13

Non-Metric Biological Affinity

Inion hook

Metopic trace

Major sutures simple

Sloping eye orbits

Depressed nasion

"Tower" nasals

Large nasal spine

Retreating zygomatics

No prognathism

Carabelli's cusp

Parabolic dental arcade

Bilobate chin

Prominent chin

Pinched \& slanted ascending ramus

Straight gonial angle

Rounded external auditory meatus

Oval window visible

Palatine suture bulging

S-shaped zygomatico-maxillary suture

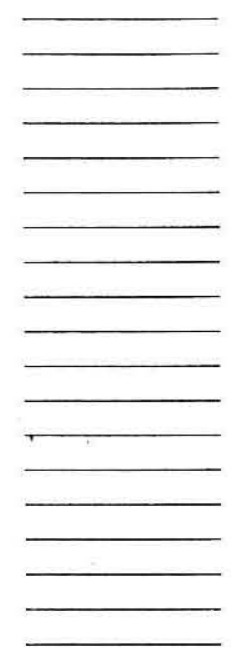

Comments: 
Burial No.

Date:

Recorder:

Page 8 of 13

Cranial Metric Data

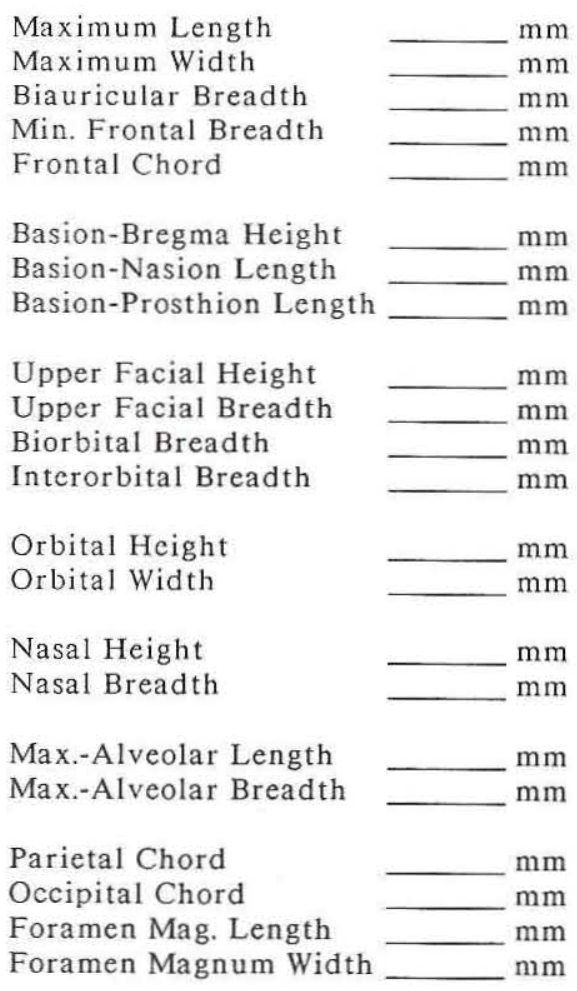

Mandibular Length

Bicondylar Brcadth

Ascending Ramus Hcight

Chin Height

Height of mand. body

Breadth of mand. body

Bigonial Breadth

Minimum Ramus Brcadth

Maximum Ramus Breadth

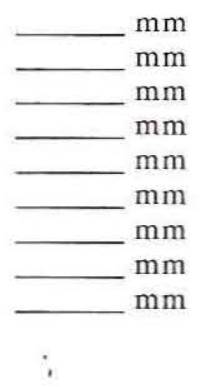


Burial No.

Date:

Recorder:

Postcranial Metric Data

Humerus

Maximum length

Max. diameter (MS)

Min. diameter

Vertical maximum

diameter of head

Transverse diameter

of head

Biepicond. width

Radius

Maximum length

A-P diameter (MS)

M-L diameter (MS)

UIna

Maximum length

Min. circumference

A-P diameter (MS)

M-L diameter (MS)

Physiol. length

Femur

Maximum length

Bicondylar length

Midshaft circum.

Ant-Post diameter

Transverse diameter

Head diameter

Bicondylar width

A-P subtroch. dia.

M-L subtroch. dia.

Tibia

Maximum length

Circumference (NF)

A-P diameter (NF)

M-L diameter (NF)

Prox. epiph. breadth

Distal epip. breadth
Fibula

Maximum length

Maximum diameter (MS)

Scapula

Maximum height

Maximum breadth

Clavicle

Maximum length

Anterior dia. (MS)

Superior dia. (MS)

Os coxa

Maximum height

Maximum width

Ischial length

Pubis length

Sacrum

Anterior length

Ant. sup. breadth

Max. tran. dia. base 
Burial No.

Date:

Recorder:

Non-Metric Traits

1. Metopic Suture:

$0=a b s e n t$

$1=$ partial

$2=$ complete

$9=$ unobservable

2. Supraorbital Structures

a. Supraorbital notch:

$0=a b s e n t$

$1=$ present $<1 / 2$ occluded by spicules

$2=$ present, $>1 / 2$ occluded by spicules

3 = present, degree of occlusion unknown

$4=$ multiple notches

$9=$ unobservable

b. Supraorbital foramen:

$0=$ absent

$1=$ present

2 = multiple foramina

$9=$ unobservable

3. Infraorbital Suture:

$0=a b s e n t$

$1=$ partial

2 = complete

$9=$ unobservable

4. Multiple Infraorbital Foramina:

$0=a b s e n t$

$1=$ internal division only

$2=$ two distinct foramina

$3=$ more than two distinct foramina

$9=$ unobservable

5. Zygomatico-facial Foramina:

$0=$ absent

$1=1$ large

$2=1$ large plus smaller $\mathrm{f}$.

$3=2$ large

$4=2$ large plus smaller $\mathrm{f}$.

$5=1$ small

$6=$ multiple small

$9=$ unobservable

6. Parietal Foramen:

$0=a b s e n t$

$1=$ present, on parietal

$2=$ present, sutural

$9=$ unobservable

From Buikstra and Ubelaker, 1994
L $\quad$ M R

\section{Sutural Bones}

$0=a b s e n t$

$1=$ present

$9=$ unobservable

a. epipteric bone:

b. coronal ossicle:

c. bregmatic bone:

d. sagittal ossicle:

e. apical bone:

f. lambdoid ossicle:

g. asterionic bone:

$h$ ossicle in occipito-

mastoid suture:

i. parietal notch bone:

8. Inca Bone

$0=$ absent

$1=$ complete, single bone

2 = bipartite

$3=$ tripartite

$4=$ partial

$9=$ unobservable

9. Condylar Canal:

$0=$ not patent

$1=$ patent

9 = unobservable

10. Divided Hypoglossal Canal: $0=$ absent

$1=$ partial, internal surface

$2=$ partial, within canal

$3=$ complete, internal surface

$4=$ complete, within canal

$9=$ unobservable

11. Flexure of Superior Sagittal Sulcus

$1=$ Right

$2=$ Left

3 = Bifurcate

$9=$ Unobservable

12. Foramen Ovale Incomplete: $0=a b s e n t$

$1=$ partial formation

$2=$ no definition of foramen

$9=$ unobservable
L $M \quad R$
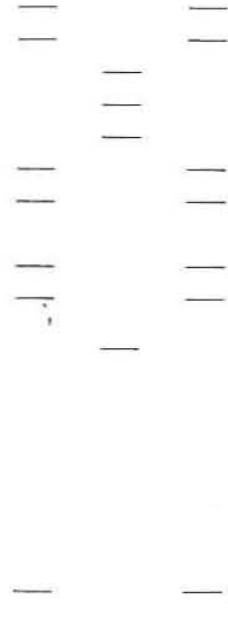

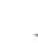

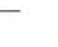


Burial No.

Date:

Recorder:

Page 11 of 13

Non-Metric Traits

L M R

13. Foramen Spinosum Incomplete:

$0=a b s e n t$

1 = partial formation

$2=$ no definition of foramen

$9=$ unobservable

14. Pterygo-spinous Bridge:

$0=a b s e n t$

1 = trace (spicule only)

2 = partial bridge

$3=$ complete bridge

$9=$ unobservable

15. Pterygo-alar Bridge:

$0=$ absent

1 = trace (spicule only)

2 = partial bridge

$3=$ complete bridge

$9=$ unobservable

16. Tympanic Dihiscence:

$$
0=a b s e n t
$$

$1=$ foramen only

2 = full defect present

$9=$ unobservable

17. Auditory Exostosis:

$0=$ absent

$1=<1 / 3$ canal occluded

$2=1 / 3-2 / 3$ canal occluded

$3=>2 / 3$ canal occluded

$9=$ unobservable

18. Mastoid Foramen

a. Location:

$0=a b s e n t$

$1=$ temporal

$2=$ sutural

$3=$ occipita

$4=$ both sutural and temporal

$5=$ both occipital and temporal

$9=$ unobservable

b. Number:

$0=a b s e n t$

$1=1$

$2=2$

$3=$ more than 2

$9=$ unobservable

19. Mental Foramen:
$0=a b s e n t$
$1=1$
$2=2$
$3=>2$
$9=$ unobservable

20. Mandibular Torus:

$0=$ absent

$1=$ trace (can palpate but not see)

2 = moderate: elevation between $2.5 \mathrm{~mm}$.

$3=$ marked: elevation greater than $5 \mathrm{~mm}$.

$9=$ unobservable

\section{Mylohyoid Bridge}

a. Location:

$0=$ absent

$1=$ near mandibular foramen

2 = center of groove

$3=$ both bridges described in 1) and 2), with hiatus

$4=$ both bridges described in, 1) and 2), no hiatus

$9=$ unobservable

b. Degree:

$0=a b s e n t$

$1=$ partial

$2=$ complete

$9=$ unobservable

22. Atlas Bridging

a. Lateral Bridging:

$0=$ absent

$1=$ partial

2 = complete

$9=$ unobservable

b. Posterior Bridging

$0=a b s e n t$

$1=$ partial

2 = complete

$9=$ unobservable

23. Accessory Transverse Foramina:

in 7 th Cervical Vertebra

$0=$ absent

$1=$ partial

2 = complete

$9=$ unobservable

24. Septal Aperture:

$0=a b s e n t$

$1=$ small foramen (pinhole) only

$2=$ true perforation

$9=$ unobservable
L $\quad M \quad R$ 
Burial \#:

Date:

Page $\overline{12 \text { of } 13}$

Texas State Cemetery Renovation Project, PAI Project \#95011

DENTAL WEAR AND DENTAL PATHOLOGY DATA MAXILLARY TEETH

RIGHT

LEFT

\begin{tabular}{|c|c|c|c|c|c|c|c|c|c|c|c|c|c|c|c|c|}
\hline VARIABLE & UM3 & UM2 & UM1 & UP4 & UP3 & UC & UI2 & UI1 & UI1 & U12 & UC & UP3 & UP4 & UM1 & UM2 & UM3 \\
\hline Presence & & & & & & & & & & & & & & & & \\
\hline Smith Wear & & & & & & & & & & & & & & & & \\
\hline Resorption & & & & & & & & & & & & & & & & \\
\hline Abcess Type & & & & & & & & & & & & & & & & \\
\hline Abcess Size & & & & & & & & & & & & & & & & \\
\hline Calculus & & & & & & & & & & & & & & & & \\
\hline Hypoplasia Type & & & & & & & & & & & & & & & & \\
\hline Distance to CEJ & & & & & & & & 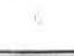 & & & & & & & & \\
\hline Hypercementosis & & & & & & & & & & & & & & & & \\
\hline Caries Location & & & & & & & & & & 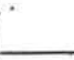 & & & & & & \\
\hline Caries Size & & & & & & & & & & & & & & & & \\
\hline Other: & & & & & & & & & & & & & & & & \\
\hline
\end{tabular}

COMMENTS: 
Burial \#:

Date:

Page $\overline{12 \text { of } 13}$

Texas State Cemetery Renovation Project, PAI Project \#95011

DENTAL WEAR AND DENTAL PATHOLOGY DATA MAXILLARY TEETH

RIGHT

LEFT

\begin{tabular}{|c|c|c|c|c|c|c|c|c|c|c|c|c|c|c|c|c|}
\hline VARIABLE & UM3 & UM2 & UM1 & UP4 & UP3 & UC & UI2 & UI1 & UI1 & UI2 & UC & UP3 & UP4 & UM1 & UM2 & UM3 \\
\hline Presence & & & & & & & & & & & & & & & & \\
\hline Smith Wear & & & & & & & & & & & & & & & & \\
\hline Resorption & & & & & & & & & & & & & & & & \\
\hline Abcess Type & & & & & & & & & & & & & & & & \\
\hline Abcess Size & & & & & & & & & & & & & & & & \\
\hline Calculus & & & & & & & & & & & & & & & & \\
\hline Hypoplasia Type & & & & & & & & & & & & & & & & \\
\hline Distance to CEJ & & & & & & & & 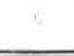 & & & & & & & & \\
\hline Hypercementosis & & & & & & & & & & & & & & & & \\
\hline Caries Location & & & & & & & & & & 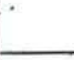 & & & & & & \\
\hline Caries Size & & & & & & & & & & & & & & & & \\
\hline Other: & & & & & & & & & & & & & & & & \\
\hline
\end{tabular}

COMMENTS: 
Texas State Cemetery Renovation Project, PAI Project \#95011

\section{DENTAL WEAR AND DENTAL PATHOLOGY DATA}

MANDIBULAR TEETH

LEFT

RIGHT

\begin{tabular}{|c|c|c|c|c|c|c|c|c|c|c|c|c|c|c|c|c|}
\hline & \multicolumn{8}{|c|}{ LEFT } & \multicolumn{8}{|c|}{ RIGHT } \\
\hline VARIABLE & LM3 & LM2 & LM1 & LP4 & LP3 & LC & LI2 & LI1 & LI1 & $\mathrm{LI} 2$ & LC & LP3 & LP4 & LM1 & LM2 & LM3 \\
\hline Presence & & & & & & & & & & & & & & & & \\
\hline Smith Wear & & & & & & & & & & & & & & & & \\
\hline Resorption & & & & & & & & & & & & & & & & \\
\hline Abcess Type & & & & & & & & & & & & & & & & \\
\hline Abcess Size & & & & & & & & & & & & & & & & \\
\hline Calculus & & & & & & & & & & & & & & & & \\
\hline Hypoplasia Type & & & & & & & & & & & & & & & & \\
\hline Distance to CEJ & & & & & & & & & & & & & & & & \\
\hline Hypercementosis & & & & & & & & & & & & & & & & \\
\hline Caries Location & & & & & & & & & $\therefore$ & & & & & & & \\
\hline Caries Size & & & & & & & & & & & & & & & & \\
\hline Other: & & & & & & & & & & & & & & & & \\
\hline
\end{tabular}

COMMENTS: 



\title{
APPENDIX D: Skeletal Inventory for Analyzed Individuals at the Texas State Cemetery
}

\author{
Compiled by
}

Helen Danzeiser Dockall 

This appendix provides a detailed list of the skeletal remains recovered from each of the analyzed individuals from the State Cemetery. The skeletal sample consists of 56 individuals, noting that one excavated grave contained a sealed iron coffin (Burial 57) that was moved intact.

The condition of each recovered element is indicated by:

$$
\begin{aligned}
& \mathrm{W}=\text { whole } \\
& \mathrm{WE}=\text { whole, eroded } \\
& \mathrm{P}=\text { partial } \\
& \mathrm{C}=\text { complete } \\
& \mathrm{F}=\text { fragmentary }
\end{aligned}
$$

In addition, the following condition designations are used for incomplete long bones:

$$
\begin{aligned}
& \mathrm{P}=\text { proximal (instead of partial) } \\
& \mathrm{S}=\text { shaft } \\
& \mathrm{D}=\text { distal }
\end{aligned}
$$

Other elements, such as sesamoids, ossified cartilage, and the hyoid, are listed in the "Other" column if they were recovered from an individual. 


\begin{tabular}{|c|c|c|c|c|c|c|c|c|c|c|c|}
\hline & Frontal & \multicolumn{2}{|c|}{ Parietal } & \multicolumn{2}{|c|}{ Temporal } & \multirow[t]{2}{*}{ Occipital } & \multirow[t]{2}{*}{ Sphenoid } & \multicolumn{2}{|c|}{ Nasal } & \multicolumn{2}{|c|}{ Zygomatic } \\
\hline Burial \# & & $\mathrm{L}$ & $R$ & $\mathrm{~L}$ & $\mathrm{R}$ & & & $\mathrm{L}$ & $\mathbf{R}$ & & $R$ \\
\hline 1 & W & W & W & W & W & W & W & W & W & W & W \\
\hline 2 & $\mathrm{~W}$ & W & W & W & W & W & $F$ & $P$ & $P$ & W & W \\
\hline 3 & W & W & W & W & W & W & - & - & - & W & W \\
\hline 4 & W & W & W & W & W & W & $\mathrm{W}$ & - & - & W & W \\
\hline 5 & WE & $P$ & $P$ & W & W & $P$ & - & - & - & - & - \\
\hline 6 & $\mathrm{P}$ & W & W & W & W & $\mathrm{W}$ & $P$ & - & - & W & W \\
\hline 7 & WE & W & W & - & WE & WE & - & - & - & - & - \\
\hline 8 & W & W & W & $P$ & $P$ & $\mathrm{P}$ & $F$ & $P$ & $P$ & - & $\mathrm{P}$ \\
\hline 9 & W & $P$ & $P$ & $P$ & $P$ & $P$ & $F$ & $P$ & $P$ & $P$ & W \\
\hline 10 & $F$ & $F$ & $F$ & $P$ & W & $P$ & - & - & - & W & W \\
\hline 11 & $\mathrm{~W}$ & W & W & W & $\mathrm{W}$ & $\mathrm{W}$ & $F$ & WE & WE & $\mathrm{W}$ & W \\
\hline 12 & W & W & W & W & W & W & W & W & WE & W & W \\
\hline 13 & $P$ & $P$ & $P$ & $P$ & $P$ & $P$ & $F$ & - & - & - & - \\
\hline 14 & W & W & W & W & W & WE & $F$ & WE & WE & $\mathrm{F}$ & W \\
\hline 15 & W & $\mathrm{P}$ & $P$ & $\mathrm{P}$ & $P$ & $F$ & $\mathrm{~F}$ & - & - & W & W \\
\hline 16 & W & W & W & W & W & W & W & W & $W$ & W & W \\
\hline 17 & W & W & W & W & $P$ & $P$ & $P$ & W & - & W & W \\
\hline 18 & $F$ & $P$ & W & $P$ & $W$ & $P$ & $F$ & - & - & W & W \\
\hline 19 & $P$ & $\mathrm{~F}$ & $F$ & W & $P$ & $F$ & $\mathrm{~F}$ & - & - & W & $P$ \\
\hline 20 & $P$ & $F$ & $\mathrm{~F}$ & $P$ & W & $F$ & - & - & - & W & W \\
\hline 21 & W & W & W & W & $\mathrm{W}$ & WE & $F$ & W & W & W & W \\
\hline 22 & $\mathrm{~F}$ & $F$ & $F$ & WE & WE & $\mathrm{P}$ & $\mathrm{F}$ & W & $\mathrm{W}$ & $\mathrm{W}$ & W \\
\hline 23 & WE & $F$ & $F$ & $P$ & $P$ & $\mathrm{~F}$ & $F$ & W & W & W & W \\
\hline 24 & $\mathrm{~F}$ & $\mathrm{~F}$ & $F$ & $F$ & $P$ & $F$ & $F$ & - & - & - & - \\
\hline 25 & W & $F$ & $F$ & WE & $P$ & $F$ & $F$ & - & - & W & W \\
\hline 26 & $\mathrm{~F}$ & $F$ & $F$ & W & W & $F$ & $F$ & - & - & W & W \\
\hline 27 & $P$ & $P$ & $P$ & $P$ & $P$ & $F$ & - & W & $P$ & $P$ & W \\
\hline 28 & $P$ & $P$ & $F$ & W & $P$ & $F$ & $F$ & - & - & $P$ & - \\
\hline 29 & $P$ & $P$ & $P$ & W & $P$ & $F$ & $F$ & - & - & W & W \\
\hline 30 & W & WE & WE & WE & WE & $F$ & $F$ & - & - & $P$ & W \\
\hline 31 & $\mathrm{~W}$ & $P$ & $P$ & $P$ & W & $P$ & $F$ & $P$ & $P$ & W & W \\
\hline 32 & $\mathrm{~F}$ & $\mathrm{~F}$ & $F$ & $P$ & $P$ & $F$ & $F$ & - & - & $W, F$ & $\mathrm{~W}$ \\
\hline 33 & $P, F$ & $P, F$ & $\mathrm{P}, \mathrm{F}$ & $\mathrm{P}$ & $\mathrm{P}$ & $P, F$ & $\mathrm{~F}$ & WE & W & W & W \\
\hline 34 & W & $P$ & $P$ & $P$ & $\mathrm{~W}$ & $P$ & $F$ & $F$ & - & W & W \\
\hline 35 & $\mathrm{~W}$ & $P$ & $P$ & $P$ & $P$ & $F$ & $P$ & W & W & - & W \\
\hline 36 & $\mathrm{~W}$ & $F$ & $F$ & W & WE & $F$ & $F$ & $P$ & $P$ & W & W \\
\hline 37 & W & $F$ & $F$ & WE & $W$ & $F$ & $F$ & - & - & - & W \\
\hline 38 & $P$ & $\mathrm{~F}$ & $F$ & $P$ & $P$ & $P$ & $F$ & W & $P$ & W & $P$ \\
\hline 39 & $P$ & $P$ & W & W & W & $P$ & $F$ & - & - & W & - \\
\hline 40 & W & $F, P$ & $F, P$ & WE & WE & $F$ & $F$ & - & - & $W$ & - \\
\hline 41 & $F$ & $F$ & $F$ & WE & WE & $F$ & - & - & - & $P$ & $P$ \\
\hline 42 & W & $P$ & $P$ & $P$ & $W$ & $P$ & $F$ & W & $P$ & W & W \\
\hline 43 & $F$ & $F$ & $P$ & $P$ & $P$ & $P$ & $F$ & - & - & $P$ & $F$ \\
\hline 44 & $P$ & $P$ & $P$ & $P$ & $P$ & $P$ & $F$ & W & W & $P$ & - \\
\hline 45 & $F$ & $\mathrm{~F}$ & $F$ & $F$ & $F$ & $F$ & $F$ & - & - & - & W \\
\hline 46 & W & W & W & W & W & $W$ & $F$ & $P$ & $P$ & $\mathrm{~W}$ & W \\
\hline 47 & W & W & W & W & W & W & $P$ & W & W & $F$ & $P$ \\
\hline 48 & W & W & W & W & W & W & WE & W & W & W & W \\
\hline 49 & $W$ & $P$ & $F$ & $W$ & $P$ & $P$ & WE & - & - & W & $\mathrm{W}$ \\
\hline 50 & $P$ & $P$ & $P$ & - & WE & $F$ & $F$ & - & - & $P$ & W \\
\hline 51 & $F$ & $F$ & $F$ & $F$ & $P$ & $F$ & - & - & - & - & W \\
\hline 52 & W & W & WE & W & $P$ & $P$ & $P$ & $\mathrm{~W}$ & W & W & W \\
\hline 53 & W & WE & $F$ & WE & WE & $F$ & $F$ & $P$ & $P$ & $P$ & $\mathrm{~W}$ \\
\hline 54 & W & W & W & W & W & W & $\mathrm{P}$ & - & - & - & W \\
\hline 55 & $F$ & $P, F$ & $F$ & W & WE & WE & $F$ & - & - & W & W \\
\hline 56 & $P$ & $F$ & $F$ & W & W & $P, F$ & $F$ & $P$ & $P$ & W & W \\
\hline
\end{tabular}




\begin{tabular}{|c|c|c|c|c|c|c|c|c|c|c|c|}
\hline & \multicolumn{2}{|c|}{ Lacrimal } & \multicolumn{2}{|c|}{ Maxilla } & \multicolumn{2}{|c|}{ Palatine } & Mandible & \multicolumn{2}{|c|}{ Clavicle } & \multicolumn{2}{|c|}{ Scapula } \\
\hline Burial \# & $\mathrm{L}$ & $\mathrm{R}$ & $\mathrm{L}$ & $\mathrm{R}$ & $\mathrm{L}$ & $\mathrm{R}$ & & $\mathrm{L}$ & $\mathrm{R}$ & $\mathrm{L}$ & $\mathrm{R}$ \\
\hline 1 & - & - & $\mathrm{F}$ & $F$ & - & - & W & WE & WE & $F$ & $\mathrm{~F}$ \\
\hline 2 & $\mathrm{~F}$ & - & $P$ & W & - & - & W & W & W & $\mathrm{F}$ & $\mathrm{F}$ \\
\hline 3 & - & - & $P$ & - & - & - & W & - & $F$ & $\mathrm{P}$ & $\mathrm{P}$ \\
\hline 4 & - & - & W & WE & W & W & W & W & W & $F$ & $F$ \\
\hline 5 & - & - & - & W & - & - & W & $S$ & WE & $P$ & $F$ \\
\hline 6 & - & - & $\mathrm{P}$ & $\mathrm{P}$ & - & - & W & - & WE & - & $\mathrm{P}$ \\
\hline 7 & - & - & $\mathrm{F}$ & $\mathrm{F}$ & - & - & W & $S$ & S & $P$ & $\mathrm{P}$ \\
\hline 8 & - & - & $P$ & $P$ & W & W & W & WE & WE & - & $\mathrm{P}$ \\
\hline 9 & - & - & $F$ & - & - & - & WE & WE & WE & $\mathrm{P}$ & $P$ \\
\hline 10 & - & - & WE & WE & $P$ & $P$ & WE & WE & W & $P$ & $P$ \\
\hline 11 & - & - & WE & WE & $\mathrm{F}$ & $\mathrm{F}$ & W,F & WE & WE & $P$ & $\mathrm{P}$ \\
\hline 12 & - & - & - & - & - & - & WE & $\mathrm{P}$ & $\mathrm{P}$ & $F$ & $F$ \\
\hline 13 & - & - & $\mathrm{P}$ & $\mathrm{F}$ & - & - & $P$ & WE & WE & $F$ & $F$ \\
\hline 14 & - & - & WE & WE & WE & WE & W & W & WE & $F$ & $\mathrm{P}$ \\
\hline 15 & - & - & $F$ & $F$ & - & - & WE & W & W & $F$ & $\mathrm{P}$ \\
\hline 16 & W & $\mathrm{W}$ & W & W & W & W & W & W & W & $P, F$ & $\mathrm{P}$ \\
\hline 17 & W & $\mathrm{P}$ & $P$ & W & W & W & W & W & $F$ & $\mathrm{P}$ & $F$ \\
\hline 18 & - & - & $P$ & $P$ & - & - & WE & $\mathrm{W}$ & $F$ & $F$ & $F$ \\
\hline 19 & - & - & $F$ & - & - & - & $P, F$ & - & WE & $F$ & $F$ \\
\hline 20 & - & - & $P$ & $P$ & - & - & $P$ & $P$ & WE & $\mathrm{P}$ & $P$ \\
\hline 21 & - & - & $P$ & $\mathrm{~W}$ & W & $w$ & W & $\mathrm{W}$ & $W$ & $P$ & $\mathrm{~W}$ \\
\hline 22 & - & - & $P$ & $P$ & - & - & WE & $S$ & - & $\mathrm{F}$ & $P, F$ \\
\hline 23 & - & - & $F$ & $F$ & - & - & WE,F & WE & WE & $F$ & $F$ \\
\hline 24 & - & - & $F$ & $F$ & - & - & $\mathrm{F}$ & $F$ & - & $F$ & $F$ \\
\hline 25 & - & - & - & $P$ & - & - & WE & WE & $S$ & $\mathrm{P}$ & $\mathrm{P}$ \\
\hline 26 & - & - & WE & WE & - & - & WE & W & W & $P, F$ & $P, F$ \\
\hline 27 & - & - & - & $P$ & - & - & W & W & - & 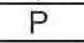 & $F$ \\
\hline 28 & - & - & $P$ & $P$ & - & - & $P$ & $F$ & $F$ & $F$ & $P$ \\
\hline 29 & - & - & W & W & W & W & $P$ & W & $P$ & $F$ & $F$ \\
\hline 30 & - & - & WE & - & - & - & WE & $P$ & $P$ & $P$ & $P$ \\
\hline 31 & - & - & $P$ & $\mathrm{P}$ & - & - & WE & $\mathrm{P}$ & $P$ & $P, F$ & $F$ \\
\hline 32 & - & - & WE & $P, F$ & - & - & WE & - & W & $P$ & $P, F$ \\
\hline 33 & - & - & W & W & WE & - & $\mathrm{W}, \mathrm{F}$ & WE & - & $\mathrm{W}, \mathrm{F}$ & $F$ \\
\hline 34 & - & - & W & W & - & - & W & $W$ & $\mathrm{P}$ & $\bar{P}$ & $F$ \\
\hline 35 & - & - & $P$ & $\mathrm{P}$ & - & - & WE & W & W & $P$ & $\mathrm{P}$ \\
\hline 36 & - & - & $\mathrm{P}$ & $\mathrm{P}$ & - & - & WE & $W$ & W & $\mathrm{P}$ & $\mathrm{P}$ \\
\hline 37 & - & - & WE & W & - & $F$ & WE,F & WE & W & $F$ & WE \\
\hline 38 & - & - & $P$ & $\mathrm{~W}$ & $\mathrm{P}$ & $\mathrm{W}$ & $W$ & $W$ & W & $\mathrm{W}, \mathrm{F}$ & W \\
\hline 39 & - & - & $P$ & $P$ & $W$ & $P$ & W & $\mathrm{W}$ & W & $P$ & W \\
\hline 40 & - & - & $P$ & $\mathrm{P}$ & - & - & WE & $\mathrm{W}$ & W & $\mathrm{P}$ & $F$ \\
\hline 41 & - & - & - & - & - & - & WE & W & $F$ & $F$ & WE \\
\hline 42 & - & - & $F$ & - & - & - & $P$ & WE & W & $F$ & $P$ \\
\hline 43 & - & - & $\mathrm{P}$ & $\bar{P}$ & - & - & $P$ & WE & $F$ & $P$ & $F$ \\
\hline 44 & - & - & $F$ & $\mathrm{P}$ & - & - & WE & W & W & $F$ & $F$ \\
\hline 45 & - & - & WE & $P$ & - & - & $P$ & $F$ & - & WE & $P$ \\
\hline 46 & - & - & $P$ & $W$ & $P$ & $P$ & WE & $W$ & $W$ & WE & $P$ \\
\hline 47 & - & - & $\mathrm{W}$ & W & $P$ & W & WE & $W$ & $W$ & $F$ & WE \\
\hline 48 & $W$ & W & $P$ & $\mathrm{P}$ & - & - & $W$ & $W$ & WE & WE & $F$ \\
\hline 49 & - & - & $P$ & $P$ & - & - & $W$ & $W$ & $W$ & $F$ & $F$ \\
\hline 50 & - & - & $P$ & $P$ & - & - & WE & WE & $W$ & $P$ & $P$ \\
\hline 51 & - & - & - & - & - & - & $P$ & $\mathrm{~W}$ & $P$ & WE & $F$ \\
\hline 52 & $W$ & $\mathrm{~W}$ & - & $F$ & - & - & WE & $W$ & - & $\mathrm{P}$ & $P$ \\
\hline 53 & - & - & W & $P$ & - & - & WE & $F$ & $F$ & $F$ & $P, F$ \\
\hline 54 & - & - & $P$ & $P$ & - & - & W,F & W & - & $P$ & $F$ \\
\hline 55 & - & - & - & $F$ & - & - & WE & WE & $S$ & $P$ & $P$ \\
\hline 56 & - & - & - & $P, F$ & - & - & WE & WE,F & WE,F & $P, F$ & $P, F$ \\
\hline
\end{tabular}




\begin{tabular}{|c|c|c|c|c|c|c|c|c|c|c|}
\hline & Sternum & \multicolumn{3}{|c|}{ Ribs } & \multicolumn{2}{|c|}{ Humerus } & \multicolumn{2}{|c|}{ Radius } & \multicolumn{2}{|c|}{ UIna } \\
\hline Burial \# & & L & $\mathrm{R}$ & $\mathrm{U}$ & $\mathrm{L}$ & $\mathrm{R}$ & $\mathrm{L}$ & $R$ & $\mathrm{~L}$ & $R$ \\
\hline 1 & - & $11, \mathrm{~F}$ & - & - & WE & WE & WE & WE & WE & WE \\
\hline 2 & $F$ & - & - & $42, F$ & WE & WE & WE & D & WE & WE \\
\hline 3 & - & $1, \mathrm{~W}$ & 4,WE & $13, \mathrm{~F}$ & WE & WE & W & WE & WE & WE \\
\hline 4 & W & - & - & $32, F$ & WE & WE & WE & WE & W & WE \\
\hline 5 & - & - & - & $45, \mathrm{~F}$ & WE & WE & WE & WE & WE & WE \\
\hline 6 & - & - & - & - & WE & WE & W & $S, D$ & WE & WE \\
\hline 7 & - & $2, F$ & - & - & $P, S$ & $\mathrm{~s}$ & WE & $S, P$ & WE & S \\
\hline 8 & - & $1, P$ & - & $28, F$ & WE & WE & WE & WE & WE & WE \\
\hline 9 & - & - & - & $58, \mathrm{~F}$ & WE & WE & WE & WE & WE & WE \\
\hline 10 & - & $2, \mathrm{~W}$ & $1, \mathrm{~W}$ & - & $\mathrm{W}$ & $P, S, D$ & WE & $\mathrm{W}$ & WE & W \\
\hline 11 & - & $5, W E$ & $8, W E$ & $22, \mathrm{~F}$ & WE & WE & W & W & WE & W \\
\hline 12 & - & - & - & $25, F$ & WE & WE & WE & WE & WE & WE \\
\hline 13 & - & - & - & $35, F$ & WE & $S, D$ & $S, D$ & W & $S, P$ & W \\
\hline 14 & - & - & - & $10, \mathrm{~F}$ & $S, D$ & W & $S, P$ & W & W & W \\
\hline 15 & - & $9, P$ & $7, P$ & $12, \mathrm{~F}$ & W & $P, S, D$ & W & W & W & $S, P$ \\
\hline 16 & - & $9, F$ & $9, F$ & $47, \mathrm{~F}$ & W & W & $S, P$ & $\mathrm{~W}$ & $S, P$ & W \\
\hline 17 & $P$ & $11, P$ & $9, P$ & $22, \mathrm{~F}$ & W & $\mathrm{W}$ & $S, P$ & $S, P$ & W & $S, P$ \\
\hline 18 & - & $7, P$ & $6, P$ & $12, \mathrm{~F}$ & $P, S, D$ & W & W & $S, P, D$ & $S, P, D$ & W \\
\hline 19 & - & - & - & $6, \mathrm{~F}$ & $S, D, P$ & $\mathrm{~W}$ & $S, D$ & $S, P$ & $S, P$ & $S, P$ \\
\hline 20 & - & $4, P$ & $7, P$ & $17, \mathrm{~F}$ & W & $S, D$ & W & W & $S, P$ & $S, P$ \\
\hline 21 & $F$ & $7, P$ & $10, P$ & $18, \mathrm{~F}$ & W & W & W & W & W & $\mathrm{W}$ \\
\hline 22 & - & $3, P$ & $6, P$ & $16, \mathrm{~F}$ & $S, D, P$ & $\mathrm{~W}$ & $S, D, P$ & $\mathrm{~W}$ & $\mathrm{~W}$ & W \\
\hline 23 & - & $6, \mathrm{~F}$ & $4, F$ & $20, F$ & $P, S, D$ & $S, D$ & $S, D$ & $\mathrm{~W}$ & $\mathrm{~W}$ & W \\
\hline 24 & - & $2, F$ & - & - & $S, D, P$ & $P$ & W & - & $S, P$ & - \\
\hline 25 & - & $9, P$ & $9, P$ & $7, F$ & $S, D, P$ & $S, D$ & $\mathrm{~W}$ & $S, D$ & $P, S, D$ & $S, P$ \\
\hline 26 & - & - & - & $50, F$ & W & $S, D$ & W & $W$ & W & WE \\
\hline 27 & $\mathrm{~F}$ & $12, P$ & $12, P$ & $6, F$ & W & W & W & W & W & W \\
\hline 28 & - & $4, P$ & $7, P$ & $12, F$ & $\mathrm{D}$ & W & $\mathrm{W}$ & $S, P$ & $P, S, D$ & $P, S, D$ \\
\hline 29 & - & $7, P$ & $5, P$ & $14, \mathrm{~F}$ & W & W & $S, P$ & $W$ & $P, S, D$ & W \\
\hline 30 & - & $7, P$ & $9, P$ & $8, F$ & $P, S, D$ & $P, S, D$ & W & $S, P$ & $S, P$ & W \\
\hline 31 & $P$ & $6, P$ & $11, P$ & $21, \mathrm{~F}$ & $P, S, D$ & W & $\mathrm{W}$ & W & W & W \\
\hline 32 & - & $8, P$ & $12, P$ & $20, F$ & W & $P, S, D$ & $S, P$ & $S, P$ & $S, P$ & $S, P$ \\
\hline 33 & $\mathrm{~W}$ & $12, F$ & $12, \mathrm{~F}$ & - & W & WE & $S, P$ & $S, D$ & $S, P$ & $S, P$ \\
\hline 34 & $F$ & $9, P$ & $9, P$ & $12, \mathrm{~F}$ & $S, D$ & W & WE & $W$ & $S, P$ & W \\
\hline 35 & $\bar{W}$ & $9, F$ & $9, F$ & $11, \mathrm{~F}$ & W & $S, P$ & W & $S, P$ & $\mathrm{~W}$ & WE \\
\hline 36 & $P$ & 12,WE & $12, \mathrm{WE}$ & - & W & W & $P, S, D$ & $W$ & W & W \\
\hline 37 & - & 7,WE & 8,WE & $6, F$ & WE & W & $S, D$ & W & $S, P$ & W \\
\hline 38 & $\mathrm{~W}$ & $11, P$ & $10, P$ & $16, \mathrm{~F}$ & W & $P, S, D$ & W & W & W & W \\
\hline 39 & $F$ & $10, P$ & $10, P$ & $22, F$ & W & W & W & W & W & $\mathrm{W}$ \\
\hline 40 & $P$ & $10, F$ & 12,WE & - & $S, D$ & W & $\mathrm{W}$ & W & W & $\mathrm{W}$ \\
\hline 41 & - & $7, F$ & $7, \mathrm{~F}$ & $20, F$ & W & $S, D$ & W & W & $P, S, D$ & W \\
\hline 42 & $F$ & $9, P$ & $11, P$ & $13, \mathrm{~F}$ & $P, D, S$ & $S, D$ & $S, P$ & $w$ & W & W \\
\hline 43 & $F$ & $8, P$ & $4, P$ & $11, \mathrm{~F}$ & W & $P, S, D$ & $S, D$ & $S, P$ & W & $P, S$ \\
\hline 44 & - & $10, P$ & $9, P$ & $13, \mathrm{~F}$ & $\mathrm{~W}$ & $P, S, D$ & $w$ & $\mathrm{~W}$ & $\mathrm{~W}$ & $P, S, D$ \\
\hline 45 & - & - & - & $40, \mathrm{~F}$ & W & $S, D$ & W & $P, S, D$ & W & W \\
\hline 46 & $P$ & $12, \mathrm{P}$ & $12, P$ & - & W & S & W & WE & $P, D$ & W \\
\hline 47 & - & $10, P$ & $12, P$ & $10, \mathrm{~F}$ & W & W & $\mathrm{W}$ & W & W & W \\
\hline 48 & - & $12, \mathrm{~F}$ & $12, \mathrm{~F}$ & - & W & $P, S, D$ & $W, F$ & $F, P$ & W & $F, P$ \\
\hline 49 & - & $12, P$ & $12, P$ & $8, F$ & W & W & $\mathrm{W}$ & W & W & W \\
\hline 50 & $P$ & $12, \mathrm{~F}$ & $12, F$ & - & W & W & S & W & $\mathrm{W}, \mathrm{F}$ & W \\
\hline 51 & $\mathrm{~W}$ & $9, P$ & $9, P$ & $9, F$ & $\mathrm{~W}$ & W & W & W & $\mathrm{W}$ & $S, P$ \\
\hline 52 & - & $11, P$ & $10, P$ & $3, F$ & W & W & $F$ & $F$ & $F$ & $S, P$ \\
\hline 53 & - & $6, F$ & $12, F$ & $9, F$ & S,D & W & W & W & WE & $\mathrm{W}$ \\
\hline 54 & - & $3, P$ & $1, P$ & $12, \mathrm{~F}$ & W & $S, P$ & $\mathrm{~W}$ & WE & $P, S, D$ & - \\
\hline 55 & $P$ & $12, F$ & $12, \mathrm{~F}$ & - & $S, D$ & $D, P$ & $P, S$ & W & W & $\mathrm{W}$ \\
\hline 56 & - & $6, P$ & $7, P$ & $8, P$ & $P, S, D$ & W & $W, F$ & $S, D$ & WE & W \\
\hline
\end{tabular}


Appendix D: Skeletal Inventory

\begin{tabular}{|c|c|c|c|c|c|c|c|c|}
\hline & \multicolumn{2}{|c|}{ Carpals } & \multicolumn{3}{|c|}{ Metacarpals } & Hand Phal. & Cervical V. & Thoracic V. \\
\hline Burial \# & L & $\mathrm{R}$ & L & $\mathrm{R}$ & $U$ & & & \\
\hline 1 & - & - & - & - & 4,WE & 1,WE & - & $4, P$ \\
\hline 2 & $1, \mathrm{~W}$ & - & $5, W$ & $2, W$ & $1, W E$ & $12, W E$ & $5, P$ & $8, P$ \\
\hline 3 & - & $3, \mathrm{~W}$ & $4, \mathrm{~W}$ & $5, \mathrm{~W}$ & - & $4, \mathrm{~W}$ & $7, \mathrm{C}$ & $11, P$ \\
\hline 4 & $4, W$ & $6, \mathrm{~W}$ & $5, \mathrm{WE}$ & $2, W$ & - & $13, \mathrm{~W}$ & $6, \mathrm{C}$ & $4, P$ \\
\hline 5 & $6, W$ & $4, W$ & $5, \mathrm{~W}$ & $4, \mathrm{~W}$ & - & $20, W$ & $7, P$ & $12, P$ \\
\hline 6 & - & $6, \mathrm{~W}$ & $3, W$ & 4,WE & - & $16, \mathrm{~W}$ & $5, \mathrm{C}$ & $5, P$ \\
\hline 7 & - & $1, \mathrm{~W}$ & $1, \mathrm{~W}$ & - & $4, F$ & $1, \mathrm{~W}$ & $3, \mathrm{~F}$ & - \\
\hline 8 & - & $2, W$ & $5, W E$ & 5,WE & - & $11, \mathrm{~W}$ & $6, P$ & $11, P$ \\
\hline 9 & $5, \mathrm{~W}$ & $5, \mathrm{~W}$ & $3, W E$ & 1,WE & 4,WE & $13, \mathrm{~W}$ & $4, P$ & $8, \mathrm{~F}$ \\
\hline 10 & $4, W$ & $8, W$ & $5, \mathrm{~W}$ & $5, \mathrm{~W}$ & - & $25, \mathrm{~W}$ & $7, P$ & $5, P$ \\
\hline 11 & $5, W$ & $5, W$ & $5, W$ & $4, W$ & - & $18, W$ & $5, P$ & $12, P$ \\
\hline 12 & $5, \mathrm{~W}$ & $8, W$ & $5, W$ & $5, \mathrm{~W}$ & - & $20, W$ & $7, P$ & $6, P$ \\
\hline 13 & $6, \mathrm{~W}$ & $8, \mathrm{~W}$ & $5, W$ & $5, \mathrm{~W}$ & - & $20, W$ & $5, P$ & $10, P$ \\
\hline 14 & $7, \mathrm{~W}$ & $7, W$ & $5, W$ & $5, W$ & - & $17, \mathrm{~W}$ & $7, P$ & $3, P$ \\
\hline 15 & $7, \mathrm{~W}$ & $8, W$ & $4, W$ & $5, \mathrm{~W}$ & - & $28, W$ & $7, P$ & $8, P$ \\
\hline 16 & $8, W$ & $7, W$ & $5, W$ & $5, \mathrm{~W}$ & - & $21, \mathrm{~W}$ & $7, \mathrm{C}$ & $12, \mathrm{C}$ \\
\hline 17 & $6, \mathrm{~W}$ & $6, \mathrm{~W}$ & $5, \mathrm{~W}$ & $5, \mathrm{~W}$ & - & $20, W$ & $7, \mathrm{C}$ & $11, P$ \\
\hline 18 & $7, \mathrm{~W}$ & $8, W$ & $5, W$ & $5, \mathrm{~W}$ & - & $25, \mathrm{~W}$ & $6, P$ & $10, P$ \\
\hline 19 & $8, \mathrm{~W}$ & $8 \mathrm{~W}$ & $4, W E$ & $5, W E$ & - & $25, W$ & $6, P$ & $5, P$ \\
\hline 20 & $7, \mathrm{~W}$ & $8, W$ & $4, W$ & $5, \mathrm{~W}$ & - & $19, W$ & - & $8, P$ \\
\hline 21 & $7, \mathrm{~W}$ & $8, W$ & $5, W$ & $4, \mathrm{~W}$ & - & $24, \mathrm{~W}$ & $7, \mathrm{C}$ & $12, P$ \\
\hline 22 & $8, \mathrm{~W}$ & $8, W$ & $5, \mathrm{~W}$ & $5, \mathrm{~W}$ & - & $24, W$ & - & $5, P$ \\
\hline 23 & $8, \mathrm{~W}$ & $8, \mathrm{~W}$ & $5, W$ & $5, \mathrm{~W}$ & - & $27 \mathrm{~W}$ & $2, \mathrm{C}$ & $4, P$ \\
\hline 24 & $7, \mathrm{~W}$ & $5, \mathrm{~W}$ & $4, W$ & $4, W$ & - & $14, W$ & $1, \mathrm{P}$ & - \\
\hline 25 & $5, \mathrm{~W}$ & $8, W$ & $5, \mathrm{~W}$ & $5, \mathrm{~W}$ & - & $21 \mathrm{~W}$ & $2, P$ & $11, P$ \\
\hline 26 & $8, \mathrm{~W}$ & $8, \mathrm{~W}$ & $5, \mathrm{~W}$ & $5, \mathrm{~W}$ & - & $19, W$ & $7, P$ & $12, P$ \\
\hline 27 & $7, \mathrm{~W}$ & $6, \mathrm{~W}$ & $5, W$ & $5, \mathrm{~W}$ & - & $23, W$ & $7, P$ & $12, P$ \\
\hline 28 & $6, \mathrm{~W}$ & $7, \mathrm{~W}$ & $5, W$ & $5, \mathrm{~W}$ & - & $17, \mathrm{~W}$ & $3, P$ & $12, P$ \\
\hline 29 & $8, W$ & $8, W$ & $5, W$ & $5, W$ & - & $23, W$ & $7, P$ & $10, P$ \\
\hline 30 & $8, W$ & $6, \mathrm{~W}$ & $5, W$ & $5, \mathrm{~W}$ & - & $22, W$ & $6, P$ & $9, P$ \\
\hline 31 & $8, W$ & $7, \mathrm{~W}$ & $5, W$ & $5, \mathrm{~W}$ & - & $20, \mathrm{~W}$ & $7, P$ & $12, P$ \\
\hline 32 & $7, \mathrm{~W}$ & $8, W$ & $5, W$ & $5, \mathrm{~W}$ & - & $22, \mathrm{~W}$ & $7, P$ & $12, P$ \\
\hline 33 & $6, W$ & $7, \mathrm{~W}$ & $5, W$ & $5, \mathrm{~W}$ & - & $22, \mathrm{~W}$ & $7, P$ & $12, P$ \\
\hline 34 & $6, \mathrm{~W}$ & $8 \mathrm{~W}$ & $5, W$ & $5, \mathrm{~W}$ & - & $23 \mathrm{~W}$ & $7, P$ & $12, P$ \\
\hline 35 & $8, W$ & $7, \mathrm{~W}$ & $3, W$ & $5, \mathrm{~W}$ & - & $23 \mathrm{~W}$ & $7, \mathrm{C}$ & $12, \mathrm{C}$ \\
\hline 36 & $8, W$ & $8, W$ & $5, W$ & $5, \mathrm{~W}$ & - & $25, W$ & $7, \mathrm{C}$ & $12, \mathrm{C}$ \\
\hline 37 & $8, W$ & $6, \mathrm{~W}$ & $4, W$ & $5, \mathrm{~W}$ & - & $22, W$ & $7, \mathrm{C}$ & $5, P$ \\
\hline 38 & $7, \mathrm{~W}$ & $8, \mathrm{~W}$ & $5, W$ & $5, \mathrm{~W}$ & - & $21, \mathrm{~W}$ & $7, \mathrm{C}$ & $12, P$ \\
\hline 39 & $6, \mathrm{~W}$ & $8, \mathrm{~W}$ & $5, W$ & $5, \mathrm{~W}$ & - & $26, \mathrm{~W}$ & $7, \mathrm{C}$ & $12, P$ \\
\hline 40 & $6, \mathrm{~W}$ & $5, \mathrm{~W}$ & $5, W$ & $4, \mathrm{~W}$ & - & $23, \mathrm{~W}$ & $6, \mathrm{C}$ & $11, P$ \\
\hline 41 & $5, W$ & $6, \mathrm{~W}$ & $5, W E$ & $5, W$ & - & $18, W$ & $3, P$ & $10, P$ \\
\hline 42 & $8, W$ & $8, \mathrm{~W}$ & $5, W$ & $5, \mathrm{~W}$ & - & $26, W$ & $4, C$ & $11, P$ \\
\hline 43 & $8, W$ & $5, \mathrm{~W}$ & $4, W$ & $4, \mathrm{~W}$ & - & $23, W$ & $6, P$ & $10, P$ \\
\hline 44 & $7, \mathrm{~W}$ & $8, \mathrm{~W}$ & $5, W$ & $5, \mathrm{~W}$ & - & $26, \mathrm{~W}$ & $7, C$ & $12, \mathrm{C}$ \\
\hline 45 & $7, \mathrm{~W}$ & $6, \mathrm{~W}$ & $4, W$ & $4, W$ & - & $22, W$ & $2, P$ & $\mathrm{~F}$ \\
\hline 46 & $7, \mathrm{~W}$ & $7, \mathrm{~W}$ & $5, W$ & $5, \mathrm{~W}$ & - & $18, W$ & $7, C$ & $12, \mathrm{C}$ \\
\hline 47 & $8, W$ & $8, W$ & $5, W$ & $5, \mathrm{~W}$ & - & $22, W$ & $7, \mathrm{C}$ & $12, \mathrm{C}$ \\
\hline 48 & $7, \mathrm{~W}$ & $4, \mathrm{~W}$ & $5, W$ & $5, \mathrm{~W}$ & - & $15, \mathrm{~W}$ & $7, C$ & $12, \mathrm{C}$ \\
\hline 49 & $7, \mathrm{~W}$ & $6, \mathrm{~W}$ & $4, W$ & $5, \mathrm{~W}$ & - & $17, \mathrm{~W}$ & $6, \mathrm{C}$ & $12, \mathrm{C}$ \\
\hline 50 & $5, \mathrm{~W}$ & $7, \mathrm{~W}$ & $5, W$ & $3, \mathrm{~W}$ & - & $23, \mathrm{~W}$ & $1, P$ & $3, P$ \\
\hline 51 & $5, W$ & $2, W$ & $5, W$ & $5, W$ & - & $15, \mathrm{~W}$ & $5, \mathrm{C}$ & $11, \mathrm{C}$ \\
\hline 52 & $3, \mathrm{~W}$ & $1, \mathrm{~W}$ & $5, W$ & $3, W$ & - & $15, W$ & $5, \mathrm{C}$ & $12, \mathrm{C}$ \\
\hline 53 & $3, \mathrm{~W}$ & $5, \mathrm{~W}$ & $5, W$ & $5, \mathrm{~W}$ & - & $21, W$ & $7, \mathrm{C}$ & $4, P$ \\
\hline 54 & $7, \mathrm{~W}$ & $5, \mathrm{~W}$ & $5, W$ & $3, W E$ & - & $21, W$ & $7, \mathrm{C}$ & $9, P$ \\
\hline 55 & $8, \mathrm{~W}$ & $7, \mathrm{~W}$ & $5, W$ & $5, \mathrm{~W}$ & - & $24, \mathrm{~W}$ & $7, C$ & $9, F$ \\
\hline 56 & $8, \mathrm{~W}$ & $8, \mathrm{~W}$ & $5, W$ & $5, \mathrm{~W}$ & - & $24, W$ & $7, P$ & $8, P$ \\
\hline
\end{tabular}




\begin{tabular}{|c|c|c|c|c|c|c|c|c|c|}
\hline & Lumbar V. & Sacrum & Coccyx & \multicolumn{2}{|c|}{ Ilium } & \multicolumn{2}{|c|}{ Ischium } & \multicolumn{2}{|c|}{ Pubis } \\
\hline Burial \# & & & & $L$ & $R$ & $\mathrm{~L}$ & $\mathrm{R}$ & $\mathrm{L}$ & $\mathrm{R}$ \\
\hline 1 & $1, P$ & - & - & WE & WE & - & - & - & - \\
\hline 2 & $1, P$ & $F$ & - & - & $F$ & $F$ & $\mathrm{~F}$ & - & - \\
\hline 3 & $5, P$ & - & - & $F$ & $F$ & - & $\mathrm{P}$ & - & - \\
\hline 4 & - & $P$ & - & WE & $F$ & - & - & - & - \\
\hline 5 & $2, P$ & - & - & $\mathrm{F}$ & $\mathrm{F}$ & - & - & - & - \\
\hline 6 & $1, P$ & $F$ & - & $F$ & $F$ & - & - & - & - \\
\hline 7 & - & - & - & $F$ & $F$ & - & - & - & - \\
\hline 8 & $5, P$ & - & - & - & - & - & - & - & - \\
\hline 9 & $4, F$ & $F$ & - & $P$ & $F$ & $F$ & $P$ & $F$ & $F$ \\
\hline 10 & $2, P$ & - & - & $F$ & $F$ & $F$ & W & $F$ & $F$ \\
\hline 11 & $5, P$ & $P$ & - & $\mathrm{W}$ & $\mathrm{W}, \mathrm{F}$ & $P$ & $W, F$ & - & - \\
\hline 12 & $5, P$ & - & - & $F$ & $\mathrm{~F}$ & $F$ & $\mathrm{~F}$ & $F$ & $F$ \\
\hline 13 & $3, P$ & - & - & $P$ & $P$ & $F$ & $F$ & $\mathrm{~F}$ & $F$ \\
\hline 14 & - & $P$ & - & $P$ & $P$ & WE & $F$ & - & - \\
\hline 15 & $5, C$ & $P$ & - & $P$ & $P$ & $P$ & $\mathrm{P}$ & $P$ & - \\
\hline 16 & $5, \mathrm{C}$ & $P$ & - & W & W & W & W & W & $\mathrm{W}$ \\
\hline 17 & $5, \mathrm{C}$ & $P$ & - & WE & $P$ & $\mathrm{~W}$ & W & - & $\mathrm{P}$ \\
\hline 18 & $3, \mathrm{C}$ & $F$ & - & $F$ & $F$ & $F$ & $F$ & $F$ & $F$ \\
\hline 19 & - & - & - & $F$ & $\mathrm{~F}$ & $\mathrm{~F}$ & F. & - & - \\
\hline 20 & $5, P$ & $F$ & - & W & $P$ & WE & - & - & - \\
\hline 21 & $5, P$ & $F$ & - & WE & WE & W & W & $\mathrm{W}$ & $\mathrm{W}$ \\
\hline 22 & $4, P$ & $P$ & - & $F$ & WE & WE & $F$ & WE & - \\
\hline 23 & $3, P$ & $P$ & - & $F$ & WE & WE & WE & - & - \\
\hline 24 & - & - & - & $F$ & $F$ & $\mathrm{~F}$ & $F$ & - & - \\
\hline 25 & $5, C$ & $P$ & - & WE & WE & WE & WE & - & - \\
\hline 26 & $5, C$ & $P$ & - & W & $F$ & $P$ & $F$ & $F$ & $F$ \\
\hline 27 & $6, P$ & $P$ & - & $\mathrm{W}$ & W & W & $P$ & - & $P$ \\
\hline 28 & $4, P$ & $\mathrm{P}, \mathrm{F}$ & - & $\mathrm{P}$ & WE & - & WE & - & - \\
\hline 29 & $2, P$ & W & 1 & $P$ & $P$ & W & W & - & $\mathrm{W}$ \\
\hline 30 & $3, P$ & $P$ & 1 & W & WE & W & WE & - & $\mathrm{P}$ \\
\hline 31 & $5, \mathrm{C}$ & $P$ & 2 & $P$ & $F$ & W & $P$ & W & $\mathrm{W}$ \\
\hline 32 & $5, P$ & $F$ & 3 & W & W & $P$ & W & - & - \\
\hline 33 & $5, C$ & $W$ & - & $\mathrm{W}$ & $F$ & W & WE & $\mathrm{W}, \mathrm{F}$ & $W, F$ \\
\hline 34 & $5, P$ & $F$ & - & $\mathrm{W}$ & $F$ & $F$ & $F$ & $F$ & $F$ \\
\hline 35 & $5, \mathrm{C}$ & $\mathrm{W}$ & - & W & W & $W$ & W & $F$ & W \\
\hline 36 & $5, C$ & W & 3 & W & $W$ & W & W & WE & WE \\
\hline 37 & - & $P$ & - & $F$ & WE & $F$ & $F$ & $F$ & $F$ \\
\hline 38 & $5, P$ & $W$ & 1 & $W$ & W & $W$ & $F$ & $F$ & - \\
\hline 39 & $6, P$ & W & 1 & W & W & W & W & $P$ & $P$ \\
\hline 40 & $3, P$ & - & - & $\mathrm{F}$ & WE & W & W & - & $F$ \\
\hline 41 & $4, P$ & $F$ & - & $P$ & $P$ & $P$ & W & $F$ & $F$ \\
\hline 42 & $5, P$ & - & - & $P$ & $P$ & $P$ & $F$ & $F$ & $F$ \\
\hline 43 & $4, P$ & - & - & $F$ & $F$ & $P$ & $P$ & - & - \\
\hline 44 & $5, C$ & $F$ & - & WE & WE & W & $P$ & $\mathrm{~W}$ & W \\
\hline 45 & $F$ & - & - & $F$ & $F$ & $F$ & $F$ & - & - \\
\hline 46 & $5, \mathrm{C}$ & $P$ & 1 & $P$ & WE & $P$ & $P$ & $P$ & WE \\
\hline 47 & $5, \mathrm{C}$ & W & - & W & W & W & $\mathrm{W}$ & $\mathrm{W}$ & $\mathrm{W}$ \\
\hline 48 & $5, \mathrm{C}$ & $P, F$ & - & WE & WE & WE & W & W & W \\
\hline 49 & $5, P$ & $F$ & - & $P$ & W & $W$ & $\mathrm{~W}$ & W & $W$ \\
\hline 50 & - & $P, F$ & - & $F$ & $F$ & - & - & $F$ & WE \\
\hline 51 & $5, \mathrm{C}$ & W & - & $\mathrm{P}$ & WE & W & $\mathrm{P}$ & W & $\mathrm{W}$ \\
\hline 52 & $5, C$ & $P$ & - & WE & $P$ & W & $\mathrm{W}$ & $F$ & - \\
\hline 53 & $2, P$ & $P, F$ & 1 & WE & $P$ & $P$ & $\mathrm{~W}$ & $W$ & - \\
\hline 54 & $5, P$ & $F$ & 1 & W & $P$ & W & $F$ & - & $P$ \\
\hline 55 & $4, F$ & $F$ & - & $F$ & $F$ & $P$ & WE & - & WE \\
\hline 56 & $2, P$ & $P, F$ & - & $P$ & $P$ & $P$ & $P$ & WE & WE \\
\hline
\end{tabular}




\begin{tabular}{|c|c|c|c|c|c|c|c|c|c|c|}
\hline & \multicolumn{2}{|c|}{ Femur } & \multicolumn{2}{|c|}{ Patella } & \multicolumn{3}{|c|}{ Tibia } & \multicolumn{3}{|c|}{ Fibula } \\
\hline Burial \# & L & $\mathrm{R}$ & L & $\mathrm{R}$ & L & $\mathrm{R}$ & $\mathrm{U}$ & L & $\mathrm{R}$ & $\mathrm{U}$ \\
\hline 1 & WE & WE & - & WE & WE & WE & - & $\mathrm{F}$ & $\mathrm{F}$ & - \\
\hline 2 & - & WE & - & W & - & WE & - & $\mathrm{D}, \mathrm{F}$ & $\mathrm{D}, \mathrm{F}$ & - \\
\hline 3 & WE & WE & - & - & WE & W & - & WE & WE & - \\
\hline 4 & WE & WE & - & W & WE & WE & - & WE & WE & - \\
\hline 5 & $\mathrm{~S}$ & $S, D$ & W & W & $S$ & $S$ & - & $\mathrm{s}$ & $S, D$ & $\begin{array}{l}- \\
-\end{array}$ \\
\hline 6 & WE & WE & - & WE & - & - & $P$ & - & $S$ & - \\
\hline 7 & WE & WE & - & $\mathrm{W}$ & $P$ & $P$ & - & - & - & $\mathrm{s}$ \\
\hline 8 & WE & WE & - & - & WE & WE & - & WE & WE & - \\
\hline 9 & WE & WE & $\mathrm{W}$ & - & WE & WE & - & WE & $F$ & - \\
\hline 10 & WE & WE & W & W & WE & WE & - & $S, F$ & $S$ & - \\
\hline 11 & W & WE & $\mathrm{W}$ & - & $S, D$ & W & - & $S, D$ & $S, D$ & - \\
\hline 12 & W & W & $\mathrm{W}$ & W & $w$ & W & - & WE & WE & - \\
\hline 13 & WE & $S, D$ & $\mathrm{~W}$ & W & $S, D$ & - & - & $S, D$ & WE & - \\
\hline 14 & W & $\mathrm{W}$ & $\mathrm{W}$ & W & $S, D$ & $S, D$ & - & WE & $S, D$ & - \\
\hline 15 & $S, P$ & $S, P$ & - & - & $S, D$ & $P$ & - & WE & WE & - \\
\hline 16 & $\mathrm{~W}$ & W & - & - & W & W & - & $S, D$ & $\mathrm{~s}$ & - \\
\hline 17 & W & W & W & - & W & W & - & $S, D$ & $S, D$ & - \\
\hline 18 & WE & WE & $\mathrm{W}$ & W & $S, D$ & W & - & W & $W$ & - \\
\hline 19 & $S, P$ & $S, P, D$ & W & W & $S, D$ & $F$ & - & $\mathrm{F}$. & WE & - \\
\hline 20 & $W$ & WE & WE & $W E$ & WE & W & - & $W$ & W & - \\
\hline 21 & W & $W$ & W & $\mathrm{W}$ & W & $\mathrm{W}$ & - & $\mathrm{W}$ & $\mathrm{W}$ & - \\
\hline 22 & W & WE & $W$ & W & W & W & - & $W$ & $\mathrm{~W}$ & - \\
\hline 23 & $S, D$ & $S, D$ & $W$ & W & W & W & - & $\mathrm{W}$ & $W$ & - \\
\hline 24 & $S, D$ & $F$ & $P$ & W & $F$ & $F$ & - & $\mathrm{D}$ & $P, D$ & - \\
\hline 25 & $P, S, D$ & $P, S, D$ & $\mathrm{~W}$ & - & $S, D$ & $\mathrm{~S}$ & - & D & - & - \\
\hline 26 & W & $S, P$ & $\mathrm{~W}$ & W & $S, D$ & $S, D$ & - & $S, D$ & $S$ & - \\
\hline 27 & $P, S, D$ & W & $\mathrm{W}$ & $W$ & W & - & - & $S, P$ & WE & - \\
\hline 28 & $P, S, D$ & $P, S$ & - & $W$ & $S, D$ & WE & - & $S, D$ & $P, S, D$ & - \\
\hline 29 & W & $W$ & $\mathrm{~W}$ & $W$ & W & W & - & $\mathrm{W}$ & $W$ & - \\
\hline 30 & $P, S, D$ & $P, S, D$ & $\mathrm{~W}$ & $W$ & $S, D$ & $S, D$ & - & $S, D$ & $P, S, D$ & - \\
\hline 31 & W & W & W & W & $S, D$ & $W$ & - & WE & WE & - \\
\hline 32 & $S, P$ & $S, P$ & $\mathrm{~W}$ & $W$ & $S, D$ & $P, S, D$ & - & $S, P$ & $P, S, D$ & - \\
\hline 33 & $W$ & $S, D$ & $W$ & - & W & WE & - & $P, S, D$ & $S$ & - \\
\hline 34 & $S, P$ & $S, P$ & W & $W$ & $S, D$ & $S, D$ & - & $S, P$ & $\mathrm{~W}$ & - \\
\hline 35 & $W$ & W & $W$ & W & W & W & - & $W$ & W & - \\
\hline 36 & $W$ & W & $W$ & W & W & W & - & W & W & - \\
\hline 37 & $S, D$ & $S, D$ & W & W & $S, D$ & W & - & $P, S, D$ & $S, D$ & - \\
\hline 38 & $W$ & W & $W$ & $\mathrm{~W}$ & W & $W$ & - & W & $\mathrm{W}$ & - \\
\hline 39 & W & $W$ & - & W & W & $W$ & - & W & $S, D$ & - \\
\hline 40 & $F$ & $F, W$ & W & W & W & $W$ & - & $P, S, D$ & W & - \\
\hline 41 & $P, S$ & WE & - & W & $F$ & $W$ & - & $S, D$ & W & - \\
\hline 42 & $P, S$ & WE & $W$ & W & $S, D$ & $S, D$ & - & $S, D$ & $S, D$ & - \\
\hline 43 & $S, P$ & WE & W & - & $S, D$ & WE & - & $S, D$ & $S, D$ & - \\
\hline 44 & $W$ & W & W & W & W & W & - & $P, S, D$ & $P, S, D$ & - \\
\hline 45 & $S, P$ & $S$ & - & W & $\mathrm{S}$ & $S, D$ & - & $P, S$ & W & - \\
\hline 46 & W & $P, S, D$ & - & W & W & $S, D$ & - & $S, D$ & $S, D$ & - \\
\hline 47 & W & W & $W$ & W & W & $\mathrm{W}$ & - & WE & $\mathrm{W}$ & - \\
\hline 48 & W & W & W & WE & W & $S, P$ & - & $S, D$ & $S, D$ & - \\
\hline 49 & W & W & W & $W$ & W & $\mathrm{W}$ & - & WE & WE & - \\
\hline 50 & $S$ & $S, P$ & W & W & $S, D$ & $\mathrm{~S}$ & - & $S, P$ & $S, P$ & - \\
\hline 51 & W & $S, D$ & - & W & $W$ & $S, D$ & - & $S, D$ & $F$ & - \\
\hline 52 & W & $S, D$ & W & $\mathrm{F}$ & W & W & - & W & $\mathrm{W}$ & - \\
\hline 53 & $P, S, D$ & $S, P$ & W & W & W & W & - & $S, D$ & $P, D, S$ & - \\
\hline 54 & $P, S$ & WE & $W$ & W & W & $S, D$ & - & D & $S, P$ & - \\
\hline 55 & $\mathrm{~S}$ & $S$ & $\mathrm{~W}$ & $W$ & $D, S$ & $\mathrm{~S}$ & - & $S, F$ & $S, F$ & - \\
\hline 56 & $P, S, D$ & $S, P$ & W & W & $S$ & $S$ & - & $S, D$ & $S, D$ & $\begin{array}{l}- \\
-\end{array}$ \\
\hline
\end{tabular}




\begin{tabular}{|c|c|c|c|c|c|c|c|c|}
\hline & \multicolumn{3}{|c|}{ Metatarsals } & \multicolumn{3}{|c|}{ Tarsals } & Foot Phal. & Other \\
\hline Burial \# & $\mathrm{L}$ & $\mathrm{R}$ & $\mathrm{U}$ & $\mathrm{L}$ & $\mathrm{R}$ & $\mathrm{U}$ & & \\
\hline 1 & - & - & - & - & 1,WE & - & - & - \\
\hline 2 & $3, \mathrm{~W}$ & $3, \mathrm{~W}$ & - & $4, \mathrm{~W}$ & $4, \mathrm{~W}$ & - & $1, \mathrm{~W}$ & - \\
\hline 3 & $5, \mathrm{~W}$ & $2, W$ & - & $4, \mathrm{~W}$ & $5, W$ & - & $2, \mathrm{~W}$ & cartilage \\
\hline 4 & $5, \mathrm{WE}$ & $5, W E$ & - & $5, \mathrm{~W}$ & $5, W$ & - & $1, \mathrm{~W}$ & cartilage \\
\hline 5 & $2, W E$ & $3, W E$ & - & $6, \mathrm{~W}$ & $6, \mathrm{~W}$ & - & $1, \mathrm{~W}$ & hyoid \\
\hline 6 & - & - & - & - & - & - & - & - \\
\hline 7 & - & - & 3,5 & - & - & $2, F$ & - & - \\
\hline 8 & $3, \mathrm{WE}$ & - & $6, W E$ & $4, \mathrm{~W}$ & 4,WE & - & 2,WE & - \\
\hline 9 & $2, W E$ & $3, \mathrm{WE}$ & $1, \mathrm{WE}$ & $2, W E$ & $4, W$ & - & $6, W$ & cartilage, sesamoid \\
\hline 10 & $4, \mathrm{~W}$ & $4, W$ & - & $4, \mathrm{~W}$ & $5, \mathrm{~W}$ & - & $10, \mathrm{~W}$ & cartilage, hyoid \\
\hline 11 & $5, \mathrm{WE}$ & 5,WE & - & $7, \mathrm{~W}$ & $7, \mathrm{~W}$ & - & $7, \mathrm{~W}$ & cartilage \\
\hline 12 & $5, \mathrm{~W}$ & $5, \mathrm{~W}$ & - & $6, \mathrm{~W}$ & $7, \mathrm{~W}$ & - & $14, \mathrm{~W}$ & cartilage \\
\hline 13 & $5, \mathrm{~W}$ & $5, \mathrm{~W}$ & - & $7, \mathrm{~W}$ & $7, \mathrm{~W}$ & - & $18, W$ & sesamoid \\
\hline 14 & $5, S, D$ & $5, S, D$ & - & $6, \mathrm{~W}$ & $6, \mathrm{~W}$ & - & $2, S, D$ & cartilage \\
\hline 15 & $5, \mathrm{~W}$ & $5, \mathrm{~W}$ & - & $7, \mathrm{~W}$ & $6, \mathrm{~W}$ & - & $15, \mathrm{~W}$ & sesamoids \\
\hline 16 & $5, \mathrm{~W}$ & $5, \mathrm{~W}$ & - & $6, \mathrm{~W}$ & $6, \mathrm{~W}$ & - & $14, \mathrm{~W}$ & cartilage, cricoid, hyoid, sesamoids \\
\hline 17 & $5, \mathrm{~W}$ & $5, \mathrm{~W}$ & - & $7, \mathrm{~W}$ & $7, \mathrm{~W}$ & - & $19, \mathrm{~W}$ & sesamoids \\
\hline 18 & $5, \mathrm{~W}$ & $5, \mathrm{~W}$ & - & $7, \mathrm{~W}$ & $7, \mathrm{~W}$ & - & $12, \mathrm{~W}$ & sesamoids, hyoid \\
\hline 19 & $5, \mathrm{WE}$ & 5,WE & - & $4, \mathrm{~W}$ & $5, \mathrm{~W}$ & $3, \mathrm{~F}$ & $8, \mathrm{~W}$ & sesamoidș \\
\hline 20 & $5, \mathrm{~W}$ & $5, \mathrm{~W}$ & - & $7, \mathrm{~W}$ & $7, \mathrm{~W}$ & - & $12, \mathrm{~W}$ & - \\
\hline 21 & $5, \mathrm{~W}$ & $5, \mathrm{~W}$ & - & $7, \mathrm{~W}$ & $7, \mathrm{~W}$ & - & $20, \mathrm{~W}$ & cartilage, sesamoids \\
\hline 22 & $5, \mathrm{~W}$ & $5, \mathrm{~W}$ & - & $7, \mathrm{~W}$ & $7, \mathrm{~W}$ & - & $13, \mathrm{~W}$ & sesamoids \\
\hline 23 & $4, \mathrm{~W}$ & $5, \mathrm{~W}$ & - & $6, \mathrm{~W}$ & $7, \mathrm{~W}$ & - & $12, \mathrm{~W}$ & - \\
\hline 24 & $2, \mathrm{~F}$ & $3, W E$ & $3, \mathrm{~F}$ & $7, \mathrm{~W}$ & $7, \mathrm{~W}$ & - & $6, \mathrm{~W}$ & sesamoid \\
\hline 25 & $5, \mathrm{~W}$ & $5, \mathrm{~W}$ & - & $7, \mathrm{~W}$ & $7, \mathrm{~W}$ & - & $22, \mathrm{~W}$ & sesamoids \\
\hline 26 & $4, \mathrm{~W}$ & $5, \mathrm{~W}$ & - & $7, \mathrm{~W}$ & $7, \mathrm{~W}$ & - & $6, \mathrm{~W}$ & hyoid \\
\hline 27 & $5, \mathrm{~W}$ & $5, W E$ & - & $7, \mathrm{~W}$ & $7, \mathrm{~W}$ & - & $6, \mathrm{WE}$ & - \\
\hline 28 & $5, \mathrm{~W}$ & $5, \mathrm{~W}$ & - & $7, \mathrm{~W}$ & $7, \mathrm{~W}$ & - & $14, \mathrm{~W}$ & sesamoid \\
\hline 29 & $5, \mathrm{~W}$ & $5, \mathrm{~W}$ & - & $7, \mathrm{~W}$ & $7, \mathrm{~W}$ & - & $12, \mathrm{~W}$ & hyoid \\
\hline 30 & $5, \mathrm{~W}$ & $5, \mathrm{~W}$ & - & $7, \mathrm{~W}$ & $7, \mathrm{~W}$ & - & $19, \mathrm{~W}$ & hyoid, sesamoid \\
\hline 31 & $5, \mathrm{~W}$ & $5, \mathrm{~W}$ & - & $7, \mathrm{~W}$ & $7, \mathrm{~W}$ & - & $12, \mathrm{~W}$ & cartilage \\
\hline 32 & $5, \mathrm{~W}$ & $5, \mathrm{~W}$ & - & $7, \mathrm{~W}$ & $7, \mathrm{~W}$ & - & $25, \mathrm{~W}$ & cartilage, sesamoids \\
\hline 33 & $5, \mathrm{~W}$ & $5, \mathrm{~W}$ & - & $6, \mathrm{~W}$ & $6, \mathrm{~W}$ & - & $19, \mathrm{~W}$ & hyoid, sesamoids \\
\hline 34 & $4, \mathrm{~W}$ & $5, \mathrm{~W}$ & - & $7, W$ & $7, \mathrm{~W}$ & - & $9, \mathrm{~W}$ & - \\
\hline 35 & $5, \mathrm{~W}$ & $5, \mathrm{~W}$ & - & $7, \mathrm{~W}$ & $7, \mathrm{~W}$ & - & $12, \mathrm{~W}$ & sesamoids \\
\hline 36 & $5, \mathrm{~W}$ & $5, \mathrm{~W}$ & - & $7, \mathrm{~W}$ & $7, \mathrm{~W}$ & - & $22, \mathrm{~W}$ & hyoid, cartilage, sesamoids \\
\hline 37 & $5, \mathrm{~W}$ & $5, \mathrm{~W}$ & - & $7, \mathrm{~W}$ & $7, \mathrm{~W}$ & - & $20, W$ & hyoid, ear ossification, sesamoids \\
\hline 38 & $5, \mathrm{~W}$ & $5, \mathrm{~W}$ & - & $7, \mathrm{~W}$ & $7, \mathrm{~W}$ & - & $6, \mathrm{~W}$ & - \\
\hline 39 & $5, \mathrm{~W}$ & $5, \mathrm{~W}$ & - & $7, \mathrm{~W}$ & $7, \mathrm{~W}$ & - & $14, \mathrm{~W}$ & hyoid, cartilage, sesamoids \\
\hline 40 & $5, \mathrm{~W}$ & $5, \mathrm{~W}$ & - & $7, \mathrm{~W}$ & $6, \mathrm{~W}$ & - & $8, \mathrm{~W}$ & hyoid, cartilage, sesamoid \\
\hline 41 & $5, \mathrm{~W}$ & $5, \mathrm{WE}$ & - & $7, \mathrm{~W}$ & $7, \mathrm{~W}$ & - & $11, \mathrm{~W}$ & hyoid, sesamoid \\
\hline 42 & $5, \mathrm{~W}$ & $5, \mathrm{~W}$ & - & $6, \mathrm{~W}$ & $7, \mathrm{~W}$ & - & $24, W$ & sesamoids \\
\hline 43 & $5, \mathrm{~W}$ & $5, \mathrm{~W}$ & - & $7, \mathrm{~W}$ & $7, \mathrm{~W}$ & - & $13, \mathrm{~W}$ & sesamoids \\
\hline 44 & $5, \mathrm{~W}$ & $5, \mathrm{~W}$ & - & $7, \mathrm{~W}$ & $7, \mathrm{~W}$ & - & $11, \mathrm{~W}$ & hyoid, cartilage, sesamoids \\
\hline 45 & $5, \mathrm{~W}$ & $5, \mathrm{~W}$ & - & $7 . \mathrm{W}$ & $7, \mathrm{~W}$ & - & $12, \mathrm{~W}$ & sesamoids \\
\hline 46 & $5, \mathrm{~W}$ & $5, \mathrm{~W}$ & - & $7, \mathrm{~W}$ & $7, W$ & - & $10, \mathrm{~W}$ & cartilage, sesamoids \\
\hline 47 & $5, \mathrm{~W}$ & $5, \mathrm{~W}$ & - & $6, \mathrm{~W}$ & $7, \mathrm{~W}$ & - & $16, W$ & sesamoids \\
\hline 48 & $5, \mathrm{~W}$ & $4, \mathrm{~W}$ & - & $6, \mathrm{~W}$ & $4, \mathrm{~W}$ & - & $5, \mathrm{~W}$ & - \\
\hline 49 & $5, \mathrm{~W}$ & $5, W$ & - & $7, \mathrm{~W}$ & $7, \mathrm{~W}$ & - & $15, \mathrm{~W}$ & hyoid, cartilage, sesamoids \\
\hline 50 & $5, W E$ & $5, W$ & - & $7, W E$ & $6, \mathrm{~W}$ & - & $21, \mathrm{~W}$ & hyoid, sesamoids \\
\hline 51 & $2, \mathrm{~W}$ & 4,WE & - & $5, \mathrm{~W}$ & 7.WE & - & $19, \mathrm{~W}$ & cartilage \\
\hline 52 & $5, \mathrm{~W}$ & $5, \mathrm{~W}$ & - & $7, \mathrm{~W}$ & $7, \mathrm{~W}$ & - & $1, \mathrm{~W}$ & cartilage \\
\hline 53 & $5, \mathrm{~W}$ & $5, W$ & - & $6, \mathrm{~W}$ & $7, \mathrm{~W}$ & - & $11, \mathrm{~W}$ & hyoid, cartilage, sesamoids \\
\hline 54 & $5, \mathrm{~W}$ & $4, W$ & - & $7, \mathrm{~W}$ & $7, \mathrm{~W}$ & - & $21, W$ & sesamoids \\
\hline 55 & $5, \mathrm{~W}$ & $3, \mathrm{WE}$ & - & $7, W E$ & $4, W E$ & - & $20, \mathrm{~W}$ & hyoid, cartilage, sesamoids \\
\hline 56 & $5, \mathrm{~W}$ & $4, W$ & - & $7, \mathrm{~W}$ & $7, \mathrm{~W}$ & - & $22, W$ & hyoid, cartilage, sesamoids \\
\hline
\end{tabular}




\section{APPENDIX E: Skeletal Cranial and Posteranial Metric Data from Analyzed Individuals at the Texas State Cemetery}

Compiled by

Helen Danzeiser Dockall 


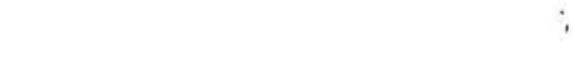


This appendix displays metric data recorded from each analyzed individual; the first section provides cranial metrics, and the second section presents postcranial metrics. All measurements, except stature, are recorded in millimeters and were taken following the definitions provided by Buikstra and Ubelaker (i994). Stature is calculated in centimeters following Trotter and Gleser (1952) in Bass (1987).

\section{CRANIAL METRICS KEY}

$\begin{array}{ll}1 & \text { Maximum length } \\ 2 & \text { Maximum width } \\ 3 & \text { Biauricular breadth } \\ 4 & \text { Minimum frontal width } \\ 5 & \text { Frontal chord } \\ 6 & \text { Basion-bregma height } \\ 7 & \text { Basion-nasion height } \\ 8 & \text { Basion-prosthion height } \\ 9 & \text { Upper facial height } \\ 10 & \text { Upper facial breadth } \\ 11 & \text { Biorbital breadth } \\ 12 & \text { Interorbital breadth } \\ 13 & \text { Orbital height } \\ 14 & \text { Orbital width } \\ 15 & \text { Nasal height } \\ 16 & \text { Nasal breadth }\end{array}$
17 Maxillo-alveolar length
18 Maxillo-alveolar breadth
19 Parietal chord
20 Occipital chord
21 Foramen magnum length
22 Foramen magnum width
23 Mandibular length
24 Bicondylar breadth
25 Ascending ramus height
26 Chin height
27 Height of mandibular body
28 Breadth of mandibular body
29 Bigonial breadth
30 Minimum ramus breadth
31 Maximum ramus breadth

\section{POSTCRANIAL METRICS KEY}

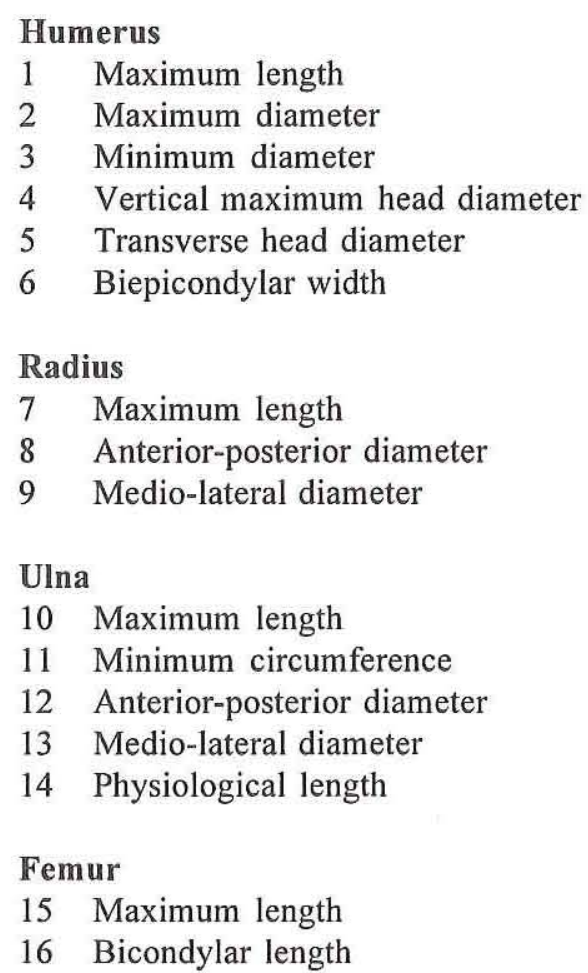

17 Midshaft circumference

18 Anterior-posterior diameter

19 Transverse diameter

20 Head diameter

21 Bicondylar width

22 Anterior-posterior subtrochanteric diameter

23 Medial-lateral subtrochanteric diameter

24 Maximum length

Tibia

25 Circumference

26 Anterior-posterior diameter

27 Medio-lateral diameter

28 Proximal epiphyseal breadth

29 Distal epiphyseal breadth

Fibula

30 Maximum length

31 Maximum diameter

Scapula

32 Maximum height

33 Maximum breadth 


\section{Clavicle}

34 Maximum length

35 Anterior diameter

36 Superior diameter

Os Coxa

37 Maximum height

38 Maximum width

39 Ischial length

40 Pubis length

\section{Sacrum}

41 Anterior length

42 Anterior superior breadth

43 Maximum transverse diameter of base

44 Stature (cm; corrected for age)

\section{REFERENCES CITED}

Bass, William M.

1987 Human Osteology: A Laboratory and Field Manual. 3rd ed. Special Publication No. 2. Missouri Archaeological Society, Columbia.

Buikstra, Jane E., and Douglas H. Ubelaker (editors)

1994 Standards for Data Collection from Human Skeletal Remains. Research Series No. 44. Arkansas Archeological Survey, Fayetteville.

Trotter, Mildred, and Goldine C. Gleser

1952 Estimation of Stature from Long Bones of American Whites and Negroes. American Journal of Physical Anthropology 10:463-514. 
Appendix E: Skeletal Cranial and Postcranial Metric Data

\begin{tabular}{|c|c|c|c|c|c|c|c|c|c|c|c|c|}
\hline & & \multicolumn{11}{|c|}{ Cranial Measurements } \\
\hline Burial \# & Sex & 1 & 2 & 3 & 4 & 5 & 6 & 7 & 8 & 9 & 10 & 11 \\
\hline 1 & $\mathrm{~F}$ & 183 & 137 & 133 & 97 & 115 & - & - & - & - & 99 & 89 \\
\hline 2 & $M$ & 185 & 143 & 146 & 104 & 115 & - & - & - & - & 112 & 100 \\
\hline 3 & $M$ & 187 & 149 & 141 & 101 & 120 & 147 & 101 & - & - & 104 & - \\
\hline 4 & $\mathrm{M}$ & 191 & 142 & 143 & 101 & 114 & 145 & 143 & - & - & 109 & - \\
\hline 5 & $\mathrm{M}$ & - & - & - & - & - & - & - & - & - & - & - \\
\hline 6 & $M$ & - & 141 & 142 & - & - & 146 & - & - & $\begin{array}{l}- \\
-\end{array}$ & - & - \\
\hline 7 & $M$ & - & 143 & - & - & - & - & - & - & - & - & - \\
\hline 8 & $\mathrm{M}$ & 191 & - & - & 100 & 118 & - & - & - & - & - & - \\
\hline 9 & $\mathrm{M}$ & - & - & - & - & - & - & - & - & - & - & - \\
\hline 10 & $M$ & - & - & - & - & - & - & - & - & 68 & - & - \\
\hline 11 & $M$ & 181 & 150 & - & 104 & 114 & - & - & - & - & - & - \\
\hline 12 & $M$ & 188 & 136 & - & 97 & 123 & 141 & 109 & - & - & - & - \\
\hline 13 & $M$ & - & - & - & - & - & - & - & - & - & - & - \\
\hline 14 & $M$ & 171 & 135 & 132 & 92 & 116 & - & - & - & - & - & - \\
\hline 15 & $M$ & - & - & - & 96 & 106 & - & - & - & - & - & - \\
\hline 16 & $M$ & 189 & 142 & 151 & 99 & 122 & 147 & 107 & 94 & 69 & 110 & 101 \\
\hline 17 & $M$ & 185 & 139 & 141 & 101 & 121 & - & - & - & - & 107 & - \\
\hline 18 & $M$ & - & - & - & - & - & - & - & - & - & - & - \\
\hline 19 & $M$ & - & - & - & - & - & - & - & - & - & - & - \\
\hline 20 & $M$ & - & - & - & $\therefore$ & - & - & - & - & - & - & - \\
\hline 21 & $M$ & 168 & 153 & 149 & 108 & 115 & - & - & - & - & - & - \\
\hline 22 & $M$ & - & - & - & - & - & - & - & - & - & - & - \\
\hline 23 & $M$ & - & - & - & - & - & - & - & - & - & - & - \\
\hline 24 & $M$ & - & - & - & - & - & - & - & - & - & - & - \\
\hline 25 & $M$ & - & - & - & 102 & 117 & - & - & - & - & 114 & 103 \\
\hline 26 & $M$ & - & - & - & - & - & - & - & - & - & - & - \\
\hline 27 & $M$ & - & - & - & - & - & - & - & - & - & - & - \\
\hline 28 & $M$ & - & - & - & - & - & - & - & - & - & - & - \\
\hline 29 & $M$ & - & - & - & 105 & - & - & - & - & - & 109 & - \\
\hline 30 & $M$ & - & - & - & 97 & 112 & - & - & - & - & - & - \\
\hline 31 & $M$ & - & - & - & - & 120 & - & - & - & - & - & - \\
\hline 32 & $M$ & - & - & - & - & - & - & - & - & - & - & - \\
\hline 33 & $M$ & - & - & - & - & - & - & - & - & - & - & - \\
\hline 34 & $M$ & - & - & - & 106 & 114 & - & - & - & - & - & - \\
\hline 35 & $M$ & - & - & - & - & - & - & - & - & - & - & - \\
\hline 36 & $M$ & - & - & - & 103 & 113 & - & - & - & - & 108 & - \\
\hline 37 & $M$ & - & - & - & 103 & 113 & - & - & - & - & 110 & - \\
\hline 38 & $M$ & - & - & - & - & - & - & - & - & - & - & - \\
\hline 39 & $M$ & 171 & - & - & 96 & 112 & - & - & - & - & - & - \\
\hline 40 & $M$ & - & - & - & 91 & 116 & - & - & - & - & 96 & - \\
\hline 41 & $M$ & - & - & - & - & - & - & - & - & - & - & - \\
\hline 42 & $M$ & - & - & - & 100 & 119 & - & - & - & - & - & - \\
\hline 43 & $M$ & - & - & - & - & - & - & - & - & - & - & - \\
\hline 44 & $M$ & - & - & - & - & 117 & - & - & - & - & - & - \\
\hline 45 & $M$ & - & - & - & - & - & - & - & - & - & - & - \\
\hline 46 & $M$ & 173 & 144 & 130 & 91 & 112 & 134 & 92 & - & - & 102 & 93 \\
\hline 47 & $M$ & 218 & 146 & 142 & 103 & 117 & 144 & 95 & - & - & 114 & 107 \\
\hline 48 & $F$ & 185 & 140 & 138 & 95 & 112 & 128 & 96 & - & - & 102 & 95 \\
\hline 49 & $M$ & - & - & - & - & 114 & - & - & - & - & - & - \\
\hline 50 & $F$ & - & - & - & - & - & - & - & - & - & - & - \\
\hline 51 & $F$ & - & - & - & - & - & - & - & - & - & - & - \\
\hline 52 & $M$ & - & - & - & 101 & 116 & - & - & - & - & 109 & 100 \\
\hline 53 & $M$ & - & - & - & 104 & - & - & - & - & - & 109 & 101 \\
\hline 54 & $\mathrm{~F}$ & 169 & 137 & 131 & 94 & 113 & 125 & 95 & - & - & 98 & 92 \\
\hline 55 & $F$ & - & - & - & - & - & - & - & - & - & - & - \\
\hline 56 & $M$ & - & - & - & - & - & - & - & - & - & - & - \\
\hline
\end{tabular}




\begin{tabular}{|c|c|c|c|c|c|c|c|c|c|c|c|}
\hline & & \multicolumn{10}{|c|}{ Cranial Measurements } \\
\hline Burial \# & Sex & 12 & 13 & 14 & 15 & 16 & 17 & 18 & 19 & 20 & 21 \\
\hline 1 & $\mathrm{~F}$ & - & - & - & - & - & - & - & 110 & - & - \\
\hline 2 & $M$ & - & - & - & - & - & - & - & 109 & 106 & - \\
\hline 3 & $M$ & - & - & - & - & - & - & - & 117 & 125 & 40 \\
\hline 4 & $M$ & - & 36 & 48 & - & - & - & - & 120 & 105 & 43 \\
\hline 5 & $M$ & - & - & - & - & - & - & - & - & - & - \\
\hline 6 & $M$ & - & - & - & - & - & - & - & 112 & 111 & 38 \\
\hline 7 & $M$ & - & - & - & - & - & - & - & 122 & - & - \\
\hline 8 & $M$ & - & - & - & - & - & - & - & 116 & - & - \\
\hline 9 & $M$ & - & - & - & - & - & - & - & - & - & - \\
\hline 10 & $M$ & 20 & 39 & 50 & 58 & 24 & - & - & - & - & - \\
\hline 11 & $M$ & - & - & - & - & - & - & - & 118 & - & - \\
\hline 12 & $M$ & - & - & - & - & - & - & - & 121 & - & 36 \\
\hline 13 & $M$ & - & - & - & - & - & - & - & - & - & - \\
\hline 14 & $M$ & - & - & - & - & - & 45 & - & 112 & - & - \\
\hline 15 & $M$ & - & - & - & - & - & - & - & - & - & - \\
\hline 16 & $M$ & 19 & 35 & 44 & 55 & 26 & 55 & - & 122 & 102 & 42 \\
\hline 17 & $M$ & - & - & - & - & - & - & - & 156 & - & - \\
\hline 18 & $M$ & - & - & - & - & - & - & - & 112 & - & - \\
\hline 19 & $M$ & - & - & - & - & - & - & - & $\div$ & - & - \\
\hline 20 & $M$ & - & - & - & - & - & - & - & - & - & - \\
\hline 21 & $M$ & - & - & - & - & - & - & - & 119 & 98 & - \\
\hline 22 & $M$ & - & - & - & - & - & - & - & - & - & - \\
\hline 23 & $M$ & - & - & - & - & - & - & - & - & - & - \\
\hline 24 & $M$ & - & - & - & - & - & - & - & - & - & - \\
\hline 25 & $M$ & - & - & - & - & - & - & - & - & - & - \\
\hline 26 & $M$ & - & - & - & - & - & - & - & - & - & - \\
\hline 27 & $M$ & - & - & - & - & - & - & - & - & - & - \\
\hline 28 & $M$ & - & - & - & - & - & - & - & - & - & - \\
\hline 29 & $M$ & - & - & - & - & 21 & 54 & 58 & - & - & - \\
\hline 30 & $M$ & - & - & - & - & - & - & - & - & - & - \\
\hline 31 & $M$ & - & - & - & - & - & - & - & 139 & - & - \\
\hline 32 & $M$ & - & - & - & - & - & - & - & - & - & - \\
\hline 33 & $M$ & - & - & - & - & - & - & - & - & - & - \\
\hline 34 & $M$ & - & - & - & - & - & - & - & - & - & - \\
\hline 35 & $M$ & - & - & - & - & - & - & - & - & - & - \\
\hline 36 & $M$ & - & - & - & - & - & - & - & - & - & - \\
\hline 37 & $M$ & - & - & - & - & - & - & - & - & - & - \\
\hline 38 & $M$ & - & - & - & - & - & - & - & - & - & - \\
\hline 39 & $M$ & - & - & - & - & - & - & - & 112 & - & - \\
\hline 40 & $M$ & - & - & - & - & - & - & - & - & 104 & - \\
\hline 41 & $M$ & - & - & - & - & - & - & - & - & - & - \\
\hline 42 & $M$ & - & - & - & - & - & - & - & - & - & - \\
\hline 43 & $M$ & - & - & - & - & - & - & - & - & 101 & - \\
\hline 44 & $M$ & - & - & - & - & - & - & - & - & - & - \\
\hline 45 & $M$ & - & - & - & - & - & - & - & - & - & - \\
\hline 46 & $M$ & 20 & - & - & - & - & - & - & 101 & 103 & 34 \\
\hline 47 & $M$ & - & - & - & - & - & - & - & 125 & 98 & 37 \\
\hline 48 & $\mathrm{~F}$ & 17 & 33 & 38 & - & - & - & - & 115 & 100 & 37 \\
\hline 49 & $M$ & - & - & - & - & - & - & - & - & - & - \\
\hline 50 & $\mathrm{~F}$ & - & - & - & - & - & - & - & - & - & - \\
\hline 51 & $F$ & - & - & - & - & - & - & - & - & - & $1-$ \\
\hline 52 & $M$ & 26 & 35 & 45 & - & - & - & - & - & - & - \\
\hline 53 & $M$ & - & - & - & - & - & - & - & - & - & - \\
\hline 54 & $F$ & - & - & - & - & - & - & - & 110 & 103 & 38 \\
\hline 55 & $\mathrm{~F}$ & - & - & - & - & - & - & - & - & 87 & - \\
\hline 56 & $M$ & - & - & - & - & - & - & - & - & - & - \\
\hline
\end{tabular}




\begin{tabular}{|c|c|c|c|c|c|c|c|c|c|c|c|}
\hline & & \multicolumn{10}{|c|}{ Cranial Measurements } \\
\hline Burial \# & Sex & 22 & 23 & 24 & 25 & 26 & 27 & 28 & 29 & 30 & 31 \\
\hline 1 & $\mathrm{~F}$ & - & - & - & - & - & - & - & - & - & - \\
\hline 2 & $M$ & - & - & - & 67 & - & - & - & 101 & 30 & 39 \\
\hline 3 & $M$ & 30 & - & - & 72 & - & - & - & 102 & 30 & 40 \\
\hline 4 & $M$ & 36 & - & - & 59 & - & - & - & 99 & 31 & 41 \\
\hline 5 & $M$ & - & - & - & 64 & - & - & - & 109 & 31 & 47 \\
\hline 6 & $M$ & 30 & - & - & - & - & - & - & - & 33 & 42 \\
\hline 7 & $\mathrm{M}$ & - & - & - & 63 & - & - & - & 102 & 33 & 41 \\
\hline 8 & $M$ & - & - & - & - & 31 & - & 13 & - & 32 & - \\
\hline 9 & $M$ & - & 97 & - & 66 & 25 & - & 13 & 102 & 28 & 37 \\
\hline 10 & $M$ & - & - & - & 61 & - & - & - & - & 33 & - \\
\hline 11 & $M$ & - & - & - & 65 & - & 32 & 11 & - & 35 & 47 \\
\hline 12 & $M$ & - & - & - & 59 & 34 & 34 & 9 & - & 28 & 39 \\
\hline 13 & $M$ & - & - & - & - & - & - & - & - & - & - \\
\hline 14 & $M$ & - & - & - & 51 & - & - & - & 95 & 28 & 39 \\
\hline 15 & $M$ & - & - & - & - & - & - & - & - & 34 & 39 \\
\hline 16 & $M$ & 37 & - & 132 & 70 & - & - & - & 107 & 31 & 42 \\
\hline 17 & $M$ & - & - & 126 & 63 & 25 & 31 & 9 & 104 & 32 & 43 \\
\hline 18 & $M$ & - & 115 & - & 65 & 30 & 25 & 11 & 102 & 31 & 36 \\
\hline 19 & $M$ & - & - & - & - & 27 & 30 & 12 & $\therefore$ & - & - \\
\hline 20 & $M$ & - & - & - & - & - & 32 & 13 & - & - & - \\
\hline 21 & $M$ & - & 104 & 121 & 64 & 23 & 30 & 12 & 101 & 30 & 39 \\
\hline 22 & $M$ & - & - & - & 62 & - & 35 & 15 & - & 42 & 54 \\
\hline 23 & $M$ & - & - & - & 67 & - & 29 & 13 & - & 32 & 39 \\
\hline 24 & $M$ & - & - & - & - & - & - & - & - & - & - \\
\hline 25 & $M$ & - & - & - & - & 25 & - & 12 & - & 34 & - \\
\hline 26 & $M$ & - & - & - & - & 33 & - & - & - & - & - \\
\hline 27 & $M$ & - & - & 119 & 56 & 34 & 33 & 13 & 115 & - & - \\
\hline 28 & $M$ & - & - & - & - & - & - & - & - & 23 & - \\
\hline 29 & $M$ & - & - & - & - & - & 29 & 10 & - & - & - \\
\hline 30 & $M$ & - & - & - & - & - & - & - & - & - & - \\
\hline 31 & $M$ & - & - & - & 63 & 27 & 33 & 12 & - & 28 & 38 \\
\hline 32 & $M$ & - & - & - & - & 27 & - & - & 112 & 30 & - \\
\hline 33 & $M$ & - & - & 126 & 66 & 29 & 25 & 14 & 113 & 39 & 53 \\
\hline 34 & $M$ & - & - & - & 71 & 32 & 32 & 12 & - & 38 & 48 \\
\hline 35 & $M$ & - & 100 & - & 62 & 26 & 25 & 9 & 109 & 24 & 37 \\
\hline 36 & $M$ & - & - & - & - & 32 & 31 & 10 & - & - & - \\
\hline 37 & $M$ & - & - & - & 52 & - & 28 & 16 & - & 31 & 40 \\
\hline 38 & $M$ & - & 103 & - & 58 & 27 & 29 & 11 & 98 & 31 & 45 \\
\hline 39 & $M$ & - & - & 127 & 59 & 26 & 25 & 13 & 99 & 33 & 43 \\
\hline 40 & $M$ & - & - & - & - & - & - & - & - & 28 & - \\
\hline 41 & $M$ & - & - & - & - & - & - & - & 98 & - & - \\
\hline 42 & $M$ & - & - & - & - & 28 & 25 & 13 & - & - & - \\
\hline 43 & $M$ & - & - & - & - & - & 31 & 11 & - & - & - \\
\hline 44 & $M$ & - & 111 & 118 & 53 & 31 & 29 & 11 & 96 & 28 & 34 \\
\hline 45 & $M$ & - & - & - & - & - & 37 & 13 & - & - & - \\
\hline 46 & $M$ & 27 & 101 & - & 65 & - & - & - & 104 & 31 & 40 \\
\hline 47 & $M$ & 31 & 113 & 125 & 69 & 23 & 21 & 12 & 106 & 36 & 45 \\
\hline 48 & $\mathrm{~F}$ & 31 & 117 & 116 & 61 & - & - & - & 102 & 21 & 37 \\
\hline 49 & $M$ & - & - & 131 & 58 & - & - & - & 103 & 33 & 42 \\
\hline 50 & $F$ & - & 105 & - & 57 & 31 & 28 & 12 & - & 32 & 36 \\
\hline 51 & $F$ & - & - & - & - & - & - & - & - & 26 & 39 \\
\hline 52 & $M$ & - & - & - & 61 & 32 & 34 & 11 & 102 & 29 & 41 \\
\hline 53 & $M$ & - & - & - & 57 & 28 & - & 10 & - & 32 & 43 \\
\hline 54 & $F$ & 31 & - & - & - & - & - & - & - & 29 & 37 \\
\hline 55 & $F$ & - & - & - & - & - & - & - & 93 & 29 & - \\
\hline 56 & $M$ & - & 104 & 124 & 62 & - & - & - & - & 30 & 44 \\
\hline
\end{tabular}




\begin{tabular}{|c|c|c|c|c|c|c|c|c|c|c|c|c|}
\hline & & \multicolumn{11}{|c|}{ Postcranial Measurements } \\
\hline Burial \# & Sex & 1 & 2 & 3 & 4 & 5 & 6 & 7 & 8 & 9 & 10 & 11 \\
\hline 1 & $\mathrm{~F}$ & - & 20 & 17 & - & - & - & - & - & - & - & - \\
\hline 2 & $\mathrm{M}$ & - & 21 & 19 & 54 & 45 & - & - & - & - & - & - \\
\hline 3 & $M$ & - & 23 & 20 & - & - & 71 & 266 & 15 & 13 & - & 40 \\
\hline 4 & $M$ & - & 26 & 22 & - & - & - & - & 14 & 19 & 266 & 43 \\
\hline 5 & $M$ & - & 24.5 & 20 & - & - & 60 & - & 11.5 & 16 & - & - \\
\hline 6 & $M$ & - & 25 & - & - & - & 64 & 246 & 13 & 17.5 & - & - \\
\hline 7 & $M$ & - & - & - & - & - & - & - & - & - & - & - \\
\hline 8 & $M$ & - & 25 & 22 & - & - & 66 & - & 13 & 18 & - & - \\
\hline 9 & $M$ & - & 23 & 17 & - & - & - & - & 12 & 19 & - & 40 \\
\hline 10 & $M$ & 355 & 25 & 23 & 55 & 49 & 73 & 259 & 13 & 18 & 279 & 40 \\
\hline 11 & $M$ & - & 24 & 21 & - & - & 66 & 258 & 13 & 17 & 277 & 41 \\
\hline 12 & $M$ & - & 23 & 19 & - & - & 66 & - & 16 & 11 & - & 37 \\
\hline 13 & $M$ & - & 22 & 20 & - & - & 63 & 255 & 12 & 16 & 277 & 40 \\
\hline 14 & $M$ & 315 & 21 & 18 & 49 & 44 & 61 & 236 & 12 & 14 & 253 & 33 \\
\hline 15 & $M$ & 313 & 21 & 19 & - & - & 61 & 234 & 13 & 16 & 245 & 40 \\
\hline 16 & $M$ & 374 & 23 & 20 & 53 & 48 & 64 & 282 & 15 & 18 & 305 & 41 \\
\hline 17 & $M$ & 331 & 25 & 19 & 45 & 43 & 62 & - & - & - & 255 & 40 \\
\hline 18 & $M$ & 357 & 24 & 21 & 56 & 50 & 67 & - & - & - & 288 & 45 \\
\hline 19 & $M$ & 347 & 27 & 22 & 51 & - & 68 & - & - & - & - & - \\
\hline 20 & $M$ & - & 25 & 19 & $r$ & - & 62 & - & 11 & 17 & - & - \\
\hline 21 & $M$ & 319 & 26 & 17 & 47 & 44 & 65 & 255 & 12 & 16 & 274 & 43 \\
\hline 22 & $M$ & 360 & 24 & 20 & 50 & 44 & 64 & 257 & 13 & 17 & 263 & 40 \\
\hline 23 & $M$ & - & 25 & 22 & - & - & - & 240 & 14 & 15 & 255 & 40 \\
\hline 24 & $M$ & - & - & - & - & - & - & 252 & 16 & 18 & - & - \\
\hline 25 & $M$ & - & - & - & - & - & 72 & 259 & 16 & 19 & - & - \\
\hline 26 & $M$ & 318 & 30 & 23 & 48 & 42 & 64 & 235 & 15 & 18 & 261 & 46 \\
\hline 27 & $M$ & 332 & 22 & 19.5 & 51 & 47 & 66 & 259 & 13 & 16 & 276 & 42 \\
\hline 28 & $M$ & 323 & 26 & 21 & 49 & 46 & 67 & 228 & 13 & 16 & - & - \\
\hline 29 & $M$ & 350 & 23 & 16 & 48 & 42 & 63 & 270 & 12 & 15 & 291 & 40 \\
\hline 30 & $M$ & - & 25 & 20 & - & - & 65 & 243 & 12 & 15 & 267 & 39 \\
\hline 31 & $M$ & 358 & 24 & 21 & 52 & 46 & 69 & 266 & 14 & 18 & 290 & 43 \\
\hline 32 & $M$ & 330 & 24 & 20 & 48 & 41 & 61 & - & - & - & - & - \\
\hline 33 & $M$ & 359 & 22 & 19.5 & 50 & 45 & 65 & - & - & - & - & - \\
\hline 34 & $M$ & 362 & 27 & 23 & 53 & 48 & 71 & 276 & 15 & 19 & 292 & 45 \\
\hline 35 & $M$ & 340 & 19 & 17 & 50 & 47 & 63 & 251 & 11 & 14 & 270 & 36 \\
\hline 36 & $M$ & 319 & 19 & 18 & 49 & 42 & 61 & 234 & 12.5 & 15 & 247 & 35 \\
\hline 37 & $M$ & 334 & 25 & 20 & 51 & 45 & 61 & 258 & 13 & 17 & 272 & 44 \\
\hline 38 & $M$ & - & 21 & 19 & - & - & 68 & 265 & 14 & 17 & 276 & 39 \\
\hline 39 & $M$ & 316 & 23 & 21 & 50 & 45 & 60 & 233 & 14 & 18 & 242 & 44 \\
\hline 40 & $M$ & 325 & 25 & 23 & 50 & 45 & 67 & 253 & 13 & 16 & 272 & 41 \\
\hline 41 & $M$ & 305 & 24 & 21 & 46 & 43 & 62 & 229 & 12 & 17 & - & - \\
\hline 42 & $M$ & - & - & 20 & - & - & 65 & 233 & 14 & 18 & 255 & 44 \\
\hline 43 & $M$ & 359 & 26 & 24 & 50 & 44 & 71 & - & - & - & - & - \\
\hline 44 & $M$ & 345 & 22 & 20 & 48 & 43 & 67 & 255 & 12 & 17 & 274 & 43 \\
\hline 45 & $M$ & 352 & 25 & 22 & 55 & 47 & 71 & 253 & 16 & 19 & 274 & - \\
\hline 46 & $M$ & 323 & 22 & 20 & 50 & 42 & 61 & 234 & 14 & 17 & 255 & 41 \\
\hline 47 & $M$ & 328 & 26 & 20 & 53 & 47 & 68 & 242 & 15 & 19 & 262 & 44 \\
\hline 48 & $F$ & 286 & 20 & 16 & 40 & - & 51 & - & - & - & 229 & 35 \\
\hline 49 & $M$ & 316 & 23 & 19 & 48 & 45 & 66 & 246 & 13 & 15 & 262 & 38 \\
\hline 50 & $F$ & 332 & 20 & 19 & 45 & 39 & 51 & - & - & - & - & - \\
\hline 51 & $\mathrm{~F}$ & 286 & 20 & 17 & 39 & 36 & 51 & 208 & 10 & 14 & - & - \\
\hline 52 & $M$ & 336 & 23 & 20 & 49 & 43 & - & - & - & - & 266 & 38 \\
\hline 53 & $M$ & 334 & 24 & 22 & 52 & 47 & 64 & 252 & 13 & 19 & 273 & 41 \\
\hline 54 & $\mathrm{~F}$ & 281 & 19 & 14 & 43 & 39 & 54 & 214 & 14 & 9 & - & - \\
\hline 55 & $F$ & - & - & - & - & - & 49 & 228 & 14 & 10 & 238 & 34 \\
\hline 56 & $M$ & 323 & 23 & 21 & 48 & 42 & 66 & 247 & 11 & 16 & 267 & 42 \\
\hline
\end{tabular}


Appendix E: Skeletal Cranial and Postcranial Metric Data

\begin{tabular}{|c|c|c|c|c|c|c|c|c|c|c|c|c|}
\hline & + & \multicolumn{11}{|c|}{ Postcranial Measurements } \\
\hline Burial \# & Sex & 12 & 13 & 14 & 15 & 16 & 17 & 18 & 19 & 20 & 21 & 22 \\
\hline 1 & $\mathrm{~F}$ & - & - & - & - & - & - & - & - & 42 & - & 28 \\
\hline 2 & $\mathrm{M}$ & - & - & - & - & - & - & - & - & - & - & 27 \\
\hline 3 & $\mathrm{M}$ & - & - & - & - & - & 90 & 27 & 31 & - & - & 26 \\
\hline 4 & $\bar{M}$ & 19 & 17 & 233 & - & - & 95 & 33 & 28 & - & - & 31 \\
\hline 5 & $\mathrm{M}$ & 13 & 18 & - & - & - & - & - & - & - & - & - \\
\hline 6 & $\mathrm{M}$ & - & - & - & - & - & 96 & 31 & 30 & - & - & - \\
\hline 7 & $\mathrm{M}$ & - & - & - & - & - & - & - & - & - & - & - \\
\hline 8 & $\mathrm{M}$ & 16 & 17 & - & - & - & - & - & - & - & - & - \\
\hline 9 & $M$ & 18 & 12 & - & - & - & 91 & 31 & 26 & - & - & 34 \\
\hline 10 & $M$ & 16 & 20 & 251 & - & - & 107 & 34 & 33 & 52 & - & 33 \\
\hline 11 & $M$ & 14 & 18 & 249 & 496 & - & 95 & 30 & 31 & 50 & - & 29 \\
\hline 12 & $M$ & 16 & 12 & - & 473 & 468 & 87 & 28 & 26 & 49 & 89 & 31 \\
\hline 13 & $M$ & 15 & 16 & 244 & - & - & 92 & 31 & 28 & - & - & 30 \\
\hline 14 & $M$ & 14 & 15 & 227 & 440 & 437 & 84 & 28 & 28 & 45 & 81 & 25 \\
\hline 15 & $M$ & 14 & 17 & 220 & - & - & - & - & - & - & - & - \\
\hline 16 & $M$ & 17 & 22 & 270 & 524 & 520 & 107 & 36 & 32 & 51 & 90 & 31 \\
\hline 17 & $M$ & 18 & 17 & 225 & 461 & 458 & 94 & 32 & 27 & 44 & - & 30 \\
\hline 18 & $M$ & 16 & 19 & 257 & - & - & - & - & - & - & - & - \\
\hline 19 & $M$ & - & - & - & - & - & - & - & - & - & - & - \\
\hline 20 & $M$ & 15 & 19 & - & 43.9 & - & 88 & 28 & 29 & 46 & - & 29 \\
\hline 21 & $M$ & 18 & 17 & 247 & 438 & 435 & 89 & 30 & 26 & 47 & 83 & 27 \\
\hline 22 & $M$ & 14 & 17 & 237 & 490 & 487 & 97 & 29 & 32 & 51 & 87 & 30 \\
\hline 23 & $M$ & 18 & 14 & 225 & - & - & - & - & - & - & 86 & - \\
\hline 24 & $M$ & - & - & - & - & - & - & - & - & - & - & - \\
\hline 25 & $M$ & - & - & - & - & - & - & - & - & 52 & - & 34 \\
\hline 26 & $M$ & 18 & 20 & 231 & 461 & 459 & 99 & 33 & 30 & 47 & 86 & 34 \\
\hline 27 & $M$ & 14 & 18 & 251 & 476 & 475 & 95 & 31 & 30 & 50 & - & 29 \\
\hline 28 & $M$ & - & - & - & - & - & - & - & - & 49 & - & 29 \\
\hline 29 & $M$ & 14 & 18 & 262 & 496 & 494 & 96 & 33 & 28 & 46 & 85 & 30 \\
\hline 30 & $M$ & 14 & 17 & 238 & - & - & 86 & 27 & 28 & 48 & 91 & 28 \\
\hline 31 & $M$ & 14 & 17 & 259 & 510 & 508 & 96 & 33 & 29 & 51 & 91 & 31 \\
\hline 32 & $M$ & - & - & - & - & - & 86 & 27 & 27 & 46 & - & 26 \\
\hline 33 & $M$ & - & - & - & 502 & - & 96 & 36 & 28 & 50 & - & 30 \\
\hline 34 & $M$ & 17 & 21 & 264 & - & - & 103 & - & - & 49 & - & 32 \\
\hline 35 & $M$ & 11 & 16 & 244 & 476 & 473 & 86 & 28 & 27 & 50 & 82 & 29 \\
\hline 36 & $M$ & 13 & 16 & 224 & 451 & 447 & 89 & 29 & 28 & 47 & 82 & 29 \\
\hline 37 & $M$ & 14 & 18 & 246 & - & - & 100 & 35 & 30 & - & - & 29 \\
\hline 38 & $M$ & 12 & 15 & 248 & 488 & - & - & - & - & 49 & 86 & 34 \\
\hline 39 & $M$ & 14 & 19 & 218 & 432 & 427 & 91 & 30 & 29 & 47 & 85 & 30 \\
\hline 40 & $M$ & 15 & 19 & 242 & - & - & - & - & - & 51 & 85 & - \\
\hline 41 & $M$ & - & - & - & - & - & - & - & - & - & - & - \\
\hline 42 & $M$ & 13 & 19 & 220 & - & - & - & - & - & - & - & - \\
\hline 43 & $M$ & - & - & - & - & - & - & - & - & 47 & - & 34 \\
\hline 44 & $M$ & 15 & 19 & 242 & 464 & 462 & 95 & 29 & 30 & 47 & 84 & 29 \\
\hline 45 & $M$ & 15 & 19 & 244 & - & - & - & - & - & - & - & - \\
\hline 46 & $M$ & 14 & 19 & 228 & 428 & 423 & 89 & 27 & 29 & 47 & 84 & 28 \\
\hline 47 & $M$ & 15 & 20 & 238 & 465 & 462 & 102 & 34 & 31 & 53 & - & 34 \\
\hline 48 & $\mathrm{~F}$ & 10 & 16 & 203 & 414 & 411 & 81 & 28 & 23 & 40 & 70 & 27 \\
\hline 49 & $M$ & 14 & 19 & 235 & 465 & - & 95 & 32 & 28 & 47 & - & 30 \\
\hline 50 & $F$ & - & - & - & - & - & - & - & - & - & - & - \\
\hline 51 & $F$ & - & - & - & 395 & - & 83 & 26 & 27 & 39 & 71 & - \\
\hline 52 & $M$ & 12 & 17 & 241 & 491 & 488 & 94 & 29 & 31 & 52 & 86 & 29 \\
\hline 53 & $M$ & 15 & 19 & 246 & - & - & - & - & - & 54 & - & - \\
\hline 54 & $\mathrm{~F}$ & 10 & 13 & - & - & - & 78 & 23 & 27 & 43 & - & 27 \\
\hline 55 & $F$ & 10 & 14 & - & - & - & - & - & - & - & - & 28 \\
\hline 5 & $M$ & 14 & 17 & 235 & - & - & - & - & - & 48 & - & - \\
\hline
\end{tabular}


Texas State Cemetery Project

\begin{tabular}{|c|c|c|c|c|c|c|c|c|c|c|c|c|}
\hline & & \multicolumn{11}{|c|}{ Postcranial Measurements } \\
\hline Burial \# & Sex & 23 & 24 & 25 & 26 & 27 & 28 & 29 & 30 & 31 & 32 & 33 \\
\hline 1 & $F$ & 29 & - & 97 & 35 & 25 & - & - & - & - & - & - \\
\hline 2 & $M$ & 35 & - & 98 & 37 & 24 & - & - & - & - & - & - \\
\hline 3 & $M$ & 35 & 400 & - & - & - & - & 48 & - & - & - & - \\
\hline 4 & $M$ & 29 & 389 & 106 & 37 & 26 & - & 51 & - & - & - & - \\
\hline 5 & $M$ & - & - & 96 & 35 & 23 & - & - & - & - & - & - \\
\hline 6 & $M$ & - & - & - & - & - & - & - & - & - & - & - \\
\hline 7 & $M$ & - & - & 95 & 35 & 23 & - & - & - & - & - & - \\
\hline 8 & $M$ & - & - & - & - & - & - & - & - & - & - & - \\
\hline 9 & $M$ & 29 & - & 104 & 38 & 26 & - & - & - & 16 & - & - \\
\hline 10 & $M$ & 37 & - & 110 & 42 & 25 & - & 50 & - & - & - & - \\
\hline 11 & $M$ & 35 & 387 & 100 & 38 & 22 & - & 48 & - & 11 & - & - \\
\hline 12 & $M$ & 38 & 385 & 92 & 33 & 22 & 80 & 52 & - & 15 & - & - \\
\hline 13 & $M$ & 29 & - & 98 & 38 & 23 & - & 45 & - & - & - & - \\
\hline 14 & $M$ & 31 & - & 88 & 34 & 23 & - & 44 & - & 13 & - & - \\
\hline 15 & $M$ & - & - & 96 & 35 & 24 & - & 46 & - & - & - & - \\
\hline 16 & $M$ & 38 & 414 & 110 & 41 & 27 & 82 & - & - & - & - & - \\
\hline 17 & $M$ & 30 & 372 & 93 & 38 & 25 & 73 & 53 & - & 7 & - & - \\
\hline 18 & $M$ & - & 393 & 107 & 38 & 27 & 83 & 51 & - & - & - & - \\
\hline 19 & $M$ & - & - & - & - & - & - & - & - & - & - & - \\
\hline 20 & $M$ & 34 & 365 & 94 & .27 & 31 & - & 41 & 365 & 15 & - & - \\
\hline 21 & $M$ & 31 & 366 & 90 & 30 & 25 & 77 & 44 & 360 & 18 & - & 111 \\
\hline 22 & $M$ & 35 & 400 & 103 & 38 & 27 & 83 & 51 & 398 & 13 & - & - \\
\hline 23 & $M$ & - & 359 & 97 & 35 & 25 & 79 & 45 & 360 & 16 & - & - \\
\hline 24 & $M$ & - & - & - & - & - & - & - & - & - & - & - \\
\hline 25 & $M$ & 36 & - & - & - & - & - & - & - & - & - & - \\
\hline 26 & $M$ & 33 & 368 & 111 & 41 & 31 & - & 47 & - & - & - & - \\
\hline 27 & $M$ & 32 & - & 96 & 35 & 26 & 80 & - & - & - & - & - \\
\hline 28 & $M$ & 28 & - & - & - & - & - & 45 & - & 13 & - & - \\
\hline 29 & $M$ & 32 & 417 & 99 & 31 & 28 & 78 & 55 & 480 & 17 & - & - \\
\hline 30 & $M$ & 32 & - & 97 & 34 & 26 & - & 49 & - & - & - & - \\
\hline 31 & $M$ & 34 & 416 & 98 & 35 & 24 & 84 & 51 & - & - & - & - \\
\hline 32 & $M$ & 30 & - & 96 & 36 & 25 & 77 & 48 & - & - & - & - \\
\hline 33 & $M$ & 31 & 415 & 101 & 36 & 27 & 80 & 45 & - & - & - & - \\
\hline 34 & $M$ & 35 & - & - & - & - & - & - & 417 & 18 & - & - \\
\hline 35 & $M$ & 32 & 395 & 88 & 33 & 22 & - & 46 & 393 & 14 & - & - \\
\hline 36 & $M$ & 31 & 342 & 89 & 32 & 24 & 77 & 47 & 345 & 12 & - & - \\
\hline 37 & $M$ & 32 & 376 & 105 & 38 & 26 & 84 & 47 & - & - & - & - \\
\hline 38 & $M$ & 33 & 400 & 102 & 40 & 26 & 80 & 50 & 383 & 14 & - & - \\
\hline 39 & $M$ & 34 & 343 & 101 & 36 & 25 & 79 & 48 & 349 & 17 & - & 110 \\
\hline 40 & $M$ & - & 382 & 100 & 37 & 25 & 80 & 46 & 379 & 15 & - & - \\
\hline 41 & $M$ & - & 339 & 94 & 33 & 26 & 77 & 45 & 335 & 16 & - & - \\
\hline 42 & $M$ & - & - & - & - & - & - & 46 & - & - & - & - \\
\hline 43 & $M$ & 39 & - & - & - & - & - & - & - & - & - & - \\
\hline 44 & $M$ & 36 & 381 & 98 & 37 & 24 & - & 47 & - & - & - & - \\
\hline 45 & $M$ & - & - & 100 & 37 & 24 & - & - & 390 & 16 & - & - \\
\hline 46 & $M$ & 33 & 359 & 93 & 35 & 21 & 76 & 44 & - & - & - & - \\
\hline 47 & $M$ & 35 & 370 & 104 & 38 & 27 & 85 & 51 & 357 & 17 & - & 113 \\
\hline 48 & $F$ & 26 & 324 & 83 & 30 & 21 & 64 & 40 & - & - & - & 89 \\
\hline 49 & $M$ & 32 & 394 & 98 & 37 & 24 & - & 44 & - & - & - & - \\
\hline 50 & $F$ & - & - & 78 & 27 & 19 & - & 39 & - & - & - & - \\
\hline 51 & $\mathrm{~F}$ & - & 336 & 87 & 31 & 24 & 67 & 41 & - & - & - & 97 \\
\hline 52 & $M$ & 37 & 400 & 115 & 45 & 28 & 80 & 49 & 388 & 15 & - & - \\
\hline 53 & $M$ & - & 374 & 95 & 35 & 24 & 83 & 43 & - & - & - & - \\
\hline 54 & $F$ & 31 & 345 & 83 & 23 & 24 & 69 & 46 & - & - & - & - \\
\hline 55 & $F$ & 26 & - & - & 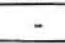 & - & - & - & - & - & - & - \\
\hline 56 & $M$ & - & - & 90 & 33 & 21 & - & - & - & - & - & - \\
\hline
\end{tabular}




\begin{tabular}{|c|c|c|c|c|c|c|c|c|c|c|c|c|}
\hline & & \multicolumn{11}{|c|}{ Postcranial Measurements } \\
\hline Burial \# & Sex & 34 & 35 & 36 & 37 & 38 & 39 & 40 & 41 & 42 & 43 & 44 \\
\hline 1 & $F$ & - & - & - & - & - & - & - & - & - & - & \\
\hline 2 & $M$ & - & 11 & 11 & - & - & - & - & - & - & - & \\
\hline 3 & $M$ & - & 14 & 11 & - & - & - & - & - & - & - & 177.4 \\
\hline 4 & $M$ & 141 & 15 & 12 & - & - & - & - & - & - & - & 173.32 \\
\hline 5 & $M$ & - & 13 & 11 & - & - & - & - & - & - & - & 176.02 \\
\hline 6 & $M$ & - & - & - & - & - & - & - & - & - & - & 184.1 \\
\hline 7 & $M$ & - & - & - & - & - & - & - & - & - & - & \\
\hline 8 & $M$ & - & 15 & 12 & - & - & - & - & - & - & - & 177.66 \\
\hline 9 & $M$ & - & 8 & 7 & - & - & - & - & - & - & - & \\
\hline 10 & $M$ & 152 & 13 & 14 & - & - & - & - & - & - & - & 175.59 \\
\hline 11 & $M$ & - & 14 & 10 & - & - & - & - & - & - & - & 174.87 \\
\hline 12 & $M$ & - & - & - & - & - & - & - & - & - & - & 172 \\
\hline 13 & $M$ & - & 13 & 11 & - & $\begin{array}{lll}- \\
-\end{array}$ & - & - & - & - & - & 173.71 \\
\hline 14 & $M$ & - & - & - & - & - & - & - & - & - & - & 163.72 \\
\hline 15 & $M$ & 150 & 12 & 10 & - & - & - & - & - & - & - & 162.7 \\
\hline 16 & $M$ & 180 & 15 & 11 & 235 & - & - & - & - & - & - & 182.22 \\
\hline 17 & $M$ & 154 & 9 & 12 & - & - & - & - & - & - & - & 169.22 \\
\hline 18 & $M$ & 161 & 12 & 12 & - & - & - & - & - & - & - & 174.46 \\
\hline 19 & $M$ & - & - & - & - & - & - & - & - & - & - & 174.62 \\
\hline 20 & $M$ & - & - & - & .- & - & - & - & - & - & - & 165.25 \\
\hline 21 & $M$ & 148 & 16 & 10 & - & - & - & - & - & - & - & 165.67 \\
\hline 22 & $M$ & - & - & - & - & - & - & - & - & - & - & 176.23 \\
\hline 23 & $M$ & - & - & - & - & - & - & - & $\begin{array}{ll}- \\
-\end{array}$ & - & - & 166.48 \\
\hline 24 & $M$ & - & - & - & - & - & - & - & - & - & - & 170.34 \\
\hline 25 & $M$ & - & - & - & - & - & - & - & - & - & - & 174.78 \\
\hline 26 & $M$ & 155 & 16 & 12 & - & - & - & - & - & - & - & 167.58 \\
\hline 27 & $M$ & 141 & 15 & 10 & 228 & - & - & - & - & - & - & 171.4 \\
\hline 28 & $M$ & - & - & - & - & - & - & - & - & - & - & 164.98 \\
\hline 29 & $M$ & 150 & 12 & 9 & - & - & 92 & 89 & - & - & - & 179.23 \\
\hline 30 & $M$ & - & - & - & 221 & - & - & - & - & - & - & 169.36 \\
\hline 31 & $M$ & - & - & - & - & - & - & - & - & - & - & 181.45 \\
\hline 32 & $M$ & 145 & 13.5 & 12 & - & - & - & - & - & - & - & 169.72 \\
\hline 33 & $M$ & - & - & - & 223 & - & - & - & - & - & - & 179.84 \\
\hline 34 & $M$ & - & - & - & - & - & - & - & - & - & - & 179.51 \\
\hline 35 & $M$ & 142 & 10 & 9 & 229 & - & 97 & 85 & 130 & 123 & 49 & 173.8 \\
\hline 36 & $M$ & 144 & 11 & 9 & - & - & - & - & 117 & 100 & 53 & 165.2 \\
\hline 37 & $M$ & 143 & 16 & 11 & - & - & - & - & - & - & - & 170.3 \\
\hline 38 & $M$ & - & - & - & 237 & - & - & - & - & - & - & 175.56 \\
\hline 39 & $M$ & 145 & 14 & 12 & 217 & 157 & - & - & - & 101 & 49 & 162.04 \\
\hline 40 & $M$ & 140 & 13 & 12 & - & - & - & - & - & - & - & 172.78 \\
\hline 41 & $M$ & 150 & 12.5 & 10 & - & - & - & - & - & - & - & 160.88 \\
\hline 42 & $M$ & 155 & 15 & 10 & - & - & - & - & - & - & - & 164.99 \\
\hline 43 & $M$ & - & - & - & - & - & - & - & - & - & - & 178.42 \\
\hline 44 & $M$ & 160 & 14 & 11 & - & - & - & - & - & - & - & 171.27 \\
\hline 45 & $M$ & - & - & - & - & - & - & - & - & - & - & 173.98 \\
\hline 46 & $M$ & 127 & 14 & 12 & - & - & - & - & - & - & - & 163.55 \\
\hline 47 & $M$ & 165 & 14 & 13 & - & - & - & - & - & - & - & 169.3 \\
\hline 48 & $\mathrm{~F}$ & 138 & 9 & 8 & - & - & - & - & - & - & - & 153.23 \\
\hline 49 & $M$ & 146 & 13 & 11 & - & - & - & - & - & - & - & 171.7 \\
\hline 50 & $\mathrm{~F}$ & 160 & 11 & 8 & - & - & - & - & - & - & - & 167 \\
\hline 51 & $\mathrm{~F}$ & 137 & 11 & 8 & - & - & - & - & 108 & 119 & 46 & 152.38 \\
\hline 52 & $M$ & 152 & 11 & 12 & - & - & - & - & - & - & - & 175.27 \\
\hline 53 & $M$ & - & - & - & - & - & - & - & - & - & - & 170.12 \\
\hline 54 & $\mathrm{~F}$ & 128 & 9 & 9 & - & - & - & - & - & - & - & 158.4 \\
\hline 55 & $\mathrm{~F}$ & - & - & - & - & - & - & - & - & - & - & 158.31 \\
\hline 56 & $M$ & - & - & - & - & - & - & - & - & - & - & 166.02 \\
\hline
\end{tabular}





\section{APPENDIX F: Skeletal Cranial and Postcranial Nonmetric Traits for Analyzed Individuals from the Texas State Cemetery}

Compiled by

Helen Danzeiser Dockall 


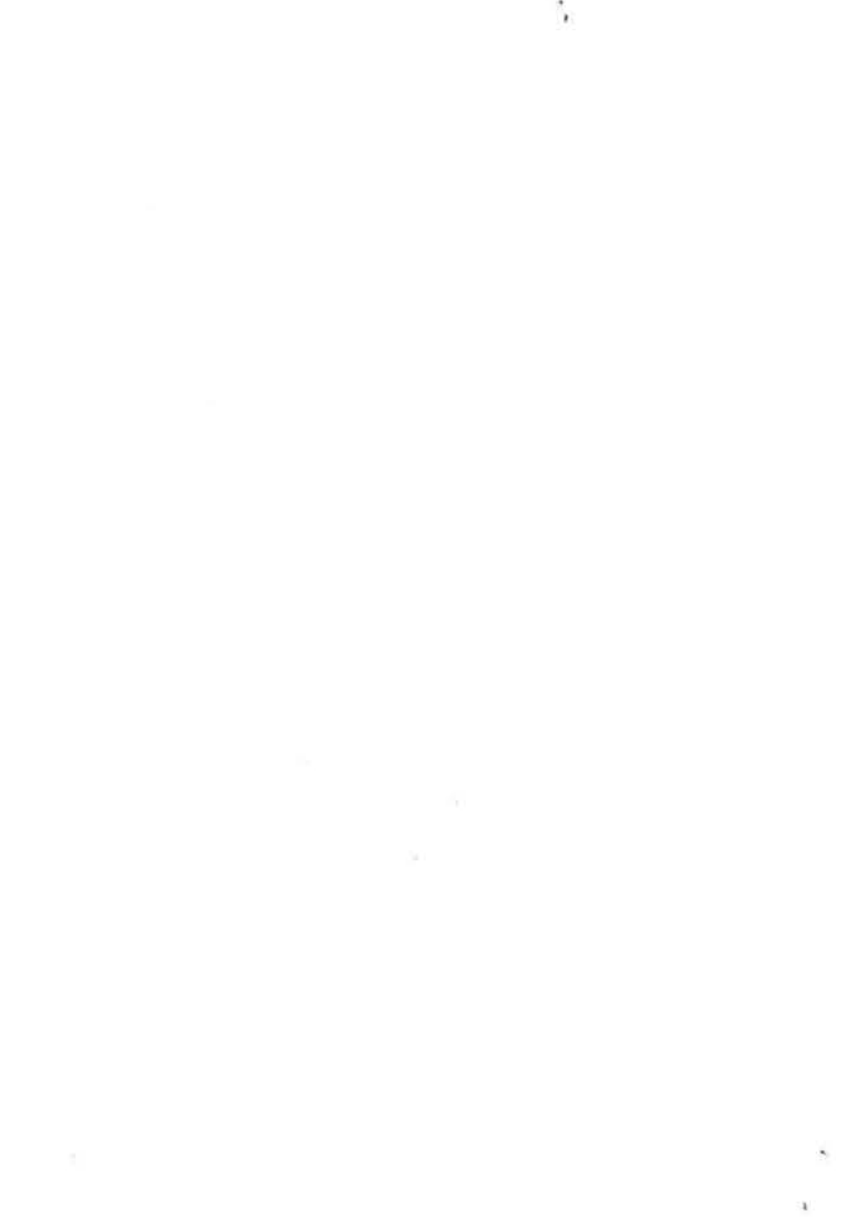


Skeletal nonmetric data associated with each individual analyzed from the Texas State Cemetery are presented in this appendix. Methodology for assessing nonmetric traits followed Buikstra and Ubelaker (1994).

\section{KEY TO VALUES LISTED FOR EACH ANALYZED TRAIT}

$$
\begin{aligned}
& 0=\text { Absent } \\
& 1=\text { Present } \\
& 2=\text { Partial } \\
& 3=\text { Complete } \\
& 4=\text { Multiple }
\end{aligned}
$$

$$
\begin{aligned}
& 5=\text { Right } \\
& 6=\text { Left } \\
& 7=\text { Both } \\
& 8=\text { Unobservable }
\end{aligned}
$$

\section{NONMETRIC TRAITS KEY}

$\begin{aligned} 1 & \text { Metopic suture } \\ 2 & \text { Supraorbital notch } \\ 3 & \text { Supraorbital foramen } \\ 4 & \text { Infraorbital suture } \\ 5 & \text { Infraorbital foramina } \\ 6 & \text { Zygomatico-facial foramina } \\ 7 & \text { Parietal foramen } \\ 8 & \text { Epipteric bone } \\ 9 & \text { Coronal ossicle } \\ 10 & \text { Bregmatic bone } \\ 11 & \text { Sagittal ossicle } \\ 12 & \text { Apical bone } \\ 13 & \text { Lambdoid ossicle } \\ 14 & \text { Asterionic bone } \\ 15 & \text { Occipito-mastoid ossicle } \\ 16 & \text { Parietal notch bone } \\ 17 & \text { Condylar canal }\end{aligned}$

1 
Texas State Cemetery Project

\begin{tabular}{|c|c|c|c|c|c|c|c|c|c|c|c|c|}
\hline & & \multicolumn{11}{|c|}{ Cranial } \\
\hline Burial \# & Sex & 1 & & & & & & & & & & \\
\hline & & & $\mathrm{L}$ & $R$ & $\mathrm{~L}$ & $R$ & $\mathrm{~L}$ & $R$ & $\mathrm{~L}$ & $R$ & $\mathrm{~L}$ & $\mathrm{R}$ \\
\hline 1 & $F$ & 0 & 0 & 1 & 1 & 0 & 9 & 9 & 9 & 9 & 4 & 4 \\
\hline 2 & $M$ & 2 & 1 & 1 & 0 & 0 & 9 & 0 & 0 & 0 & 1 & 1 \\
\hline 3 & $M$ & 2 & 0 & 0 & 1 & 1 & 9 & 9 & 9 & 9 & 4 & 4 \\
\hline 4 & $M$ & 2 & 1 & 1 & 0 & 0 & 0 & 0 & 9 & 9 & 1 & 4 \\
\hline 5 & $M$ & 9 & 9 & 9 & 9 & 9 & 9 & 0 & 9 & 0 & 9 & 9 \\
\hline 6 & $M$ & 2 & 1 & 1 & 9 & 9 & 9 & 9 & 9 & 9 & 9 & 4 \\
\hline 7 & $M$ & 9 & 9 & 9 & 9 & 9 & 9 & 9 & 9 & 9 & 9 & 9 \\
\hline 8 & $M$ & 0 & 1 & 1 & 0 & 0 & 9 & 9 & 9 & 9 & 4 & 9 \\
\hline 9 & $M$ & 2 & 1 & 1 & 0 & 0 & 9 & 9 & 9 & 9 & 4 & 1 \\
\hline 10 & $M$ & 2 & 9 & 1 & 9 & 1 & 9 & 0 & 9 & 1 & 4 & 4 \\
\hline 11 & $M$ & 2 & 1 & 1 & 0 & 0 & 9 & 0 & 9 & 0 & 9 & 1 \\
\hline 12 & $M$ & 2 & 1 & 0 & 1 & 1 & 9 & 9 & 9 & 9 & 1 & 1 \\
\hline 13 & $M$ & 3 & 1 & 1 & 4 & 4 & 9 & 9 & 9 & 9 & 4 & 1 \\
\hline 14 & $M$ & 2 & 1 & 1 & 0 & 0 & 9 & 9 & 9 & 9 & 9 & 1 \\
\hline 15 & $M$ & 2 & 0 & 0 & 4 & 1 & 9 & 9 & 9 & 9 & 1 & 4 \\
\hline 16 & $M$ & 2 & 0 & 1 & 1 & 0 & 0 & 0 & 0 & 0 & 4 & 1 \\
\hline 17 & $M$ & 2 & 1 & 1 & 0 & 0 & 0 & 0 & 9 & 9 & 1 & 4 \\
\hline 18 & $M$ & 9 & 9 & 9 & 9 & 9 & 9 & 9 & 9 & .9 & 4 & 4 \\
\hline 19 & $M$ & 9 & 9 & 9 & 9 & 9 & 0 & 0 & 9 & 9 & 4 & 4 \\
\hline 20 & $M$ & 2 & 1 & 9 & 0 & 9 & 9 & 9 & 9 & 9 & 4 & 4 \\
\hline 21 & M & 2 & 0 & 0 & 0 & 4 & 0 & 0 & 0 & 0 & 0 & 0 \\
\hline 22 & $M$ & 2 & 9 & 1 & 9 & 0 & 9 & 9 & 9 & 9 & 4 & 9 \\
\hline 23 & $M$ & 9 & 9 & 9 & 9 & 9 & 9 & 9 & 9 & 9 & 1 & 1 \\
\hline 24 & $M$ & 9 & 9 & 9 & 9 & 9 & 9 & 9 & 9 & 9 & 9 & 9 \\
\hline 25 & $M$ & 2 & 1 & 1 & 0 & 0 & 9 & 9 & 9 & 9 & 1 & 4 \\
\hline 26 & $M$ & 2 & 9 & 9 & 9 & 9 & 0 & 9 & 0 & 9 & 1 & 4 \\
\hline 27 & $M$ & 2 & 1 & 1 & 1 & 0 & 9 & 9 & 9 & 9 & 4 & 4 \\
\hline 28 & $M$ & 9 & 9 & 9 & 9 & 9 & 9 & 9 & 9 & 9 & 9 & 9 \\
\hline 29 & $M$ & 2 & 1 & 0 & 0 & 1 & 0 & 0 & 4 & 4 & 4 & 1 \\
\hline 30 & $M$ & 0 & 1 & 1 & 0 & 0 & 0 & 9 & 0 & 9 & 9 & 4 \\
\hline 31 & $M$ & 2 & 1 & 0 & 0 & 1 & 9 & 9 & 9 & 0 & 4 & 1 \\
\hline 32 & $M$ & 3 & 0 & 0 & 1 & 4 & 0 & 9 & 0 & 9 & 4 & 4 \\
\hline 33 & $M$ & 2 & 1 & 1 & 0 & 0 & 0 & 0 & 0 & 0 & 4 & 0 \\
\hline 34 & $M$ & 2 & 1 & 1 & 1 & 4 & 9 & 9 & 9 & 9 & 4 & 4 \\
\hline 35 & $M$ & 2 & 1 & 0 & 4 & 4 & 9 & 9 & 9 & 9 & 9 & 0 \\
\hline 36 & $M$ & 2 & 1 & 0 & 4 & 4 & 0 & 9 & 0 & 0 & 1 & 1 \\
\hline 37 & $M$ & 0 & 1 & 1 & 1 & 0 & 0 & 0 & 0 & 0 & 9 & 4 \\
\hline 38 & $M$ & 2 & 0 & 0 & 1 & 1 & 9 & 9 & 9 & 9 & 4 & 4 \\
\hline 39 & $M$ & 2 & 1 & 1 & 0 & 0 & 9 & 9 & 9 & 9 & 1 & 9 \\
\hline 40 & $M$ & 2 & 1 & 1 & 0 & 0 & 9 & 9 & 9 & 9 & 1 & 9 \\
\hline 41 & $M$ & 2 & 1 & 1 & 1 & 0 & 9 & 9 & 9 & 9 & 9 & 4 \\
\hline 42 & $M$ & 2 & 0 & 1 & 1 & 1 & 9 & 9 & 9 & 9 & 4 & 4 \\
\hline 43 & $M$ & 2 & 9 & 1 & 9 & 0 & 9 & 9 & 9 & 9 & 0 & 9 \\
\hline 44 & $M$ & 2 & 1 & 9 & 1 & 0 & 0 & 9 & 0 & 9 & 1 & 9 \\
\hline 45 & $M$ & 2 & 1 & 1 & 0 & 0 & 9 & 9 & 9 & 9 & 9 & 0 \\
\hline 46 & $M$ & 2 & 1 & 1 & 0 & 0 & 9 & 0 & 9 & 0 & 4 & 4 \\
\hline 47 & $M$ & 2 & 1 & 1 & 0 & 0 & 0 & 0 & 9 & 9 & 4 & 1 \\
\hline 48 & $F$ & 2 & 1 & 1 & 0 & 0 & 0 & 9 & 0 & 9 & 1 & 1 \\
\hline 49 & $M$ & 2 & 1 & 1 & 4 & 4 & 9 & 9 & 9 & 9 & 4 & 4 \\
\hline 50 & $F$ & 9 & 9 & 9 & 9 & 9 & 9 & 9 & 9 & 9 & 9 & 1 \\
\hline 51 & $F$ & 9 & 9 & 9 & 9 & 9 & 9 & 9 & 9 & 9 & 9 & 0 \\
\hline 52 & $M$ & 2 & 0 & 1 & 4 & 1 & 9 & 0 & 9 & 0 & 4 & 0 \\
\hline 53 & $M$ & 2 & 1 & 9 & 0 & 9 & 0 & 9 & 0 & 9 & 9 & 4 \\
\hline 54 & $F$ & 2 & 1 & 0 & 1 & 4 & 9 & 9 & 9 & 9 & 9 & 1 \\
\hline 55 & $F$ & 9 & 9 & 9 & 9 & 9 & 9 & 9 & 9 & 9 & 4 & 4 \\
\hline 56 & $M$ & 9 & 1 & 9 & 0 & 9 & 9 & 9 & 9 & 9 & 4 & 1 \\
\hline
\end{tabular}


Appendix F: Skeletal Cranial and Postcranial Nonmetric Traits

\begin{tabular}{|c|c|c|c|c|c|c|c|c|c|c|c|c|}
\hline \multicolumn{2}{|c|}{+} & \multicolumn{11}{|c|}{ Cranial } \\
\hline Burial \# & Sex & \multicolumn{2}{|c|}{7} & \multicolumn{2}{|c|}{8} & \multicolumn{2}{|c|}{9} & \multirow[t]{2}{*}{10} & \multirow[t]{2}{*}{11} & \multirow[t]{2}{*}{12} & \multicolumn{2}{|c|}{13} \\
\hline & & $\mathrm{L}$ & $\mathrm{R}$ & $\mathrm{L}$ & $\mathrm{R}$ & $\mathrm{L}$ & $\mathrm{R}$ & & & & $\mathrm{L}$ & $\mathrm{R}$ \\
\hline 1 & $\mathrm{~F}$ & 0 & 0 & 0 & 0 & 0 & 0 & 0 & 0 & 0 & 0 & 0 \\
\hline 2 & $M$ & 1 & 1 & 0 & 0 & 0 & 0 & 0 & 0 & 0 & 0 & 0 \\
\hline 3 & $M$ & 1 & 0 & 0 & 0 & 0 & 0 & 0 & 0 & 0 & 0 & 0 \\
\hline 4 & $M$ & 0 & 1 & 0 & 0 & 0 & 0 & 9 & 9 & 9 & 9 & 9 \\
\hline 5 & $M$ & 9 & 9 & 9 & 9 & 0 & 0 & 0 & 9 & 9 & 9 & 9 \\
\hline 6 & $M$ & 0 & 0 & 0 & 0 & 0 & 0 & 0 & 9 & 0 & 9 & 0 \\
\hline 7 & $M$ & 0 & 0 & 0 & 0 & 0 & 0 & 0 & 9 & 0 & 9 & 9 \\
\hline 8 & $M$ & 0 & 1 & 9 & 9 & 9 & 9 & 9 & 1 & 0 & 1 & 1 \\
\hline 9 & $M$ & 1 & 1 & 9 & 9 & 0 & 0 & 0 & 1 & 9 & 9 & 9 \\
\hline 10 & $M$ & 9 & 9 & 9 & 9 & 9 & 9 & 9 & 9 & 9 & 9 & 9 \\
\hline 11 & $M$ & 1 & 1 & 0 & 0 & 0 & 0 & 0 & 0 & 0 & 1 & 0 \\
\hline 12 & $M$ & 1 & 1 & 0 & 0 & 0 & 0 & 0 & 1 & 0 & 1 & 0 \\
\hline 13 & $M$ & 9 & 1 & 9 & 9 & 9 & 9 & 9 & 1 & 9 & 9 & 9 \\
\hline 14 & $M$ & 1 & 1 & 0 & 0 & 1 & 1 & 0 & 1 & 0 & 1 & 1 \\
\hline 15 & $M$ & 0 & 1 & 9 & 9 & 9 & 9 & 0 & 9 & 9 & 9 & 9 \\
\hline 16 & $M$ & 1 & 1 & 0 & 0 & 1 & 0 & 0 & 0 & 0 & 1 & 1 \\
\hline 17 & $M$ & 1 & 1 & 0 & 0 & 9 & 9 & 9 & 9 & 9 & 1 & 1 \\
\hline 18 & $M$ & 0 & 0 & 9 & 9 & 0 & 0 & 0 & 1 & 9 & 9 & 9 \\
\hline 19 & $M$ & 9 & 9 & 9 & . 9 & 0 & 0 & 0 & 9 & 9 & 9 & 9 \\
\hline 20 & $M$ & 9 & 9 & 0 & 0 & 0 & 0 & 0 & 0 & 9 & 9 & 9 \\
\hline 21 & $M$ & 1 & 1 & 0 & 0 & 9 & 9 & 9 & 9 & 9 & 0 & 1 \\
\hline 22 & $M$ & 1 & 1 & 9 & 9 & 9 & 9 & 9 & 9 & 0 & 0 & 0 \\
\hline 23 & $M$ & 1 & 1 & 9 & 9 & 0 & 0 & 0 & 9 & 9 & 9 & 9 \\
\hline 24 & $M$ & 9 & 9 & 9 & 9 & 9 & 9 & 9 & 9 & 9 & 9 & 9 \\
\hline 25 & $M$ & 9 & 9 & 9 & 9 & 0 & 0 & 0 & 9 & 9 & 9 & 9 \\
\hline 26 & $M$ & 0 & 0 & 9 & 9 & 9 & 9 & 0 & 9 & 9 & 9 & 9 \\
\hline 27 & $M$ & 0 & 0 & 9 & 9 & 0 & 0 & 0 & 0 & 9 & 9 & 9 \\
\hline 28 & $M$ & 1 & 1 & 9 & 9 & 0 & 0 & 0 & 0 & 9 & 9 & 9 \\
\hline 29 & $M$ & 9 & 9 & 9 & 9 & 9 & 9 & 9 & 9 & 9 & 9 & 9 \\
\hline 30 & $M$ & 0 & 1 & 9 & 9 & 0 & 0 & 0 & 0 & 9 & 9 & 9 \\
\hline 31 & $M$ & 1 & 1 & 9 & 9 & 9 & 9 & 9 & 9 & 9 & 9 & 9 \\
\hline 32 & $M$ & 0 & 1 & 9 & 9 & 9 & 9 & 9 & 9 & 0 & 1 & 1 \\
\hline 33 & $M$ & 1 & 1 & 9 & 9 & 9 & 9 & 9 & 9 & 9 & 9 & 9 \\
\hline 34 & $M$ & 9 & 9 & 9 & 9 & 0 & 0 & 1 & 1 & 9 & 9 & 9 \\
\hline 35 & $M$ & 1 & 1 & 9 & 9 & 9 & 9 & 9 & 9 & 9 & 9 & 9 \\
\hline 36 & $M$ & 1 & 0 & 9 & 9 & 0 & 0 & 0 & 9 & 9 & 9 & 1 \\
\hline 37 & $M$ & 1 & 1 & 9 & 9 & 0 & 0 & 0 & 9 & 9 & 9 & 9 \\
\hline 38 & $M$ & 9 & 9 & 0 & 0 & 0 & 0 & 0 & 0 & 0 & 9 & 9 \\
\hline 39 & $M$ & 0 & 0 & 9 & 9 & 9 & 9 & 9 & 9 & 9 & 9 & 9 \\
\hline 40 & $M$ & 0 & 1 & 9 & 9 & 0 & 0 & 0 & 9 & 9 & 9 & 9 \\
\hline 41 & $M$ & 1 & 1 & 9 & 9 & 9 & 9 & 9 & 9 & 9 & 9 & 9 \\
\hline 42 & $M$ & 9 & 9 & 0 & 0 & 0 & 0 & 0 & 0 & 9 & 9 & 9 \\
\hline 43 & $M$ & 1 & 1 & 9 & 9 & 9 & 9 & 9 & 9 & 0 & 0 & 1 \\
\hline 44 & $M$ & 0 & 0 & 0 & 0 & 0 & 0 & 0 & 0 & 0 & 9 & 1 \\
\hline 45 & $M$ & 9 & 9 & 9 & 9 & 9 & 9 & 9 & 9 & 9 & 9 & 9 \\
\hline 46 & $M$ & 0 & 0 & 0 & 0 & 0 & 0 & 0 & 9 & 9 & 9 & 9 \\
\hline 47 & $M$ & 1 & 1 & 0 & 0 & 1 & 0 & 0 & 1 & 0 & 1 & 1 \\
\hline 48 & $\mathrm{~F}$ & 9 & 9 & 0 & 0 & 9 & 9 & 0 & 9 & 9 & 9 & 9 \\
\hline 49 & $M$ & 9 & 9 & 9 & 9 & 9 & 1 & 0 & 9 & 9 & 9 & 9 \\
\hline 50 & $F$ & 0 & 1 & 9 & 9 & 0 & 0 & 0 & 9 & 9 & 9 & 9 \\
\hline 51 & $\mathrm{~F}$ & 0 & 0 & 9 & 9 & 9 & 9 & 9 & 9 & 9 & 9 & 9 \\
\hline 52 & $M$ & 1 & 1 & 0 & 0 & 1 & 0 & 0 & 0 & 0 & 0 & 9 \\
\hline 53 & $M$ & 1 & 1 & 9 & 9 & 9 & 9 & 9 & 9 & 9 & 9 & 9 \\
\hline 54 & $F$ & 1 & 1 & 9 & 9 & 9 & 9 & 9 & 9 & 9 & 9 & 9 \\
\hline 55 & $F$ & 9 & 9 & 9 & 9 & 9 & 9 & 9 & 9 & 9 & 9 & 9 \\
\hline 56 & $M$ & 0 & 1 & 9 & 9 & 9 & 9 & 9 & 9 & 9 & 9 & 9 \\
\hline
\end{tabular}


Texas Staie Cemetery Project

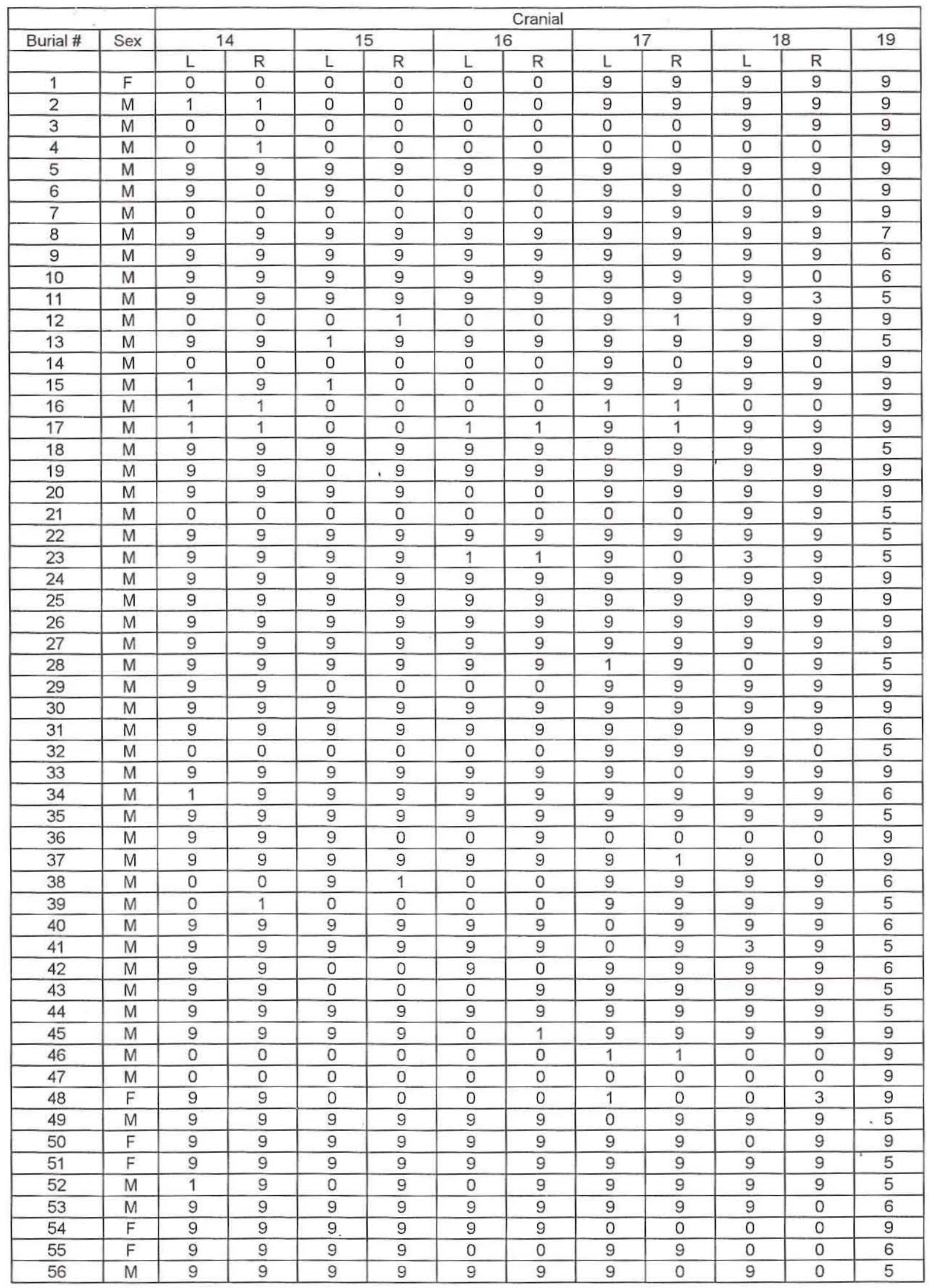




\begin{tabular}{|c|c|c|c|c|c|c|c|c|c|c|c|}
\hline & \multirow{3}{*}{ Sex } & \multicolumn{10}{|c|}{ Cranial } \\
\hline \multirow[t]{2}{*}{ Burial \# } & & \multicolumn{2}{|c|}{20} & \multicolumn{2}{|c|}{21} & \multicolumn{2}{|c|}{22} & \multicolumn{2}{|c|}{23} & \multicolumn{2}{|c|}{24} \\
\hline & & $\mathrm{L}$ & $\mathrm{R}$ & L & $R$ & $\mathrm{~L}$ & $\mathrm{R}$ & $\mathrm{L}$ & $R$ & $\mathrm{~L}$ & $\mathrm{R}$ \\
\hline 1 & $\mathrm{~F}$ & 9 & 9 & 9 & 9 & 9 & 9 & 9 & 9 & 9 & 9 \\
\hline 2 & $M$ & 9 & 9 & 9 & 9 & 9 & 9 & 9 & 9 & 9 & 9 \\
\hline 3 & $M$ & 9 & 9 & 9 & 9 & 9 & 9 & 9 & 9 & 9 & 9 \\
\hline 4 & $M$ & 0 & 0 & 2 & 2 & 9 & 9 & 9 & 9 & 0 & 0 \\
\hline 5 & $M$ & 9 & 9 & 9 & 9 & 9 & 9 & 9 & 9 & 9 & 0 \\
\hline 6 & $M$ & 0 & 0 & 9 & 9 & 9 & 9 & 9 & 9 & 9 & 9 \\
\hline 7 & $M$ & 9 & 9 & 9 & 9 & 9 & 9 & 9 & 9 & 9 & 9 \\
\hline 8 & $M$ & 9 & 9 & 9 & 9 & 9 & 9 & 9 & 9 & 0 & 0 \\
\hline 9 & $M$ & 9 & 9 & 9 & 9 & 9 & 9 & 9 & 9 & 0 & 0 \\
\hline 10 & $M$ & 9 & 9 & 9 & 9 & 9 & 9 & 9 & 9 & 9 & 9 \\
\hline 11 & $M$ & 9 & 9 & 9 & 9 & 9 & 9 & 9 & 9 & 0 & 0 \\
\hline 12 & $M$ & 9 & 9 & 9 & 9 & 0 & 0 & 9 & 2 & 0 & 0 \\
\hline 13 & $M$ & 9 & 9 & 9 & 9 & 9 & 9 & 9 & 9 & 0 & 0 \\
\hline 14 & $M$ & 9 & 9 & 9 & 9 & 9 & 9 & 9 & 9 & 9 & 9 \\
\hline 15 & $M$ & 9 & 9 & 9 & 9 & 9 & 9 & 9 & 9 & 0 & 0 \\
\hline 16 & $M$ & 0 & 0 & 9 & 9 & 2 & 2 & 9 & 9 & 0 & 0 \\
\hline 17 & $M$ & 9 & 9 & 9 & 9 & 9 & 9 & 9 & 9 & 9 & 9 \\
\hline 18 & $M$ & 9 & 9 & 9 & 9 & 9 & 9 & 9 & .9 & 0 & 0 \\
\hline 19 & $M$ & 9 & 9 & 9 & 9 & 9 & 9 & 9 & 9 & 0 & 0 \\
\hline 20 & $M$ & 9 & 9 & 9 & 9 & 9 & 9 & 9 & 9 & 0 & 0 \\
\hline 21 & $M$ & 9 & 9 & 9 & 9 & 9 & 9 & 9 & 9 & 0 & 0 \\
\hline 22 & $M$ & 9 & 9 & 9 & 9 & 9 & 9 & 9 & 9 & 0 & 0 \\
\hline 23 & $M$ & 9 & 9 & 9 & 9 & 9 & 9 & 9 & 9 & 0 & 9 \\
\hline 24 & $M$ & 9 & 9 & 9 & 9 & 9 & 9 & 9 & 9 & 9 & 9 \\
\hline 25 & $M$ & 9 & 9 & 9 & 9 & 9 & 9 & 9 & 9 & 0 & 0 \\
\hline 26 & $M$ & 9 & 9 & 9 & 9 & 9 & 9 & 9 & 9 & 9 & 9 \\
\hline 27 & $M$ & 9 & 9 & 9 & 9 & 9 & 9 & 9 & 9 & 0 & 0 \\
\hline 28 & $M$ & 9 & 9 & 9 & 9 & 9 & 9 & 9 & 9 & 9 & 9 \\
\hline 29 & $M$ & 9 & 9 & 9 & 9 & 9 & 9 & 9 & 9 & 0 & 0 \\
\hline 30 & $M$ & 9 & 9 & 9 & 9 & 9 & 9 & 9 & 9 & 0 & 0 \\
\hline 31 & $M$ & 9 & 9 & 9 & 9 & 9 & 9 & 9 & 9 & 0 & 0 \\
\hline 32 & $M$ & 9 & 9 & 9 & 9 & 9 & 9 & 9 & 9 & 0 & 0 \\
\hline 33 & $M$ & 9 & 9 & 9 & 9 & 9 & 9 & 9 & 9 & 0 & 0 \\
\hline 34 & $M$ & 9 & 9 & 9 & 9 & 9 & 9 & 9 & 9 & 1 & 0 \\
\hline 35 & $M$ & 9 & 9 & 9 & 9 & 9 & 9 & 9 & 9 & 0 & 0 \\
\hline 36 & $M$ & 9 & 9 & 9 & 9 & 9 & 9 & 9 & 9 & 0 & 0 \\
\hline 37 & $M$ & 9 & 9 & 9 & 9 & 9 & 9 & 9 & 9 & 0 & 0 \\
\hline 38 & $M$ & 9 & 9 & 9 & 9 & 9 & 9 & 9 & 9 & 0 & 0 \\
\hline 39 & $M$ & 9 & 9 & 9 & 9 & 9 & 9 & 9 & 9 & 0 & 0 \\
\hline 40 & $M$ & 9 & 9 & 9 & 9 & 9 & 9 & 9 & 9 & 0 & 0 \\
\hline 41 & $M$ & 9 & 9 & 9 & 9 & 9 & 9 & 9 & 9 & 0 & 0 \\
\hline 42 & $M$ & 9 & 9 & 9 & 9 & 9 & 9 & 9 & 9 & 0 & 0 \\
\hline 43 & $M$ & 9 & 9 & 9 & 9 & 9 & 9 & 9 & 9 & 0 & 0 \\
\hline 44 & $M$ & 9 & 9 & 9 & 9 & 9 & 9 & 9 & 9 & 0 & 0 \\
\hline 45 & $M$ & 9 & 9 & 9 & 9 & 9 & 9 & 9 & 9 & 0 & 0 \\
\hline 46 & $M$ & 9 & 9 & 9 & 9 & 9 & 9 & 9 & 9 & 0 & 0 \\
\hline 47 & $M$ & 0 & 0 & 3 & 3 & 0 & 0 & 0 & 3 & 0 & 0 \\
\hline 48 & $F$ & 0 & 0 & 3 & 3 & 2 & 2 & 0 & 0 & 0 & 0 \\
\hline 49 & $M$ & 9 & 9 & 9 & 9 & 9 & 9 & 9 & 9 & 0 & 0 \\
\hline 50 & $F$ & 9 & 9 & 9 & 9 & 9 & 9 & 9 & 9 & 9 & 0 \\
\hline 51 & $F$ & 9 & 9 & 9 & 9 & 9 & 9 & 9 & 9 & 9 & 9 \\
\hline 52 & $M$ & 9 & 9 & 9 & 9 & 9 & 9 & 9 & 9 & 0 & 0 \\
\hline 53 & $M$ & 9 & 9 & 9 & 9 & 9 & 9 & 9 & 9 & 0 & 0 \\
\hline 54 & $F$ & 0 & 0 & 3 & 0 & 0 & 2 & 0 & 0 & 0 & 0 \\
\hline 55 & $F$ & 9 & 9 & 9 & 9 & 9 & 9 & 9 & 9 & 0 & 0 \\
\hline 56 & $M$ & 9 & 9 & 9 & 9 & 9 & 9 & 9 & 9 & 0 & 0 \\
\hline
\end{tabular}


Texas State Cemetery Project

\begin{tabular}{|c|c|c|c|c|c|c|c|c|c|c|c|}
\hline \multirow{3}{*}{ Burial \# } & \multirow{3}{*}{ Sex } & \multicolumn{10}{|c|}{ Cranial } \\
\hline & & \multicolumn{2}{|c|}{25} & \multicolumn{2}{|c|}{26} & \multicolumn{2}{|c|}{27} & \multicolumn{2}{|c|}{28} & \multicolumn{2}{|c|}{29} \\
\hline & & $\mathrm{L}$ & $\mathrm{R}$ & L & $\mathrm{R}$ & $L$ & $R$ & $\mathrm{~L}$ & $R$ & $\mathrm{~L}$ & $\mathrm{R}$ \\
\hline 1 & $\mathrm{~F}$ & 0 & 0 & 0 & 0 & 9 & 9 & 9 & 9 & 9 & 9 \\
\hline 2 & $M$ & 0 & 0 & 0 & 0 & 1 & 1 & 1 & 1 & 0 & 0 \\
\hline 3 & $M$ & 0 & 0 & 1 & 1 & 1 & 1 & 0 & 0 & 0 & 0 \\
\hline 4 & $M$ & 0 & 0 & 0 & 0 & 1 & 1 & 0 & 0 & 0 & 0 \\
\hline 5 & $M$ & 9 & 0 & 9 & 1 & 9 & 9 & 9 & 9 & 9 & 9 \\
\hline 6 & $M$ & 0 & 0 & 1 & 1 & 1 & 1 & 0 & 0 & 0 & 0 \\
\hline 7 & $M$ & 9 & 0 & 9 & 0 & 9 & 9 & 9 & 9 & 9 & 9 \\
\hline 8 & $M$ & 9 & 9 & 4 & 4 & 1 & 1 & 0 & 0 & 0 & 0 \\
\hline 9 & $M$ & 0 & 0 & 1 & 0 & 1 & 1 & 1 & 1 & 0 & 0 \\
\hline 10 & $M$ & 0 & 0 & 1 & 1 & 1 & 1 & 1 & 1 & 0 & 0 \\
\hline 11 & $M$ & 0 & 0 & 0 & 0 & 1 & 1 & 0 & 0 & 0 & 0 \\
\hline 12 & $M$ & 0 & 0 & 1 & 1 & 1 & 1 & 0 & 0 & 9 & 0 \\
\hline 13 & $M$ & 1 & 1 & 4 & 4 & 1 & 1 & 0 & 0 & 9 & 0 \\
\hline 14 & $M$ & 0 & 0 & 4 & 4 & 1 & 1 & 0 & 0 & 0 & 0 \\
\hline 15 & $M$ & 0 & 0 & 4 & 1 & 1 & 1 & 1 & 1 & 0 & 9 \\
\hline 16 & $M$ & 9 & 0 & 0 & 0 & 1 & 1 & 0 & 0 & 0 & 0 \\
\hline 17 & $M$ & 0 & 1 & 1 & 4 & 1 & 1 & 1 & 1 & 0 & 0 \\
\hline 18 & $M$ & 0 & 0 & 1 & 0 & 1 & 1 & 0 & 0 & 0 & 0 \\
\hline 19 & $M$ & 0 & 0 & 1 & 1 & 1 & 1 & 0 & 0 & 0 & 9 \\
\hline 20 & $M$ & 0 & 0 & 1 & 0 & 1 & 4 & 0 & 0 & 9 & 9 \\
\hline 21 & $M$ & 0 & 0 & 4 & 1 & 1 & 1 & 1 & 1 & 0 & 0 \\
\hline 22 & $M$ & 0 & 0 & 4 & 4 & 1 & 1 & 1 & 1 & 9 & 0 \\
\hline 23 & $M$ & 0 & 0 & 4 & 4 & 1 & 1 & 0 & 0 & 0 & 9 \\
\hline 24 & $M$ & 0 & 0 & 0 & 1 & 9 & 1 & 0 & 0 & 9 & 9 \\
\hline 25 & $M$ & 0 & 0 & 1 & 1 & 1 & 1 & 1 & 1 & 9 & 0 \\
\hline 26 & $M$ & 0 & 0 & 0 & 0 & 1 & 1 & 0 & 0 & 0 & 0 \\
\hline 27 & $M$ & 0 & 0 & 4 & 1 & 1 & 1 & 0 & 1 & 2 & 9 \\
\hline 28 & $M$ & 0 & 0 & 1 & 1 & 1 & 1 & 0 & 0 & 0 & 9 \\
\hline 29 & $M$ & 0 & 0 & 1 & 0 & 1 & 1 & 9 & 1 & 0 & 9 \\
\hline 30 & $M$ & 0 & 0 & 1 & 1 & 1 & 1 & 1 & 1 & 0 & 0 \\
\hline 31 & $M$ & 0 & 0 & 4 & 1 & 1 & 1 & 9 & 1 & 0 & 0 \\
\hline 32 & $M$ & 0 & 0 & 0 & 0 & 1 & 1 & 0 & 0 & 0 & 0 \\
\hline 33 & $M$ & 0 & 0 & 4 & 1 & 1 & 9 & 1 & 1 & 0 & 0 \\
\hline 34 & $M$ & 0 & 0 & 0 & 0 & 1 & 1 & 0 & 0 & 0 & 0 \\
\hline 35 & $M$ & 0 & 0 & 0 & 0 & 1 & 1 & 0 & 0 & 3 & 3 \\
\hline 36 & $M$ & 0 & 0 & 0 & 0 & 1 & 1 & 0 & 0 & 3 & 9 \\
\hline 37 & $M$ & 0 & 0 & 1 & 4 & 1 & 1 & 1 & 1 & 0 & 0 \\
\hline 38 & $M$ & 0 & 0 & 1 & 0 & 1 & 1 & 0 & 0 & 0 & 0 \\
\hline 39 & $M$ & 0 & 9 & 1 & 1 & 1 & 1 & 1 & 1 & 0 & 0 \\
\hline 40 & $M$ & 0 & 0 & 1 & 9 & 1 & 1 & 0 & 0 & 9 & 0 \\
\hline 41 & $M$ & 0 & 0 & 1 & 9 & 1 & 1 & 1 & 1 & 9 & 3 \\
\hline 42 & $M$ & 0 & 0 & 0 & 0 & 1 & 9 & 0 & 9 & 9 & 9 \\
\hline 43 & $M$ & 0 & 9 & 4 & 1 & 9 & 1 & 9 & 1 & 9 & 9 \\
\hline 44 & $M$ & 0 & 0 & 0 & 0 & 1 & 1 & 0 & 0 & 2 & 0 \\
\hline 45 & $M$ & 0 & 9 & 0 & 1 & 1 & 9 & 0 & 9 & 0 & 9 \\
\hline 46 & $M$ & 0 & 0 & 4 & 4 & 1 & 1 & 0 & 0 & 0 & 0 \\
\hline 47 & $M$ & 0 & 0 & 0 & 1 & 1 & 1 & 0 & 0 & 1 & 0 \\
\hline 48 & $\mathrm{~F}$ & 0 & 0 & 1 & 0 & 1 & 1 & 0 & 0 & 0 & 0 \\
\hline 49 & $M$ & 0 & 9 & 0 & 9 & 1 & 0 & 9 & 0 & 9 & 0 \\
\hline 50 & $\mathrm{~F}$ & 9 & 0 & 9 & 0 & 9 & 1 & 1 & 1 & 0 & 9 \\
\hline 51 & $F$ & 0 & 0 & 0 & 1 & 9 & 0 & 9 & 0 & 9 & 3 \\
\hline 52 & $M$ & 0 & 0 & 4 & 9 & 1 & 1 & 1 & 1 & 0 & 0 \\
\hline 53 & $M$ & 0 & 0 & 1 & 1 & 1 & 1 & 1 & 1 & 9 & 0 \\
\hline 54 & $F$ & 1 & 1 & 9 & 1 & 1 & 1 & 0 & 0 & 0 & 1 \\
\hline 55 & $\mathrm{~F}$ & 0 & 0 & 0 & 9 & 1 & 1 & 0 & 0 & 0 & 0 \\
\hline 56 & $M$ & 0 & 0 & 4 & 1 & 1 & 1 & 0 & 0 & 0 & 0 \\
\hline
\end{tabular}


Appendix F: Skeletal Cranial and Postcranial Nonmetric Traits

\begin{tabular}{|c|c|c|c|c|c|c|c|c|c|}
\hline \multirow{3}{*}{ Burial \# } & \multirow{3}{*}{ Sex } & \multicolumn{8}{|c|}{ Postcranial } \\
\hline & & \multicolumn{2}{|c|}{30} & \multicolumn{2}{|c|}{31} & \multicolumn{2}{|c|}{32} & \multicolumn{2}{|c|}{33} \\
\hline & & $\mathrm{L}$ & $\mathrm{R}$ & $\mathrm{L}$ & $\mathrm{R}$ & $\mathrm{L}$ & $\mathrm{R}$ & $L$ & $R$ \\
\hline 1 & $\mathrm{~F}$ & 9 & 9 & 9 & 9 & 9 & 9 & 1 & 9 \\
\hline 2 & $M$ & 9 & 9 & 9 & 9 & 9 & 9 & 0 & 0 \\
\hline 3 & $M$ & 0 & 0 & 0 & 0 & 9 & 9 & 0 & 0 \\
\hline 4 & $M$ & 0 & 0 & 0 & 0 & 9 & 9 & 1 & 9 \\
\hline 5 & $M$ & 9 & 9 & 0 & 0 & 0 & 0 & 0 & 0 \\
\hline 6 & $M$ & 9 & 9 & 9 & 9 & 9 & 9 & 0 & 0 \\
\hline 7 & $M$ & 9 & 9 & 9 & 9 & 9 & 9 & 9 & 9 \\
\hline 8 & $M$ & 0 & 0 & 0 & 0 & 9 & 9 & 0 & 0 \\
\hline 9 & $M$ & 9 & 9 & 9 & 9 & 9 & 9 & 0 & 0 \\
\hline 10 & $M$ & 0 & 0 & 3 & 2 & 9 & 9 & 0 & 0 \\
\hline 11 & $M$ & 9 & 9 & 9 & 9 & 9 & 9 & 0 & 0 \\
\hline 12 & $M$ & 0 & 0 & 3 & 9 & 9 & 9 & 0 & 0 \\
\hline 13 & $M$ & 0 & 0 & 0 & 0 & 9 & 9 & 0 & 0 \\
\hline 14 & $M$ & 9 & 9 & 9 & 9 & 9 & 9 & 0 & 0 \\
\hline 15 & $M$ & 9 & 0 & 9 & 0 & 9 & 9 & 0 & 0 \\
\hline 16 & $M$ & 0 & 0 & 3 & 0 & 3 & 3 & 0 & 0 \\
\hline 17 & $M$ & 0 & 0 & 0 & 0 & 9 & 9 & 0 & 0 \\
\hline 18 & $M$ & 0 & 0 & 0 & 0 & 9 & 9 & 0 & 0 \\
\hline 19 & $M$ & 9 & 9 & .9 & 9 & 9 & 9 & 0 & 0 \\
\hline 20 & $M$ & 9 & 9 & 9 & 9 & 9 & 9 & 0 & 0 \\
\hline 21 & $M$ & 0 & 0 & 3 & 3 & 3 & 3 & 0 & 0 \\
\hline 22 & $M$ & 9 & 9 & 9 & 9 & 9 & 9 & 1 & 0 \\
\hline 23 & $M$ & 9 & 9 & 9 & 9 & 9 & 9 & 0 & 0 \\
\hline 24 & $M$ & 9 & 9 & 9 & 9 & 9 & 9 & 0 & 9 \\
\hline 25 & $M$ & 9 & 9 & 9 & 9 & 9 & 9 & 0 & 0 \\
\hline 26 & $M$ & 9 & 9 & 9 & 9 & 0 & 0 & 0 & 0 \\
\hline 27 & $M$ & 0 & 0 & 2 & 2 & 9 & 9 & 0 & 0 \\
\hline 28 & $M$ & 0 & 0 & 0 & 0 & 9 & 9 & 0 & 0 \\
\hline 29 & $M$ & 9 & 9 & 9 & 9 & 9 & 9 & 0 & 0 \\
\hline 30 & $M$ & 9 & 9 & 9 & 9 & 9 & 9 & 0 & 0 \\
\hline 31 & $M$ & 9 & 9 & 9 & 9 & 9 & 9 & 0 & 0 \\
\hline 32 & $M$ & 9 & 9 & 9 & 9 & 9 & 9 & 0 & 0 \\
\hline 33 & $M$ & 0 & 0 & 0 & 0 & 9 & 9 & 0 & 0 \\
\hline 34 & $M$ & 9 & 9 & 9 & 9 & 3 & 9 & 0 & 0 \\
\hline 35 & $M$ & 0 & 0 & 0 & 0 & 9 & 9 & 0 & 0 \\
\hline 36 & $M$ & 0 & 0 & 0 & 0 & 0 & 0 & 0 & 0 \\
\hline 37 & $M$ & 0 & 0 & 0 & 0 & 9 & 9 & 0 & 0 \\
\hline 38 & $\mathrm{M}$ & 0 & 0 & 0 & 0 & 9 & 2 & 0 & 0 \\
\hline 39 & $M$ & 0 & 0 & 0 & 0 & 0 & 0 & 0 & 0 \\
\hline 40 & $M$ & 9 & 9 & 9 & 9 & 9 & 9 & 0 & 0 \\
\hline 41 & $M$ & 9 & 9 & 9 & 9 & 9 & 9 & 0 & 0 \\
\hline 42 & $M$ & 9 & 9 & 9 & 9 & 3 & 3 & 0 & 0 \\
\hline 43 & $M$ & 9 & 9 & 9 & 9 & 9 & 9 & 0 & 0 \\
\hline 44 & $M$ & 0 & 0 & 0 & 0 & 0 & 0 & 0 & 0 \\
\hline 45 & $M$ & 0 & 0 & 0 & 3 & 9 & 9 & 0 & 0 \\
\hline 46 & $M$ & 9 & 0 & 9 & 0 & 0 & 0 & 0 & 0 \\
\hline 47 & $\mathrm{M}$ & 0 & 0 & 0 & 0 & 2 & 3 & 0 & 0 \\
\hline 48 & $F$ & 0 & 0 & 0 & 0 & 0 & 0 & 0 & 0 \\
\hline 49 & $M$ & 9 & 9 & 9 & 9 & 0 & 0 & 0 & 0 \\
\hline 50 & $\mathrm{~F}$ & 9 & 9 & 9 & 9 & 9 & 9 & 0 & 0 \\
\hline 51 & $F$ & 0 & 0 & 0 & 0 & 2 & 3 & 0 & $1^{1}$ \\
\hline 52 & $M$ & 9 & 9 & 9 & 9 & 0 & 0 & 0 & 0 \\
\hline 53 & $M$ & 0 & 9 & 0 & 9 & 0 & 0 & 0 & 0 \\
\hline 54 & $F$ & 0 & 0 & 0 & 0 & 0 & 0 & 0 & 0 \\
\hline 55 & $F$ & 0 & 0 & 0 & 0 & 9 & 9 & 0 & 0 \\
\hline 56 & $M$ & 0 & 0 & 0 & 0 & 0 & 0 & 0 & 0 \\
\hline
\end{tabular}




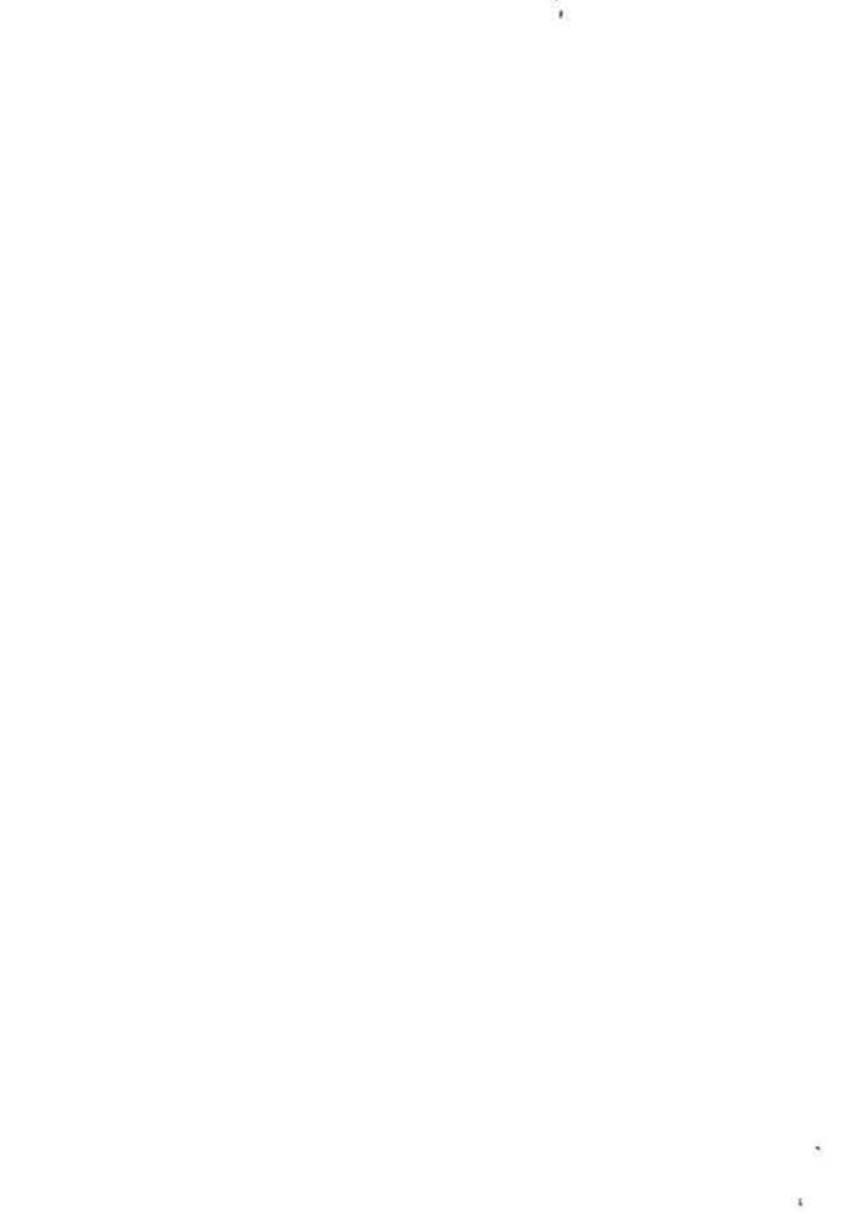




\title{
APPENDIX G: Dental and Skeletal Pathology Data for Analyzed Individuals from the Texas State Cemetery
}

\author{
Compiled by
}

Helen Danzeiser Dockall 

This appendix is composed of several tables detailing the disorders observed on the individuals excavated from the State Cemetery. Tables documenting dental disorders include data on abscesses, alveolar resorption, calculus, caries, hypercementosis, linear enamel hypoplasias, and wear. All of these tables are divided into maxillary and mandibular dental arcades, and all teeth are listed by sides. Skeletal pathology data are listed in the last table in this appendix. Keys associated with each table follow.

\section{DENTAL DISORDER CODES}

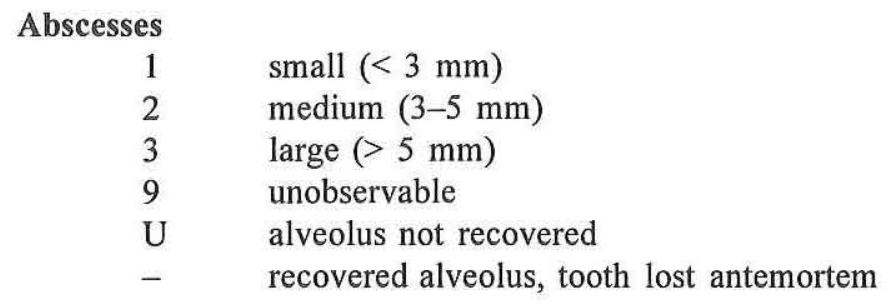

\section{Alveolar Resorption}

$1 \quad$ slight (1-3 mm)

2 moderate (4-5 mm)

3 severe $(>5 \mathrm{~mm})$

$\mathrm{U} \quad$ tooth or alveolar area not recovered (postmortem loss)

- recovered alveolus, tooth lost antemortem

\section{Calculus}

0 none

1 small areas

2 coalescent areas

3 three-dimensional deposits

$\mathrm{U}$ tooth or alveolar area not recovered

- $\quad$ tooth lost antemortem

\section{Caries}

0 none

1 occlusal surface

2 interproximal mesial

3 interproximal distal

4 buccal/labial

5 lingual

6 cervical mesial

7 cervical distal

8 gross

$\mathrm{U}$ tooth or alveolar area not recovered (postmortem loss)

- $\quad$ tooth lost antemortem

\section{Hypercementosis}

0 absent

1 present

9 unobservable

U tooth or alveolar area lost postmortem

- $\quad$ tooth lost antemortem 


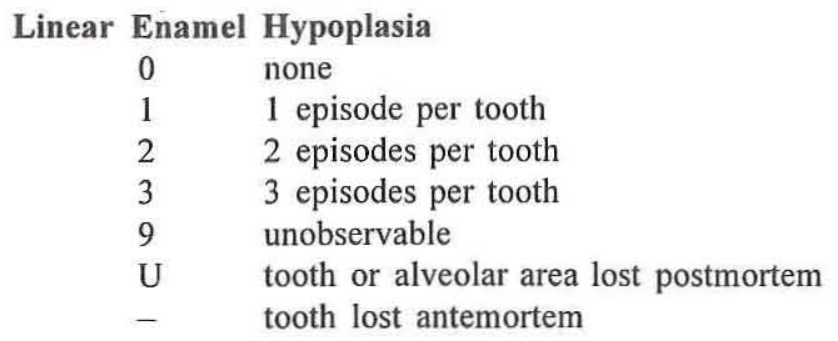

Wear (codes follow Smith 1984)

1 unworn to polished

2 blunting of cusps

3 pinpoint to moderate dentin exposure

$4 \quad$ large but still separate dentin exposures

5 two dentin areas coalesced

6 three or four dentin areas coalesced

7 dentin exposed on surface, enamel ring still preserved

8 worn to root

$\mathrm{U}$ tooth or alveolar area lost, postmortem

- $\quad$ tooth lost antemortem

\section{SKELETAL DISORDER CODES}

1 Cribra orbitalia

2 Porotic hyperostosis

3 General cranial thickening

4 Active periostitis/osteitis, upper body

$5 \quad$ Healed periostitis/osteitis, upper body

6 Healed periostitis/osteitis, ribs

7 Active periostitis/osteitis, lower body

8 Healed periostitis/osteitis, lower body

9 Depression fracture

10 Fracture, upper body

11 Fracture, lower body

12 Fracture, ribs

13 Dislocation, upper body

14 Dislocation, lower body

15 Wound, upper body

16 Wound, lower body

17 Wound, ribs

18 Degenerative joint disease, upper body

19 Degenerative joint disease, lower body

20 Vertebral degenerative joint disease

21 Schmorl's nodes

22 Enthesophytes, upper body

23 Enthesophytes, lower body

24 Neoplasm

25 Lytic lesion

26 Improper ossification

27 Joint fusion

28 Vertebral osteophytosis 
Appendix G: Dental and Skeletal Pathology Data

\section{REFERENCE CITED}

Smith, B. Holly

1984 Patterns of Molar Wear in Hunter-Gatherers and Agriculturalists. American Journal of Physical Anthropology 63(1):39-56. 
Texas State Cemetery Project

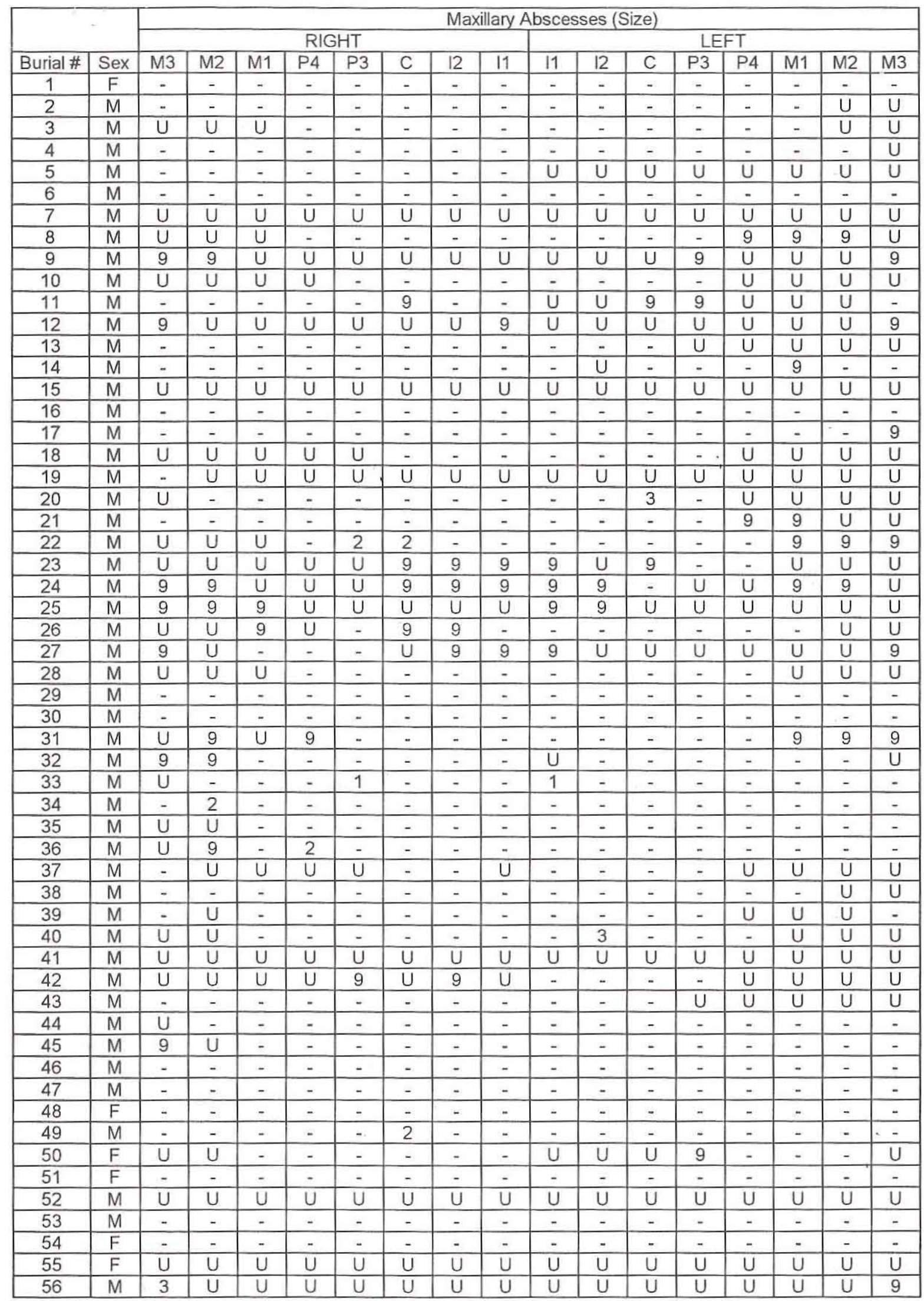


Appendix G: Dental and Skeletal Pathology Data

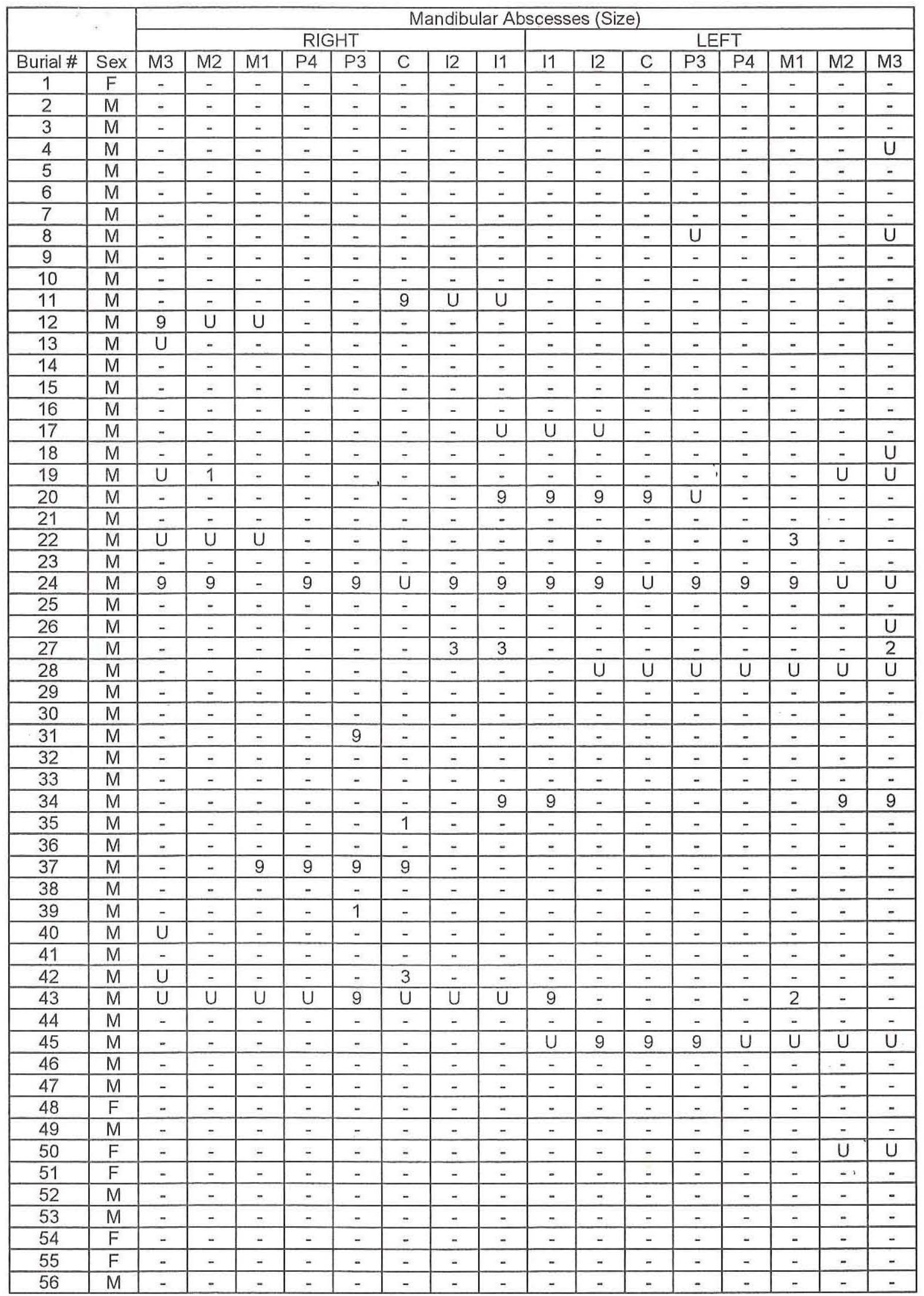




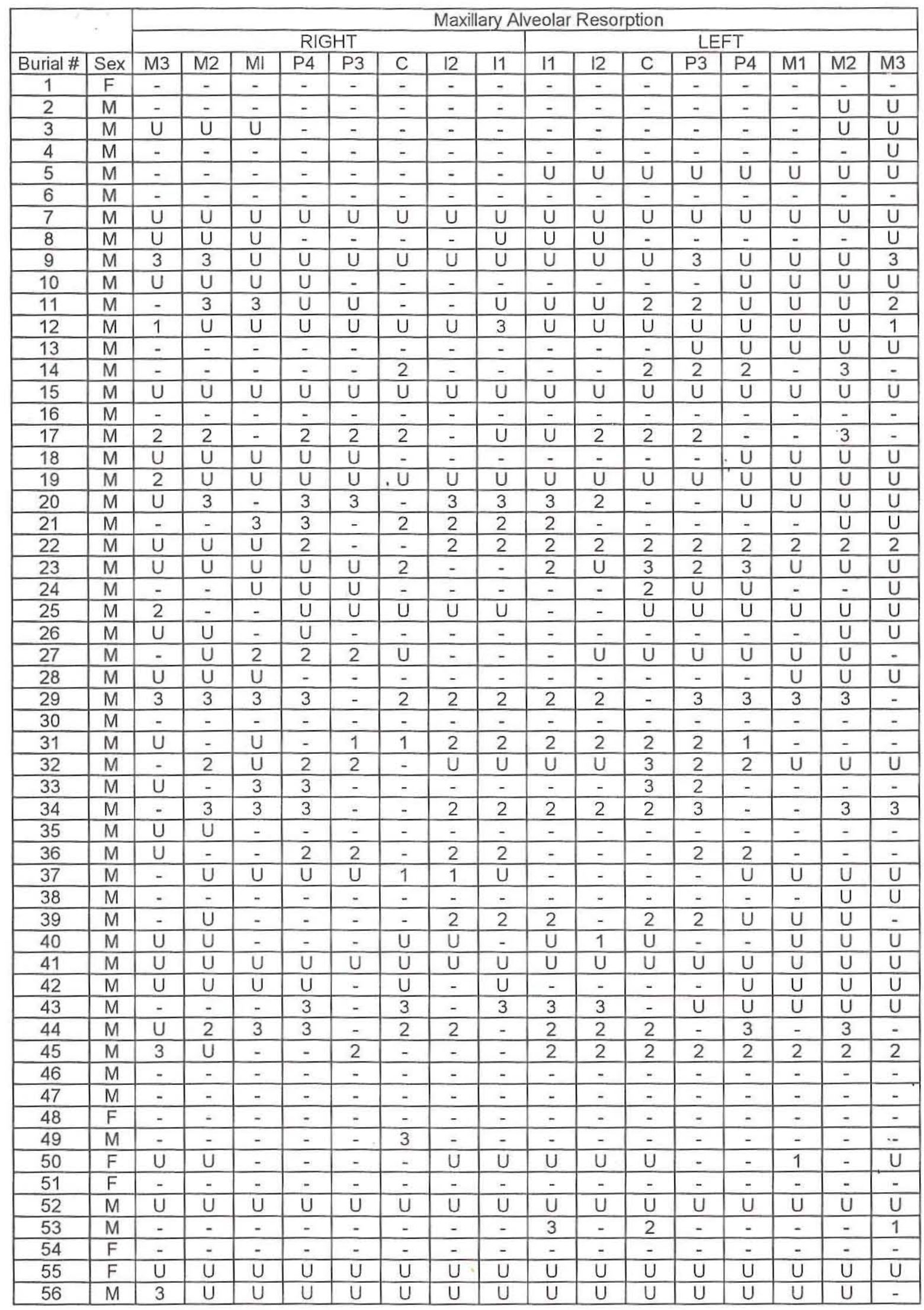




\begin{tabular}{|c|c|c|c|c|c|c|c|c|c|c|c|c|c|c|c|c|c|}
\hline \multirow{2}{*}{\multicolumn{2}{|c|}{$\theta$}} & \multicolumn{16}{|c|}{ Mandibular Alveolar Resorption } \\
\hline & & \multicolumn{8}{|c|}{ LEFT } & \multicolumn{8}{|c|}{ RIGHT } \\
\hline Burial \# & Sex & M3 & M2 & $\mathrm{MI}$ & P4 & P3 & $\mathrm{C}$ & 12 & 11 & 11 & 12 & $\mathrm{C}$ & $\mathrm{P} 3$ & P4 & M1 & M2 & $\mathrm{M} 3$ \\
\hline 1 & $\mathrm{~F}$ & - & - & - & - & - & - & - & - & - & - & - & - & - & - & - & - \\
\hline 2 & $M$ & - & - & - & - & - & - & - & - & - & - & - & - & - & - & - & - \\
\hline 3 & $\mathrm{M}$ & - & - & - & - & - & - & - & - & - & - & - & - & - & - & - & - \\
\hline 4 & $\mathrm{M}$ & - & - & - & - & - & - & - & - & - & - & - & - & - & - & - & $U$ \\
\hline 5 & $M$ & - & - & - & - & - & - & - & - & - & - & - & - & - & - & - & - \\
\hline 6 & $M$ & - & - & - & - & - & - & - & - & - & - & - & - & - & - & - & - \\
\hline 7 & $M$ & 3 & - & - & - & - & - & - & - & - & - & - & - & - & - & - & - \\
\hline 8 & $M$ & 3 & 3 & 3 & 3 & 1 & $\mathrm{U}$ & $U$ & $U$ & $U$ & $U$ & - & $\mathrm{U}$ & 3 & 3 & 3 & $U$ \\
\hline 9 & $M$ & 2 & - & - & - & 2 & 2 & - & $U$ & $U$ & $U$ & 2 & - & - & - & - & - \\
\hline 10 & $M$ & - & - & - & - & - & $U$ & $U$ & $U$ & $U$ & $U$ & - & - & - & - & - & $\mathrm{U}$ \\
\hline 11 & $M$ & 2 & - & - & 2 & 2 & - & $\mathrm{U}$ & $U$ & 2 & 2 & $U$ & 2 & 2 & - & - & 2 \\
\hline 12 & $M$ & 2 & $U$ & $U$ & 3 & 3 & 2 & 2 & 3 & 1 & 1 & 1 & 1 & 1 & - & - & 2 \\
\hline 13 & $M$ & $\mathrm{U}$ & - & - & - & - & - & - & - & - & - & - & - & - & - & - & - \\
\hline 14 & $M$ & - & - & - & - & - & - & - & - & - & - & - & - & - & - & - & - \\
\hline 15 & $M$ & - & - & - & - & - & - & - & - & - & - & - & - & - & - & - & - \\
\hline 16 & $M$ & - & - & - & - & - & - & - & - & - & - & - & - & - & - & - & - \\
\hline 17 & $M$ & 2 & - & 2 & 2 & 2 & 2 & 2 & $U$ & $U$ & $U$ & 2 & 2 & 2 & 2 & 2 & - \\
\hline 18 & $M$ & - & - & - & - & 3 & 3 & 3 & - & - & - & - & - & - & - & - & $U$ \\
\hline 19 & $M$ & $\mathrm{U}$ & - & - & - & - & . & - & - & - & - & - & - & - & - & $U$ & $U$ \\
\hline 20 & $M$ & - & - & - & 3 & 2 & 3 & 3 & - & - & - & - & $U$ & 3 & - & - & - \\
\hline 21 & $M$ & - & - & - & 2 & 2 & 3 & 3 & 3 & 3 & 3 & 2 & 3 & - & - & - & - \\
\hline 22 & $M$ & $U$ & $U$ & $U$ & 1 & 1 & 1 & 1 & 1 & - & 1 & 1 & 1 & 1 & 1 & 2 & 2 \\
\hline 23 & $M$ & $U$ & - & - & - & 3 & 3 & 3 & - & - & 3 & 3 & 2 & 2 & 2 & $U$ & $U$ \\
\hline 24 & $M$ & - & - & 3 & - & - & $U$ & - & - & - & - & $U$ & - & - & - & $U$ & $\mathrm{U}$ \\
\hline 25 & $M$ & - & - & $U$ & $U$ & - & - & - & - & - & - & - & - & $U$ & - & - & $U$ \\
\hline 26 & $M$ & - & - & - & - & 3 & 3 & 3 & - & - & - & - & - & - & - & 3 & $U$ \\
\hline 27 & $M$ & 1 & 2 & - & 2 & 1 & 1 & $U$ & $U$ & 2 & 2 & 1 & 1 & 3 & - & 3 & 1 \\
\hline 28 & $M$ & - & - & - & - & - & - & - & - & - & $\bar{U}$ & $U$ & $\mathrm{U}$ & $\mathrm{U}$ & $U$ & $U$ & $U$ \\
\hline 29 & $M$ & - & 3 & 3 & 3 & 2 & 2 & 2 & 2 & 2 & 2 & 2 & 2 & 2 & 3 & 3 & 3 \\
\hline 30 & $M$ & - & - & - & - & - & - & - & - & - & - & - & 2 & - & - & - & $U$ \\
\hline 31 & $M$ & - & 1 & - & - & - & - & - & - & 2 & 2 & 2 & 1 & 1 & 1 & 1 & - \\
\hline 32 & $M$ & - & - & - & 3 & 2 & 3 & $U$ & $U$ & 3 & 3 & 3 & - & 2 & - & - & - \\
\hline 33 & $M$ & - & - & - & - & - & 3 & 3 & $U$ & - & - & $\mathrm{U}$ & 3 & 3 & - & - & - \\
\hline 34 & $M$ & 2 & 3 & - & - & 3 & 2 & 2 & - & - & 2 & 3 & 2 & 2 & - & 3 & 3 \\
\hline 35 & $M$ & - & - & - & - & - & 3 & - & - & - & - & 3 & - & - & - & - & - \\
\hline 36 & $M$ & 1 & 1 & 1 & 1 & 1 & 1 & - & - & - & - & 2 & - & - & - & - & - \\
\hline 37 & $M$ & $\mathrm{U}$ & - & - & - & - & - & - & $U$ & $U$ & - & - & - & - & - & - & - \\
\hline 38 & $M$ & - & - & - & - & - & - & - & - & - & - & - & 3 & - & - & 3 & - \\
\hline 39 & $M$ & 3 & 2 & - & - & 3 & 3 & 2 & 2 & 2 & 2 & 3 & 3 & - & - & 3 & - \\
\hline 40 & $M$ & $U$ & - & - & 2 & $\mathrm{U}$ & $U$ & - & - & - & - & - & $U$ & $U$ & - & - & - \\
\hline 41 & $M$ & - & - & - & - & - & - & - & - & - & - & - & - & - & - & - & - \\
\hline 42 & $M$ & $\mathrm{U}$ & - & - & - & - & - & - & - & - & - & - & - & - & - & - & - \\
\hline 43 & $M$ & $U$ & $U$ & $\mathrm{U}$ & $U$ & - & $U$ & $U$ & $U$ & - & - & 3 & 3 & 3 & - & 3 & - \\
\hline 44 & $M$ & - & - & - & 3 & 2 & 2 & 2 & 2 & 2 & 2 & 3 & 2 & - & - & - & - \\
\hline 45 & $M$ & 2 & 2 & 2 & 2 & - & - & - & - & $U$ & - & - & - & $\mathrm{U}$ & $U$ & $U$ & $\mathrm{U}$ \\
\hline 46 & $M$ & - & - & - & - & - & - & - & - & - & - & - & - & - & - & - & - \\
\hline 47 & $M$ & - & - & - & - & - & - & - & - & - & - & 3 & - & - & - & - & - \\
\hline 48 & $\mathrm{~F}$ & - & - & - & - & - & - & - & - & - & - & - & - & - & - & - & - \\
\hline 49 & $M$ & - & - & - & - & - & - & - & - & - & - & - & - & - & - & - & $\ldots$ \\
\hline 50 & $F$ & - & - & - & - & - & - & - & - & - & - & - & - & - & - & $U$ & $U$ \\
\hline 51 & $F$ & - & - & - & - & - & - & - & - & - & - & - & - & - & - & - & - \\
\hline 52 & $M$ & - & - & - & - & 2 & 2 & 2 & - & - & 3 & 3 & 3 & - & - & - & - \\
\hline 53 & $M$ & 1 & - & - & - & - & 3 & 3 & 3 & 3 & 3 & 3 & - & - & - & - & 1 \\
\hline 54 & $F$ & - & - & - & - & - & - & - & - & - & - & - & - & - & - & - & - \\
\hline 55 & $F$ & - & - & - & - & - & - & - & - & - & - & - & - & - & - & - & - \\
\hline 56 & $M$ & - & - & - & - & - & - & - & - & - & - & - & - & - & - & - & - \\
\hline
\end{tabular}




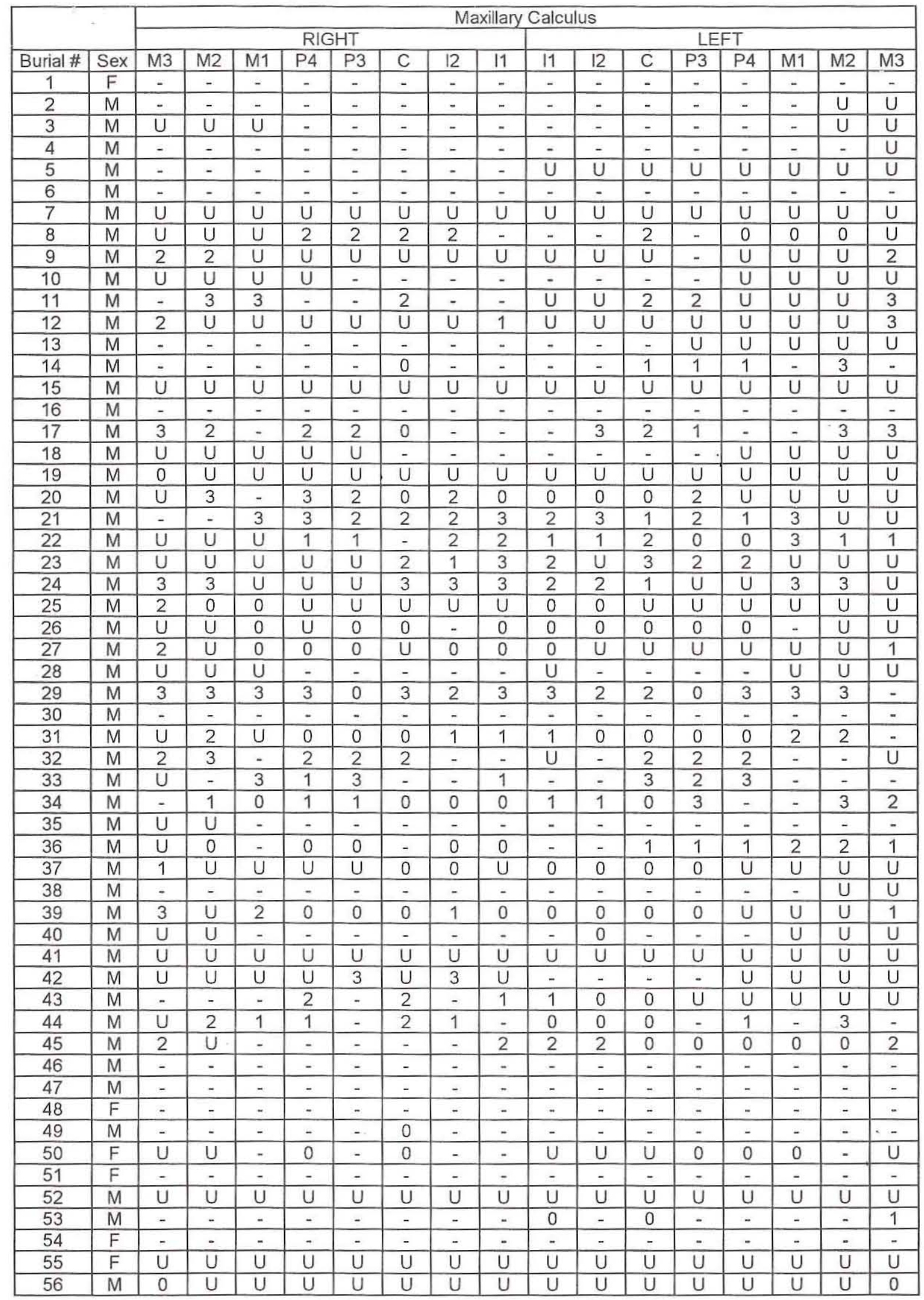


Appendix G: Dental and Skeletal Pathology Data

\begin{tabular}{|c|c|c|c|c|c|c|c|c|c|c|c|c|c|c|c|c|c|}
\hline & \multicolumn{16}{|c|}{ Mandibular Calculus } \\
\hline & & \multicolumn{8}{|c|}{ LEFT } & \multicolumn{8}{|c|}{ RIGHT } \\
\hline Burial \# & Sex & M3 & M2 & M1 & P4 & P3 & C & 12 & 11 & 11 & 12 & C & P3 & P4 & M1 & M2 & M3 \\
\hline 1 & $F$ & - & - & - & - & - & - & - & - & - & - & - & - & - & - & - & - \\
\hline 2 & $M$ & - & - & - & - & - & - & - & - & - & - & - & - & - & - & - & - \\
\hline 3 & $M$ & - & - & - & - & - & - & - & - & - & - & - & - & - & - & - & - \\
\hline 4 & $M$ & - & - & - & - & - & - & - & - & - & - & - & - & - & - & - & $U$ \\
\hline 5 & $M$ & - & - & - & - & - & - & - & - & - & - & - & - & - & - & - & - \\
\hline 6 & $M$ & - & - & - & - & - & - & - & - & - & - & - & - & - & - & - & - \\
\hline 7 & $M$ & 3 & - & - & - & - & 1 & 1 & 1 & - & - & 1 & - & - & - & - & - \\
\hline 8 & $M$ & - & - & - & - & 0 & - & - & - & - & - & - & $U$ & - & - & - & $U$ \\
\hline 9 & $M$ & 2 & - & - & - & 2 & 2 & 2 & - & - & - & 2 & 2 & - & - & - & - \\
\hline 10 & $M$ & - & - & - & - & - & - & - & - & - & - & 1 & - & - & - & - & - \\
\hline 11 & $M$ & 2 & - & - & 1 & 1 & 2 & $\mathrm{U}$ & $U$ & 3 & 3 & - & 1 & 1 & - & - & 2 \\
\hline 12 & $M$ & 3 & $U$ & U & 3 & 3 & 3 & 3 & 3 & 3 & 3 & 3 & 3 & 3 & - & - & 3 \\
\hline 13 & $M$ & $U$ & - & - & - & - & - & - & - & - & - & - & - & - & - & - & - \\
\hline 14 & $M$ & - & - & - & - & - & - & - & - & - & - & - & - & - & - & - & - \\
\hline 15 & $M$ & - & - & - & - & - & - & - & - & - & - & - & - & - & - & - & - \\
\hline 16 & $M$ & - & - & - & - & - & - & - & - & - & - & - & - & - & - & - & - \\
\hline 17 & $M$ & 3 & - & 3 & 2 & 3 & 3 & 1 & $U$ & $U$ & $U$ & 2 & 1 & 1 & 2 & 3 & - \\
\hline 18 & $M$ & - & - & - & - & 0 & 1 & 1 & - & - & - & - & - & - & - & - & $U$ \\
\hline 19 & $M$ & $U$ & 0 & - & 0 & 0 & 0 & - & - & - & - & - & - & - & - & $U$ & $\bar{U}$ \\
\hline 20 & $M$ & - & - & - & 3 & 1 & 2 & 1 & 1 & 1 & 1 & 2 & $U$ & 0 & - & - & - \\
\hline 21 & $M$ & - & - & - & 1 & 3 & 2 & 3 & 0 & 0 & 3 & 3 & 3 & - & - & - & - \\
\hline 22 & $M$ & - & - & - & 0 & 0 & 0 & 0 & 0 & 0 & 0 & 0 & 0 & 0 & - & 0 & 0 \\
\hline 23 & $M$ & - & - & - & 1 & 1 & 1 & 2 & - & - & 3 & 3 & 2 & 2 & 2 & - & - \\
\hline 24 & $M$ & 3 & 2 & 2 & 3 & 1 & $U$ & 3 & 2 & 2 & 3 & $U$ & 3 & 3 & 3 & $U$ & $U$ \\
\hline 25 & $M$ & - & 0 & - & - & - & - & 0 & - & - & - & - & - & - & - & - & - \\
\hline 26 & $M$ & - & - & - & 0 & 0 & 0 & 0 & 0 & - & - & 0 & - & - & - & 0 & $U$ \\
\hline 27 & $M$ & 2 & 1 & - & 2 & 2 & 2 & - & - & 0 & 2 & 2 & 0 & 2 & - & 2 & 3 \\
\hline 28 & $M$ & - & - & - & - & - & - & - & - & - & $\bar{U}$ & $\vec{U}$ & $U$ & $\bar{U}$ & $U$ & $U$ & $\mathrm{U}$ \\
\hline 29 & $M$ & - & 2 & 1 & 0 & 0 & 3 & 3 & 3 & 3 & 3 & 3 & 3 & 2 & 3 & 3 & 3 \\
\hline 30 & $M$ & - & - & - & - & - & 1 & 1 & 1 & - & 1 & 1 & 1 & - & - & - & - \\
\hline 31 & $M$ & - & 2 & - & - & 0 & 0 & - & - & 0 & 0 & 1 & 0 & 0 & 1 & 1 & - \\
\hline 32 & $M$ & - & - & - & 3 & 1 & 2 & - & - & 2 & 2 & 2 & 0 & 2 & 1 & - & - \\
\hline 33 & $M$ & - & - & - & 0 & - & 2 & 2 & - & - & - & - & 2 & 2 & - & - & - \\
\hline 34 & $M$ & 2 & 2 & 0 & 0 & 0 & 0 & 0 & 0 & 0 & 0 & 0 & 0 & 0 & 0 & 0 & 2 \\
\hline 35 & $M$ & - & - & - & - & - & 3 & - & - & - & - & 3 & - & - & - & - & - \\
\hline 36 & $M$ & 2 & 0 & 0 & 0 & 0 & 1 & 1 & 1 & 1 & 1 & 1 & - & - & - & - & - \\
\hline 37 & $M$ & 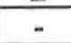 & - & - & - & 2 & 2 & 2 & - & - & 2 & 2 & 2 & - & - & - & - \\
\hline 38 & $M$ & - & - & - & - & - & - & - & - & - & - & - & 1 & - & - & 3 & - \\
\hline 39 & $M$ & 3 & 2 & - & - & 0 & 2 & 3 & 3 & 2 & 1 & 2 & 0 & - & - & 2 & - \\
\hline 40 & $M$ & $U$ & - & - & 1 & - & - & - & - & - & - & - & - & - & - & - & - \\
\hline 41 & $M$ & - & - & - & - & - & - & - & - & - & - & - & - & - & - & - & - \\
\hline 42 & $M$ & $U$ & - & - & - & - & - & - & - & - & - & - & - & - & - & - & - \\
\hline 43 & $M$ & $U$ & $\bar{U}$ & $U$ & $\bar{U}$ & 3 & $\mathrm{U}$ & $\mathrm{U}$ & $U$ & 2 & - & 2 & 0 & 0 & - & 1 & - \\
\hline 44 & $M$ & - & - & - & 0 & 0 & 0 & 1 & 1 & 1 & 1 & 0 & 0 & 0 & - & - & - \\
\hline 45 & $M$ & 0 & 0 & 0 & 0 & 0 & 0 & 0 & 0 & $\mathrm{U}$ & 0 & 0 & 0 & $U$ & $U$ & $U$ & $U$ \\
\hline 46 & $M$ & - & - & - & - & - & - & - & - & - & - & - & - & - & - & - & - \\
\hline 47 & $M$ & - & - & - & - & - & - & - & - & - & - & 3 & - & - & - & - & - \\
\hline 48 & $F$ & - & - & - & - & - & - & - & - & - & - & - & - & - & - & - & - \\
\hline 49 & $M$ & - & - & - & - & - & - & - & - & - & - & - & - & - & - & - & - \\
\hline 50 & $\mathrm{~F}$ & - & - & 0 & 0 & 0 & 0 & 0 & 0 & 0 & 0 & 0 & 0 & 0 & 0 & $U$ & $U$ \\
\hline 51 & $\mathrm{~F}$ & $U$ & $U$ & $U$ & U & $U$ & $U$ & $U$ & $U$ & - & - & - & - & - & - & - & - \\
\hline 52 & $M$ & - & - & - & - & 2 & 2 & 3 & - & - & 2 & 3 & 3 & - & - & - & - \\
\hline 53 & $M$ & 2 & - & - & - & - & 0 & 0 & 1 & 1 & 0 & 1 & - & - & - & - & 1 \\
\hline 54 & $\mathrm{~F}$ & - & - & - & - & - & - & - & - & - & - & - & - & - & - & - & - \\
\hline 55 & $F$ & - & - & - & - & - & - & - & - & - & - & - & - & - & - & - & - \\
\hline 56 & $M$ & - & - & - & - & - & - & - & - & - & - & - & - & - & - & - & - \\
\hline
\end{tabular}









\begin{tabular}{|c|c|c|c|c|c|c|c|c|c|c|c|c|c|c|c|c|c|}
\hline & \multicolumn{16}{|c|}{ Mandibular Caries (Type) } \\
\hline & & \multicolumn{8}{|c|}{ LEFT } & \multicolumn{8}{|c|}{ RIGHT } \\
\hline Burial \# & Sex & M3 & M2 & M1 & P4 & P3 & C & 12 & 11 & 11 & 12 & C & P3 & P4 & M1 & M2 & $\mathrm{M} 3$ \\
\hline 1 & $\mathrm{~F}$ & - & - & - & - & - & - & - & - & - & - & - & - & - & - & - & - \\
\hline 2 & $\mathrm{M}$ & - & - & - & - & - & $\begin{array}{ll}- \\
-\end{array}$ & - & - & - & - & - & - & - & - & - & - \\
\hline 3 & $M$ & - & - & - & - & - & - & - & - & - & - & - & - & - & - & - & - \\
\hline 4 & $M$ & - & - & - & - & - & $\begin{array}{lll}- \\
-\end{array}$ & - & - & - & - & - & - & - & - & - & $\bar{U}$ \\
\hline 5 & $M$ & - & - & - & - & - & $\begin{array}{ll}- \\
-\end{array}$ & - & - & - & - & - & - & - & - & - & - \\
\hline 6 & $M$ & - & - & - & - & - & - & - & - & - & - & - & - & - & - & - & - \\
\hline 7 & $M$ & 0 & - & - & - & - & 0 & 0 & 0 & - & - & 0 & - & - & - & - & - \\
\hline 8 & $M$ & - & - & - & - & 0 & - & - & - & - & - & - & $U$ & - & - & - & $\bar{U}$ \\
\hline 9 & $M$ & 1 & - & - & - & 0 & 0 & 1 & - & - & - & 0 & 1 & - & - & - & - \\
\hline 10 & $M$ & - & - & - & - & - & - & - & - & - & - & 3 & - & - & - & - & - \\
\hline 11 & $M$ & 0 & - & - & 0 & 0 & 0 & $U$ & $U$ & 0 & 0 & - & 0 & 0 & - & - & 0 \\
\hline 12 & $M$ & 1 & $U$ & $U$ & 0 & 0 & 0 & 0 & 0 & 0 & 0 & 0 & 0 & 0 & - & - & 0 \\
\hline 13 & $M$ & $U$ & - & - & - & - & - & - & - & - & - & - & - & - & - & - & - \\
\hline 14 & $M$ & - & - & - & - & - & - & - & - & - & - & - & - & - & - & - & - \\
\hline 15 & $M$ & - & - & - & - & - & - & - & - & - & - & - & - & - & - & - & - \\
\hline 16 & $M$ & - & - & - & - & - & - & - & - & - & - & - & - & - & - & - & - \\
\hline 17 & $M$ & 0 & - & 1 & 0 & 0 & 0 & 0 & $U$ & $U$ & $U$ & 0 & 0 & 0 & 0 & 0 & - \\
\hline 18 & $M$ & - & - & - & - & 0 & 3 & 6 & - & - & - & - & - & - & - & - & $U$ \\
\hline 19 & $M$ & $U$ & 8 & - & 0 & 0 & 0 & - & - & - & - & - & - & $\therefore$ & - & $U$ & $U$ \\
\hline 20 & $M$ & - & - & - & 0 & 0 & 0 & 0 & 0 & 0 & 0 & 0 & $U$ & 0 & - & - & - \\
\hline 21 & $M$ & - & - & - & 0 & 0 & 0 & 0 & 0 & 0 & 0 & 0 & 0 & - & - & - & - \\
\hline 22 & $M$ & - & - & - & 0 & 0 & 0 & 0 & 0 & 0 & 0 & 0 & 0 & 0 & 8 & 7 & 0 \\
\hline 23 & $M$ & $U$ & - & - & 0 & 0 & 0 & 0 & - & - & 0 & 0 & 0 & 0 & 0 & - & $U$ \\
\hline 24 & $M$ & 0 & 0 & 0 & 0 & 0 & $U$ & 0 & 0 & 0 & 0 & $U$ & 0 & 0 & 0 & $U$ & $U$ \\
\hline 25 & $M$ & - & 6,1 & - & - & 6,7 & 6 & 7 & - & - & - & - & - & - & - & - & - \\
\hline 26 & $M$ & - & - & - & 0 & 0 & 0 & 6,7 & 3 & - & 8 & 8 & - & - & - & 0 & $U$ \\
\hline 27 & $M$ & 0 & 0 & - & 0 & 0 & 0 & - & - & 0 & 0 & 0 & 0 & 0 & - & 0 & 0 \\
\hline 28 & $M$ & - & - & - & - & - & - & - & - & - & $U$ & $U$ & $U$ & $U$ & $U$ & $U$ & $\bar{U}$ \\
\hline 29 & $M$ & - & 0 & 0 & 0 & 0 & 0 & 0 & 0 & 0 & 0 & 0 & 0 & 0 & 0 & 0 & 0 \\
\hline 30 & $M$ & 9 & - & - & - & - & 0 & 2,3 & 8 & 8 & 6 & 4 & 4 & - & - & - & - \\
\hline 31 & $M$ & - & 5 & - & - & 0 & 0 & - & - & 0 & 0 & 0 & 0 & 0 & 1 & 0 & - \\
\hline 32 & $M$ & - & - & - & 0 & 0 & 2 & - & - & 0 & 0 & 4 & 0 & 0 & 0 & - & - \\
\hline 33 & $M$ & - & - & - & 0 & - & 0 & 0 & - & - & - & - & 0 & 0 & - & - & - \\
\hline 34 & $M$ & 0 & 0 & - & - & 0 & 0 & 0 & 0 & 0 & 0 & 0 & 0 & 0 & - & 0 & 0 \\
\hline 35 & $M$ & - & - & - & - & - & 8 & - & - & - & - & 0 & - & - & - & - & - \\
\hline 36 & $M$ & 0 & 6 & 7 & 0 & 0 & 0 & 0 & 0 & 0 & 0 & 7 & - & - & - & - & - \\
\hline 37 & $M$ & - & - & - & - & 0 & 6 & 6 & - & - & 7 & 6 & 7 & - & - & - & - \\
\hline 38 & $M$ & - & - & - & - & - & - & - & - & - & - & 0 & 0 & - & - & 4 & - \\
\hline 39 & $M$ & 0 & 0 & - & - & 8 & 0 & 0 & 0 & 7 & 0 & 6 & 8 & - & - & 1 & - \\
\hline 40 & $M$ & $U$ & 0 & 0 & $2,3,3$ & - & - & - & - & - & - & - & - & - & - & - & - \\
\hline 41 & $M$ & - & - & - & - & - & - & - & - & - & - & - & - & - & - & - & - \\
\hline 42 & $M$ & $U$ & - & - & - & - & - & - & - & - & - & - & - & - & - & - & - \\
\hline 43 & $M$ & $U$ & $U$ & $U$ & $U$ & 0 & $U$ & $U$ & $U$ & 6,6 & - & 0 & 0 & 0 & - & 8,1 & - \\
\hline 44 & $M$ & - & - & - & 0 & 0 & 0 & 0 & 2 & 2 & 0 & 8 & 0 & - & - & - & - \\
\hline 45 & $M$ & 2 & 3 & 0 & 0 & 0 & 0 & 0 & 0 & $U$ & 0 & 0 & 0 & $U$ & $U$ & $U$ & $U$ \\
\hline 46 & $M$ & - & - & - & - & - & - & - & - & - & - & - & - & - & - & - & - \\
\hline 47 & $M$ & - & - & - & - & - & - & - & - & - & - & 0 & - & - & - & - & - \\
\hline 48 & $\mathrm{~F}$ & - & - & - & - & - & - & - & - & - & - & - & - & - & - & - & - \\
\hline 49 & $M$ & - & - & - & - & - & - & - & - & - & - & - & - & - & - & - & - \\
\hline 50 & $F$ & - & - & 0 & 0 & 0 & 0 & 0 & 0 & 0 & 0 & 0 & 0 & 0 & 0 & $U$ & $\bar{U}$ \\
\hline 51 & $\mathrm{~F}$ & - & - & - & - & - & - & - & - & - & - & - & - & - & - & - & - \\
\hline 52 & $M$ & - & - & - & - & 0 & 0 & 0 & - & - & 0 & 0 & 0 & - & - & - & - \\
\hline 53 & $M$ & 4 & - & - & - & - & 4 & 0 & 0 & 0 & 3 & 0 & - & - & - & - & 9 \\
\hline 54 & $\mathrm{~F}$ & - & - & - & - & - & - & - & - & - & - & - & - & - & - & - & - \\
\hline 55 & $\mathrm{~F}$ & - & - & - & - & - & - & - & - & - & - & - & - & - & - & - & - \\
\hline 56 & $M$ & - & - & - & - & - & - & - & - & - & - & - & - & - & - & - & - \\
\hline
\end{tabular}




\begin{tabular}{|c|c|c|c|c|c|c|c|c|c|c|c|c|c|c|c|c|c|}
\hline & \multicolumn{16}{|c|}{ Maxillary Dental Wear } \\
\hline & & \multicolumn{8}{|c|}{ RIGHT } & \multicolumn{8}{|c|}{ LEFT } \\
\hline Burial \# & Sex & M3 & $\mathrm{M} 2$ & M1 & P4 & P3 & $\mathrm{C}$ & 12 & 11 & 11 & 12 & $\mathrm{C}$ & P3 & P4 & M1 & $\mathrm{M} 2$ & M3 \\
\hline 1 & $\mathrm{~F}$ & - & - & - & - & - & - & - & - & - & - & - & - & - & - & - & - \\
\hline 2 & $M$ & - & - & - & - & - & - & - & - & - & - & - & - & - & - & $\mathrm{U}$ & $\mathrm{U}$ \\
\hline 3 & $M$ & $\mathrm{U}$ & $U$ & $\mathrm{U}$ & - & - & - & - & - & - & - & - & - & - & - & $U$ & $U$ \\
\hline 4 & $M$ & - & - & - & - & - & - & - & - & - & - & - & - & - & - & - & $\mathrm{U}$ \\
\hline 5 & $M$ & - & - & - & - & - & - & - & - & $\mathrm{U}$ & $\mathrm{U}$ & $\mathrm{U}$ & U & $\mathrm{U}$ & $\mathrm{U}$ & $\mathrm{U}$ & $\mathrm{U}$ \\
\hline 6 & $M$ & - & - & - & - & - & - & - & - & - & - & - & - & - & - & - & - \\
\hline 7 & $M$ & $U$ & $U$ & $U$ & $\bar{U}$ & $\mathrm{U}$ & $U$ & $\mathrm{U}$ & $U$ & $U$ & $U$ & $U$ & $\mathrm{U}$ & $\mathrm{U}$ & $U$ & $U$ & $\mathrm{U}$ \\
\hline 8 & $M$ & $U$ & U & $U$ & 7 & 8 & 8 & 8 & $U$ & $U$ & $U$ & 8 & - & 5 & 8 & 6 & $U$ \\
\hline 9 & $M$ & 1 & 2 & $\mathrm{U}$ & $\mathrm{U}$ & $\mathrm{U}$ & $U$ & $U$ & $U$ & $U$ & $\mathrm{U}$ & $U$ & 4 & $\mathrm{U}$ & $U$ & $U$ & 1 \\
\hline 10 & $M$ & $U$ & $U$ & $U$ & $U$ & - & - & - & - & - & - & - & - & $U$ & $U$ & $U$ & $U$ \\
\hline 11 & $M$ & - & 5 & 5 & $\mathrm{U}$ & $\mathrm{U}$ & 4 & - & $U$ & $U$ & $\mathrm{U}$ & 4 & 4 & $U$ & $\mathrm{U}$ & $U$ & 3 \\
\hline 12 & $M$ & - & $U$ & $\bar{U}$ & $U$ & $U$ & $U$ & $U$ & 3 & $U$ & $U$ & $U$ & $U$ & $U$ & $U$ & $U$ & 2 \\
\hline 13 & $M$ & - & - & - & - & - & - & - & - & - & - & - & $\mathrm{U}$ & $\mathrm{U}$ & $U$ & $U$ & $U$ \\
\hline 14 & $M$ & - & - & - & - & - & 8 & - & - & - & - & 4 & 5 & 5 & - & 2 & - \\
\hline 15 & $M$ & $\mathrm{U}$ & $\mathrm{U}$ & $\mathrm{U}$ & $\mathrm{U}$ & $\bar{U}$ & $\mathrm{U}$ & $U$ & $U$ & $\mathrm{U}$ & $\mathrm{U}$ & $U$ & $U$ & $\mathrm{U}$ & $\mathrm{U}$ & $\mathrm{U}$ & $\mathrm{U}$ \\
\hline 16 & $M$ & - & - & - & - & - & - & - & - & - & - & - & - & - & - & - & - \\
\hline 17 & $M$ & 2 & 2 & - & 2 & 2 & 4 & - & $\mathrm{U}$ & $U$ & 5 & 6 & 5 & - & - & 2 & 2 \\
\hline 18 & $M$ & $\mathrm{U}$ & $U$ & $U$ & $U$ & $U$ & - & - & - & - & - & - & - & $U$ & $U$ & $U$ & $\mathrm{U}$ \\
\hline 19 & $M$ & - & $U$ & $U$ & $U$ & $U$ & $U$ & $U$ & $U$ & $U$ & $U$ & $U$ & $U$ & $\mathrm{U}$ & $U$ & $U$ & $U$ \\
\hline 20 & $M$ & $U$ & 6 & - & 6 & 5 & 8 & 6 & 6 & 7 & 6 & 8 & 8 & $U$ & $U$ & $U$ & $\mathrm{U}$ \\
\hline 21 & $M$ & - & - & 5 & 4 & 5 & 5 & 4 & 4 & 4 & 3 & 4 & 4 & 5 & 4 & $U$ & $U$ \\
\hline 22 & $M$ & $U$ & $U$ & $\mathrm{U}$ & 5 & 5 & - & 5 & 5 & 5 & 5 & 5 & 5 & 5 & 7 & 6 & 6 \\
\hline 23 & $M$ & $U$ & $U$ & $\bar{U}$ & $U$ & $\bar{U}$ & 4 & 6 & 6 & 6 & $U$ & 4 & 4 & 4 & $U$ & $U$ & $U$ \\
\hline 24 & $M$ & 5 & 4 & $\bar{U}$ & 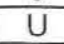 & $U$ & 6 & 5 & 5 & 5 & 5 & 5 & U & $U$ & 5 & 4 & $U$ \\
\hline 25 & $M$ & 5 & 5 & 4 & $\mathrm{U}$ & $U$ & $U$ & $U$ & $U$ & 5 & 4 & $U$ & $\bar{U}$ & $\mathrm{U}$ & $U$ & $U$ & $U$ \\
\hline 26 & $M$ & $U$ & $U$ & 5 & $U$ & 5 & 4 & 8 & 6 & - & 8 & 8 & 8 & - & - & $U$ & $U$ \\
\hline 27 & $M$ & 6 & $U$ & 6 & 5 & 8 & $U$ & 8 & 8 & 8 & $U$ & $U$ & $U$ & $\mathrm{U}$ & $U$ & $U$ & 5 \\
\hline 28 & $M$ & $U$ & $\mathrm{U}$ & $\bar{U}$ & - & - & - & - & - & - & - & - & - & - & $\mathrm{U}$ & $\mathrm{U}$ & $\mathrm{U}$ \\
\hline 29 & $M$ & 1 & 2 & 5 & 4 & 8 & 4 & 3 & 4 & 4 & 4 & 4 & 8 & 4 & 6 & 4 & - \\
\hline 30 & $M$ & - & - & - & - & - & - & - & - & - & - & - & - & - & - & - & - \\
\hline 31 & $M$ & $U$ & 1 & $\mathrm{U}$ & 5 & 5 & 4 & 4 & 5 & 5 & 4 & 3 & 1 & 1 & 1 & 1 & 1 \\
\hline 32 & $M$ & 2 & 3 & 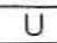 & 4 & 4 & 4 & $U$ & $U$ & $U$ & $U$ & 4 & 4 & 3 & $U$ & $U$ & $U$ \\
\hline 33 & $M$ & $U$ & - & 6 & 5 & 7 & - & - & 8 & - & - & 6 & 6 & 5 & - & - & - \\
\hline 34 & $M$ & - & 8 & 8 & 5 & 6 & 7 & 7 & 7 & 6 & 6 & 8 & 8 & - & - & 3 & 3 \\
\hline 35 & $M$ & $\mathrm{U}$ & $U$ & - & - & - & - & - & - & - & - & - & - & - & - & - & - \\
\hline 36 & $M$ & $U$ & 5 & - & 8 & 8 & - & 8 & 8 & - & - & 7 & 6 & 2 & 3 & 2 & 1 \\
\hline 37 & $M$ & 1 & $U$ & $U$ & $U$ & $U$ & 6 & 5 & $U$ & - & - & - & - & $\bar{U}$ & $U$ & $\bar{U}$ & $U$ \\
\hline 38 & $M$ & - & - & - & - & - & - & - & - & - & - & - & - & - & - & $U$ & $\mathrm{U}$ \\
\hline 39 & $M$ & 2 & $U$ & 7 & - & - & - & 8 & 7 & 7 & - & 6 & 6 & $\mathrm{U}$ & $U$ & $U$ & 2 \\
\hline 40 & $M$ & $U$ & $U$ & - & - & - & $U$ & $U$ & 3 & $U$ & 7 & $\mathrm{U}$ & - & - & $U$ & $U$ & $\mathrm{U}$ \\
\hline 41 & $M$ & $U$ & $U$ & $U$ & $\bar{U}$ & $\mathrm{U}$ & $U$ & $U$ & $U$ & $\mathrm{U}$ & $\mathrm{U}$ & $\mathrm{U}$ & $U$ & $U$ & $U$ & $U$ & $\mathrm{U}$ \\
\hline 42 & $M$ & $U$ & $U$ & $U$ & $U$ & 7 & $U$ & 5 & $U$ & - & - & - & - & $\mathrm{U}$ & $U$ & $U$ & $U$ \\
\hline 43 & $M$ & - & - & - & 5 & - & 5 & - & 5 & 4 & 3 & 8 & $U$ & $\mathrm{U}$ & $U$ & $U$ & $U$ \\
\hline 44 & $M$ & $U$ & 5 & 3 & 4 & - & 8 & 8 & - & 8 & 8 & 7 & - & 6 & - & 3 & - \\
\hline 45 & $M$ & 3 & $U$ & - & - & - & - & - & 5 & 5 & 4 & 5 & 5 & 5 & 6 & 4 & 3 \\
\hline 46 & $M$ & - & - & - & - & - & - & - & - & - & - & - & - & - & - & - & - \\
\hline 47 & $M$ & - & - & - & - & - & - & - & - & - & - & - & - & - & - & - & - \\
\hline 48 & $\mathrm{~F}$ & - & - & - & - & - & - & - & - & - & - & - & - & - & - & - & - \\
\hline 49 & $M$ & - & - & - & - & - & - & - & - & - & - & - & - & - & - & - & - \\
\hline 50 & $F$ & $\mathrm{U}$ & $U$ & - & 7 & - & 8 & $U$ & $U$ & $U$ & $U$ & $\mathrm{U}$ & 7 & 6 & 6 & - & - \\
\hline 51 & $F$ & - & - & - & - & - & - & - & - & - & - & - & - & - & - & - & - \\
\hline 52 & $M$ & $\mathrm{U}$ & $\mathrm{U}$ & $\bar{U}$ & $U$ & $\mathrm{U}$ & $U$ & $U$ & $\mathrm{U}$ & $U$ & $U$ & $\mathrm{U}$ & $\bar{U}$ & $\mathrm{U}$ & $U$ & $U$ & $U$ \\
\hline 53 & $M$ & - & - & - & - & - & - & - & - & 6 & - & 7 & - & - & - & - & 3 \\
\hline 54 & $F$ & - & - & - & - & - & - & - & - & - & - & - & - & - & - & - & - \\
\hline 55 & $F$ & $U$ & $U$ & $U$ & $U$ & $U$ & $U$ & $U$ & $U$ & $U$ & $U$ & $U$ & $U$ & $U$ & $U$ & $U$ & $U$ \\
\hline 56 & $M$ & 2 & $U$ & $U$ & $U$ & $U$ & $U$ & $U$ & $U$ & $U$ & $U$ & $U$ & $U$ & $U$ & $U$ & $U$ & 2 \\
\hline
\end{tabular}




\begin{tabular}{|c|c|c|c|c|c|c|c|c|c|c|c|c|c|c|c|c|c|}
\hline & \multicolumn{16}{|c|}{ Mandibular Dental Wear } \\
\hline & & \multicolumn{8}{|c|}{ LEFT } & \multicolumn{8}{|c|}{ RIGHT } \\
\hline Burial \# & Sex & $\mathrm{M} 3$ & M2 & M1 & P4 & P3 & C & 12 & 11 & 11 & 12 & C & P3 & P4 & M1 & M2 & M3 \\
\hline 1 & $\mathrm{~F}$ & - & - & - & - & - & - & - & - & - & - & - & - & - & - & - & $\cdot$ \\
\hline 2 & $M$ & - & - & - & - & - & - & - & - & - & - & - & - & - & - & - & - \\
\hline 3 & $M$ & - & - & - & - & - & - & - & - & - & - & - & - & - & - & - & - \\
\hline 4 & $\mathrm{M}$ & - & - & - & - & - & - & - & - & - & - & - & - & - & - & - & $\mathrm{U}$ \\
\hline 5 & $M$ & - & - & - & - & - & - & - & - & - & - & - & - & - & - & - & - \\
\hline 6 & $M$ & - & - & - & - & - & - & - & - & - & - & - & - & - & - & - & - \\
\hline 7 & $M$ & 3 & - & - & - & - & 6 & 7 & 7 & - & - & 6 & - & - & - & - & - \\
\hline 8 & $M$ & - & - & - & - & 8 & $U$ & U & $U$ & $U$ & $\mathrm{U}$ & - & $U$ & - & - & - & $U$ \\
\hline 9 & $M$ & 1 & - & - & - & 5 & 5 & 8 & U & $U$ & $U$ & 6 & 8 & - & - & - & - \\
\hline 10 & $M$ & - & - & - & - & - & $U$ & $U$ & $U$ & $U$ & $U$ & 5 & - & - & - & - & $U$ \\
\hline 11 & $M$ & 5 & - & - & 4 & 4 & 4 & $U$ & $U$ & 5 & 5 & $\bar{U}$ & 4 & 4 & - & - & 5 \\
\hline 12 & $M$ & 2 & $U$ & $\mathrm{U}$ & 7 & 6 & 5 & 4 & 4 & 3 & 3 & 4 & 4 & 7 & - & - & 1 \\
\hline 13 & $M$ & $U$ & - & - & - & - & - & - & - & - & - & - & - & - & - & - & - \\
\hline 14 & $M$ & - & - & - & - & - & - & - & - & - & - & - & - & - & - & - & - \\
\hline 15 & $M$ & - & - & - & - & - & - & - & - & - & - & - & - & - & - & - & - \\
\hline 16 & $M$ & - & - & - & - & - & - & - & - & - & - & - & - & - & - & - & - \\
\hline 17 & $M$ & 2 & - & 1 & 3 & 5 & 4 & 4 & $U$ & $U$ & $U$ & 4 & 2 & 2 & 3 & 1 & - \\
\hline 18 & $M$ & - & - & - & - & 8 & 5 & 6 & - & - & - & - & - & - & - & - & $U$ \\
\hline 19 & $M$ & $\mathrm{U}$ & 8 & - & 8 & 8 & 8 & - & - & - & - & - & - & - & - & $U$ & $U$ \\
\hline 20 & $M$ & - & - & - & 5 & 6 & 5 & 5 & 5 & 7 & 7 & 5 & $\bar{U}$ & 8 & - & - & - \\
\hline 21 & $M$ & - & - & - & 3 & 3 & 3 & 3 & 4 & 4 & 3 & 3 & 3 & - & - & - & - \\
\hline 22 & $M$ & $\mathrm{U}$ & $U$ & $\mathrm{U}$ & 5 & 5 & 5 & 5 & 5 & 5 & 5 & 5 & 5 & 5 & - & 7 & 6 \\
\hline 23 & $M$ & $U$ & - & - & 3 & 3 & 4 & 5 & - & - & 5 & 5 & 3 & 3 & 5 & $U$ & $U$ \\
\hline 24 & $M$ & 7 & 7 & 4 & 2 & 4 & $U$ & 7 & 7 & 7 & 7 & $\bar{U}$ & 4 & 2 & 5 & $U$ & $U$ \\
\hline 25 & $M$ & - & 4 & $\dot{U}$ & $\mathrm{U}$ & 3 & 5 & 2 & - & - & - & - & - & $U$ & - & - & $U$ \\
\hline 26 & $M$ & - & - & - & 8 & 6 & 6 & 6 & - & - & - & - & - & - & - & 5 & $U$ \\
\hline 27 & $\mathrm{M}$ & 8 & 8 & - & 6 & 7 & 7 & $U$ & $U$ & 8 & 8 & 7 & 8 & 8 & - & 8 & 7 \\
\hline 28 & $M$ & - & - & - & - & - & - & - & - & - & $U$ & $U$ & $U$ & $U$ & $U$ & $U$ & $U$ \\
\hline 29 & $M$ & - & 8 & 7 & 3 & 4 & 4 & 3 & 4 & 4 & 3 & 3 & 4 & 3 & 5 & 4 & 2 \\
\hline 30 & $\mathrm{M}$ & - & - & - & - & - & 6 & 4 & 8 & 8 & 4 & 6 & 6 & - & - & - & $U$ \\
\hline 31 & $M$ & - & 1 & - & - & 4 & 2 & - & - & 4 & 4 & 4 & 4 & 5 & 5 & 6 & - \\
\hline 32 & $M$ & - & - & - & 3 & 4 & 4 & $U$ & $\bar{U}$ & 3 & 3 & 4 & 5 & 4 & 6 & - & - \\
\hline 33 & $M$ & - & - & - & 8 & - & 5 & 6 & $U$ & - & - & $\dot{U}$ & 6 & 6 & - & - & - \\
\hline 34 & $\bar{M}$ & 3 & 8 & - & - & 8 & 5 & 6 & 6 & 6 & 6 & 7 & 8 & 8 & - & 8 & 8 \\
\hline 35 & $M$ & - & - & - & - & - & 4 & - & - & - & - & 5 & - & - & - & - & - \\
\hline 36 & $M$ & 4 & 6 & 6 & 7 & 7 & 0 & 6 & 6 & 6 & 4 & 4 & - & - & - & - & - \\
\hline 37 & $M$ & $U$ & - & - & - & 5 & 5 & 5 & $U$ & $U$ & 5 & 5 & 4 & - & - & - & - \\
\hline 38 & $M$ & - & - & - & - & - & - & - & - & - & - & 8 & 2 & - & - & 6 & - \\
\hline 39 & $M$ & 3 & 6 & - & - & 6 & 5 & 4 & 4 & 4 & 4 & 5 & - & - & - & 6 & - \\
\hline 40 & $M$ & $U$ & - & - & 2 & $U$ & $U$ & - & - & - & - & - & $U$ & $U$ & - & - & - \\
\hline 41 & $M$ & - & - & - & - & - & - & - & - & - & - & - & - & - & - & - & - \\
\hline 42 & $M$ & $\mathrm{U}$ & - & - & - & - & - & - & - & - & - & - & - & - & - & - & - \\
\hline 43 & $M$ & $U$ & $\mathrm{U}$ & $U$ & $U$ & 5 & $U$ & $U$ & $U$ & 4 & - & 5 & 4 & 4 & - & 6 & - \\
\hline 44 & $M$ & - & - & - & 5 & 5 & 5 & 5 & 5 & 5 & 5 & 8 & 6 & - & - & - & - \\
\hline 45 & $M$ & 4 & 7 & 7 & 5 & 4 & 4 & 4 & 4 & $\bar{U}$ & 4 & 3 & 4 & $\bar{U}$ & $\mathrm{U}$ & $U$ & $\bar{U}$ \\
\hline 46 & $M$ & - & - & - & - & - & - & - & - & - & - & - & - & - & - & - & - \\
\hline 47 & $M$ & - & - & - & - & - & - & - & - & - & - & 4 & - & - & - & - & - \\
\hline 48 & $F$ & - & - & - & - & - & - & - & - & - & - & - & - & - & - & - & - \\
\hline 49 & $M$ & - & - & - & - & - & - & - & - & - & - & - & - & - & - & - & - \\
\hline 50 & $F$ & - & - & 4 & 3 & 3 & 3 & 3 & 4 & 4 & 3 & 3 & 3 & 3 & 4 & $U$ & $U$ \\
\hline 51 & $F$ & - & - & - & - & - & - & - & - & - & - & - & - & - & - & - & - \\
\hline 52 & $M$ & - & - & - & - & 5 & 5 & 5 & - & - & 3 & 5 & 5 & - & - & - & - \\
\hline 53 & $M$ & 3 & - & - & - & - & 5 & 5 & 5 & 5 & 4 & 4 & - & - & - & - & - \\
\hline 54 & $F$ & - & - & - & - & - & - & - & - & - & - & - & - & - & - & - & - \\
\hline 55 & $F$ & - & - & - & - & - & - & - & - & - & - & - & - & - & - & - & - \\
\hline 56 & $M$ & - & - & - & - & - & - & - & - & - & - & - & - & - & - & - & - \\
\hline
\end{tabular}




\begin{tabular}{|c|c|c|c|c|c|c|c|c|c|c|c|c|c|c|c|c|c|}
\hline & \multicolumn{16}{|c|}{ Maxillary Hypercementosis } \\
\hline & & \multicolumn{8}{|c|}{ RIGHT } & \multicolumn{8}{|c|}{ LEFT } \\
\hline Burial \# & Sex & M3 & M2 & M1 & P4 & $\mathrm{P} 3$ & $\mathrm{C}$ & 12 & 11 & 11 & 12 & $\mathrm{C}$ & P3 & P4 & M1 & M2 & $\mathrm{M3}^{3}$ \\
\hline 1 & $\mathrm{~F}$ & - & - & - & - & - & - & - & - & - & - & - & - & - & - & - & - \\
\hline 2 & $M$ & - & - & - & - & - & - & - & - & - & - & - & - & - & - & $\mathrm{U}$ & $\mathrm{U}$ \\
\hline 3 & $M$ & $\mathrm{U}$ & $\mathrm{U}$ & $U$ & - & - & - & - & - & - & - & - & - & - & - & U & $\bar{U}$ \\
\hline 4 & $M$ & - & - & - & - & - & - & - & - & - & - & - & - & - & - & - & $\bar{U}$ \\
\hline 5 & $M$ & - & - & - & - & - & - & - & - & $\mathrm{U}$ & $\mathrm{U}$ & $\mathrm{U}$ & $\mathrm{U}$ & $\mathrm{U}$ & $\mathrm{U}$ & $U$ & $\mathrm{U}$ \\
\hline 6 & $M$ & - & - & - & - & - & - & - & - & - & - & - & - & - & - & - & - \\
\hline 7 & $M$ & $U$ & $\mathrm{U}$ & $U$ & $\bar{U}$ & $U$ & $\mathrm{U}$ & $U$ & $\mathrm{U}$ & $\mathrm{U}$ & $\mathrm{U}$ & $\mathrm{U}$ & $U$ & $\mathrm{U}$ & $U$ & $\mathrm{U}$ & $\mathrm{U}$ \\
\hline 8 & $M$ & $\mathrm{U}$ & $U$ & $U$ & 9 & 9 & 9 & 9 & - & - & - & 9 & - & 0 & 0 & 0 & $\mathrm{U}$ \\
\hline 9 & $M$ & 0 & 0 & $U$ & $U$ & $U$ & $U$ & $U$ & $U$ & $U$ & $\mathrm{U}$ & $U$ & 0 & $U$ & $\mathrm{U}$ & U & 0 \\
\hline 10 & $M$ & $U$ & $U$ & $U$ & $U$ & - & - & - & - & - & - & - & - & $U$ & $U$ & $\mathrm{U}$ & $\mathrm{U}$ \\
\hline 11 & $M$ & - & 0 & 0 & - & - & 0 & - & - & $U$ & $U$ & 0 & 0 & $U$ & $\mathrm{U}$ & $U$ & 9 \\
\hline 12 & $M$ & 0 & $U$ & $U$ & $U$ & $U$ & $U$ & $U$ & 0 & $U$ & $U$ & $U$ & $U$ & $U$ & $U$ & $\mathrm{U}$ & 0 \\
\hline 13 & $M$ & - & - & - & - & - & - & - & - & - & - & - & $U$ & $U$ & $U$ & $U$ & $\bar{U}$ \\
\hline 14 & $M$ & - & - & - & - & - & 0 & - & - & - & - & 0 & 9 & 9 & - & 0 & - \\
\hline 15 & $M$ & $\mathrm{U}$ & $\mathrm{U}$ & $U$ & $U$ & $U$ & $U$ & $U$ & $U$ & $U$ & $\mathrm{U}$ & $U$ & $U$ & $U$ & $U$ & $U$ & $\mathrm{U}$ \\
\hline 16 & $M$ & - & - & - & - & - & - & - & - & - & - & - & - & - & - & - & - \\
\hline 17 & $M$ & 9 & 9 & - & 9 & 9 & 9 & - & - & - & 9 & 9 & 9 & - & - & 9 & 0 \\
\hline 18 & $M$ & $U$ & $U$ & $U$ & $U$ & $U$ & - & - & - & - & - & - & - & $U$ & $U$ & $U$ & $\mathrm{U}$ \\
\hline 19 & $M$ & 9 & $U$ & $U$ & $U$ & $U$ & $U$ & $U$ & $U$ & $U$ & $U$ & $\mathrm{U}$ & $U^{\prime}$ & $U$ & $U$ & $U$ & $U$ \\
\hline 20 & $M$ & $U$ & 1 & - & 9 & 0 & 1 & 9 & 9 & 1 & 0 & 1 & 9 & $U$ & $U$ & $U$ & $U$ \\
\hline 21 & $M$ & - & - & 1 & 9 & 0 & 9 & 9 & 9 & 9 & 9 & 9 & 9 & 0 & 0 & $U$ & $\mathrm{U}$ \\
\hline 22 & $M$ & $U$ & $U$ & $U$ & 9 & 9 & 9 & 0 & 0 & 9 & 9 & 9 & 9 & 9 & 0 & 0 & 0 \\
\hline 23 & $M$ & $U$ & $\mathrm{U}$ & $\mathrm{U}$ & $U$ & $U$ & 0 & 0 & 0 & 0 & $U$ & 0 & 9 & 9 & $U$ & $\mathrm{U}$ & $\bar{U}$ \\
\hline 24 & $M$ & 0 & 0 & $U$ & $U$ & $U$ & 0 & 0 & 0 & 0 & 0 & 0 & $U$ & $U$ & 0 & 0 & $U$ \\
\hline 25 & $M$ & 0 & 0 & 0 & $U$ & $U$ & $U$ & $U$ & $U$ & 0 & 0 & $\mathrm{U}$ & $U$ & $U$ & $U$ & $U$ & $U$ \\
\hline 26 & $M$ & $U$ & $U$ & 0 & $U$ & 9 & 0 & 0 & 0 & 9 & 9 & 9 & 9 & 0 & - & $U$ & $\mathrm{U}$ \\
\hline 27 & $M$ & 0 & $U$ & 9 & 9 & 9 & $U$ & 0 & 0 & 0 & $U$ & $U$ & $U$ & $U$ & $U$ & $U$ & 0 \\
\hline 28 & $M$ & $U$ & $U$ & $U$ & - & - & - & - & - & - & 0 & - & - & - & $U$ & $U$ & $\bar{U}$ \\
\hline 29 & $M$ & 0 & 0 & 0 & 9 & 9 & 9 & 9 & 9 & 9 & 9 & 9 & 9 & 0 & 0 & 0 & - \\
\hline 30 & $M$ & - & - & - & - & - & - & - & - & - & - & - & - & - & - & - & - \\
\hline 31 & $M$ & $\mathrm{U}$ & 0 & $U$ & 0 & 9 & 9 & 9 & 9 & 9 & 9 & 9 & 9 & 9 & 0 & 0 & 0 \\
\hline 32 & $M$ & 0 & 0 & - & 9 & 9 & 9 & - & - & $U$ & - & 9 & 9 & 9 & - & - & $\bar{U}$ \\
\hline 33 & $M$ & $U$ & - & 0 & 1 & 1 & - & - & 0 & - & - & 0 & 0 & 0 & - & - & - \\
\hline 34 & $M$ & - & 9 & 1 & 1 & 9 & 9 & 9 & 9 & 9 & 9 & 9 & 1 & - & - & 9 & 9 \\
\hline 35 & $M$ & $U$ & $U$ & - & - & - & - & - & - & - & - & - & - & - & - & - & - \\
\hline 36 & $M$ & $U$ & 1 & - & 0 & 0 & - & 0 & 0 & - & - & 9 & 9 & 9 & 9 & 0 & 0 \\
\hline 37 & $M$ & 0 & $\mathrm{U}$ & $U$ & $U$ & $U$ & 0 & 0 & $U$ & 9 & 9 & 9 & 9 & $U$ & $U$ & $\mathrm{U}$ & $U$ \\
\hline 38 & $M$ & - & - & - & - & - & - & - & - & - & - & - & - & - & - & $U$ & $U$ \\
\hline 39 & $M$ & 1 & $U$ & 1 & - & - & - & 9 & 9 & 9 & - & 9 & 9 & $U$ & $U$ & $U$ & 1 \\
\hline 40 & $M$ & $U$ & $U$ & - & - & - & - & - & - & - & 9 & - & - & - & $U$ & $U$ & $\bar{U}$ \\
\hline 41 & $M$ & $U$ & $U$ & $U$ & $U$ & $U$ & $U$ & $U$ & $U$ & $\mathrm{U}$ & $U$ & $\mathrm{U}$ & $U$ & $U$ & $U$ & $U$ & $\bar{U}$ \\
\hline 42 & $M$ & $U$ & $U$ & $U$ & $U$ & 0 & $U$ & 0 & $U$ & - & - & - & - & $U$ & $U$ & $U$ & $U$ \\
\hline 43 & $M$ & - & - & - & 9 & - & 0 & - & 0 & 9 & 0 & 0 & $U$ & $\mathrm{U}$ & $U$ & $U$ & $\bar{U}$ \\
\hline 44 & $M$ & $U$ & 9 & 9 & 9 & - & 9 & 9 & - & 0 & 9 & 0 & - & 9 & - & 9 & - \\
\hline 45 & $M$ & 0 & $U$ & - & - & 0 & - & 0 & 0 & 0 & 9 & 9 & 9 & 9 & 9 & 9 & 0 \\
\hline 46 & $M$ & - & - & - & - & - & - & - & - & - & - & - & - & - & - & - & - \\
\hline 47 & $M$ & - & - & - & - & - & - & - & - & - & - & - & - & - & - & - & - \\
\hline 48 & $\mathrm{~F}$ & - & - & - & - & - & - & - & - & - & - & - & - & - & - & - & - \\
\hline 49 & $M$ & - & - & - & - & - & 0 & - & - & - & - & - & - & - & - & - & - \\
\hline 50 & $F$ & $U$ & $\mathrm{U}$ & - & 0 & - & 0 & - & - & $U$ & $\mathrm{U}$ & $U$ & 0 & 0 & 9 & 1 & - \\
\hline 51 & $F$ & - & - & - & - & - & - & - & - & - & - & - & - & - & - & -1 & - \\
\hline 52 & $M$ & $U$ & $\mathrm{U}$ & $U$ & $U$ & $U$ & $U$ & $\mathrm{U}$ & $\mathrm{U}$ & $\mathrm{U}$ & $\mathrm{U}$ & $U$ & $U$ & $\mathrm{U}$ & $U$ & $\mathrm{U}$ & $\mathrm{U}$ \\
\hline 53 & $M$ & - & - & - & - & - & - & - & - & 0 & - & 0 & - & - & - & - & 0 \\
\hline 54 & $\mathrm{~F}$ & - & - & - & - & - & - & - & - & - & 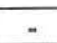 & - & - & - & - & - & - \\
\hline 55 & $F$ & $U$ & $U$ & $U$ & $U$ & $U$ & $U$ & $U$ & $U$ & $U$ & $\mathrm{U}$ & $U$ & $U$ & $U$ & $U$ & $U$ & $\mathrm{U}$ \\
\hline 56 & $M$ & 1 & $U$ & $U$ & $U$ & $U$ & $U$ & $U$ & $U$ & $U$ & $U$ & $U$ & $U$ & $U$ & $U$ & U & 1 \\
\hline
\end{tabular}




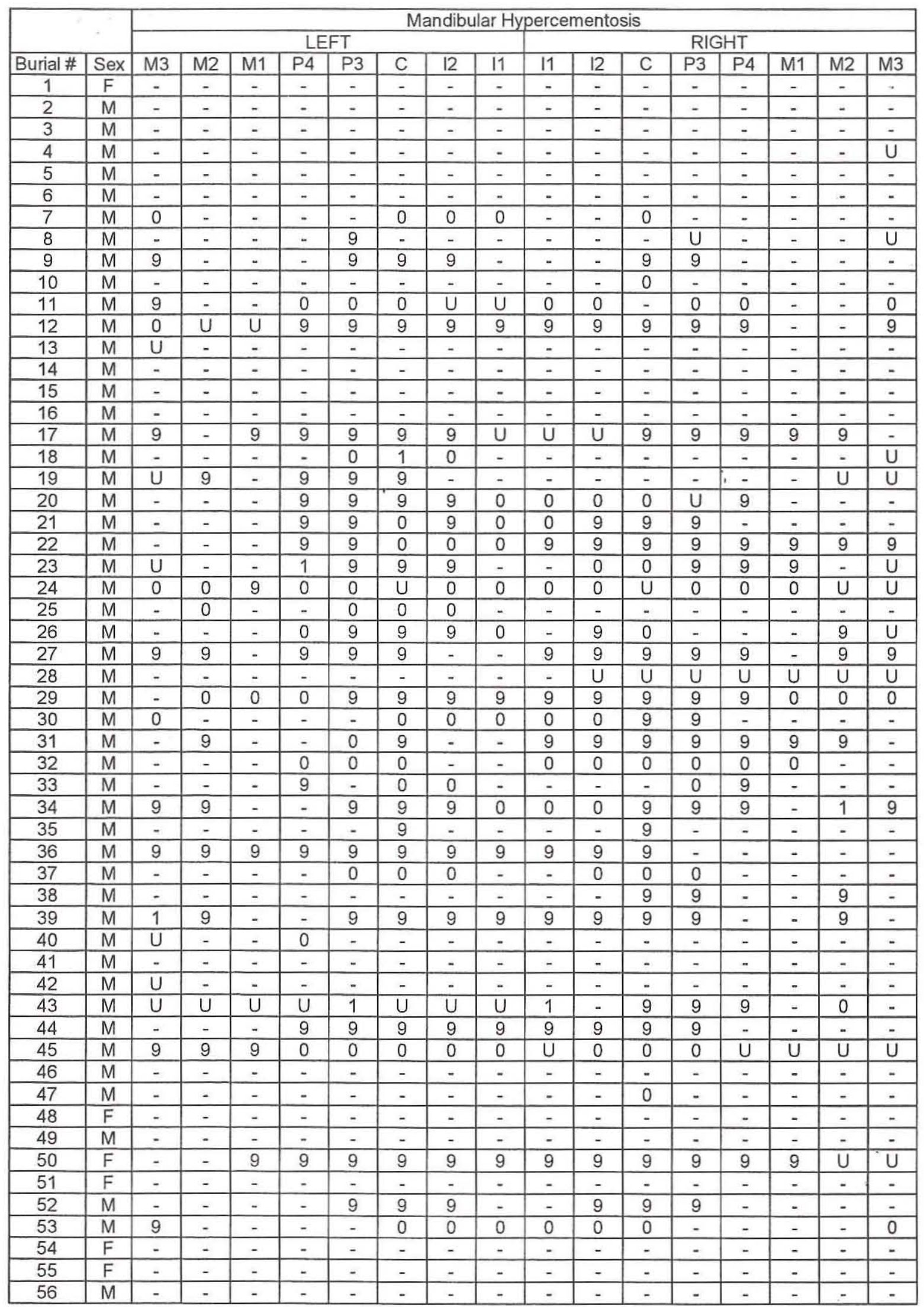




\begin{tabular}{|c|c|c|c|c|c|c|c|c|c|c|c|c|c|c|c|c|c|}
\hline & \multicolumn{16}{|c|}{ Linear Enamal Hypoplasias- Maxillary (\# of episodes) } \\
\hline & & \multicolumn{8}{|c|}{ RIGHT } & \multicolumn{8}{|c|}{ LEFT } \\
\hline Burial \# & Sex & M3 & M2 & M1 & $\mathrm{P} 4$ & $\mathrm{P} 3$ & $\mathrm{C}$ & 12 & 11 & 11 & 12 & $\mathrm{C}$ & P3 & P4 & M1 & M2 & $\mathrm{M} 3$ \\
\hline 1 & $\mathrm{~F}$ & - & - & - & - & - & - & - & - & - & - & - & - & - & - & - & - \\
\hline 2 & $\mathrm{M}$ & - & - & - & - & - & - & - & - & - & - & - & - & - & - & $\mathrm{U}$ & $\mathrm{U}$ \\
\hline 3 & $\mathrm{M}$ & $U$ & $U$ & $U$ & - & - & - & - & - & - & - & - & - & - & - & $U$ & $U$ \\
\hline 4 & $M$ & - & - & - & - & - & - & - & - & - & - & - & - & - & - & - & $U$ \\
\hline 5 & $M$ & - & - & - & - & - & - & - & - & $U$ & $U$ & $U$ & $\mathrm{U}$ & $U$ & $U$ & $U$ & $\mathrm{U}$ \\
\hline 6 & $\mathrm{M}$ & - & - & - & - & - & - & - & - & - & - & - & - & - & - & - & - \\
\hline 7 & $M$ & $U$ & $U$ & $U$ & $U$ & $U$ & $U$ & $U$ & $U$ & $U$ & $U$ & $U$ & $U$ & $U$ & $U$ & $\mathrm{U}$ & $U$ \\
\hline 8 & $M$ & $U$ & $U$ & $U$ & 0 & 9 & 9 & 9 & - & - & - & 9 & - & 0 & 0 & 0 & $U$ \\
\hline 9 & $M$ & 0 & 0 & $U$ & $U$ & $\mathrm{U}$ & $U$ & $U$ & $U$ & $U$ & $U$ & $\mathrm{U}$ & 0 & $U$ & $U$ & $\mathrm{U}$ & 0 \\
\hline 10 & $M$ & $U$ & $U$ & $U$ & $U$ & - & - & - & - & - & - & - & - & $U$ & $U$ & $U$ & $U$ \\
\hline 11 & $M$ & - & 9 & 0 & - & - & 0 & - & - & $\mathrm{U}$ & $U$ & 0 & 0 & $\mathrm{U}$ & $U$ & $\mathrm{U}$ & 0 \\
\hline 12 & $M$ & 0 & $U$ & $U$ & $U$ & $\mathrm{U}$ & $U$ & $U$ & 0 & $U$ & $U$ & $U$ & $U$ & $\mathrm{U}$ & $U$ & $U$ & 0 \\
\hline 13 & $M$ & - & - & - & - & - & - & - & - & - & - & - & $U$ & $U$ & $U$ & $U$ & $U$ \\
\hline 14 & $M$ & - & - & - & - & - & 9 & - & - & - & - & 3 & 0 & 0 & - & 0 & - \\
\hline 15 & $M$ & $U$ & $U$ & $U$ & $U$ & $U$ & $U$ & $\mathrm{U}$ & $U$ & $\mathrm{U}$ & $U$ & $U$ & $U$ & $U$ & $U$ & $U$ & $\mathrm{U}$ \\
\hline 16 & $M$ & - & - & - & - & - & - & - & - & - & - & - & - & - & - & - & - \\
\hline 17 & $M$ & 0 & 0 & - & 0 & 0 & 0 & - & - & - & 0 & 0 & 0 & - & - & 0 & 0 \\
\hline 18 & $M$ & $U$ & $U$ & $U$ & $\mathrm{U}$ & $U$ & - & - & - & - & - & - & - & $U$ & $U$ & $U$ & $U$ \\
\hline 19 & $M$ & 0 & U & $U$ & $U$ & $\mathrm{U}$ & $U$ & $U$ & $U$ & $U$ & $U$ & $\mathrm{U}$ & $\mathrm{U}$ & $U$ & $U$ & $U$ & $U$ \\
\hline 20 & $M$ & $\mathrm{U}$ & 0 & - & 0 & 0 & 0 & 0 & 0 & 0 & 0 & 0 & 0 & $U$ & $U$ & $U$ & $U$ \\
\hline 21 & $M$ & - & - & 0 & 0 & 0 & 0 & 0 & 0 & 0 & 0 & 0 & 0 & 0 & 0 & $U$ & $U$ \\
\hline 22 & $M$ & $U$ & $U$ & $U$ & 0 & 0 & 9 & 0 & 0 & 0 & 0 & 0 & 0 & 0 & 0 & 0 & 0 \\
\hline 23 & $M$ & $U$ & $U$ & $U$ & $U$ & $U$ & 1 & 0 & 1 & 1 & $U$ & 1 & 0 & 0 & $U$ & $U$ & $U$ \\
\hline 24 & $M$ & 0 & 0 & $U$ & $U$ & $U$ & 2 & 2 & 2 & 2 & 3 & 1 & $U$ & $U$ & 0 & 0 & $U$ \\
\hline 25 & $M$ & 0 & 0 & 0 & $U$ & $U$ & $\bar{U}$ & $U$ & $\bar{U}$ & 1 & 1 & $U$ & $U$ & $U$ & $U$ & $U$ & $U$ \\
\hline 26 & $M$ & $U$ & U & 0 & $U$ & 0 & 0 & 9 & 0 & 9 & 9 & 9 & 9 & 9 & - & $U$ & U \\
\hline 27 & $M$ & 0 & $U$ & 0 & 0 & 0 & $U$ & 0 & 0 & 0 & $U$ & $U$ & $U$ & $U$ & $U$ & $U$ & 0 \\
\hline 28 & $M$ & $U$ & $U$ & $U$ & - & - & - & - & - & - & 9 & - & - & - & $U$ & $U$ & $U$ \\
\hline 29 & $M$ & 0 & 0 & 0 & 0 & 0 & 0 & 0 & 0 & 0 & 0 & 0 & 0 & 0 & 0 & 0 & - \\
\hline 30 & $M$ & - & - & - & - & - & - & - & - & - & - & - & - & - & - & - & - \\
\hline 31 & $M$ & $U$ & 0 & $U$ & 0 & 0 & 0 & 0 & 0 & 0 & 0 & 0 & 0 & 0 & 0 & 0 & 0 \\
\hline 32 & $M$ & 0 & 0 & - & 0 & 0 & 0 & - & - & $\mathrm{U}$ & - & 0 & 0 & 0 & - & - & $\mathrm{U}$ \\
\hline 33 & $M$ & $U$ & - & 9 & 0 & 9 & - & - & 9 & - & - & 0 & 0 & 0 & - & - & - \\
\hline 34 & $M$ & - & 0 & 0 & 0 & 0 & 0 & 0 & 0 & 0 & 0 & 0 & 0 & - & - & 0 & 0 \\
\hline 35 & $M$ & $\mathrm{U}$ & $U$ & - & - & - & - & - & - & - & - & - & - & - & - & - & - \\
\hline 36 & $M$ & $U$ & 0 & - & 9 & 9 & - & 9 & 9 & - & - & 9 & 0 & 0 & 9 & 9 & 0 \\
\hline 37 & $M$ & 0 & $U$ & $U$ & $\mathrm{U}$ & $U$ & 2 & 0 & $U$ & 9 & 9 & 9 & 9 & $U$ & $U$ & $U$ & $U$ \\
\hline 38 & $M$ & - & - & - & - & - & - & - & - & - & - & - & - & - & - & $U$ & $U$ \\
\hline 39 & $M$ & 0 & $\mathrm{U}$ & 0 & - & - & - & 0 & 0 & 0 & - & 0 & 0 & $U$ & $\mathrm{U}$ & $U$ & 0 \\
\hline 40 & $M$ & $\mathrm{U}$ & $U$ & - & - & - & - & - & - & - & 9 & - & - & - & $U$ & $U$ & $U$ \\
\hline 41 & $M$ & $U$ & $U$ & $U$ & $U$ & $U$ & $U$ & $U$ & $U$ & $U$ & $\mathrm{U}$ & $U$ & $U$ & $U$ & $U$ & $U$ & $U$ \\
\hline 42 & $M$ & $U$ & $\mathrm{U}$ & $U$ & $U$ & 0 & $U$ & 0 & $\mathrm{U}$ & - & - & - & - & $U$ & $\mathrm{U}$ & $U$ & $U$ \\
\hline 43 & $M$ & - & - & - & 0 & - & 0 & - & 0 & 0 & 0 & 0 & $U$ & $U$ & $U$ & $U$ & $U$ \\
\hline 44 & $M$ & $U$ & 0 & 0 & 0 & - & 0 & 0 & - & 0 & 0 & 0 & - & 0 & - & 0 & - \\
\hline 45 & $M$ & 0 & $U$ & - & - & 9 & - & 9 & 0 & 0 & 0 & 0 & 0 & 0 & 0 & 0 & 0 \\
\hline 46 & $M$ & - & - & - & - & - & - & - & - & - & - & - & - & - & - & - & - \\
\hline 47 & $M$ & - & - & - & - & - & - & - & - & - & - & - & - & - & - & - & - \\
\hline 48 & $F$ & - & - & - & - & - & - & - & - & - & - & - & - & - & - & - & - \\
\hline 49 & $M$ & - & - & - & - & - & 0 & - & - & - & - & - & - & - & - & - & - \\
\hline 50 & $F$ & $U$ & $\mathrm{U}$ & - & 0 & - & 0 & - & - & $U$ & $U$ & $U$ & 0 & 0 & 0 & 9 & $U$ \\
\hline 51 & $F$ & - & - & - & - & - & - & - & - & - & - & - & - & - & - & - & - \\
\hline 52 & $M$ & $U$ & $U$ & $U$ & $U$ & $U$ & $U$ & $U$ & $U$ & $U$ & $\mathrm{U}$ & $U$ & $U$ & $U$ & $U$ & $\mathrm{U}$ & $U$ \\
\hline 53 & $M$ & - & - & - & - & - & - & - & - & 2 & - & 0 & - & - & - & - & 0 \\
\hline 54 & $\mathrm{~F}$ & - & - & - & - & - & - & - & - & - & - & - & - & - & - & - & - \\
\hline 55 & $F$ & $U$ & $U$ & $U$ & $U$ & $U$ & $U$ & $U$ & $U$ & $U$ & $U$ & $U$ & $\mathrm{U}$ & $U$ & $U$ & $U$ & $U$ \\
\hline 56 & $M$ & 0 & $U$ & $\mathrm{U}$ & $U$ & $U$ & $U$ & $U$ & $\mathrm{U}$ & $U$ & $U$ & $U$ & $U$ & $U$ & $U$ & $U$ & 0 \\
\hline
\end{tabular}




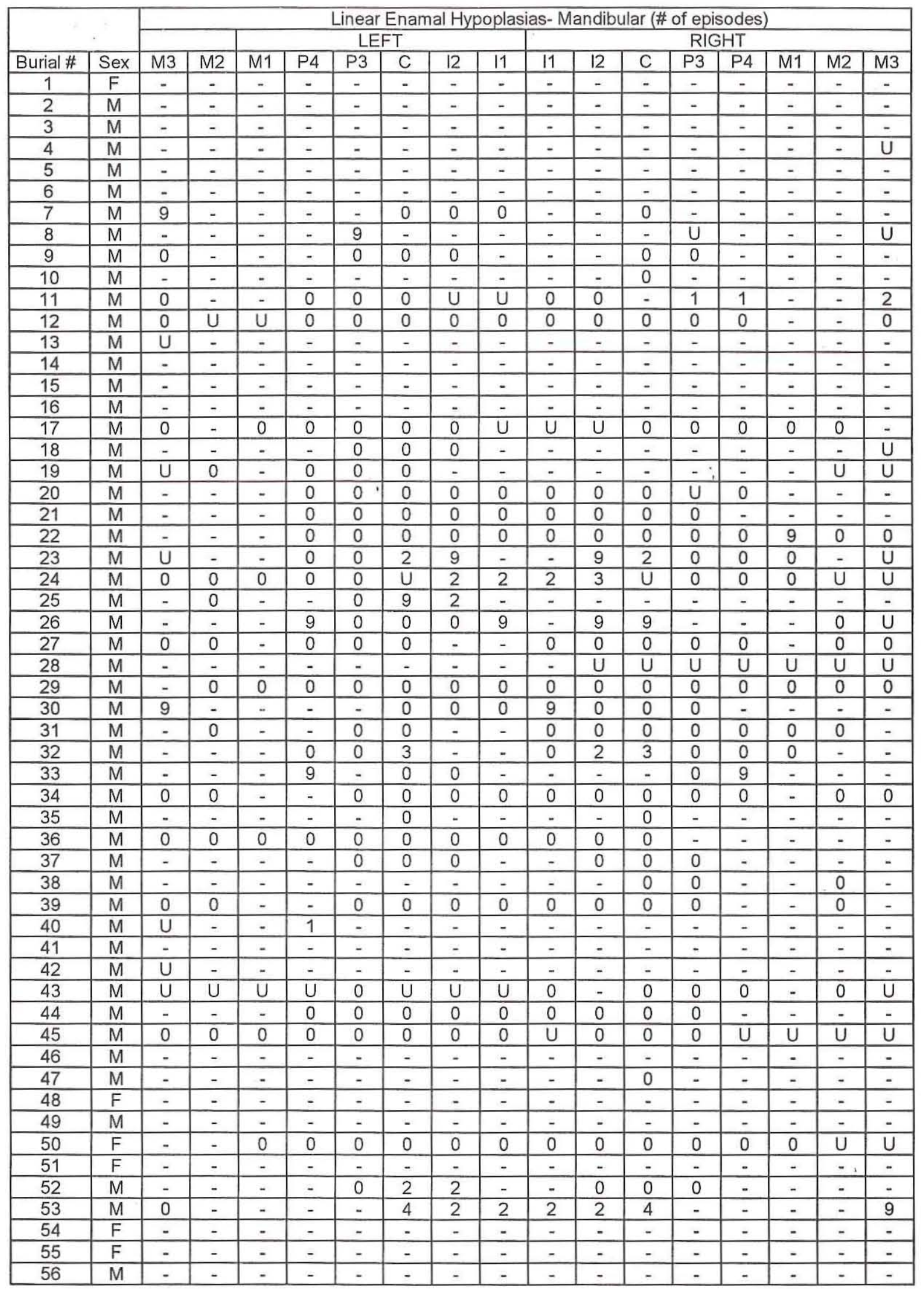


Texas State Cemetery Project

\begin{tabular}{|c|c|c|c|c|c|c|c|c|c|c|c|c|c|c|c|}
\hline 7 & & \multicolumn{14}{|c|}{ Skeletal Pathology } \\
\hline Burial \# & Sex & 1 & 2 & 3 & 4 & 5 & 6 & 7 & 8 & 9 & 10 & 11 & 12 & 13 & 14 \\
\hline 1 & $\mathrm{~F}$ & - & - & - & - & - & - & - & - & - & - & - & - & - & - \\
\hline 2 & $M$ & - & - & - & - & - & - & - & - & - & $\mathrm{P}$ & - & - & - & - \\
\hline 3 & $\mathrm{M}$ & - & - & - & - & - & - & - & $\mathrm{P}$ & - & - & - & - & - & - \\
\hline 4 & $M$ & - & - & - & - & $\mathrm{P}$ & - & - & - & $P$ & - & - & - & - & - \\
\hline 5 & $M$ & - & - & - & - & - & - & - & - & - & - & - & - & - & - \\
\hline 6 & $M$ & - & - & - & - & - & - & - & - & - & $P$ & - & - & - & - \\
\hline 7 & $M$ & - & - & - & - & - & - & - & - & - & - & $P$ & - & - & - \\
\hline 8 & $M$ & - & - & - & - & - & - & $P$ & $P$ & - & - & - & - & - & - \\
\hline 9 & $M$ & - & - & - & - & $\mathrm{P}$ & - & - & $P$ & - & $P$ & $P$ & $\mathrm{P}$ & - & - \\
\hline 10 & $M$ & - & - & - & - & - & - & - & - & - & - & - & - & - & - \\
\hline 11 & $M$ & - & - & - & $P$ & $P$ & - & - & - & - & - & - & - & - & - \\
\hline 12 & $M$ & - & - & - & - & - & - & - & $P$ & - & - & - & - & - & - \\
\hline 13 & $M$ & - & $P$ & $P$ & - & - & - & - & - & - & - & - & - & - & - \\
\hline 14 & $M$ & - & - & - & - & - & - & - & - & $P$ & - & - & - & - & $\mathrm{P}$ \\
\hline 15 & $M$ & - & - & - & - & - & - & - & - & - & $P$ & - & - & - & - \\
\hline 16 & $M$ & - & - & - & - & - & - & - & $P$ & - & - & $P$ & - & - & - \\
\hline 17 & $M$ & - & - & - & - & - & - & - & - & - & - & - & - & - & - \\
\hline 18 & $M$ & - & - & - & - & - & - & - & $P$ & - & $P$ & $P$ & - & - & - \\
\hline 19 & $M$ & - & - & - & - & - & - & - & - & - & - & $\doteqdot$ & - & - & - \\
\hline 20 & $M$ & - & - & - & - & $\mathrm{P}$ & - & - & - & - & $\mathrm{P}$ & $P$ & $P$ & - & - \\
\hline 21 & $M$ & - & - & - & - & $P$ & - & - & - & - & - & - & - & - & - \\
\hline 22 & $M$ & - & - & $\mathrm{P}$ & - & - & - & - & - & - & $\mathrm{P}$ & - & - & - & - \\
\hline 23 & $\mathrm{M}$ & - & - & - & - & - & - & - & - & - & - & - & $P$ & - & - \\
\hline 24 & $M$ & - & - & - & - & - & - & - & $P$ & - & - & $P$ & - & - & - \\
\hline 25 & $M$ & - & - & - & - & - & - & - & - & - & - & - & - & - & - \\
\hline 26 & $M$ & - & - & - & - & - & - & - & - & - & - & - & - & - & - \\
\hline 27 & $M$ & - & - & $\mathrm{P}$ & - & $P$ & - & - & - & - & - & - & - & - & - \\
\hline 28 & $M$ & - & - & - & $P$ & $P$ & - & - & - & - & - & - & - & - & - \\
\hline 29 & $M$ & - & - & - & - & $P$ & - & - & - & - & - & - & - & - & - \\
\hline 30 & $M$ & - & - & - & - & - & - & - & - & - & - & - & - & - & - \\
\hline 31 & $M$ & - & - & - & $\mathrm{P}$ & $\mathrm{P}$ & - & - & - & - & $P$ & - & $\mathrm{P}$ & - & - \\
\hline 32 & $M$ & - & - & - & - & - & - & - & - & - & - & - & - & - & - \\
\hline 33 & $M$ & - & - & - & - & $P$ & - & $P$ & $\mathrm{P}$ & - & - & - & - & - & - \\
\hline 34 & $M$ & - & - & - & $P$ & $P$ & - & - & - & - & - & - & $\mathrm{P}$ & - & - \\
\hline 35 & $M$ & $P$ & - & - & $\mathrm{P}$ & - & - & - & - & - & - & - & $P$ & - & - \\
\hline 36 & $M$ & - & - & - & - & - & - & - & - & - & - & - & - & $\mathrm{P}$ & - \\
\hline 37 & $M$ & - & - & - & - & $P$ & - & - & - & - & $P$ & - & $P$ & - & - \\
\hline 38 & $M$ & - & - & - & - & $P$ & $P$ & - & - & - & $P$ & - & $\mathrm{P}$ & - & - \\
\hline 39 & $M$ & - & - & - & $P$ & $P$ & $P$ & - & - & $P$ & - & - & - & - & - \\
\hline 40 & $M$ & - & - & - & $P$ & $P$ & $P$ & - & - & - & - & - & - & $P$ & - \\
\hline 41 & $M$ & - & - & - & - & $P$ & - & - & - & - & $P$ & - & - & - & - \\
\hline 42 & $M$ & - & - & - & - & $P$ & - & - & - & - & - & - & - & - & - \\
\hline 43 & $M$ & - & - & - & - & - & - & - & - & - & - & - & - & - & - \\
\hline 44 & $M$ & - & - & - & - & $P$ & - & - & - & - & - & - & - & - & - \\
\hline 45 & $M$ & - & - & - & - & $P$ & - & - & - & - & - & - & - & - & - \\
\hline 46 & $\mathrm{M}$ & - & - & - & - & $P$ & - & - & - & - & - & - & - & - & $\mathrm{P}$ \\
\hline 47 & $M$ & - & - & - & - & - & - & - & - & - & - & - & - & - & - \\
\hline 48 & $F$ & - & - & - & - & - & - & - & - & - & - & - & - & - & - \\
\hline 49 & $M$ & - & - & - & $P$ & $P$ & - & - & - & - & - & - & - & - & - \\
\hline 50 & $F$ & - & - & - & - & - & - & - & - & - & $\mathrm{P}$ & $\mathrm{P}$ & $P$ & - & - \\
\hline 51 & $\mathrm{~F}$ & - & - & - & - & $\mathrm{P}$ & - & - & - & - & $\mathrm{P}$ & - & - & - & - \\
\hline 52 & $M$ & - & - & - & - & - & - & - & - & - & - & - & - & - & - \\
\hline 53 & $M$ & $P$ & - & $P$ & $P$ & $P$ & - & - & - & $P$ & - & - & - & - & - \\
\hline 54 & $\mathrm{~F}$ & - & - & - & - & - & - & - & - & - & - & - & - & - & - \\
\hline 55 & $F$ & - & - & $\mathrm{P}$ & - & $P$ & - & - & $P$ & - & - & - & - & - & - \\
\hline 56 & $M$ & - & - & - & - & - & $P$ & - & - & - & - & - & - & - & - \\
\hline
\end{tabular}




\begin{tabular}{|c|c|c|c|c|c|c|c|c|c|c|c|c|c|c|c|}
\hline & & \multicolumn{14}{|c|}{ Skeletal Pathology } \\
\hline Burial \# & Sex & 15 & 16 & 17 & 18 & 19 & 20 & 21 & 22 & 23 & 24 & 25 & 26 & 27 & 28 \\
\hline 1 & $\mathrm{~F}$ & - & - & - & $\mathrm{P}$ & $\mathrm{P}$ & $\mathrm{P}$ & - & - & - & - & - & - & - & - \\
\hline 2 & $M$ & - & - & 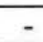 & $P$ & $P$ & $P$ & - & - & - & - & - & 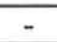 & - & - \\
\hline 3 & $M$ & - & $\mathrm{P}$ & - & $P$ & $P$ & $\mathrm{P}$ & - & - & - & - & - & $\begin{array}{ll}-- & \\
-\end{array}$ & - & $P$ \\
\hline 4 & $M$ & - & - & - & $\mathrm{P}$ & $P$ & $\mathrm{P}$ & - & - & - & - & $P$ & - & - & $P$ \\
\hline 5 & $M$ & - & - & - & $\mathrm{P}$ & $\mathrm{P}$ & $\mathrm{P}$ & - & $\mathrm{P}$ & - & - & - & - & - & $P$ \\
\hline 6 & $M$ & - & - & - & $P$ & $\mathrm{P}$ & $\mathrm{P}$ & - & - & $P$ & - & - & - & $P$ & $P$ \\
\hline 7 & $M$ & - & - & - & $P$ & $P$ & $\mathrm{P}$ & - & - & - & - & - & - & - & $P$ \\
\hline 8 & $M$ & - & - & - & $\mathrm{P}$ & $P$ & $\mathrm{P}$ & - & $P$ & $\mathrm{P}$ & - & - & $\begin{array}{ll}- & \\
\end{array}$ & - & - \\
\hline 9 & $M$ & - & - & - & - & - & $\mathrm{P}$ & - & - & - & $P$ & - & - & - & - \\
\hline 10 & $M$ & - & - & - & $\mathrm{P}$ & $P$ & $\mathrm{P}$ & - & $P$ & $\mathrm{P}$ & - & - & $\mathrm{P}$ & - & $P$ \\
\hline 11 & $M$ & - & - & - & $P$ & $P$ & $\mathrm{P}$ & - & - & - & - & - & - & - & $P$ \\
\hline 12 & $M$ & - & - & - & $P$ & $P$ & $\mathrm{P}$ & - & $\mathrm{P}$ & - & - & - & $P$ & - & - \\
\hline 13 & $M$ & - & - & - & $P$ & $P$ & $P$ & $P$ & - & - & - & - & - & $P$ & - \\
\hline 14 & $M$ & - & - & - & $P$ & $P$ & $P$ & - & - & $P$ & - & - & - & - & - \\
\hline 15 & $M$ & - & - & - & $P$ & $P$ & $P$ & - & - & - & - & - & - & - & - \\
\hline 16 & $M$ & - & - & $P$ & $P$ & $P$ & $\mathrm{P}$ & - & - & - & - & - & - & $P$ & $P$ \\
\hline 17 & $M$ & - & - & - & $P$ & $P$ & $P$ & - & - & - & $P$ & - & - & - & - \\
\hline 18 & $M$ & - & - & - & $P$ & $P$ & $P$ & $P$ & - & - & $P$ & - & - & - & - \\
\hline 19 & $M$ & - & - & - & $P$ & $P$ & $\mathrm{P}$ & - & - & - & - & 7 & - & - & - \\
\hline 20 & $M$ & - & - & - & $P$ & - & - & - & $P$ & $\mathrm{P}$ & - & $\because$ & - & - & - \\
\hline 21 & $M$ & - & - & - & $P$ & $P$ & $P$ & - & - & - & - & - & - & $P$ & $P$ \\
\hline 22 & $M$ & - & - & - & $P$ & $P$ & $\mathrm{P}$ & - & - & $\mathrm{P}$ & - & - & - & - & - \\
\hline 23 & $M$ & - & - & - & $P$ & $P$ & $P$ & - & $P$ & - & - & - & - & - & - \\
\hline 24 & $M$ & - & - & - & $P$ & $P$ & - & - & - & - & - & - & - & - & - \\
\hline 25 & $M$ & - & - & - & $P$ & $P$ & $P$ & $P$ & $P$ & - & - & - & - & - & $P$ \\
\hline 26 & $M$ & - & - & - & $P$ & $P$ & $P$ & $P$ & - & - & - & - & - & - & $P$ \\
\hline 27 & $M$ & - & - & - & $P$ & $P$ & $P$ & $P$ & - & - & - & - & - & - & $P$ \\
\hline 28 & $M$ & - & - & - & $P$ & $P$ & $\mathrm{P}$ & - & - & - & - & - & - & - & - \\
\hline 29 & $M$ & - & - & - & $P$ & $P$ & - & $P$ & - & $\mathrm{P}$ & - & - & $\mathrm{P}$ & $P$ & - \\
\hline 30 & $M$ & - & - & - & $P$ & - & $P$ & - & $P$ & - & $P$ & - & - & - & - \\
\hline 31 & $M$ & - & - & - & $P$ & $P$ & $P$ & - & - & - & $P$ & - & - & - & - \\
\hline 32 & $M$ & - & - & - & $P$ & - & $P$ & - & - & - & - & - & - & $P$ & $P$ \\
\hline 33 & $M$ & - & - & - & - & $P$ & $P$ & $P$ & - & $P$ & - & - & - & $P$ & $P$ \\
\hline 34 & $M$ & - & - & - & $P$ & - & $P$ & $P$ & - & - & - & - & - & $P$ & - \\
\hline 35 & $M$ & $P$ & - & - & $P$ & $P$ & $P$ & $P$ & - & - & - & - & - & $P$ & - \\
\hline 36 & $M$ & - & - & - & $P$ & $P$ & $P$ & $P$ & $P$ & - & - & - & $P$ & $P$ & $P$ \\
\hline 37 & $M$ & - & - & - & $P$ & - & $P$ & - & - & - & - & - & - & - & - \\
\hline 38 & $M$ & - & - & - & $P$ & $P$ & $\mathrm{P}$ & $P$ & - & $P$ & - & - & - & $P$ & - \\
\hline 39 & $M$ & - & - & - & $P$ & $P$ & $\mathrm{P}$ & $P$ & $P$ & $P$ & - & - & $P$ & - & $P$ \\
\hline 40 & $M$ & $P$ & - & - & $P$ & $P$ & $P$ & $P$ & - & - & - & - & - & - & - \\
\hline 41 & $M$ & $P$ & - & - & $P$ & $P$ & $P$ & $P$ & $P$ & - & - & - & - & $P$ & $P$ \\
\hline 42 & $M$ & - & - & - & $P$ & $P$ & $P$ & $P$ & $P$ & - & - & - & $P$ & $P$ & $P$ \\
\hline 43 & $M$ & - & - & - & $P$ & $P$ & $P$ & - & - & $P$ & - & - & $P$ & - & - \\
\hline 44 & $M$ & - & - & - & $P$ & $P$ & $\mathrm{P}$ & $P$ & $P$ & - & - & - & $P$ & - & - \\
\hline 45 & $M$ & - & - & - & $P$ & $P$ & - & - & - & - & - & - & - & - & - \\
\hline 46 & $M$ & - & - & - & $P$ & $P$ & $\mathrm{P}$ & $P$ & - & - & $P$ & - & - & - & $P$ \\
\hline 47 & $M$ & - & - & - & $P$ & $P$ & $\mathrm{P}$ & - & - & - & - & - & $\mathrm{P}$ & $P$ & $P$ \\
\hline 48 & $F$ & - & - & - & $P$ & & $P$ & - & - & - & - & - & - & - & $P$ \\
\hline 49 & $M$ & - & - & - & $P$ & $P$ & $P$ & $P$ & - & $P$ & - & - & $P$ & $P$ & $P$ \\
\hline 50 & $F$ & - & - & - & $P$ & $P$ & - & - & - & - & $P$ & - & - & $P$ & $\vec{P}$ \\
\hline 51 & $F$ & - & - & - & $P$ & $P$ & $P$ & - & - & - & - & - & - & $P$ & $P$ \\
\hline 52 & $M$ & - & - & - & $P$ & $P$ & $P$ & - & - & - & - & - & - & $P$ & $P$ \\
\hline 53 & $M$ & - & - & - & $P$ & $P$ & $P$ & - & - & - & $P$ & - & - & $P$ & $P$ \\
\hline 54 & $F$ & - & - & - & $P$ & $P$ & $P$ & - & - & - & - & - & - & $P$ & $P$ \\
\hline 55 & $F$ & - & - & - & $P$ & $P$ & $P$ & - & - & - & - & - & - & $P$ & $P$ \\
\hline 56 & $M$ & - & - & - & $P$ & $P$ & $P$ & - & - & - & - & - & $P$ & $P$ & $P$ \\
\hline
\end{tabular}




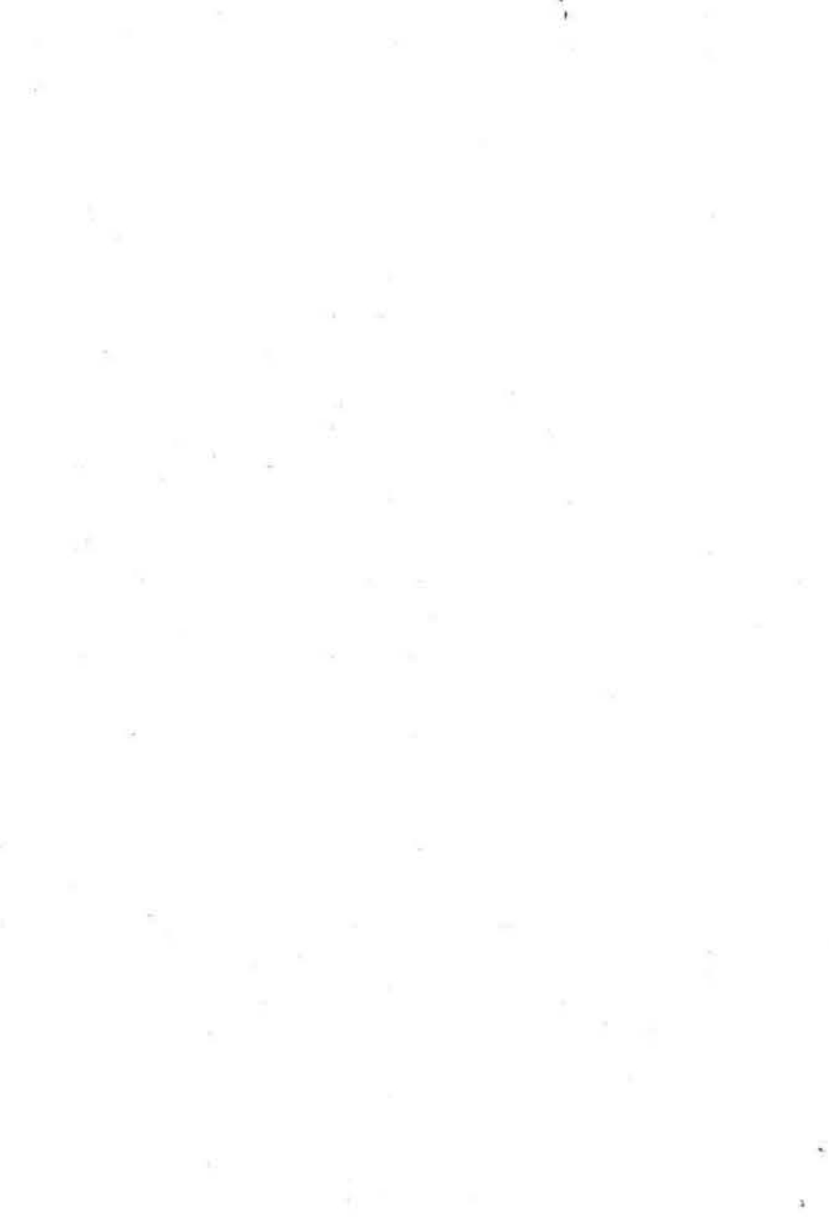


APPENDIX H: Notification of Next of Kin of Excavated Individuals at the Texas State Cemetery

Douglas K. Boyd 

One major focus of the archeological investigations conducted by Prewitt and Associates, Inc. (PAI), at the State Cemetery involved the excavation and relocation of 57 burials of Confederate veterans and spouses. As the owner/manager of the State Cemetery, the General Services Commission (GSC) was under no legal obligation to notify or obtain permission from the next of kin (i.e., the closest living relatives) of individuals whose remains were to be moved as part of its Texas State Cemetery Restoration and Enhancement Project. Texas laws pertaining to cemeteries (most of which are found in Chapters 694-712 of the state's Health and Safety Code) are explicit. It is legal for certified cemetery associations or organizations to move burials from one plot to another plot within the same cemetery without notifying, or obtaining permission from, the next of kin. This course of action may be legal, but there is potential that others will perceive it as underhanded, immoral, or even illegal. For projects involving state agencies and the use of public monies, it always is wise to be cautious and avoid situations that might be controversial. Consequently, before beginning the burial excavations, all of the parties involved - the GSC, Texas Parks and Wildlife Department (TPWD), Texas Historical Commission, Emily Little Architects, and PAI - agreed that a reasonable effort to identify and notify next of kin should be made.

The research to identify next of kin was conducted by Janice Hughes, Director of Development and Public Information for the GSC's State Cemetery project; her administrative assistant, Amy Bryant; and Vicki Hagen, Research Assistant, with the TPWD. The first stage of research, examining the existing State Cemetery burial records in the GSC files, revealed that the burials fell into two groups. Other than what was stated on their headstones, almost nothing was known about the 46 individuals buried in Section F. Apparently, because almost all of these individuals lived at the Confederate Home for Men and were dependent upon the state when they died, there were no records of next of kin in the GSC files. Attempts to locate obituaries were unsuccessful, and death certificates obtained for some of these individuals listed no next of kin. The researchers quickly ran out of leads in trying to identify relatives of these people. At this point, all of the parties agreed upon two things with respect to the individuals buried in Section F: (1) with no solid leads to go on, it would be costly and time consuming to conduct comprehensive research to identify their next of kin; and (2) even if the research was done, it was likely that no next of kin would be identified for many of these people because they probably had no living relatives at the time of their deaths. A unanimous decision was made to suspend the next of kin research for the Section F burials and to ask the United Daughters of the Confederacy (UDC) and the Sons of Confederate Veterans (SCV) to act as the next of kin on their behalf. These organizations had already expressed their support for the renovation project and were aware that the work would involve the relocation of Confederate burials. They enthusiastically agreed to act as next of kin for the 45 Confederate veterans and 1 spouse buried in Section F, and they immediately began to plan a ceremony for the reinterments.

Research to identify next of kin for the Section D burials was somewhat more productive. The researchers found references to relatives of some individuals in the GSC State Cemetery files, and they were able to obtain some death certificates listing next of kin through the Texas Bureau of Vital Statistics. In addition, obituaries published in the Austin Statesman (the precursor to the Austin American-Statesman) listed next of kin for many of these individuals. Some records gave addresses or phone numbers that were long out of date, but searching for individual's names in telephone directories from the towns and cities where they last resided proved to be productive in some cases. Eventually, the researchers were successful in locating and contacting 4 people who were identified as next of kin for 7 of the the 11 individuals buried in Section D. No next of kin were identified for John S. and Margaret C. Pannell or George T. and Josephine Walker. The next of kin who were notified are:

Ms. Mary Boyd of Manor, Texas: descendant of Jacob and Mary Ivy Burleson

Mr. Robert Bradfield of Boulder, Colorado: descendant of James O. and Louisa A. Bradfield

Ms. Jackie Fickel of Austin, Texas: descendant of George Washington and Emma J. Kyser 
Ms. Jackie Tomerlin of San Antonio, Texas: descendant of Dr. Johin R. Ward

These individuals initially were contacted by telephone; no one had any concerns or objections to the burial relocations, and several of the relatives expressed their support for the renovation project. After the telephone contacts, each person was sent letters discussing the relocation of their ancestor's burial(s). The primary letter, personally addressed to each relative, was sent by TPWD. Accompanying each of these were two additional letters addressed to the "Confederate Families"; these were statements of general support for the
State Cemetery renovation project and the Confederate burial relocations from the Albert Sidney Johnston Chapter 105 of the UDC and the Texas Division of the SCV. An example of the TPWD letter and copies of the UDC and SCV letters are included in this appendix.

Because these relatives and descendant organizations were consulted prior to the burial exhumations, potentially controversial situations were avoided, and the excavation and relocation effort proceeded without delay. This is due in large part to the efforts of the UDC and the SCV, whose cooperation and support were essential in the successful completion of the project. 


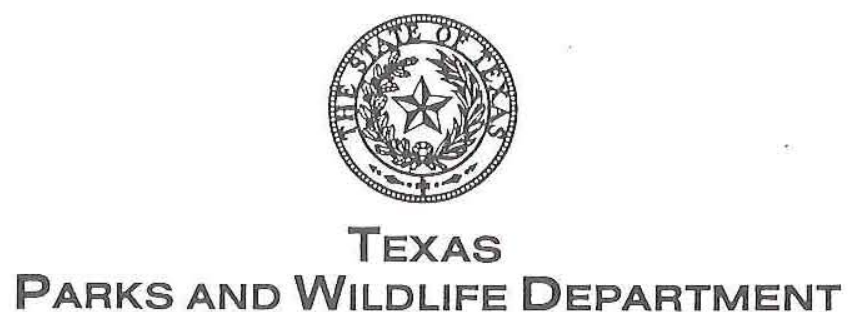

4200 Smlth School Road - Austin, Texas 78744 512-389-4800

\section{TEXAS STATE CEMETERY RESTORATION AND ENHANCEMENT}

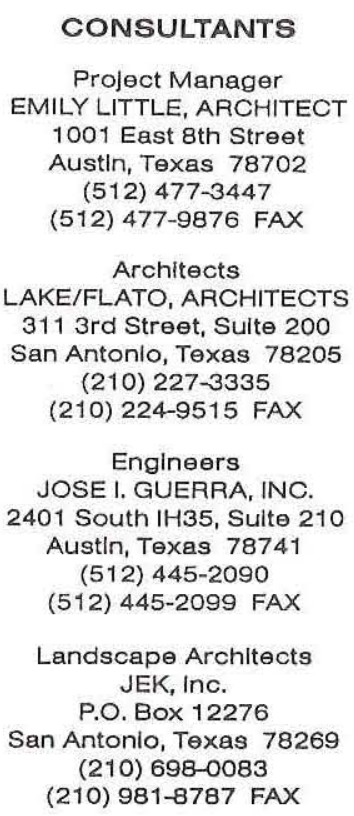

July 25, 1995

Certified Mail - Return Receipt Requested

Ms. Jackie Tomerlin

215 Park Lane

San Antonio, Texas 78212

Dear Ms. Tomerlin:

As mentioned to you in a phone conversation last week week, the Texas Parks and Wildlife Department is beginning work on the Restoration and Enhancement of the State Cemetery, located in Austin, Texas. We are writing to confirm our verbal notification of the necessity to relocate the remains of Dr. John R. Ward, for whom you are believed to be the next-of-kin.

The burial exhumations are being conducted by Prewitt and Associates, Inc., a private archeological consulting firm in Austin, Texas. The work will be done by hand, carefully and respectfully, using standard archeological techniques. The burial exhumations will be done during the latter part of July and early August, 1995, but are not open to the public out of respect to the individuals and their descendants.

The relocation efforts are required by the need to protect the headstones from vehicle traffic on Texas Highway 165, which now serves as the main roadway through the cemetery. Some headstones have already been hit by vehicles parking along the roadway. The relocation is necessary to prevent further damage to the headstones from automobile traffic. The reinterment will occur in a nearby shaded area in the same section of the State Cemetery, which will be beautifully landscaped.

It is our intent with this letter to notify you of this work. By State law, a Disinterment Permit which requires notification of next of kin is "not required if a body is to be disinterred and reinterred in the same cemetery," We would like you to be aware of the project and to know that it has received widespread support. For your information, enclosed are letters of support from the United Daughters of the Confederacy and the United Sons of the Confederacy. Should you have any questions about the reinterment process, please call Janice Hughes, 463-0605, at the General Services Commission, administration offices of the State Cemetery.

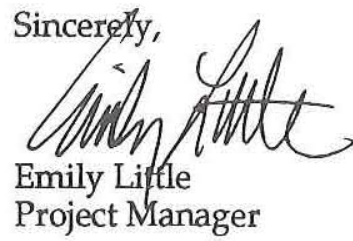




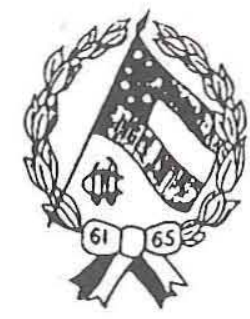

\author{
ALBERT SIDNEY JOHNSTON \\ CHAPTER NO. 105 \\ United Daughters of the Confederacy \\ AUSTIN, TEXAS
}

2307 Bownan Avenue

Austin, Texas 78703

July 12, 1995

To Confederate Families:

The Daughters of the Confederavy, notable theAlbert Sidney Johmston Chapter here in Austin, have been interested in the State Cemetery for many years, visiting often the graves of those buried in the Confederate Section and honoring these patriots on special occasions. It has been our dream for some time that there would be funding available for the proper restoration of this special place and now, we are witnessing this work!

We have been involved with the restoration since it inception and could. not be more pleased with the methods and care being taken to do the work properly and with the utmost respect for those buried there. Under the able guidance of the Historic State Centery Project persomel, we have seen that the work being done is done inthe most professional, respective manner and will be a credit to the people buried there. We are confident that the work being done now will enable generations yet to come to enjoy the history of out State through those who served it and now rest in this beautiful place.

Please contact me or members of our group if there are any questions you have concerning this work. We will be happy to supply you with any help or information that you may require.

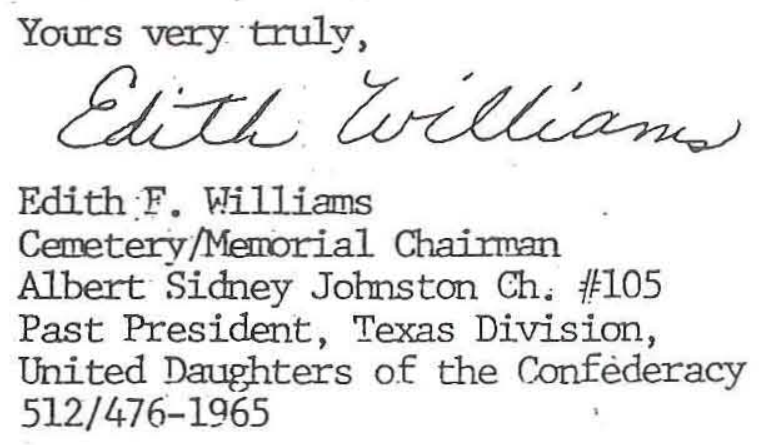


GOmEGOAN T. HECTOR 5914 Sunshina Dive "ghector@ienet.edu"-Internet (512) $451.3490 \mathrm{Fa}$

First L. Commander

241 Ralston

Converse, Texas 7810

(210) 659-1795

Second U. Commander

CLYDE HERON

1309 East 43rd Street

Cossa, Texas 7976

Third U. Commande

JOHN C. PERAY

Salado. Texas 76571

(817) $947-0396$

Central Texas Bg. Commander

DAVIO W. FRAN

Hawkins. Texas 75765

(903) $769-2250$

East Texas Bg. Commander

T. KEVIN MCCALL

11992 Wilson Hill $L n$.
Bullard. Toxas 75757

Bullard. Texas 75

(903) 894.3697

Gult Coast Bg. Commander

JOHN M. "JACK- STICH

7822 Spruce Cove Driva

(713) $550-6441$

No. Texas Bg. Commander

224 Riog gwood Drive

224 Riogewood Driv

(214) $562-7110$

So. Texas Bg. Commander

BRUCE E. AVRETT

7434 High Siepper

San Antonio. Tex
(210) 647-0328

W. Texas Bg. Commander

DAVID PILGRIM

Route 1. Box 177

(915) $776-2820$

Archivist

Archivist

P.O. Box 705

Hillsboro. Texas 78645

(817) 582.384

Chaptain

DR. JAMES LEWIS

16922 Dorman Drive

(512) 255-6997

Color Sergeant

JAMES B. MOORE

1703 Buccanneet

\begin{tabular}{l} 
(903) $759-6726$ \\
\hline
\end{tabular}

Historian

ROSS J. COX SR.

Livingston, Texas 7735

(409) 327.7576

Judge Adrocale

9065 Jollywille Road

Austin, Texas 7875

(512) $346-572$

Quartermaster

STEVEN S. VON ROEDER

1010 W. Rundberg Lane

Austin, Texas 78

Surgeon

DR. CHARLES BELL

212 Sagecrest

(210) $494-9643$
(Aintonis.

Aides-de-Cam

Aides-de-Carmp
JOHN E. CARR, III

118 W. College Sreet
Faitidid. Texas 75840

(903) 389.6755

G. TODO HECTOR

5914 Sunshine Dive
Austin. Texas 78757

(512) 451 -7220

BARNEY HILBURN

P.O. Box 597

Hallsville. Texas 75650

(903) 668.2394

TIMOTHY C. PRINGLE

513 West Pioneer

irving. Toxas 75601
(214) 254-3513

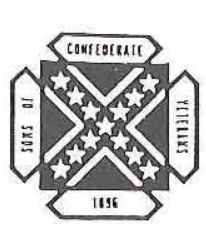

Adiutant
BILL CAMPBELL

P.O. Box 1705

Austin. Yaxas 78767-1705

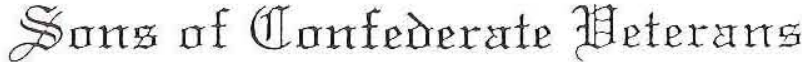

TEXAS DIVISION

July 11, 1995

Dear Confederate Families:

My name is Rev. Dr. James Lewis, and I am the Austin Commander of the Sons of Confederate Veterans and the Texas Division Chaplain for the SCV-Army of the Trans-Mississippi. I have had the pleasure of touring our State Cemetery and reviewing the work to improve the Confederate graves and to relocate over fifty grave sites. I am impressed with the Commission's work to honor your relatives and to keep their resting place a hollowed ground. The Sons of Confederate Veterans is keeping up with all the work and plan to have a Re-dedication and Memorial Service when all the work has finished. Let us reassure you that we are vitally concerned with the proper handling and care for our Confederate ancestors and their gravesites. If you wish to have any further information or wish to contact me personally, please feel free to call or write. We will alert you as to the Re-dedication Service and hope to meet with you at that time.

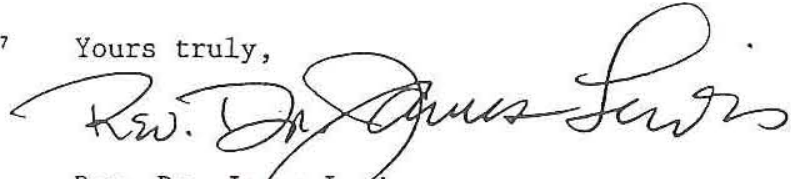

Rev. Dr. Janes Lewis

Koenig Lane Chxistian Church

908 Old Koenig Lane

Austin, TX, 78756-1507

(512) 454-7679

JHL

$\mathrm{CC}: 1$

CORRESPONDENCE SHOULD BE ADORESSED TO INOIVIDUAL CONCERNED 

APPENDIX I: Memorial Service for Confederate Reinterment, Texas State Cemetery, 7 August 1995

Douglas K. Boyd 

The local and state chapters of two Confederate descendant organizations-Albert Sidney Johnston Chapter 105 of the United Daughters of the Confederacy (UDC) and the Texas Division of the Sons of Confederate Veterans (SCV) - were closely involved with the removal and relocation of burials in the Confederate sections of the Texas State Cemetery. Contacted early in the planning stages, these organizations wholeheartedly supported the cemetery renovation project and Prewitt and Associates' (PAI) burial relocation work. When invited to visit the cemetery to see the burial excavations firsthand, many of their officers and members attended and were pleased with the respectful treatment of the remains. On their first visit during the first week of burial excavations, members of the UDC and SCV conducted a prayer service, led by Dr. James Lewis (SCV, Texas Division chaplain).

From the start, the UDC and SCV envisioned a solemn reburial ceremony during which the remains would be reinterred. Coordinating their efforts with the General Services Commission, Texas Parks and Wildlife Department, and PAI, these groups took the lead in planning the ceremony. From a logistical standpoint, it was not practical to reinter all of the burials on the same day as the ceremony. Consequently, 55 of the 57 burials were reinterred on the day that the last grave was excavated, 31 July 1995 . The other two reburial boxes were retained until the following week when the ceremony was scheduled.

On the bright, sunny morning of 7 August 1995, a crowd gathered under the shade of several majestic oaks to pay their final respects to the former Confederate men and women whose remains had been unearthed (Figure 52). Less than 30 yards northeast of General Albert Sidney Johnston's monument and grave, the two reburial boxes containing the remains of a former Confederate States Army captain and his wife were covered in lace, awaiting reburial. Upon arrival, visitors were given a service program and agenda prepared by the UDC (presented in this appendix) and a black ribbon to pin on their chests. Dressed in heavy wool Confederate uniforms, an honor guard of SCV members held the Texas state, First National Confederate, and Confederate battle flags

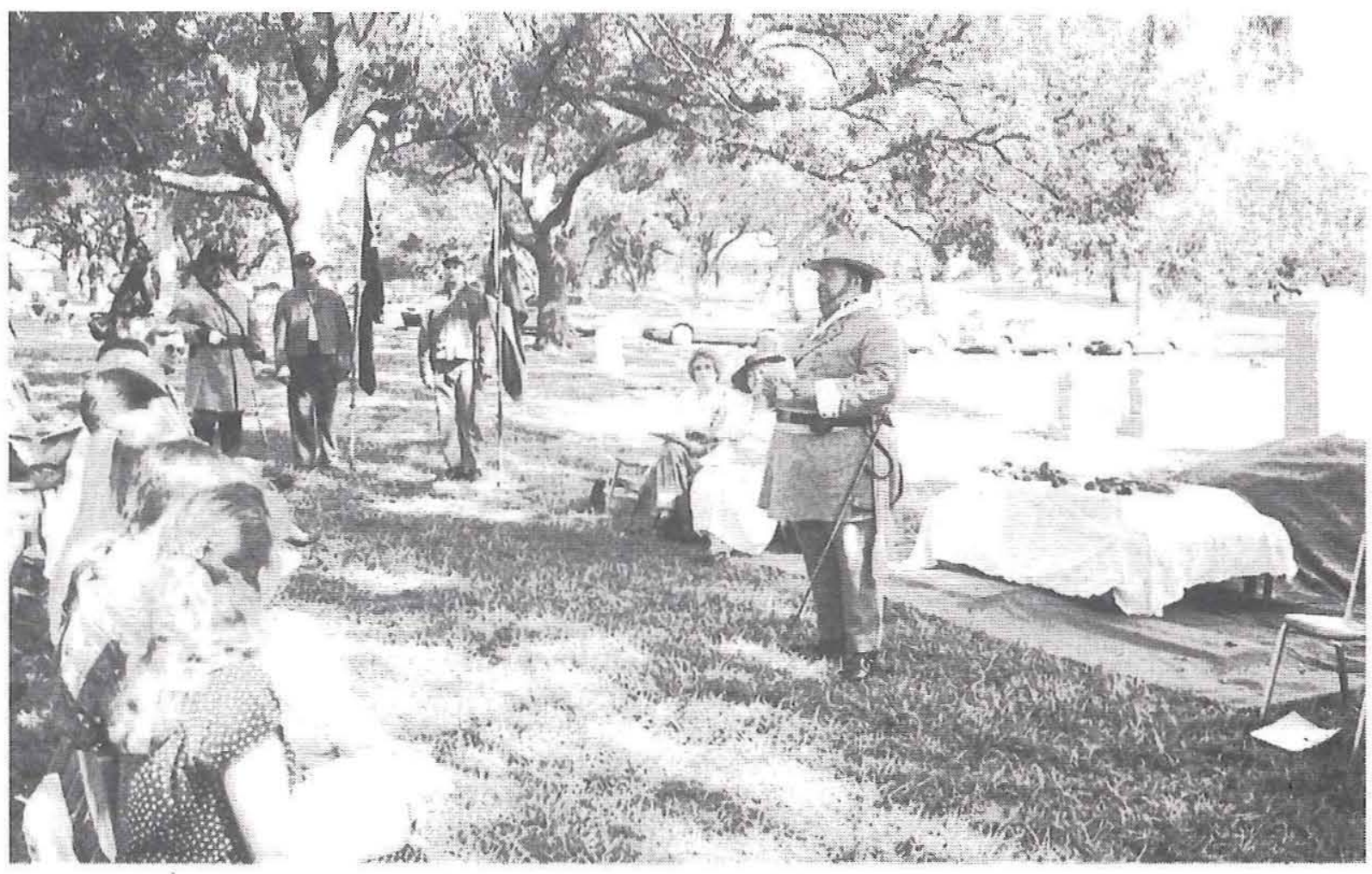

Figure 52. With the honor guard in the background, Gregory Hector (Texas Division commander for the Sons of Confederate Veterans) spoke to the crowd at the memorial service for the Confederate reinterment at the Texas State Cemetery, 7 August 1995. 
throughout the hour-long ceremony. Following introductory remarks by several participants, a memorial tribute to the Confederate veterans was presented by Dr. Lewis, and Doris Birden (UDC, Texas Division chaplain) presented a memorial tribute to the women of the Confederacy. Gregory Hector (SCV, Texas Division commander) read the text of a nineteenth-century funeral ritual used by the United Confederate Veterans when burying their comrades. The names of the 57 people whose remains were reinterred were read by Edith
Williams (UDC, Albert Sidney Johnston Chapter 105 and Texas Division past president) and Martha Hartzog (UDC, Albert Sidney Johnston Chapter 105). The memorial service ended with the distant sound of taps played by a lone trumpeter. The words of the century-old United Confederate Veterans funeral rite remind us: "Once more the bugle call has sounded and another comrade, obedient to the signal, has laid down to his last sleep" (Austin American-Statesman, Tuesday August 8, 1995, page B3). 
Memorial Service

Confederate Reinterment

State Cemetary, Austin, Texas

August 7th, 1995

Participants:

- Doris Birden, Texas Division, U.D.C.

- Carl Deichmann, 8th Texas Cavalry, Texas National Guard

- Jackie Fickel, Descendant of G.W. Kyser

- Martha Hartzog, U.D.C.

- Greg Hector, Texas Division, S.C.V.

- Janice Hughes, Historic State Cemetary Project, G.S.C.

- Dr. James Lewis, Texas Division, S.C.V.

- Edith Williams, Albert Sidney Johnston Chapter 105, U.D.C.
Special hanks:

- Lt. Govenor Bob Bullock

- General Services Commission

- Emily Little, Architect

- Lower Colorado River Authority

- Prewitt \& Associates, Inc., Consulting Archeologists

- State Preservation Board

- Texas Parks \& Wildlife

- Texas Historical Commission

- Texas Department of Transportation

- Weed-Corley-Fish Funeral Home

"Blessed Be the tie that Binds, our hearts in Christian love, the fellowship of kindred minds is like to that above. "

Taps 
Mattie J. Guess

Samuel Gentry

Joseph Watkins

William E. Rogers

Richard A. Tiner

Joseph R. Benton

P. H. West

J. M. Wyatt

T. J. McCulloch

J. M. Bates

F. A. Bott

L. A. Bernard

J. F. Hargrove

J. M. Turner

John Ferron

J. V. Davenport

A. F. Brock

J. B. Ormand

James W. Hogan
Jarrett Cromer

W. W. Hill

M. C. Kelly

J. A. Alexander

I. C. Briggs

J. R. Simmon

J. F. Smith

J. Y. Porter

J. W. Johnson

J. P. Thomas

L. E. Trezervant

W. H. Stewart

J. M. Adams

S. L. Stanley

L. R. Moody

H. A. Bowdoin

J. H. Walker

D. P. Brown

J. H. Morgan
A. D. Starnes

D. R. Jacks

William Shry

A. G. Bird

C. C. Hagler

J. T. Bowden

Jubal Willis

A. M. Robinson

George W. Kyser

Emma J. Kyser

George T. Walker

Josephine M. Walker

Margaret C. Pannell

John S. Pannell

Jacob Burleson

Mary Burleson

Louisa A. Bradfield

James O. Bradfield

Dr. John R. Ward

Military Records for Veterans were researched and provided by the Harold B. Simpson Confederate Research Center, Hill College, Hillsboro, through the efforts of Assistant Director Mrs. Peggy Fox.

The efforts and considerations of all agencies and individuals involved in this historic project are gratefully acknowledged by the Albert Sidney Johnston Chapter 105 of United Daughters of the Confederacy, Sons of Confederate Veterans, Austin Civil War Round Table, Austin Genealogical Society, Save Texas Cemetery Association, and many other interested citizens. 


\section{Confederate Reinterment Memorial Service \\ State Cemetery, Austin, Texas \\ August 7, 1995}

Agenda

Introduction: $\quad$ Edith Williams

Overview: Janice Hughes, Project Chairman

Recognition of project participants

Project Details: Doug Boyd, Archeologist

Historical Significance: Greg Hector, Commander, Texas Division Sons of Confederate Veterans

Personal/Family Significance: Jackie Fickel, descendent of Confederate Veteran G. W. Kyser

Memorials:

To Confederate Veterans: Dr. James Lewis, Chaplain, Texas Division Sons of Confederate Veterans

To Women of the Confederacy: Doris Birden, Chaplain, Texas Division United Daughters of the Confederacy

Reading of the Roll: $\quad$ Edith F. Williams, Past President Texas Division UDC

Martha Hartzog, Albert Sidney Johnston Ch. 105, UDC

Benediction: $\quad$ Dr. James Lewis

Taps: $\quad$ Carl Deichmann, 8th Texas Cavalry, Texas State Guard 


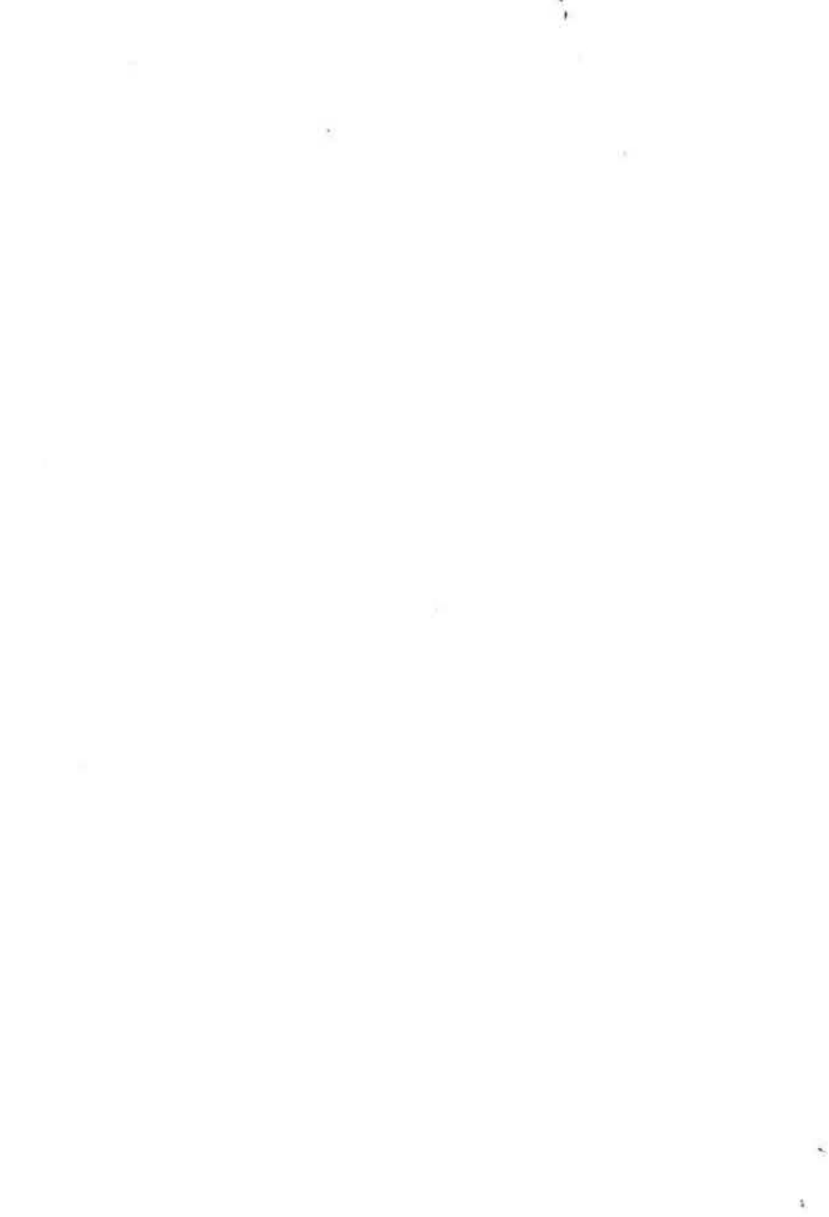




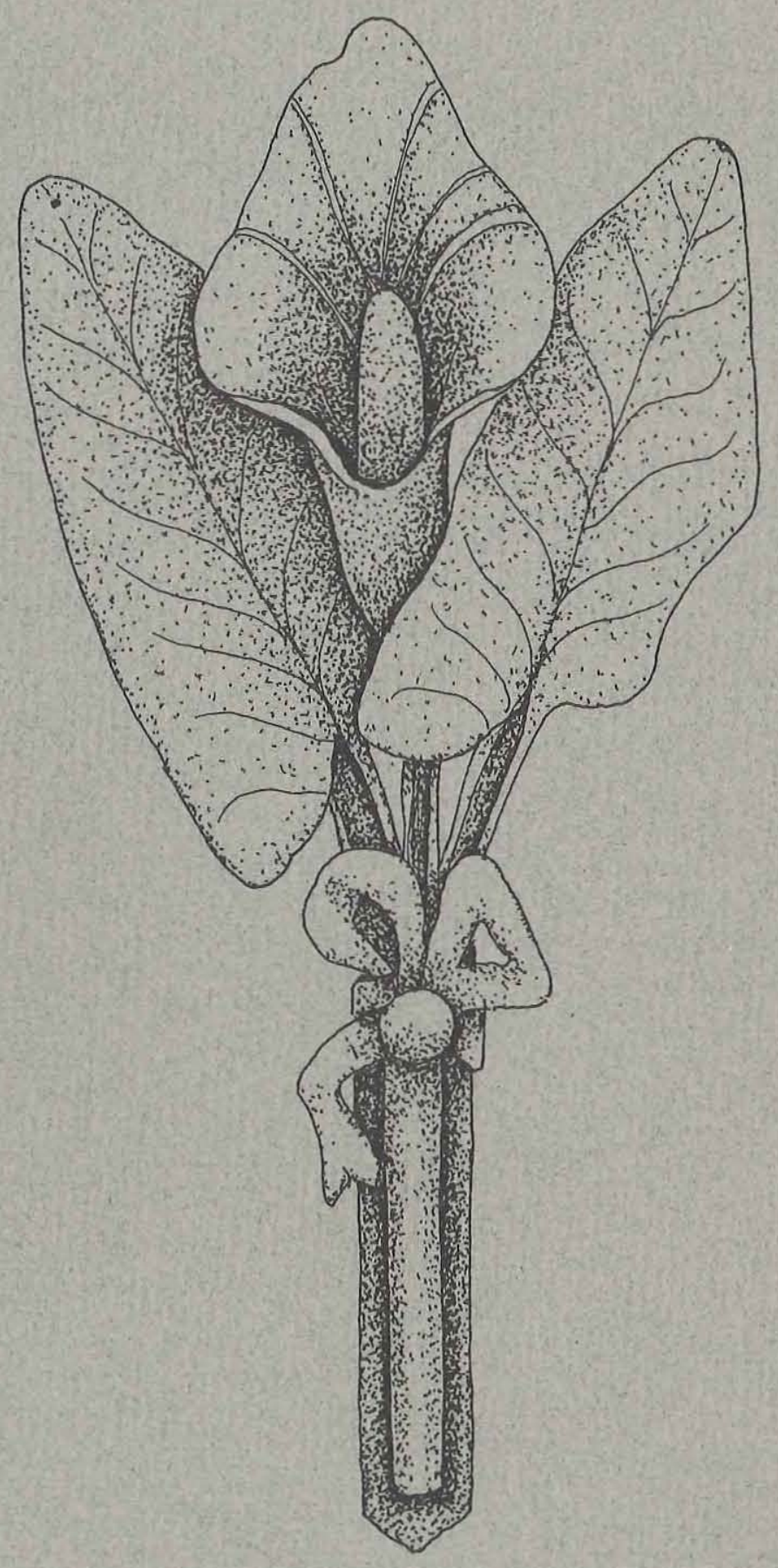

